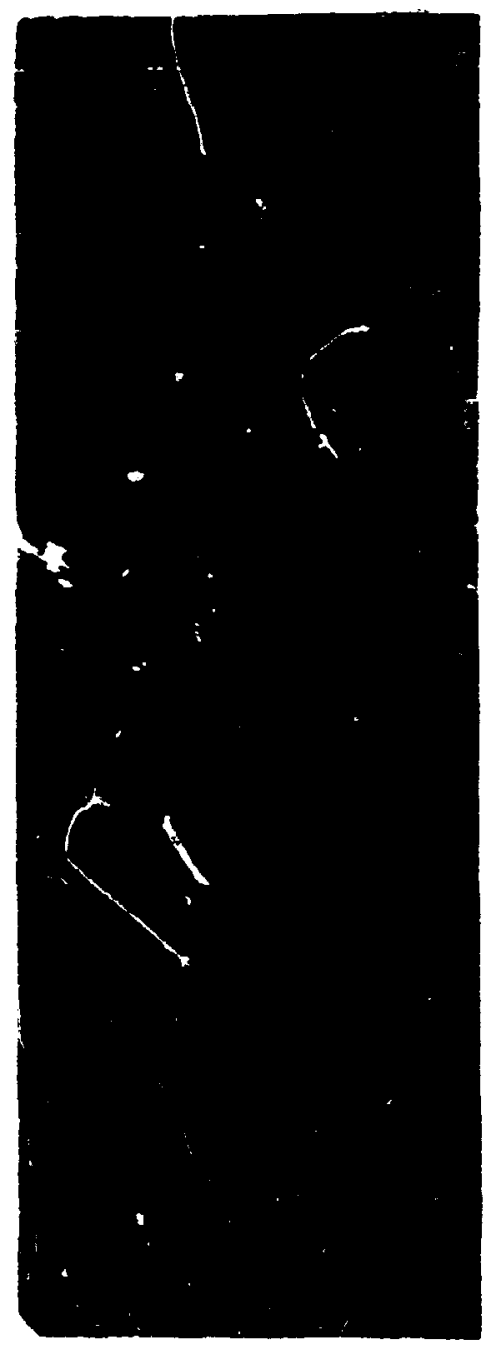

$$
\ln -11: 0
$$

ORINL-4953

\title{
The Use of Supernovae Light Curves for Testing the Expansion Hypothesis and Other Cosmological Relations
}

B. W. Rust

\section{MASTER}

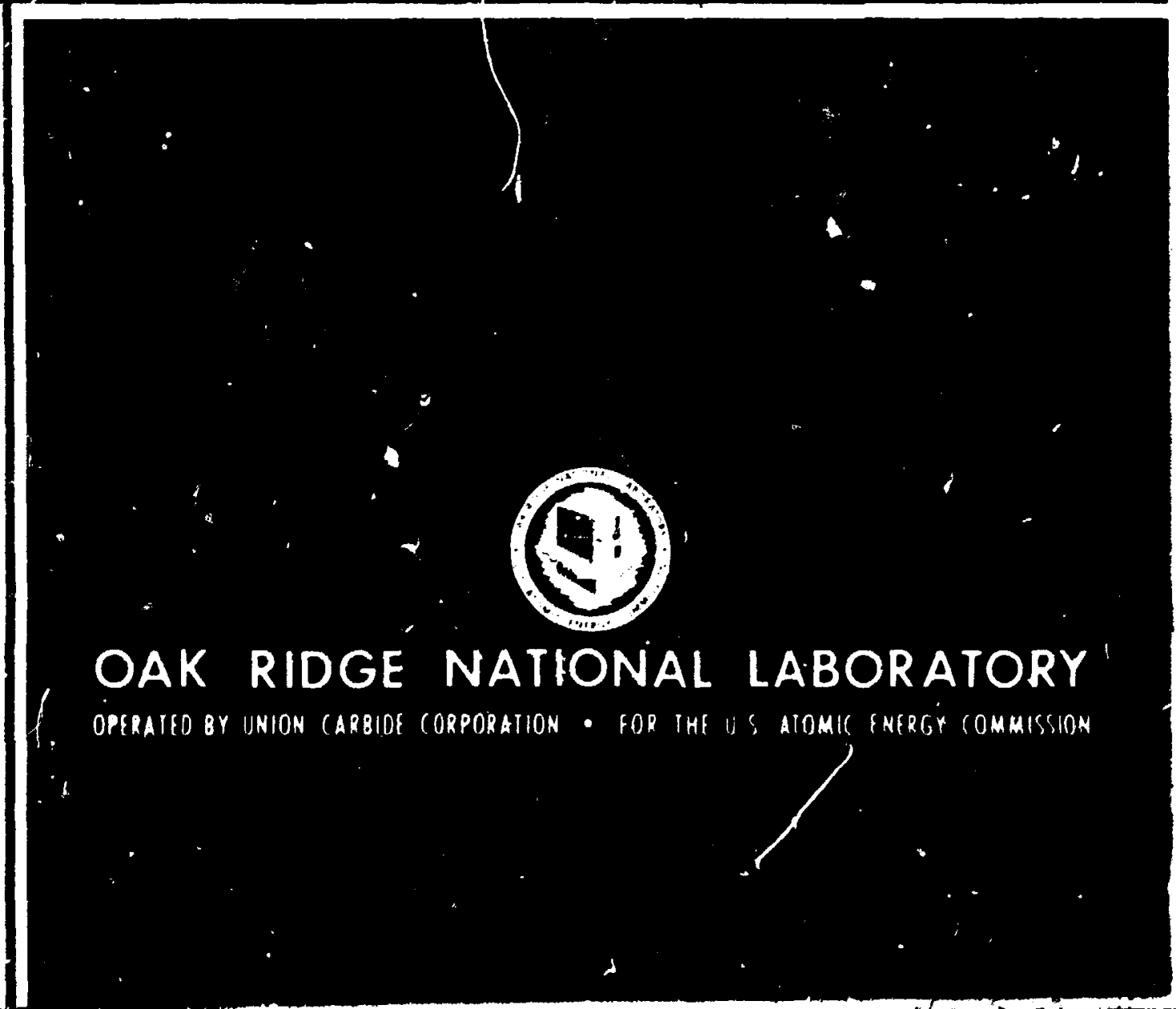


Printed in .he United States of America. Available from Natio al Technical information. Service

U.S. Department of Commerce 5285 Port Ro /al Road. Springfield. Virginia 22161

Price: Printed Copy S10.60: Microfiche \$2.25

This report was prepared as an account of work sponsored by the United States Government. Nether the United States nor the United Stater. Alomic Energy Commission. nor any of their employees. nor any of their contractors, subcontrac. rors, or their employees, makiss any worranty. express or implied, or assumes any legl hability on esponsitility for the accuiacy. completeness or usefilness of any information, apparalus. produc: or process disclosed, or represents that its use would not inf ringe srivately ouned right is. 


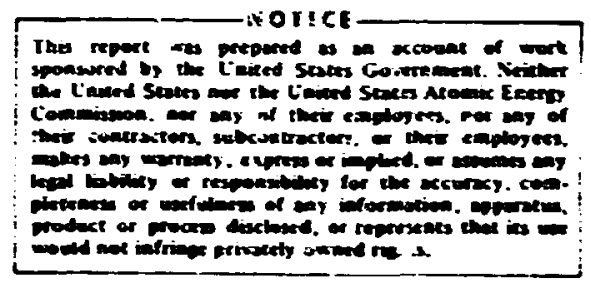

$$
\begin{gathered}
\text { ORNi-4953 } \\
\text { UC-34b } \\
\text { Physics - Cosmic and Terrestrial }
\end{gathered}
$$

Contract IIC. W-i $1405-e n g-26$

COMPUTER SCIENCES DIVISIOH

THE USE OF SUPERHOVAE LIGHT CURVES FOR TESTING

TUE EXPANSION HYPOTHESIS AND OTHER COSMOLOGICAL RETATIONS

(Dissertation)

B. H. Rust

This report has been adopted from a dissertation presented to the University of Illinois in partial fulfillment of the requirements for the degree of Doctcr of Philosophy in Astronomy by Bert Woodard Rust

\section{DECEMBER 1974}

OAK RIDGE NATIONAL LABORATORY
Oak Ridge, Tennessee 37830
Operated by
UNION CARBIDE COKPORATION
POr the
U.S. ATOMIC ENERGY COMMISSION 


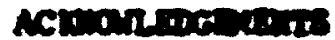

The enttor astinouledges the Conputer setences Division, Loctied at Oak Ridere Detionel Inborntory, operated by Unton Curblde Corporat sa, maclear Divisica, for the U.S. Atade Dery Cumission.

The artwor would libe to thank Professor E. C. Olson for sort and encouradas arice ariag the preparation of this thests and profeseor

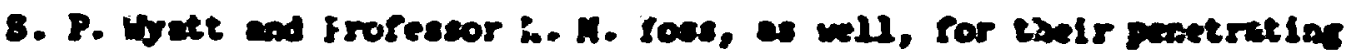

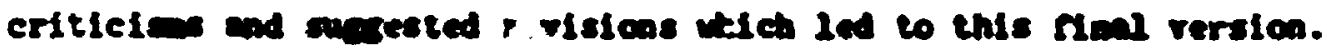

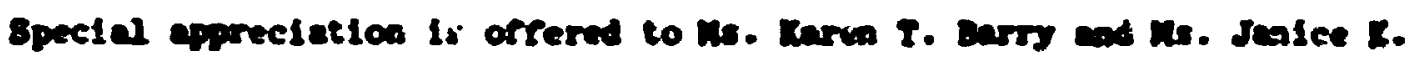

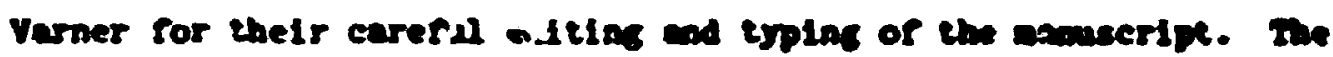
athor vould alco like to cheak frofeceor ronted maletel for grovidiag

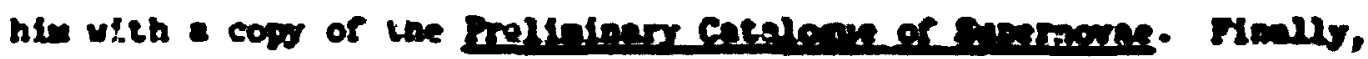

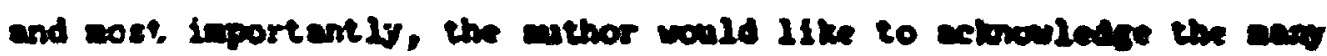

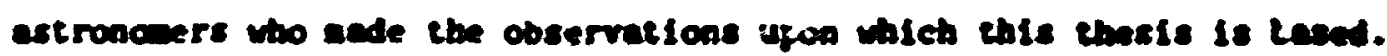


TARE OP Coirdits

CHiren Page

i. nrmouctiar ................... :

2. CUNSAPS AWD THE FOSSIBILTIY OF MOR-DOPFLER

ReD strfTs ........................ =

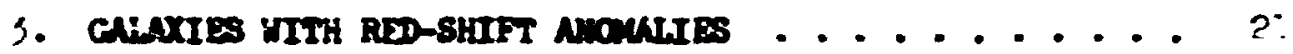

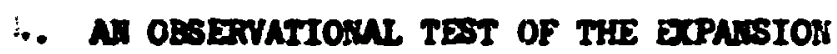

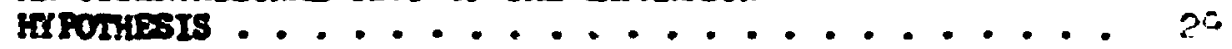

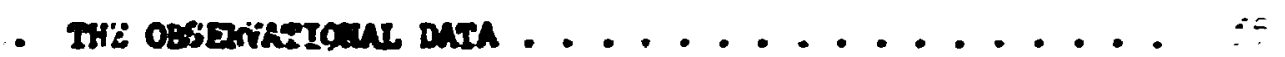

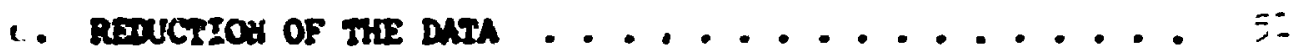

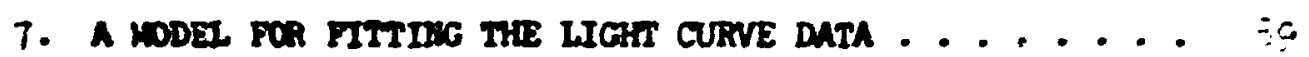

․ TUE RESUIS OF THE FTTS . . . . . . . . . . . :

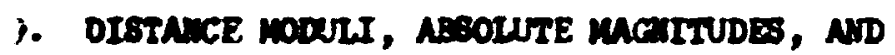

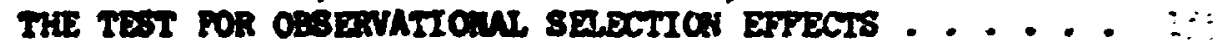

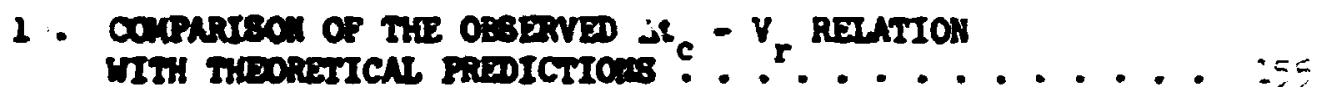

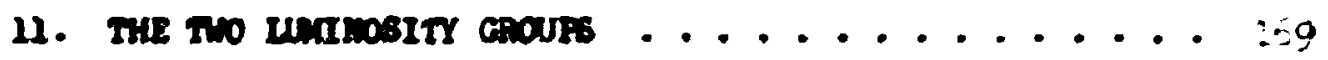

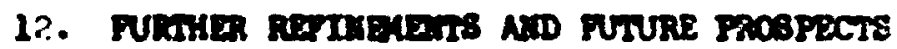

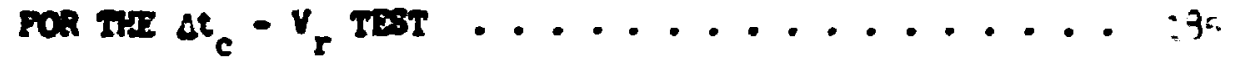

1;. THE RED 8HITT - MACITTDE REATTCA AND A

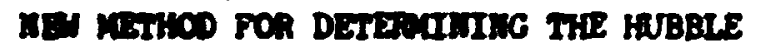

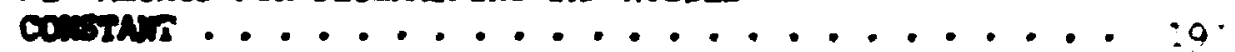

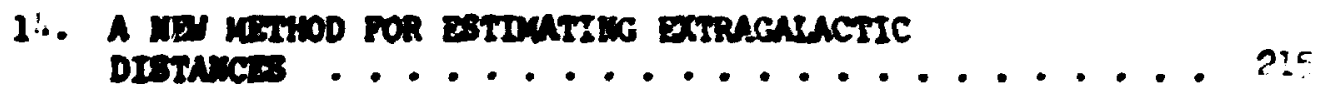

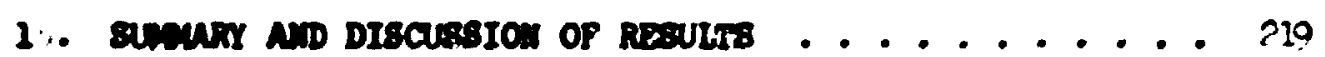

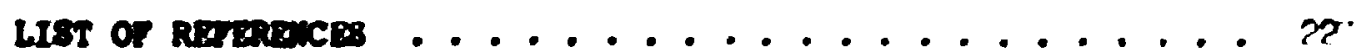


APFidDICES

1. IIS OABERED ND REDUCED DATh ........... 2:-

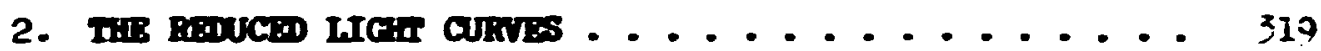

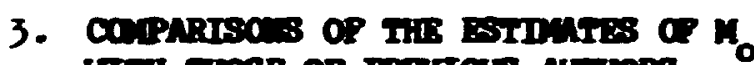

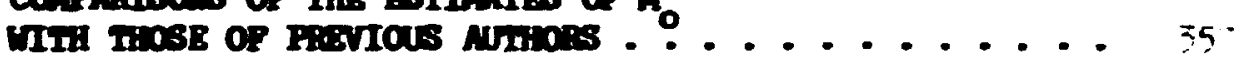

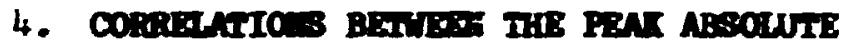
MFITUD:S OP THE SHFEOUNE $N D$

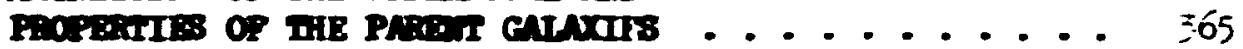

5. TESTS FOR STSTantic EPBCE II ESTIMATIN THE $\mathrm{n}_{0} \ldots \ldots \ldots$

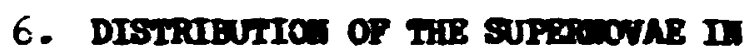

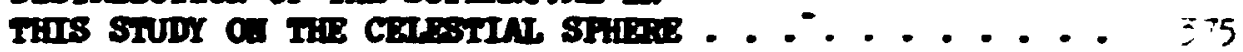

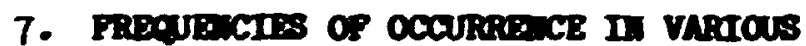
TIPES OP CATAREB 
LIST OF FIGURES

Figure Page

L-1 The Light Curves of Supernorae sul337c, $\sin 937 \mathrm{~d}$, and $\sin 33$. ............... =

-1 The Light Curve Measured at Prairie Observatory for SilY73i .............. . .

6-1 Pskorskii's (B-V) $)^{-t}$ Relation ............

$t-2$ The ( $\left.{ }_{\mathrm{pg}}{ }^{-\mathrm{m}} \mathrm{pr}\right)_{0}^{-t}$ Relation Derived from Pskorskii's $(B-V)_{0}-t$ Relation .............

t-3 Pskovskii's Point k Method for Determining

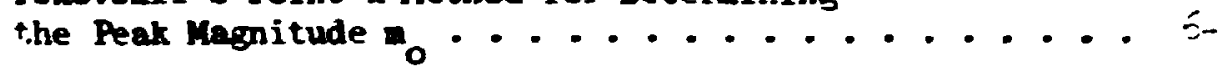

t-4 Pskovskii's Average Light Curve Method for Determining the Day $t_{0}$ of Peak Brightness .......

6-) The Scale Correttion for Converting Kaho's Magnitudes to the B System .............. ?

7-1 The Morrison-Sartori Light Echo Model ......... $\mathscr{Q}$.

7-2 Horrison's and Sartori's Pit of Their Model to the Light Curve for $\operatorname{SH1} 337 \mathrm{~d} \ldots . . . . .$. .

7-3 Rust's Pit of Horrison's and Sartori's Model to the Light Curve for 5 N1937a ......... 13.

7-is Plt of Morrison's and Sartori's Model to Three Different Regions of the Light Curve

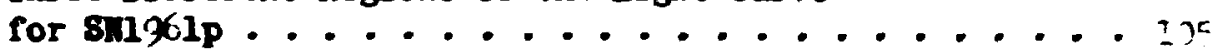

8-1 The Distribution of $\Delta t_{c}$ for the 21 supernovae with Mearured Red Shifts $\leq 2000 \mathrm{~m} / \mathrm{sec} . . . . . . .2$.

3-2 The Regression of at on Symbolic Velocity of Recession ... . . . . . . . . . . . 12t

8-3 The Regression of ste on the Nuber of Points Used fro the fit ..................?

-1 Regression of Absolute Magnitude $M_{0}$ on the Comparison Paraeter $\Delta t_{c} \ldots .$. . . . . . . . 15: 
vil

Figure

Page

9-2 Regression of Absulute Magitude $m_{0}$ on the Syizalic Velocity of Recession .......... 15 I

10-1 Comparison of the at ${ }_{a}^{-V_{Y}}$ Regression Line vith the Precictions of the Various meories ....... 165

11-1 Regresaf ons of Absolute Mngnitude on the Cocparison Paracter for the Two Ininosity

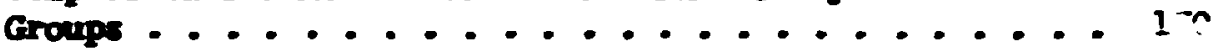

11-2 Absolute Magnitude is a Punction of $\Delta t c$ for Totally Uncorrected Magnitudes, with Tro Groups Distinguished ............ If6

11-3 The Distribution of $n_{0}$ for the no Groups Taken Together and Separately .......... 173

11-4 Distribution of the $\Delta t_{c}$ for the 21 supernovee Comon to the Present Study and the study of

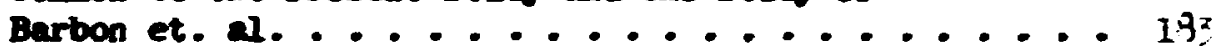

12-1 Reconciled $\boldsymbol{n}_{0}-\Delta t_{c}$ Relation ........... 136

$12-2$ Reconciled $\Delta t_{c}-v_{p}$ Relation ............ 198

13-1 The Regression of $\mathrm{B}_{0}$ on $10 \mathrm{~g}\left(\mathrm{v}_{\mathrm{r}}\right)$ Compared with the Best-Pitting Linear and Guadratic Lars ... 2n?

13-2 The $n_{0}-\log \left(V_{\mathbf{r}}\right)$ Relation for the Reconciled Saple . . 207

13-3 The Best-pitting Linear bubble lew for Bach of the Two Indinosity Groups ............. 2 ...99

14-1 The Velocity-Distance Relation for the Local

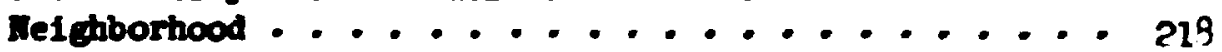

N2-1 The Light Curves of the supernoves Ised in Inis study .................. \2n

13-1 Comparison of the Aheolute Magoitudes with Those Obtalned by Previous Authors ......... zij9

13-2 Conparisen of the Total Absorption Corrections calculated by Rust and by Pekovski1 ......... $x_{51}$ 
A3-3 Total Absorption Correction as a Punction of color brcess ................ 35́2

Air-1 Peak Absoiute Magnitude as a Punction of the Hubble Iype of the Parent Galaxy......... Iín

A:-2 Regression of Peak Absolute Megnitude on the Integreted Absolute Magnitude of the Parent Galevy for Pzhorskit's smple ..........

14-3 Regression of Peak Absuiute Megnitude on the Integrated Absolute Magnitude of the Parent Galov for Rust's smple............. is

Á-1 Distribution in Equatorial Coordinates of the Supernove in This study .............

17-1 Distribution of Supernove in the Various Types of Calaries ................ s's 
2-1 csos with Seall Angular Separations from Bright Gelaxies . . . . . . . . . . . . 19

3-1 Red Shifts of the Galaxies Apparently

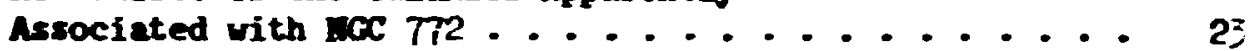

3-2 Residual Red Shifts of the Galaxies in Jenkkole's Study ................ 29

:-1 Prairie Observatory Measurement of the

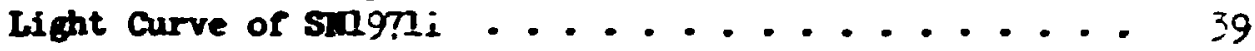

j-2 reneral Infortation Abost the Strernova = Ineidiei in this Stuiy.......................... it

6-1 Comparison of Messured $n_{\text {pg }}$ Magnitudes with Values Computed fro B, V Magnitudes ......... 52

6-2 The Peak Magnitudes and Dates of Prak Brightness for the Supernovae in this study ....... 69

6-3 Sumary of the Techniques Used tc Convert the Magnitudes from the Various Systens of Measurement to the Stendard a Systea ........ Ts

6-4 simary of the Photanetric Data and Conversions Used to Obtain the Light Curve for this study ...... 80

7-1 Results of the Pits of Morrison's and Sartori's Model to Three Different Regions of the Light

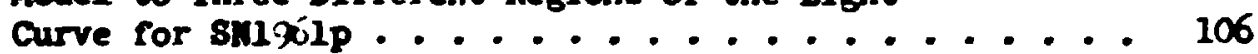

7-2 Effect of Changes in the Estimate of $t_{0}$ on Various Comparison Pareeters $\Delta t \ldots . .$. . . . . . . .

7-3 Effect of Changes in the Estimate of an Various

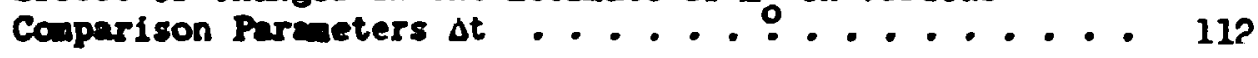

8-1 Sumary of the Pinal Results of the fits ....... 113

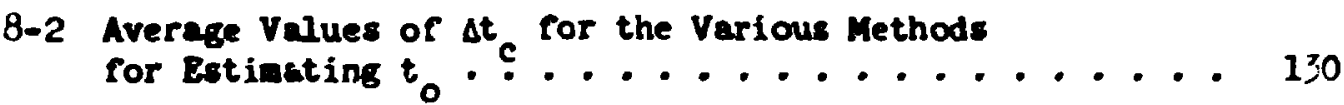

8-3 Average Values of $\Delta t_{c}$ for the Various Methods of Estiating $\mathrm{m}_{0} . \mathrm{C}^{\mathrm{C}}$. . . . . . . . . . . 136

2-1 Average Absorptions in Various Types of Galaxies . . . 140 
Table

Page

9-2 Sumary of the Calculaticis of the Corrected Peak Apparent Maznitudes $\mathrm{a}_{0}$........... I's?

9-3 Sumary of the Cainulations of the Peak

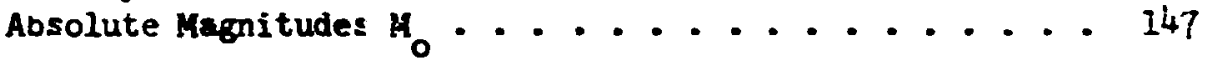

10-1 Sensitivity Study of the Effect of the Value Adopted for $H$ on the Regression of $\Delta t_{c}$ on $v_{r} \ldots \ldots \ldots$........................ 167

11-1 The Two Groups of Supernovae ............. 171

11-2 Paraneters or the Relations between $M_{0}$ and $\Delta t_{c}$ for the Groups, Taken Separately and Together ................ 172

11-3 Comparison of the "Fast" and "Slcw" Groups of Barbon, Ciatti, and Rosino with the Luminosity Groups of the Present Study .......... 181

12-1 The Power of a Sample with the Same $\mathbf{V}_{\mathbf{r}}$-Distribution as the Present one to Discriminate Between Alternative Theoretical Predictions ......190

12-2 Sample Requirements for Discriminating at the 95\% Level of Significance Between Pairs of Alternate Predictions for the Slope of the

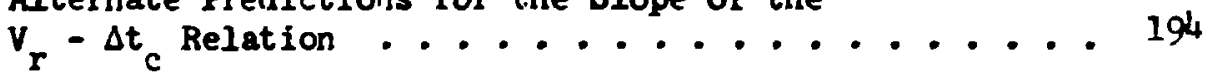

13-1 Results of the $m_{0}-\log \left(v_{r}\right)$ Regressions ....... 206

Al-1 The Observed and Reduced Data Used in This Study . . 238

A3-1 Comparison of the Absolute Magnitudes with Those of Previous Studies . . . . . . . . 357

A ${ }^{4-1}$ Average Peak Absolute Magnitudes as a Function of Galary Type for the Estimates of Pskovskil

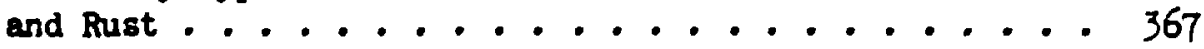

Af-1 Sumary of the Nurber of Times Each Method of Estimating $m$ was Used for the Two Luminosity

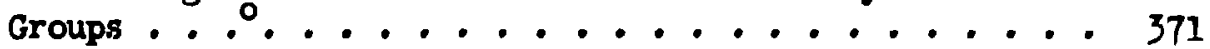

A 5-2 Sumary of the Number of Times Each Method of Estimating the Absorption in the Parent Galaxy was Used in Bach Lunfnosity Group .......... 373

A7-1 Number of Superiovae in Different Types of Galaxies . . 379 
This thesis is primarily concerned with a t.est of the exparsion hypothesis based on the relation $\Delta t_{\text {obs }}=\left(1+v_{r} / c\right) \Delta t_{\text {int }}$ whers it $_{\text {int }}$ is the time lapse characterizing some phenomenon in a distant balexy, it obs is the observed time lapse and $v_{r}$ is the symbolic velocity of recession. If the red shift is appler effect; the observed time lopse shculd be lengthened by the same factor as the wave length of the light. Many athor: have suggested type I supernove for shisi a test because of thin ir great luminosity and the uniformity of their light curves, but apparent ly the test has heretofore rever actuall; ceen performed. Thirty-six light curves were gathered frow the literature and one (SN1971i) was measured. All of the light curves were reduced to a comon ( $\mathrm{m}_{\mathrm{pg}}$ ) photonstric system. The comparison time lapse, $\Delta t_{c}$, was taken to be the time required for the brightness to fall frow $0^{m} j$ below peak to $2^{\text {mo }} \cdot 5$ below peak. The straight line regression of $\Delta t_{c}$ on $v_{r}$ gives a correlation coefficient significant at the $93 \%$ level, and she simple static Euclidean hypotheais is rejected at that level. The regression line also deviates fron the prediction of the classizal expansion hypothesis. Better agreement was obtained using the shronczeometric theory of I. E. Segal (1972 Astron. and Astrophy3. 18, 143), but the scatter in the present data makes :t impossinile to distinguish between these alternate hypotheses at the $95 \%$ confidence level. The question of how many additional light curves would be needed to give definitive tests is addressed. It is shown that at the present rate of supernova discoverles, only a few more years would be required to obtain the necessary data if light curves are aystematically measured for the more distant supernovae. 
Peak absolute aagnitudes $M_{0}$ were calculated and a plot of $M_{0}$ against $\Delta t{ }_{c}$ gave two well separated bands with a high degree of correlation (significant at the 99.516 level) within each band. These bands almost surely represent two distinct populations of Type I supernova:, each having a characteristic linear relation between the rate of decline in brightness, $\Delta t_{c}$, and the maximu luminusity $M_{j}$. The slopess of these relations are not sensitive to erro-s in estimating the $M_{0}$ so if an independent method is used to recalibrate the zero points, then they can be used for estianating extragalactic distances by a method analagous to the use of Cepheid variable period-luminosity relations. Also they can br: combined with the corresponding relations between $\log \left(v_{r}\right)$ and peak apparent magnitude mo to obtain a new method for estimating the Hubble constant $H$, assuming that the velxity distance law is truly linear. Supernovae are ideal candidates for testing the linearity of that relation because they are point sources ant hence do not require aperture corrections. The regression of $m_{0}$ on $\log \left(v_{r}\right)$ for the present sample gave a slope intermediate between the predictions of a linear and a quadratic relation. Both of those predictions are refected at the $7:$ level, but the present sample is dominated by relatively nearby galuxies. The $\mathrm{M}_{0}-$ $\Delta t_{c}$ relations were recalibrated using six supernovae in the virgo cluster together with de Vaucouleurs' [IAU Symposium No. 1.16 (1772) 353-366] best estimate of its distance modulus. These relations were used to construct a velocit,v-distance plot for the supernovae with distances less than $30 \mathrm{Mp}^{\circ}$ The resulting plot gave extremely good agreement with the quadratic relation found by de vaucouleurs for nearby groups and clusters. Combining 
the reculibrated $M_{0}-\Delta t c$ relations with the best fitting linep - socity distance relations for the entire seaple gave $H=32 / \mathrm{ha} / \mathrm{sec} / M_{p e}$ for the Hubble constant. 
CHPIER 1

Introsucto

The aim of this thesis is to put the expapding universe hupcthesis to an cbservaticnal test. The test, which is based on supernow 1f int curves, has been suggested mas times, but, tc the author's bnowleder, has never acturily been applied.

Few of the hypotheses of modern selence enjos an acceptance so universel as that of the expanding universe. The evidence supporting this hypothesis is coupelling but it is all of one kind - nenely, meesurewents of the red shifte of lipes in the spectin of distant galaxies. These weasureaents and their interpretetion as Doppler velocity effect constitute the ouly observitional evidence directly supporting the hpothesis. In spite of this the ide is widely acepred, perhape In pert because of other conolderetions. Inese other consterstions include: (1) the expansion hypothesis bas not led to an oblous contradictions with other comologdeal date; (2) wo cae has ween able to find a better or nore attrective interpintation of the red-able measurewents; and (3) an expmaing universe resolve way of the theoretical difficulties and paradowes mich plagad igen contury sosmologists.

Host of the comolodeel thought of the last contury we dondrated by the view that the uatrerse is infini:-, Fue:Idean, iniform, statie

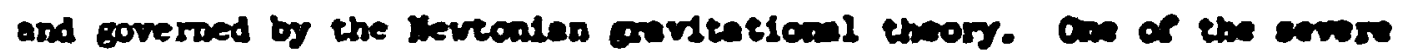

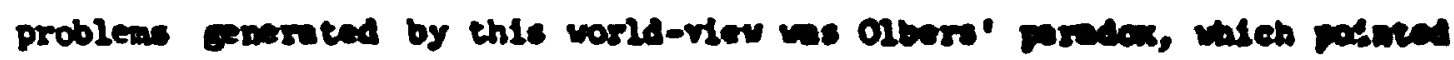




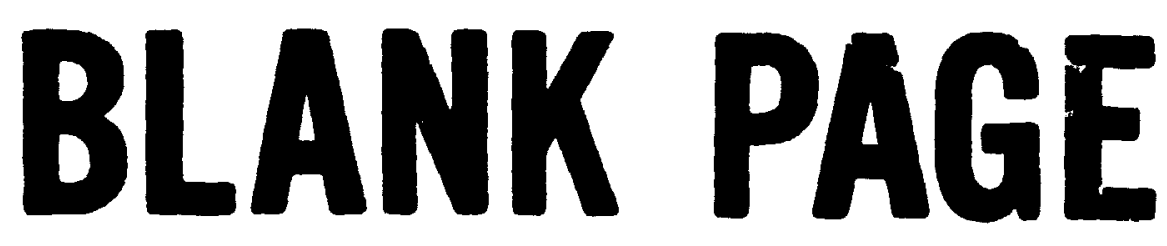


sut tinat the sky in such a vorid shoula be everyihere as brigint as the dist cf the sun. Marecrer, in such a universe the gravitationel potential at an peint becones infinite. Conrlier's hierarchic nodel was an attempt to arcid these difriculties. Other attenpts to deal with the zrovitaticnil problem censisted in the ad hoe addition to Polsson's equation of sodifying factors whict: had very little effect orer sisell dist3.ces but wtich crer large distances produced repulotions strongr than the gravitational forces. It wa not until the early tucatieth century that coseclogists reallzed that these probleas could be avoided zcre essily by dropping the assumption that. the universe is static. In 1917 de Sitter Introduced a cosmolozy which, although it was besed or a static metric, was on the verge of being a non-static model. It predicted a systematic lavering of the frequency of light from distant sources, the so-called "de Sitter erfect," which ws attributed to a slowing down of time at large distances from the observer. In 1922 Lanczus and Priedmann introduced cosmologies vith actunl timedeperderit metrics. It is this work - especially that of Priedanan tinat is ofter cited by present-day theoreticians to support the claim tinst the expension was predicted theoretically before it wa actually observed. Actually, these clains are not completely justified for, al though Priedmann's nodel did have variable radius, Friedmann himself did not relate his results to the extragalactic red-shift miasurements wich were known at the time. Purthermore his work ws not given much attention by other theoreticians until almost ten years later when the systersatic red-sinft effect was well established by observetions. 
The first successful weasureaent of a spectral shift of enother glaxy us ade in 1912 by Slipher, who cbtained a radial veloeity for YBI whose spectrum is blue-shifted. Dy 1925 scone 45 such redial relocities had been measured, almast all by Silpher. After only a fev such seasurements had been made, observars began to try to use thea in order to derive the solar motion relative to the extroglactic nebulne. In i918 Wirtz pointed out that the wasured nebuiar velocities could not be expieined without allowing for a systematic velocity effect in addition to the solar velocity. He proposed the addition of the "K-tern" which taken to be constant velocity that mist be sittracted from the nebuiar velocities before the solar motion is evaluated. The most astunishing thinf, about the "K-term" was its value - eppradmately $800 \mathrm{~km} / \mathrm{sec}$. In $1922 \mathrm{Wirtz}$ sugested that the "K-term" wight represent a sy:tematic recession of the other galaxies from ours and further that the "K-term" might not be constant but rather a function of distance. He actually found a rough ccrrelation between increasing red sinfte and decreasing angular diameters of the galaxies. The latter quantity was the only avellable nebular distance indicator at that time. Ints vork of Wirtz, like that of Priedmann, wa for the most part overlooked by the then practicing theoriats, same of whom were at the save tive working on the "de Sitter effect" without making a connection between the spectral shifts and the kinematics of the source piaxtes. Eddington was one of the flrst theorlsts to speak of radial velocities of the inxies and of the expansion of the universe. In his book, Ine rathantign Theory of Relativity published in 1922, he acknowledged the assistance 
a slipher, who had provided for hin a coplete list ef the "redial velocities" thet had been nosound up tc that tine.

Pert of the reason that the Doppler-veloelty hypotbesis us som-

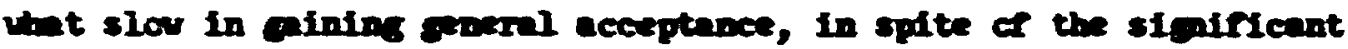
nober of seasured red shirts, ws that it wa not yet definitely estabIished that the cther glaxdes ing outside the milly hr. Mis Intter feat us accoplished in 1924 by bubble, who deterginod the distance to

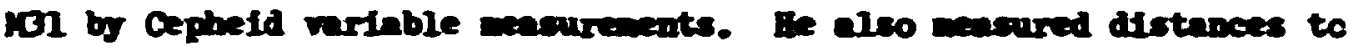
other nearby elexdes, out to about 10,000,000 lifht sears, wing Cepheids and superdint stars as distance indicators. Do 1929 ide low the reiative distances to is gaiaxies and to the Virgo cluster. Using thise distances together with Slipher's radil velocity meacurements, be ws able to obtain his Pacous linear "velocity-distance relation", which can be veltten

$$
\mathbf{v}_{\mathbf{r}}=\mathbf{E} \mathbf{r}
$$

were $V_{r}$ is radial. veloctty, $I$ is distance, and $i$ is the Hubble constsist. According to Forth (1), Bubble was not ecqualited with the work of Prledom, but be did belleve that his relation aldht represent the de Sitter efrect.

The velue Inftiali; obtained by Hubble for the recession constant II we $500 \mathrm{~km} / \mathrm{sec}$ per Hpe. Detween 1988 and 1936 fromeco extended the work of Sligher and Hubble. Using the Vount ilson 100-inch rentector, to wo able to seasuse rablal velcoltles as hith os $42,000 \mathrm{ba} / \mathrm{cec}$. Durlog the 1930's there vere several enall sevisions of the wost on

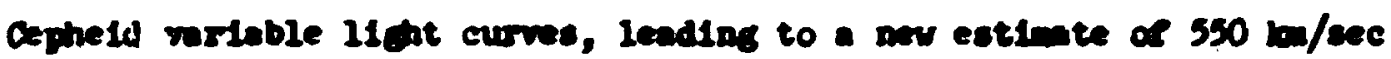




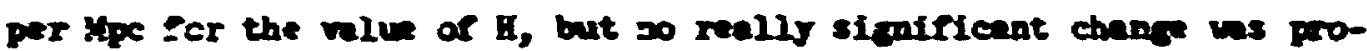
pesed until 1952, when Bade denchetreted the exdstence of tuo different populations of the Copheids. He uss able to show that ape I Copheid ns about 1.5 monitudes brifater than a Iype II Copheid with the sane perlod. Sloce the oupheids that had been observed in other plaxies vere Typ I, whereas the ones in the Milky lay which had been used to

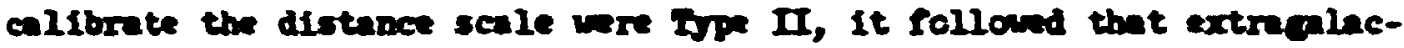
tic distances had been sstemetically underestiseted. Inen these consficretions we telen Into account, the estimte of I us revised doumind to $180 \mathrm{~km} / \mathrm{sec}$ per Hpe. Hore recent estinetes of I five values between 53 and $115 \mathrm{~km} / \mathrm{sec}$ per lpe with the nost often quoted value being $100 \mathrm{~m} / \mathrm{sec}$ per spe. Inis latter value is the one that will be slopted for use in this thesis.

Although Hubble's vort condnced most astronomers that the universe Is expanding, there were a few who felt that the grstematic red-shift effect 15 cased no: by systematic neb:lar recessio.s b:t rather by progressive reddening of the llobt whlle it is traveiling from the soirce to the observer. Zulaby proposed a Gavitational analogue of the Compon effect in which the photons transfer momentan and enerey to anj gravitating mtter which thes encounter on their journeys. Althouch Zirlch's 1dee found sane observational support, the evidence wa not conpelising enough to convince mang other astronomers. Other sucested alternatives Incluided a proponal by J. Q. Stewnt that IIgt quanta becone futiared durlns thels journeys, and a proposal by P. I. Wold that the rad oblets 
are cased by a sectiar caeng in tie wioclty o: ifcht as a faction of tim. Weither of the proposels ettrected a significent foliouring in the estrononical somanity.

one property thet Doppler rad shifts wet pessess is a constaney of the reletive shift dijh for all velues of $h$. Hiviztie (2) has described

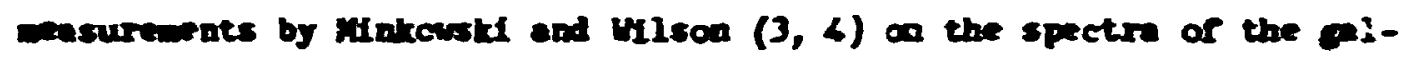
exies Growe $A$ and wec 4151 which reveal no significant reilation in the mive of $\Delta \lambda / \lambda$ between the riclet and red ends of the risul spectre. These mesurenents established the constancy of $a, / \alpha$ over the werelength Ieng of 3400 to 6600 Angtrons. Bven wore convincling evidence for the constancy of $\Delta \lambda / \lambda$ comes from the $21-c$ redinl velocities seasured by rodio astronosers. The first successful $21-c$ measurements of exterin 1 plaxtes were acconplished in 1954 by terr, Hindan, and Robinson (5), wto observed the Magellanic Clouds, and in 1956 by van de Hulst, Rainond, and ren woerden (6), who obtained a centrel radial velocity and a rotation curve for Ml. Since that time, $21-c e$ velocities have been weaswed for about 130 galexies ranging between $-343 \mathrm{kd} / \mathrm{sec}$ and $+2620 \mathrm{~kg} / \mathrm{sec}$. These measurements indicate that the optical and rodio measurenente of $\Delta \lambda / \lambda$ egree to within one percent. For the few cases were there were I Iofficant discrepancies, the optical velocitien were recently reneasured by Pord, Bubin, and Roberte (7), with the result that the new optical vives are much better agreement with the rodio measurenente than do the old oces.

The acreewent between the optical and radio weasurements estab11shes, cosstancy of the relative red shifts over a wevelength wito 


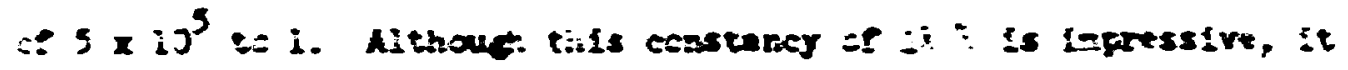

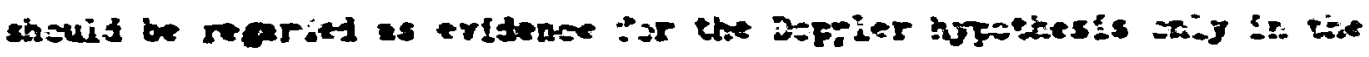

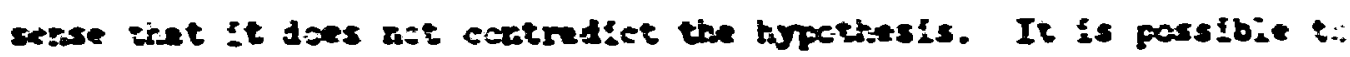

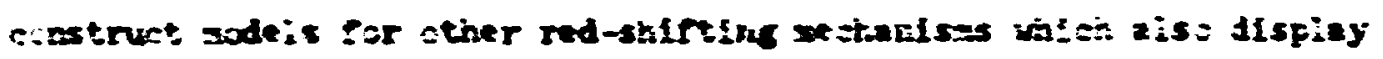

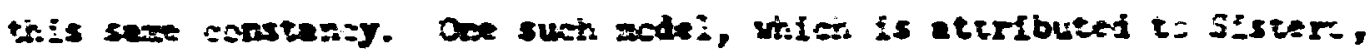
has resertiy beer described by 4. C. ArF (3). It involves the forwad scettering of the pinetons fras the saurce by reietivistil eiectros

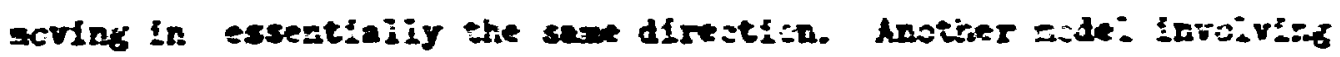

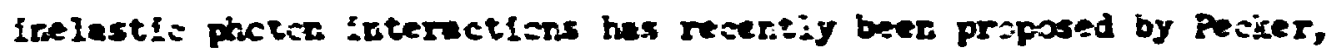

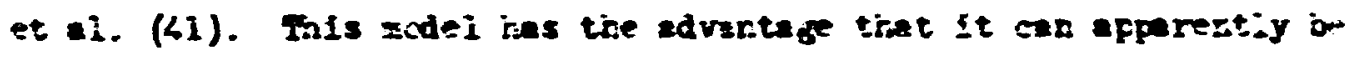
test,ei falriy rodily in. tise iaberstory. Other godels vilich attribute ibe red shift to the space-time gecaetry $c:$ the universe are discussed in Chapter 1? of this thesis.

Chapters 2 and 3 revies a few of the recert observaticrs wtich see to suggest that at least part of the extragalactic red shifts an be caused by sose effect otiner than recessior ai relocity. These chapters wake no atteapt to $\mathrm{g}$ ive an exhaustive review of the very considerable work 1r: this area. Mhe; are mant to euggest that the giession of the nature of the red ahift is stij.l an oper. 0:. a:. to asterscore tiae need for an irdependerst test of the expansion hypotheais.

Chapter - gives a brief description of the test that is performed In this thesis. This test secks a correlation between the rate of sall of the light curves of Type I supernovae and the symolic velocities of recession of their parant galaxies. Type I supernovae are the ideal candidates for this kind of test because of their great. luminosity ard the uniforwity of their light curves. 
Cupter 5 deceribes the observetional date used for the test.

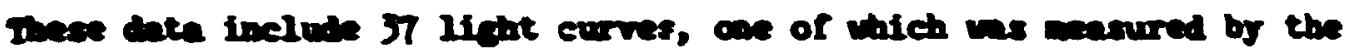
prosent author ad his calleagnes et Prairie Cbservetory. The other licht curves wore gathered frow the liternture.

Chater 6 eseeribes the reduction of the light curves to $a$ comon

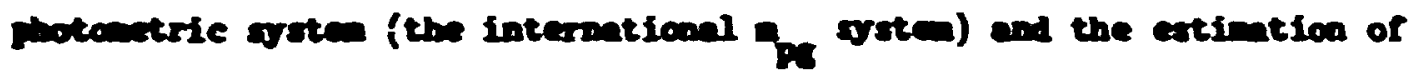

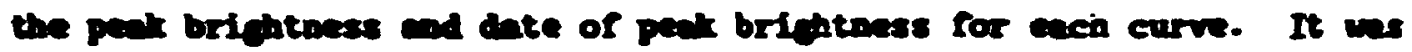

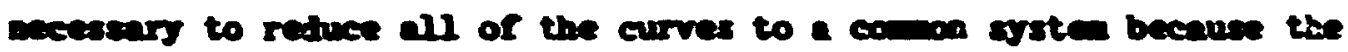
rate of decline in briphtoces no be different in diffarent ovtens.

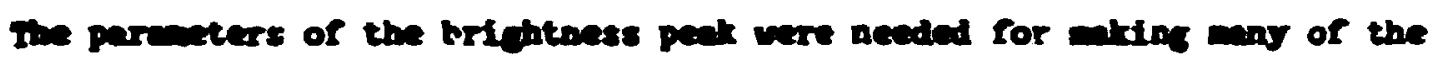
photonetric coaversicas and for fitting a mel to the observed light curves.

Cupter 7 describes the nodel thet wa fitted to the light curves and the fitting procedure. It elso deseribes the cholce of the comparison parmeter used for the test. The wodel and the comparison paraneter were chosen to dive a consistent nensure of the rate of decline of the light eurves even for frapentary lifut curves. The sodel that we chosen wes the lint-echo wodel of worrison and sartori, and the fitting procedure we nop-linear least squares.

Cheter 3 dres the results of the rits. The intringic distribution of the coperison porcuster ms extinated usting only the 21 supernove in the study with eeasured symbolic velocities less than $2000 \mathrm{kr} / \mathrm{sec}$. The everage value for this subsaple was used to estinate the prediction of the copension hypothesis for the slope of the reletion between the comparison parmater and he ambolic velosity of recession. The repression of compurison paraneter on veloctty of recesstion was performed 
using the entire saple, and in spite of the vide scatter in the date. the correlation as found to be sionificant at the 93: level. The slope of the regression line was wore than ilve tibes crester than the: presictes by the expansion hypothesis. Extensive tests were performed tc determine Whether this larcer than expected slope could have resulted from systematic errors in the dete reduction and fitting procedures. No systementie errors were found.

Chapter 9 is concerned with estinating the absolute mapicudes of the supernove if this sople. Althougld these estinates are interesting in thenselves, the main reason for computing them wes to check for lininosity selection effects in the sample. No selection effects were detected, but an apparent division of the sacple into two distinct luainosity subgroups wes found. The discusstion of these subgroups was deferred to chapter 11 .

Chepter 10 reviews some of the theories that have been proposed as alternatives to the expansion hypothesis and compares the observed relation between the comparison parameter and the symbolin velocity of recession with the relations predicted by the various theories. Most of the theories predict the sane relation as either the classical expansion or the stratic Euclidean hypothesis. One of the theories that was reviewed is the covariant chronogeometry proposed recently by the natheratician I. E. Segel. The derivation that is given for the predicted relation is based on the present author's interpretation of the theory. That prediction gives much better agreement with the observed regression line than does the prediction of the expanstion hypothesis, but the scacter in the data is too great to reject the expansion hypothesis 
or the static Euclidean hypothesis at the traditionally accepted $95^{\circ}$; Ievel of significance (the former was rejected at the 91 and the latter at the 93 level). Since seven of the supernovae in the sturly id not have measured red shifts, it vas necessary to calculate estimates for their symbolic velocities. These estimates depend on the value adopted for the Hubble constant. Therefore, a sensitivity study was performed in order to determine the effect of changes in the adopted value on the regression line obtained from the observed dats. The results of this study, witich are reported at the end of chapter 10, indicate that reasonable changes in the Hubble constant do not produce very large changes in the regressior line, whic: agrees best with Segal's theory in all cases.

Chapter 11 returns to the question of the two disti:lct luminosity groups in the sample. These groups, which were first noted in Chapter 9, appear as two well separated bands in the graph of the relation between the comparison parameter (rate of fall of the light curve) and the estimated peak absolute magnitude. In each of the bands, the correlation between these two parameters is significant at a level exceeding $99.5 \%$. Extensive tests were performed in order to determine whether or not tinis division resulted from systematic errors in the estimates of the peak apperent or peak absolute magnitudes. No systematic effects were found, so it was concluded that the two groups probably do represent two distinct populations of type I supernove. The chapter ends with a comparison of these two groups with previous schemes that have been proposed for dividing the parent population into subpopulations. 
Chapter 12 discusses further refiraments and future prospects for the comparison parameter-symbalic velocity test which take the two lunizosity populations into acc unt. It is recessary to consiâer the effert of the two groups because they nct only hare different average luminosities but also different average values of the comparison parameter. Since the slopes of the relations between these quantities are so similar for the two groups, it was possible to reconcile the two so that together they simulated a single sample with less scatter in the cowperison parameter than the unreconciled saple. The regression of comparisor. parameter or symbol fc velocity gave results very similar to those obtained from the unreconciled samle, with Segal's theor: giving the kest agreement with the regression line. The scatter in the reconciled sampie was used to extimate the number of additional light curves that must be cbtained for various limiting symbolic velocities in order to discriminate at the $95 \%$ level of significance among the various alternative theories.

Chapter 13 discusises the red shift-apparent magnitude relation aefined by the supernovae in the present sample. The slope of this relation is a very important paraneter because its value determines the form of the velocity-distance relatior. Observations of galaxies cannot be usea to give an independent estimate of this parameter because the necessary aperture corrections require an assumption about the form of the relation. Supernovae are the ideal candidates for this analyais because they are extremely bright point sources with reasonably small scetter in intrinsic luminosities. Previous studies using supernovae have agsumed that the Hubble law is valid and held the slope fixed during 
the regression. In the present study, the peak apparent aronitude was regressed on $\log \left(V_{I}\right)$ with both the siope and the intereept free to vary. The slope of the resulting regression line wa less than the value predictad by a linear velocity-distance relation but greater than the velue predicted by a quadratic one. Both of these possibilities were rejected at significance levels greater than 958. The results are qualitatively the sane if the two luainosity groups are analyzed separately, but the saple is dominated by low red-shift objects. Therefore, the results way be nore indicative of a local anomaly in the relation than of a true rejection of the linear Hubble las (or of the quadratic law). If the linear law is accepted, then the regressions for the two separate luninosity groups can be cambined with the two corresponding regression relations between the comparison parameter and the absolute magnitude to give a new method for estimating the Hubble constant. This method is described in the last part of Chapter 13. When the method was applied to the present semple, the resulting estimate was $\mathrm{H}=92 \mathrm{~km} / \mathrm{sec} / \mathrm{Mpc}$.

Chapter 14 describes a new method for estimating distances to supernovae using the relaticis between the couparison parameter and the peak absolute magnitude in a manner analogous to the use of cepheid variable period-1uminosity relations for estimating distances. It was show in Chapter 13 that the errors in estimatirig the absolute magnitudes did not produce an error in the slope of the relation between comparison parameter and absolute magnitude, and any zero-point error that might have been introduced was hopefully removed by recalibrating the intercept uaing the six supernovae wich occurred in the virgo cluster. It is this 
recalibrated relation that should be used for distence estination. The ethod was aplied to the supernove in the saple whose distances are less than $30 \mathrm{Mpc}$, and the resultins distance estinates were used to construct a graph of the local velocity-distance relation. This plot we compared to the one given recentily by de Vencouleurs which was besed on average distances to nearby clusters. The agreement between the two ws extreaely oood, with the supernove data adifing confingatory eridence to de Veucouleurs' hypothesis that the local velocity-distance relation is quadratic rather than linear.

Chapter 15 gives arief sumary of the results obtained in the chapters that precede $1 t$. 
IAPRA 2

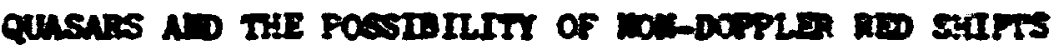

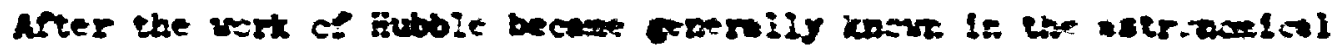

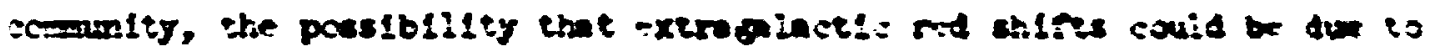

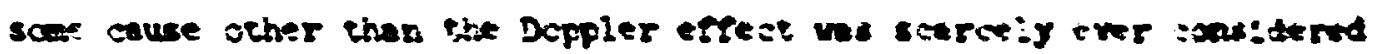

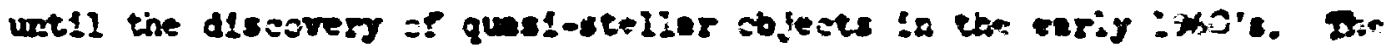
first aSO red chift wes seasured in 1263 by sermidt (i0). Ilxce thon more than 200 QSO red shifte beve been seasured. Host of these red

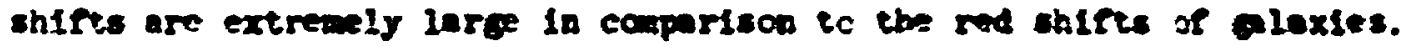
Although sont astronarers, probubly the anority of thes, eccepted Doppler interpretation of trese red sisift, a signir!cant meber sough: a non-Doppler explanation. In pertlculsr, a nubber of then verked in the mechenism of grevitational red shift until it wes shom to be an untemable hypothesis for a muber of reasons. Hot the least of these reasons vas that the densities required to produce the red shifes vould preclude the appearence in the spectre of certain emission lines that are actually observed.

The Doppler schocl was at first divided into twc branches - one that held that the QSO's are actually at the comological distances Indicated by combinine, their measured red shifts with a hubble-type velocity distance relationship and one that held that the QSO's vere local objects which had reletivistic velocities because they origlnated In tremendous explosions in ow ow and/or other nearby galaxies. The locel orfgin theory was hard pressed to explain the sbsence of blue- 


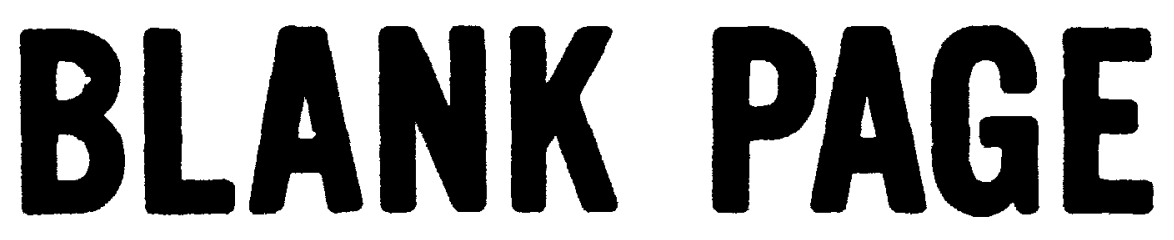


alfred quans and us virtuils compieseis abandoned after the rative by Jefrress (II) and by Luvten and Satth (i2) to find ans significent proper sotices far quasers.

The stomel=gleai-Deppler partisons scch rax into difricuities aiso. oce if the firet tinlags they attempted to do, as soca es encugh data becane areliable, was $t=$ use the 250's $t=$ extend the Hubble relatioush'p. Eaverer, in i*66, Hoyle and Bubide (13) demonstrated that there is alsast ne asrreleticn between the apparent mgoitudes and red shifts of the 250's and tinet what Ifttie ccrrelation exists is lost in a scatter that Is aeariy as inro as the span of the relation.2 Even warse scatter was foud In the relation between red shift and rajlo fivo density measurements. This scatter vas generaily interpreted as evidence that aso's have yidely verying opticel and radic luminosities, a circuastance which dces nut contradict their belng at cosmclogical distances, but which dces render thez unsultable for extending the fubble relationship. But hicyle and Burbidg: also pictted a icg II-log S relaticnship for the 38 2SO's yhlch, ot that time, had knom red shifts. The result was a stroldit-line relationsifip with a slcpe very close to -1.5, which corresponds te Euclidean space. When these same QSO's were plotted as a relatIon between red shift and radio apparent magnitude, the result was a complete scatter diagram. This means that if one assumes the uswal distance-volume interpretation of the $\log$ N-108 S reletion, then it is n:cessary to conclude that the aso red shifts have nothiug to du with their distances. Conversely. If the red shifts are assumed to be cosmolcalcal distance indicators, then it is necessary to abandon the Beometrical interpretation of the log $\mathrm{N}-10 \mathrm{~g} S$ relation. 
Ancther difficulty vith the ccsaclogical hypotioes is is the apparent lask of correlaticn between the lccations cn the celestial sphere of 250's with low red shifts and the lcceticn of clusters of ealaxies vith the sane red shifts. Acconding tc Arp (8), none of the nine aso's loncrn In 1969 tc have red shifts $2 \leq 0.2 \mathrm{mall}$ in coe of the 272 cluoters listed in Abell's catelcgue (14) of the richest clusters containing plaxies brighter than a Imiting mgaltude ccrrespending to $2=0.2$. In fact, a study by Bahcall (25) shcwed that even if the Abell cluster d1aneters are doubled, the resulting regioss on the celestial sphere do not contain any of the 9 QSO's vith $z \leq 0.2$. Since weii over 50 percent of all gelaxies are knom to lie in clusters, it is very difficult to explain why QSO's should systematically arcid these basic mass concentretions if they are truly at the distances indicated by their red shifts. This objection to a cosmological distance scale for QSO's loses some of its force, perhaps, when a recent afsccvery by Gunn (16) is taken Into account. Ounn has found that the QSO PKS $2251+11$, which has a red shift $2=0.323$, 1s superposed on a small cluster of giaxies. One of the falaxies has a measured red shift of $2=0.33$. The red shifts of both the aso and the graxy as well as that of another glaxy in the cluster have recently been remeasured by Robinson and Hampler (17). These measurements, made wth greater resolution, confirmed Gunn's earlier conclusions about the agreement of the red shifts.

Although it seems fairiy certain that Gunn has indeed found a aso superposed on a cluster of galaxies with the same red shift, this one case does not definitely establish that QSO red shifts are cosmological. 
Tr-- remains she possibility that Fis 2251-11 is a relatirely wearis biest between us and the sluster. Isis question vald be imediately r:sclved if sther $250-$-luter solncidences are disccrered. Ino previous

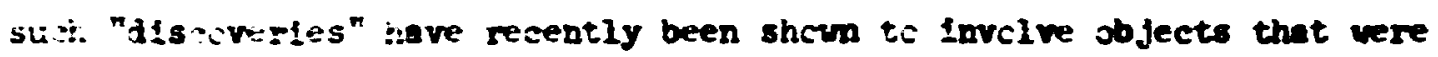
nit really $450^{\circ} s$ (is). Thus after s iveral years of uct cn the problem, only one such ceinoldence nas been found.

Recent sbservations, on tine cther hand, seem to Indicate that at least some of the QSO's are associated uth nearby orlaxies, The olaxy ITCC 520, wich is goxy nuber 157 in Arp's Ating of Peculiar Qalaxies (19), is a very bright and very disrupted olaxy which has been sincos $(20,21)$ to have ifnes of radic scurces enanating from it. Four of these radio sources are 200 's which fall along a stralght line that terainetes on the plaxy (8). The total angular extent of the system is abcut 3 degress. The red shifts of the cour QSO's are $z=0.67,0.72$, 0.77 , and 2.11. The red shift of the faxy is $z=0.007$. The radio properties of the aSO's vary in a systematic way along the lins. Flux densitiss decrease and spectral indices flatten with increasing distance Pron the laxy. It seems rather unlikely that such a configuration could cccur as a result of chance projection effects.

At the present time two QSO's have been observed to be connected to galaxies witn differing red shifts by luminous fllaments. The first to be observed was the QSO Markarian 205, which has a red shift of 0.070 and has been show by Arp (22) to be connected by a luninous tube (faintiy visible in Ha) to the laxy MGC 4319, whose red shift 180.006 . The second 250 shown to be connected to a nearby gaxy was discovered by 


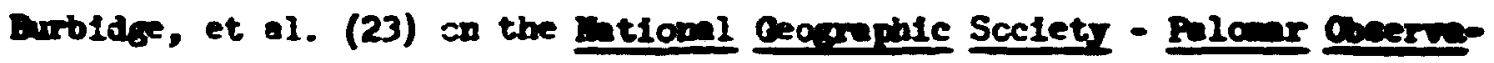
torl Sol survey prints. The redio quie: 090 P.IL 1226: whica bas red shift $z=0.404$, is shown on the S1x Survey prints to be consected by a Iusinous bridge tc the Sb giaxy IC 1746, wich has red shift $2=$ 0.026. The bridge is clearer on the red print than on the blue. A later plate taken by Arp with the 200 -inch Bale telescope on 103a-J emulsion does not reveal the bridge but does shov a nonstellar canpact object exactly between the QSO and the elaxy. This compact object is not visible on the Slo Survey prints.

Burbidge, et al. (23) also made a statistical comprison of the distribution of the 47 known 950 's in the $3 \mathrm{C}$ and $3 \mathrm{CR}$ catalogues with the galaxies in the Reference Catalogue of Bright Galaries. They found four QSO's wuch closer to bright galaxies then would be expected if the 47 were distributed randonly on the celestial sphere. The four folaxy aso pairs are listed in Table 2-1.

Table 2-1

QSO's With Small Angular Separations Prom Bright Galaxies

\begin{tabular}{|c|c|c|c|c|}
\hline QSO & Calaxy & Separation & 2 (QSO) & $z$ (Galaxy) \\
\hline $3 c 232$ & ITCC 3067 & $1 \cdot .9$ & 0.534 & 0.0050 \\
\hline $3 \mathrm{C} 268.4$ & MGC 4138 & 21.9 & 1.400 & 0.0036 \\
\hline 3c 275.1 & IGC 4651 & 31.5 & 0.557 & 0.0025 \\
\hline $3 c=09.1$ & $\operatorname{MGC} 5832$ & $6 ' .2$ & 0.904 & 0.0020 \\
\hline
\end{tabular}


In each case the red shift of the QSO is very mach inger than that of the olas. Durbldge, et al. eationted the probability of $h$ such clase pelring cecurring by chance to be leas than 0.005 .

The evdence for close associntion between QSO's and pearts folndes Is rurtber strengthered by the recent discovers by Arp, et al. (24) that the radic source 30455 is a 450 which 18 situnted 23" northeast of the

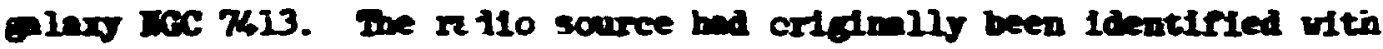
the elas, but more accurate measurements of its radio position by R. In Adgie revealed that the source was actually associated with the faint. $\left(E_{y}=19\right)$ blue stellar object northeast of the elasy. Optical studies by Arp, et al. revealed the object to be a 050 with red shift $z=0.543$. The red shift of the onaxy was weasured to be $2=0.03321$.

As ware associations between QSO's of hich red shift and nearby gaxies are discovered, it becones wre nearly certain that at least same of the USO's are relatively local objects. Purthernore, since nowe of them have been observed tc have blue shifts, it becanes more appareat that at least part of the red shifts are due to sowething other than velocity effects. 
consen 3

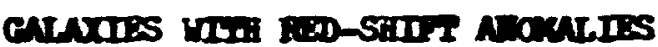

Although nont elades thet bure bees cbeerved appear to cbej the Huble 1n, there ore a few exceptions wich seen to heve discrepant red stifts. Ose such exple is the elad IC 3483, wich is a werber of a triple systen composed of IC 3481 , an anvijyorss galasy (whici sinall be called anon. in the following tex:), and IC 3i48;. A detefled deseription of this system bas been given by 2ufikg (25). The radial velisefities deduced fros the ceesured red shifts of the three galexies are:

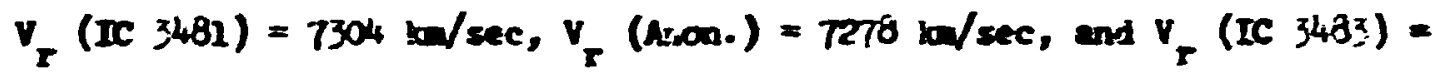
$103 \mathrm{kd} / \mathrm{sec}$. The three are connected in a chain by two raintly luanous bridges which ere epparently composed of stars ratier than elvorescent cases. The presence of these bridges rules out the possibility that IC 3483 is a nearby foregrount calexy which projects into the chain by chance. If all three red shifts are pure velocity shifts, then the velocity of IC 3483 relative to the other is wach larger then the typical relocity disperstion observed in large clusters $(-2 \times 00 \mathrm{~km} / \mathrm{sec})$.

Another example of a chain of alexles in which one member has a discrepant red shift is the chaid W 172, which has been described by sargent (26). Four of the glaxies in this chain of five have red shifes correspondins to velocities of ebout $16,000 \mathrm{~km} / \mathrm{sec}$, but the fifth has an epperent velocity of $36,860 \mathrm{~km} / \mathrm{sec}$. Sargent ove statistical erguwents to counter the possibility that the discrepant olaxy is really a bekpround olaxy which projecte into the chain by chance. He concluded 
that the probability of such an securreace is caly abcut 1 in 5000 . If the glaxy is at the sane distance as the cthers, and if all the red shifts are strietly velceity efrects, then tis: tise-sole far the discrepant elay te cross the system is $-3 \times 10^{6}$ years and its kinetic enero is $10^{60}-10^{62}$ eras.

Another croup vith a dis:repant meber is Stephan's Quintet, wich hes recently been investipted by murbide and Durbide (27). Inis is a

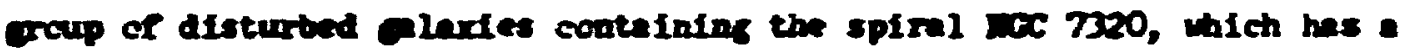

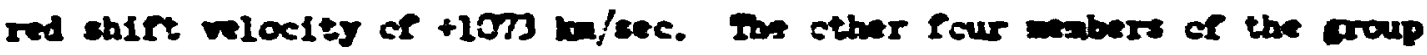

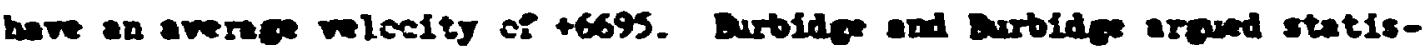
tically that the probebility that woc 7320 is a forecreund alexy projecting Inte the croup is lass than 1 in 100C. Purthermare, they were able to cbeain an estinte of Its ass from its retation surve. They coacluded from this estimate that if it is a forecreud alaxy at the indicated red-shife distance, then it is extromely dwarfish and denser by sbout two orders of megitude than nenel spirel olaxies. If ICC 7320 is really a member of the croup, and if tes red shift is a true velceity indicetor, then it is in a state of explosive expansion out of the syster tomend us. Durbida and Durbidare calculate that the kinstic enero involved would be $=7 \times 10^{61}$ eros.

The three examples that have just been diven involve croups in which all of the galaxies arn more or less the seme size. Recent work by H. C. Arp on plaxies wth smaller companion graxies has raised the possibility that such companions sometimes have excess red shifts. One example is the disturbed spiral olaxy naC 772 wich, according to Arp (28), 


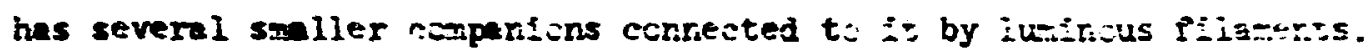
From the sever cbserved compenians, frp picied the three brititest İr spectrai cbservaticns. Following ins netation the tiree

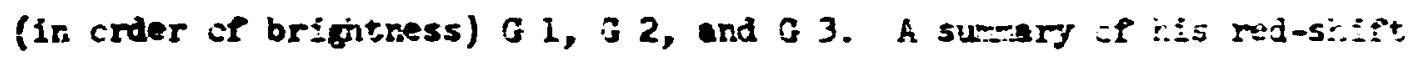
geasurements is given fir the Rilaving tabie.

Thabe 3-i

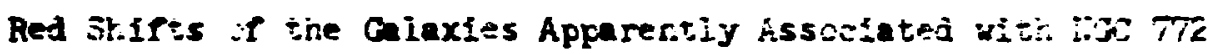

\begin{tabular}{|c|c|}
\hline Ceisxy & Red srifs (st ses) \\
\hline KGC 772 & 2,437 \\
\hline 61 & 2,454 \\
\hline G 2 & 29,174 \\
\hline G 3 & 19,663 \\
\hline
\end{tabular}

Arp a rgued inecnclusiveiy on the basis of the liubbio red stift aprarent magnitude reiationship and the cbserved propirties of 62 and o ; that they cculd not be background galaxies. Iis direct photcegranisis evidence was, however, more conclusive. Ho coseryed that 6 is on th: end of a dcubl: spiral a rm from NGC 772 and that 63 is on a Iumincus protuberance of an isopicte of NGC 772 .

Another exampls of a galaxy with an excess red shift companicn is NGC 7603 , wich has recentiy been studied by Arp (29). It has a redshift velority of $8,800 \mathrm{~km} / \mathrm{sec}$ whlle the companion, which is connected to it by a luminous pllament, has a velcelty of $16,900 \mathrm{~km} / \mathrm{s} 0 \mathrm{c}$. Acturiz, there are two filamnts connecting the galaxies, on of them being? 
spiral arm of NCC 7603 and the cther cutside the spiral arm, curving more sherply inic the compenicn. NGC 7603 is very disturbed and the companion is peculiar, having a core of high surface brightness and a halo of lor surface brightness. The halc has a slightly deformed bright rim at the point where the spizal am enters it. Thus there is virtially nc doubi that the twe galaxies are at the same distance and am interacting with each other.

In all of the examples given sc far, the discrepant red shifts migit be explained by an explesive expersicn of the discrepant member cr nembers cut of the grcup. This is a very attractive possibility for Etenhen's Quintet, in which the fcur non-discrepant members appear tc be very disturbed. The chain W 172, on the other hand, dces nct appear to be disturbed, and the glaxies in the triplet IC 3481 , Aricn., IC 3483 are connected by luminous bridges of apparently stellar matter. Furthermore, the energies demanded by such explosive events are extremely high, altiough p:rhaps not unreascnable for cbjects as big as galaxies. The times required for the discrepant ner.ters to cross their respective grcups are of the crder of $10^{6}$ years, sc that such explcsions woulil have to be fairly irequent everits if many grcups are to be observed wth the discrepant member still in the group. Alzo, it seems reasonable to expect that the stare in such a discrepant member should all be young, having formed after the exploston.

Both of the galaxies NCC 772 and NGC 7603 are highly disturbed sC that it 18 tempting to interpret the excess red shifts of the smiller companions as a true velocity effect with the higher velocities of the 
ccapanions being attributed to their being explcsively ejected from the larger galaxy. Probebly the most effective argument ageinst this inte:pretation is the cre given by Arp (29) in consecticn with NGC 7603 and its companion. According tc Arp, if the red shift difference is indicative of a true velccity difference, then the tiro galaxies are separating tco fast for gravitational interaction to have formed a ccnnecting bridge between them. Thus he is led tc the ccnclusion that at least part of the red shift difference is caused by some non-velocity effect.

Ancther reascn for discarding the di rerential velocity interpietation for discrepent red shifts of compenion giaxies is that mcst of the discrepancles are excess red shifts and only a fev excesb blue shifts are observed. Thus, unless one is willing to accept the proposition thet parent galaxies preferentielly eject their compantone in directions avor from us, ore is forced to admit a non-velocity comp nent of the red shifts of the companions. fo course the examples given so far, namely NGC 772 with its two companions of excess red shift and NCC 7603 with its companion, do not constitute a very large sample, but a study Involving a larger sample has recently been made by Arp (30). He picked for the study three groups of galaxies in which one galaxy is unquestionably the dominant member and in which the others are unquestionably companions. These groups were $M 31$ and 1 :s four companions, $M 81$ and Its five companions, and NGC 5128 and 1ts four compentions. Of the 13 companions he found that 12 had higher red shifte than the primary. He took the meesured red shifts Prom the de Vaucouleurs Reference Catalogue 
If Bright Galaxies sc that mest of thein were the mians of two or more cptical determinations which isually did nct differ by mere than 20 kn/ses. Five of them had radic determinaticns which agreed to abcut the same accuracy. Tc the abcre described sample, he alsc added six spiral gaxies which have companticns on the ends cf spiral arws. Of this tetal sample of i 9 companicns he found that 16 had excess red shifts and only three had excess blue shifts. The distribution of the residual red shifts, 2 (ccmpanion) - 2 (dcminant), shous a proncunced asymetry toward pcsitive values and is strongly peaked at abcut $75 \mathrm{~km} / \mathrm{sec}$. Ten of the companions in the sample have residual red shifts in the range $50-100 \mathrm{~km} / \mathrm{sec}$, and five more of them have even greater residual red shifts.

According tc Arp, his sample of 19 companions zontains essentiglly all the small companicns with kncwn red shifis and known with certainty to belong tc a group cbvicusly dominated by a larger galaxy. He has been criticized in his cholce of sample by B. M. Lewis (31). Lewl. maintained that a better sample is obtained by including groups regardless of whether the. have obviously dominant members, as long as a working rule :or choosing a tominant member is consfstently folloxed. lising such a sample ccntalning 186 galaxies, he obtained a residual red shift distribution containing 103 excess red shift: and 83 biue shifts and with meen of about $+40-50 \mathrm{~km} / \mathrm{sec}$. He claimed, however, that this slight asymetry toward excess red shifts is not signzficant and is probebly the resilt of observational errors, one of the a being the mistaken identification of foreground galaxies as dominant members of 
raster moving grcups in ihe beckground. He alsc studied the residua: red shifts of groxies wtich ere members of peirs. For his sample ie chose the pairs fru two studies by Page $(42,43)$ and found no significant asymetry in the residunl red shifts.

ATP's reply (32) to Lewis' critieisa was short and direct. He argued that Levis' rule for picking the daminent members of groups was very speculative and that the data for Page's pairs vere concleteiy inapplicable since they vere orfiginally chosen to be more or less equal pairs. He pointed cut that Lewis did find an esymetry, even using questionable data, and then tried to explain it away by the very projection effect that he (Arp) had sought to avoid by limiting his sample to groups whose memberships were certein. Arp's final assessment of Lewls' criticisms is eloquent encugh to bear repeating:

Th sumary, then, Lewis has tested with lower weigh: and inapplicable deta. In spite of this he confirms the original result. He then postulates that this confirmation is due to $\pi$. . . the mistaken adoption of foreground and relatively low velocity galaxies as dominant members of groups." But it was this very objection thst I was trylng to avold by excluding the lover-weight data in the Pirst place.

Even more recent evidence for non-velocity red shifts in gaxies has been published by Jakkole (33). He made a study of red shifts of galaxies in clusters, groups and pairs using the dimensionless parameter $u=\Delta V / \sigma_{v}$ where $\Delta V=V($ galaxy $)-V($ system) is the residual red shift of the oplaxy (expressed as a velocity) and $\sigma_{v}$ is the red shift dispersion of the system. This particular parameter was chosen so that systems of differing sizes and velocity dispersions could be analyzed together. 
He found that in almost all the different ikfinds of systens studied, E, So, and Sa galaxies show an excess of residual blue shifts while Sb and Sc spirals show an excess of residual red shifts. His values for $\overline{I V}$ (average $4 V$ ), $\Sigma_{y}$, and $\bar{u}$ (average $u$ ) are gdven in Tuble 3-2. Within the different types he alsc found significant correlations between red shifts

Table 3-2

Residuai Red Shifts of the Galaxies in Jankkola's Study

\begin{tabular}{lcccc}
\hline & $\begin{array}{c}\text { Huber } \\
\text { Inpe }\end{array}$ & $\begin{array}{c}\overline{\Delta V} \\
(\mathrm{~km} / \mathrm{sec})\end{array}$ & $\begin{array}{c}\mathrm{J}_{\mathrm{v}} \\
\mathrm{km} / \mathrm{sec})\end{array}$ & $\overline{\mathrm{u}}$ \\
\hline $\mathrm{E}$ & 131 & -39 & 645 & -0.07 \\
$\mathrm{SO}$ & 114 & -28 & 433 & -0.05 \\
$\mathrm{Se}$ & 73 & -124 & 463 & -0.28 \\
$\mathrm{Sb}$ & 84 & +56 & 406 & +0.13 \\
$\mathrm{Sc}$ & 51 & +131 & 517 & +0.20 \\
\hline
\end{tabular}

and various cther parameters such as absolute magnitude. The implications of his results are perhaps best expressed in his own words: The result means that in scme part even for normal gaxies, of late Hubble types, wth small color indices and smali inclinations, part of the red shift cannot be explained by systematic velocity". 


\section{CHAPrDT 4}

\section{A. OBSERVATIOAAL TOST OP THE EXPAISIOR HIPOIIESIS}

The apparent discoveries of non-velocity red sinifts in nearby QSO's and ordinary gejaxies lends a special urgency to the search for an independent test of the expansion hypothesis. Even if the recent discoveries had not been made, such a test would still have been higily desirable, since any scientific hypothesis which is based on only one bit of evidence must be regarded as provisional at best. Even though tine expanding universe idea has doarinated twentieth century cosmology, quite a number of workers have worried about testing the reality of the expension. In 1935 W. H. McCrea published a paper (34) entitled "Observable Relations in Relativistic Cosmology" in which he pointed out tinat, if the expansion is Indeed real, then any periodic phenomenon in another galaxy must be subject to the same Doppler effect as th ? radiation from that falaxy. In particular he suggested that the periods of Cepheid variable stars in a distant plaxy should be lengthened in the same proportion as the vavelength of the adiation from the galaxy.

A variation of the same idea appeared agin in 1939 in a paper by 0. c. Wilson (35), who pointed out that if the red shift is a Doppler effect, then two events occurring in a distant alaxy wh observed red shift $V / c$ would appear to us to have a longer time separation than to an observer in that plaxy. If $\Delta t_{0}$ is the time lapse measured by the distant observer, then, according to Wilson, the time lapse measured by us would be

$$
\Delta t=\Delta t_{0}\left(1+\frac{V}{c}\right)
$$


of course this formula is good oniy for, alaxies which are not far enough auaj to have apparent velocities large enough to require a relativistic treatment. Mlson we impressed by the then recent deterninations by Bade and Ivitty of "he 1 ight curves of three superwovar in otinir gelaxies. Because of the good agreesent of the shapes of the three cur:es, be sugeste that silh ilght curves would grovide a kood test of the expansion hypothesis. For a supernow in a distant onery with velocity $V$, he argued: "Hence, the light curve of a supernove occurring in such a nebula should appear to be expanded along the axis In the ratio $\left(1+V^{\prime}(c): 1\right.$ vith respect to the 'standard' lint curve Given by relatively nearby objects."

The sane Idea anporred again in 1955 in a paper by S. H. Milford (36), who was fumiliar with McCrea's earlier paper but not vith Wilson's. Milford pointed out that Cepheids could not be used for a test because they are not intrinsically lininous enough to be observed in any but the very nearest pasixies. He sugjested that Type I supernovae are the only objects whith are known to be luminous enough to be seen at very great distances and which possess the necessary degree of similar$1^{+}, y$ in their intrinsic light curves.

The devlining portion of the light curve of a Type I supernove consists of two parts: an inttial rapid decline to about three magnitudes below peak brightnes8, occurring in about 35 - 40 days, followed by a slower, very nearly linear decline which continues until the supernove becomes too faint to be observed. The light curves of the three supernovae which so impressed wilson are shown in Pig. !h-1 in order to 

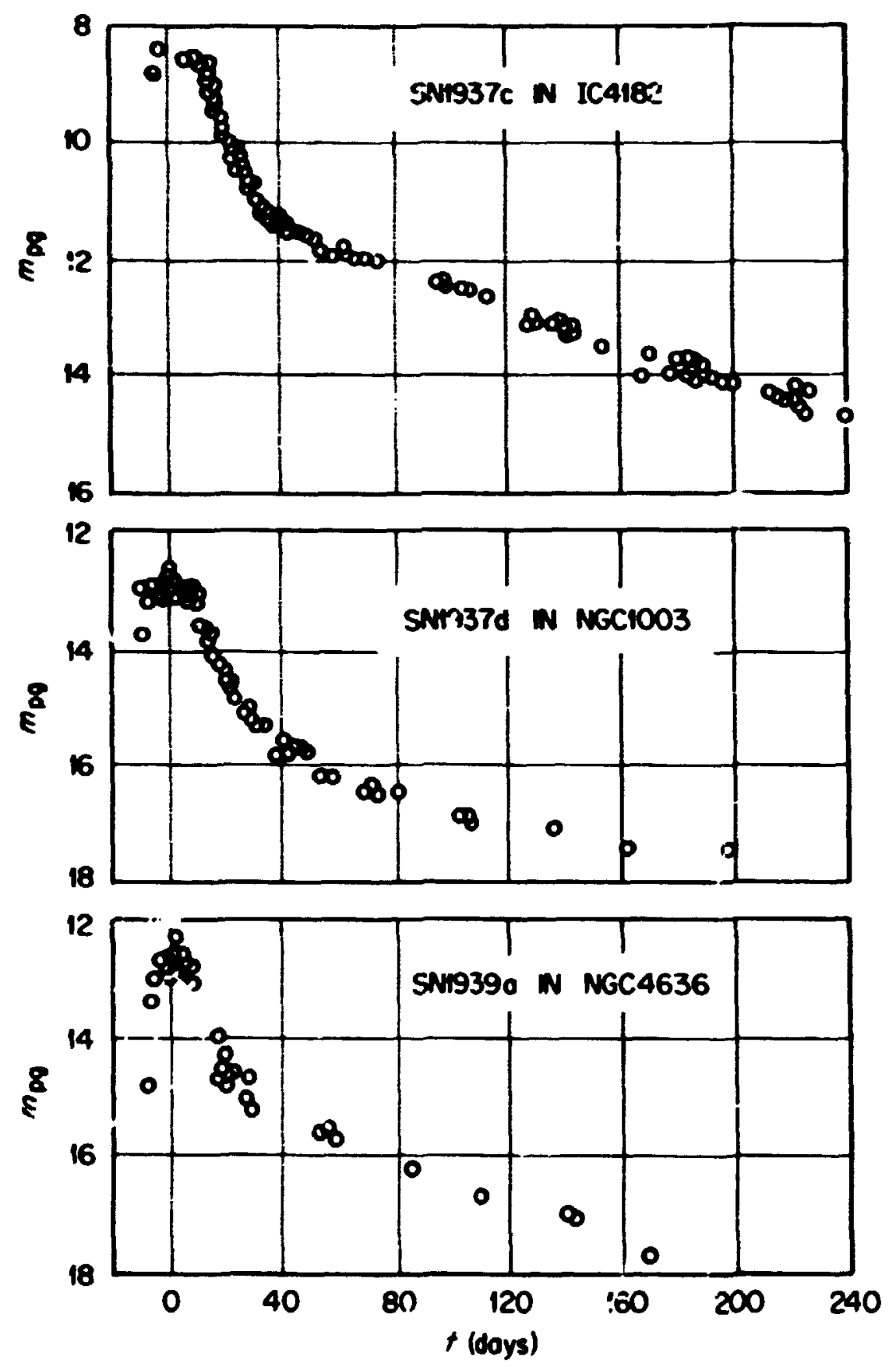

Figure 4-1. The Light Curves of Supernovae SN1937c, SN1937d, and SN1939a. 
illustrete the form of th Type I light curve and the basic unfforml:y of the phencmenon.

Milfcrd suggested that the test of the expansion hypothesis should be based on the linear decline portion of the light curve. Using a mery general homogeneous, 1sotropic, general relativistic cosiological model he ves able to show that the observed rate of decline, expressed in terus of photogrephic monitude $n_{p}$, is related to the intrinsic rate by

$$
\left(\frac{d p}{d t}\right)_{a b s}=\frac{1}{1+2}\left(\frac{a p}{d t}\right)_{1 n t}
$$

where $z$ is the observed red shift. He noted that this result is identical to one that he had obtained earlier (37) using special relativity. He stated that the same test could also be derived for cosmological models even more general than the one he used. He noted that only differences in magnitude need be measured along with the corresponding time lapses, thus avoiding the problem of determining an absolute zero point for the magnitude scale.

Milford pointed out that the greatest disadvantage of his proposed test was that it applied to the linear decline portion of the light curve, which starts three magnitudes below the maximum brightness. In spite of this disadvantage, he concluded that the test was still practically possible with existing equipment. Inis same problem was discussed again in 1961 by PInz1 (38), who proposed the same time lapse test that Wilson had previously proposed. Pinzi polnted out that the initial decline portion of the light curve offered the bast opportunity 
for applying the test because this brichter portion an be seen for supernove at creater distances, but he concluded that using this portion would require several observtions and statistical wethods because ". . the decay of the luninosity of supernove during the first 100 dags is not a very regular phenomenon." be was evidently under the inpression that the linear decline portion of the curve, if it vere bricht enough, would not require statisticel nethods in the epplication of the test. In actual fact, there is as weh variation from one supernove to another in this later part of the light curve as in the earlier wore repidy falling part. But at the tive Pinzi ws writing his paper a large nuber of astronomers belfeved tist all Type I supernove bad almost identical light curves after the initial bright part, with the Iuminosity decaying according to an exponential law with a balf-life of 55 days. It had been pointed out by Burbidge, et al. (39) that this is the same as the hall-life of the transuranic element ${ }^{254} \mathrm{cr}$, and it ws widely believed that the linear decilne portion of the light curve could be explained by the redicactive decay of this and other heary isotopes. More recentiy Mihalas has shown (40) that many supernove exhiblt considerable deviations from a 55-day half-life decline, and the radicactive decay theory has been abandoned by most astronomers. Thus, regerdiess of wich section of the light curve is used, it is necessary to obtain as many light curves as possible in order to reduce statistically the fluctuations caused by the intrinsic variations Irom one supernova to another. The chief task of this thesis will be to appiy wison's test to the bright part of type I supernova 1ight: curves. 
CinPeer 5

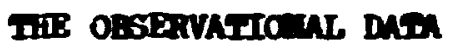

The first observed extraglactic supernove we the 1885 cutburst in the Andraneda golexy, which was at first thought to be a comon now. This nistaken identification led to a drastic underestimete of the distance tc $\times$ 31, thus causing grest difriculties for those astronomers wo were trying to prove that the spirnl "nobulae" vere truly extregalactic objects. This difficulty lingered uatil 1917, when the work of Ritchey and curtis revealed the distinction between ordinary novee and supernovee.

In the years between 1825 and 1936 a total of 15 supernovee vas discovered by various observers. The first systenatic seerch for supernorae ins carried out between 1936 and 1941 by Zwick and Johnson with the 18-Inch Schaidt teiescope ot Hount Palomr. Mis patrol Jielded a total of $19 \mathrm{new}$ discoverles. In the years between 1941 and 1956 discoveries by varlous observers brought the total maber of discoveries up to 54. A sumary of these discoveries was reported by Zwick in the Handbuch der Physik (44). In 1956 an international copperative search was organized by Zuliky. Observatorles participeting in this effort Included Polom and Mount Mlson, Stewnd, Tomatzintla, Meudon, Astago, Berme, Crimea, and Corgoba. Prellainary resilits of this search were reported by $\mathrm{Zwick}$ in 1965 (45). Since that tine a muber of other observatories have joined in the search for supernove, and at present on the ave:ege about 15 nev discurerles are made each year. Karpowicz and Rudnick1 have published a complete cataloove of all the 


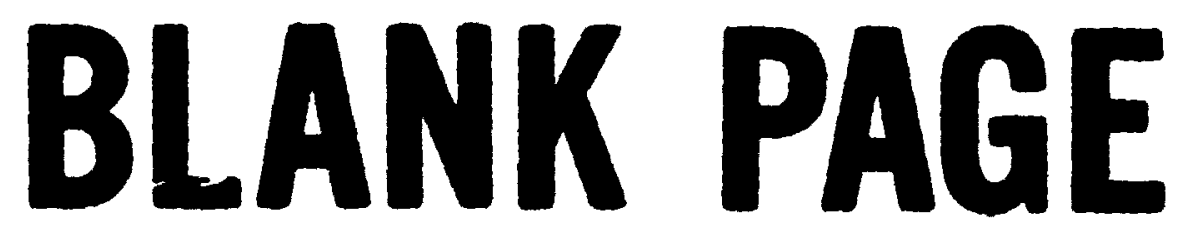


supernove discorerad up to 1967 (46). A sumery list of all the dis-

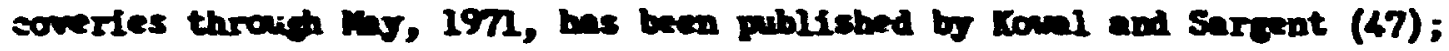
It includes 300 superwove.

Obererntios of the lipht curves and spectre of supernover beve revenled thet there are at least two very different types of suf movec. zrick and aw of his callenges believe that they here found five different types, wich they call type I, II, III, IV, and V, but only a few of the lntter three types bere ever been identified. Of the 300 superwove in roml and sarcent's List, 83 have been classified accordIng to type. Of these 83, 51 are tupe I, 26 are type II, 2 are type III, 1 is type IV, and 3 are type $V$.

A description of the properties of the various types of supernove can be found in recent survey articles by Zuiclo (45) and Mirkoustel (48). Type I supernove are remattable in having untform light curves and hich intrinsic luninosities. The ligt curves for type I were described In Chapter 4. The 11 cht curves for type II supernove are generally natter and have much wider intrinsic varintions than those of type I. The peak luanosities of the verlous types of supernorae have been the subject of recent studies by Koml (49) and Priconkil $(50,51)$, who rind that type I supernove are on the average about two angitudes brighter than type II. Because of their lower luanosities and the irregularities In their light curves, type II supernove are not suitable for testing the expansion hypothesis.

Not every one of the 51 identifled type I supernove in Kown and Sergent's 11st is a suitable candidate for the test proposed in 
this thesis. Same were observed only sporadically so it is possible to obtain only very fragmentary light curves for them. The ones for which good light. cy-res de exist heve been measured in mary different monitude systems, racging from the visual observations for the 1885 Androneda outburst to nodern narrow kand photoelectric photoneter weasurements. Because the light curves may decay at different rates in differint werelength bands, it is necessary to reduce all of the light curves to a cainon maitude systen. These reductions to a camen photometric system are the subject of the next chapter.

Although most of the datn usei in this thesis vere gathered from the existing literature, one of the light curves was actually measured by the author and other members of the University of Illinois Astronomy Department. These observations have been reported by Deming, Rust, and Olson in a paper for the Publicetions of the Astronomical Society of the Pacifie (52). The results of a preliminary reduction of the data will also be given in this thesis in order to illustrate how the various kinds of photometric data are reduced to a common system. The supernova in question is the 1977 outburst in the galaxy NGC 5055 (M 63), which was aiscovered by G. Jolly on May 24, 1971 (53). It was observed at the University of Illinols Prairie Observatory using the four-inch Ross camera and the 40-inch reflector. The Ross camera observations were made on IIa-0 plates without a filter so that the resulting photometric system was very nearly the standard international photographic magnitude system, denoted in this thesis by the symbol $\mathrm{mpg}_{\mathrm{pg}}$ The 40-1nch reflector nbservations include photoelectric $B$ and $V$ observations and photographic $B, v$, and $m_{p g}$ observations. 
The observed data vere reducrd using a sequence of comparison stars whose $B$ and $V$ magnitudes vere measured photoelectrically and whose $\mathrm{pg}$ magnitudes vere then synthesized according to the standard sonversion Pormula

$$
m_{\text {pg }}=B-0.29+0.18(B-v) .
$$

The details of the reduction and the final resultil.g magnitudes are given in (52). Table 5-1 gives the results of a pinif-inor reduction. Although equation (5-1) was originally derived for transforming the magattudes of main sequence stars, it works quite vell for transforming supernova magnitudes. For sxample, when it is applied to the $B$ and $v$ magnitudes measured on $6 / 22 / 7$ and on $7 / 16 / 71$, it gives $m_{p g}$ magnitudes of 14.65 and 15.21. The corresponding measiured $\mathrm{mpg}_{\mathrm{pg}}$ magitudes on these dates were 14.60 and 15.25 . When all of the measured B and $\mathrm{V}$ magnitudes are converted to $\mathrm{m}_{\mathrm{pg}}$ by Eq. (5.1), the result is the light curve: shown in Pig. 5-1, which also shows a messurement made on Kay 20, 1977, by ran Herk and Schoenmaker $(54,55)$ and one made on Moy 25, 1971, by K. Ishida (56). These last two neasu;ements are shown as open circles while the Prafrie Observatory measurements are shown in closed circles. The measurement by van Herk and Schoemaker was made orlginally in the $\mathrm{m}_{\mathrm{pg}}$ system, while that of Ishida was made in the UBV system and converted to $\mathrm{m}_{\mathrm{Fg}} \mathrm{k} / \mathrm{Eq}$. (5.1).

A thorough search of the literature revealed 36 other type I supernove wth light curves complete enough to de used in this study. Some of these light curves were extremely well defined by the observations, while others were somewhat fragmentary although still usable. 
Pable 5-1

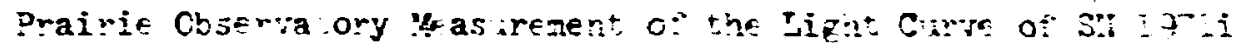

\begin{tabular}{|c|c|c|c|c|c|}
\hline Dete & Telescope & Recorde: & B & v & ${ }^{m} p g$ \\
\hline $5 / 30 / 71$ & Ross & Phctogripi. & & & 12.1 \\
\hline $5 / 30 / 71$ & 40 inch & Photcelec. & 12.45 & 12.10 & \\
\hline $5 / 31 / 72$ & Ross & Photograph. & & & 11.8 \\
\hline $5 / 31 / 71$ & 40 inch & Photoelec. & 12.29 & 11.98 & \\
\hline $6 / 1 / 71$ & Ross & Phctograph. & & & 11.7 \\
\hline $6 / 1 / 71$ & 40 inch & Photoelec. & 11.94 & 11.51 & \\
\hline $6 / 3 / 71$ & Ross & Photograph. & & & 12.3 \\
\hline $6 / 9 / 71$ & 40 inch & Photograph. & 13.12 & 12.20 & \\
\hline $6 / 10 / 71$ & 40 inch & Photograph. & 13.45 & 12.30 & \\
\hline $6 / 14 / 71$ & 40 inch & Photograph. & 13.95 & 12.70 & \\
\hline $6 / 16 / 71$ & 40 inch & Photograph. & 13.95 & 12.75 & \\
\hline $6 / 17 / 71$ & Ross & Photogra ph. & & & 14.10 \\
\hline $6 / 22 / 71$ & 40 inch & Photograph. & 14.70 & 13.35 & 14.60 \\
\hline $6 / 23 / 71$ & $40 \mathrm{inch}$ & Fhotoelec. & 14.58 & 13.39 & \\
\hline $6 / 29 / 71$ & 40 jnch & Photoelec. & 15.06 & 13.83 & \\
\hline $7 / 3 / 71$ & 40 inch & Photoelec. & 14.83 & 13.97 & \\
\hline $7 / 14 / 71$ & 40 inch & Photoelec. & 15.25 & 14.05 & \\
\hline $7 / 16 / 71$ & 40 inch & Photograph. & 15.35 & 14.50 & 15.25 \\
\hline $7 / 29 / 71$ & 40 inch & Photograph. & 15.45 & 14.90 & \\
\hline $7 / 31 / 71$ & 40 inch & Photograph. & 15.50 & 15.00 & \\
\hline $8 / 2 / 71$ & 40 inch & Photogreph. & 15.50 & 14.90 & \\
\hline $8 / 3 / 71$ & 40 inch & Photograph. & 15.30 & 15.05 & \\
\hline $3 / 14 / 71$ & 40 Inch & Photograph. & 15.8 & & \\
\hline
\end{tabular}




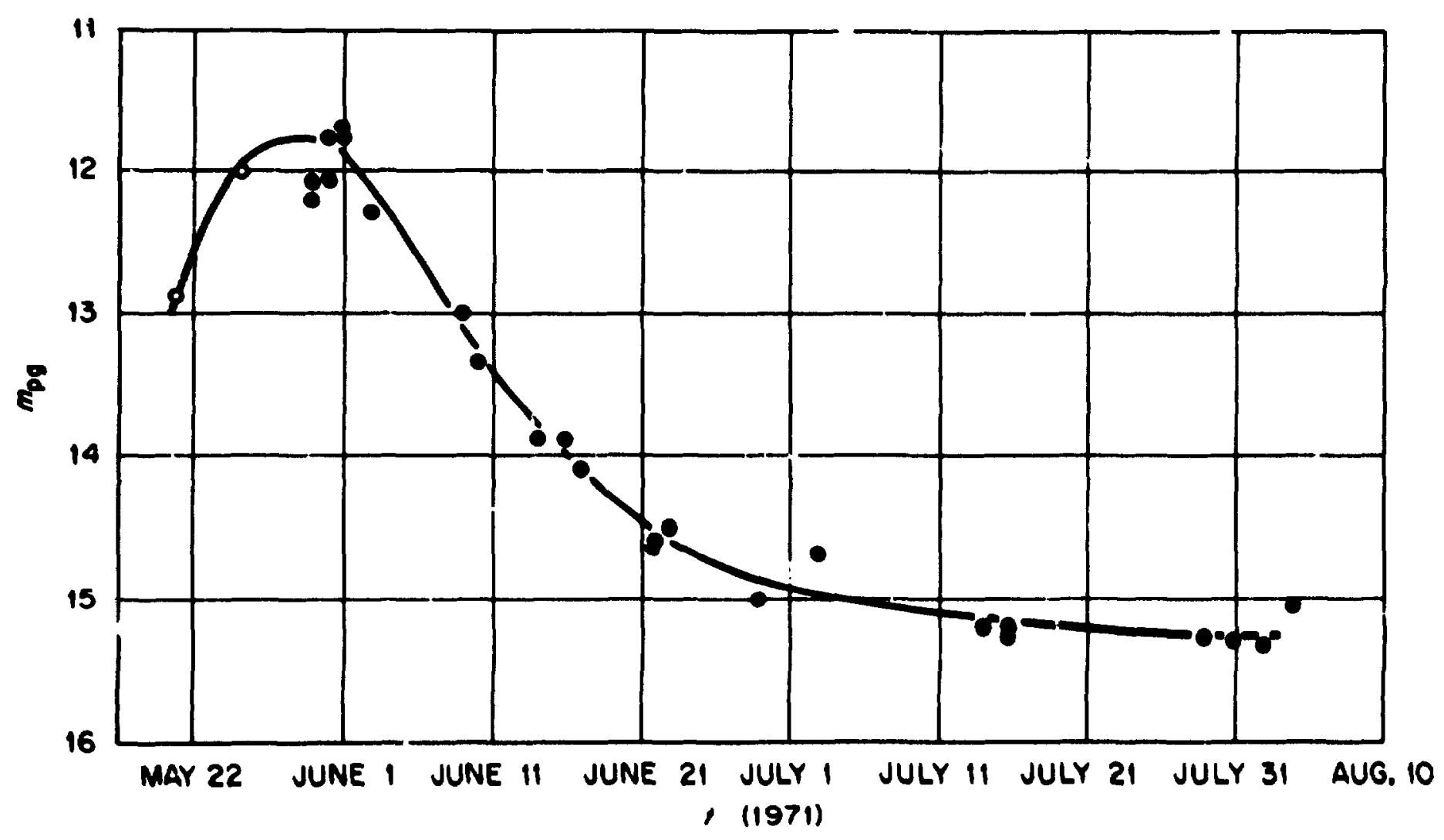

Figure 5-1. The Light Curve Mrasired at Prairle Observatory ror SN19731. 
Tobl: 5-2 lists all the supernove used azri gives for such of them, the observers, the mgnitude systems in wict. the mesurererts were made, and the observetionai references. It also lists sane of the relevent the sbout the parent ealexies in wich the supernovee occurred.

Colum 1 gives the supernove desigmetion, which eonsists of tire year of ocmurrence followed by a letter designeting the order of cenurrence within thet yeer.

Column 2 gives the discovery muber of the supernove. It is a continuntion of a numbering system first used by Zwicky, and since adopted by others, in which the supernove are numbered consecutively in the orter of their discovery.

Colum 3 contains the name of the parent galaxy in wich the outburst occurred.

Colum 4 fives the right ascension (epcch 1950.0) of the parent galaxy.

Colum 5 gives the declimtion (epoch iyxu.0) of the parent galaxy.

Colunn 6 contains the Hubble type of the parent laxy. Coluen 7 ares the symbolic velocity of recession of the parent galaxy e: gressed in $\mathrm{km} / \mathrm{sec}$. Entries in this colum which are not enclosed in parentheses are based on measured red shifts, taken for the most part, from the Reference Catalogue of de Vancouleurs and de Vancouleurs (117) and from a paper by Humson, Maysll, and Sandage (113). In a few cases the given red shifts were measured by the supernova observers. In the cases where no red shifts have been measured for 
the golexies, the symbolis velccities were corputed from the velocitydistance relationship with the Hubble constant equal to $10 \mathrm{C} \mathrm{km} / \mathrm{sec} / \mathrm{Hoc}$, using distance estimates obiafned by comparing the apperent magnitudes of th: glaxies with the absolute gnitudes derived from various luninosity functions for glaxies. More detalls on these ealculaticns vill be given in Capter 9. Symbolic velucities calculated in this reshion are the ones enclosed by perentheses.

Colum 3 contains the apperent photographic magnitudes of the parent gaxies. Hany of these magnitudes are svernges of measurements taken by more than one observer. The preferred sources vere Holmberg (120), Pettit (121), and Humeson, Myall, and Sandage (118). Other sources included Bigay (122), de Vancouleurs and de Vancouleurs (117), and Zwikky, et al. $(123,124)$. The magnitudes listed here have not been corrected for absorption within our own gaxy.

Column 9 lists, for each supernova, all the observers whose measurements were used in the final light, curves given in this thesis. For some objects additional observations exist, but were not used because they were either (a) measured in a magnitude system which could not be converted to the standard mpg system, or (b) measured in some magnitude sjstem other than $\mathrm{p}_{\mathrm{pg}}$ but were largely redundant because many measurements existed for that supernova, or (c) measured only at times several months after the peak so that. they were outside the time range of interest. Although they were not used for composing the final 11ght curves, some of these discarded mgnitudes were, nonetheless, used to derive color excesses in order to estimate internal absorptions within 


\section{4}

the perent laxies. These estimes are dsscribed in Chapter $y$, and the references to the date usid are biven there.

Cclumn 10 gives, for each observer, tine magnitude systec cr systems in wich the measurements were mede. The symbcls used in this coluan are:

$\mathbf{m}_{\text {Hs }}=$ visual mentituie meesured by eye,

$n_{\text {PG }}=$ internetionel standerd photographic magnitude,

n $_{\text {pr }}=$ photorisual monitude,

$B$ = biue gnitude in UBV system,

$V=$ yellow magitude ir. UBV system (same as $\mathrm{m}_{\mathrm{pv}}$ ),

$n_{K}=$ blue megnitude in system of Kaho $(98,108)$,

$b=$ blie magitude in system of marx and Pfau (111).

Colum 11 ares, for each observer, the reference to the article where the date were published.

Colum 12 is used for additionel cominents about the supernove or one of the sets of measurements. These caments are listed as footnotes at the end of the table.

Tables listing all the magnitude data used in this thesis are given in Appendix 1. All of the gaitudes were reduced to the standard - pg system for consistency. These reductions are described in the next chapter. Appendix 1 glves both the unreduced and the reduced data. 


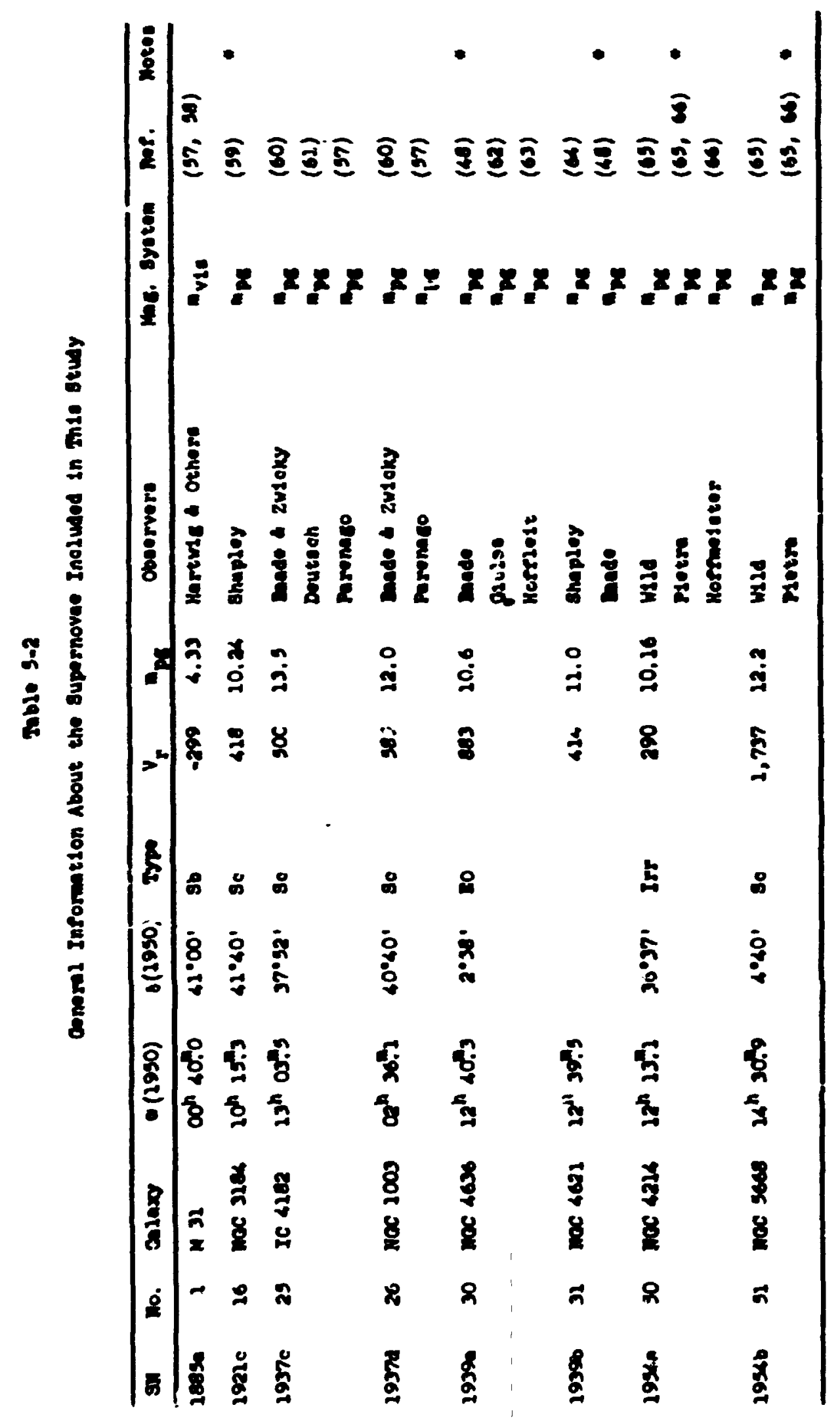


Table 5-2 (Coritinued)

\begin{tabular}{|c|c|c|c|c|c|c|c|c|c|c|c|}
\hline Sin & No. & Oolexy & - $(2950)$ &.$(1950)$ & Tspo & $v_{r}$ & $m_{p}$ & Cbeervers & Mnc. Byotem & Rot. & Nutes \\
\hline 195sin & 53 & Anon. & $1^{h} 05.0$ & $-13 \cdot 30^{\prime}$ & sen & 26,002 & 25.7 & zudoky & & (67) & $\bullet$ \\
\hline 2956 & 4 & noc 9992 & $21^{n} 55.0$ & $53^{\circ} 39^{\prime}$ & $s D 0$ & 1,059 & 10.56 & 2uleky \& karpoules & $\operatorname{tovv}_{\mathrm{pv}}$ & $(68)$ & \\
\hline 19570 & 55 & $\operatorname{noc} 2241$ & $\operatorname{og}^{h} 28.5$ & $52^{\circ} 12^{\prime}$ & sb & 631 & 10.05 & $\begin{array}{l}\text { zwleky \& karpoutes } \\
\text { Eertole } \\
\text { Wonsel }\end{array}$ & $\mathbf{n}$ & $\begin{array}{l}(69) \\
(70) \\
(71)\end{array}$ & $\bullet$ \\
\hline 19570 & 56 & noc 4374 & $12^{h} 22^{m} !$ & $23^{*} 10^{\prime}$ & $\mathbf{E}$ & 934 & 10.35 & $\begin{array}{l}\text { Ertole } \\
\text { Cote } \\
\text { Romano } \\
\text { LI Isin }\end{array}$ & & $\begin{array}{l}(70) \\
(72) \\
(75) \\
(73)\end{array}$ & \\
\hline 1959c & 62 & Anon. & $23^{h} 0.08$ & $3 \bullet 401$ & SDC & 2,990 & 15.8 & Mahades & $a_{p}{ }^{3}, v$ & $(76)$ & \\
\hline 1960 & 69 & noc 496 & $12^{n} 29.1$ & $4 \cdot 13 \cdot$ & SDe & 1,773 & 11.9 & $\begin{array}{l}\text { Dertole } \\
\text { Huth } \\
\text { kulikov } \\
\text { Dempests } \\
\text { mannsno }\end{array}$ & $m_{0}$ & $\begin{array}{l}(70) \\
(76) \\
(77) \\
(70) \\
(79)\end{array}$ & \\
\hline $1960 r$ & 86 & HCC 4382 & $12^{n} 22 \cdot 9$ & $18^{\circ} 28^{\prime}$ & so & 773 & 10.05 & $\begin{array}{l}\text { enrole } \\
\text { zasteov } \\
\text { entes }\end{array}$ & ${ }_{m, v}^{m}$ & $\begin{array}{l}(70) \\
(80) \\
(81)\end{array}$ & \\
\hline 2961d & 87 & Anon. & $22^{h} 48.3$ & $28^{\circ} 08^{\prime}$ & so & 7.700 & 25.0 & Zutoky & 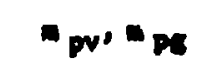 & (82) & \\
\hline
\end{tabular}




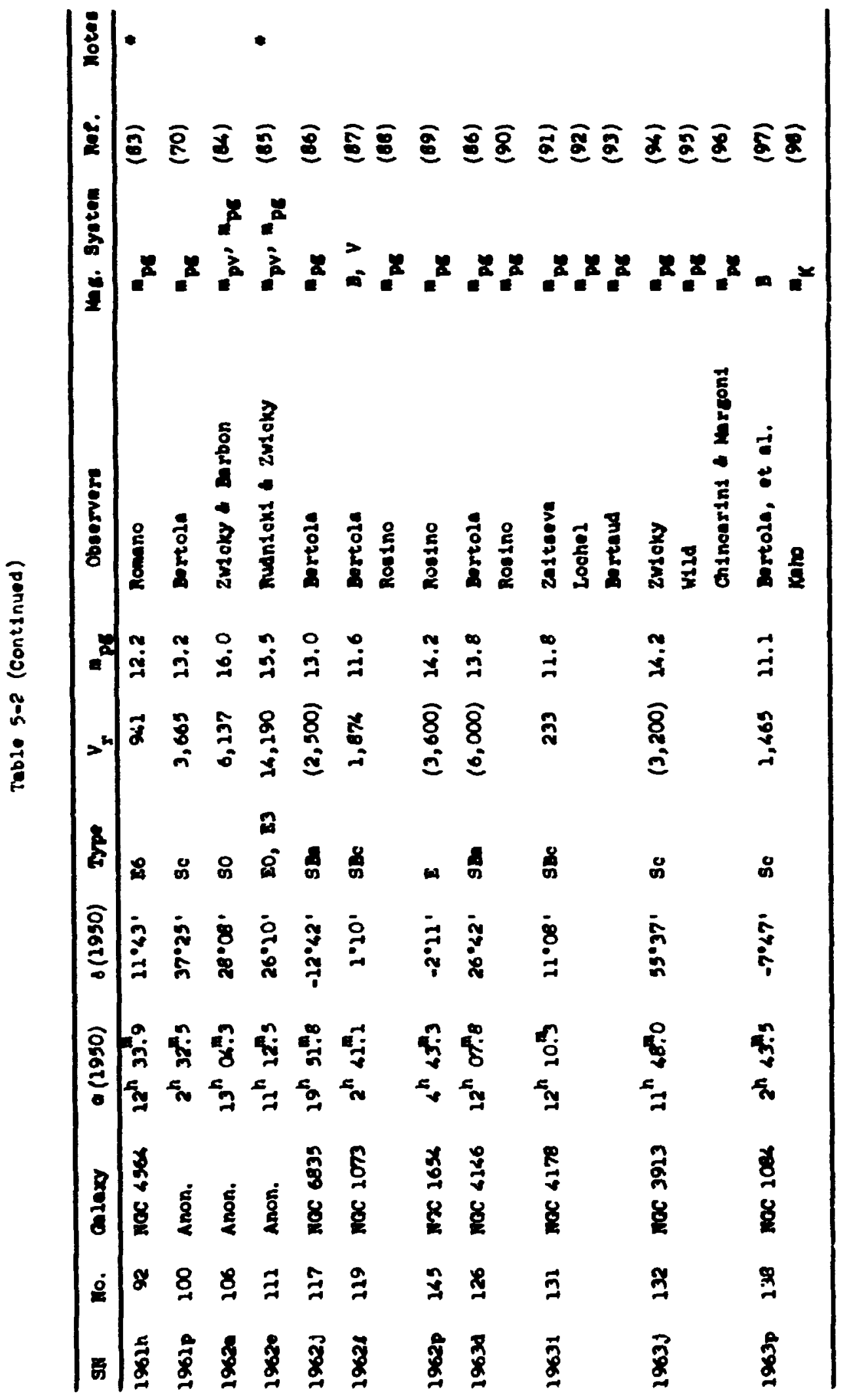


rable 5-a (Continued)

\begin{tabular}{|c|c|c|c|c|c|c|c|c|c|c|c|}
\hline SI & No. & $\cos \operatorname{laxy}$ & - (1950) & $4(1950)$ & Type & ${ }^{\prime} r$ & mpe & Dobenrveru & Mac. Syotem & Rer. & Mores \\
\hline 1964e & 150 & Anon. & $12^{h}=66^{m} 6$ & $32 \cdot 59 \cdot$ & SBC & $(2,900)$ & 26.3 & $\begin{array}{l}\text { Lovale } \\
\text { Ainart } \\
\text { Cnuadse } \\
\text { inlteeva } \\
\text { Lochal }\end{array}$ & $m_{p}^{m}$ & $\begin{array}{l}(29) \\
(200) \\
(101) \\
(102) \\
(203)\end{array}$ & \\
\hline 2964: & 259 & Noc 3938 & $12^{h} \cdot 30^{n} .2$ & $46 \cdot 231$ & Sc & 874 & 10.8 & Enrtole, et al. & $m_{p}$ & (97) & \\
\hline 19651 & 170 & $\operatorname{NaC} 4753$ & $12^{n} 49.8$ & $-0.50^{\circ}$ & Irr & 1,364 & 10.7 & $\begin{array}{l}\text { Ven tyone \& Penarin } \\
\text { Clett1 \& Erbon }\end{array}$ & & $\begin{array}{l}(2 \alpha) \\
(20 s)\end{array}$ & \\
\hline $2966 \mathrm{~J}$ & 186 & NoS 3298 & $10^{n} 16.9$ & 49.491 & 3ev & 649 & 20.8 & $\begin{array}{l}\text { Wild } \\
\text { Chincarini \& porinotto } \\
\text { Kaho }\end{array}$ & $\begin{array}{l}m_{p e} \\
m_{k}\end{array}$ & $\begin{array}{l}(208) \\
(207) \\
(108)\end{array}$ & \\
\hline 1966k & 181 & Anon. & $12^{n} 25^{n} \cdot 6$ & $28^{\circ} 33^{\prime}$ & so & $(5, \infty 00)$ & 14.7 & Rudnickt & top' npv & $(100)$ & \\
\hline $1966 n$ & 198 & Anos. & $6^{n} x^{m} \cdot 3$ & $-3 \cdot x 3^{\prime}$ & sa? & $(9,800)$ & 26.0 & Nlatt1 - Drbon & $m_{p c}$ & (10s) & \\
\hline $1967 c$ & 192 & MOC 3389 & $10^{1 /} \cdot 45.8$ & 12.481 & $3 c$ & 1,276 & 22.1 & $\begin{array}{l}\text { de Vhncouleura, ot al. } \\
\text { Marx \& Psau } \\
\text { Dorsov, ot \&l. } \\
\text { Chundse \& Erbltehvisl } \\
\text { Kaho }\end{array}$ & $\begin{array}{l}\text { D, v } \\
b \\
\sim v \\
m_{p v} \\
m_{k}\end{array}$ & $\begin{array}{l}(210) \\
(121) \\
(212) \\
(123) \\
(103)\end{array}$ & - \\
\hline
\end{tabular}


Table 9-2 (Continued)

\begin{tabular}{|c|c|c|c|c|c|c|c|c|c|c|c|}
\hline $3 n$ & No. & Ondexy & $0(1230)$ & $A(1950)$ & mpe & $v_{r}$ & $m$ & Cbeervers & Mas. syoken & Mer. & motes \\
\hline 19600 & 211 & $\operatorname{Noc} 2713$ & 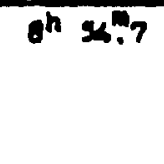 & $3^{\circ} 06^{\prime}$ & sb & 3,810 & :A.7 & $\begin{array}{l}\text { Onevim } \\
\text { Awoov } \\
\text { Clattl \& Erbon }\end{array}$ & $m_{n}^{\infty}$ & $\begin{array}{l}(214) \\
(92) \\
(205)\end{array}$ & $\bullet$ \\
\hline $2969 c$ & 233 & $\operatorname{noc} 3022$ & $22^{n} 38.6$ & $47^{\circ} 90^{\prime}$ & se & 3,220 & 23.0 & Ertore + clastes & $D, v$ & (225) & \\
\hline $19 m 1$ & 299 & noc soss & $23^{n} 233^{m, 5}$ & $42^{\circ} 17^{\circ}$ & sb & 920 & 9.2 & 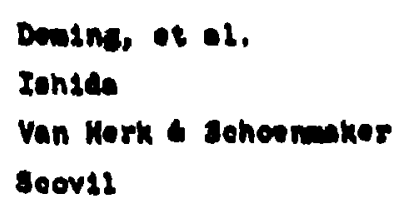 & 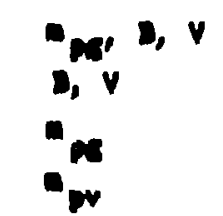 & $\begin{array}{l}(52) \\
(36) \\
(54,59) \\
(226)\end{array}$ & \\
\hline
\end{tabular}




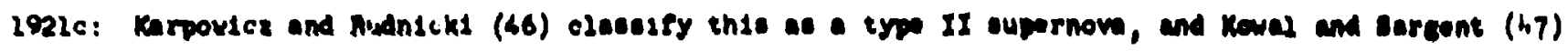

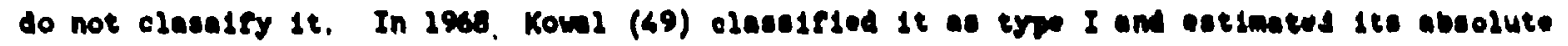

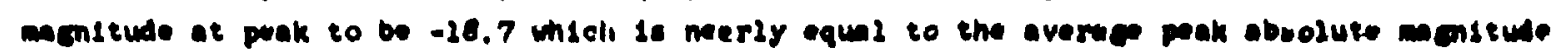
that he tound for type I and more than two maenletudes brichter than the avorace that ho found for eype II. The liche eurve, although enowhat frocontary, do ontirely cenolotent wth the type I interpretation. Loupled with ite hich intrinose luminoeity, it is olmost certeln that SW l921e mo Indeed a type I supernova.

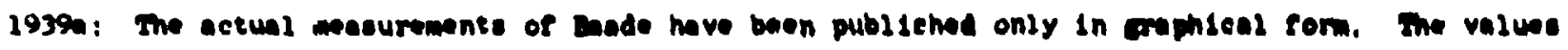

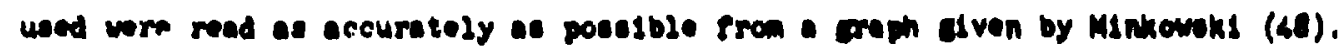

3'39\%: Sare as note for SN 2939

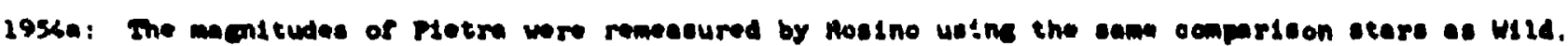

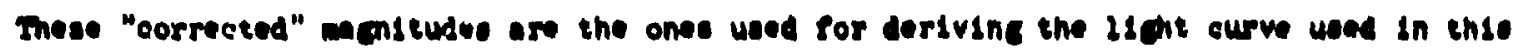
thesels.

19360: Same ne noee for sN 19340.

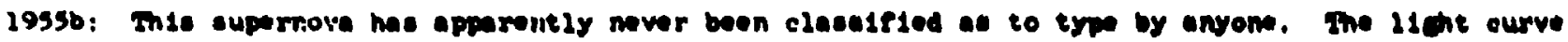
1. consiftent with : eype I Interppotation, an zwloky (67) estimated that it we Intrin-

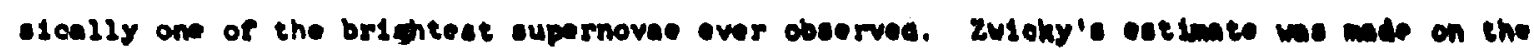

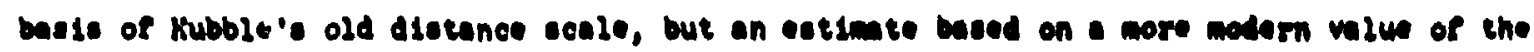

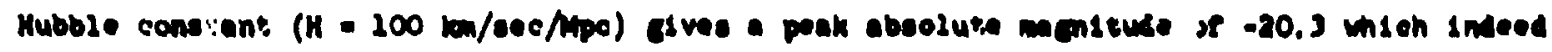

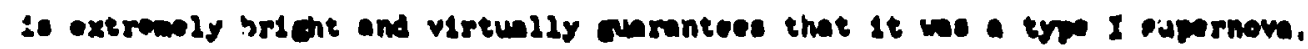


1957a: Bertola claselfled thle supernova ae type I, but Zulcky claselested df as type II. The 21eht curve atronely indleates type I, but eatlmates of lte poak absolute macnitude are much lower than the averace for eype I and are. In fact, consletent with a type II Inter. protation. The spectra that were obtalned do not settle the matter elther may. Muasure. ments of the color index indleate an extremely hich decree of reddening and hence a lare amount of aboorption vithin the parent elaxy. This absopption correction le caloulated In Chapter 9. It amounts to almost three auniltides, and makes the peak liminosity consistene with the eype I interpretation.

1961h: The 11cht eurve for thds supernove we too fragentary to be useful in the test of the expansion hypothesis, but it to useful for other calculetions whlch ure described in Crapter 8 .

1762e: Th1s eupernova oceurred on a luninous bridge between two elliptical galax! ar, Accordine to Rudnlckl ane zulcky (85), the bridge lo apparently composed of late type stars.

296\%': According to Berzov, et al., the1s photonetrle syatem 1s very elose to the B ayetem, but small systematic differences are prosent.

1968e; The mognitudes of Rusev wore read as accurately as pesalble from a craph st vwit by Pakovak11 (s1). 
CHAPTER 6

REDUCTION OF THE DAT $\%$

Lighit curves of type I superncrae exhibit a high degree of uniPorrity, but the possibility that the ret: of devline in luminosity is different in different wave length bands must be allswed for if the rate or decline is to be used to test for the Dcppler effect. All the supernovec used in the test must have their light curves expressed in the same bandpass or magnitude system. A cuick inspection $c_{1}^{\prime}$ Table 5-2 reveals that the most comonly used system thus far has beer: the standara $m_{p g}$ system. Furthermcre, tine spertrum of the typical type I supernova is dominated by a wide bright band centered between $4600 \mathrm{~A}$ and $4700 \AA$ [see, for examples, refs. $(60),(86),(87),(96),(97)$, and (107)]. This band, which is generall.y interpreted as the 14686 , $n=4 \rightarrow n=3$ transition of HeII, is completely encompass $d$ by the bandpass of the $m_{p g}$ system and, in fact, iypically contains about one half of the total photographic intensity. Thus, the logical choice for the comnon magnitude system is the $\mathrm{m}_{\mathrm{pg}}$ system.

In the preceding chapter, a light curve was given for SN 19711 (Fig. 5-1), in which part of the magnitudes wert measured $m$ pg and pert were calculated by the standard transformation equation,

$$
\mathbf{m}_{\mathbf{p g}}=\mathrm{B}-0.29+0.18(\mathrm{~B}-\mathrm{V}) \text {, }
$$

using measured $B$ and $V$ magnitudes. There were two nights in which both $B, V$ and $m_{p g}$ magnitudes were measured by the same technique on the same telescope. A comparison of the measured and caiculaied $\mathrm{m}_{\mathrm{pg}}$ magnitudes for those nights is given in Table 6-1. 
Table 6-1

Comparison of Heasured $\mathbf{m}$ pg Hagnitudes

With Values Computed From B, V Mognitudes

\begin{tabular}{lcc}
\hline Date & Measured m & B, $V \rightarrow$ m $_{\text {pG }}$ by $(6-1)$ \\
\hline $6 / 22 / 71$ & 14.60 & 14.65 \\
$7,16 / 71$ & 15.25 & 15.21 \\
\hline
\end{tabular}

The agreement is quite good. In other cases where both $B, V$ and $m_{p g}$ magnitudes are available, 5q. $(5-1)$ gives the same sort of result, with the average discrepancies between the calculated and the measured mpg lying within the range of scatter due to measuring errors. Particular examples are SN $1962 l$ and SN 1965i, whose light curves can be found in Appendix 2. Thus, Eq. (6-1), which was originally derivad for converting the magnitudes of main sequence stars, apparently gives accurate conversions for supernova magnitudes also.

It is easy to use Eq. $(6-1)$ when both $B$ and $V$ measurements are available, bit some supernova observers have measured only $B$ or else only V (or, what is equivalert, only $m_{p v}$ or only u $_{v i s}$ ). The work of the Russian a.itronomer Yu. P. Pskovski). (51, 125) on the time dependense of the colors of supernovae maises it posstble to use Eq. (6-1) for converting the magnitudes even in these cases. Pskovskil has determined the relationship between the intris. . B-y color of a supernova and the time in days after the date of maximum brightness. In 
(51) he gre this relationship in the form of a graph which is shom in Figure 6-1. The crdimete (B-V), is the intrinsic color of the supernova light, 1.e., the color of the light before it is reddened by sbsorption in our own and the parent galaxy of the supernova. It represents the avereze of the color curves of six different supernove all corrected for reddening due to absorption. These corrections were determired by shifting the various color curves vertically unt $\leqslant$ all six were superimposed. The only remaining problem then was to callbrete the resulting composite color curve by determining the absclute color excess,

$$
E(B-V)=(B-v)-(B-v),
$$

for one or more of the component light curves. One of the supernoree used for this purpose was SN 1954a, which occurred in the irregular galaxy FCC 4214. According to Pskovski1, the amount of reddening in the perent galaxy is negligible for elliptical and irregular balaxies. Thus in the case of SII 1954a, it was only necessary to worry about the reddening in our own galaxy. S1uce IGC 4214 is located at galactic latitude $b^{I I}=78^{\circ} .07$, this reddening was smal1, and Pskovskil was able to estimate it by using the Lick sounts of faint galaxies in nelghboring areas of the sky.

It is quite easy to convert B magnitudes to " and Pigure i-1, provided that the date of maximum brightness of the supernova 18 known. For each B magnitude to be converted, the value of (B - V). for that day is read from the craph and the mpg magnitude 


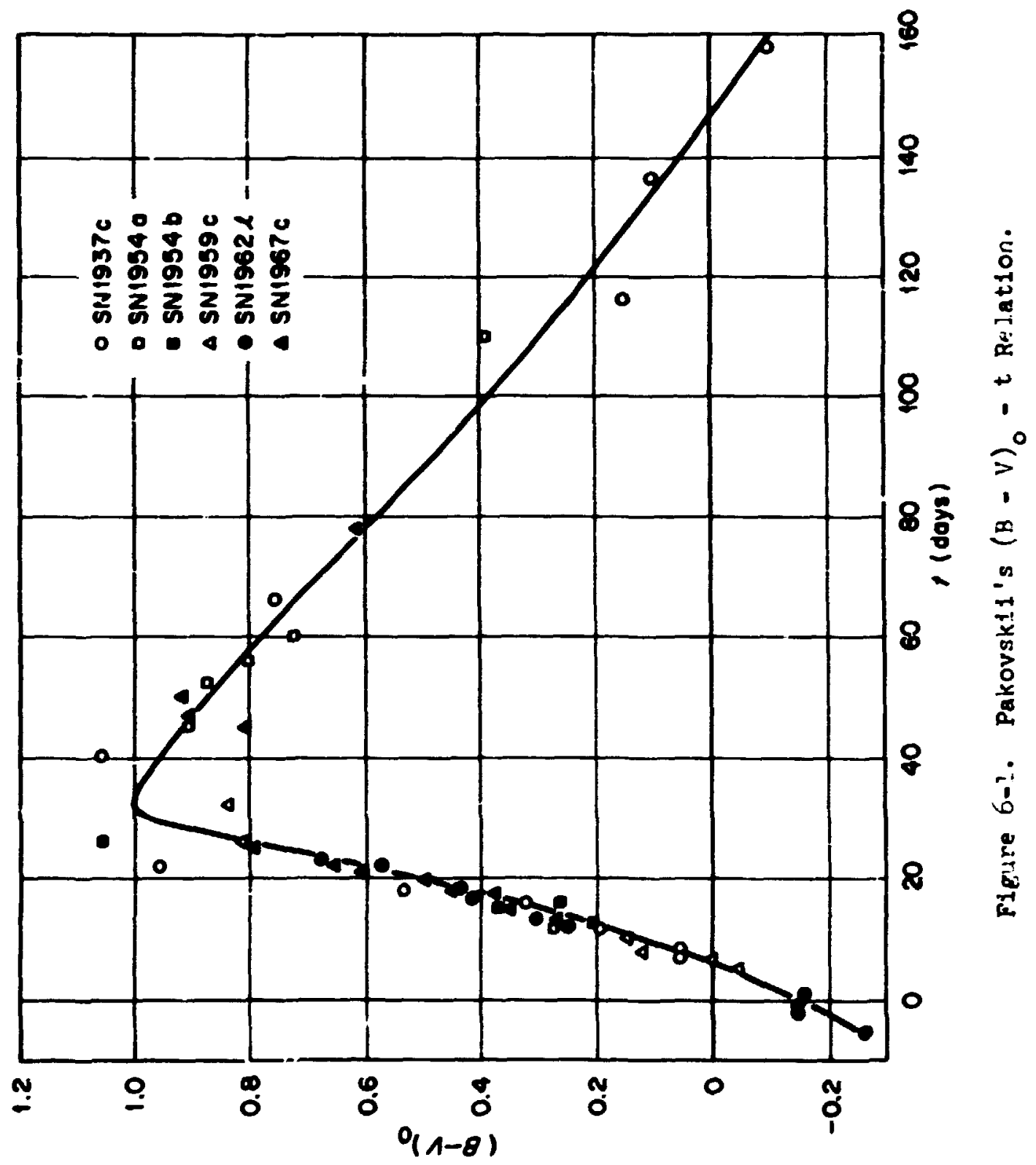


is calculated by

$$
\mathbf{m}_{\mathbf{p B}}=\mathrm{B}-0.29 \div 0.18(\mathrm{~B}-\mathrm{V}) .
$$

of course, there will be a zero polnt exrcr in these magnitudes because of the unknown amount of reddening due tc absorption. In scme ceses it is possible to estimate this reddening correction. One comen siturtion is tc have both $B$ and $V$ measurements for a fev days, but $B$ only for cther days. The color excess $E(B-V)$ can then be determined from the vertical shift needed to bring the Pskovskif colcr curve ir.to colncidence with the measured values cf $(B-V)$. This color excess can then be added to values of (B - V). read from the graph, and the resulting corrected B - 7 colors can then be used to convert the B magnitudes tc $m_{\mathrm{pg}}$ by means of Eq. $(6-1)$ rather than by $(6-2)$.

Another situation that arises quite often is to have scre measured $B$ magnitudes and no $v$ magnitudes and to also have scme ineasured $m_{\mathrm{Pg}}$ magnitudes. In these cases the $B$ magnitudes can be converted to mpg by means of Eq. (6-2) and the zero point correction can be determined from the rertical shift required to bring the light curve of the converted agnitudes into coincidence with the light curve of the measured $m_{\text {pg }}$ magnitudes.

If only $B$ magniludes are avallatle, then it is not possible to determine the zero polint error in the (6-2). But 11 ght curves obtalned by this method can still be used to test the expansion hypothesis because it is the slope, or rate of decline, 
of the light curve that is used for the test. Since a zero point error siply shifts the entire curve vertically by a constant anount, the rete of decline is not changed by the error.

The Pskovskil graph can also be used to convert magnitudes measured In the $V$ system. One way to carry out this conversion is tc note that If $v$ is subtrected from both sides of Eq. $(6-1)$, the result is

$$
\mathrm{m}_{\mathrm{pB}}-\mathrm{V}=\mathrm{B}-\mathrm{V}-0.29+0.18(\mathrm{~B}-\mathrm{V}) \text {, }
$$

which can also be witten

$$
\mathrm{PB}_{\mathrm{PB}}=\mathrm{V}-0.29+1.18(\mathrm{~B}-\mathrm{V})
$$

If measura? values of both $B$ and $V$ are avallable, then the $V$ wagntudes can be converted directly to $m_{p g}$ by means of $(6-3 ;$. If only $v$ magnitudes are avai?able, then the corresponding velues of $(3-v)$. can be read from the Psi il graph and the comversion can be accomplished by

$$
\mathrm{m}_{\mathrm{PB}}=\mathrm{v}-0.29+1.18(\mathrm{~B}-\mathrm{v}) \ldots
$$

or course, there will be a zero point error in the magnitudes determined by the latter formula, and all of the counents that were made in the preceding paragraphs with regard to the zero point errors in the conversion of $B$ magnitudes can be rephrased to apply here also. Since the av system is just another name for $V$ and since it was designed to be the photographic equivalent of the $\mathrm{m}$ vis system, Eq. $(6-4)$ can also be witten as

$$
m_{p g}=m_{p v}-0.29+1.18(B-v) 。,
$$

or as 


$$
q_{p B}=u_{\text {vis }}-0.29+1.18(B-v) \cdot .
$$

There is another way by which por or pis magnitudes can be con-

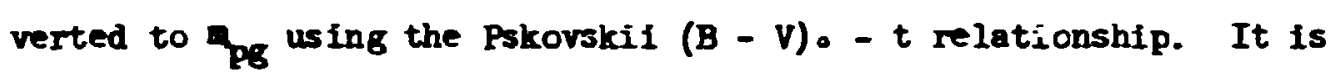
apparent from Eq. (6-5) that intrinsic (mpg - mpv) colcr indices [dencted כy $\left.\left(m_{p z}-m_{p v}\right).\right]$ can be calculated from intrinsic (B - v) color: by means of the equation

$$
\left(m_{\text {pB }}-m_{\text {pv }}\right)_{0}=1.19(B-v)_{0}-0.29
$$

By $t$ is means, the Pskovskif (B - v). - t relationship is converted to an $\left(m_{p g}-m_{p v}\right)$. - t relation. The result of this conversion is siown graphically in Pigure 6-2. Measured $m_{p v}$ cr $\mathbf{m}_{v i s}$ magnitudes can be converted to $m_{p g}$ by reading the corresponding $\left(m_{p g}-m_{p v}\right)$. values from this grapt and adding them to the measured magnitudes. This conversion will also contain en unknown zero point, shift.

All of the megnf iude conversion method: based on Pskovskil's $(B-v)$ - $t$ relation require a knowledge of the date $t_{0}$ on which the supernova attained maximum brightness. For a well observed supernova, it is usually an easy matter to determine $t_{0}$ and the peak magnitude $m_{0}$ simply by inspecting the light curve. For more fragmentary light curves, this method is often not feasible, but Pskovskif (51) has developed several methods for estimating $t_{0}$ and $m_{0}$ in such cases. Before discussing these methods, it seems appropriate to pcint out that in cases where a number of B - V measurements are avallable, covering a time span of two weeks or wore, it is possible to use the (B - V) - t relationship itself for determining $t_{0}$. This is done by shifting the graph of the 
58

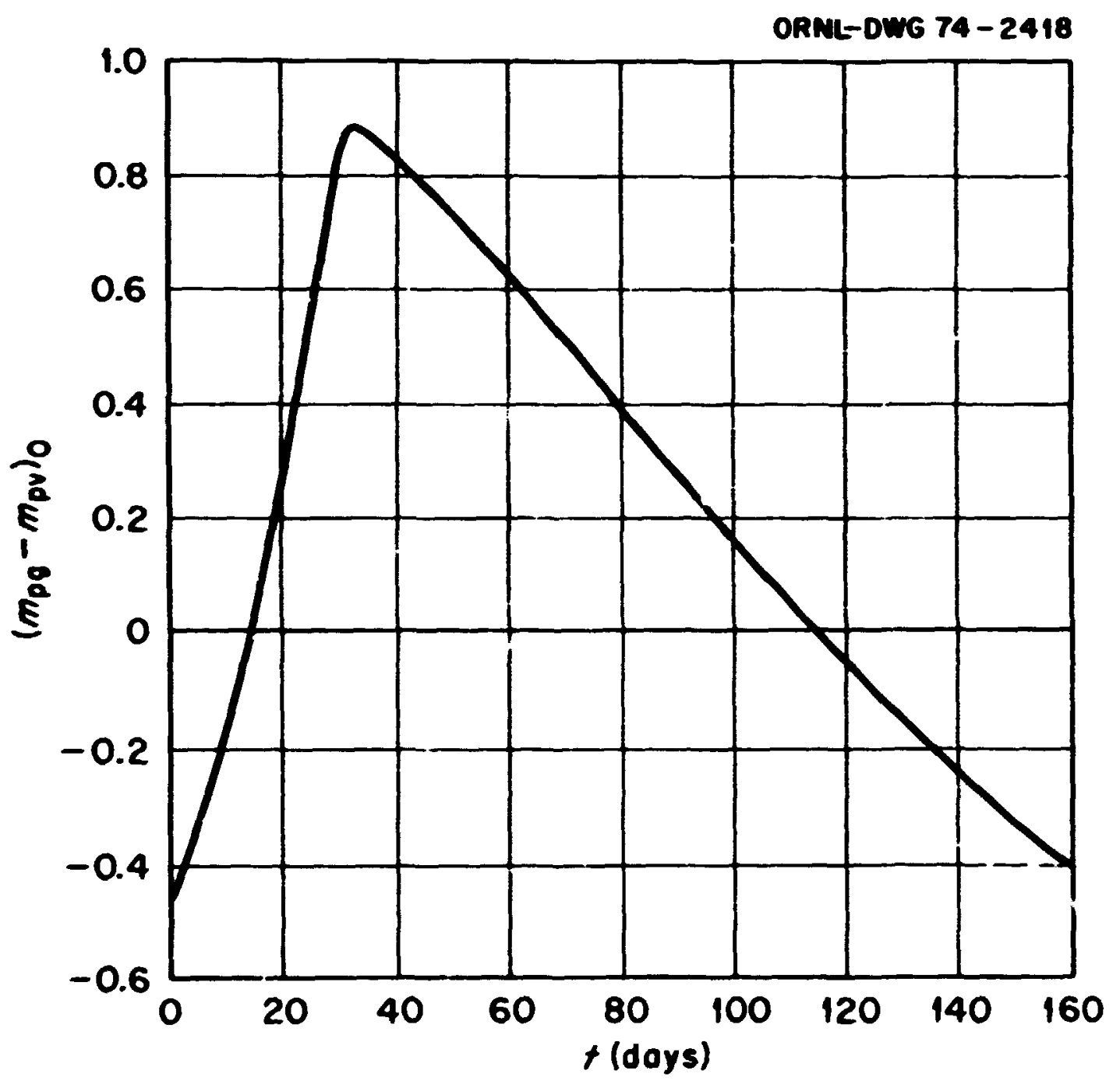

Fig:re 6-2. Tie $\left(m_{p p}-m_{p v}\right)_{0}-t$ Relation Drriver from Pskovikit's $(B-V)-t$ Rolation. 
relationship horizontally unill it coincides with the observed date. of course, the horizontal shifts must be accompanied by simultaneous vertical shifts to take into account the reddening. Thus, the finel "fit" of the curve to the measured date gives both the date of maximum $t_{0}$ and the color excess $E(B-v)$. The min limitation of this technique is the extent of the mensured data which is required. Becsuse the color curve is very nearly ifnear on both sides of the peak, wich occurs at about 33 days after maximum, the measured data rust span a considerable time range and shculd preferably span the peak in order tc decies=ine unambiguciusly both $t_{0}$ and $E(B-v)$. Of course, ir one of these parameters cen be independently detemined, then the other one can be unambiguusily estimated by shifting the color curve in only soe direction, and this cen be accomplished even with a small number of measured points covering only a short time span. This is a particularly useful technique for determining the color excess once $t_{0}$ is known. Values of $E(B-v)$ obtained in this way can then be used to determine the absorption correction for the magnitudes. Similari.y, if the neasured color indices are ( $m_{p g}-m_{p v}$ ) indices, then the same technique can be used for estimating $\mathrm{E}\left(m_{\mathrm{pg}}-\mathrm{m}_{\mathrm{pv}}\right)$ color excesses simply by using the converted ( $\left.m_{p g}-m_{p v}\right)_{0}-t$ relation given in Figure 6-2. The use of color excesses, determined by these methods, for correcting the peak magnitudes $m_{0}$ will be discussed in Chapter 9.

One method which Pskovskil and number of other observers have used quite successfully for estimating the date to of maximum brightness of a supernova is baced upon the time behavior of the spectrum of the 
supernove. Many observers have noticed that the bands in the spectrun of a typical type I supernors shift to the red as the ligit curve decays. According to Pskovkil, the best band to use for estirating the phase of the light curve 18 the $\lambda 4686$ band, wich daninates the photographic region of the spectrum. He wa able to establish the relationship between the phase and the position of the center of the band by using supernove with muerous neasured spectra and also well defirsd light curves from which he couid estimate $t_{0}$. He mas then able to use this relationship to estivate the date $t_{c}$ for three supernove having fragmentary light curves but with a number of good spectral obsirvations spread over several days. The details of the wethod ere Given in (51).

The spectral method requires sereral good spectro taken on different nights. This constraint limits the method to supernove wich are relatively nearby so that they are bright enough for good spectra to be obtained. Furtherwore, if a number of good spectra are taken, ther it is quite likely that a good light curve is measured also, so that the spectrum estimate is not needed except as confirmation.

Pskovski1 has also developed two other good methods for sstimating - and $t_{0}$ which use only the fraguentarily observed light curves. Both of the methods are analogous to procedures that are used for estimating the maxime of nove with incomplete light curves. One of then involves the use of a series ce average light curves, and the other reconstructs the maximum from the point where the slope of the light curve changes from rapld decay to gradul decay. 
Pskoraldi's sverege light curve wethod grew out of his studies of the retes of decline of the light curves of the various types of supernove (50). He found that if streight libes are fitted to the repidly descending portions of vell observed tJpe I lifht curves, then the retes of fall of the resulting strafint lines vare between the extrewes of 1 annitude per six days acd 1 manitude per 12 dajs. In (5!) he lenoted this rate of fall by the letter $\underline{b}$. He selested a croup of weli defined licht curves and separeted then into four different subcroups so that all the curves in a diven subproup had approndentely the sume b. The four subgroups were sharecterized by the four valves $\underline{b}=6, \varepsilon, 10$, and 12 . He then averacad all of the licht surves within each subgroup and thus obtained four sverage licht curves corsespondins to the four $\underline{b}$ milues. Using these averng 11 oht curves, he was then able to estinte $a_{0}$ and $t_{0}$ for $m$ w frequentary licht curves whose peaks were tot well deilined by existing observations. The method wes applicable in cases where there were smath observations in the repid decay portion to dive a cood straight ilne fit. Usirg the vive or $\underline{b}$ defined by the straight line fit, he could choose the arst appropriate average light surve. He then fitted that average light curve to the frementary light cirve axd used the fitted rurve to extrapolate banmrds in order to estimete $a_{0}$ and $t_{0}$

Pukorikif's foint-of-slope-chane wethed is besed on this observetion that the point at which the slope changes fram rapid decay to Graval decay almost elmys occurs betwen 2.8 and 3.3 monitudes below peak brifhtpess and is equi, on the everag, to 3.1 monitudes below 


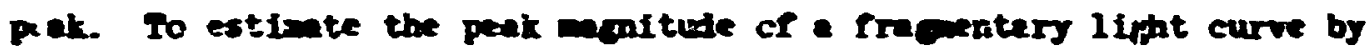
this athod, Pskorsili fitted streight lines to the nopid iecey partica and the cadual decey portion. Ie used the letter $\underline{E}$ to depote the polnt at wich these two sareicht lines intriected, and dencting the cosresponding menstude by $\mathrm{n}_{k}$, he celculated the estinats of the peak mentude as by the formule

$$
a_{0}=a_{k}-3
$$

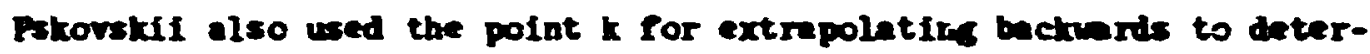

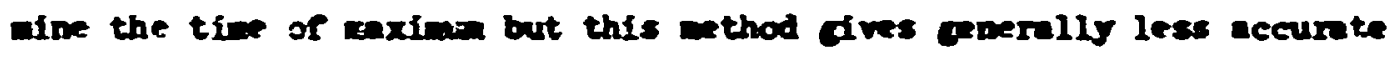
estimates of $t_{0}$ than does the averece light curve nethod.

Doplying these wethods to superoove vith well deternined ilght curves, it vas possible to estizate the average errors of all the wethois. IE found that the eccurecies of the $t_{0}$ computed by the point $k$ we thod rnaged from 1 to 5 days wereas the accuretes of the sverng 11 int urve estimetes were 0.5 to 1.5 das. The spectral wethad eve the lapst accurary, with errors on the order of \pm 5 deys. In estinting the peak monitude, the averne light curve wethod ove accurecies of o.0s to O.2. The sccuracies of the point $k$ estimetes of a were comparab!e.

It is a metural extension of Pskovskif's work to combine his point $k$ and average light curve rethods. There are undoubtedly severel mys to combine then, bit one naturel wethod, wich the present author has found to be effestive, is first to apply the point $k$ wethod in order to obtain an estimate of $m_{0}$ and of the sireight line slope $b$ of the repidly 
relling sefon: of the light curve, and then to fit the nost closely sorrespoding everage light curve to the aesured licht curve using the point $k$ estiate of $a_{0}$ as a constraint. Uains the $a_{0}$ censtre int mes to the only undeterined perameier of the fit ind hence renoves sowe of the wbiguity of the fittins netince since only horizontal shifts aleng the tint axis are required. mis technique is illustrated for the supernove 5I 1957e in FIgures 6-3 and 6-6. Figure 6-3 fllustretes the point $k$ wethod. The strefont live fit to the repid desrent portion of the ligh curve intersects the strejat line fit to the later portion at a point $k$ with menitude $h=16.95$. Sirce this point sccurs, on the average, 3.1 menitudes belor peek brifhtiess, the best estimte for peak brightaess is $n_{0}=13.85$. The soly remining problen is to estimte the date of maxima $t_{0}$. Since the slope of the straidht line fit to the repid descent portion is -1 agitude per 6 days, Pskorskif 's b I 5 amrog light curve is used in Ploure 6-to obtain the estinate of $t_{0^{*}}$ The solid points represent mesured angitudes and the open circles conacted by the curve represent the overnge light curve. The latter is shifted ang thr time isxis, wit: its peak almys ronstreined to $1 \mathrm{i}$ : on the horizontel stroi ght line corresponding to $=_{0}=13.85$, until the best fit to the meesured light curve is obtalnd. In the cese of SII 1957, this best fit appers to orcur et $t_{0}=$ Fteb. 27, 1957. Pskovikil's wethods were designed for use on freguentery light curves mesured in the po systo:m. For some of the supernove used in this study (o G., SI 1962e and SI 1966k) the light curves were fregmentery, with most of the misnitudes measured in the apv rether than 


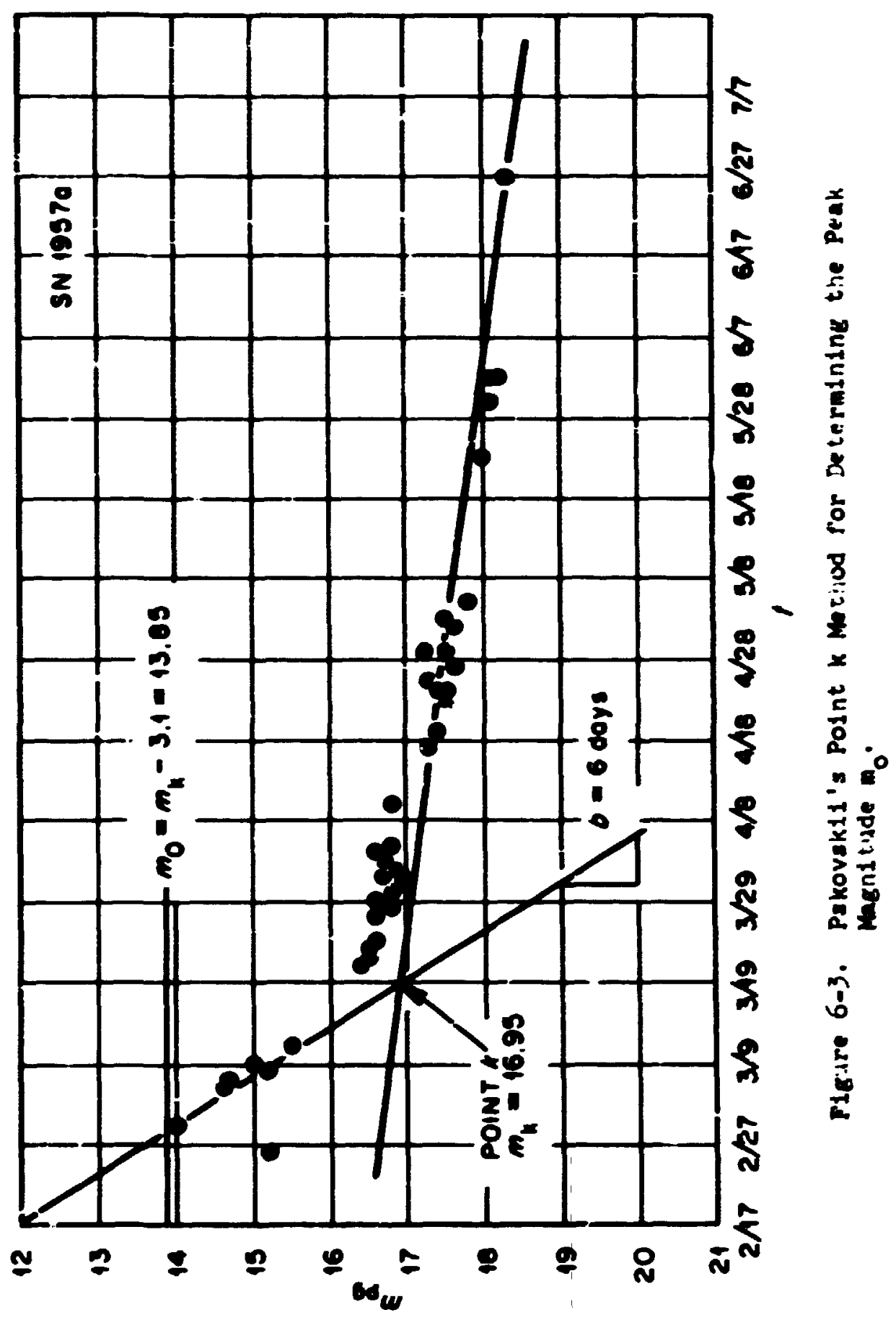




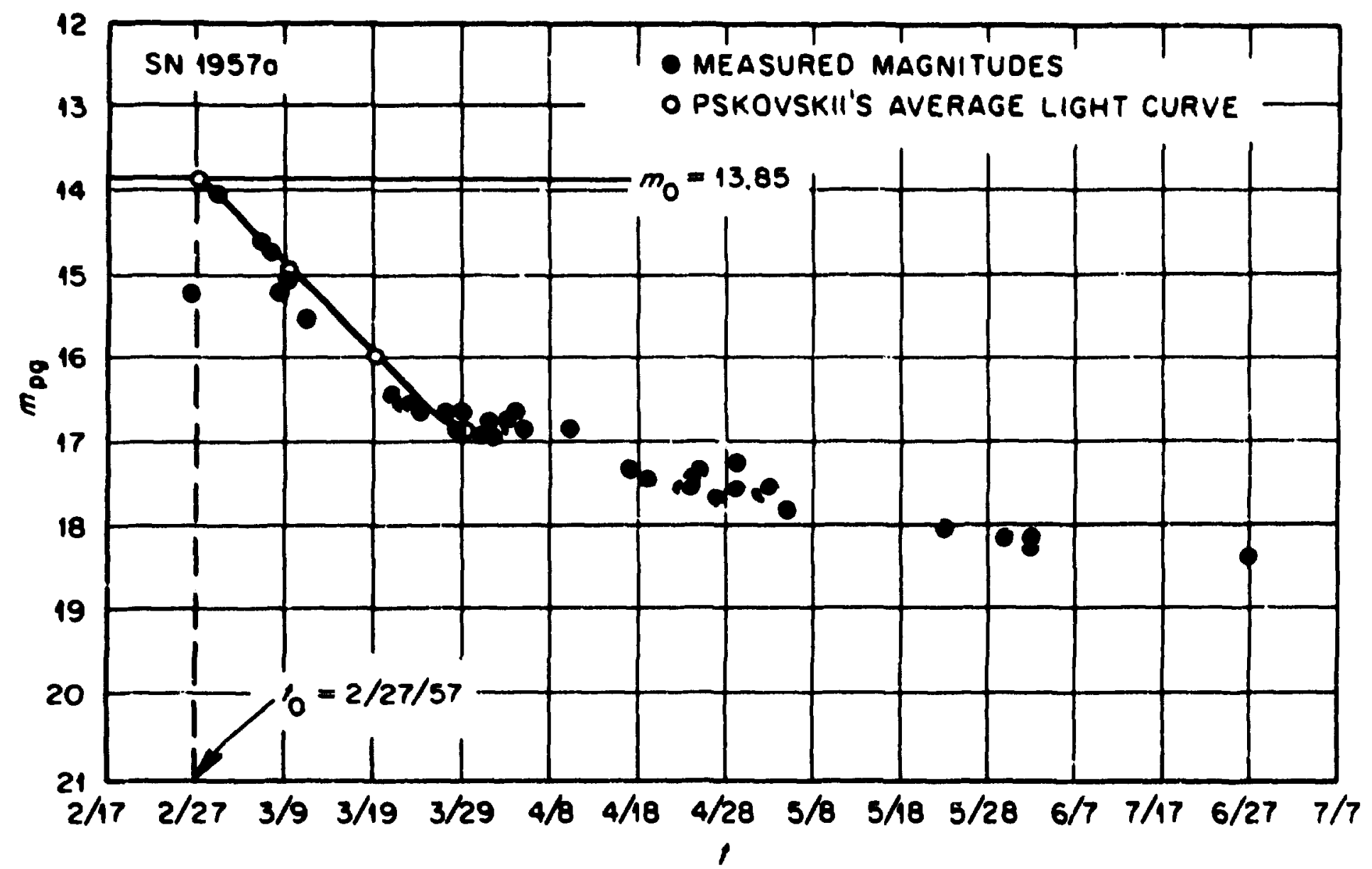

F1g:re 6-4. Fskovsk11's Average Ii2g:t Curve Metilat for Determining tise Day to Peak Brig!titiess. 
the $m_{p g}$ systen. These $m_{p r}$ manltudes could not be converted directly $t_{c} m_{p g}$ by means of the $\left(m_{p g}-m_{p v}\right)$ - - $t$ relaticn discussed earlier because the date of maximum. $t_{0}$, was not known: on the other hand $t_{0}$ sculd not be estimated directly inom the extropolation techniques because the magnitudes were measured ir the $\mathbf{m p r}_{\mathrm{pys}}$ syem. The method adopted in such cases was an iterative one. Berinning with ar initial guess for $t_{o}$, the $m_{p v}$ magnitudes were converted to $m_{p g}$ using ti.. Pskovski $\left(m_{p g}-m_{p v}\right),-t$ relationship with the assumed $t_{o}$ - A nev estimate of $t_{0}$ was then obtained by applying the combined point $k$, average light curve method desfribed in the preceding peragraph. The whole roress was then repeated until the rstimates for $t_{0}$ converged. This final converger. value and tine final converted magnitudes gave a ronsistant ?ight curve which was adopted as the best estimate. In most cases there were a few measured valies of ${ }_{\mathrm{pg}}$ so that it was possible also to determine the absorption correction which could then be used to eliminat= the zero point orror in the magnitude conversions. Although this iterated ronvers:en method used the Pakovskil (mp $\left.m_{p v}\right)_{0}-\tau$ relation, the point $k$ extrapolation method, and the average light curve method, it wll be referred to in this thesis simply as the: iterated point k method. Experiments with different starting est1mates $t_{2}$ revealed thet a poor initial estimate would usualiy fail to give a converging iteration but that. good estimates all gave convergence to the same: final valut. Is some cases, poor initial estimates geve convergence also but the rate of convergence was considerably slowr. 
Table 6,-2 gives. Pcr the 37 superricve used in this study, the dates of maximum, the prak manitudes, and the methods used tc obtsin them In eacr. sast.

Column 1 gives the supernove designation.

Colum 2 gives the discovery number in the Zwicky sequez:e.

Cclumn 3 gives the name of tins parent groxy.

Column 4 gives tine estimeted peak magnitude of the supernove in

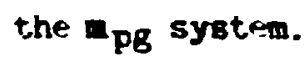

Colum 5 gives the method by shich the pea. magnitude estimate us cotained. The abbreviations in this crlum can be interpreted as follcws: obs. 1. c. means inspection of tinc observed light curve, pt. $k$ means Pskorskil's point $k$ wethod, av. 1. c. means Pskcrekil's average light curve method, and iterated pt. $k$ means the iterated point $k$ method.

Column 6 gives the estimated date of maximum efther on the Julian dey calendar or in month/day/year notation, depending for each supernova on how most of the observations were given in the 11terature.

Column 7 gives the method by wich the estimated date of maximum was obtained. Most of the abbreviations in thia column are the same as thcse in column 5. The two abbreviations which do not appear in column 5 are obs. color curve, which means that $t_{0}$ was obtained by fitting measured color indices to one of Pskovskif's color index-time relations, and spectrum wich peans that $t_{0}$ was estimated from one or more spectre of the supernova. 
Colv 8 indicetes additional notes about the supernom. A single $P$ weans that the estimates $n_{0}$ ard $t_{0}$ wre both those or Pakorkil, and - single $R$ meers that roth vere done by the present author. Ine conbination $P, R$ means that the ${ }_{0}$ estimate is that of Pakovskif and the $t_{0}$ estimate ws done by the present author. Sinilarly the combination $R$. P means that $a_{0}$ is due to the present euthor and $t_{0}$ is due to Pskorsklf. The symbi * In this column indicates addition: coments given in the notes following the table.

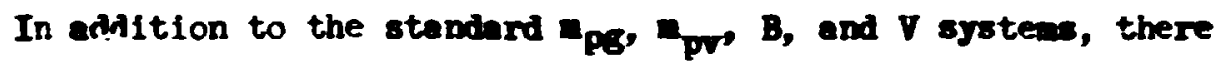
were two other magnitude system mich were used by same obcervers of some of the light curves included in this study. One of these systems ws that of Kaho $(98,108)$ who used Puji FL-OII plates. According to Kaho, these plates are blu- sensitive, but they do not correspond exactly to either the ${ }_{\mathrm{pg}}$ or the B system. Severel of the supernove observed by Kaho vere also observed in the B system by varlous ocher observers. In almost, all of these cases some of the coupririson stars used by the other observers were also used as comparison stars by Kho. By comporing the B-mogitudes of these comon comparison stars wth the magnitudes measured by Kaho, it wa possible to establish the reletionshlp between the two systems. This relationship is show in Mare 6-5, where wegnitudes in Kho's system are denoted by $\mathbf{n}_{K}$. For each of the common comparison stars, the difference $B-a_{K}$ is plotted aginst - The date appear to Indicate that Kaho's magnitudes bave a non1tnear scale error. Tre four supernove wth common observed compartBon store were SII $1962 \ell$ which wes elso observed by Bertole (87), 8II 1963p 


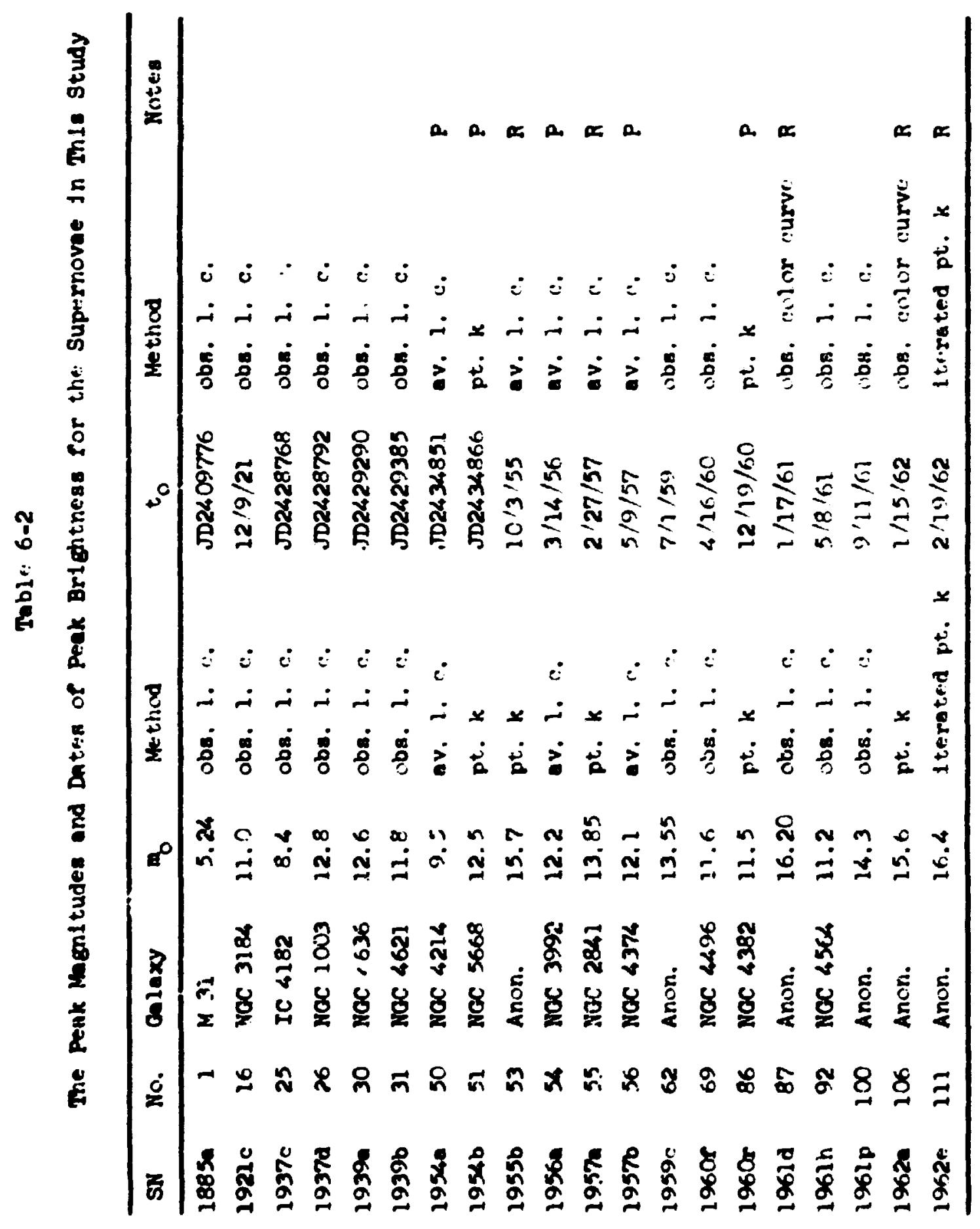




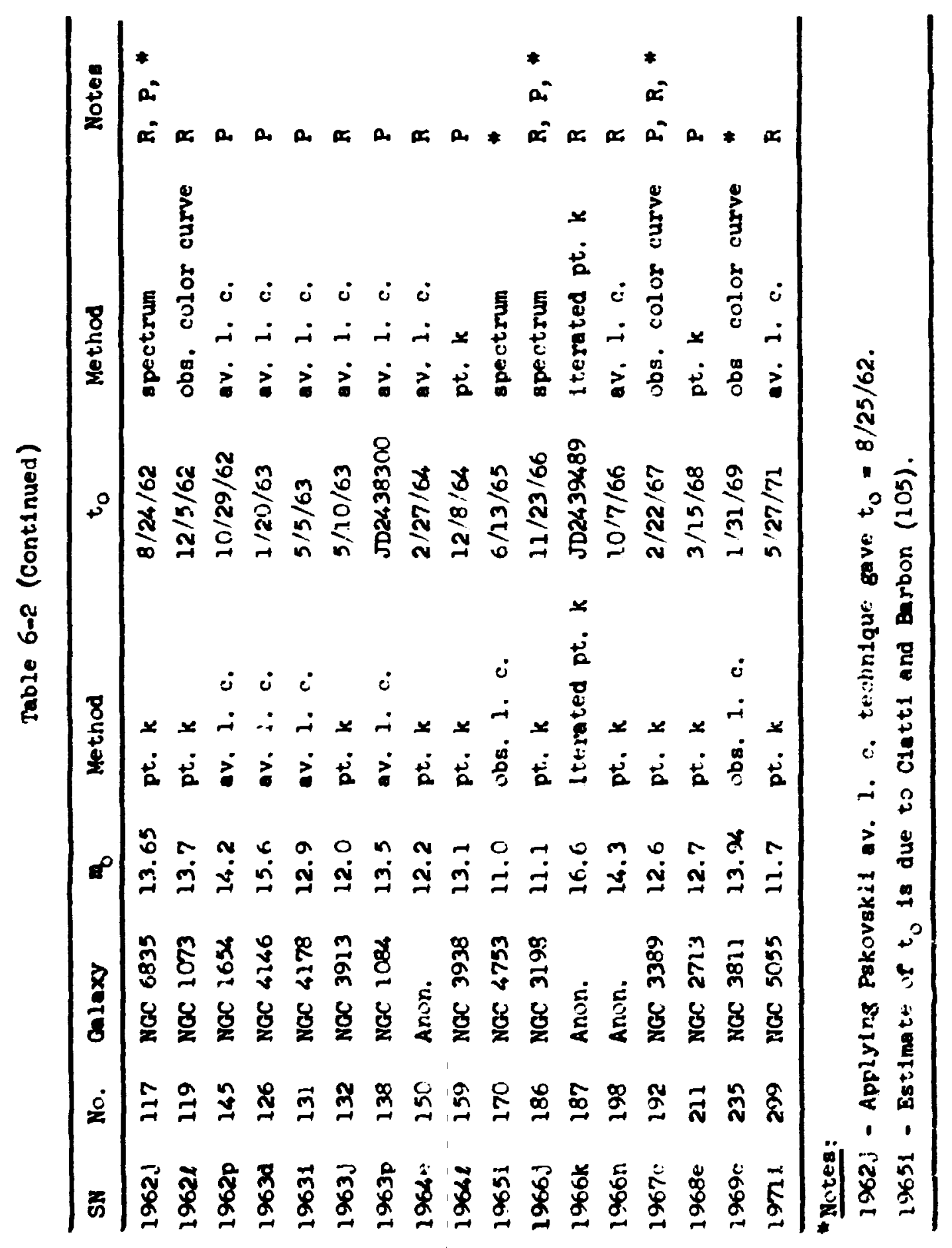


iable i-a (Cont1nua:1)

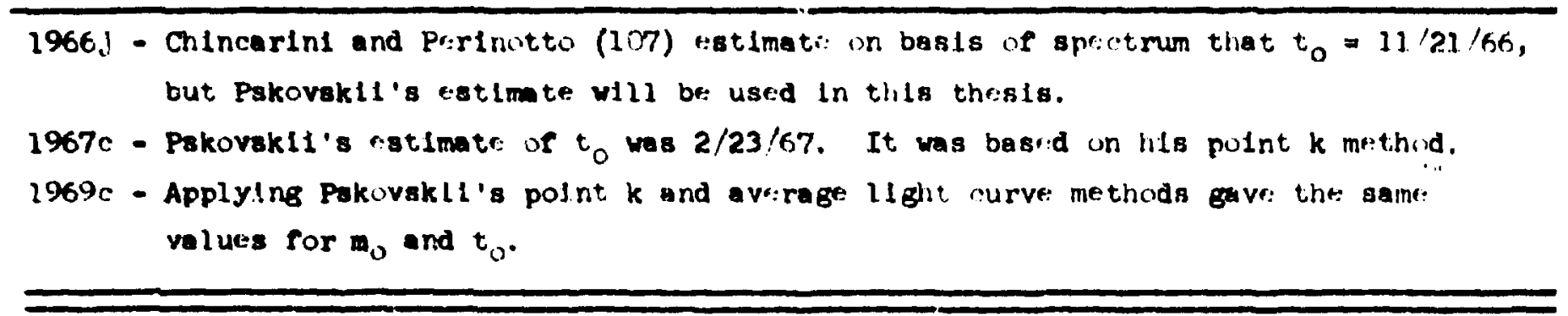




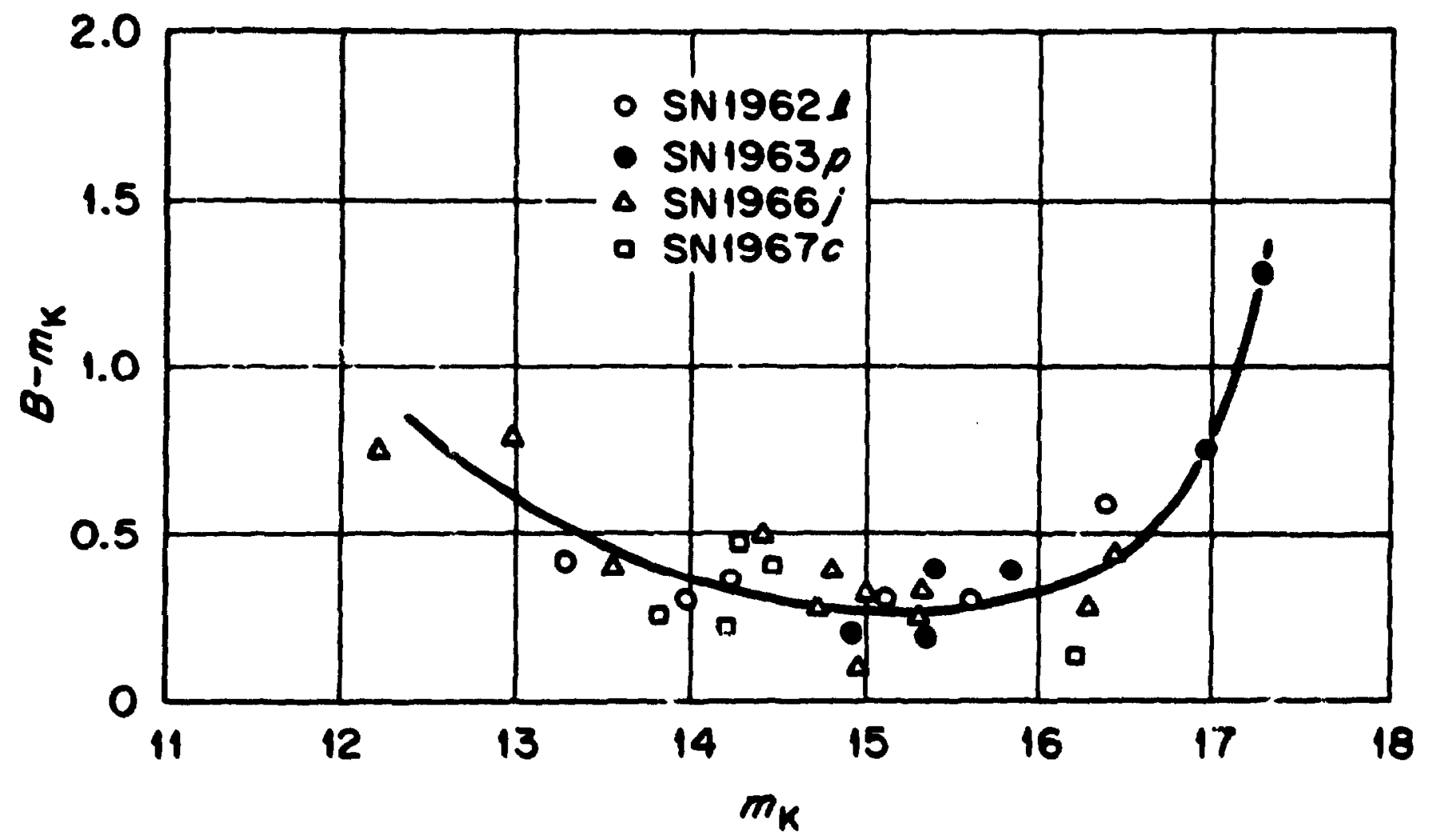

Figure 6-5. The Scale Correction for Converting Kario's Magnitildes to tise B System. 
which ws observed b: Bertole, Mameno, and perinotis (97), SII 1966j whick wes observed iy Chincerini and Perinotto (107), and ST 1967e utich ws also roserved by deVaucculeurs, Sclheim, and Brom (110). The points for SN 1962 vere arbitrarily selected as the standard and the ncints for the other three sets of comperisor stars were sibifted vertically to give the best possible agreement with those of the standard. Thus the relation shown in the Plgure has an indetermilate constant zerc-point error which vas propagated into any magnitudes converted Prom $m_{K}$ to $B$ by means of the relationship. The $B$ magnitudes obtained Prom this relationship could then be converted to ${ }_{\text {pg }}$ magnitudes either by Eq. (6-1) if the color excess $E(B-V)$ was lnc:m or by Eq. $(6-2)$ if it was not know. I: the latter case, an additional unknown zero point error was added to the error from the $m_{K}$ to B transformation. In some cases it was possibie to determine the required zero-point correction by compering the converted magnitudes to magnitudes measured in one of the other systems. In cases where it was not poseible to determine the zero-point correction, the basic shape of the curve was not altered by the constant zero-point error, and so fts slope could stiil be used for testing the expansion hypothesis.

The other non-standard magnitude system used for light curves treated in this thesis is the b magnitude system of Marx and PFau (111). This system is related to the $B$ gystem by the relation

$$
B=b+0.14(B-V)
$$

Combining this expression with Er. (6-1) Gives

$$
\mathbf{m}_{\mathrm{pg}}=\mathrm{b}-0.29+0.32(\mathrm{~B}-\mathrm{v})
$$


If the values of $B$ - V are unitnown, the transformation can be ande by

$$
\mathrm{n}_{\mathrm{pG}}=\mathrm{b}-0.29+0.32(\mathrm{~B}-\mathrm{v}) \text {. }
$$

where $(B-V)$. is obtained from Pskorskif's $\left(B-V_{3}\right)$ - t relat $\pm c n$.

If this latter relation is used, there will, of course, be an unknown zero-point error in the converted ragnitude because of the unknom cclcr excess $E(B-V)$ due to absorption.

Thus far, this chapter has described the various techniques that were used to reduce the light curves to the stanjard mpg system. Many of these techniques required accurate estimates of the peaik magnitude $m_{0}$ and the date of its occurrence $t_{0}$, so the techniques used for ootaining those estimates have also been described. Table 6-2 gave a sumwary of those estimetes and the method used for each of the supernovae in the study. The chief purpose of the discussion given in this chapter has been to develop the background needed in order to construct a simflar table, which gives for each supernova a sumary of the techniques used to reduce all of the measured magnitudes to the mpg system. Before dofing that, hovever, it is convenient to sumarlze the various conversion methods that were used. This is done in Table 6-3. Column 1 gives the system or systems of measurement. Column 2 brieriy describes the method used for conversion to the $\mathrm{m}_{\mathrm{pg}}$ system. Column 3 gives a Roman numeral code which will be wed as an abbreviation for the method. Column 4 gives additional comments about the method.

In many cases it was recessary to know the color excesses of the supernovae in order to eliminate zero point errors in the conversion. In most of these crses, it was possible to derive these color excesses 
Table 6-3 (Continued)

\begin{tabular}{|c|c|c|c|}
\hline Measured & Converaton & Code & Comments \\
\hline$v$ only & $m_{P B}=v-0.29+1.18(B-v)_{0}$ & v & $\begin{array}{l}\text { In general, there wll be a } \\
\text { zero point error beciuse of } \\
\text { the unknown color oxcess. }\end{array}$ \\
\hline$m_{p v}$ and some $m_{p B}$ & $\begin{array}{l}\text { (a) nights when both } \mathrm{m}_{\mathrm{pg}}, \mathrm{m}_{\mathrm{pv}} \text { measured: } \\
\mathrm{C}=\left(\mathrm{m}_{\mathrm{pg}}-\mathrm{m}_{\mathrm{pv}}\right)-\left({ }_{\mathrm{pg}}-\mathrm{m}_{\mathrm{pv}}\right)_{0} \\
\text { determines } \mathrm{C} . \\
\text { (b) nights when only } \mathrm{m}_{\mathrm{pv}} \text { measured: } \\
m_{\mathrm{pg}}=m_{\mathrm{pv}}+\left[\left(m_{\mathrm{pg}}-m_{\mathrm{pv}}\right)_{0}+\mathrm{C}\right]\end{array}$ & $v \pi$ & 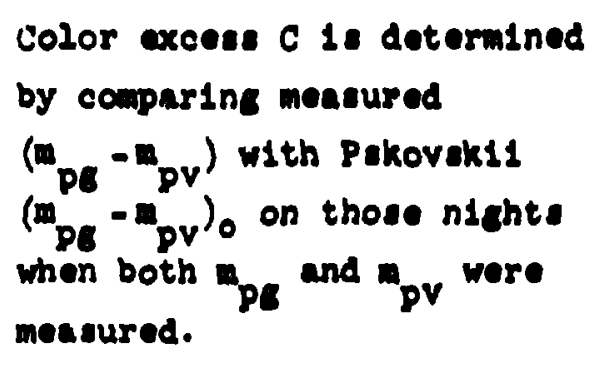 \\
\hline $\mathrm{pv}_{\mathrm{pV}}$ and some $\mathrm{m}_{\mathrm{PB}}$ & $\begin{array}{l}\text { (a) nights when both } m_{p B}, m_{p v} \text { measured: } \\
\quad(B-v)=\frac{\left(m_{p g}-m_{p v}\right)+0.29}{p_{.18}}, \\
c=(B-v)-(B-v)_{0} \\
\text { (b) nights when only } m_{p v}^{m} \text { measured: } \\
a_{p g}=a_{p v}-0.29+1.18\left[(B-v)_{0}+C\right] .\end{array}$ & VII & 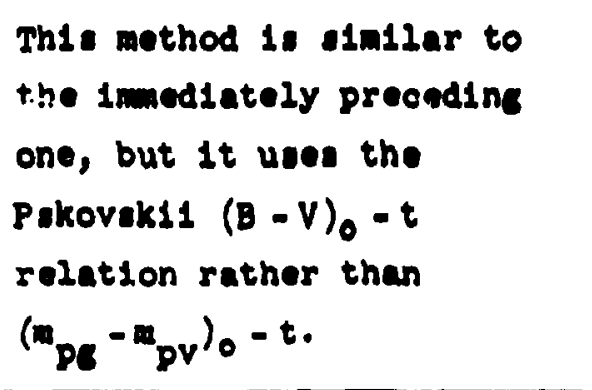 \\
\hline$m_{v i s}$ or $m_{p v}$ only & $m_{P G}=m_{p V}+\left(m_{P G}-m_{p V}\right)_{0}$ & VIII & $\begin{array}{l}\text { In eneral, there whl be a } \\
\text { zero point error because of } \\
\text { the unknown color excess. }\end{array}$ \\
\hline
\end{tabular}


Table 6-3 (Continued)

\begin{tabular}{|c|c|c|c|}
\hline Measured & Conversion & Code & Comments \\
\hline (Kaho) & $\begin{array}{l}\text { (1) } B=m_{K}+\left(B-m_{K}\right) \\
\text { with }\left(B-m_{K}\right) \text { determined from the } \\
\text { relation in Figure } 6.5 \text {. } \\
\text { (2) }{ }_{P B}=B-0.29+0.18\left[(B-v)_{0}+C\right] \\
\text { if color excess } C \text { is known, or } \\
{ }^{P B}=B-0.29+0.18(B-V ; 0 \\
\text { if } C \text { is not known }\end{array}$ & $I X$ & $\begin{array}{l}\text { Step (1) will, in ceneral, } \\
\text { Blve a zoro point erroi. } \\
\text { step (2) will dive an adl. } \\
\text { tlonal zero polnt error if } \\
\text { C 1e not determined by other } \\
\text { measurement. }\end{array}$ \\
\hline (Marx and Pfau) & $\begin{array}{l}m_{p g}=b-0.29+0.32\left[(B-V)_{0}+C\right] \\
\text { if color excess } C \text { is known, or } \\
{ }_{p g}=b-0.29+0.32(B-V)_{0} \\
\text { if } C \text { is not knom. }\end{array}$ & $x$ & $\begin{array}{l}\text { There wil be a zero point } \\
\text { error if the color excess } \\
\text { C 1E not determined by } \\
\text { other measurements. }\end{array}$ \\
\hline
\end{tabular}


by caparing measured $(B-V)-t$ data inth Pstorstit's (B - V $)_{0}$ - t relation for in some cases comparing reasured ( $\left.\mathrm{m}_{\mathrm{pg}}-\mathrm{a}_{\mathrm{pr}}\right)-t$ data with the

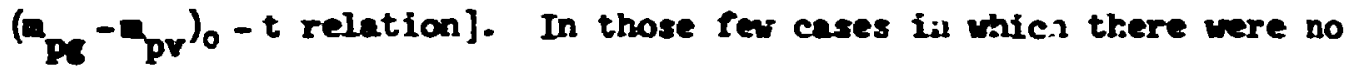
measured color indices, the conversions preserved the siape of the curve even though they nay have introduced a zero point error. Color excesses were determined for every supernove for which color indices had been measured, regardless of whether or noc the excesses were needed for magnitude conversions. These color excess data will be used again in Chapter 9 for computing absorption corrections to the supernovae peak magnitudes.

Table 6-4 gives the final summary of the techniques used for reducing each of the light curves to the standard ${ }_{p g}$ system. Colisan 1 gives the supernova desigration. Colum \& gives its numioer in the Zwicky numbering system. Colum 3 gives the name of the parent galaxy. Column 4 contains the rames of the various observers. Coliunn 5 gives, for each of the observers, the magnitude system or systems used fo: the observations. Column 6 gires the method used for converting the magnitudes if such a conversion was necessary. The method is indicated by a Roman numeral In the range $I$ to $X$. These Roman numerals correspond to the ones given in column 3 of Tabie 6-3. In some cases it was necessary to make a zero point correction in the magnitudes of one or more of the observers. Column 7 gives these zero point corrections. Column 8 cor.tains the word "yes" if there was a possible zero-point error in the conversion. Note that in many cases a conversion introduced a zero point error which could be removed by compaifing the converted magnitudes to m magnitudes measured by other observers. These corrections were included in the 
conversion, so coluan fi contains a "yes" only if there was no vay to correct the error. Colunr 9 contains the $E(B-V)$ color excess and Colunn 10 contains the Eif pg $^{-\mathbb{k}_{\mathrm{pv}}}$ ) color excess for those supernovae wich had measired color indices. Colunn 11 contains an asterisk (*) for those supernovae which have additional information given in a note at the end of the table.

When all the magnitude conversions were completed for a given supernova, the resulting $m_{p g}$ light curves from all the observers were used as input for an IBM 360 computer program, called EDTT, wich combined the various light curves from different observers into a single final light curve for the supernova. The final light curves were plotted on a Calcomp plotter and an inspection of the plot immediate?y showed whether some of the light curves of individual observers still needed zero-point corrections. The final combined light curves were later fitted in the least squares sense by an analytic function derived from a theoretical model wich is described in the next chapter. The light curves plotted out by EDIT were also very useful for determiring the limits of the fit [only the rapid decline portion of the curve was fitted]. EDIT also punched out the combined light curves on IBM cards which were later used as input data cards for the fitting program.

Plots of all the combined light, curves are given in Apperidix 2. These plots also show the results of the fits described ir. the next chapter. 
Table 6.4

Sumary of the Plotemetrlo Dete and Converelonn

Uaed te obtaln the Liche curves for thls study

\begin{tabular}{|c|c|c|c|c|c|c|c|c|c|c|}
\hline $\mathbf{s e n}$ & no. & calery & observers & mase. & Converaton & $\begin{array}{l}\text { 20ro-pt. } \\
\text { Corree. }\end{array}$ & $\begin{array}{l}\text { 2oro-pt. } \\
\text { Error }\end{array}$ & $E(B-V)$ & $P\left(n_{p e}-\omega_{p w}\right)$ & moter \\
\hline 1805a & 1 & M31 & Hartudz and othere & mis & VIII & & yes & & & \\
\hline $1921 \mathrm{c}$ & 16 & noc3184 & snoples & & & & & & & \\
\hline $1937 \mathrm{C}$ & 25 & 104182 & $\begin{array}{l}\text { seade and zarloky } \\
\text { Deutech } \\
\text { Faremero }\end{array}$ & & & & & 0.05 & & - \\
\hline $1977 \mathrm{~d}$ & 26 & moc1003 & $\begin{array}{l}\text { Pande and zarleky } \\
\text { Parenego }\end{array}$ & & & & & 0.45 & & - \\
\hline 1939a & 30 & 0004636 & $\begin{array}{l}\text { Bace } \\
\text { Gtoles } \\
\text { Hornedt }\end{array}$ & & & +0.5 & & 0.49 & & - \\
\hline 19390 & $\mathbf{3 2}$ & 1004621 & $\begin{array}{l}\text { anoples } \\
\text { saces }\end{array}$ & & & & & & & \\
\hline 1954a & 50 & nocto214 & $\begin{array}{l}\text { Hidd } \\
\text { PHotre } \\
\text { Hornetater }\end{array}$ & & & & & 0.23 & 0.25 & $\dot{.}$ \\
\hline
\end{tabular}


31

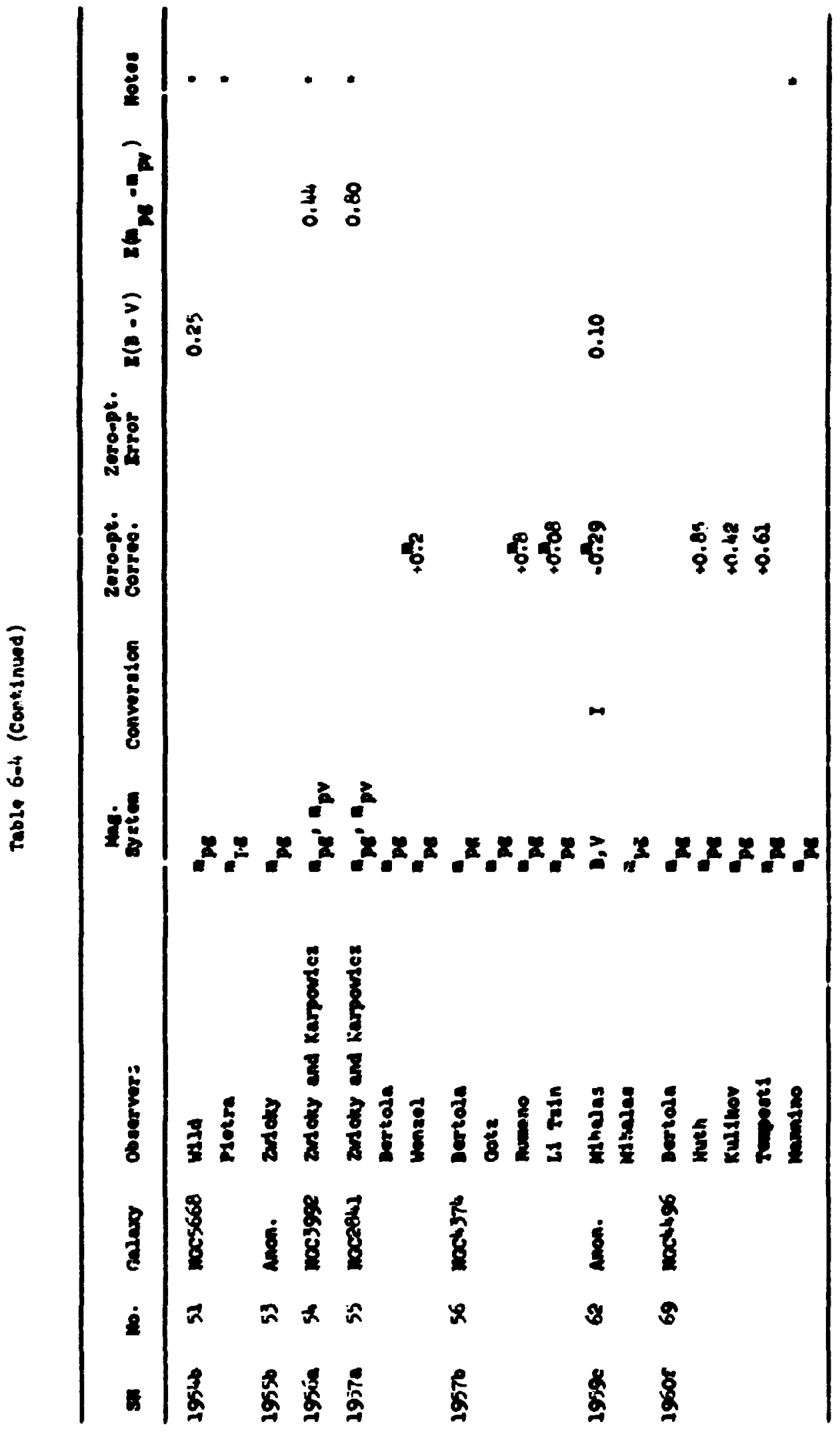




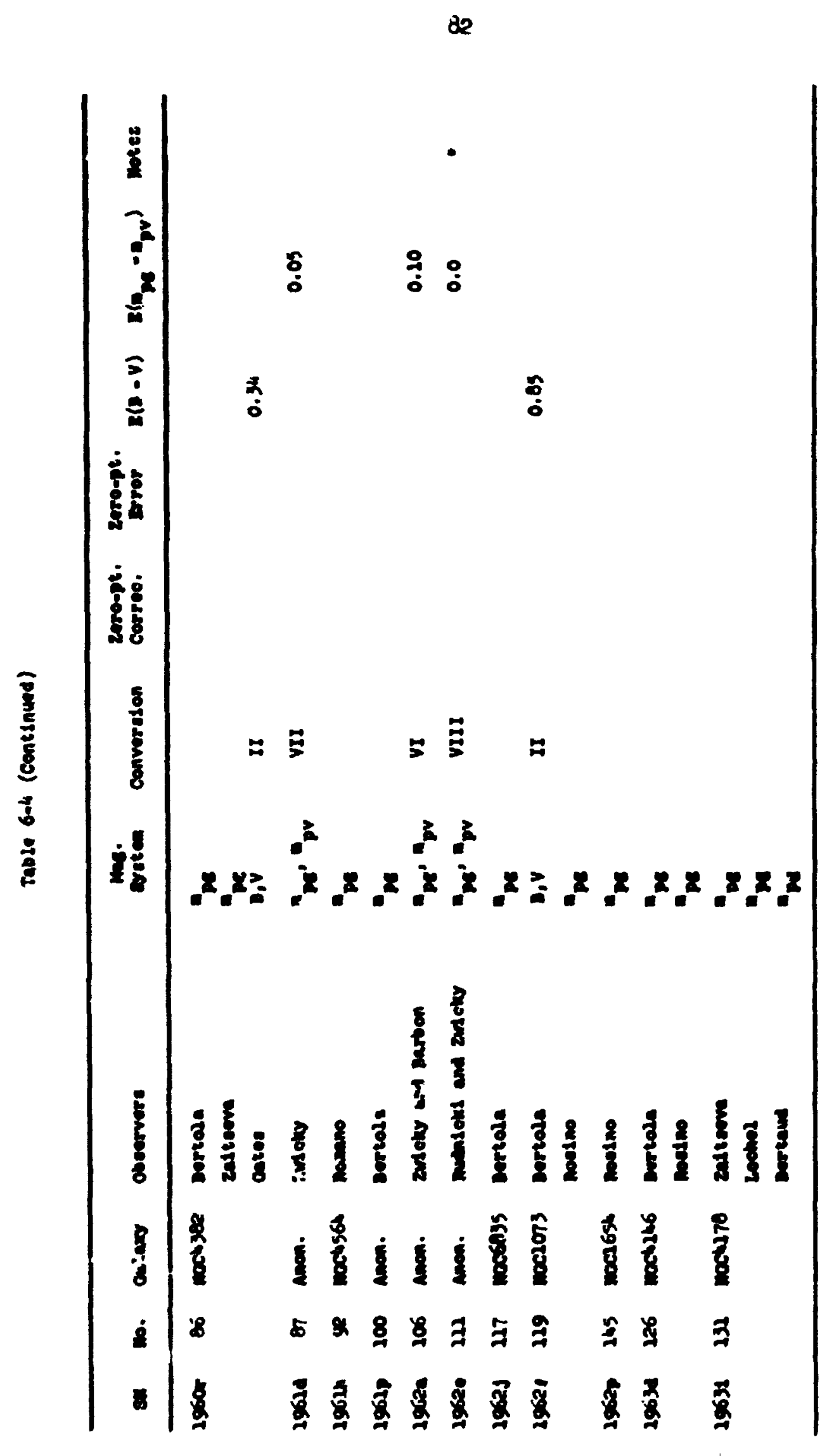


Table 6-4 (Continued)

\begin{tabular}{|c|c|c|c|c|c|c|c|c|c|c|}
\hline 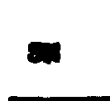 & $\mathbf{m o .}$ & coleses & Cosempers: & $\max$ & converalon & Laro-ph. & toro-pt. & $8(3-v)$ & $g\left(a_{n}-n_{p w}\right)$ & Notos \\
\hline 25630 & 230 & mocseses & 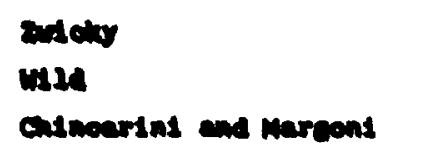 & & & & & & & - \\
\hline 29630 & 230 & nocsol & remelale or al. & 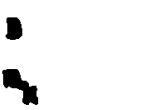 & $\begin{array}{l}\mathbf{I V} \\
\mathbf{I X}\end{array}$ & .0109 & you & & & \\
\hline 15060 & 150 & nom. & 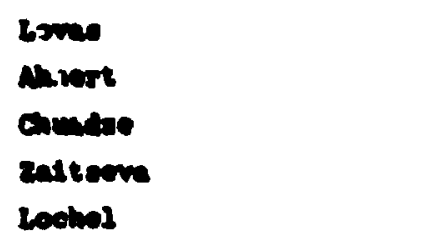 & & & $\begin{array}{l}.016 \\
-0.935 \\
-0.96\end{array}$ & & & & \\
\hline 150h1 & 139 & mocssso & sertale, ot al. & & & & & & & \\
\hline 25634 & 270 & moch7s3 & 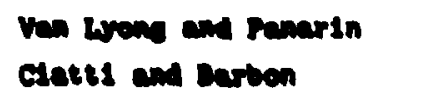 & & III & & & 0.03 & & - \\
\hline 19664 & 186 & mechese & 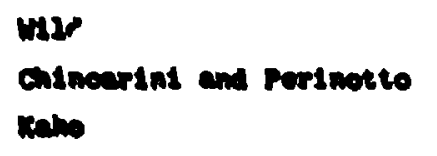 & $k$ & $\begin{array}{l}\text { IV } \\
\text { Dx }\end{array}$ & - & & & & - \\
\hline 2960 & 280 & nnom. & manis okt & & $\mathbf{v}$ & & & & one & \\
\hline 1566 & 290 & m. & Csests and Darten & $3 x$ & & & & & & \\
\hline
\end{tabular}




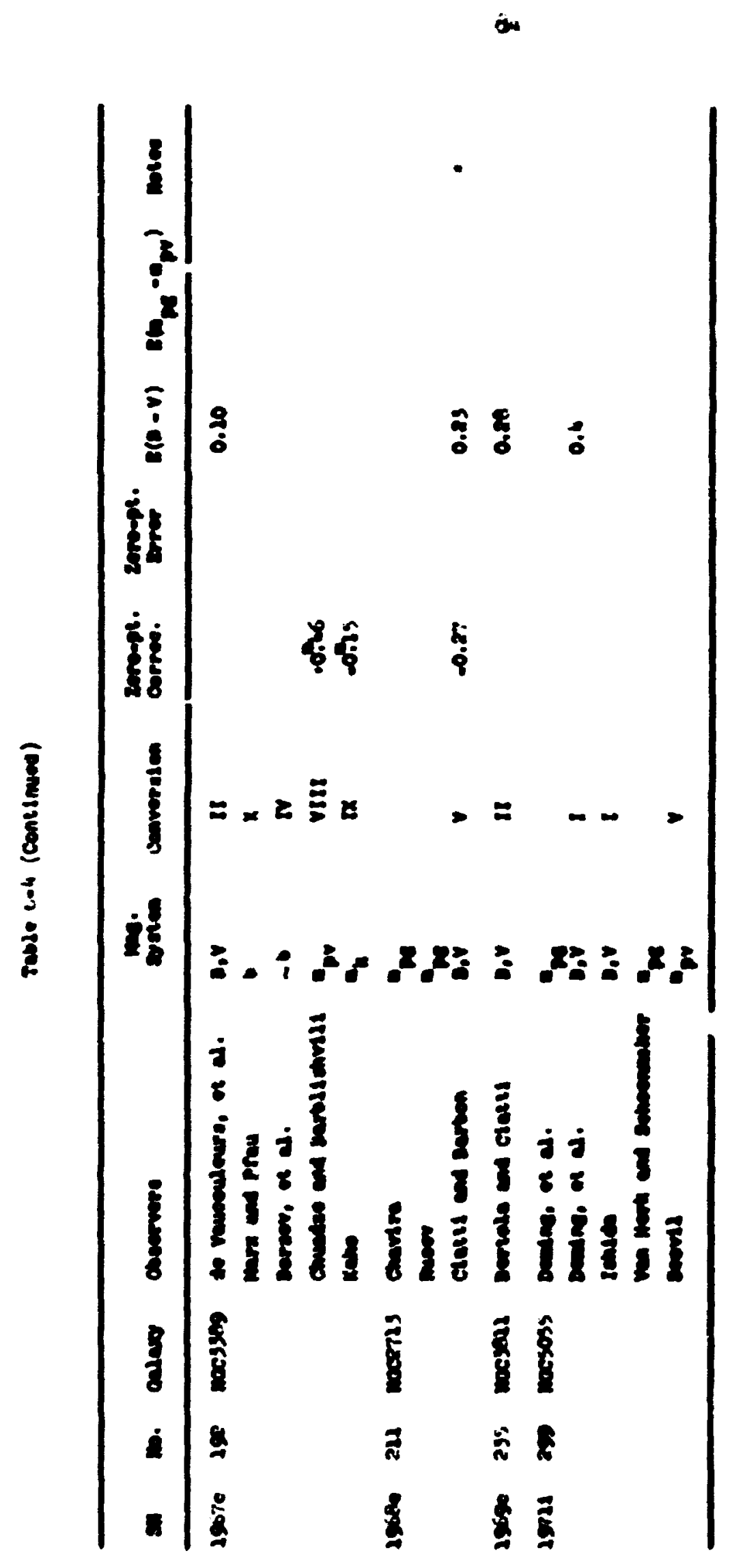




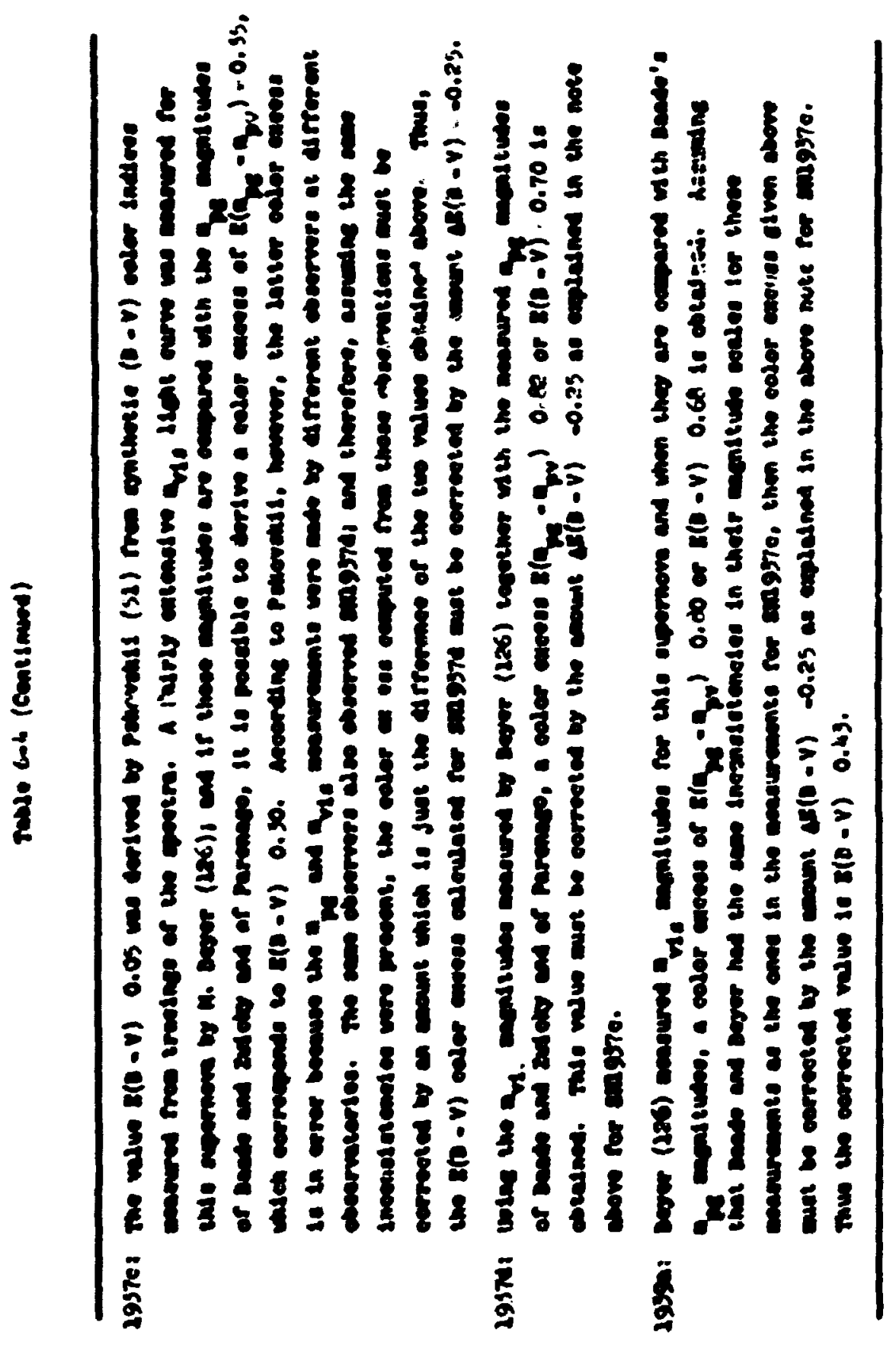




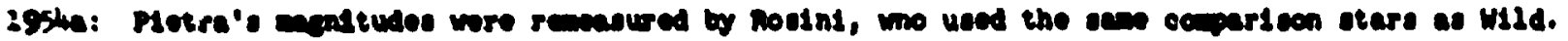

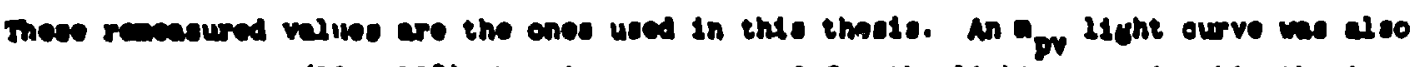

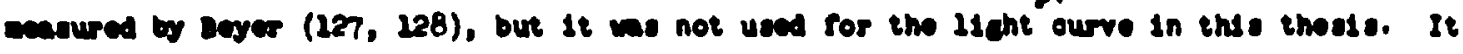

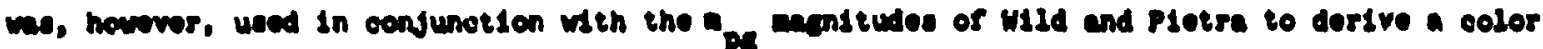

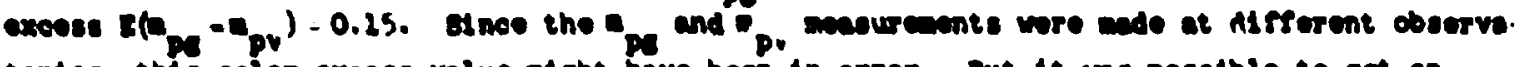

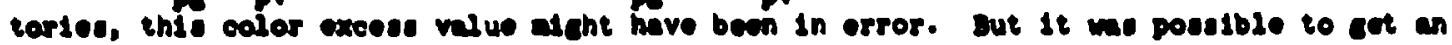

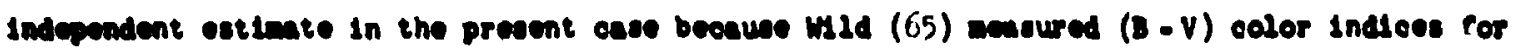

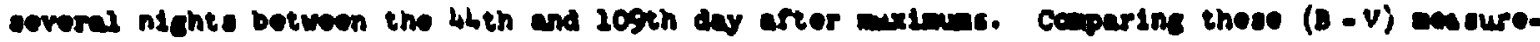

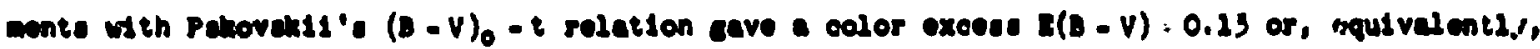
$\left.\sin _{\mathrm{pg}}-\mathrm{apv}_{\mathrm{pv}}\right)=0.25$.

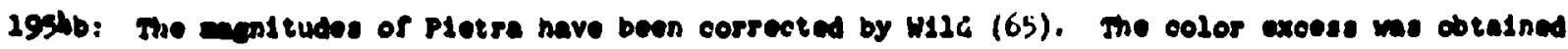

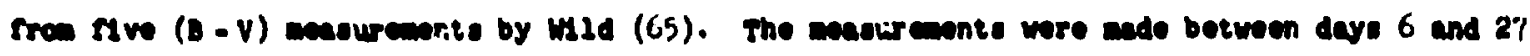

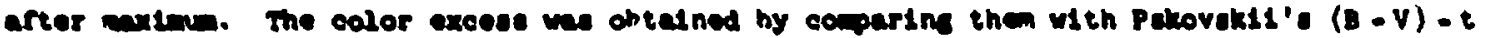
rolation.

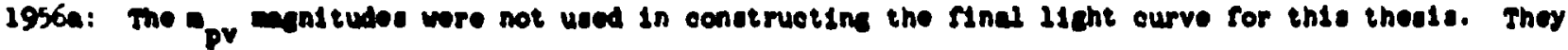
wore, howver, used Is dortiving the oelor exoess.

195ia: The apv angltudes wre int used in conotruoting the rinal light ourve for thit thease. They

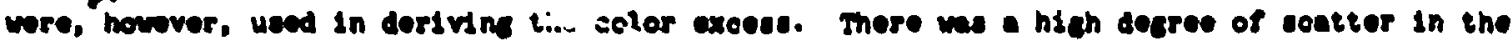

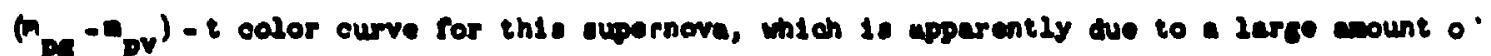
obacising eatter between ua and 1t. Inte lerge ebsorption la probebly the cavae of the low coparont suatioulity of ths superrova. 


\section{Table 6-4 (Continued)}

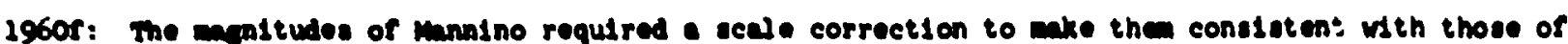

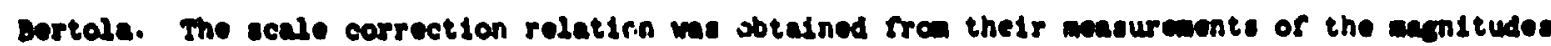

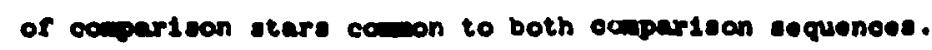

19620: Thore wore not enough meesured values of $n_{p e}-{ }^{-h}$ py to alve the color excees directly, but the color axcese can be taken to be 0 because the eupornova appoared in a ralnt laninous bridge

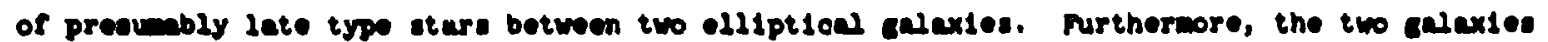

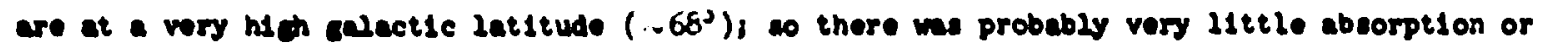
reddening of the lieht within our orm calery.

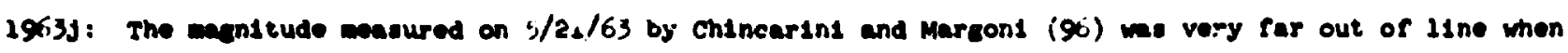
compered to the other masured magnztudes. It was theresore Judeed to bo in orror and was andted rrom the dight curve uoed in this study.

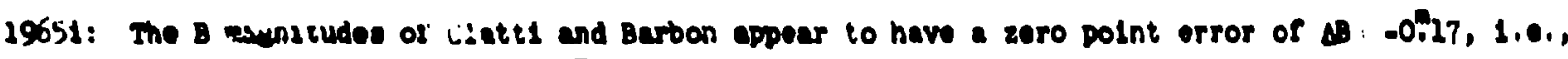

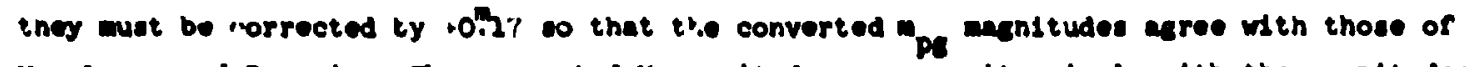
van lyone and Panarin. The converted $V$ caenst tudes aeree quite nleely with the maenltudes of Van tyone and Panarin without any zero polnt correction. The B correction was aleo taken Into secount in computine the color axcese $E(B-V)$.

1960j: Th10 aupornova oceurred at the extrene edee of the elexy so there was probably not very much reddenine or abeorption of 1t, 21aht in 1ts parent calexy. Thus any zoro-polnt orror 1ritroduced by the anenitude convo-alons wa probebly quite ands.

196hlo: The B menitudes of clattl and Barbon appear to have a zoro polnt error, 20 they wore not ueod In conatruetine the ilgint curve for this theste. They wore used in determining the color excese E(B - v), but the zero point error was taken into eccount. (800 al so note above for smlgcist.) 


\section{CHAPTER 7}

\section{MODE POR FITTDG THE LIGHT CUAVE DATA}

Once the observed lighi curve data had been collected and reduced to a comon photonetric syster, it was necessary to determine a standard parameter to be uset as a measure of the rate of decline of each of the light zurves. It would have been simplest $j$ ust to fit straight lines to the rapid decline portior. of each light curve and to use the slope of the line as the standard parameter. But wany of the light curves were somenhat fragmentary, and in some cases the gaps in the data would have wade the fitting of such a phosically urmotivited function a rather arbitrary procedure. This was especially true in those cases in whicn gaps occurred at the verv beginning or the very end of the rapid decline portion of the light curve. In such cases it would have been difficult, an! perheps : in impossib:a, to dotsmine currectiy a wean straight ine fit to the entire raplj dicline region. A better procedure seened to te to fit the light curves with a function wich is aerived frna a physically motivated asdel. The physical sheory would hopefully giarantee that the function would correctly fit through the gaps in the data, and rurthermore, even in curves where there are no gaps, wouid give a better fit to the data than would a simple straight line. Portunately there does exist a physically weil-motivased model for the type I apernova event which gives a relatively simple funstional expression for the ifgt curve. This model is the optical reverberation theory of Morrison and Sartori. Morrison and Sartori have described their acdel quite extensively in their papers (129, 130), so there : no point in giving anything sore 
than a brief descriftion of it in this thesis. Basicallij, th. model assumes that th? light froe \& supernov's cones not fran the explosion itself but rather from the response o: circumsteilar matter to the explosion. The explosion prociuces a strong ultraviolet pulst yhich in turn excites nucrescence in the circuastellar medium at jistances cut to about I light year. For type I supernovae this secondarj radiaticn is thought to be excited in a helium rich envilope which ras formed around the presupernova star by mass ejection. The proper,ies ci such ar envelope have recently been investigated in a paper by Arnett : $1 ; 1$ ). In the case of type II supernovae, no appreciable mass ejection is

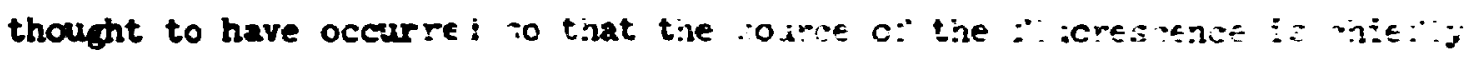
the inierstellar medium. Thus, type II superrovas are not so luainous as type $T$, and nurtherwore occur cnly in galaxies which are rich in gas, i.e. spirals and irregulars. In addition, the spectra of type II supernovae are dominated by the lines of hydrogen while those of $t_{j}$ pe I are dominated by the..-3 transition of He II. In both cases the spectra are characteristic of a low density gas with Doppler broadened atomic lines present from the first. The uptical reverberation model also accounts quits naturally for the fact that supernor a light curves never exhibit secondary maxima since the cbserver is seeing, even on the first daj, a considerable anount of light exitted from regicns several ight months from the explosion. This optical echo effect produce a smoothing of the light received, which obscures any structure in the primary pulse. 
The light esto phencoenor is illustrated in Eigure $7-1$. The superncra is ist point $S$ enj ckserver is at point $C$ which is st a jistance $i$ iroe $S$. The cicserver :irst detects the superncva st time $\frac{\text { L }}{a}$ aiter the

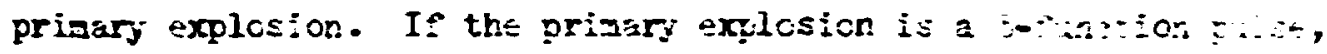
then at time $t$ :iter this first detection ths obs orver is receiving secondary rajiation from the poirts on the ellipscijal sur:ace de ined by

$$
\boldsymbol{r}+\mathbf{j}=\mathbf{L}-\mathbf{c t} \text {. }
$$

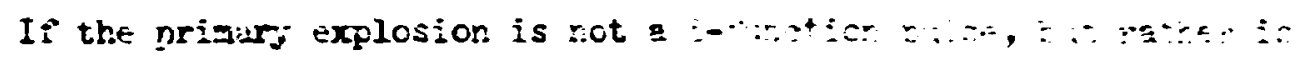
spread over a time interval it, then the cisserver is receivi $r g$, at otserver time $t$, light fram en ellipscidsl shell xhose triciness is zcit.

Morrison and Sartcri constructed their madel by considering a single line of the secondary spectrum e.g., the .. - Ztransition of

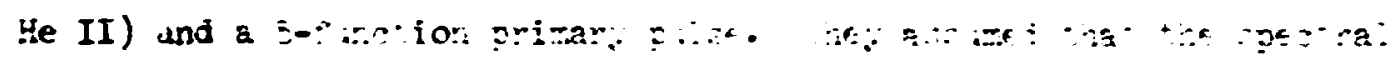
intensity $\frac{d v}{d v}\left(\frac{p h o t o n s}{h i}\right)$ of tho primary plise was equal to a constent

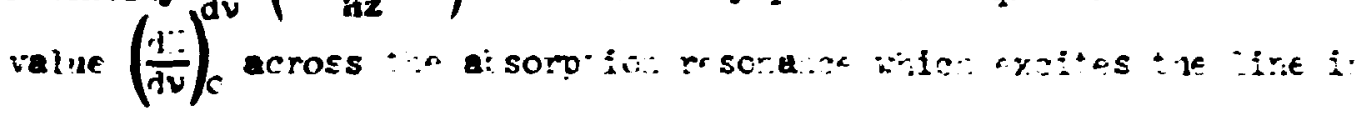
question. They assumed that the secondary emitters were dist ibuted isotropically about the supernova. If the number density, absorptson optical depth, and cross-section for absorption at distance $r$ from the supernova are denoted by $n(r), \tau_{v}(r), a_{j}(r)$ respectively, and if the probability that an absorber which is excited to the proper initial state will decay by emitting the line in question is denoted by $\alpha$, then the luminosicy at observer time $t$ was show to be

$$
\mathscr{Q}(t)=2 \alpha c\left(\frac{d N}{d v}\right)_{0} \int_{\frac{c t}{2}}^{\infty} d r \frac{n(r)}{r} \int d v e^{-T} v^{\prime}\left(r^{\prime} \sigma_{v}(r),\right.
$$




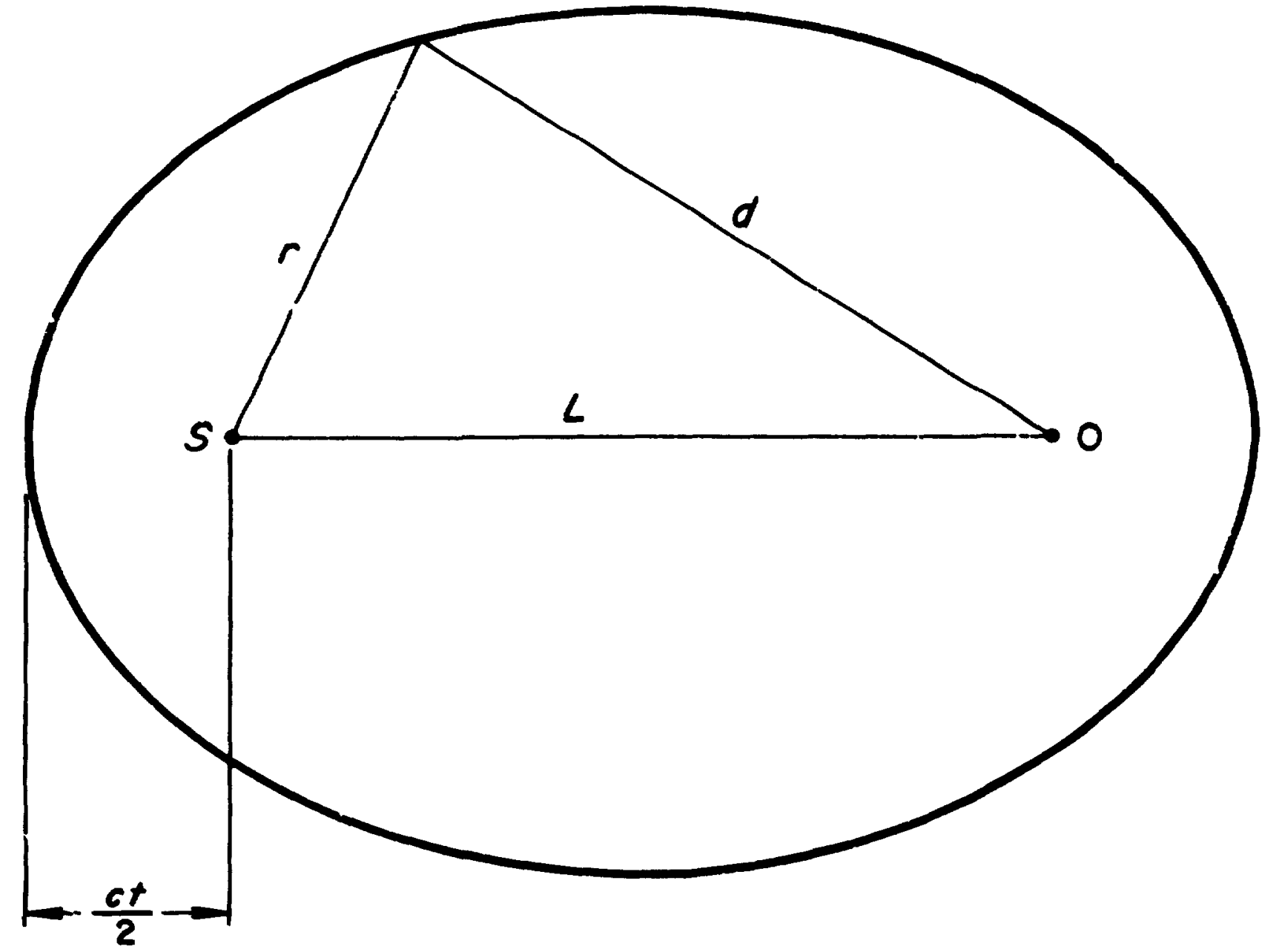

Figure 7-1. The Morrizon-Sartorl IAght Echo Model.

$F_{1}$ 
where the last integral is taken scross the ebsorption resconance. This is the basic equation of their theory. They then Rurther simplified the nodel by assuing that the absorption resonance is approxinated by a rectengle of width $\Delta v$ and further that both $\Delta v$ and the nuber density $n(r)$ are indepencient of $r$. This weans that $T_{v}(r)$ is independent of $v$ within the line and is diven by the equation

$$
T_{v}(\mathbf{r})=\frac{\mathbf{r}}{\Lambda} \text {, }
$$

white $A$ is the wan free path of the photons within the unifor envelope. Thes were then able to shor that the Indnosity is given by

$$
\mathscr{Q}(t)=\left(\frac{a n e^{2}}{2 n}\right)=\left(\frac{d v}{d v}\right), E_{1}\left(\frac{c t}{2 \Lambda}\right)
$$

where $e$ and a are the electran sinarge and ans, $f$ is the oscillator strength of the transition, $n$ is the uniform muber density and $B_{1}\left(\frac{c t}{2 \Lambda}\right)$ denotes the exponentiel interal function evaluated for the argnent $\frac{c t}{2 h}$. This latter function is defined by the expression

$$
\xi_{1}(x)=\int_{2}^{\infty} \frac{e^{-x z}}{2} d z \text {. }
$$

Morrison and Sartori called the axdel defined by Equation (7-4) their uniforn model. One cannot expect such a simple nodel to fit the entire ligbt curve, and in fact they show that for a 8-function primary pulse, the lueinosity defined by Bq. (7-4) always decreases. Hence, the model is only good for the declining portion of the light curve. Like almost everyone who has worked with type I light curves, they sought to flt their model to the exponential tall of the light curve and wre extremely successpul in doing it. Pigure (7-2) shows their fit 


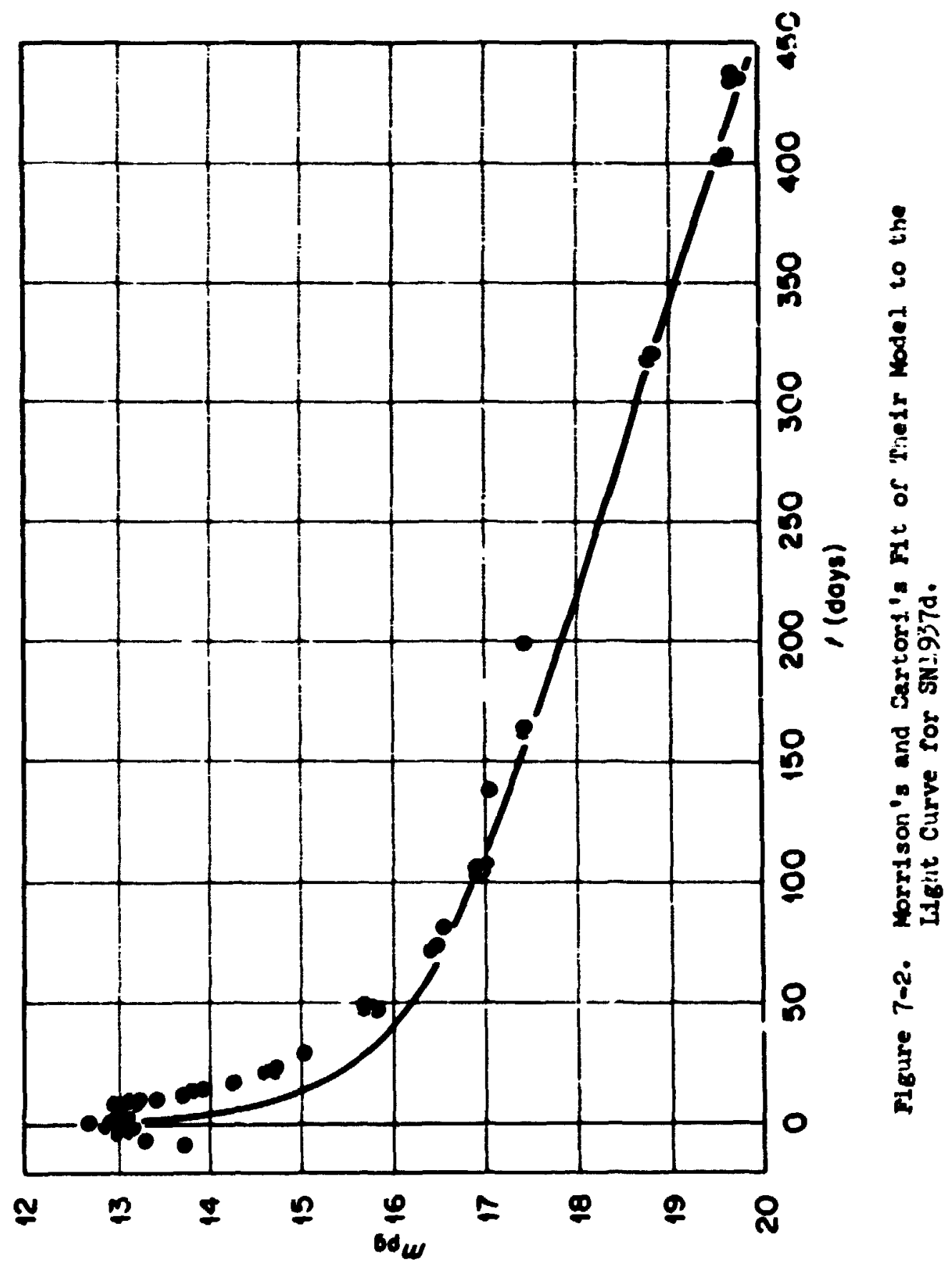




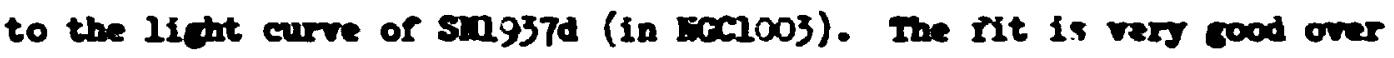
the range ron sbout day 75 arter nexing to the last recorded observetions nearly 350 days later. Their other fits were fust es cood ar better; they were, for exople, shle to fit the liont curve for 820937 . (in IC4182) nron sbout day 30 to bout day 600 arter nadin. The values of A for their fits rence beimen 50 and 100 lint days thes inglying helius densities in the range of 1 to 4 ions $\mathrm{cm}^{-3}$.

Nthounh forrison's and Surtari's fits to the talls of the light curves are inpressive evidence for the correctness of their nodel, they are not of wch use far anelyzing the date in this thesis since it is the rapid decisise portion of the lint curve that is being considered here. But upon inspecting their fits, the present author concluded that the save model wight be used to fit that portion of the lifht curve also, if the tail were sioply ignored. Of course andler values of $A$ would be expected fron such fits since the rapid decline portion originates tron the echo imeraction of th- prifary pulse with the inner layers of the circustellar errelope. The fon densities in these inner lavers would be expected to be greater than in the outer layers, and thus the wean free path of the photons would be less.

In order to perform any fits at all with the nodel, it is necessary to reduce Eq. $(7-4)$ to an expression which relates observable quantitias. Iuping all the constant autiplying factors on the right of (7-4) into - single constant value $k$ gives

$$
\mathscr{L}(t)=k E_{1}\left(\frac{c t}{2 A}\right) \text {. }
$$

In weasuring a light curve, the apparent magnitude $m$, rather than 
10uinosity $\mathcal{C}$ is cbserved. There are at least two wows of converting Bq. (7-6) to an expression invalving $n(t)$. One wer is besed on the relation

$$
a(t)-z_{0}=-2.5 \log \left[\frac{g(t)}{d L_{0}}\right]
$$

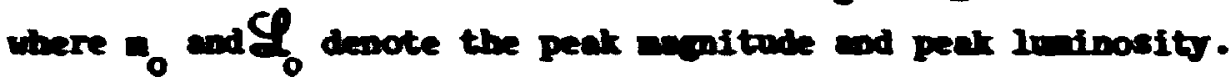

Sobstitutins (7-6) into this expression and replacing the grotient $k / L_{0}$ by a single constent $C$ dives

$$
m(t)-n_{0}=-2.5108\left[C B_{1}\left(\frac{c t}{2 \alpha}\right)\right] \text {. }
$$

Ins expression could then be used for fitting the observed 1 ight curve. The constants $C$ and $A$ wonld be the unlown paraneters to be deterninid by the best nt.

inocher wa to reduce Eq. $(7-6)$ to an expression imciving monitudes is to renrite $(7-7)$ in the form

$$
\frac{1}{108^{-1}\left\{0.4\left[\mathrm{n}(t)-a_{0}\right]\right\}}=\frac{C(t)}{d f_{0}} \text {. }
$$

Substituting (7-6) into this lact expression give.i

$$
\frac{1}{\log ^{-1}\left\{0.4\left[(t)-a_{a}\right]\right\}}=\operatorname{cs}_{1}\left(\frac{c t}{2 \lambda}\right) \text {, }
$$

which imvolves only measured quantities and the two constacts $C$ and $\Lambda$ to be determined by the fit. In order to choose anich of the wo expressions $(7-8)$ and $(7-9)$ gives the best PIte, it is Nrot neceseary to specify the fitting procedure.

The urual criterion of best fit is the least equares principle and that is the one that was chosen here. since both $(7-8)$ and $(7-9)$ are non-1inear in the paracters to be deterndned, the procedure 
necessarify involves mo-1ibear least spures. The solution techaigee thet was chosen wes a sipple iteration wich besins with initial estinates $c^{(0)}$ and $A^{(0)}$ and cal zulates at each sisp, 1 , iproved estinates

$$
\begin{aligned}
& c^{(1)}=c^{(1-1)}+\Delta c^{(1)}, \\
& x^{(1)}=A^{(1-1)}+\Delta n^{(1)},
\end{aligned}
$$

where the corrections $\Delta^{(1)}$ and $\Delta^{(1)}$ are obtained by solving a inear least squares problen. Equation (7-9) was chosed as the farmatias to use because it gives a ach sippler linear leat squares problen at each step than does $(7-8)$.

It is comenient to rewrite Equation $(7-9)$ in the forn

$$
y(t)=\operatorname{cE}\left(\frac{c t}{2 \Lambda}\right)
$$

where

$$
y(t)=\frac{1}{\log ^{-1}\left\{0.4\left[n(t)-n_{0}\right]\right\}} .
$$

A light curve consixts of a total of, sa $M$, observed polot: $\left[t_{i}, a_{i}\right]$ from waich the set of polnts $\left[t_{1}, y_{1}\right]$ cen be computed by neans of Eq. (7-11). The leart squares problen that aut be solved then is that of aintaling the expresstion

$$
D=\sum_{n=1}^{n}\left[y_{1}-c \varepsilon_{1}\left(\frac{c t}{2 \pi}\right]^{2}\right.
$$

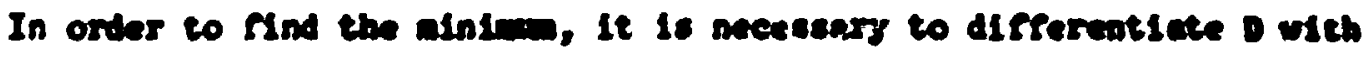
respect to the two parturters $C$ and $A$ and to set these two derivetives equal to zero. Iakins into sceount that the exponemis intepral,

$$
f(x)=\left\{\frac{e^{-2 x}}{x} \times x\right.
$$


has as its derivative

$$
\frac{d S_{1}(:)}{d z}=-\frac{e^{-z}}{2}
$$

one gets

$$
\begin{aligned}
& \frac{\partial \partial}{\partial c}=\sum_{i=1}^{M}\left[y_{I}-c E_{1}\left(\frac{c t_{i}}{2 \lambda}\right)\right] E_{1}\left(\frac{c t_{i}}{2 \lambda}\right)=0, \\
& \frac{\partial D}{\partial X}=\sum_{i=1}^{M}\left[y_{1}-c E_{1}\left(\frac{c t_{i}}{2 \lambda}\right)\right] \frac{c}{\Lambda} \exp \left[-\frac{c t_{i}}{2 h}\right]=i
\end{aligned}
$$

These turo equations are anslogous to the wormal equations which arise in connection with linear least squares probleas. They are, however, non-linear in the unknon: paraneters s and $A$, and bence, ther anst be solved iteratively. The it: sative technique that was chosen is besed upon a Taylor series expansion in terns of $C$ and $A$. If $c^{(0)}$ and $\Lambda^{(0)}$ are estimates of $C$ and $\lambda$, then for exch point $t_{i}$, the fitting runction can be witten

$$
\begin{aligned}
& c E_{-}\left(\frac{c t_{i}}{2 \Lambda}\right)=c^{(0)} E_{1}\left(\frac{c t_{i}}{2 s^{(0)}}\right)+\left.\frac{\partial\left[c E_{1}\left(\frac{c t_{i}}{2 \Lambda}\right)\right]}{\partial c}\right|_{c=c} i^{(0)}\left(c-c^{(0)}\right)
\end{aligned}
$$

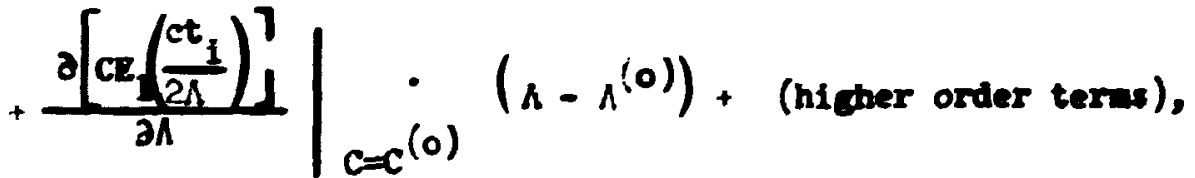

$$
\begin{aligned}
& n=I^{(0)}
\end{aligned}
$$

where the higher order terms are products of the hicher order derivatives with respect to $c$ and $\Lambda$ wth higher porers of the quantities $\left(c-c^{(0)}\right)$ and $\left(A-\Lambda^{(0)}\right)$, including terms with aixed derivatives and alxed powers. 
In arder to obtain a nargeble iterative technique, one drops the higher arder terses. Defining $\alpha$ and $M$ by

$$
\begin{aligned}
& \Delta=c-c^{(0)}, \\
& M=a-A^{(0)},
\end{aligned}
$$

calculating the required derivatives, and igporins the hicher ardar terns dres

$\operatorname{co}\left(\frac{\mathrm{et}_{i}}{2 n}\right) \equiv c^{(0)} E_{1}\left(\frac{\mathrm{ct}_{1}}{2 \Lambda^{(0)}}\right)+E_{1}\left(\frac{\mathrm{ct}_{1}}{2 \Lambda^{(0)}}\right) \Delta c+\frac{c^{(0)}}{\Lambda(0)} \exp \left[-\frac{\mathrm{ct}_{1}}{2 \Lambda(0)}\right] \Delta$.

If this expression is substituted into Equations (7-13) and (7-14), with the values $c^{(0)}$ and $\Lambda^{(0)}$ being substituted also in the auliplying fector outside the square brackets, one obtains, after considerable alobraic siplifications, the two equations

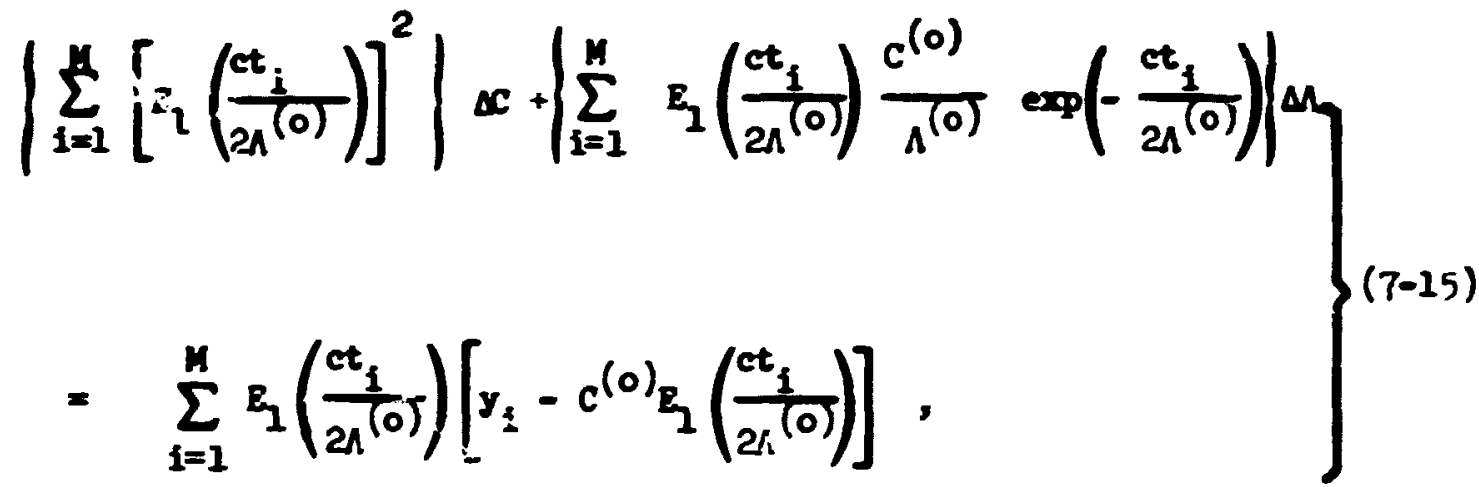

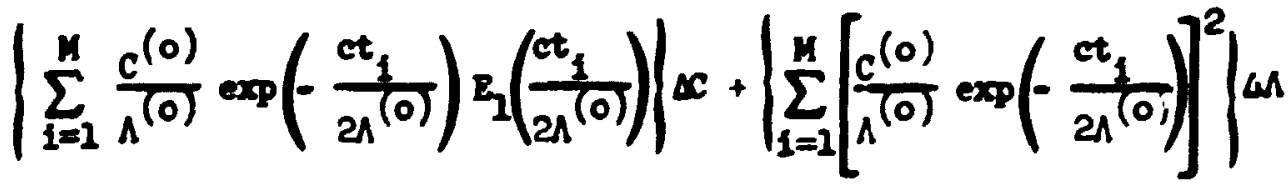

$$
\begin{aligned}
& =\sum_{i=1}^{M} \frac{c^{(0)}}{\Lambda^{(0)}} \exp \left(-\frac{c t_{1}}{2 \Lambda^{(0)}}\right)\left[y_{1}-c^{(0)} z_{1}\left(\frac{c t_{1}}{2 \Lambda^{(0)}}\right)\right] .
\end{aligned}
$$


These two equations ar linear in the unlmown paranters $\Delta C$ and $M$. They are, in ract, the noreal equations for a linear least squares problea. If this linear least squares problen is vieved as an overdeternined systen of linear equations, then the system natrix is civen by

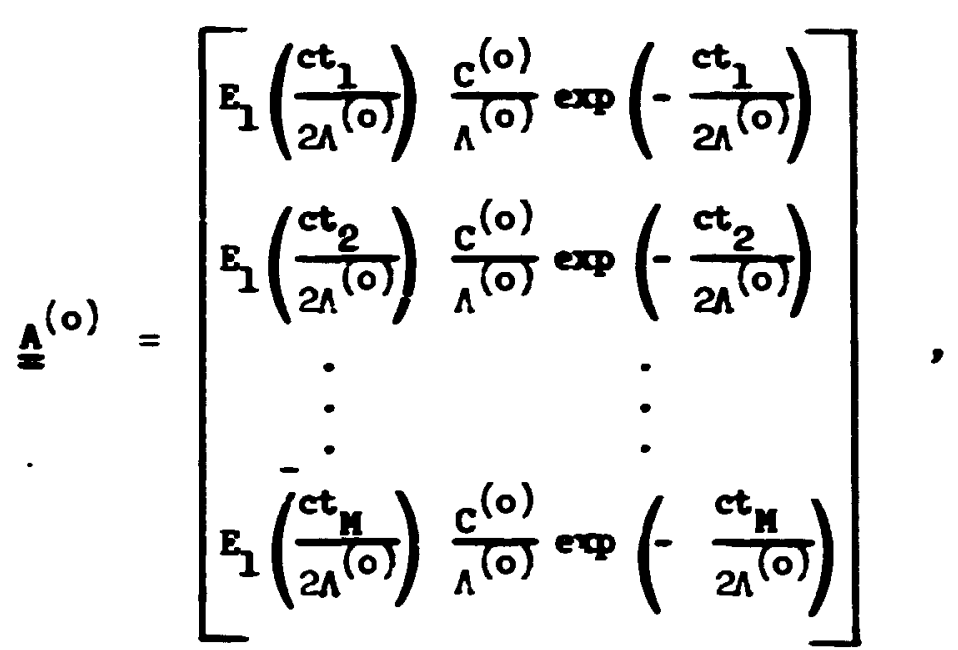

the right hand side rector is given by

$$
\underline{b}^{(0)}=\left[\begin{array}{c}
y_{1}-c^{(0)} E_{1}\left(\frac{c t_{1}}{2 n}\right) \\
y_{2}-c^{(0)} E_{1}\left(\frac{c t_{2}}{2 n}\right) \\
\vdots \\
\vdots \\
y_{n}-c^{(0)} E_{1}\left(\frac{c t_{n}}{2 n}\right)
\end{array}\right]
$$

and the required solution vector is

$$
x^{(0)}=\left[\begin{array}{l}
\Delta c^{(0)} \\
\Delta^{(0)}
\end{array}\right]
$$


of course, if $M>2$, then the syste

$$
\underline{\underline{A}}^{(0)} \underline{\underline{x}}=\underline{b}^{(0)}
$$

will not generally heve aw exact solitions. The least squares solution $\underline{x}^{(0)}$ is the best spproximate solution, i.e. best in the sense that it ninifizes the su of the squares of the deviations, a quantity which can be uritten in vector-atirix notation as $\left(\underline{b}^{(0)}-\underline{A}^{(c)} \underline{\underline{x}}\right)^{\mathrm{T}}\left(\underline{b}^{(0)}-\underline{\underline{A}}^{(0)} \underline{x}\right)$. The least squnres solution is, howemr, the exoct solution of the set of Dornel equations

$$
\left[A^{(0)}\right] T_{\underline{A}}{ }^{(0)} \underline{X}^{(0)}=\left[A^{(0)}\right] T_{\underline{\underline{b}}}^{(0)} .
$$

This last expression is fust the rector-antrix way of writing Eqs. (7-15) and $(7-16)$ as can easily be verified by substituting Eqs. (7-17) : (7-18), and (7-19) into the above expression.

once the solution vector $\underline{x}^{(0)}$ is obtained, new, and hoperully inproved, estinates of $C$ and $\Lambda$ can be calculated by

$$
\left.\begin{array}{l}
c^{(1)}=c^{(0)}+x^{(0)}, \\
\Lambda^{(1)}=\Lambda^{(0)}+A^{(0)} \cdot
\end{array}\right\}
$$

Then the wole process can be repeated, using the new estinates $c^{(1)}$ and $\Lambda^{(1)}$ to compute two new corrections $\Delta^{(1)}$ and $\Delta \Lambda^{(1)}$, which are in turn used to $c$ upute new estimates $c^{(2)}$ and $\Lambda^{(2)}$, etc. The iterative nethod thus consists of solving at each step a linear least squares problem in order to obtain the next correction to the solution of the non-1inear problew. The 1teration is continued until the corrected solution paraseters converge to a suitable miber of decinal places (provided of course that the iteration does converge). 
There are a we: af good rays for solving the linear least square problen at each step. The classiral nethod is to form the nornal equations (7-20), or equiralently, $\{?-15\}$ and $\left.\{-1\}^{\prime}\right\}$, and to solve thea. More odern techniques, developed anizly for use on mutonatic digital computers, calculate the solution dirzetly from the extrix $\hat{N}$, Eq. $(7-17)$, and tive vector b, Eq. $(7-13)$. One of the latter eethods was chosen for the progran used here - mainly because of the relative ease with which it could be generalized in case a different or sore couplex nodel should be adopted in the ruture. In such a case it would be necessary only to chinge the input atrix $A$ and the input vector $\underline{b}$ to sccomodate the nex nodel. The remainder of the computer progran would not be changed.

The wethod that was chosen is the Householder orthogenal factorization technique which was invented by Alston S. Householder, who refers to it as ractoriation by elementary Heraitian natrices (132). The specific algorith that was used has been described by Gene Colub (133). A PORTRAN progran was written for the IBI Systen 36 ; computer of the University of Illinois Digital Computer Laboratory. This program was designed to accept as input: (a) the light curve data from the EDIT progran described in the previous chapter, (b) the time liatts for which the fit was desired (e.g. Prom 10 to 40 days after maximan brightness), and $(c)$ the initial estimates $c^{(0)}$ and $\Lambda^{(0)}$. It set up the iteration and allowed it to run until either: (a) the parameters had converged to the desired accuracy ( 4 to ; decimal places), (b) a pre-specifled, upper-linting muber of iterations had been completed, or (c) the parameters began to diverge wildly. For solving the linear least squares 
problea at each step, it called a subroutine naaed DLISG which yas obtained ran tine Ial Scientific Subratine Paciege ? 1 ; ! . This subroutine uses the Householder ractorization tectnique to obtain the solution. The prograx also used the subroutine EXPI $11 \geq=1$ from the sase Subroutine Package for calculating the values of the exponential integral runction needed in forming the matrix $\stackrel{A}{*}$ and the vector $\underline{b}$ at eact: step. The progran gave as output the inal "convergei" valies oi tire paramters and the observed light curve together with the i:tted light curre bot?. in tabular and graphical fora. An exaple of the graphical output is given in Figure $7-3$. The keight of the vertical straight line at $t=$ : represents the estimate of the peak magnitude $g_{0}$. The fitted curve ras obtained anter ; iter-tions of the non-linear least souares program. The initial estimates for the two parameters $c$ : the fit were $c \cdot 0 !=1 .{ }^{0}$ and $\Lambda^{(0)}=6.9$. The final converged values were $c=. ;-91$ and $\Lambda=3.995$.

The curve gives a very good fit of the observed data in the rapid decay section but diverges widely from the observed data in the slowly decaying tail. In fact, no attempt was made tc fit the latter segment. The only data used in the fitting procedure were the observations taken between $t=i$ and $t=2$ disys. There is no need to fit the data outside the region used for the expansion test. Purtherwore, a few test runs som revealed that the Morrison-Sartori Model is not capable of simulaneously fitting both segents of the light curve. The results of three of these test runs are lllustrated in $F^{\ddagger}$ gure $7-2$. . The observed

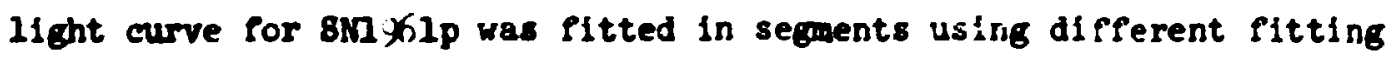
limits for each fit. The fitting limits together with the resulting 


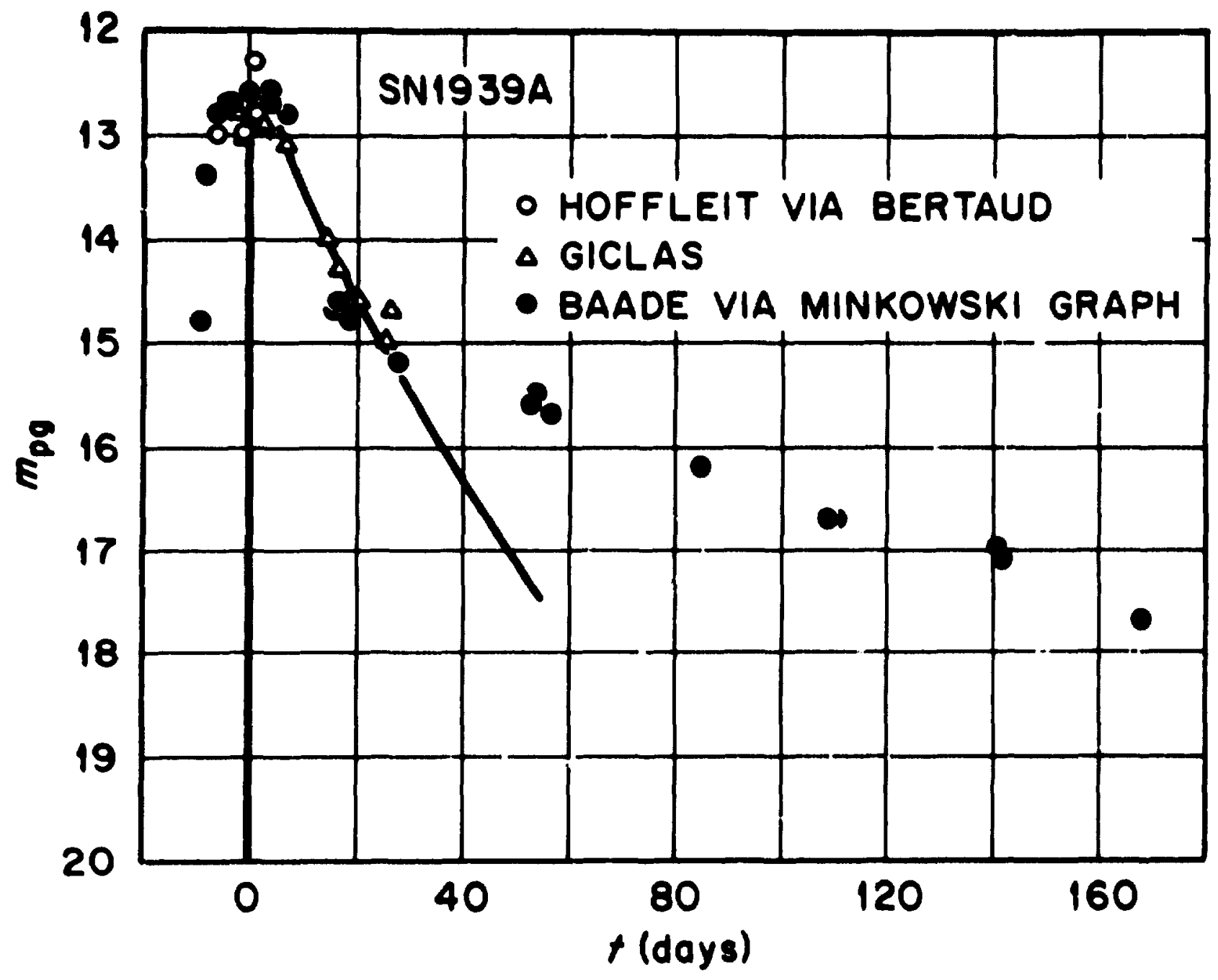

Figure 7-3. Rust's Fit of Morrison's and Sartori's Morlet to the Light Curve rur SN1939a. 

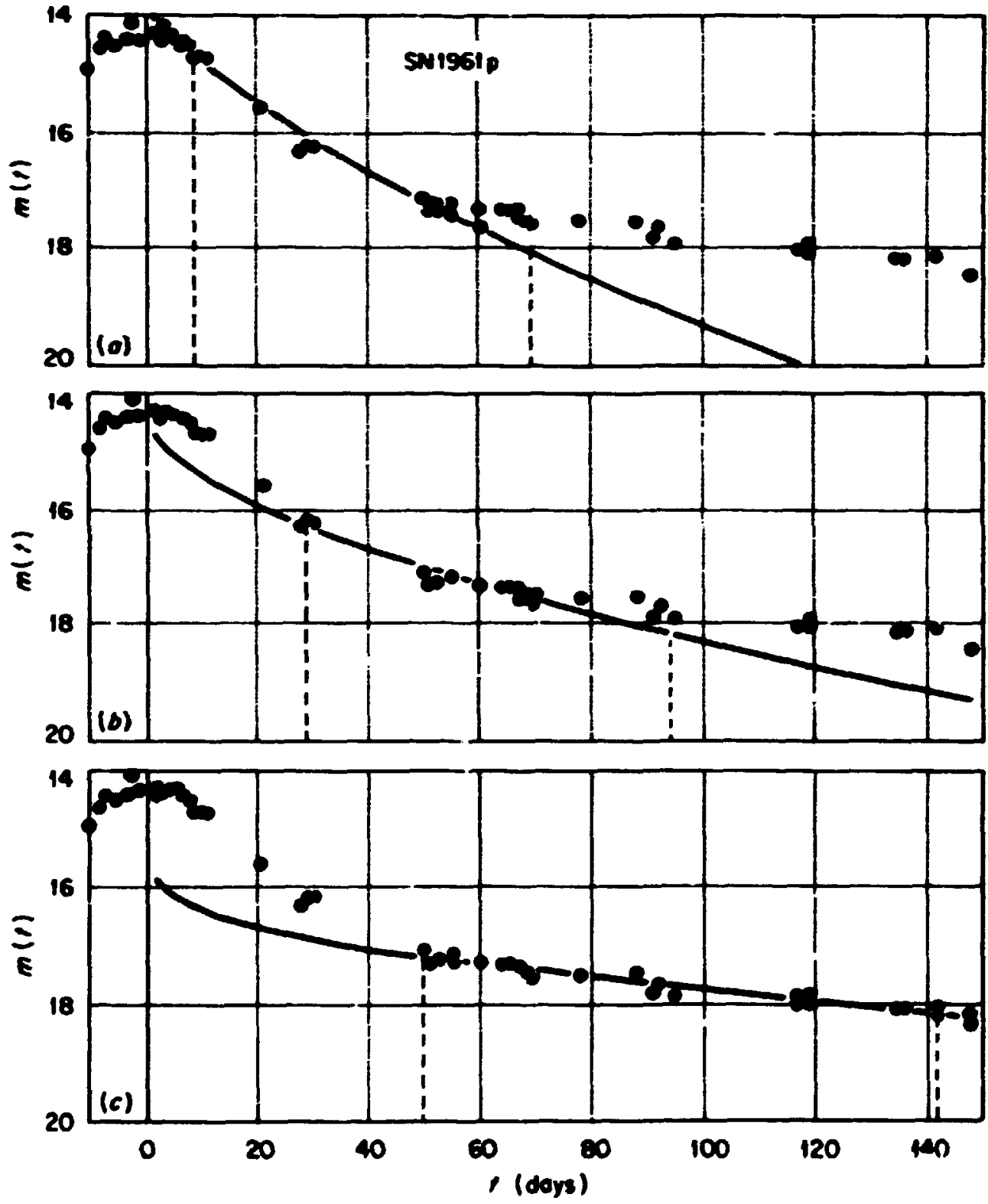

Figure 7-4. Fit of Morrison's and Sartori's Model to Three Different Regions of the Light Cisrve for SN196lp. 
final parameier values $C$ and $s$ are given in Table ${ }^{-}-1$. The fittirg

$$
\text { Table } 7-.1
$$

Results of the FIts of Morrison's and Sartori's Model to Three Different Regions of the Light Curve :or SN $x$ ip.

\begin{tabular}{|c|c|c|c|c|c|}
\hline Fit & \multicolumn{2}{|c|}{$\begin{array}{l}\text { Fitting limits } \\
\left.\text { (days after } t_{0}\right)\end{array}$} & C & $i$ & $\begin{array}{l}\text { Tange in which } \\
\text { The Fit is cocd }\end{array}$ \\
\hline (a) & 8.6 & 68.6 & .715 & 17.0 & $4 .=-\quad=\therefore .3$ \\
\hline (b) & 28.5 & 94.5 & .246 & 34.3 & $23 .=-68 . c$ \\
\hline (c) & 50.4 & $1 \div 2.3$ & .3742 & $137 \cdot 3$ & $5 \therefore-140$. \\
\hline
\end{tabular}

limits are indicated in the figure by the dashed vertianl straight lines. The first curve, (a), gives a good fit to the rapid-declins part of the light curve but does not fit the observations over the entire range of the fitting limits. It diverges noticeably after day 55. On the other hand it extrapolates backward quite nicely fr m the loser limit and fits the observed cata back to day 4.j. This backrard extrapolation bonus was a very conmon ormurra.e in fitting the early parts of other light curves. Extendirg the range of the fitting limits to $8.6-94.5$ gave a fit (not shown in the figure) which was very similar to (a). Its range of good fit was also $4.5-55.3$ days. Thus including more points fram the tail of the light curve within the fitting limits made almost no differerce in the fit. The fit was dominated by the points in the rapid decline portion.

Skipping (b) for the moment, consider the third curve, ( $:$ ), which illustrates what iappens when the fitting limits include only points 
from the tail of the light curve. The curve fits the obser red data over the entire range of the fitiong limits. The observed date for this supernove go only through lide. L days past maxima, but Morrison and Sartori have given examples (13j) in which they were able to fit the tails of same light curves over ranges of several hundred days (e.g - they were able to fit the tail of she light curve of $\operatorname{Sm} 9$; $7 \mathrm{c}$ over a range cf $\sim 3$; days to $6 C O$ days after maximum).

Curves (3) and (c) show that the nodel can be used to fit either the rapid decline part or the tail oi the light curve quite well. Curve (b) illustrates what happens when one attempts to fit the middle section of the light curve. It is the poorest, fit of the three. The cirve does not fit the data over the entire range of the fitting limits but $t \in$ nds to favor the earlier part. This inability to succesfully fit the middie part of the light curve was noticed in other examples also. It is as though the region where the slope changes from rapid decline to slow decline urises from a physical cause that is beyond the porer of the simple uniform model to explain. On eitiner side of this region it seems quite adequate.

It is not surprising that the simple uniform model is not adequate to fit the extire declining portion of the light curve. It assumes a constant uniform density for the envelope surrounding the star. The formation of such an envelope with a radius on the order of 100 light days is very unlikely. One would rather expect a decreasing density with increasing radius, and this is exact]y what the three fits shown in Figure 7-4 predict. The values of $A$ for the three fits were (a) 17.0 , (b) 34.3 , and (c) 137.3 light days. Since $A$ is equal to the 
mean free path of piotons in the envelope, this increasing sequence of values represents a steady decrease in density. For the first 30 or 40 days the light curve represents the reponss of the denser inner layers of the envelope and after 50 days or so it represents the response of less dense outer lay zrs (or perhaps of the surrounding interstellar medium). The fact that it is easy to fit either the earlier part or the later part of the light curve separately, but not to fit through the region where the slope changes, suggests that the envelope way be composed of two regions. The assuritions of the uniform model are approximately satisfied in each region. While this is an interesting speculative hypothesis, to pursue it further is outside the scope of this thesis. It suffices for the present purpose to have a model that can be used to fit the repid-decline part of the light curve alone.

In order to test the expansion bypothesis, it is necessary to have sore property or parameter of the fitted curve which can be used in a test for correlation with red shift. If a simple straight line fit had been chosen, then the natural parameter for comparison would have been the slope of the straight line. The situation is not so simple in the case of the exponential integral fit. In the case of the straight line, the slope gives an average measure of tile rate of decline over the entire rapid-decline portion of the light curve. In the case of the exponential integral there is no easy ray to define such an average rate. Of course one might try to use the slope at a certain "standard" point in the curve, such as 25 days after $t_{0}$, or at the point where the ipparent magnitude is equal to $m_{0}+2^{m} \cdot 0$, or some other specifically designated point that could be readily determined for each fitted light 
curve. The Mar in this kind of procedure is that the slope obtainst would be very sensitive to errors in the estianates of $t_{0}$ and/or $w_{0}$. Another approach would be to use sane "standard" time lapse on the light curve. According to Equation (4-1), an observed time lapse $\Delta t$ is related to the tine lapse at, wich would be neasured by an observer in the sane galaxy with the supernova by

$$
\Delta t=\Delta t_{0}\left(1+\frac{v}{c}\right) \text {, }
$$

where $V$ is the red-shift velocity assuning that the red shift is truly a Doppler velocity effert. Thus one could pick sone "standard" time interval that could easily be deternined for each fitted light curve and could test this interval for correlations with the red-shift velocity $v$. One such time lapse would be the time required for the apparent brightness to drop by a certain amount below peak brightness, e.g. From $m_{0}$ to $m_{0}+3^{m} .0$. But this kind of time period would be sensitive to errors in the estimates of $m_{0}$ and $t_{0}$. An alternative would be to choose some time interval like the time required to change in apparent brightness from $\mathrm{m}_{0}+1^{\mathrm{m}} .0$ to $\mathrm{m}_{0}+3^{\mathrm{m}} .0$. In calculating this kind of interval, one would hopefwly subtract out most of the effects of errors in the estimates of $m_{0}$ and $t_{0}$, and, in fact a series of numerical tests, which are described in the following paragraphs showed quite clearly that this is exactly what happens.

In order to test for the effects of variations in the estimate of $t_{0}$, the light curve data for $\sin 966$ a were run through the fitting program 5 times, each time with a different value of $t_{0}$. This same points were ased in the fittine procedure each time, and the value of mo was aiso 
held constent so that the only thing that veried was the estinate of $=_{0}$ The results of these teats are sumarized in Table :-2. Colun 1 gives the estinate of $t_{0}$. Colun 2 sives the lower linit of the fitting rasse neasured in dws after $t_{0}$, and Colun 3 gives the uppar linit of the Niting range. Note that the linits of the Ntting range change by exactly the scue acunts as the estimates of $t_{j}$. Inis vas dane so that exactiy the sane data points would be uned in each of the Nive rits. Colvons 4 and 5 give the rinal converged values of th: paraeters of the Nt. Folung 6,7, and I five the miber of days (mesured nron to! required for the fitted 11 ght curre to fall to the values $a_{0}+1$, $n_{n}+2^{m} .0$ and $m_{0}+\frac{3}{3} .0$ respectively. Note that the changes in the entries along any one of these three coluns are alnost exactly the sane as tine changes in the estinates of $t_{0}$. Colung gives the muber of days required for the fitted curve to fall fram $m_{0}+1^{m}$. to $\mathrm{m}_{0}+2^{\mathrm{n}} \cdot 3$, and Colum $1:$ gives the number of days required to fall rom $m_{0}+1.0$ ic $m_{0}+3.2$. The entries in colum 7 are obtained by subtracting those in colum $e$ from colum $T$, and colum 1\% is obtained by subtrasting colum $c$ fras colum 3. The entries in these last two columns are almost invariant. This lack of sensitivity to variations In $t_{0}$ makes tinest tio parameters much be :iev candidates for the compariscn paraweter than the three quantities in colums 6,7 , and $J$.

The tests for the effects of variations in the estimate of more very similar to the ones just described for variations in $t_{0}$. The light curves of several supernovae were tested. One of these was $\operatorname{SN} 3570$, and the results, which are sumarized in Table 7-3, are quite representative. The estiwate of $t_{0}\left(t_{0}=5 \mathrm{D} 2 i 35963.3\right)$ and the fitting 


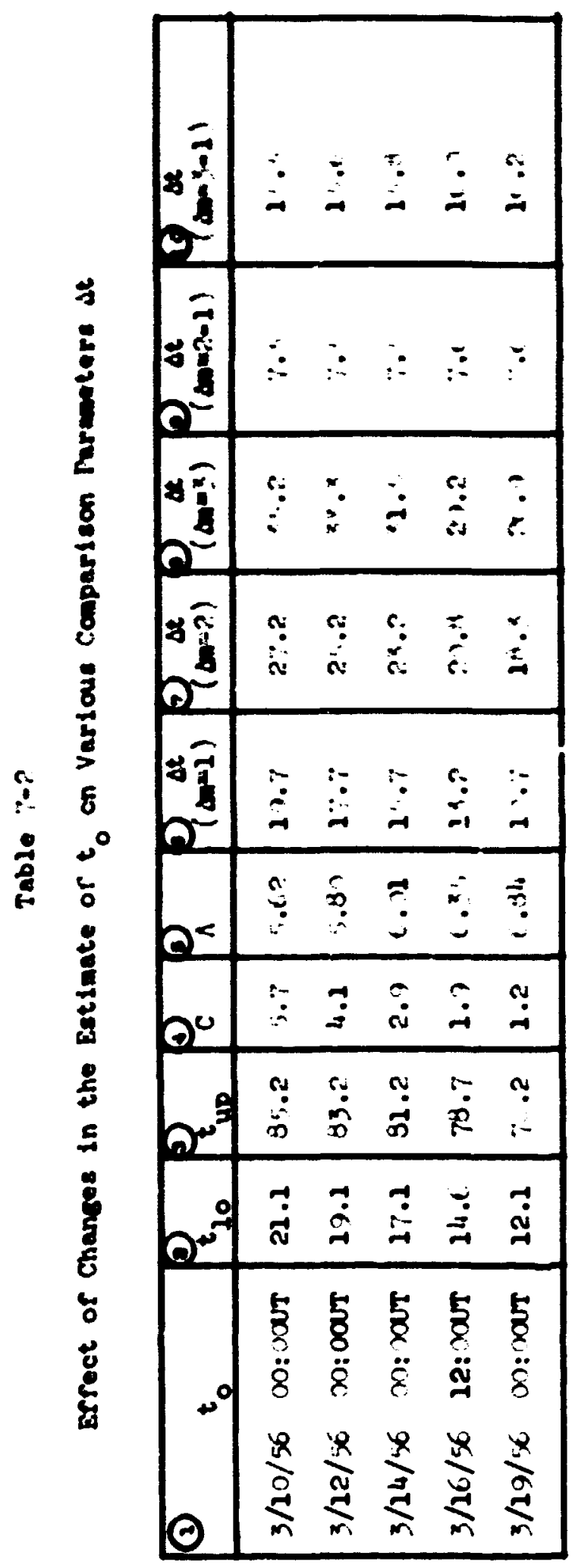


range $\left(t_{10}=9.0\right.$, and $t_{u p}=81.9$ davs after $\left.t_{0}\right)$ were helu constant wile the estinate of a was varied. Colun 1 gives the estimate of - Calyns 2 and 3 give the nad coaverged values of the fitting parmeters. Coluns 4, ie and 6 give the muber of days (neasured rrom $t_{0}$ ) reouired for the fitted light curve to fall to the values $a_{0}+1^{n} .0$, $a_{0}+2.0$, and $a_{0}+3.0$, respectively. Calun 7 gives the nuber of deys required for the fitted curve to fall fro $n_{0}+1^{n} .0$ to $n_{0}+2.0$,

Table $7-3$

Effect of Changes in the Estinate of $n_{0}$ on Various Comparison Paraneters at

\begin{tabular}{|c|c|c|c|c|c|c|c|}
\hline (1) & C & \& & $\begin{array}{l}\Delta \Delta \\
(\Delta=1)\end{array}$ & $\begin{array}{l}(\Delta) \\
(\Delta-2)\end{array}$ & $\begin{array}{l}9 \Delta \\
(\Delta=3)\end{array}$ & $\begin{array}{c}\Delta t \\
(\Delta=2-1)\end{array}$ & $\begin{array}{l}\Delta \Delta \\
(\Delta=3-1)\end{array}$ \\
\hline 12.20 & .74 & 11.0 & 11.40 & 22.29 & 35.33 & 10.89 & 23.93 \\
\hline 12.42 & .89 & 11.0 & 13.36 & 24.75 & 38.13 & 11.39 & 24.77 \\
\hline $12.6 ?$ & 1.07 & 11.0 & 15.44 & 27.30 & 40.97 & 11.86 & 25.53 \\
\hline
\end{tabular}

and Colun 8 gives the maber of dars required to fall from $a_{0}+1=0$ to $a_{0}+3=.0$. The effect of a 0.2 vartation in $m_{0} 1.8$ to produce changes of approxinately $15^{*}, 10 \%$, and $7.5 \%$ in the paraneters tabulated in coluens 4, 5, and 6, respectively. The sace variation in $\mathrm{m}_{0}$ produced changes of only about $4.5 \%$ and $3.2 \%$ in the paraseters tabulated in colums 7 and 8 . Clearly, these last two paraneters are better candidates for the comparison paraneter than the former three.

The comparison paraneter that was finally cinosen was the tiae, seanured in days, required for the fitted curve to drop from the value . $y^{m} .5$ to the value $n_{0}+2^{m} .5$. This parameter, wich shall be 
denoted by $\Delta_{c}$, is reletivel insensitive to rariutions in the eoticates of no and $t_{0}$. It describes a region of the lifht curve wich is coupletely contained in the rapid descent portion and rurthernore covers ebout 60-70\% of that region and is centered in the alale of it. Mreo, for all the aupernowe in this study, the final fltted curves gave verg good fits to the data in that region.

The merical terts revenled that the coodness of the IIt is not

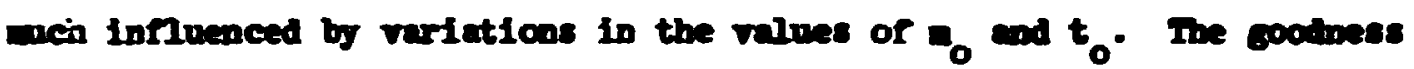
of the fit is, hovever, arfected by variations in the fitting range (1.e. the set of points used for the fit). Inis fuct has already been discussed in comection with the light curve for Sing6lp. Anothir series of tests was carried out using the lifht curve for sing37e. In this series, the light curve date was run through the fitting progran 16 times, each tive with a different fitting range. The results of these tests can be wnarized very siccinctly. If the fitting range gives a good coverage of the rapid descent portion of the curve, then the progre gives a good fit to that portion of the curve even if tho Itting range extends sonewhat into the nat portion of the curve. The fits ire somewhat better if only points from the rapid descent portion are included in the fitting range. Therefore, for all the fits used in this study, the fitting range was chosen to cover only the repid descent portion of the lifht curve.

The tests on fitting range also shored that if the fitting range is shifted and from $t_{0}$ in weh a way as to exclude the first pert of the rapid descent postion but to include the second part together with several points fron the flat portion, then the fitted curves do not 
Ave cood representations of the catire reple ceccont portion. 8afd

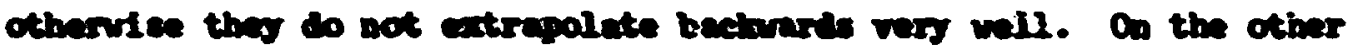
has, If the fition rape leaves out the first part (ear half or lese) of the repid deccent portion and incluses the revinder of that portion coly, with so points fro the nat partion, then the remiting Nits do extrepolate bechends to rit the first part of the curve very well.

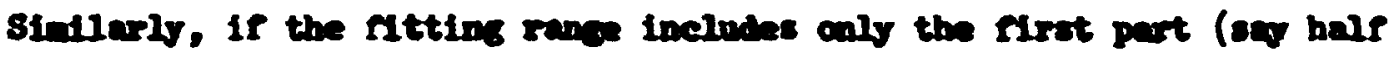

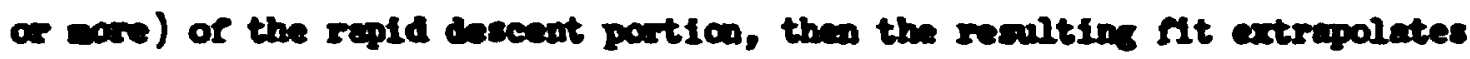
forward to dre a cood fit to the rmainder of the repld dencent partion. The, if the fits are carried out properly, then the wolel schieves one of the goels that was set for It when it vas adopted for use in this study. It helpe to $\mathrm{NII}$ in gaps in the data.

The effects of saps in the aldale of the fitting ranges were teated also. This was done by running another serfes of 16 different fits on the IfGht curve date for sin937c. The fltting range was varied and each of the 16 fits had gapa in the date which were introduced by discarding sone of the points in the alddie of the fitting range. ing results showed clearly that if the fitting range includes only points rom the rapid descent portion and that if the gap in the aldale is not too long (say not wore than half the length of the fitting range), then the fitted curves give a good representation of the data that was rewored to create the gap. It does not ware wuch difference whether the gap is centered in the alddle of the fitting range or falls silghtly earlier or slightly later in the range so long as the realning data give a fairly adequate reprecentation of the light curve. 
The ose rule that wort clearly ewerged from all the teats on fitting ranges and gaps in the data was that in dealing with a IIght curve which has gaps, it is essential to include in the fitting range anly points fron the rapid descent portion of the light curve. If the data for the light curve were somewhat sporadic, then it was sometines difficult to tell exactly where the rapid descent portion left off and the nat portion began. In such cases, the fits were carried out several tines for that light curve, using a dfferent fitting range each time. The fit which appeared to give the best representation of the data was then chosen for use in this study. One trick which helped in saking this decision was to superimpose the light curve in question on that of a supernova whose light curve did not have any gaps and which had the snape shape as the light curve in question (1.e. the poorly measured light curve was fitted by a well measured light curve). The final fitted curve was then chosen to be the one which gave the best fit to the superimposed vell-measured curve. 


\section{Charres 8}

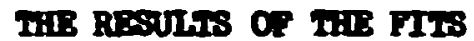

All of the light curves in this study were run through the fitting progre described in the preceding chapter. Mst of them were run several tines using different fitting ranges in order to get the best poasible fit. Wearly 100 fits were ande in order to get the final 3\% used for this study. All of the fits vere completed before any attenpt was nade to detect a correlation between the comparison paraneter $\Delta{ }_{c}$ and the redshift symolic velocity $V_{r^{*}}$ This procedure was adopted so that the final choice of flt for each light curve would be conpletely objective and uninfluenced by any preauppositions about the nature of the red shift. The graphical results of the final fits are given in Appendix 2. The final converged paraeters of the fits are given in Table 8-1.

Coluns 1 and 2 identify the supernova.

Coluns 3 and $i$ Bive the estinates of peak apparent nagitude, $\mathbf{m}_{0}$ and date of peak, $t_{0}$.

Colum 5 gives the symbolic velocity of recession, $\mathbf{V}_{\mathbf{r}}$, corresponding to the red shift of the parent galary. These velocities have not been corrected for the solar motion about the mucleus of our orn galary. The red shifts for scae of the galaries have not yet been measured. In these cases it was necessary to estinate the symbolic velocity by using the Hubble lar and various luafnosity runctions for gelaxies. The sethods used are described in more detail in the next chepter. These estinates are the values enclosed in parentheses.

Colunge 6 and 7 give the lower and upper bounds of the pitting range expressed in dys after peak brightness. 


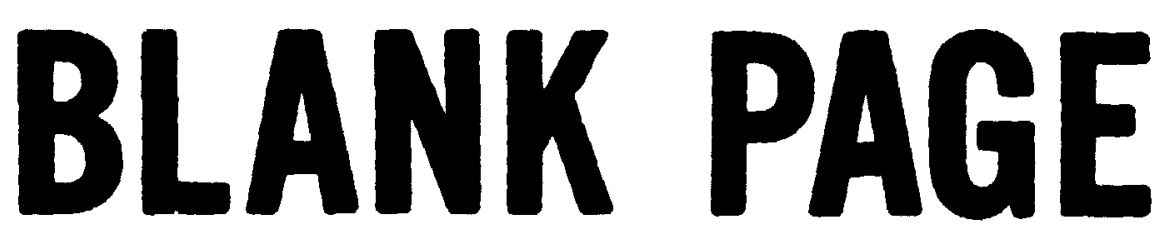


Colve 8 edves the mober or polnte used in eaking the nt. Coly as 9 an 10 dive the finel converged paracters of the Nit. Colve 11 dres the velne of the comparison paraneter at $c^{\prime}$ the

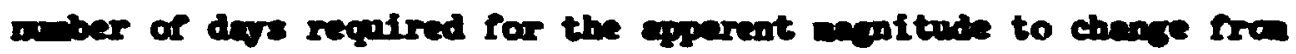
$a_{0}+0.5$ to $a_{0}+2.5$.

The anin purpose of this thesis is to test whether there is a correlation between the conparison pareneter $\Delta_{c}$ and the arbolic velocity of recession $V_{Y^{*}}$. The prodiction of the standard expending universe theory is that

$$
\Delta t_{c}=\left(1+\frac{v_{r}}{c}\right)\left(\Delta t_{c}\right)_{0}
$$

were ( $\left.\Delta t_{c}\right)_{0}$ is the intrisic velue of the comparison paranter, 1.e. the value that would be deternined by an obcerver in the sue calas as the supernove. This formuln is strictly valid only for velocities $v_{p}$ which are sall relative to the velocity of light $c$, e restriction that is conpletely satisfied by all the geloxies in this study.

Rewriting equation (8-1) in the form

$$
\Delta t_{c}=\left(\Delta_{c}\right)_{0}+\frac{\left(\Delta t_{c}\right)_{0}}{c} v_{r}
$$

eaphasizes the limear forn of the correlation that is predicted by the expending universe hypothesis. Bven though the type I supernore phenonenon is renarkably unifore, there is otill a considerable nount of variation acos supernoves is the rates at which their lualnosfties decline. Hepce, it is not reasonable to expect that ( $\left.\Delta t_{c}\right)_{0}$ is a single constent value which applies to all supernoves. Ints neans thet the expected slope of the above linear relation nast be calculated fren an estinate of the sean value of $\left(\Delta t_{c}\right)_{0}$. The best way to get such as 


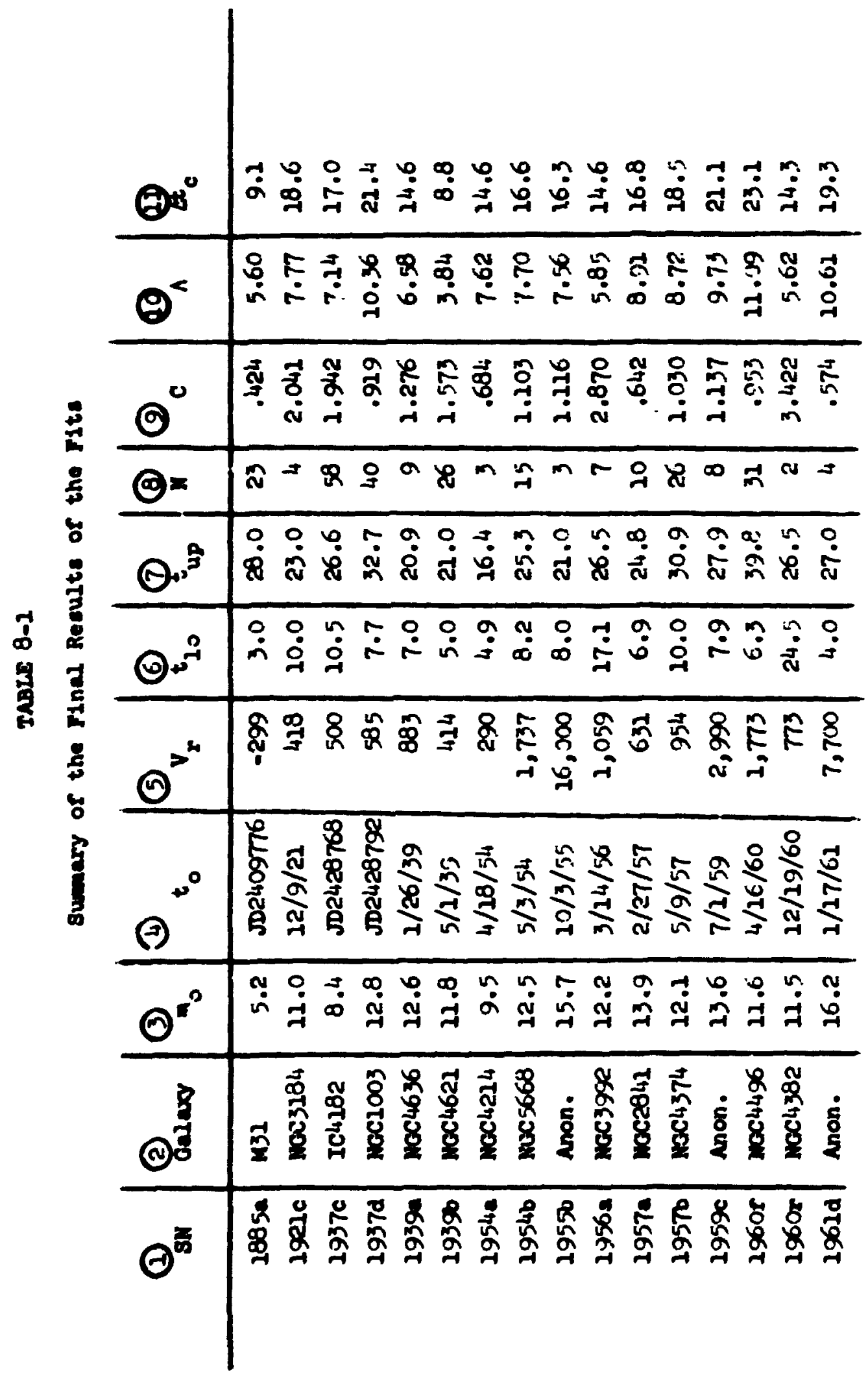


120

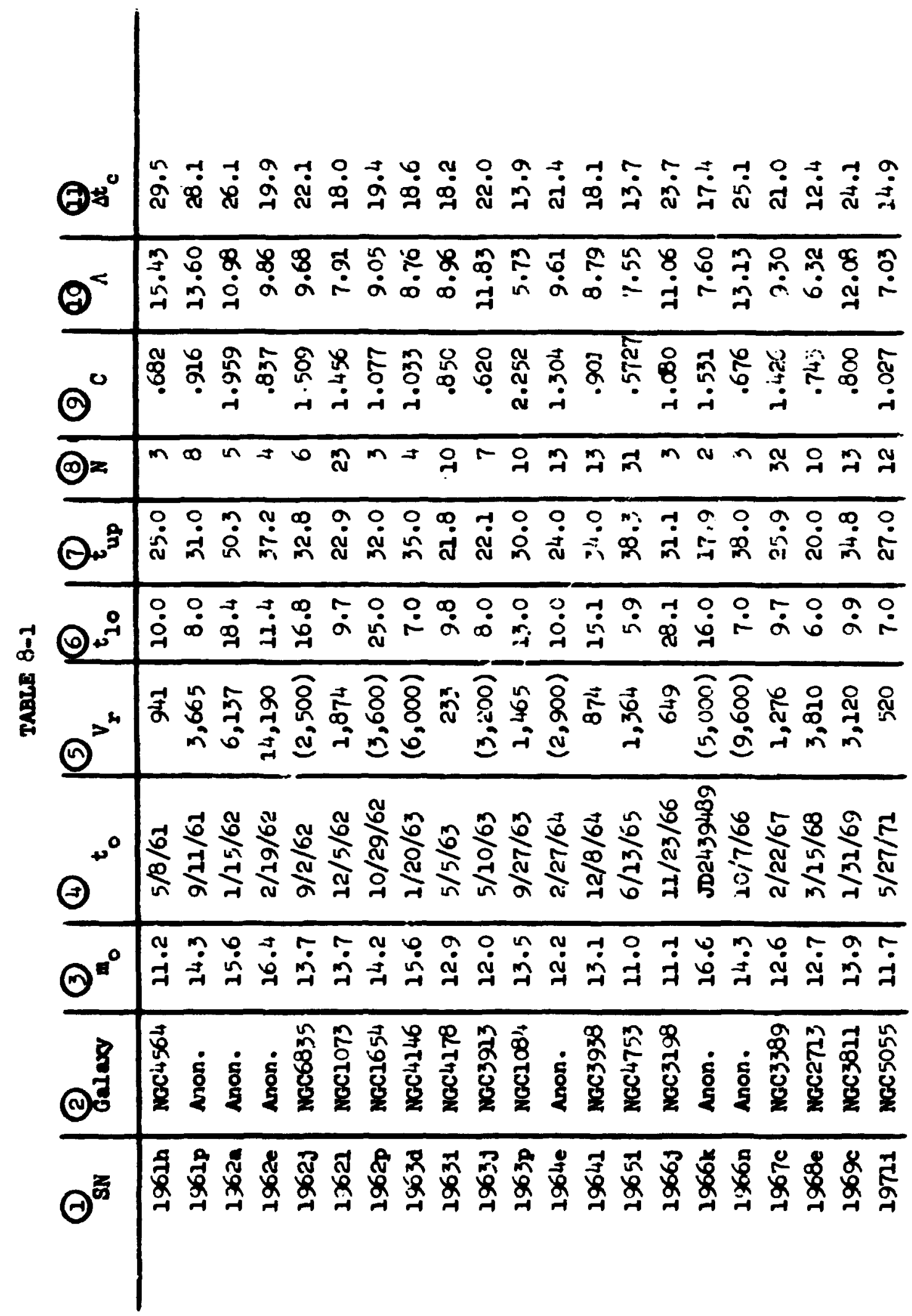


estinate is to calculate the arerage value of $\left(\Delta t_{c}\right)$ for son collestion of ifght curves which is thought to be a representative semple of the besic parent distribution of lifht curves. It is inportant to alse sure that no bias is introduced into the saple by the effect which is being tested for. In the present case, that weans that the saple should Include only light eurves for which the associated velues of $v_{r}$ are so sall that they isun is neglected. The sopple should inilude only supernovee in relatively nearby galaxies.

There are 22 supeznovae in this study with values of $V_{r}$ jess than $2000 \mathrm{~km} / \mathrm{sec}$. Nll of these symbolic recession vislocities are based on neasured red shifts. One of then, sing6ih, has $2 \Delta t_{c}$ vallie wich is wach larger than the otheris. If the other 21 are taken as a saple, the resulting average value of $\Delta t_{c}$ is

$$
\overline{\left(\Delta t_{c}\right)_{0}}=16.61 \text { days, }
$$

and the standard deviation is

$$
\sigma\left[\left(\Delta t_{c}\right)_{0}\right]=3.89 \mathrm{devs} \text {. }
$$

Por 851961k, the value of at 1829.5 days which is more than 3 standard deviations greater than the mean value. Since none of the other 21 valuer of at vary wors than 2 stendard deviations from the mean value, it is natural to curpect that 8mg61h is an outlier. Therefore, a standard outlier test, which has been described by P. E. Grubbs (136), was applied to the somple. The test is based on the statistic 


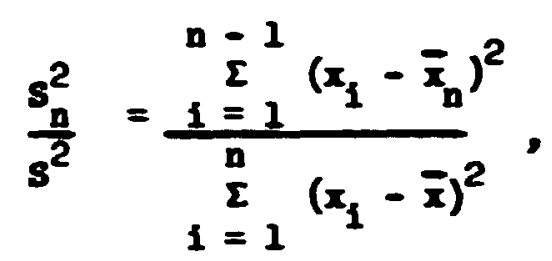

where

$$
\begin{gathered}
x_{1} \leq x_{2} \leq x_{3} \leq \ldots \leq x_{n}, \\
\bar{x}_{n}=\frac{1}{n-1} \sum_{i=1}^{n-1} x_{1},
\end{gathered}
$$

and

$$
\bar{x}=\frac{1}{n} \sum_{i=1}^{n} x_{1}
$$

In the present cantext, $n=22$, and the $x_{1}$ are the values of at arranged in increasing order with $x_{n}$ being the $\Delta_{c}$ for $1961 \mathrm{~h}, 1 . e .29 .5$. The value of $\bar{x}_{n}$ is the eversge of the semple when $1961 \mathrm{~h}$ is excluded and is equal to 16.64 . When 1961h is included in the somple the avernge $\bar{x}$ is emual to 17.23 . The vucue of the test statistic is

$$
\frac{s_{n}^{2}}{s^{2}}=0.657
$$

a value which rejects the observation at the $95 \%$ level of sifoificance. Thus the test indicates that $1961 \mathrm{~h}$ is almost certainly a true outlier and so it will be rejected in the following for any teats involving the parmeter $\Delta t_{c}$. It wili, however, be used for sone of the studies in the next chapter on the absolute wagnitudes of supernove because its 1ight curve has a very well defined, measured peak. An inspection of that light curve (see Appendix 2) shows why 1961h is an outlier. 
Although the peat is wall defined by the observetions, the pert of the curve that is of interest for determining at is derined by ouls the last three observations. The ibcervation preceding the last ane appears to be incousistent with the others, beins too hich. It probebly represents a mesweine error. It would present no problen if there were a laro auber other observations defining the light curve, but becense of the pucity of points, it carries an inordirate weight in the fitting procedure.

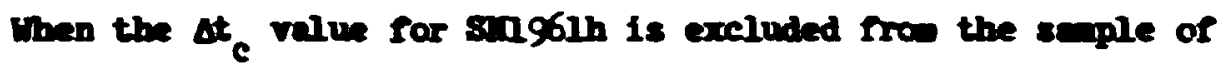
supernove with neasured sybolic veiocities less then $2000 \mathrm{~h} / \mathrm{sec}$, the resulting average value of at 1816.64 dys. Using this average as on eatinate of ( $\left.(\Delta)_{c}\right)_{0}$ dives

$$
\frac{\left.(\Delta)_{c}\right)_{0}}{c}=5.55 \times 10^{-5} \frac{\mathrm{drga}}{\mathrm{m} / \mathrm{sec}}
$$

as the eatinate for the slope of the linear relationship given by Bquation (8-2). Inis is the slope which the expanding universe hypothesis predicts for the linear correlation between $\Delta t_{C}$ and $V_{F}$ (if the two are indeed Iinearly correlated). The obvious next step is to perfor a least squares, straight Iine regression of $\Delta t_{c}$ on $v_{r}$ for all 36 supernove in the saple in order to deternine whether there is a correlation and, if so, what the slope of the correlation line is. Before doing that, hovever, it is interesting to check the distribution of at for the 22 supernovac with $V_{Y} \leq 2000 \mathrm{~km} / \mathrm{sec}$. This distribution is show in Plgure 8-1, where the relative frequency of occurrence of $\Delta t_{c}$ is plotted against the deviation of $\Delta t_{c}$ ros the average value ${\Delta t_{c}}_{0}=$ 16.64. The histogra is the observed distribution and the amooth 


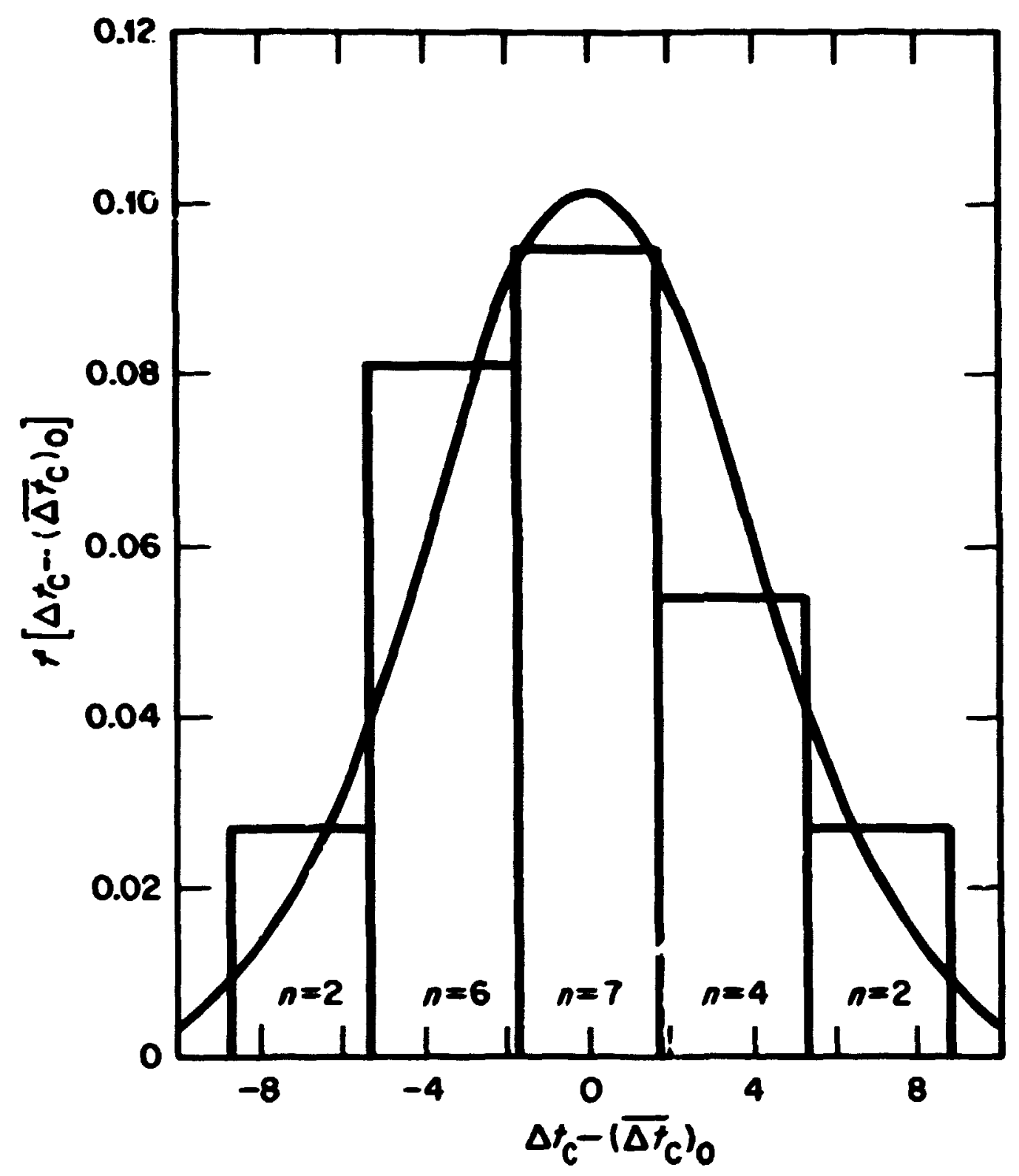

Pigure 8-1. The Distribution of $\Delta t_{c}$ for the 21 Supernove with keasired Red shifts $2000 \mathrm{k} / \mathrm{sec}$. 
curve is the pored firtrilution wich best fits the observations. Buch

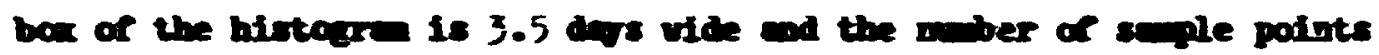

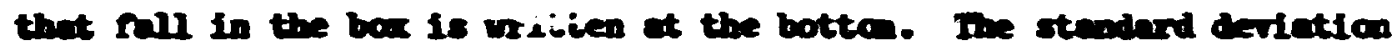
res the distribution is 3.89 dors. There are oot enough points in the

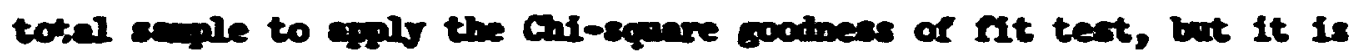
obions by fiand ingection thet the nowal distalbution fits the observed distribution quite vell.

sibe the intrinole aistribution of (at $)_{0}$ is apprently nowal, the least square technigne is eprogriate for fitting a srateht line relation to the sale of $36\left(v_{p}, a_{c}\right)$ obeervations. (The condition of nonalits is not a necessary condition to able the least equares procedure valid, but it is certafing a ourricient condition). A poidur progre, callel LDIII, which dives the output grophically, was uritten for an In: 360 computer. The result of the rit to the $36\left(\nabla_{r}, \Delta_{c}\right)$ observations is shown in Pigure 8-2. The borizodel dached line represents the average value of $\Delta t c$ for the 36 points; that averuge is

$$
\left(\overline{\Delta t_{c}}\right)=18.41 \mathrm{degs} \text {. }
$$

The solid line is the leat squares regression line,

$$
\Delta t_{c}=17.4+\left(3.21 \times 10^{-4}\right) v_{I} \text {. }
$$

The stemind deviations of the pareneters are \pm 0.9 ; for the intercept and $\pm 1.96 \times 10^{-4}$ for the slope. The latter value is quite large relative to the slope itself as should be expected considering the wide scatter in the data. The correlation coefficient is 0.27 , a value wich at first clancs seas to be 20 low that it would be impossible to eupport the hypothosis that the observations differ sionificantly fra a randan scatter disgram. 


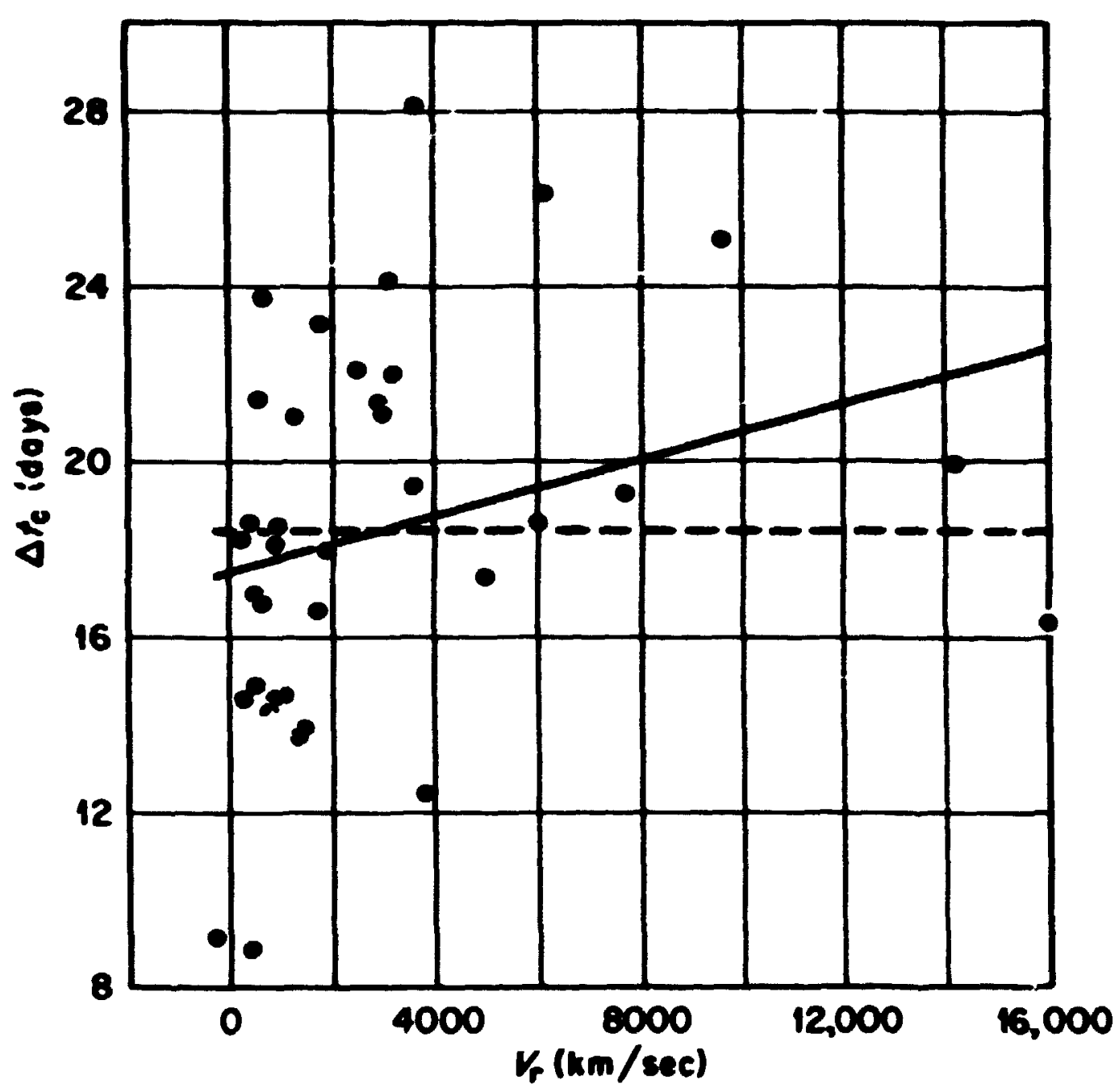

Fgure 8-2. The Regression of $\Delta t_{c}$ on Sybolic Velocity of Recession. 


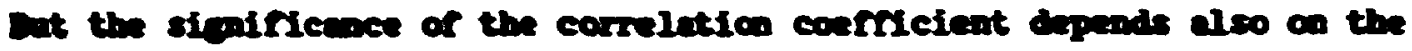

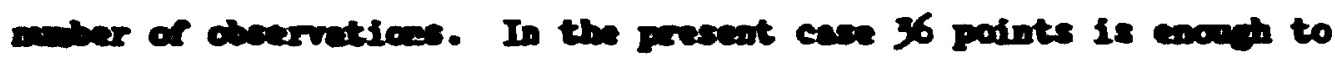

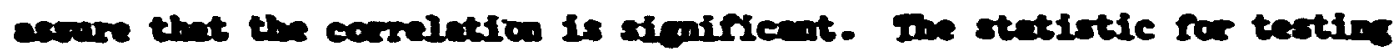
the correlation is

$$
t_{c}=\frac{\sqrt{n-2}}{\sqrt{1-r^{2}}}
$$

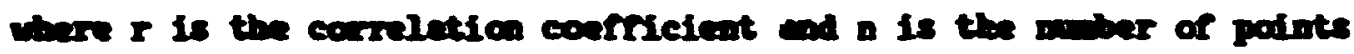
In the sople. Ite dictribution is the t-distribution with $\mathrm{a}-2$ degees of nrealde. In value of $t_{c}$ in the present case is $t_{c}=1.638$ vhi.h

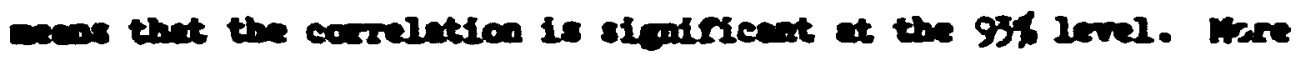

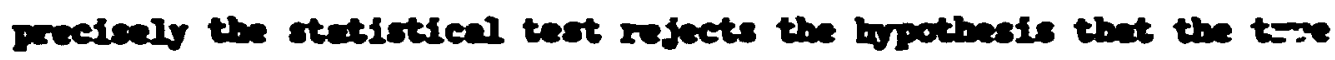

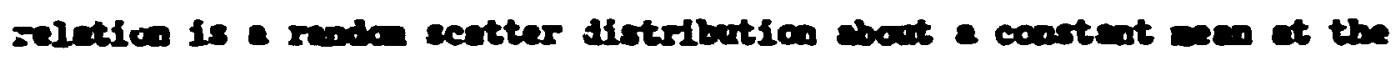
936 Ievel of sionificanes. The stutiotic fur testiog whether the slope b of the fltted lise differs non sene other value $B$ is

$$
t_{\mathbf{B}}=\frac{b-\mathbf{p}}{\mathrm{b}},
$$

where of is the stendard deviation of the Nitted slope. In the case $B=0, t_{B}$ rewices to $t_{c} ; 1 . e .$, the statistic for testing whether the fitted slope diffars rom sero is the sase as that for testing the corralation confricicat. Inos, the probabllity of obtaining a slope es large es or larger than the value $3.22 \times 10^{-4}$, If the relationship truly ware a randa distribution about a constant neen, is only 0.07 . The classical theory of a static univarse predicts a slope of sero for the Irlation istiveen at and $V_{y}$. Irous the t-test eppers to reject the lopothesis that the unfiveree is static, in opite of the creat scatter in the data. Dut the fitted slope is 


$$
3.21 \div 10^{-4}=1.36 \times 10^{-4} \frac{d}{150 e}
$$

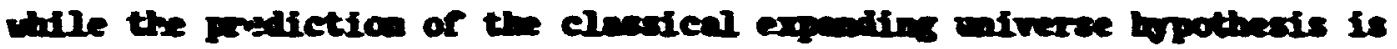

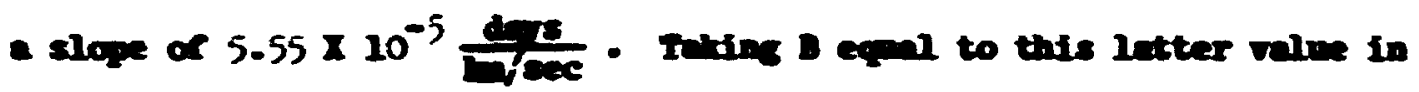

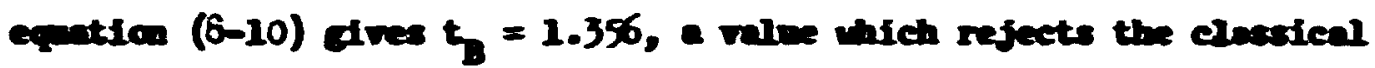
equetion hrothedis at the gis level of siguifience. Menris these

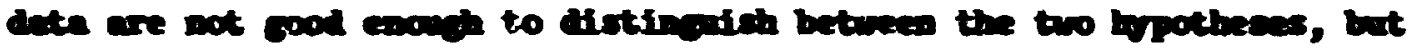

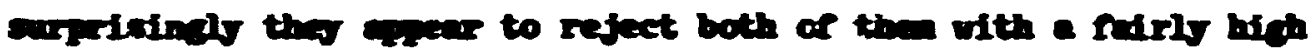

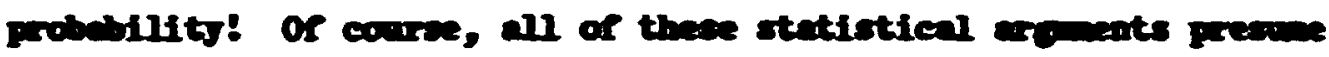
that the date are not bined by asotenefic errocs in the reductions or selection efrects in the obervations. Iherefore, the pext step is to establish wether the date are coutendinated by ach efrects.

There we three stages in the rednetion of the date at wich gystenatic errors could bave been introduced: (1) the reduction of the neasured light curves from the photanetric oysten in which they

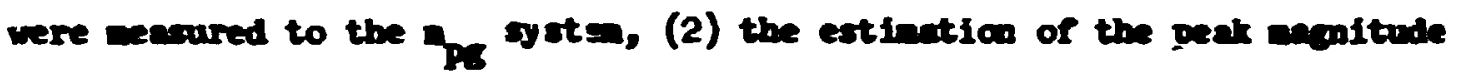
$n_{0}$ and $t i n$ of peak $t_{0}$, and (3) the fitting of the theoretical codel to the observed light curve (tive progre ar have introtheed systenatic errors depending as the mber of points in the fitting iange). These possibilities vere discussed in Chopters $t$ and 7. Those ciepters described testo that ware ande before and during the reduction process in arder to escure that no systenatic erroes were beling introtuced. The results indicated that the reductica procedures would produce a consistent set of light curves, but it 28 still possible te test the arthods rurther using the reduced lifot curves. 


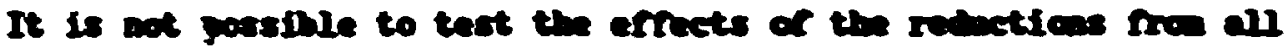

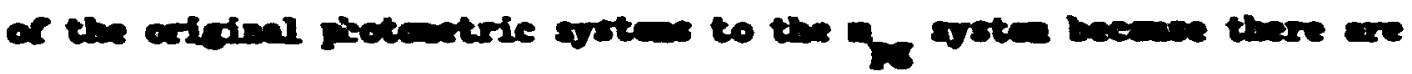

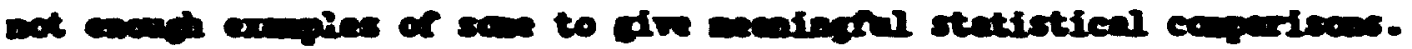

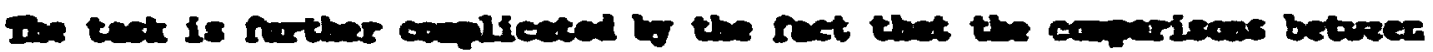

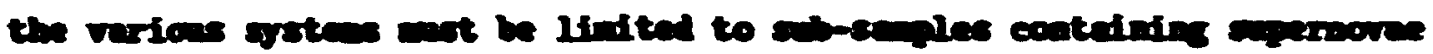

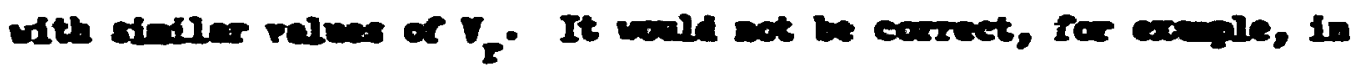

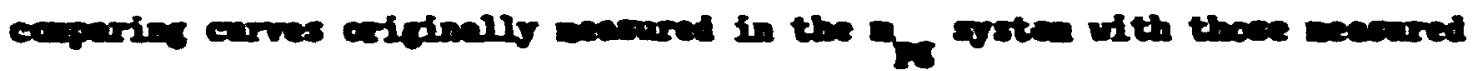

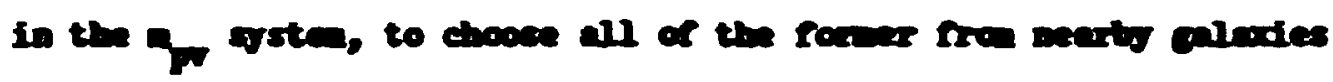

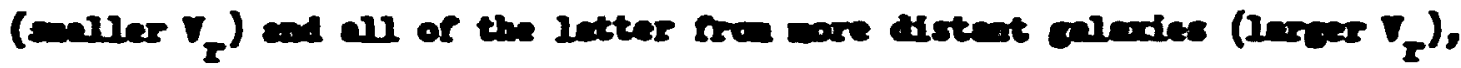

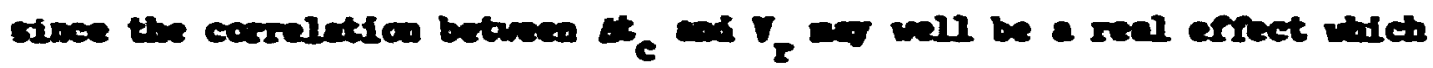

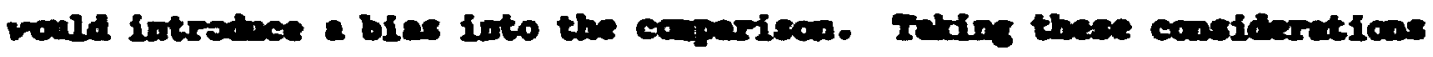

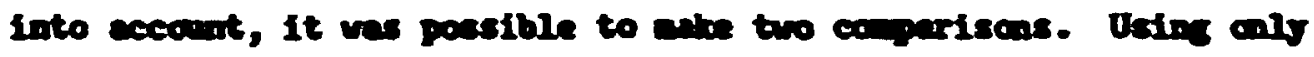
appersove with $V_{F}<2000 \mathrm{~h} / \mathrm{sec}$, there are 1211 ht curves that ware

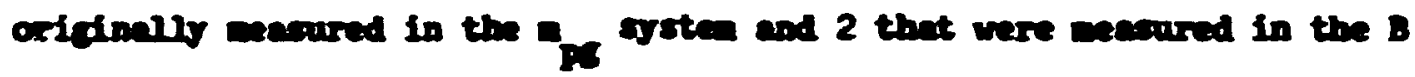

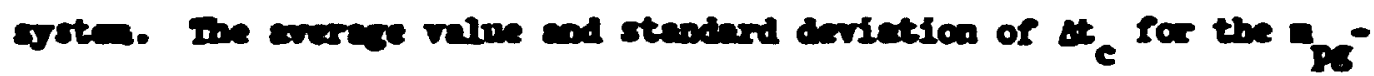
curves wave $a_{c}=17.01 \pm 3.68$ ad the correxpoudiog values for the rediced becurves were $18.80 \pm 6.94$. 8ines each of the two avernet vilues lies within ane half of a steodard arvietion of the other it is probably safe to soy that thy do not differ eipuficantly. In the velocity range $5000<V_{Y}<8000$, there are 3 ifht curves that vere oridinaly

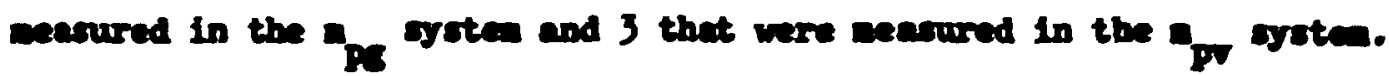
The capperteos values of at for these two semples are $20.91+4.59$ and

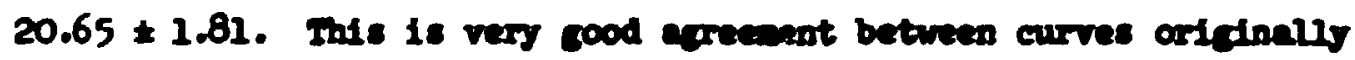
meacured in two very different menitude astens.

In testing the efrects of the metbads for estinating $t_{0}$ and $n_{0}$ only supernoves with $\mathrm{v}_{\mathbf{Y}}<200 \mathrm{~m} \mathrm{~m} / \mathrm{sec}$ wre ued. The reoults of the teste 


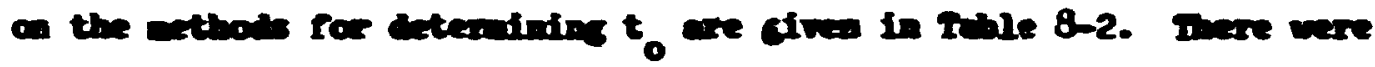

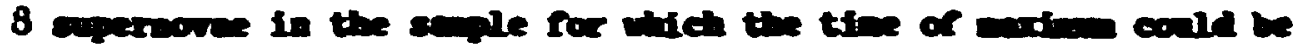

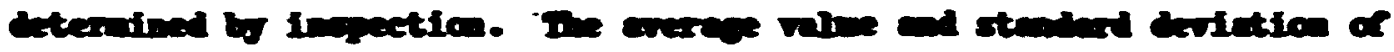

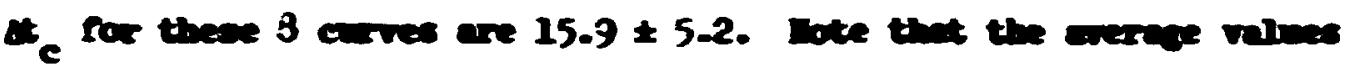

In: 8-2

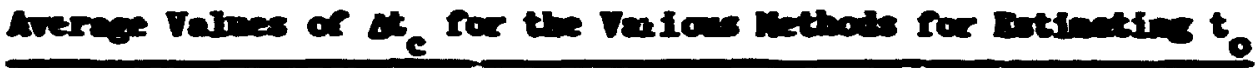

\begin{tabular}{|c|c|c|}
\hline \multicolumn{2}{|l|}{ Exthat } & $\left(\log .+\sec . \mathrm{Dev}_{0}\right)$ \\
\hline Oscerved lifut curve & 8 & $15.9=5.2$ \\
\hline Epectron nethod (Folvondil) & 2 & $18.7 \pm 7.1$ \\
\hline Point-k method (Pabovidi) & 3 & $16.3 \pm 2.9$ \\
\hline Averege light curve nethod (Plhorsidi) & 4 & $16.3 \neq 2.4$ \\
\hline Obeerved color curve nethod (but) & 2 & $19.5 \pm 2.2$ \\
\hline Average 11 dut curve nethod (Burt) & 2 & $15.8 \pm 1.3$ \\
\hline All Pshorald eotinctes & 9 & $16.8=3.2$ \\
\hline all Dot estinates & 4 & $17.7 \pm 2.6$ \\
\hline
\end{tabular}

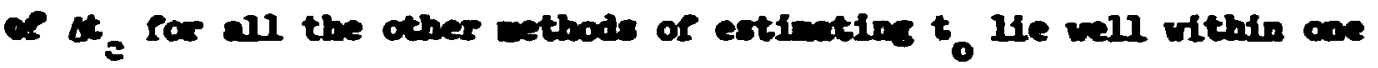

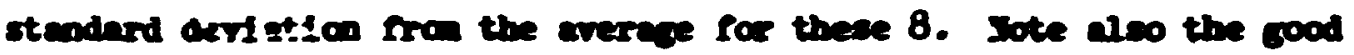
agreeneat betareen the 9 extinctes ande by Provild and the 4 ande by Bust. The results of the tests on the nethods for deterining a are diven in Table 8-3. Por 9 of the lifht curves the peal andtades ware

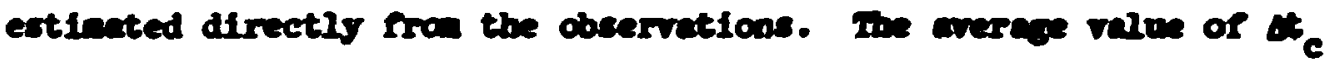
for these nine curves is $15.7 \pm 4.9$. The rebuced lifht curves for all of the other wethods cave average velues of at which are will withis one standard deviation of this value. 
mex $3-3$

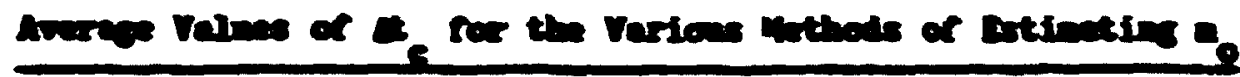

1.:

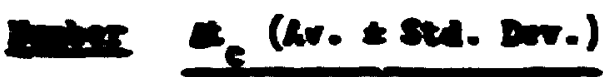

Doarvel linet exwe

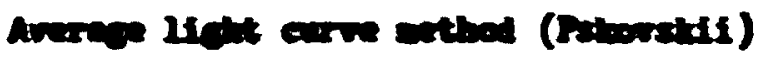

9

$15.7+4.3$

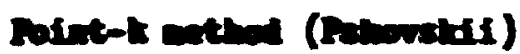

$\checkmark$

$16.3 * 5.7$

ruint-li nathod (nut)

4

$17.5 \neq 7.9$

l.

$18.3 * 5.8$

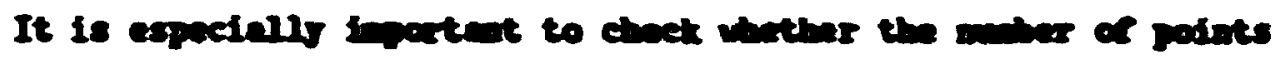

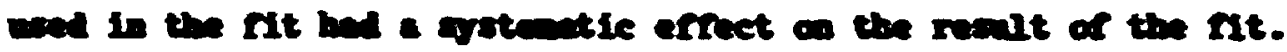

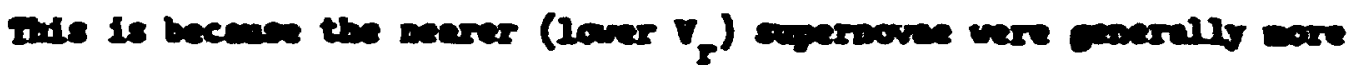

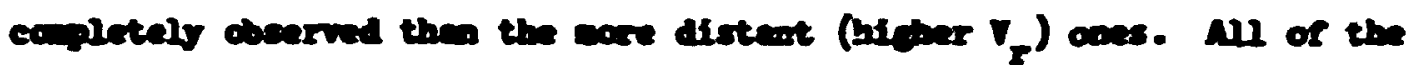

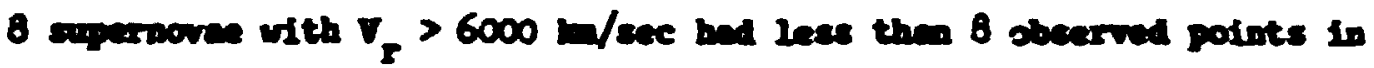
the Nitios raga; all but two of the had 4 points or lese in the reage. If the Nitiog procedure should dre sotenaticall natter

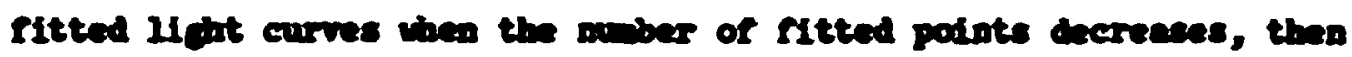
the values of at would be syotenatically hicher for larger values of

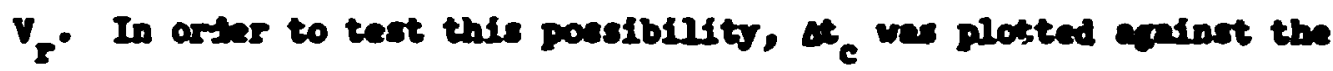

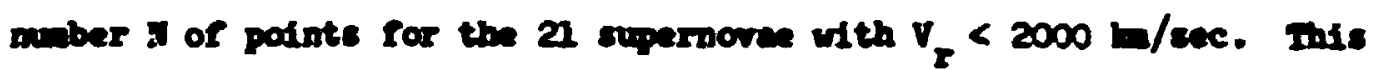

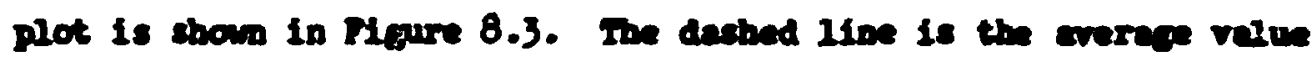
$\overline{U_{c}}=16.64$ drys. The col1d line is the result of $t$. Lest squares stratent line regession of at co $n$ which ave

$$
\Delta t_{c}=(16.0 \neq 1.4)+\left(3.22 \times 10^{-2} \neq 6.15 \times 10^{-2}\right) \cdot n \text {. }
$$

since the slope of the fltted Ine is positive, the andler velues of 1 certainly do not produce systematically natter fitted ligt curves 


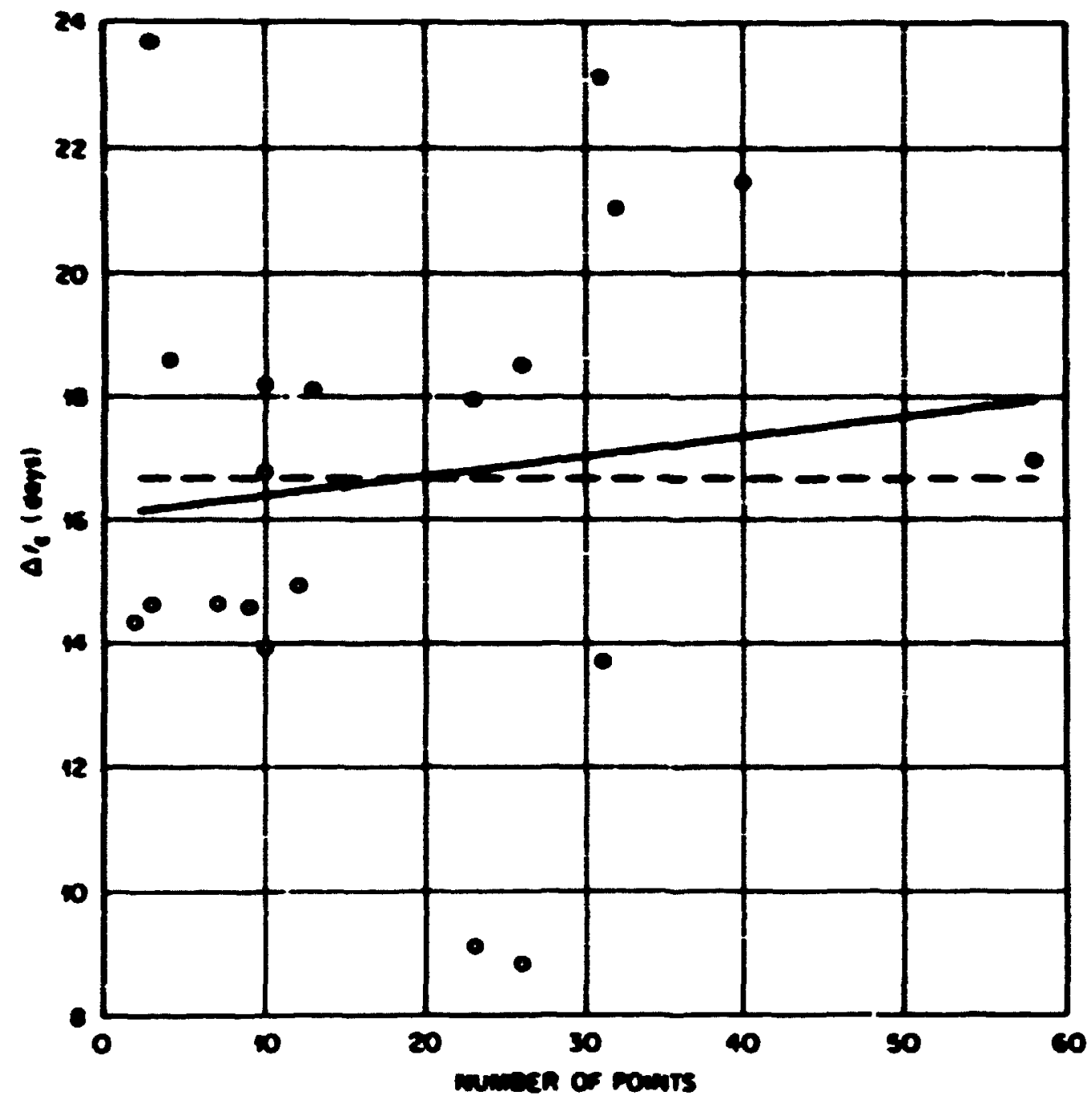

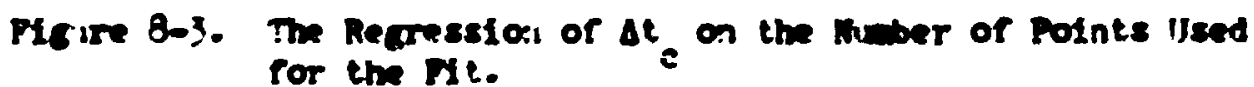




\section{8}

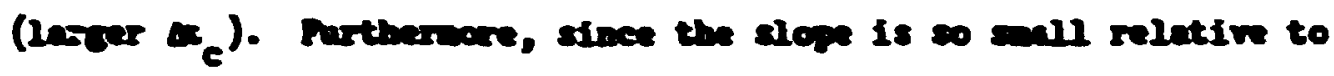

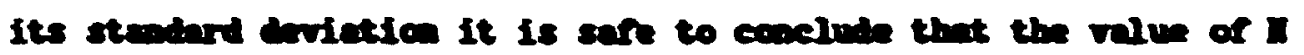

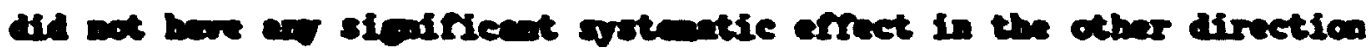
diter. In vine of the t-stelistic (0-10) for texting the pitted

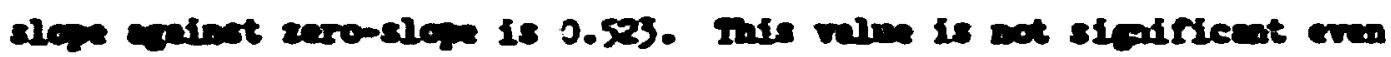

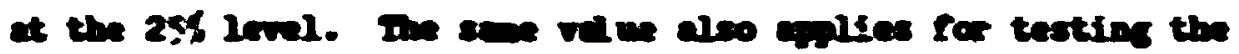

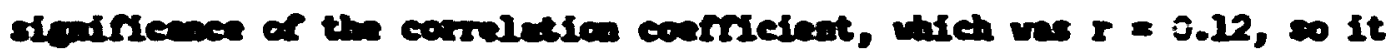

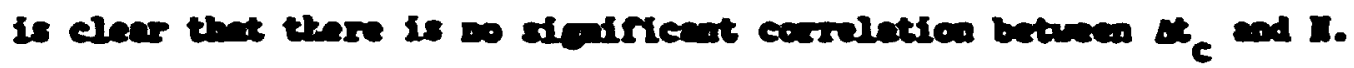


CHPTER 9

\author{
DISTANCE MDIM.I, ABSOLUTE MAGITUDES, AD THE \\ TEST FOR OBSERVATIOWL SELECTION BFTECTS
}

The tests described at the end of the preceding chapter established that the $\Delta t_{c}-v_{r}$ correlation was not the result of systenatic effects introduced by the date reduction or fitting procedures. There reanins the possibility that systematic effects way have been introsuced by the observations them ielves. Photonetric techniques have changed greatly since 1885, and sost of the earlier observations were in relatively nearby gulaxies, whereas most of the observations in the more distant galoxies have been made in wore recent times. If the changes in photometric techniques have caused systematic changes in the calibration of the ${ }_{\mathrm{Pg}}$ scale, then systeanatic effects way havi been introduced into the sample. Furthermore, one must not forjet the possibility that the calibration of the $m_{p g}$ scale night, even now, hav's systematic errors toward the faint limit; but both of these effects are beyond the control of the present author who can only assume that the care with wich the observations have been made over the years has nininized errors of this sort. It seems much wore likely that systematic errors may have been introduced, not by changes or errors in the scele, but rather by observational selection effects.

Previous studies $(49,50,13 \pi)$ of the peak Intrinsic luminosities of type I supernovae indicate a range of about 3.0 in peak absolute magitude. It is not inconcelvable that the more distant supernovae that have been observed are on the average intrinsically wore luminous than this relatively nearby ones ance the more luminous ones would be 
the pore easily Visible ones at large distances. If all the supernove mere discovered in systeantic searehes. this would be a very unlikely happening sinse systemtic search would be designed to avoid such selection effects. Sone supernovae are discovered by accident in the process of observing something else; and the possibility also remains that even if a systemtic search is not biased in discovering supernove, the selection effect couid enter the saple when the choice Is ande as to which light curres will be weasured in detall. If the saple is contaninated by this effect, and if the rate of fall of the Ifght curve is correlated with the peak absolute manitude, the correlation betwe : $\Delta t_{c}$ and $v_{r}$ night be explaired by observational selection. Therefore it is important to obtain estinates of the cbsolute magnitudes of the supernovae in this sample. Such estimates are also quite interesting in themselves.

The peak absoiute magnitudes of type I supernovae have previously been studied by van den Bergh (137), Pskovskil(50), and Kowal (49). Using a sample of 20 supernovae, van den Bergh obtained the values $M_{0}=-18.7 \pm 1.1$ for the average and standard deviation of the peak photographic absolute magnitude. Using a sample of 19 supernovae, kuwal obtained $M_{0}=-18.56 \pm 0.77$ for the same quantities. Pskovskil used a sample of 38 supernovae and grouped them according to the Hubble type of the parent galaxy. He found a slight correlation between the peak magnitude and the Hubble type, with luminosity increasing with the transition from elliptical to spiral ard irregular galaxies. The average magnitude for 2138 supernovae $\operatorname{maz} M_{0}=-19.2 \pm 0.85$. 
Van den ierd's article ild not state whether the peak apparent Egnitudes were correstad for absarption. Kowal corrected the apparent menitudes for absorption within our gelex [using $C .25 \csc (b)$ ], but ande no attent to correct for ebsorption within the parent galaxy. Sincic his average value was very close tc that obtalned by van den Bergh, it seens probable that the latter used the sane procedure. Pskovatil corrected the apparent angitudes for absorption both within our own and the parent gelexy. This latter correction is probably the reason that his estinate of the average peak luninosity is about 0.5 brighter than those of Kowal and van den Bergh.

Mineteen of the 37 supernovae in this study had partial [and in some sases fairly complete] measured color curves, with indices (B - V) or $\left(n_{p q}-m_{p v}\right)$ as a function of time. For these supernovae it was quite easy to estiwate the color excesses, either

$$
E(B-V)=(B-V)-(B-V)_{0}
$$

or

$$
E\left(m_{p g}-m_{p v}\right)=\left(m_{p q}-m_{p v}\right)-\left(m_{p g}-m_{p v}\right)_{0}
$$

by using the method of vertical shifts of Pakovakif's intrinsic color curves [Figures 6-1 and 6-2] to fit the observed colors. The method was described in Chapter 6, and the color excesses for the 19 supernovae are given in Table 6-4. These color excesses made it possible to estimate the total absorption of the supernovse light by using the well-known reddening celationship,

$$
A_{\text {tot }}=\mathbf{R} \cdot \mathbf{E}(\mathbf{B}-\mathbf{V}) \text {, }
$$

where $A_{\text {tot }}$ is the total visual absorption and $R$ is the ratio of total to selective atsorption. Since estinates of the value of the constant $R$ are based on data for our own galary, this nethod assures that the 


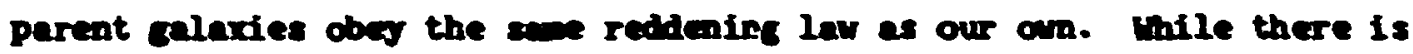

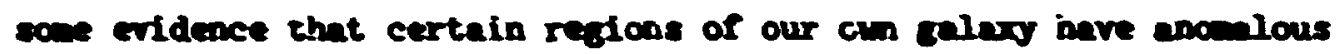
wives of $R$, It is cenerally sccepted (139, 139) that, for the absorption In the $V$ bard, the constent everaye val te

$$
\mathbf{R}=\mathbf{R}_{\mathbf{n} \mathbf{s}}=
$$

applites over wde regions of the gelexy. As a first approxination it will be assund here that this same value applies everghtere in all galexies (and in the intergalectic nediu as well, although intergalactic abserption is probably negligible).

In the ap systen, Bq. (9-3) becowes

$$
A_{P B}=R_{P B} \cdot E(B-V),
$$

where

$$
R_{\text {P6 }}=4.18
$$

This equation was used to compute the total absorptions for the 19 supernove with measured color excesses. Measured $E\left(\mathbf{n}_{\mathrm{pg}}-\mathrm{I}_{\mathrm{pv}}\right)$ color excesses were converted to $E(B-V)$ by the equation

$$
\mathrm{E}(\mathrm{B}-\mathrm{v})=0.85 \mathrm{~B}\left(\mathrm{~m}_{\mathrm{pg}}-\mathrm{m}_{\mathrm{pv}}\right)
$$

The totel absorptions rere used to calculate the corrected peak arparent magnitudes $m_{0}$. The absorptions within our own gelaxy were also computed using the standard cosecant law (139),

$$
A_{g \circ 1}=0.25 \csc \left(b^{I I}\right) \text {, }
$$

where $b^{I I}$ is the galactic latitude of the parent galarg. These values were subtracted from the total absorptions in order to deternine the absorptions within the parent galaxies. For three of the supernovae 
the ebsorptions celculated for our celexy slightly exceeder the totel absorptions conputed fron the colos excess. Two of the three parent gelaxies were ellipticals and the other was an 1:Tagular. Since eiliptisal galaxies have sanil internal absorptions, it is probabie that the bulk of the abroiption occurred within our ow gilexy, and the slight discrepancies wost likely represent swall randon deviations fran the cosecant law, elthough cae cannot copletely rule out a sall zero point error in Psicoralit's intrinsic color curves. Is uny case the discrepancies were sall and the absorptions within the parent paladies vere taken to be zero. The cosecant law results were discarded and the corrections for $\mathrm{n}_{0}$ were caiculated solely on the basis of the color excess.

Once the sborptions within the parent galaxies had been couputed for the 19 supurnovae, they were divided into three groups, and the average absorptions for these groups were celculated so that they could be used as rough estinates of the absorptions for the 18 supernovae which did not have measured colors. The three groups were (1) supernove which uppeared in high ajsorption regions of spiral galexies (e.g., in spiral arws), (2) supernovae which appeared in spiral galaxies but not in obviounly hich absorption regions, and (3) supernovae which appeared in elliptical and irregular galaxies. Butreme cases like sia62,, which occurred in an entsation region, were discarded; and average values of the absorption within the parent galaxies vere conputed for the three groups. The results are shown in Table 9-1, wich also gives the values which were adopted for correcting the apparent anghttudes of the 18 supernovae which did not have searured color excesses. 
Table 9-1

Average Abeoptions in Various Iypes of Glaties

\begin{tabular}{|c|c|c|}
\hline Group & $\begin{array}{c}\text { Averase } \\
\text { Absorption }\end{array}$ & $\begin{array}{l}\text { Adopted } \\
\text { absorption }\end{array}$ \\
\hline $\begin{array}{l}\text { Srperpore in elliptical and } \\
\text { irregular colodies. }\end{array}$ & o.0r & 0.0 \\
\hline 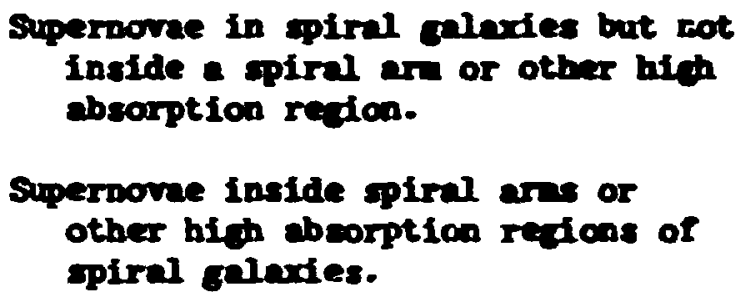 & 1.57 & 1.5 \\
\hline
\end{tabular}

These adopted corrections vere applied in a conservative wa according to the various observers' descriptions of the type of galax and the location of the supernove in 1 . The large 1.5 correction was applied only if the supernove wa definitely described as having occurred inside a spiral arn. If the location uns described as at the end of a spiral arw or on a projected extension of a spiral arm, or if the supernove cccurred anyhere else in a spiral gelary, then the aller correction 0.5 was used. After all 18 peak magnitudes were corrected in this manner for absorption wthin the parent gelaxies, they were further corrected for absorption within our own galaxy by weans of Bq. (9-8). The correction calculations are sumarized in Table $9-2$.

Coluen 1 is the supernova designation.

Colven 2 is the peak photogrephic angnitude before the absorption correction.

Colunn 3 is the B-V color excess. The supernove without entries in this coluen are the 18 which did not have seasured colors. 
141

coivg 4 is the sbsorption within the parent gellow.

Colure 5 crateins noted or coments describing the golng or the superwore's situntion in the olary. Asteriats (*) in this colum refer to notes at the end of the teble.

Colun 6 is the alactic latitude.

Colun 7 is the absorption vithin our ow onlexy.

Colve 8 is the finel corrected peak apparent monitude.

The neat step in the celculation of the peik absolute magitudes Is the ertimation of the distance nodulf of the parent galades. Van den Bergh (137) used 3 methods for estimating the distance moduli: (1) the radial velocity of the parent galaxy, (2) the mean radial velocity of the galaxy ciustel containing the galaxy, c.r (3) the lutinosity classifiration of the galaxy. For the Hubble constant be used $H=100 \mathrm{w} / \mathrm{sec} /$ Mpc. Koml (49) for the nost part adopted van den Berch's estimates. Pskovali (50) gave independent estimates using the sare methods plus two other methods whenever appropriate: (1) the angular dinensions of HII regions in the parent galextes and (2) estinates for the brigitest stars in the parent gaiacies. He also used $\mathrm{H}=100 \mathrm{kd} / \mathrm{sec} /$ Mnc.

Mearly two thirds of the supernove in this study were included in one or more of the three studies described above. Wenever possible the estinates of van den Bergh and Pakovskif were averaged with independent estinates ande for this study. Since it was necessary to obtain new estimates for more than one-third of the oupernovae, it seened reasonable to get new estimates for all of them. Furthermore, the final estimate for each supernova was obtained by averaging as many as possible estimates obtained from independent methods including the estimates of 
142

The 92

sure of the culentaten of the

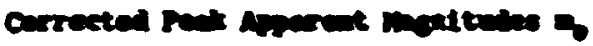

\begin{tabular}{|c|c|c|c|c|c|c|c|}
\hline$=$ & ent. & $\mathbf{E}(\boldsymbol{n}-\boldsymbol{\nabla})$ & pres. in & cotes, & $\mathbf{I}$ & Thes is & enrme. \\
\hline 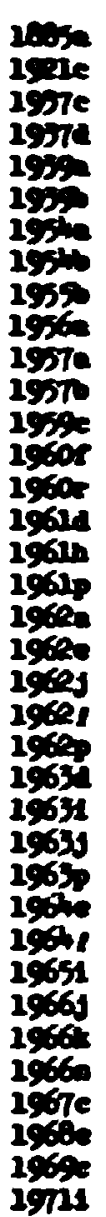 & $\begin{array}{c}5.24 \\
11.0 \\
8.4 \\
12.8 \\
12.6 \\
11.0 \\
9.5 \\
12.5 \\
15.7 \\
12.2 \\
13.85 \\
12.1 \\
13.55 \\
11.6 \\
11.5 \\
16.2 \\
11.2 \\
14.3 \\
15.6 \\
16.4 \\
13.65 \\
13.7 \\
11.2 \\
15.6 \\
12.9 \\
12.0 \\
13.5 \\
12.2 \\
13.1 \\
11.0 \\
11.1 \\
16.6 \\
14.3 \\
12.6 \\
12.7 \\
13.94 \\
11.7\end{array}$ & $\begin{array}{l}0.05 \\
0.45 \\
0.45 \\
0.13 \\
0.25 \\
0.57 \\
0.68 \\
0.10 \\
0.34 \\
0.04 \\
0.10 \\
0.0 \\
0.85\end{array}$ & $\begin{array}{l}0.50 \\
1.50 \\
0.0 \\
1.05 \\
1.52 \\
0.0 \\
0.20 \\
0.74 \\
0.50 \\
1.27 \\
2.53 \\
0.0 \\
0.15 \\
1.50 \\
1.16 \\
0.0 \\
0.0 \\
0.50 \\
0.17 \\
0.0 \\
0.50 \\
3.23 \\
0.0 \\
0.50 \\
0.50 \\
0.50 \\
0.50 \\
0.50 \\
1.50 \\
0.0 \\
1.50 \\
0.44 \\
0.50 \\
0.12 \\
0.45 \\
0.89 \\
1.41\end{array}$ & 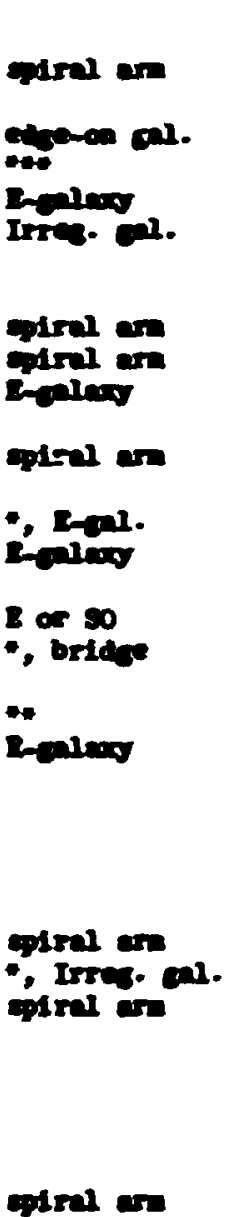 & $\begin{array}{r}-21.6 \\
55.6 \\
79.1 \\
-17.5 \\
65.5 \\
74.4 \\
70.1 \\
56.8 \\
-75.6 \\
61.9 \\
4.2 \\
74.5 \\
65.8 \\
66.3 \\
79.2 \\
89.2 \\
73.9 \\
20.8 \\
86.5 \\
66.5 \\
-19.6 \\
-50.7 \\
-28.7 \\
80.8 \\
71.4 \\
59.7 \\
-56.6 \\
59.6 \\
69.3 \\
61.7 \\
54.8 \\
68.9 \\
-31.1 \\
57.7 \\
29.2 \\
65.3 \\
74.3\end{array}$ & $\begin{array}{l}0.60 \\
0.30 \\
0.26 \\
0.23 \\
0.20 \\
0.26 \\
0.26 \\
0.30 \\
0.26 \\
0.20 \\
0.31 \\
0.26 \\
0.27 \\
0.27 \\
0.26 \\
0.25 \\
0.26 \\
0.70 \\
0.25 \\
0.27 \\
0.75 \\
0.32 \\
0.52 \\
0.25 \\
0.26 \\
0.29 \\
0.30 \\
0.31 \\
0.27 \\
0.20 \\
0.31 \\
0.27 \\
0.46 \\
0.30 \\
0.51 \\
0.26 \\
0.26\end{array}$ & 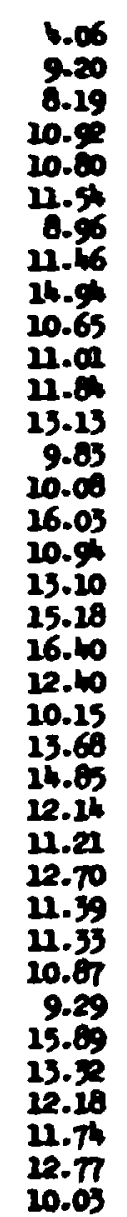 \\
\hline
\end{tabular}

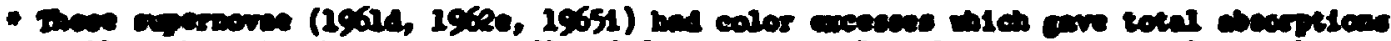

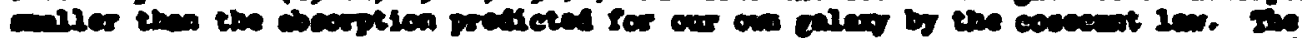

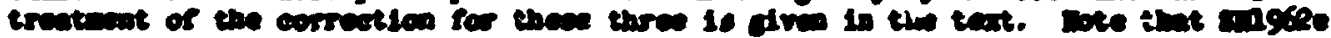

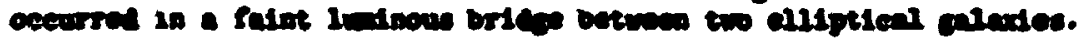

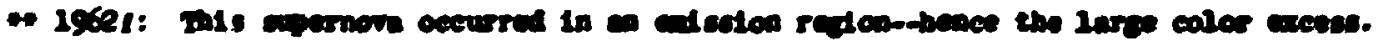

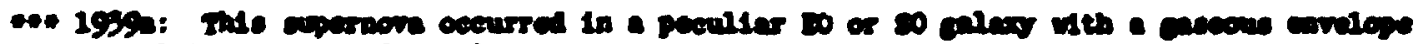

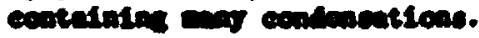


Pstovatef and ren den Bargh nenever svalleble. The nethod of everefine will be dexcribed in wore detall below.

The first step in obtaining Independent estimtes of the distence noduli was to set, estinates of the apparent pirtographic nonitudes of the parent celades corrected for absorption within our orn galas. The uncorrected apperent semitudes were obtained by evereging severel nethods es deacribed in chapter 5 (cr. Table $5-2$ and the explanation of colve 8) and are fiven in Table 5-2. These monitudes were corrected for ebsorption in our own galexy using Bq. (9-8). Io attept mes ande to correct for inclination effects in the parent gelaxdes. The corrected aparent menitudes are given in calum 3 of Table 9-3.

The new extinates of the distance noduli were obtained by four different nethods. Inree nethods colculated $(\mathbf{m}-\mathbf{M})$ by combining the corrected apparent mgnitudes with estimates of the shsolute magnitudes obtained from various luninosity functions. The ctiber netkod ma based on the sybolic recession velocity and the Hubble sonstant. The observed sybollc recession velocities are given in colum 7 of Table 5-2. only the measured values of $v_{Y}$ were used afnce the estimed values of $v_{1}$ vere theaselves calculated using the nethods based on absolute magitudes obtained fran the various ludnosity functions. The observed velocities were corrected for the solar wotion relative to the lccal group. These corrected velocities, which are given in colun b of Table 9-3, were used for the estinates of distance nodul1. The sethod consists essentially in combining the relation

$$
-M=5 \log D-5 \text {, }
$$

where $D$ is the distance measured in parsecs, wth the fubble relation

$$
v_{r}=H r
$$


When the Huble constant is expressed in the units $\mathrm{b} / \mathrm{sec} /$ mpe and $v_{r}$ is in $\mathrm{k} /$ sec, then $\mathrm{D}=10^{5} \times \mathrm{r}$, and the combined relation becones

$$
n-M=25+5 \operatorname{los}\left(\frac{V_{I}}{H}\right) \text {. }
$$

Taking $H=100 \mathrm{~kg} / \mathrm{sec} / \mathrm{mpe}$ cires

$$
-M=15+5108\left(v_{r}\right)
$$

The three luninosity function methods for estinating distance moduli

were based upon: (1) the DDO types of the parent galaxies and ran den Berch's (1'0, 141) ludnosity classification for late type galodies; (2) de Vaucouleurs' (1':2, 143) revised types of the parent galadies and van den Bereh's luninosity classification; and (3) the Hubble types of the parent galaxies and Holmberg's (119) luanosity classification for galaxies. Methods (1) and (3) are straightforward, consisting in assigning an absolute magnitude to each galaxy on the basis of its type in the classification schene. Method (2) is sonewhat more complicated and requires additional explanation. In his 1962 IAU Syposium paper (142), de Vaucouleurs gave a luninosity function for his revsed classification system which was apparently based on a recelibration of van den Bergh's luatnosity clfsses using a Hubble constant of $120 \mathrm{kd} / \mathrm{sec} /$ Mpc. Van den Bergh's original calibration is based on the value $H=100 \mathrm{ka} / \mathrm{sec} /$ Mpe which is the value adipted for this study. De Vaucouleurs also gave, in graphical form, the rialationship between his revised types and van den Bergh's luminosity classes. The sane relationahip is given in tabular form in his 1963 Astrophysical Journal Surpleaent (143). This relationship was used together with van den Bergh's calibration in order to obtain a luminosity function 
which fives for each revised gelarg tyge an absoluce menitude based on $H=100 \mathrm{k} / \mathrm{sec} / \mathrm{kpc}$. This luninosity runction we used for nethod (2). For wost of the gelaxies in this study, the revised type was obtained from the catalogue given by de Vancouleurs in the supplesent paper. In that Supplement he also geve the correlation between his revised tjpes and the fubble type. For galaxier not in his catalogue, this relation was used to obtain the revised type from the Hubble type. The distarce sodulus of each galaxy in this study was deternined by as many as possible of the four methods just described. These determinations were then combined with the estimates of van den Bergh and Pakovakil and the final values were obiained by averaging consistent, independent estimates. That is, for each galaxy, all of the available estimates were compared for consisteory and independence. If most of the est,imates were fairly close in value, but one or more was very different, then the divergent value was not included in the average. Also, if two of the estimates were obtained by the same method, e.g., if Pskovskil estimate mss based on the recession velocity and hence was identical to the present author's estimate ising the same method, then one of them was discarded before computing the average. Tre average values obtained in this manner are given in colum 5 of Table 9-3. The mean number of independent estimates used in calculating each of these average values was 2.6 .

The estimates $\mu_{0}$ of the peak ahsolute magnitudes of the supernovae were calculated from the estimates of the distance moduli by

$$
M_{0}=m_{0}-(m-M)
$$


were the ${ }_{0}$ are the peik aperent wanitudes corrected for extinction. These apperent angitudes vere diven in calues 8 of Table 9-2. Ther are repected is colun 7 of rable 9-3. The celculeted paik aboalute mani. tudes are diven in colum. 8 or the same table.

For the seven supernove whose garent caladies did not have measured shifts, the estinates of the distance codull fiven in colue 5 were used to calculate estinates for the ubalic recession velocities by means of Bq. (9-i2).

The absolute magitudes calsiluted in this study wert conpred wth those of rad ien Bergh, Kowal, and patovaldi. The details of the comparisons are given in Appendix 3 . In gene-al the agreenent was gocd when the different nethods of extinctien correction were taken jito account. In no case were there any aystentic deviations other thar: different average values. The average ${\overline{F_{0}}}_{\text {for }}$ the Rurt estimates was 0.33 brighter than the $\overline{\mathrm{M}}_{0}$ for Pskovalil's estinates, and the straight line

$$
H_{0}(\text { Psicoratii })=M_{0}(\text { Rust })+0.33
$$

gave a very good fit of ihs plotted relation $\mu_{0}$ (Pskorsk11) vs. $M_{0}$ (Must). The 0.33 difference arose from the different methods used to correct for ab.orption within the parent galary. For spira: gelexied, Pakovakil based his absorption extinates on the inclination of the piane of the gblaxy, assuming a plone-parallel wodel for the absorbing material. It is shown in Appendix 3 that Pakovskif's estinates are in wany cases not consistent with the observed color excesses in that sane highly reddened supernovae had smaller extinction corrections thar only slightly reddened one. The color excess nethod used in this study 
Tole 9-3

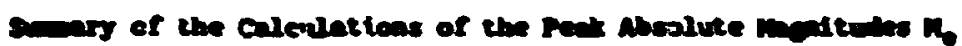

\begin{tabular}{|c|c|c|c|c|c|c|c|}
\hline$s$ & $\cos \alpha$ & ales & 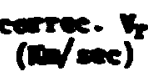 & $=-n$ & Enes & & $t_{0}$ \\
\hline 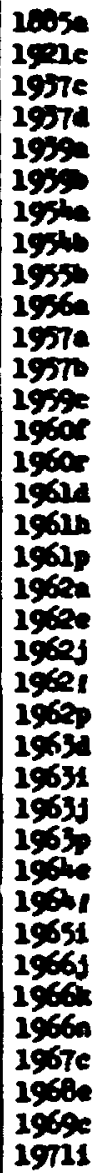 & 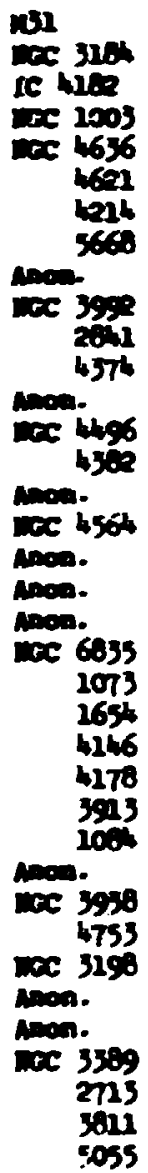 & $\begin{array}{l}3.65 \\
9.9 \\
13.25 \\
11.18 \\
10.33 \\
10.74 \\
9.90 \\
11.90 \\
15.44 \\
10.20 \\
9.69 \\
10.09 \\
15.57 \\
11.66 \\
9.80 \\
14.75 \\
11.91 \\
12.50 \\
15.75 \\
25.23 \\
12.25 \\
11.25 \\
13.60 \\
13.55 \\
11.49 \\
13.91 \\
10.80 \\
14.19 \\
10.52 \\
10.42 \\
10.51 \\
14.43 \\
15.52 \\
11.80 \\
12.19 \\
12.72 \\
9.13\end{array}$ & 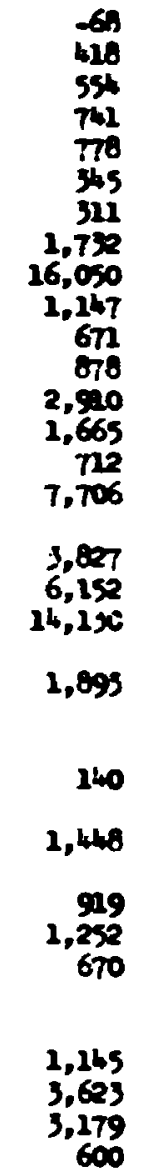 & $\begin{array}{l}23.8 \\
29.2 \\
20.6 \\
30.3 \\
30.3 \\
30.4 \\
20.8 \\
31.2 \\
34.6 \\
30.5 \\
29.7 \\
30.1 \\
33.5 \\
30.5 \\
29.9 \\
34.5 \\
30.8 \\
32.6 \\
34.2 \\
34.8 \\
22.1 \\
32.6 \\
32.8 \\
33.9 \\
30.6 \\
32.5 \\
30.8 \\
32.3 \\
30.2 \\
30.3 \\
29.9 \\
33.5 \\
34.9 \\
30.6 \\
32.0 \\
32.2 \\
20.4\end{array}$ & - & 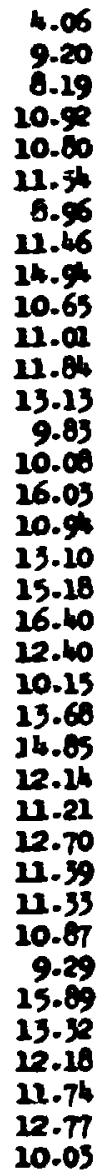 & $\begin{array}{l}-19.7 \\
-20.0 \\
-20.4 \\
-19.4 \\
-19.5 \\
-10.9 \\
-19.8 \\
-19.7 \\
-19.7 \\
-19.8 \\
-18.7 \\
-18.3 \\
-20.4 \\
-20.7 \\
-19.8 \\
-20.3 \\
-19.9 \\
-19.5 \\
-19.0 \\
-18.4 \\
-19.6 \\
20.8 \\
-19.1 \\
-19.0 \\
-10.5 \\
-21.3 \\
-28.1 \\
-20.9 \\
-18.9 \\
-19.4 \\
20.6 \\
-17.6 \\
-21.6 \\
-19.4 \\
-20.3 \\
-19.6 \\
-18.4\end{array}$ \\
\hline
\end{tabular}

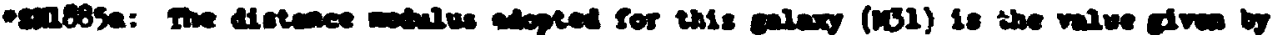
Allon (144) in atrobreten cratities. 
dass sot suffer from this sturtconing since it predicts the absorption corriztion fran the reddening.

Altlough the color excess nethod is more consietent than the inclination nethod, it is important to keep in wind that 18 of the extinction corrections were only rough estinates. The average total correction for the 19 whose corrections wexe derived from color excesses was $\bar{A}_{\text {pg }}=1.10 \pm 0.96$. The average of the 18 e.itinated corrections was $\bar{A}_{\mathrm{pg}}=0.99 \pm 0.53$. The soller standard deviation for the latter group is due to the anller range $(0-1.5)$ of the estimated corrections. The good agreenent between the sverage values deconstrates that the nethods are consistent in the sense that one did not give systeratically larger corrections than the other. The corrections were alsn checked by flotiing the final corrected $\mu_{0}$ against that part of the extinction correction attributed to the parest galaxy. The plot did not show any correlation between $M_{0}$ and the correction, nor did It revea. any significant differences between the two groups of corrections. The other large uncertainties in the $\mu_{0}$ estinates were the estinates of the distance moduli of the parent galaries. A plot of $\mathrm{M}_{0}$ against (m-M) showed that there was no significant correlation between the two. Not only does this mean that the (m-M) estimates did not introduce any systematic effects into the estimates of $M_{0}$, but it also means tnat there is probably no luminosity selection effect in the saple. Thus, even if there is a correlation betweer. the absolute magnitudes $\mu_{0}$ and the comparison parameter $\Delta t_{c}$, that correlation would not be responsible for the correlation between the $\Delta t_{c}$ and the symbolic recession velocities $\mathbf{v}_{\mathbf{r}}$ 
Before turning to the question of the relation between $M_{0}$ and $\Delta t_{c}$ It is interesting to briefly consider two correlations orifinally observed by Pstovsidf and confirned by the $M_{0}$ estinates in the present study. Oaly the results of these comparisons will be atated here, but the detalls can be fourd in Appendix 4. In his 1967 paper 0), Patovalui found a weak correlation between the $H_{0}$ and the Hubble typea of the parent golades. The present study confires this trend but the average values of $n_{0}$ for each gelas type affer in the two studies in two was: (1) the averages of Rust inerease more soothly along the sequence of galardes than do those of Patovatsi, ... Id (2) the brigtitness increase along the sequence is less for the estinates of Fust than for those of Pakovalif. Thus, the correlation appears to be more regular but less pronounced for the estinates of Rust than for those of Pskovakil.

In an earlier papar (145), Pskovikil reported a correlation beiween $M_{0}$ and the integrated absolute nagnitudes of the parent galaxies, $M_{\text {gal }}$. The estinates in the present stiv sonfirm this correlation even though there is a wide scotter in the $\mu_{0}$ eatinates. For the present saple, the regression line is

$$
\mu_{0}=-(27.9 \pm 5.1)-(0.436 \pm 0.252) M_{\mathrm{Bal}^{\prime}}
$$

and the correlation coefricient is $p=-0.28$. The t-statistic for teating this correlation is $t=-1.67$, alue which gives signticance at the 94.7\% 1evel.

The maln purpose for computing the absolute magitudes of the mpernovae wa to check for a correletion between then ind the comparison paraseter $\Delta t c^{\prime}$ i.e., between the peak luadnosity and the rate of fall of the light curvis. The result of a stralght line regression of $-\mathrm{H}_{0}$ 
on $\Delta t_{c}$ is shown in Forure 9-1. The borizontal dashed line is the average absolute mogitude and the salif line is the best Niting least squares line wich has the equation

$$
m_{0}=(-18.55 \pm 0.68)-(0.0512 \pm 0.0359) \Delta t_{c}
$$

The correlation coefficient is 0.237 and the t-statistic for testing the afgificance of the correlation has the value $t=1.43$. This Iatter value gives, with 34 degrees of freedon, algnificarce at the 927 level. A closer inspection of the plot reveals that there an be an even wore significant correlation than that revealed by the regression, for the points seen to fall into two separated bands, and each band by itself shows a wre pronounced correlation than the totality of points. These bands will be discussed in wore detail in Chapter 11. since there does appear to be a significant relation between $\Delta t_{c}$ and $n_{o}$ It is inportant to check whether $y_{0}$ is correlnted with tije sybalic velocity of recession. The regression of $H_{0}$ on $v_{r}$ is show in Ploure 9-2. The broken line is the relation $M_{0}=\bar{M}_{0}$ and the solid line is the best least squares line,

$$
\mu_{0}=(-19.53 \pm 0.20)+\left[(0.66 \pm 4.33) \times 10^{-5}\right] v_{\mathbf{r}}
$$

Since the standard deviation of the slope fis nearly seven tines creater than the slope 1tself, it is safe to sssure that the slope does not differ stenificantly from slope $=2$ ero. This conclusion is further reinforced by the value of the correlation coefficient, $0=-0.026$, and the t-statistic, $t=-0.15$. Thus, the conclusion previously drawn frow the plot of $H_{0}$ against $(n-M)$ is confirmed. There is no eloniflcant ludinosity selection in the segle. This means that, thouph there 


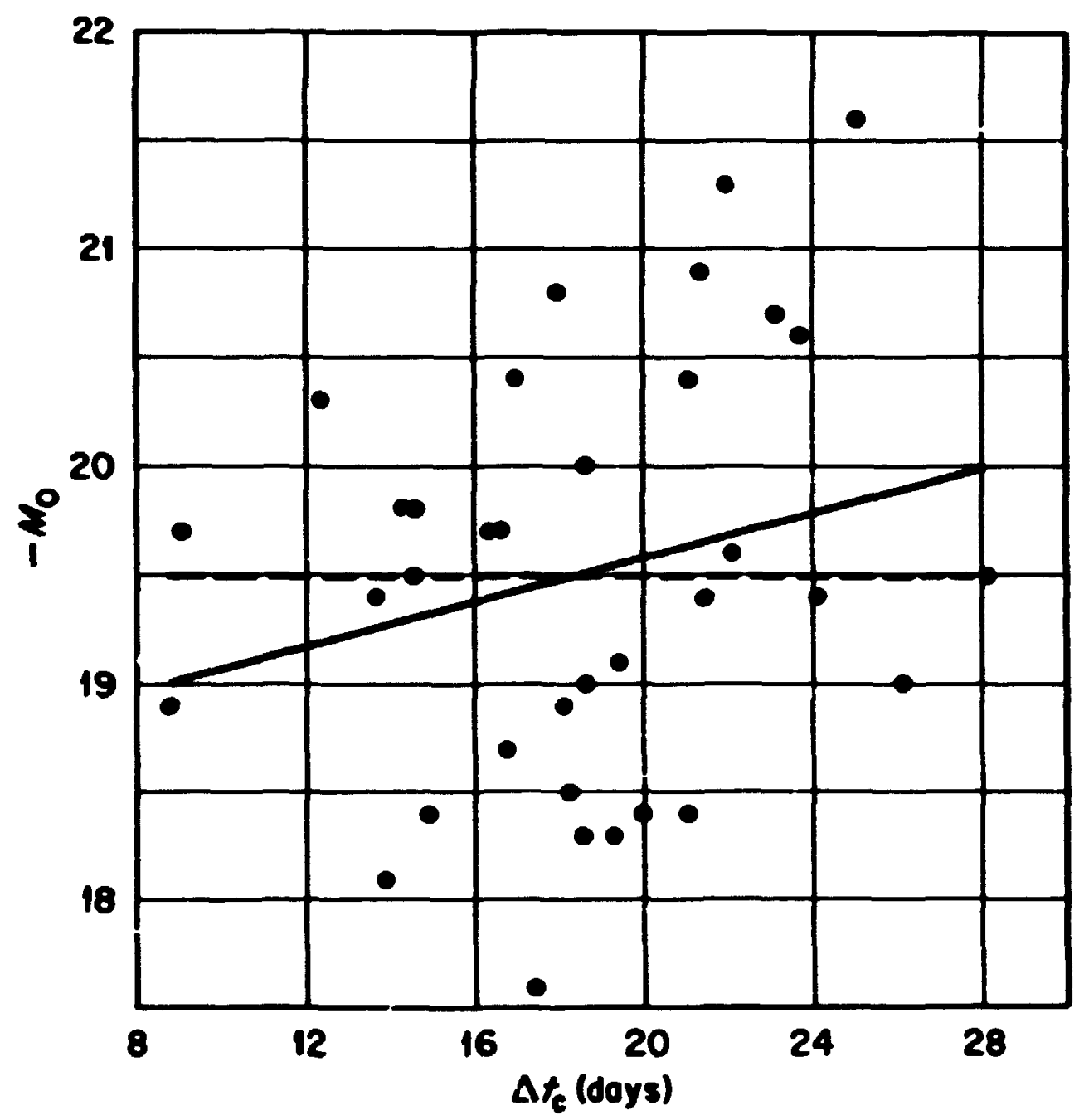

Pigure 9-1. Regression of Absolute Magnitude $M_{0}$ on the Comparison Parencter $\Delta t_{c}$. 
appareatly is a Agoificant correlation between $\Delta t$, and $H_{0}$, it is not reponable for the correlation between $\Delta t_{c}$ and $V_{r}$.

The epparent edstence of two bank in the $\mu_{0}-\Delta t c$ relntion (FIgure

9-1) susgerts that there dight be two distinct populations of type I apernorac. The question of the reality of these two populations and thefr rosequesces in the stud of spernorm theory and extragelactic artronow will be afscusead in chapters 11,12 , and 13; but Nrat, Chopter $10 \mathrm{will}$ asain tale up the min subjact of this theals, the $\Delta t_{c}-V_{r}$ relation. 


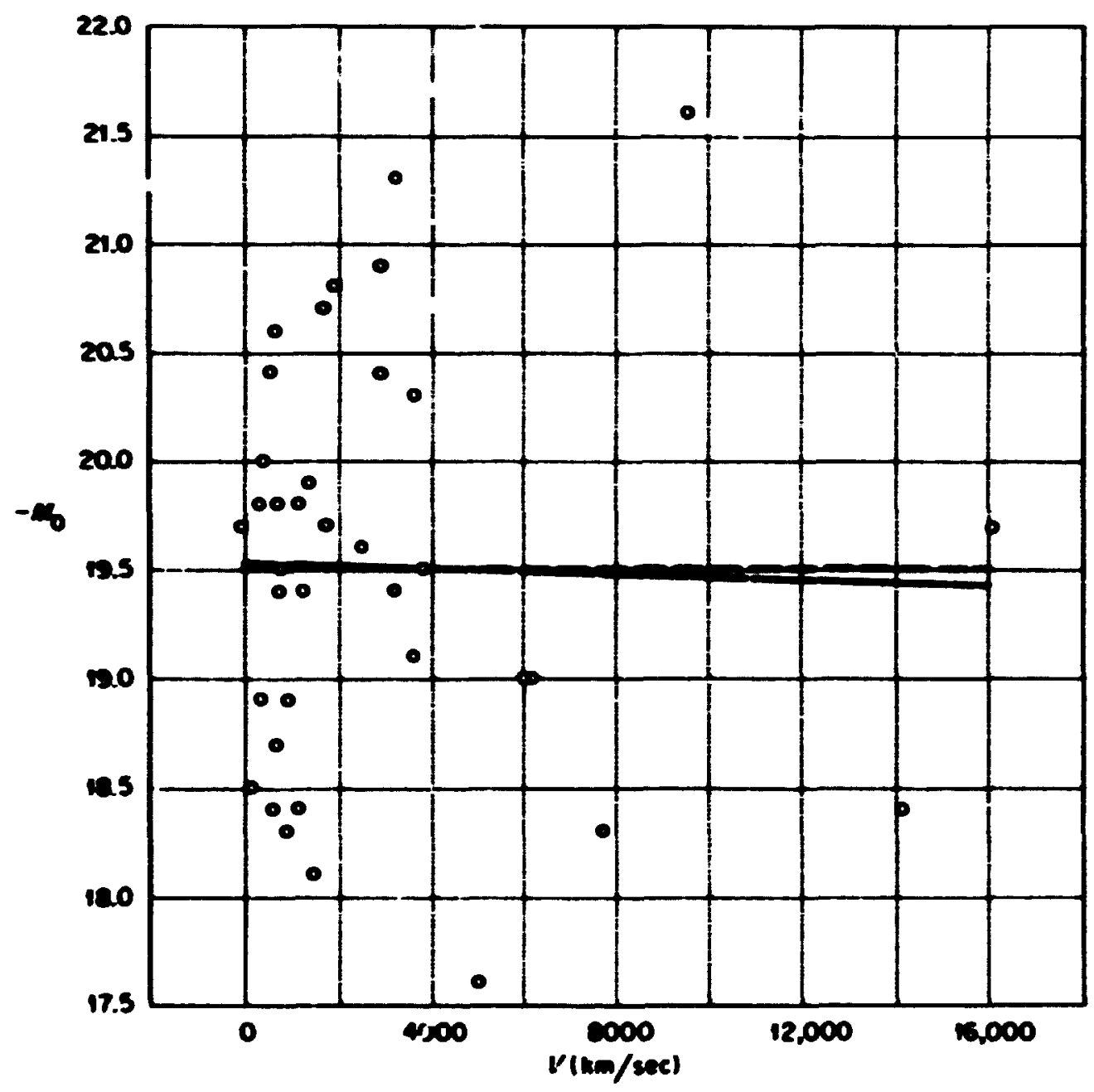
Pigure 9-2. Regression of Absolute Magnit:ade $M_{0}$ on the Syboitic
Velocity of Recession. 


\section{gupta 10

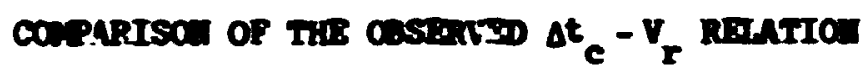

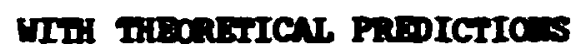

In Cupter 8 a wak but warinally simfineant correlation was found between the conperison perenter at (mber of dys required for

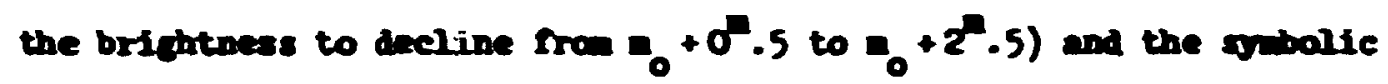

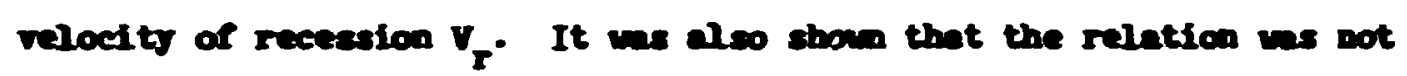
the result of data reduction or fitting errors. In cropter 9 it ws show that the relation afd not arise from an observetional selection efrect. The relation, which is show in PIgure 82, is poorly deteridned by the date, which have rer too wich scatter to discriannte reliably between a static buelidean miveres $($ slope $=0)$ and an copanding universe (slope $\left.=5.55 \times 10^{-5} \mathrm{dra} / \mathrm{t} / \mathrm{sec}\right)$, but the suprising result we that the alope of the rugression line (alope $=3.21 \times 10^{-4} \pm 1.96 \times 10^{-1}$ anglled sec) rejects both of the at a ratry hith significace level - at the 93. leval for the former and at the gis level for the latter. Therefore, it is reasonoble to ast wether there are other theories which five better ecrement with the ate even thoung the dite are cunttedy rather linited at the preaent. The important questions at this point are (1) bow may theorles are atill coaslsteat with the date, and (2) will it be possible, when 21 int curves for supernome in nore distant caluxies becose avilable, to distingulsh between these altermatives?

The nost cemonly proposed alternatives to the expending universe uypothests are varients of the "tired 11ght" theors. are of the carliest of these was the steady state theory, circe 1920, of W. D. Mackallan 
BLANK PAGE 
(152, 153, 15h) wo proposed that "rediant encrey can and does disuppenr Into the Nine structure of apece, and that socher or later this enerds rempens as the internal eaery of an aton; the birth of an aton with Its strange property of mes beling a strictly astrotonical afredr."

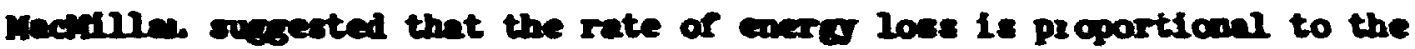

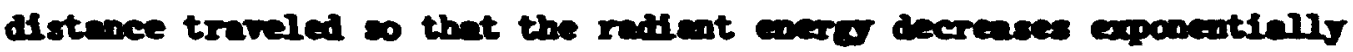
Wth distance.

A sifllar propoeal we ende ece 35 jeare later by Pinlay-Preudich (155), who sugerted that the red hift is cansed by a loas of enery in radiation flelds (perbaps due to photon-photon intersetions). He proposed the relation

$$
\frac{\Delta \mathbf{v}}{v}=-A \mathbf{T}^{\mathbf{4}} \mathbf{l}
$$

where v=frequenc, $\Delta v / v=$ redmift, $I$ is the tempereture of the raliation Field, $l$ is the path leagth throun the field, and $A$ is a proportionality constant. This relation is consietent with a lisenr bubble lew, and prewndlich combined the two in order to predict lindts on the terparature

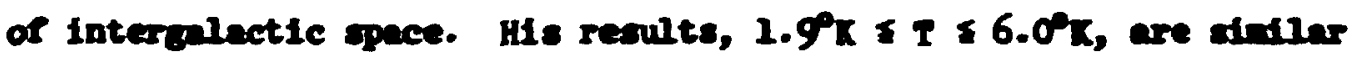
to the preafictions that Gor wade at about the som tine uring the bif bang" theory. This prediction is alnost univerally overlooked by present-dry conolodists, wo cite the leter alseovery of the corde

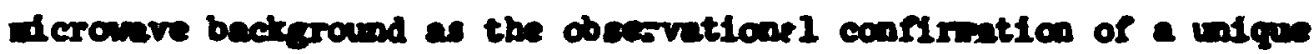
prediction of the "bis bang" theory.

Wore recent "tired 11fht" proposels have been based on the potion What the crevitational forces bave e findte range (156, 157, 158). The cravitationel cut-off is achieved by introducting an exponeatiel 
attenuation into the equation for the grevitational potential. Sinhlarly, It is essuned that the rrequency of light $v$ observed at a distance $r$ from the source is

$$
v=v_{0} \exp (-\infty)
$$

were $y_{b}$ is the frequency at the source sad a is in atteavation constant. For anil veluss of $r$, the exposential factor is well appoudinated by $(1-\infty)$ and the relatiou for observed frequency can be vitten

$$
v=v_{0}\left(1-\frac{h}{c} r\right) \text {, }
$$

vhere II Is Huble's constant and $c$ is the velocity of limt.

There are and otber variants of the "tired lipt" mpotberis, but thas all presues that the univeres is static and naw of then eseve that it is Duclidean as wil. The redubift arises not from a Doppler

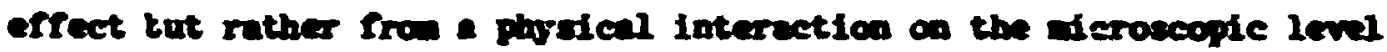
betwen the lifht an the waif throun whech it passes. If distant

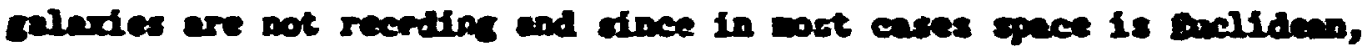
there are no tine distion effects arising frow the trangport of aleals throuth a curval spece. Thus the prodiction for the observed time iepee

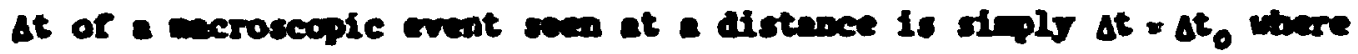
At, is the tine lepse that would be observed at the ste of the crent. Ints is the static melidea preafetior which bas slope -0 in the $\Delta t_{e}$ - Vr diegre and wich we rejected at the 936 level by the date. Another class of theories that have ben proposed as alternatives to the general relativistic eppaston thoories is conpoed of generalisations or exteneions of spoctal nelativity. The not fowous of these is Milde's Kinemetic Relativity $(159,160)$. A rery lucid copostion or

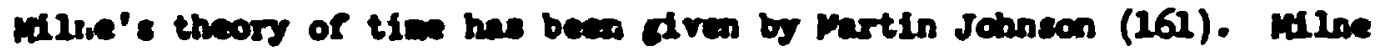


proposed that there are two time seales in the universe. ane, called t-tine or linomitic tine, is the time wheh applies on the atodic senle. The other, called t-tine or dyonic tine, is the tine unich aplites to events on the meroscopic leval. The two time seales ore reinted by the differatin equation

$$
\frac{d t}{t}=\frac{d r}{t_{0}},
$$

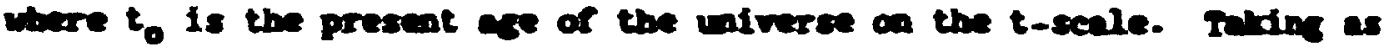
boudary cooditions $T=-$ for $t=0$ and $\tau=t=t_{0}$ at the present qpech, the Afrerminal aquation is solve to dre

$$
T=t_{0} \log \left(\frac{t}{t_{0}}\right) \cdot t_{0} \text {. }
$$

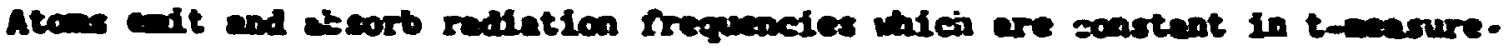
Aceording to fillos the guestion of whether ar pot the rad shift should

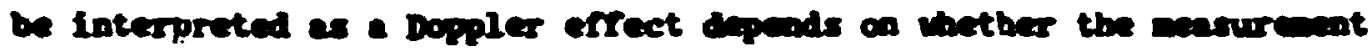
of light from dotant elexies is porerned by t-tine cr r-tine. More

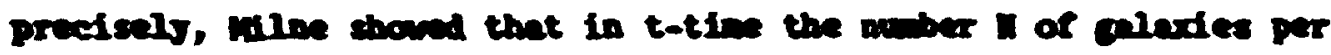
uit voluse decreaces sccording to

$$
n=\frac{\Delta t}{c\left(t^{2}-\frac{d}{c}\right)^{2}},
$$

where $t$ is the epoch of observation, d is the distasce, and 8 is a constant. Thus in the t-time seale the universe is expanding. on

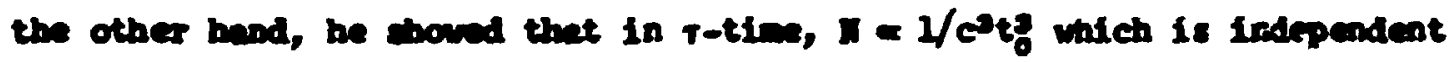
of $T$, so there is no eqpansion. There is a red shift aldee by benation

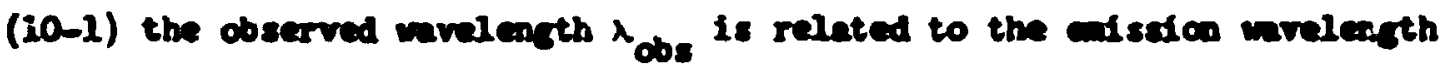
$x$ by

$$
\frac{\lambda}{t}=-\frac{\lambda_{o b s}}{t_{0}} \text {, or } \frac{\lambda_{o b s}}{\lambda_{m}}=\frac{t_{a}}{t} \text {. }
$$


Because the t-tine of obserrntior, $t_{0}$, is later then the tine $t$ of adseion,

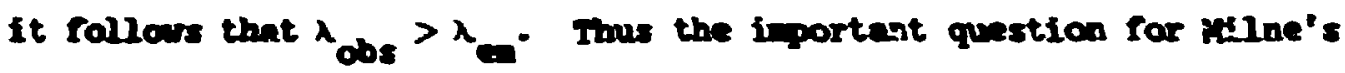
theory is not wether the universe is expanding or static--it is expandine In t-tine and static in T-tine. Feve Iportant question is Thich tine seale are we uxing wen we observe the distant gelexies?"

The event under consideration in this thesis 1 s the decline in Iudinosity of a Astant supernom. This is an event rbose occurrence Is presumbly coverned by the meroscopic :-tibe senle. It fallows quite rendily tron Equation (10-2) that for an ereat whose duration at is short conpred to the present age of the universe, 1.e., for an event such that ot $<<t_{0}$, the time lapse neasured at the ovat is the sene In either tine senle, 1.e., $\Delta t=\Delta T$. When the eveat occurs in a distant plax, thare is a long time lapse between occurrance and observation so the tar tine-senles have time to diverge and dive different observed tine 1epaes. In the T-arsten, the universe is static and the light travel tine between the occurrence and observation of the beginaing of the event is the sane as the travel time between the occurrence and observetion of the and of the erent. Inis means that ot (observed) = at (occurrence), which is the same as the prediction of the conventional otetic, Buclidea: theory.

In the t-rotea, the universe is expanding so the lifht travel tine between occurrcnce and observation increases between the beginning and ead of the event. In this case it is eany to show that if the lifht travel time is wuch aller than the present age of the universe, the observed tine lepse is diven by

$$
\text { at (observed) }=\left(1+\frac{V_{r}}{c}\right) \Delta r \text { (occurrence), }
$$


where $V_{Y}$ is the radial velocity of the ollas of ociurrence. Since all of the supernove in this stuts occurred in relativaly nearty galadies, 1.e., In calades wose distances are 11 fractions of the main distences that have been observed, the lipht trevel tines involved are certainly mon less than the se of the universe; so the dbove forming applies. The prodiction is the save as that of the stendind expading universe hypothesis. Obviously, the present test canoot, crea in principle, distinguigh between wine's theory and the standirl theories; but if it could be showe by sone other wans that iflne's theory is valid, then the test could be used to deternin which of the two tibe-scales we use in observing the distant calexies.

A wore recent variation of the speciel relatinistic theories is that of Stanislaw Bellert $(162,163)$ wo assuned that "the space of erents 1s a static space, and the red shift is : consequence of the geanetry of that space." Using two postulates which be called: (1) the postulate of equivalence of stationary frane of reference, and (2) the postulate of uniqueness concerning the neasuremeut of electrongetic wavelength, he argued that the red sift $a / \lambda_{0}$ is related to the luainosity distance D by

$$
\frac{\Delta \lambda}{\lambda_{0}}=\frac{M D}{I-W 0}
$$

were $\mathrm{K}=\mathrm{H} / \mathrm{C}$, $\mathrm{H}$ being the Hubble constent and $\mathrm{c}$ beling the velocity of 11ght. He called the constant $k$ the coefricient of redial elongation becuase objects seen from a distance hsve thelr cpparent radial dimensions or lengthened according to

$$
\Delta r=\frac{\Delta x^{\prime}}{I-x_{0}},
$$


where $\Delta x^{\prime}$ is the lenoth neasured at the object and $r_{0}$ is the distance froe the observer to the object. The epperent transverse dinensions of the object are cot changed by the distance, but tine lapses are altered by

$$
\Delta t=\frac{\Delta t^{\prime}}{1-k r_{0}},
$$

where $\Delta t^{\prime}$ is the tine lapse observed at the ste of the occurrence and $\Delta t$ is the apparent tine lapse observed at distance $f_{0}$ from the occurrence. Bellert identified the distance $r_{0}$ with the ludinosity dfstance $D$ between the ocsurrence and the observation. Combining equations (10-4) and (10-5), then, gives

$$
\Delta t=\left(1+\frac{\Delta u}{\lambda_{0}}\right) \Delta t^{\prime},
$$

or, talding $z=i \lambda / \lambda_{0}$,

$$
\Delta t=(1+z) \Delta t^{\prime} \cdot
$$

According to Bellert's theory the universe is static, but fiven an observed red shift 2 one can still define a smbolic recession velocity $V_{r}$ by $V_{r}=c z$, and using this symbolic velocity, the prediction of Bellert's theory for the test or this thesis is

$$
\Delta_{c}^{t}=\left(1+\frac{v_{r}}{c}\right)\left(\Delta t_{c}\right)_{0}
$$

which is the are as the prediction of the expanding universe theorfes.

All of the theories that have been discussed so far have ande the same prediction as either the static Euclidean theory or the classical expansion theory. There is one recent theory, however, which gives a quite different prediction. That theory is the covariant chrosogeometry of I. E. Segel $(164,165)$. Chronogeonetry was initiated by A. A. Robb (166) who called it time-space geowetry. The name chronogecmetry was coined by A. D. Fokker (167) who regarded it as an alternate 
approach to relativity theory. Segel replaced the ininowid epace-tine $M$ of pecial relativity with a particular chronogeonetry $\tilde{\mathbf{M}}$ which is locally identical to $M$ but geanetrically afferent fran $M$ in the large. Segal's treatinent of the theary is very abstruse. Ho describes II as "... i be chronogeonetry of appareatly madinal symetry, enong those wich do not adit simulaneity." He contrasted $\boldsymbol{I}$ to $M$ as fallows: minis wodel $\tilde{I}$ adits the fifteen-paraneter conformal eroup (wore exactly, a doubly-infinite-sheeted covering of this group' as its group of causality-preserving symetries, while winkorald space $M$ aduts only the eleven-parasecer group of Lorentz and scale transformations. This necessitates a nodified definition of tise, as the paraneter of a one-paraneter group of temporal displacenents distinct fron (non-conjugate to) that enployed in special relativity. The iocally negligible dfaparity between relativistic time and this new time becomes signiflcant at large distances." An exposition of the developnent of Segul's theory is far outside the scope of this thesis, and the present author has found it almost imposs.ole to assess the validity of ihe theory because of Segal's highly esoteric development. It was, horrever, falrly cany to deterine the preasction of the theory for the $\Delta t_{c}-v_{r}$ relation, which is the main subject of this theais. According to the thecry, there is a unique, lovariant, tine $T$ wich in the local nelghborhoori of an event is closely anproximated. by special relativistic tine $t$. Suppose that the event In question is the calseion of a light ray occurring at tive $t=t=0$. Accordinc to the theory, the variation of the two time scales along the ligint ray is given by the equation

$$
t=\tan T
$$


where $T$ 1s measured in "natural" units (undts for which the velocity of light is unity) and varies between $-\frac{\pi}{2}$ and $+\frac{\pi}{2}$ as $t$ varies between - and to At an later point of observation the two tim sealea are rellated 3j

$$
\frac{\partial r}{\partial t}=\frac{1}{1+t^{2}},
$$

in terms of the local apeciel relativintic coorilnates at that point. Even though the universe is atatic, there is a red shift wich arises becmuse of the discrepancy between the two tive seales. According to segel, this red chift is given by

$$
z=\tan \left(\frac{T}{2}\right)
$$

For and values of $t$ the approudnate formula

$$
2=\frac{t^{2}}{4}
$$

18 ralid. Since the red shifts of all the aupernovae in the present unple are relatively and $(2<.06)$, this latter formula will be uned. Uaing Equations (10-?) and (10-11) it is quite eary to work out the prediction of the theory for the $\Delta t_{c}-V_{Y}$ relation. Taking $\Delta T=\left(\Delta t_{c}\right)_{0}$ as the time lapse of occurrence and $\Delta t_{c}{ }^{2}$ the observed time lapse, and using the relation

$$
\Delta t=\frac{\partial t}{\partial t} \Delta t
$$

Prom elceritary calculus it rollows that

$$
\Delta t_{c}=\frac{1}{\pi / \partial t}\left(\Delta t_{c}\right)_{0} \text {. }
$$

Substituting equation (10-9) into this result gives

$$
\Delta t_{c}=\left(1+t^{2}\right)\left(\Delta t_{c}\right)_{0} \text {. }
$$

Now by Eq. (10-11), $t^{2}=4 z$ so this last expression becomes

$$
\Delta t_{c}=(1+42)\left(\Delta t_{c}\right)_{0} .
$$


Pinaly, defining a abalic velocity $v_{Y}$ by $v_{Y}=e z$ (even thoow the universe is static), the prediction becones

$$
\Delta t_{c}=\left(1+4 \frac{v_{r}}{c}\right)\left(\Delta t_{c}\right)_{0}
$$

It should be ephasized that this psediction is based on the present anthor's interpretation of Sapl's theors and is not attributed to sean hiscalf wo nov have differeat ideas sbout the voridings of the two tive scales. (mere w, for exple, be problems of interpretation dinilar to those that arose in connection with mine's theory.) In the reninder of this thesls, however, the ter "segel's chronoseonetry" wll be used as a shorthand notation for "Rust's interpretation of secel's chrosogeconetry."

The above prediction is quite Afferent from that of both the Static Duclidean theory and the clasalcal expansion theory. It predista a linear relntionahtp between $\Delta t_{c}$ and $V_{F}$ with a alope four times Greater than thet of the otraight line relation prealeted by the capandion hypothesis. Uaing the estinte $\left(\Delta t_{c}\right)_{0} / c=5.55 \times 10^{-r} \mathrm{eas} / \mathrm{ho} / \mathrm{sec}$ obtained in Chepter 8 from the 21 supernove with $\mathrm{V}_{\mathrm{r}}<2000 \mathrm{w} / \mathrm{sec}$, the slope predicted by segnl's chrosogeanetry is $2.22 \times 10^{-h} \mathrm{durd} / \mathrm{h} / \mathrm{ecc}$. This latter value is much closer to the elope of the regresudon line ( s.lope $=3.21 \times 10^{-4} \pm 1.96 \times 10^{-4}$ ) than the former. A plot of the data together with the ragression line and the three pradictions are given in Figure 10-1. Bach or the thres prodfetion 11nes is the beat fitting traight line having the slope proulcted by the correoponding theory. All have slopes lese then the least squares regresalon 2150.

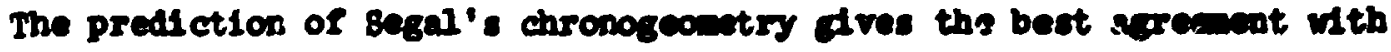
the regreasion 11ne. The t-atatiotic for teoting whether the slope 


\section{5}

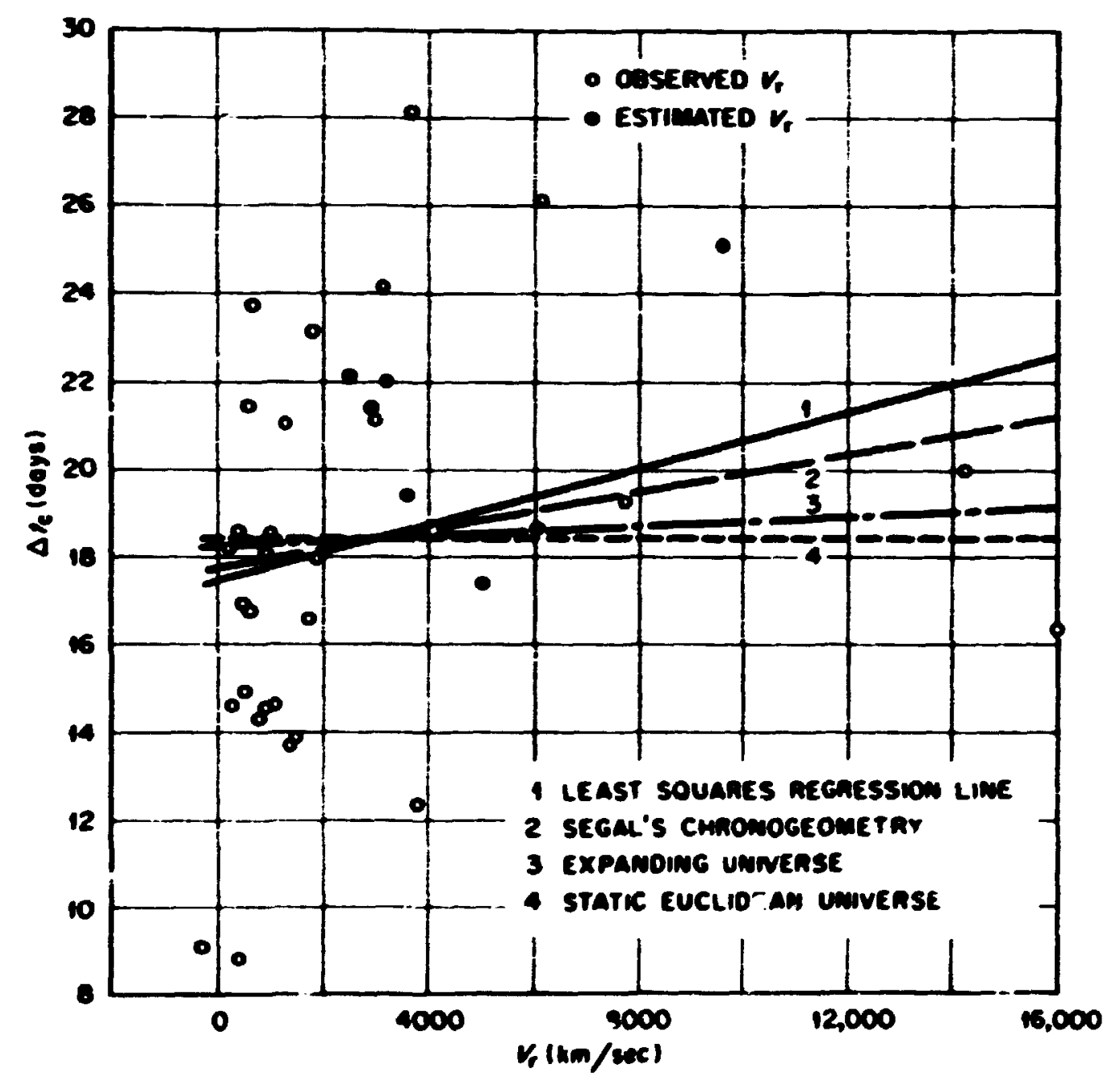

Pigure 10-1. Comparison of the $\Delta t_{c}-v_{r}$ Regreselon Line with the Predictions of the Vario:s Theories. 
of the regreasion line is aloniflemath greater than the alope of Segel's praliction has the vilue $t=0.51$. Wh 3 th degress of nrealon, this t-value rejects Seal's prediction at ouly the 69\% 1evel. Suld another w, If Sapl's theory ware true, thea one cond expect to obtain a IItted slope as creat of creater then the coe sctunly obtained bout 316 of the tire (if 36 ale polnts were used each tine). On this barls it is reasconble to sey that segel's theory is condistent with the cbserved data.

Althorgh the predictions of the Bqpaling Universe and the static Buclidean Unf verse were rejected by the t-test at the $93 \%$ and $91 \%$ Afoificance levels, repectively, one camot in all fairbess as that thes are inconsistent with the date in this saple. The scatter in the date is extrenely large and the points are not seattered unffornly over the range in $V_{y}$. There are only 15 points in the sample with $V_{r}>2000$ Wr/sec and 7 of these ald not have neavured $v_{Y}$ [Cr. Fig. 10-1]. Por those 7 polnts the asbolic velncities wre obtained from eatinates of the distance modull and the fobble relation using the value $\mathrm{H}=100$ W/ sec/nipe. Because they conpise auch a large fruction of the points with $v_{y}>2000 \mathrm{ka} / \mathrm{sec}$, it is ipostant to detendive how censtive the fitted alope is to the value of those estimates. Inis sensitivity was teated by recalculating the $7 v_{\mathbf{r}}$ estinates uning both $H=75$ and $H=125$ halsec/upe and repenting the regression for each of these two sets of eatinates. The results of these tects are suarized in Table 10-1. The first row contains the slope of the fitted regresston line together with Its stendard deviation. All of these slopes are ereater than those predleted by any of the theorles. The second row contalins the correlation 
Inle 101

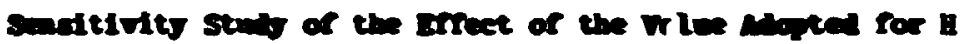

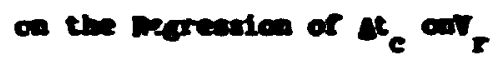

\begin{tabular}{|c|c|c|c|}
\hline & $A=T 5$ & $A=100$ & $E=125$ \\
\hline 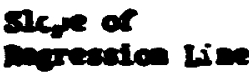 & $(2.96 \pm 2.05) \times 10^{-\alpha}$ & $(3.21 \times 1.96) \times 10^{-4}$ & $(3.30 \pm 1.6 \times) \times 10^{-1}$ \\
\hline $\begin{array}{l}\text { compintian } \\
\text { confriedert }\end{array}$ & 0.24 & 0.27 & 0.29 \\
\hline 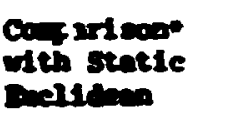 & $\begin{array}{c}=1.64 \\
906\end{array}$ & $\begin{array}{c}2=1.64 \\
931\end{array}$ & $\begin{array}{c}t=1.79 \\
96 \%\end{array}$ \\
\hline 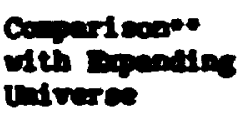 & $\begin{array}{c}=2.17 \\
876\end{array}$ & $\begin{array}{c}t=1.36 \\
986\end{array}$ & $\begin{array}{c}t=1.49 \\
g \geq 7\end{array}$ \\
\hline 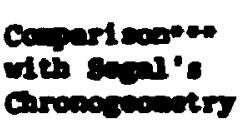 & $\begin{array}{c}=0.36 \\
a x p\end{array}$ & $\begin{array}{c}2=0.51 \\
69 x\end{array}$ & $\begin{array}{c}t=0.59 \\
7 \times 6\end{array}$ \\
\hline
\end{tabular}

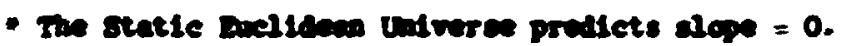

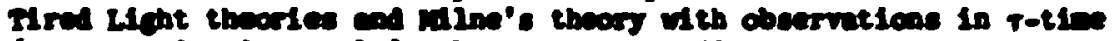

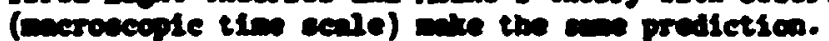

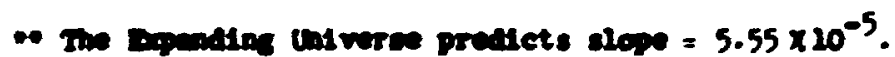

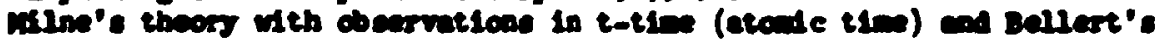

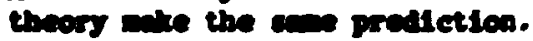

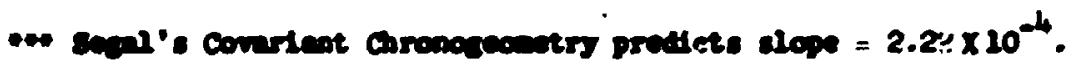


coenfielents. The depree of correlation elearly increases uth inereasing

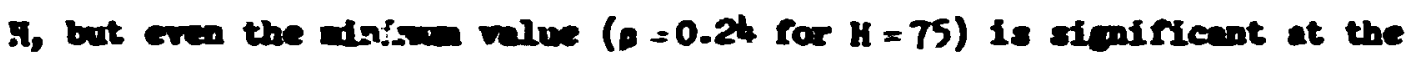
927 1evel. Dow ;, 4, and 5 contain the coppariscons with the theoretical predittions. In ench ease the velue of the t-statistic for copparing the Itted slope to the prealeted slope is adven together vith the corsegpodity sipifieance 1evel. The static Boclidean nodel is rejected It all eases wth simifience levels erceeding 90,.

All of these terts indicate that reasonable changes in the value of H do not produce qualitatively differeat results in the conparison of the represtion line and the predictions of the three theories; but both the alope of the regression line and the correlation coefficient are seasits := to the value adopted for $H$, both of then increasing with increasing velues of $\mathrm{H}$. Estinates of $\mathrm{H}$ are usually obtained from a regresetion of apparent nagnitude $n$ on $\log _{2}\left(v_{z}\right)$ for large saples of galades which boperully have sidlar intriusic luninosities. Supernove can be used for this regreserion also, and, in fact, using supernove avolda sone of the difficulties which arise from uning galades. This rubject will be discussed wore fully in chapter 13 where a new nethod for deternining the Hubble constant will also be given.

In Chepter 9 it was show that the $\mu_{0}-\Delta t c$ relation for the present saple of supernuvae apparently consists of two distinet bands which are well separated [cr. Plgure 9-1]. The presence of these bands suggests that there are two distinct populations of Type I supernovae. If that 1s true, then the effect of these two populations ast be taken into accoun: in aring the $\Delta t_{c}-V_{F}$ test [F1 gure 10-1]. The next chapter wil discuss the reality of the two populations and Chupter 12 w11l dscuss a wethod for taking then Into account in the $\Delta t_{c}-v_{r}$ relation. 
CHAPTER 11

THE TO LUAMOSTIY GROPS

Returning to the apparent existence of two separnted bands in the $M_{0}-\Delta t c$ relation, consider Figure 11-1, wich illustrates the results of perfording regressions sepurately for the two bands. The upper band, plotted as solid circles, is well separated fron the lower bend, which is plotted as open circles. The gep between the two is everywhere greater thon or equal to 0.8 . The straight lines are the least squares regression lines: for the upper band,

$$
\mu_{0}=(-18.08 \pm 0.35)-(0.122 \pm 0.020) \Delta t_{c}
$$

and for the lower band,

$$
M_{0}=(-16.74 \pm 0.58)-(0.101 \pm 0.029) \Delta t_{c}
$$

In the follow'ig text, the upper bara will be called the gore luainous group and the lower band the less luninous group, though it is not yet established whether the separation into two groups is a true luainosity effect or the result of a syotesatic bias in the reductions and calculations of the estinates of $M_{0^{*}}$ Table 11-1 gives the werberahip of the two groups together with the corresponding values of $\Delta t_{c}$ and $\mu_{0}$.

Table 11-2 gives some of the parameters which characterize the relations between $M_{0}$ and $\Delta t_{c}$ for the two sroups, taken separately and logecher. Note that the difference between the mean $M_{0}$ for the tilo groups Is 1.43 , a value nore than twice the standerd deviation in both cases. The statistic for testing the consistency of two means, $\bar{x}_{1}, \bar{x}_{2}$, is 


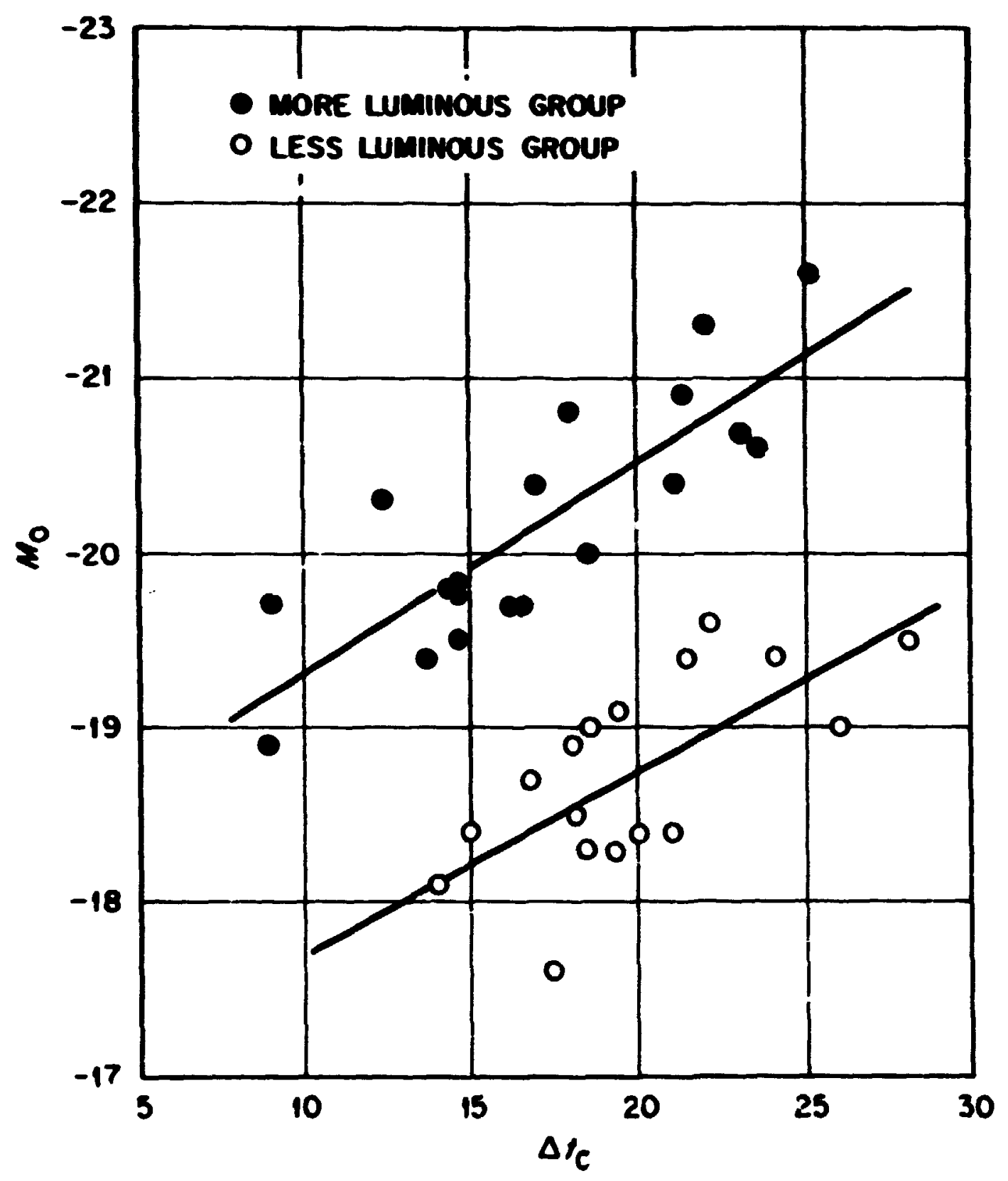

P1gure 11-1. Regressions of Absolute Magnitude on the Comparison Parameter for the Tro Iuminosity Groups. 
Table 11-1

the To Groups of supernovie

\begin{tabular}{|c|c|c|c|c|c|}
\hline \multicolumn{3}{|c|}{ More Luminous Group } & \multicolumn{3}{|c|}{ Less Lualous Group } \\
\hline$s$ & $\Delta t_{c}$ & 16 & $s$ & $\Delta \tau_{c}$ & $\boldsymbol{r}_{\mathbf{b}}$ \\
\hline $188<4$ & 9.1 & -19.7 & 1937d & 21.4 & -19.4 \\
\hline 1921e & 18.6 & 20.0 & 1957 e & 16.8 & -18.7 \\
\hline $1957 e$ & 17.0 & -20.4 & 19570 & 18.5 & -18.3 \\
\hline 1939a & 24.6 & -19.5 & 1961d & 19.3 & -28.3 \\
\hline 19390 & 8.8 & -18.9 & $1961 p$ & 28.1 & -19.5 \\
\hline $19: \mathrm{L}_{2}$ & 14.6 & -13.8 & $1962 a$ & 26.1 & -19.0 \\
\hline $1954 \mathrm{~b}$ & 15.5 & -19.7 & 1962e & 19.9 & -18.4 \\
\hline 19550 & 16.3 & -19.7 & $1962 \mathrm{j}$ & 22.1 & -19.6 \\
\hline 19562 & 14.6 & -19.8 & 1962p & 19.4 & -19.1 \\
\hline 1959e & 21.1 & 20.4 & $1963 d$ & 18.6 & -19.0 \\
\hline $1960 \mathrm{r}$ & 23.1 & -20.7 & 19631 & 18.2 & -18.5 \\
\hline $1960 \mathrm{r}$ & 14.3 & -19.8 & 1963p & 13.9 & -18.1 \\
\hline 19621 & 18.0 & -20.8 & 19641 & 18.1 & -18.9 \\
\hline $1963 \mathrm{~J}$ & 22.0 & -21.3 & $1966 \mathrm{k}$ & 17.4 & -17.6 \\
\hline 196lue & 21.4 & -20.9 & $1967 \mathrm{c}$ & 21.0 & -18.4 \\
\hline 19651 & 13.7 & -19.4 & 19690 & 24.1 & -19.4 \\
\hline $1966 \mathrm{j}$ & 23.7 & -20.6 & 19711 & 14.9 & -18.4 \\
\hline $1966 n$ & 25.1 & -21.6 & & & \\
\hline 1968e & 12.4 & -20.3 & & & \\
\hline
\end{tabular}


Table 11-2

Parmeters of the Relaticas betwen $t_{0}$ and $\Delta t c$ for the Grops, Thken sepurately and Togethe:

\begin{tabular}{|c|c|c|c|}
\hline & $\begin{array}{l}\text { More Lndincus } \\
\text { Grete }\end{array}$ & Lese Ludinous & $\begin{array}{l}\text { Both Groups } \\
\text { nlken rogutber }\end{array}$ \\
\hline Drber & 19 & $1 ?$ & 36 \\
\hline $\bar{H}_{0} \pm o\left(H_{0}\right)$ & $20.17 \pm 0.69$ & $-18.74+0.56$ & $-19.51+0.94$ \\
\hline $\begin{array}{l}\text { Intercept of } \\
\text { Regression line }\end{array}$ & $-18.08 \pm 0.35$ & $-16.74 \pm 0.58$ & $-18.55 \pm 0.68$ \\
\hline $\begin{array}{l}\text { slope of } \\
\text { Redresstion line }\end{array}$ & $-0.122 \pm 0.020$ & $-0.101 \pm 0.029$ & $-0.0512 \pm 0.0359$ \\
\hline $\begin{array}{l}\text { Correlation } \\
\text { coerifietent }\end{array}$ & 0.832 & 0.670 & 0.237 \\
\hline $\begin{array}{l}\text { t-Statistic for } \\
\text { Testing } p\end{array}$ & 6.188 & 3.499 & 2.425 \\
\hline $\begin{array}{l}\text { Significance } \\
\text { Level of Test }\end{array}$ & $\begin{array}{c}\text { greater than } \\
99.95 \%\end{array}$ & $99.7 \%$ & $92 \%$ \\
\hline$\overline{\Delta t}_{c} \pm \sigma\left(\Delta t_{c}\right)$ & $17.10 \pm 4.70$ & $19.87 \pm 3.71$ & $18.4 .1 \pm 4.33$ \\
\hline
\end{tabular}




$$
t_{1}=\frac{\bar{x}_{1}-\bar{x}_{2}}{S} \sqrt{\frac{z_{1} n_{2}}{n_{1}+\bar{n}_{2}}}
$$

where $n_{1}, n_{2}$ are the two saple sixes, and

$$
s=\sqrt{\frac{\sqrt{\left(n_{1}-1\right) \sigma_{1}^{2}+\left(n_{2}-1\right) \sigma_{2}^{2}}}{n_{1}+n_{2}-2}},
$$

with $\sigma_{1}, a_{2}$ beins the two standard deriations. This statistic bas a t-distribution with $\left(n_{1}+n_{2}-2\right)$ degrees of rreedca. For the present

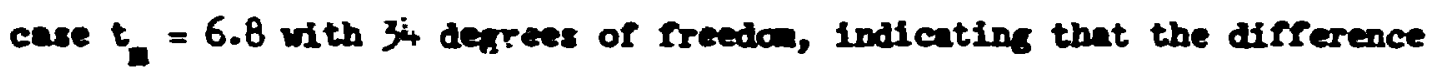
between the two weans is significant at a level exceeding $99.95 \%$.

The slopes of the regression lines differ by only 0.021 , a value conparable to the standard deviation of the slope in each case. The correlation coefficients are highly significant in both cases.

The difference between the average values of $\Delta t_{c}$ for the two groups is 2.77 days. This difference might not seem significant when compared to the two standard deviations, 4.70 days and \pm 3.71 days, but the two samples together contain 36 points, and the t-statistic for comparing the two means has the value $t_{m}=1.95$. This value, with 34 degrees of freedon, gives a significance level of $\% \%$ for the afference.

The minimum widh in the $\Delta t_{c}$ direction of the gap between the two groups is about, 5.5 days. Chepter 8 contained a thorough serisitivity analysis of the effects on the setimated $\Delta t_{c}$ values of the various techniques used in the reduction and fitting of the light curves. That study did not reveal any systematic differences large enough to account for the gap between the two groups. Furthermore, there does 
.. it sten to be any exclusive essociatson of either grcip with ons of the particular refuction techniques. If the gep does not represent a real effect, it must be the result of $a i=s$ in the sstimates or $\$$ rather then in it $c^{\circ}$

The estimates of $\mathrm{K}_{\mathrm{U}}$ were celculated by the forwula

$$
M_{0}=m_{c}-\mathbf{x}-H_{i}
$$

where the 'm - $\mathrm{M}$ : is the sstimated distance .10tulus of the galaxy and $m_{0}$ is the corrected poik apparent magnitude. A plct of $M_{0}$ as a nuction of (m - M) did rot show any hint of a separation into two luminosity groups or of any correlat: $c$ en $c_{0}$ with $(m-H)$. Th:s it the fap wer-? causel by systematic biases in estimating the $M_{0}$, they nost like $y$ would have arisen in the estimation ardior the correction of the $\mathrm{m}_{0}{ }^{\circ}$ The four different methods for estimating the original uncorrected Mo were tested for systematic differences. The details of these tests are given in Appendix . They reverled no strongly exclusive association of either luminosity group with any of the methods. rurthermore, the average values of th: $M_{0}$ for the various methods are very similar. Similar tests of the methods of correcting for absorption within the parent galaxies : described in Appendix () also showred no significantly exclusive association of either group with any of the inethods of calculating or estimating the correction. The average total correction for the more luminous group was $A_{M L}=l_{1}^{m}=0 . \hat{c} l$ and for the less luminous group was $A_{L d}=T^{m} \pm .7 \%$. The difference, $m_{17}$, is not statistically significant. 
Anotier approach to the effect of the corrections on the thal
$M_{0}-H_{c}$ relation is tc consider the relation that arises when the $u_{c}$
are calculated using the unsorrected estimates of $m_{c}$. This plet is shown in Figure 11-c. The ascissa is the same es before, but the ordirate is based upon the original mo without correstion for absorption either in our own galax or in the parent galaxy. The two groups are plotted with the same symbols as before. Tro parallel lines have been arawn which essentially separate the points into two groups. There is oniy one point in the gap betwaen tho two lines. The gap itself has a verticel separation of arout 20.5 . All of the points above the gap belong to the more luminous group, and all of the members of the less luminous group lie below the gap together with four members of the more luminous group. Thus, aside from the five members of the more inminous group that lie in or below the gap, the uncorrected magnitudes thenselyes display a tendency to separate into two groups when plotted against it ${ }_{c}$. The separation into two groups in Figure $11-2$ would probably have gone unnoticed had there not been some a priori means of identifying the points. It appiars, then, that it is the correction for absorption that sharpens the separation intc tre groups. There are two possible opposing interpretations: (2) The separation into two groups is essentially already presert in the uncorrected plot and the correction for absorption within the parent galaxy brings it to a sharper focus by reducing the randon scatter due to the absorption error, or (?) the apparent separation into two Broups in the uncorrected plot is a random fluctuation that is unfortunately emphasized by the small difference, m. 17 , in the average total corraction for the two groups. The latter 


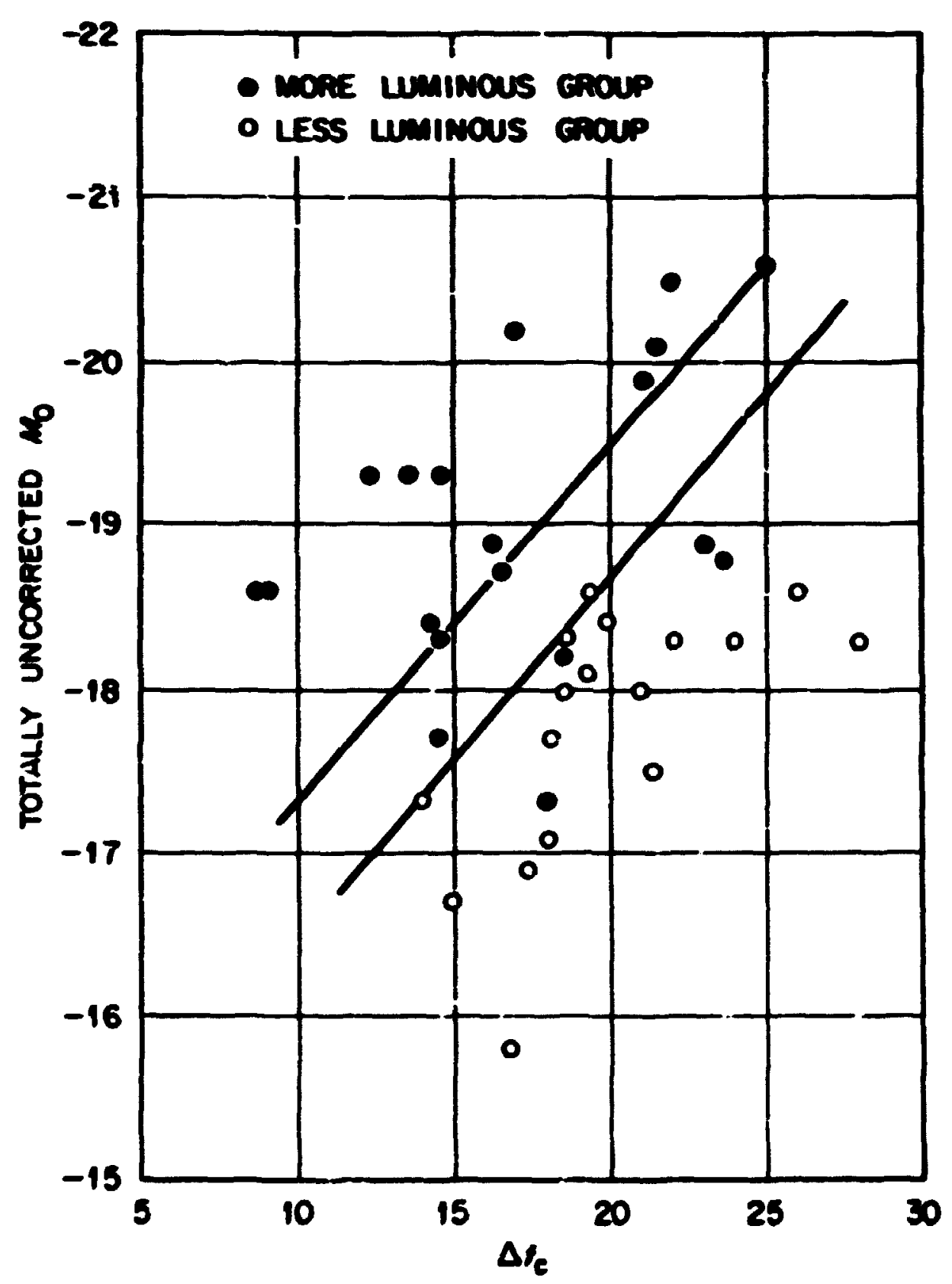

Figire i1-2. Absclute Maghit dide as a Punction of $\Delta t_{c}$ for Totally Uncorrected monitudes, wth the Tro Groups Distinguished. 
viru presuppores a chein of coinctdences tinat taken altogether is highly sprobable. Even if the gap in Pigure 11 a were essumed to be randos Puctuation, the correction process wes designed to satisn consistenthy other criterl, which have nothing to do with the location of the points in that plot. is a further check $\approx$ this line of reasoning, Figure 11-1 vas plotted agein using only superzovee vith nessured color excesses or which occurred in elifptical galexies. Although there way be coasidereble errors in the sbsorption corrections for this subsople, the corrections ars surely all corsfstent. The two bands were well defined in the plot with exactly half of the 2 points in esch band. The reaining 1 - supernove were corrected by either $1^{\text {mat }}$; or by ${ }^{m}$; depending on wht::er or not they oceurred in a spiral arm. Since there was no strencly exclueive esrocietion of either of these corrections with one of the luminosity groups acr. Appendix $i j$, it is almost certain that the addition of those supernoves to the sample ifd nct introduce ary systeantic effects either.

It would appear then that the two bands and the correlation within each bend were not caused by naws or inconsistencies in applying th? estimation and correction precestures. Th-re remains the possibility that some of the uscumptions in the procedures are incorrect. These assuaptions concem the meaning of the Hubble relation, the velue of the Hubble constant, and the varixus techniques used in constructing luainosity runctions for galexies. Even the meeruresents of the integrated epparent magnitudes of the parent calexies were based on the issumption that the Hubble relation is truly linear, this assumption being needed in order to give the proper aperture adjustments so that the intecrated angitudes are consistent for gelexies at various distances. The 
linearity of the relation for gal uxies withis 30 Mpc has recently been shellenged by de Vaucouleurs $(1+6)$, who cound two different parabolic laws for the North and South Gelectic Heais pheres. Nlthough a plot of the positions of the supernovee (cr. Appendix 6) shous that both luninosity groups coexist in the ssee parts of the sky so that the separation into luminosity groups was not caused by sone anisotropy in the Hubble law, the correlation within each group may have been affected by locel nonlinear perturbations in the 1w. The question of linearity of the Hubble law will be discussed in wore detail in Chapters 13 and 14.

Por the present, with regard to the question of the reality of the two luminosity groups, the arguents that have been given here indicate that the consistent reduction of tne best avoilable data using the currently accepted, conventional assumptions support the conclusion that the groups represent two distinct populations of Type I supernovae. If one accepts the admittedly speculative hypothesis that nomal distributions have some fundmental significance in nature, then some further support for this conclusion is given by the distribution of the asgnitudes for the two groups taken together and separately. These distributions are shown in Pigure 11-3. In each case the distribution was plotted as a histog an of 5 boxes with the width of the boxes being approximately equal to the standard deviation of the megitudes in that group. The distribution for the two groups taken together appears to be distinctly sikewed frow a normel distribution, but the two distributions taken separately appear to be reasonable approximations to norwal distribuitions, considering the sunll sizes of the two smples. The distribution for the groups taknn tcgether tecumes more sensible, then, wen it is regarded as the sum of two ncimal distributions. 

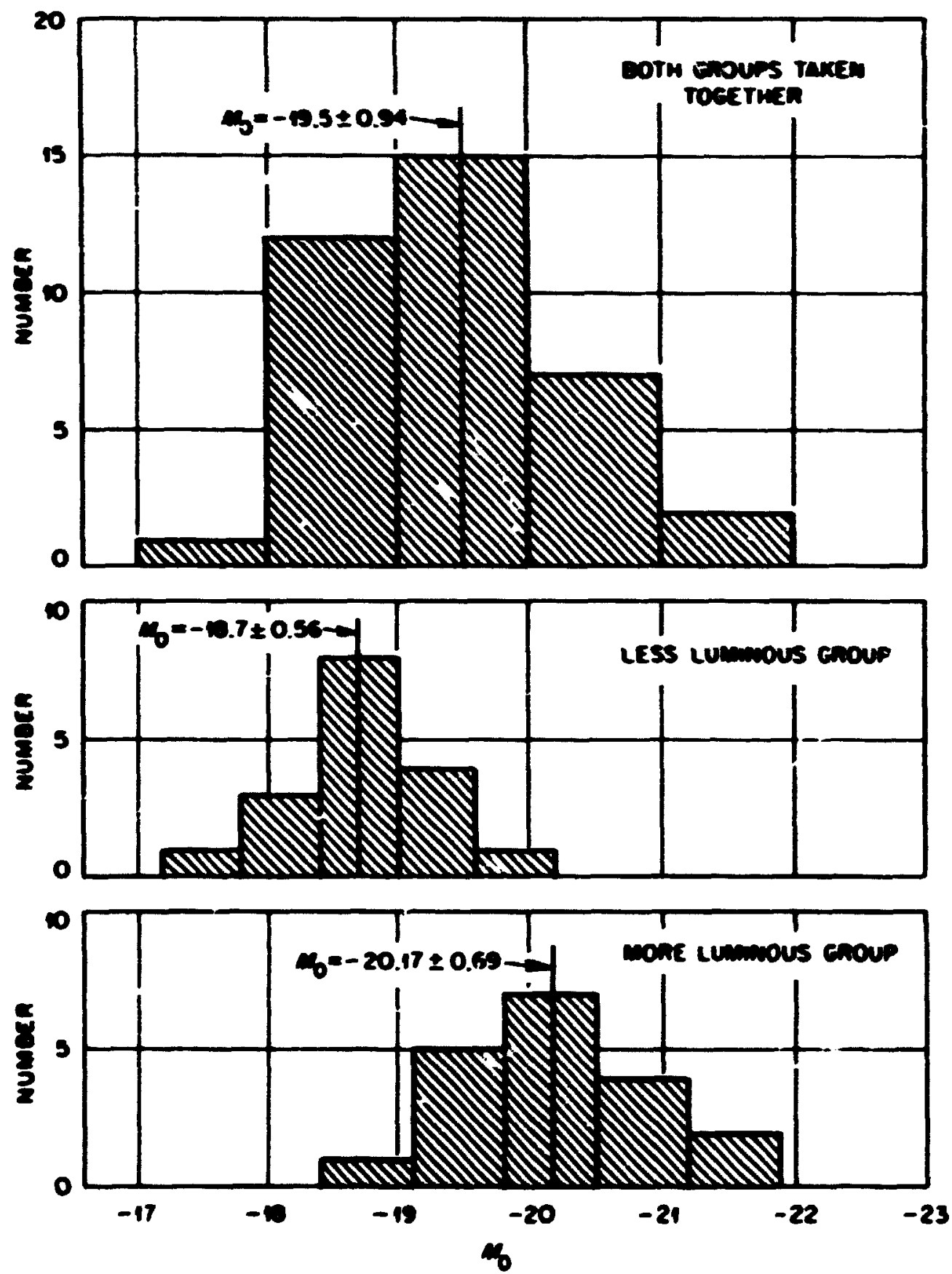

Pigire 11-3. The Distribition of $M_{0}$ for the Two row ps Faken Toge ther and Separately. 


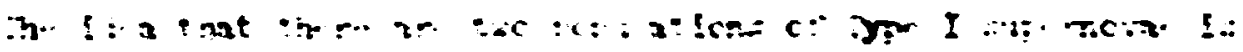

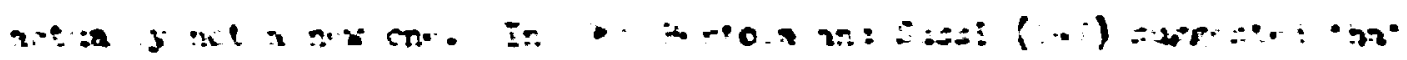

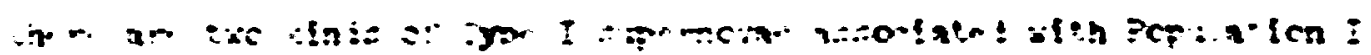

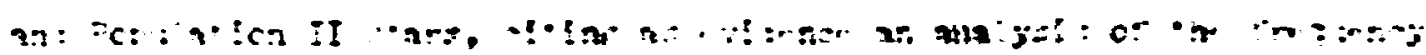

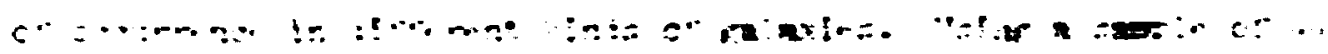

supernove, they obtalned a distribution bering two trequency andere

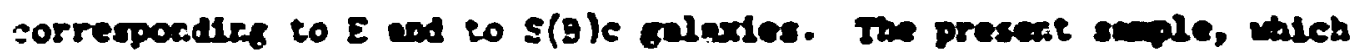

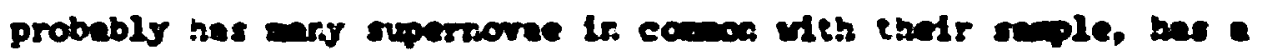
sidlar disiribution. A scoparisor of the ewo distributulans topeher

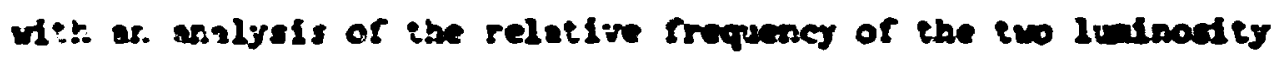

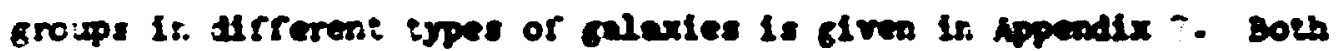
1.mirosity eroups ocest ir. ellifeleal galextes. thus rulles our an Ideatifl catior. of the tro eroups vith ropulation I $2 \mathrm{n}$ II stars. There appears to be a slicht erend for the more linlnous crow to ocm wore orten 15. Galaxtes of later ispes (So, Sc, Irr) and for the less

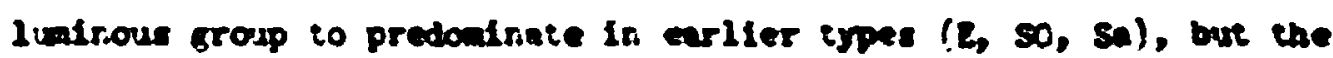

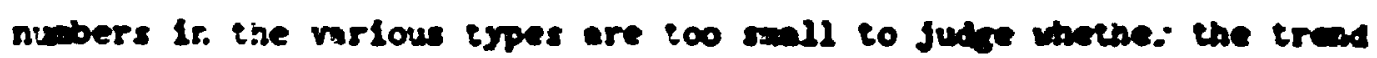
Is statistically stgaricant. Such a tendancy would explate the

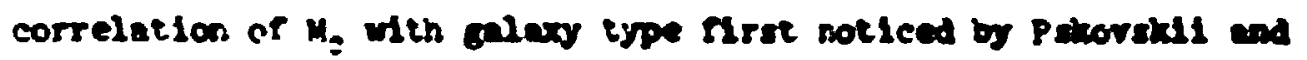
conrirmed by this seudo ist. Apposedse 6 ).

Another more recent attempt to Identify iwo distinct subtyes of ispe I supernovae ass been teseribsd by Barbon, Clatt, and bostno (10) who collected the light curves of 26 apernove and atvidat the Irico iwo groups wich they character! zed as belng "fast" or "slow" supernove. Theit eriterion for deternining mether at an spernove wa fast or slow we somentat unffectlve, "rast" supernove belac 


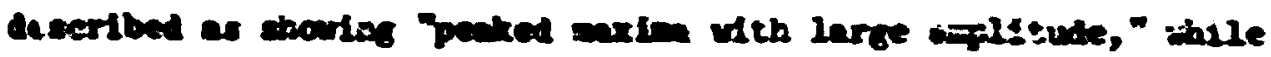

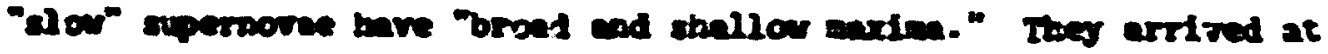
chls Astipetion bs intercomparine lighe curves, superilposting the ad shiftias then wore both the tine and the bricticress exes is order

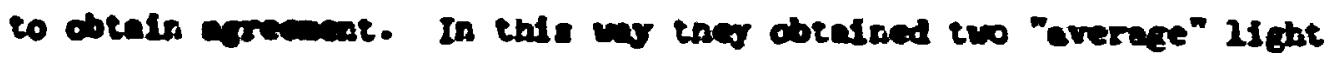
curvea mith chare.tertize the two groups. In otber words, they tried

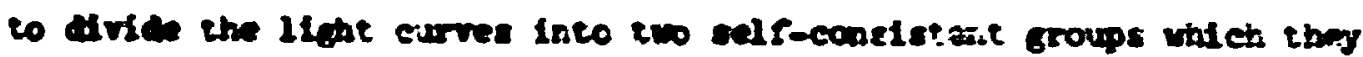
charmetertzed as telis fant or slow cecording to the parmeters of the Inal orerage lifote eurves for the groups. Suct a procedure is pecesantly abjective if there is as uderlying continum of forns of the 2lat curves. Thls arbitrariness we probably composided by thetr copariwa procedure, allorine uncosstrafned shifs: of the llgit surves

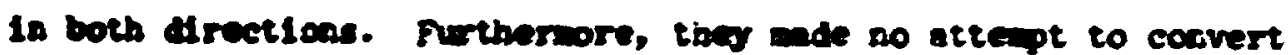

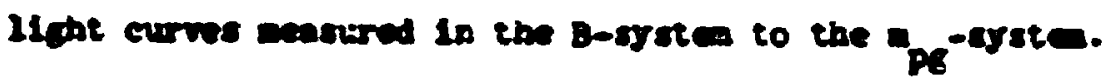
There 1s little correlation betwen the groups of Barbon et al. and those of the present stut. Toble 11-3 compres the grow nembersteff: for the 21 npermone common to the tws studies.

Thib 11-3

comparicen of the "Past" and "Mlow" Groups of sarbon, Clatt, and Bosino with the Ludinulty Groups of the Preacht study

\begin{tabular}{|c|c|c|}
\hline 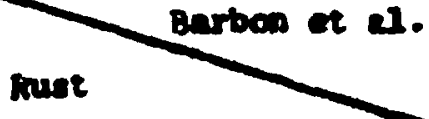 & $\begin{array}{l}\text { "Pant" } \\
\text { sugernorae }\end{array}$ & $\begin{array}{l}\text { "Slou" } \\
\text { supasnovice }\end{array}$ \\
\hline $\begin{array}{l}\text { More Lundnow } \\
\text { Grous }\end{array}$ & 3 & 8 \\
\hline $\begin{array}{l}\text { Lese tunt nowe } \\
\text { Group }\end{array}$ & 5 & 5 \\
\hline
\end{tabular}


Figure 11 - shoure the distrioution in $\Delta t_{c}$ of the 21 coman superrove with the "fast" and "slor" groups indicatea by dirferent shadings. The large overlap between the two groups indicaces that the fistinction: between fast and slow is sanewhat arbitrary. The average $\Delta t_{c}$ for the two groups ce significantly different, however. The average malues, $\overline{\Delta t}_{c}=17.14$ days for the "fast" grop and $\overline{\Delta t}_{c}=19.95$ days for the "slou" group, are very close to the avereges for the two Iu inosity groups in the present stud: $\overline{\Delta t}_{c}=17.10$ davs for the core luninous group and $\overline{\Delta t}_{c}=19.87$ fo: the less lundious grcup. The difference ontimen these latter two averaged is significant at the 9 ; 1 ievel. Barbon et al. also found little difference in the average $x_{0}$ for their Eroups, with $\overline{H_{0}}=-1 \epsilon . E 2$ and $\bar{F}_{0}=-1 \hat{C} \cdot 50$ for the "fast" and "slow" Broups, respectively. The present study gives different avereges for the two Iunirosity groups, $\bar{M}_{0}=-20.1 \%$ and $\bar{M}_{0}=-1 E .7^{4}$. Cn the bosis o: these considerations, the lunirostty groups of this study are mach more likely to represent a true d.visic.s of Type I supernove Into distirct groups than are the "fast" and "slow" categorles of Barbon et al.

If the luainosity Groups are real, and if the correlations of $M_{0}$ with $\Delta t_{c}$ are also real, then these relations will have far-reaching consequences both in the study of supernovae theory and in extraGalactic astronoay. Any successful superrova model will have to explain the existence of two groups having similar correlations between the peak luninosity and the rate of fall of the light curve, but different totel energy releases. That the peak luninosity and the rate of fall In lininosity afort be correlated is not at ail surprising. A sintinr 


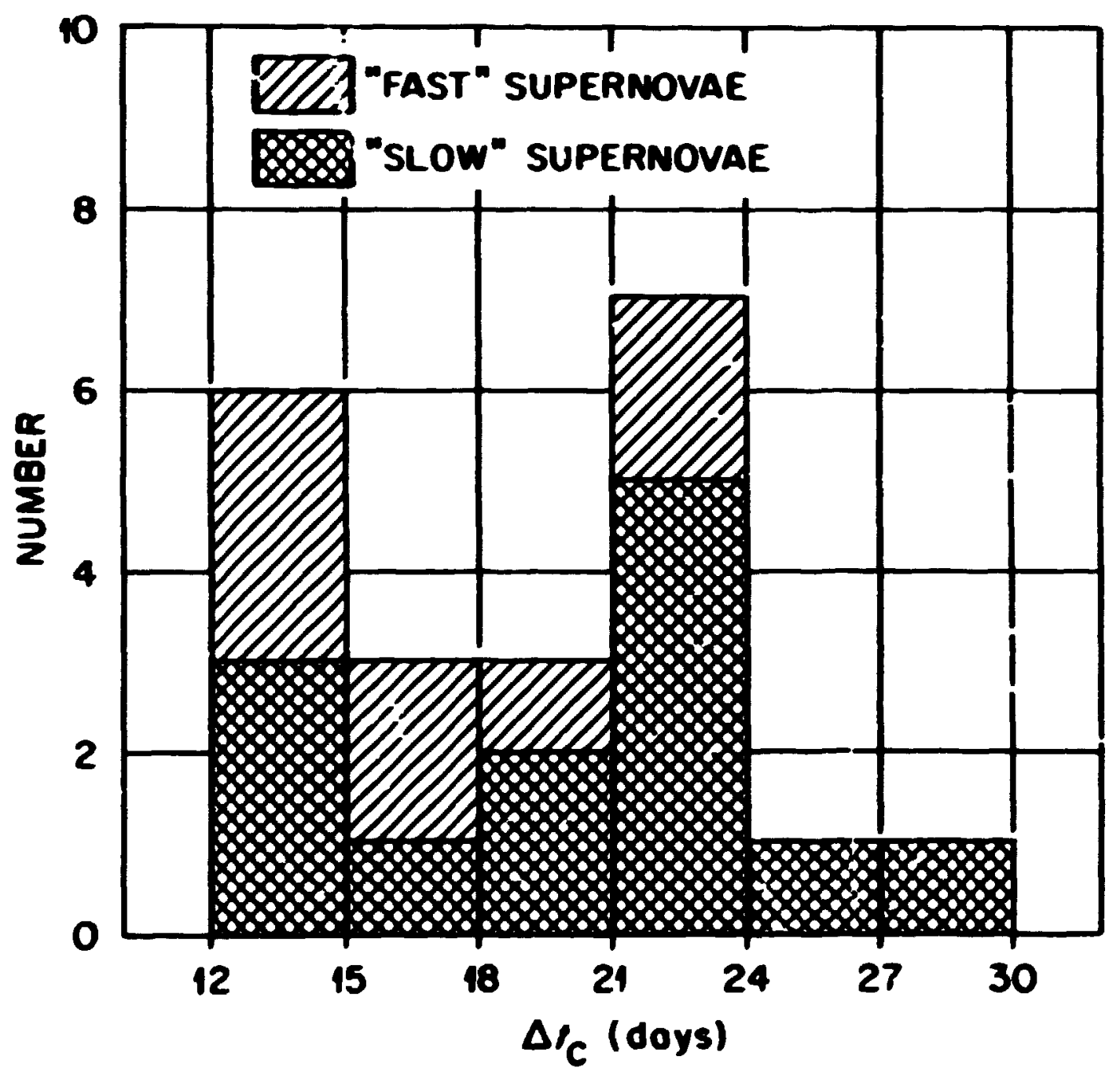

Pigire 11-4. Distrib:tion of the $\Delta:$ for the 21 Supernove Coman to the Present St:udy and tine St idy of Barbon et al. 
33

correlation has been found for ordinary corre (151), but in that case the relation between the peak luninosity ard the logarith of the rate of fall is ifnear ard in the opposite serse, with the pore lininous nove haring the sore rapidly falling ligit curres.

The relations between $x_{b}$ and at within ibe two bands are very auch analagois to the period-lindrosity relations for opheid variable stars. Thus they should provide a relativily preefse distance indicatcr that ri: $n$ be ert anded to wach larger distances thar the currestly avallable wethos of sinilar preclsion. This new wethod of distance estination sill be discussed in Chapter 14. 
CHAPTER 12

\section{FURTER REFTIDITSS NDD FUTRE PRCSPDETS}

FOR THE $d t_{c}^{-" I}$ TLST

In chapter 11 it ver show that the present saple of supernoree ves drans from two different parent populations. The two subseples have different average absolute magitiodes $\overrightarrow{\mathbf{m}}_{0}$ asi differant average values $\overline{\Delta t}{ }_{c}{ }^{-}$the comparison paraneter. The pors: for discrininatice anong cosmalogical sodels of the $\Delta t_{c}-V_{T}$ test has undoubtedly beer. lessered by this axire of populations. As nore data becone avilable, the test will surely be pestorned or tine two groups separately. For the present there are not enough ifght curves arailable in: either group to give a weaningful statistical test. Because of this fact, a more refined test was simaled by translatine the less luninous group so that it was evisistedt with the nore ludinous grcup. This was possible because of the basic sinflarity of the $M_{0}-\Delta t$ relations for ihe two groups. The slope of the $\mu_{0}-\Delta t c$ regression line for the sore lunioous group was 0.122 \pm 0.020 , and the average point wa $\left.\sqrt{\Delta t_{c}}=17.09, \bar{k}_{c}=20.17\right)$. The corr"sponding values for the less luninous group were slope $=0.101 \pm$ 0.229 and o:erage point $=\left(\overline{\Delta t_{c}} \cdot 19.87, \bar{y}_{0}=-18.74\right)$. Besause the slopes vere so sinilar, it secied natural to rectify the less luninous growp by subtractirg 2.78 dars from all of the $\Delta t_{c}$ and subtracting $1.43 \mathrm{frcm}$ all of the $M_{0}$. The result of taif adjustent is shown in Figure 12-1. The basic sifilarity of the two distributions is emphatically deanstrated by the overlap of the two groups. The line is the least-squares regresston line

$$
\mu_{0} \therefore-(18.2 \pm 0.28)-(0.115 \pm 0.016) \Delta t_{c}
$$




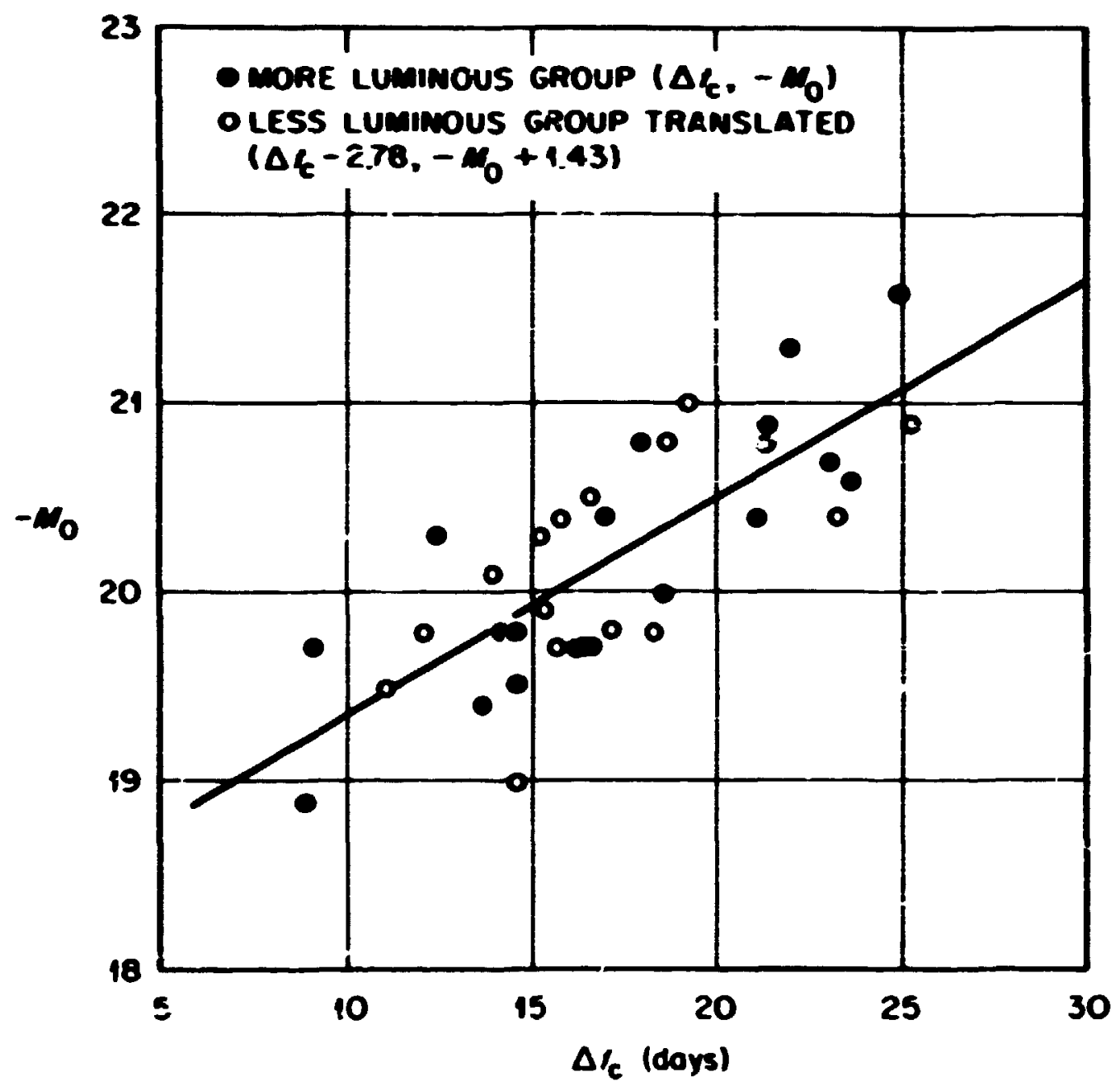

Pigire 12-1. Reconciled $M_{0}-\Delta t$ Relation. 
T:0 reconciled argitudes were regressed on $v_{r}$ in order to chech for ludinosity selection effects, and none vere found. The reconciled sarple vas therefore judb id to be appropriate for the $\Delta t_{c}-Y_{T}$ test. The $v_{r}$ - st relation for the reconeiled sample is show in Figure 12-2. The results are conpletely sinilar to those obtained with the unreconciled saple with Segal's chronogeometry giving much better agreenent with the regiession line than the other predictions. The values of the t-statistics for ccaparing the various predictions to the reet zesion line are not very me aningful since this is only a simulation. The exercise suboasts that the agreenent between Segal's theory and the observed data in the original sample did not arise as an accidental sife sffect of using a sample from wixed parent populations. It furtber gives an idea of the kind of scatter to be expected in a refined snple from either of the populations alone. This in turn gives information on the kind of data that should be obtairied in the future in order to strength: $n$ the test.

The t-statistic for comparing a fitted slope b to a predicted slope B is

$$
t_{B}=\frac{b-B}{\sigma(b)}=\frac{b-B}{\sigma\left[\left(\Delta t_{c}\right)_{0}\right]} \sqrt{2\left(v_{r_{1}}-\vec{v}_{r}\right)^{2}}
$$

where $o\left[\left(\Delta t_{c}\right)_{0}\right]$ is the standard deviation of the intrinsic variation in $\Delta t_{c}$. For the reconciled arple, the 21 supernovae with $v_{I}<2000 \mathrm{~km} / \mathrm{sec}$ have $\sigma\left[\left(\Delta t_{c}\right)_{0}\right]=3.80$ days. This is probably a good estimate of the value that would be obtained from a refined sanple drawn from only one of the parent populations. It wlll be ueed as such in the followng to calculate the number of point:, needid to give $95 \%$ 


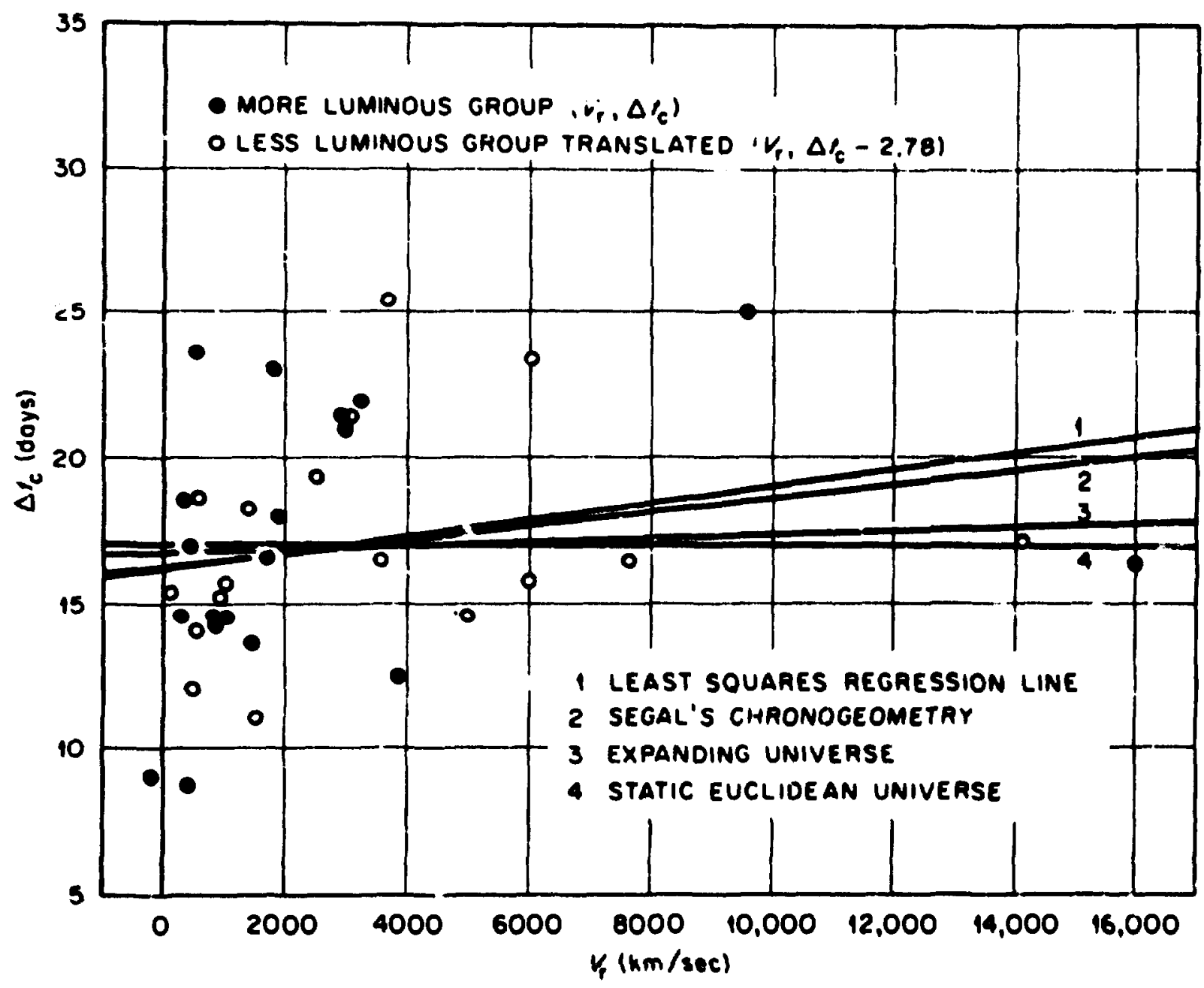

F1gure 12-2. Recona1led $\Delta t_{c}-V_{r}$ Relation. 
tests between various pairs of theoretical preaictions. Bquation (12-1) cun be used for these calculations icy assuning that a given pair predicts slopes $b$ and $B$. Once the values of $b, B$, and $\sigma\left[\left(\Delta t_{c}\right)_{0}\right]$ are fixed, the value the i-statistic, and bence the significance level of the test, can be varied oaly by choosing the sample to vary the quantity

$$
s=\sqrt{\Sigma\left(V_{r_{i}}-\bar{v}_{\mathbf{r}}\right)^{2}} .
$$

For the present semple, the range is $-299<v_{\mathbf{r}}<16,100 \mathrm{~mm} / \mathrm{sec}$, but the saple points are heavily concentrated corard the lower end; a fact cenlected by the average and standard deviaticn, $\overline{\mathbf{v}}_{\mathbf{r}}=3009: 3732 \mathrm{~km} / \mathrm{sec}$. The value or $\mathrm{S}$ is $\mathrm{S}=2.21 \times 10^{4}$. This value car be used, together with the slopes of the various predictions, in Eq. (12-1) to calculate the porer of a true refined sample with the sae $V_{r}$ distribution to discriminate betwcen the various pairs of predictions.

The present reconciled sample had $\left(\overline{\Delta t_{c}}\right)_{0}=15.56 \pm 3.80$ deys. Using this average value to calculate the predicted slopes gives:

(1) slope $=\frac{\left(\overline{\Delta t_{c}}\right)_{0}}{c}=5.2 \times 10^{-5}$, for the classical expansion hypothesis, and

(2) slope $=4 \frac{\Delta_{c} t_{0}}{c}=2.8 \times 10^{-4}$, for sezal's chronogeonetry. The prediction of the stotic Buclidean mypothesis is, of course, slope $=0$. The t-statistias and corresponding significance levej.s for testing the various predictions against one another are given in Table 12-1. None of the tests is close to the traditional $95^{\text {t }}$ value though the test of Segal's chronogecmetry against the static Euclidean hypothesis is close to the less strict $90 \%$ level which is accepted as adequate by sone statisticians. 
TRBIE 12-1

The Porer of a Suple with the Sne $\mathrm{V}_{\mathbf{r}}$-Distribution as the Present one to Discribinate Between Alternative Theoretical Predictions

\begin{tabular}{|c|c|c|}
\hline Test & t-statistic & Sicnificance Ievel \\
\hline $\begin{array}{l}\text { Bpension Hypothesis egainst } \\
\text { Static buclidean Hypothesis }\end{array}$ & .303 & 626 \\
\hline $\begin{array}{l}\text { Segal's Chronogeonetry againat } \\
\text { Static Bucildean Hyphthesis }\end{array}$ & 1.21 & $88 \%$ \\
\hline $\begin{array}{l}\text { Segul's Chronogecanetry against } \\
\text { Expansion Hrpothesis }\end{array}$ & 0.905 & $81 \%$ \\
\hline
\end{tabular}

All of the regressions of $\Delta t_{c}$ on $v_{r}$ that have been performed in both this chapter and the previous ones gave fitted slopes greater than any of the predictzd values. These laiger siopes may have resulted from the deficiency of data at larger values of $V_{r}$, but the possibility is open that the true slope actually is graater. If the grastar iope persists as more data become available, then the test 3 of that greater slope against the static Duclidean and the classical expansion hypothesiss become more powerful than any of those show in Table 12-1. More precisely, if the future data should continie to give slopes approximately the same as the results so far obtained (slope $\cong 3.0 \times 10^{-4} \mathrm{days} / \mathrm{km} / \mathrm{sec}$, say), then not toc many more data points w11 be required to refect the static Euclidean and the classical expansion hypotheses at the $95 \%$ level since the tests are almost powerful enough to reject them already with the present semple. The test for discriminating again t Segal's 
chronogeonesy would be quite difricult, however, unless the new data five a slope very wach oreater thas that given by the present saple. All of this is only speculation, and for the present it is interesting to assune that one of the three predictions is correct and to deterwine how eny wore dats wil be required to discrininate between then.

There are three was to increase the quantity $S$ [Eq. (12-2)] and hence the significance level of a given test: (1) increase the unber cf points in the semple, (2) increase the dispersion of the sample points within a given range, and (3) increase the range of sapie points. In the present sople the value of $S$ would have been greater if so any of the points had not been clustered at the larer end of the range. If they had been scattered uniformily over the range, $S$ would have been $2.77 \times 10^{4}$ rather than $2.21 \times 10^{4}$. Consider the general case of a secuple containing $\mathrm{A}$ points spread uniformly over a range $C \leq V_{r} \leq V_{m}$. The mean value of sucin a seaple is $\bar{V}_{r}=V_{m} / 2$. The value of $S$ is given by

$$
s \equiv s_{u}=\int_{0}^{V_{m}}\left(v-\frac{v_{m}}{2}\right)^{2} \frac{I}{V_{m}} d V,
$$

which gives

$$
s_{u}=v_{m} \sqrt{\frac{R}{12}}
$$

A uniform semple would give the most pleasing $V_{r}-\Delta t_{c}$ plot, but a mo:e effective yomple for increasing $s$ would be one with half of the sample points clustered at each end of the fitting range. The mean of such an end-points semple would st11l be $\bar{v}_{r}=v_{m} / 2$, but the value of 5 would be 


$$
s \equiv s_{\mathrm{EP}}=\sqrt{\Sigma\left(\frac{V_{\mathrm{E}}}{2}\right)^{2}}=\frac{v_{\mathrm{E}}}{2} \sqrt{\mathrm{I}} .
$$

Combining Eqs. $(12-3)$ and $(12-4)$ it is easy to see that if $n_{a}$ is the nuber of points with a unform distribution in $v_{\mathbf{r}}$ required to give certain value $s=S_{u}$, then the muber $K_{\text {EP }}$ of points in an snd-points distribution which would be required to give the sane value of $S$ is $\operatorname{onjy} \bar{L}_{\mathrm{EP}}=\mathbf{n}_{\mathbf{u}} / 3$

The range of the present reconclied saple extends to $16,000 \mathrm{~m} / \mathrm{sec}$. At this distance, the deviation betweed the beat fitting atraliht line for the expansion hopothesis and the slope $=0$ straight line for the static Buclidean uppothesis is only 0.83 days. The atandard deviation of the intrinsic variation of $\Delta t_{c}$ is 3.30 days, a valus 4.6 times greater thas the deviation between the two pr-distions. To exiend the range of the observations to the point whe the deviation between the predictions is equal to the intrinsic standard deviation would require observing out to $v_{r}=73,000 \mathrm{mal} / \mathrm{sec}$. Assuming $H=100 \mathrm{ma} / \mathrm{sec} / \mathrm{mpe}$ gives

$$
m-M=5 \log \left(\frac{V_{T}}{H}\right)-5=39.5
$$

as the distance nodulus corresponding to this velocity. The everege absolute angitudes of the tim luainosity groups are $\bar{n}_{0}=-20.2$ and $\bar{M}_{0}=-18.7$. The corresponding peak apparent asonitudes when the auparnovae are at distance $n-M=39.5$ 2re $0_{0}=19.1$ and $n_{0}=20.6$. In orider to obtain light curves for the kind of analysis done in this thests, it is necessary to mearure down to about $n_{0}+2.5$. Mllowing 1.0 mas, 
for extinction in our on ar: the parent colexies neens that the cbserving equipent wust be sble to reach the linits $=22.6$ for the nore 1 ininous croup and $\mathrm{a}=24.1$ for the less luninous croup. These linits are if thin the capabilities of present equipnent at large observatories.

The $V_{\mathbf{r}}=73,000 \mathrm{k} / \mathrm{sec}$ range is quite arbitrary and the tests can all be ade with saples taken out to saller liniting $\nabla_{r}$, but the andler the range, the ereater is the suple size required to ante on of the given tests definitive. Table $12-2$ gives, far various liniting $V_{\text {f }}$ the sople requirenents for discrininating at the $95 \%$ level of 518 nificance between pairs of the three alternative mpotheses that hare been d'scussed. The mubers of smple points required are given in esch case for both a unfform saple and an end-points sample. These mubers fwteh should be regarded as approudnate indicators rather then rigid speciflcations) were obtained by using Eqs. (12-1, 12-2, 12-3, 12-4) and a table of the t-diatribution (172). The nubers enclosed in parentheses should be regarded as "formal" estinates since, In sctual prectice, sore saple points mould probsbly be requirid to elfinate the possibility of spurious and saple effects.

The mbers in the teble indicate that if fepal's inronogeconetry Is truly the correct bypothesis, then the present suple cen be ensily extended to wirts this even without goins to a falnter linting $V_{Y}$.

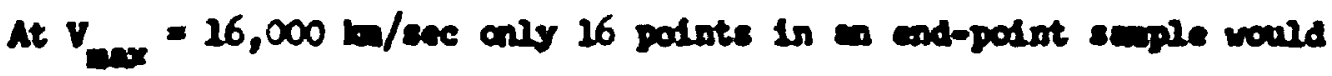
be required to elfinete the otetic Ducllween bpotbesis. Or these, the 8 points at lowe and of the renge are alrecty in the saple (in

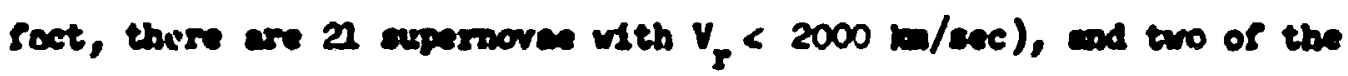
polnts at the hider and (819550 and eng62e) have already been 
TABIS 12-2

Saple Requireneats for Diserininating at the $95 \%$ Level of significace Between Pairs of Alternate Predictions for the

$$
\text { slope of the } \mathbf{V}_{\mathbf{r}}-\Delta_{c} \text { Belation }
$$

\begin{tabular}{|c|c|c|c|c|c|c|}
\hline \multicolumn{3}{|c|}{ Upper Lirit of Semple Rage, $v_{\max }=$} & 16,000 & 25,000 & 36,500 & $73, \infty 00$ \\
\hline $\begin{array}{l}\text { Inting } \\
\text { Magoitude } \\
\text { Required }\end{array}$ & \multicolumn{2}{|c|}{$\begin{array}{l}\text { Wore Intinous Group } \\
\text { Less Ininous Group }\end{array}$} & $\begin{array}{l}19.3 \\
20.8\end{array}$ & $\begin{array}{l}20.3 \\
21.8\end{array}$ & $\begin{array}{l}22.1 \\
22.6\end{array}$ & $\begin{array}{l}22.6 \\
24.1\end{array}$ \\
\hline \multirow{3}{*}{$\begin{array}{l}\text { Wuber or } \\
\text { Sople } \\
\text { Points } \\
\text { Required } \\
\text { to } \\
\text { Reliably } \\
\text { Discrininate } \\
\text { Between } \\
\text { Mlernative } \\
\text { Hpotheses }\end{array}$} & $\begin{array}{l}\text { Classical } \\
\text { Bqpansion } \\
\text { Hpothesis } \\
\text { V. } \\
\text { Stetic } \\
\text { Buclidem } \\
\text { Hpothesis }\end{array}$ & $\begin{array}{l}\text { Bud-points } \\
\text { sepple }\end{array}$ & 680 & 280 & 130 & 35 \\
\hline & $\begin{array}{c}\text { Segal's } \\
\text { Chrono- } \\
\text { geanetry } \\
\text { rs. } \\
\text { Static } \\
\text { Duclidean } \\
\text { Hupothesis }\end{array}$ & $\begin{array}{l}\text { End-points } \\
\text { semple }\end{array}$ & 45 & 20 & (4) & (2) \\
\hline & $\begin{array}{c}\text { Segel's } \\
\text { Chrono- } \\
\text { geanetry } \\
\text { ve. } \\
\text { Clessical } \\
\text { Bopansion } \\
\text { Horthesis }\end{array}$ & $\begin{array}{l}\text { Bend-points } \\
\text { 8aple }\end{array}$ & 75 & 35 & (6) & (3) \\
\hline
\end{tabular}


obtatned. So the sinple needs only six nare light curves for supernove with $V_{Y} \sim 16,000 \mathrm{~m} / \mathrm{sec}$. The 1 initing nagitudes required to chtain these light curves are attainable with telescores of internediate size equipped with inage tube devices. According to Drake Dening (173) the 40 inch telescope at Prairie Observatory could be used to obtain the basic light curve neasuresents, althosgh, if photographic techniques vere used, the photoelectric ccaparsion sequence would have to be obtained using a larger instrunent. The r.dfinl velocities would also heve to be wearured with larger instruneat.

The test of Segal's chronogenetry against the classical expansion hypothesis would be slightly more difficult since 11 nore light curves at the upper end of the range would be required. Both of the teats ne:scre much sasier with instruments which can measure light curves out to $V_{r}=25,000 \mathrm{iz} ! \mathrm{sec}$, and in fact there is little need to fo further out to verify or disprove Segal's theory.

If the additional data produces fitted slopes nore in areenen. with the classical expansion hypothesis or the static Buclidem mpotheals, It is ebsolutely essential to sonple ast to a greater linting $v_{r}$ in order to discriminate between the two. Even with $v_{\max }=36,500 \mathrm{w} / \mathrm{sec}$, an end-points sonle would require 22 light curves at the upper end of the range. But at $v_{\max }=73,000 \mathrm{~km} / \mathrm{sec}$ coly $6 \mathrm{new}$ lifht curves would be required and this is well within the copabilities of a large talescope. Fot all of the observations would require the large telescope since the peak apparent megnitude is 2.5 brighter then the faintest that mat be reached. Ans effort of this sort would require the close cl:peration of the various aystenatic arpermovu search projects. 
The Pelomar superisove seareh in 1972 (174) discovered 13 nev supernovee, seven of wich vere in enonymous galaxies vith pt $\$ 16.5$. these seven wuld certainly have been good candidates for the tests invalving Segel's chronogeonetry. It would probebly be necessary to search to even fainter monitudes than is currentily done in order to reach the $v_{\max }$ needed for testing the expansion hopothesis against the ricatif Buclidean hypothesis, although two of the supernove that were discovered occurred in galardes of menitude 18.5.

The peak mitudes obtained in the process of pathering further light curves for the $v_{r}-\Delta t c$ relation will also be vary userul for deteraining the correct slope of the $\log \left(v_{r}\right)-m_{0}$ relation. This relation, which is one of the arst iportant ubservational relations in cosmolosy, is the subject if the next chapter. 


\section{CANTER 13}

THE RDD SEIFT-MMGTTUDE REATTOR NID A MU WEHOD FUR DETBEMTING THE HUBLLE CONSTAN

The wost fundanental relation in codern cosmology has been the velocity-distance formule. Although sose of the earlier workers believed that the relation is a quadratic [cf. Lundwark (169)], it has been almost universally accepted since the time of Hubble's fundamentel work in the 1930 's that the relation is locally linear, having the form

$$
\mathbf{V}_{\mathbf{r}}=\mathrm{Hr}
$$

where $f$ is the Hubble constant. A great deal of work in the last decade has jeen devoted to secking the departures from lirearity wich are predicted for very large redahifts by the conventional Friedmann expansion sodels, but alnost no one has questioned the iinearity for red shifts 2 less than about 0.3 .

Estimates of $\mathrm{H}$ are usually obtained fros a regression of $\log \left(\mathrm{V}_{\mathbf{P}}\right)$ on apparent magnitude $m$ for large saples of galaxdes which hopefully have sindar intrinsic luanosities. Following the development of T. A. Agekyan (168), let $\mathrm{m}$ be the weasured apparent magnitude, $\Delta$ be any correction needed in that measured value, $M$ be the absolute sagnltude and $r$ be the distance to the galosy weasured in parsecs. Then,

$$
(n-\Delta)-M=5 \log \mathrm{r}-5
$$

Accoriting to the Hubble law, this expression can be writteo

$$
(B-\Delta)=5108\left(V_{Y}\right)-5 \cdot 5100(H)+M .
$$


Takirs a shole collection of galexies uith average absalute monitude $\overline{\mathbf{H}}$, cose cas wite for each of then

$$
\left(\boldsymbol{n}_{1}-\Delta_{1}\right)=5 \log \left(v_{r_{1}}\right)+(\bar{M}-5-5 \log H)+\left(\mu_{1}-\bar{M}\right)
$$

These expressions are the ecuntions of condition for a regression of $\left(m_{1}-\Delta m_{1}\right)$ on $\log \left(v_{1}\right)$. The result of such a regression is a straight line

$$
(\mathbf{A}-\Delta)=\lambda \cdot \log \left(\mathbf{V}_{\mathbf{r}}\right)+B
$$

where $A$ and $B$ are the paraneters of the rit. The $M_{1}-\bar{M}$ behave like randon errors, averaging out to zero, so one can estiante $H$ from the expression

$$
B=\bar{M}-5-5 \log H,
$$

if one knows the value of $\bar{M}$.

Note that the value of A should turn out t.o be very nearly 5 or else the linear Hubble lew is not valid. It has been a com pon practice in recent years to assume the valldity of the Hubble law and hold the constant A fixed while performing the fit. When peiaxy magnitudes are used for $\left(w_{1}-\Delta m_{1}\right)$, such a procedure does not provide an independent test of the linear Hubble law no matter how well the resulting line fits the date and no matter how and the scatter in the data. This point has been demonstrated by Segal (165), whe pointed out that the measurement of the galaxy menitudes $m_{1}$ requires an assumption of a cosmological molel in order to determine the eper:ure corrections needed to dre consistent wagnitudes of galaxies at varying distances.

The basic problem is that galexies have finite angular extent and dffuse boundaries. If the eane eperture 1s used for both distant and nearby galaxies, the magnitudes of the distant galaxies will be 
systemetically too bright because a creater portion of the luninous dists will be included. The form of the correction uniortunately depends on the deonetry of space-time, i.e., on the essumption of a comoloficel model. Segel showed that this problen canot be avoided erea by confining the semple by observing only very nerrow central portions of galaxies with eall red shifts (say $z<0.1$ ). In partinular, he proved that such low 2 observations cennot distinguish between the Hubble Law, $z \propto r$, and the quadratic, "Lundmark Law," $z \propto r^{2}$, [cf. (169) ]. ife did this by showing that if either one of the two laws is actwally ralid and if the observations are ade twice, orce with the aperture correction: designed for the hubble law and once for the Lundmark iaw, then both sets of observations will agree with the corresponding law no matter which of the two is actually valld. Thus, galexy observations cannot provide a model-independent test of the linearity of the relation. The recent monumental wort of Sandage and his collaborators provea that if the observations and reductions are made in accordance with the Friedarn nodels, then the results are consistent with a linear Hubble law. It is still possible that if the sase observations are made and reduced in accordance with some other theory, the result wight be a completely different velocity-distance relation, e.g., a quadratic law.

Segal's Covariant Chronogeonetry predicts a quadratic law for anall redinifts. In (165) he showed that if the observations are ande in a frequency range where the spectral function of the source is of the form $f(v) \propto 1 / v^{\alpha}$, where $\alpha$ is called the opectral index, then apparent agnitude $a$ is related to red shift $z$ by

$$
=2.5 \log z-2.5(2-\alpha) \log (1+2)+C
$$


where C is a constant wose value depends on the absolute aritude M. For all reasonable values of $\alpha$ and for anll values of $z$, this expression reduces to

$$
\text { a } \equiv 2.5108 z+\text { const., } \quad 0<z<0.1
$$

To see that this expressioc ectunily corresponds to a quadratic velocity distance law, it is easiest to substitute such a law into Eq. (13-2). Taking $z=k^{2} r^{2}$ where $k^{2}$ is a constant gives $r=z / k$ wich, when substitited into Eq. (13-2) gives

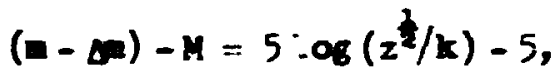

or

$$
m=5 \log \left(z^{\frac{1}{2}}\right)+[M+\Delta-5 \log k-5]
$$

which can be written

$$
m=2.5 \log z+\text { const } .
$$

To support his clain that the local red shift-distance relation is quadratic, Segal cites a 1962 paper by G. S. Hawkins (170) and a 1972 paper by de Vaucouleurs (146). Hawkins used the galaxies in the classic stuty of Humason, Mayall and Sandage (118) to obtain the regression line

$$
=2.26 \log 2+4.63 \text {, }
$$

wich gives a red shift-distance law of the form $2 \propto r^{2.22}$, and interpreted the result as evidence for a quairatic law though he aditted that, "A linear law can only be obtained from these data by postulating that systematic blases, such as selection effects, exist; and by relghting the observations in some way so as to rewove the sunpected bias." De Vaucouleurs calculated the distance modull of a sample of nearby groups of galexies ( $r<30$ Mp) using several methods and extensive 
2u:

cross-checking to obtain consistency. Then he plotted red shifts against his final distance estimates he obtwined an apparent quadratic variation. which he attributed to a local anistrcpy in the expansion lav (presumably caused by the "local supercluster").

Both of the above studies involved galaxies and hence are subjest to the sare critici:as that segal invoked in his arguments abcut the aperture effects. One way to avold some of these difficulties is to lise supernove for the analysis. Supernovae are point sources, so there is no need to worry about aperture corrections. Thus they are ideal candidates for determining the redshift-magnitude relaticn.

The redshift-magnitude relation for supernoyae has previously been studied by Kowal (49), who :o: joxed the usua: practice c: holding the slope A fixed at the value 5.0. The 29 supernovee in this study with measured red shifts were subjected to the $m-\log \left(v_{r}\right)$ analysis, but both parameters were allowed to vary in the regression. The peak apparent magnitudes $m_{0}$ of the supernovae were used as the $m_{1}$. The symbolic velocities vere corrected for the solar motion relative to the local group. In wrking with galaxies the corrections $\Delta m_{i}$ consist of: (1) the aperture effect, (2) the light travel time effect, (3) the K-correction for the effect of the red shift on the spe:terum of the ka:axy, and $\left(i_{+}\right)$the correction for absorption [cf. Humanson, Mayall, and Sandage (118)]. The first correction is unnecessary for supernove. The second correction is only required for $z \geq 1.0$ and hence does not apply for this study. A great deal of work hes been tone on deriving K-corrections for galaxies, but the spectrum of a supernova is very different from the spectrum of a galaxy; so the same $K$-corrections cannot be used. The red shs its in the present sample are all relatively $\operatorname{small}\left(V_{r} \div 16,000 \mathrm{~km} / \mathrm{sec}\right)$, and 
the pass band for the $\mathrm{m}_{\mathrm{pg}}$ system is fairly broad; so the K-corrections vere assumed to be negligible. In the case of gataxies, the fourth correction is accouplished easily using the cosecant lar, but for supernove the absorp+ion correction is more difficult because of absorption within the parent galaxies. This problem was discussed ir detafl in Chapter 9. The corrections that were calculated there were used to correct the magnitudes for the $m_{0}-\log \left(v_{r}\right)$ anaiysis.

Taking the corrected peak apparent magnitudes for $m_{1}+\Delta m_{1}$ in Equation $(13-3)$ gives

$$
\mathrm{m}_{\mathbf{o}_{\mathbf{i}}}=5 \log \left(\mathrm{V}_{\mathbf{r}_{\mathbf{i}}}\right)+(\overline{\mathbf{M}}-5-5 \log \mathrm{H})+\left(\mathbf{M}_{\mathbf{i}}-\overline{\mathbf{M}}\right)
$$

and equation $(13-4)$ becomes

$$
m_{0}=A \log \left(V_{r}\right)+B
$$

The results of the regression of $m_{0}$ on $\log \left(v_{r}\right)$ are shom in Figure 13-1, wich follows the standard convention of plotting $\log \left(V_{r}\right)$ un the $y$-axis and $m_{0}$ on the $x$-axis even though $\log \left(v_{r}\right)$ was taken as the indepesient variable in the regression. The two different luminosity groups [cf. Chapter 11] are indicated by different symbols. The supernova SMG61h was also included in the regression even though its light curve was not complete enough to give an accurate value of $\Delta t_{c}$ so that it could be classified into one of the luminosity groups. The two supernovae SM9390 and SIM963i (indicated by arrows) were juiged to bo outliers and were not included in the regression. Their gymbolic recession velocities were 345 and $140 \mathrm{~km} / \mathrm{sec}$, values of the same order of magnitude as the random peculiar velocities of galaxies; so it is not surp: ising that they deriate 80 far from the fitted curve. 


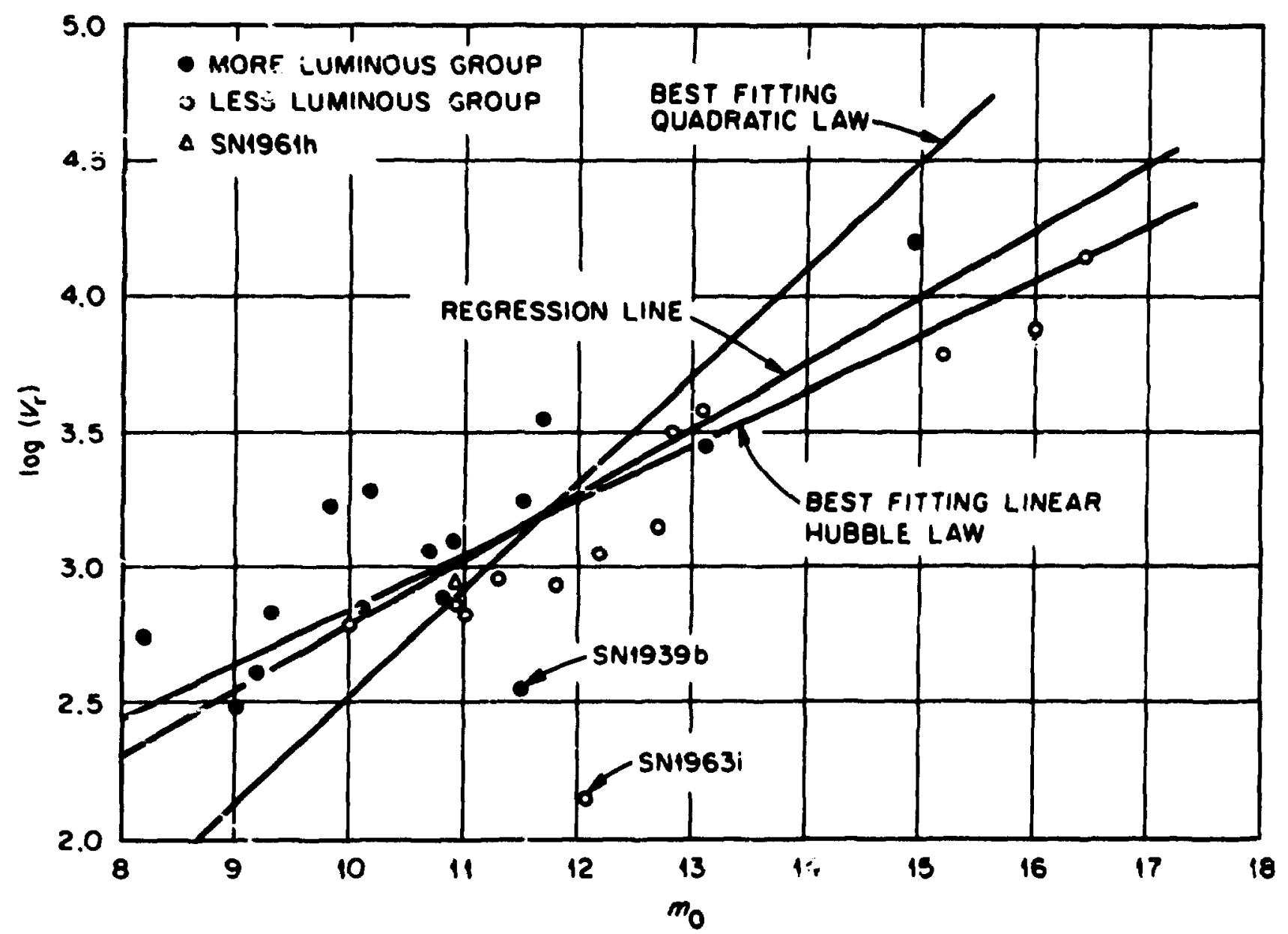

Figure 13-1. The Regression of $m_{0}$ on $\log \left(v_{r}\right)$ Compared with the Best-Fitting LInear and Quadratic Laws. 
204

Figure 13-1 also shows the best fitting lines for a linear Hubble 1av (slope =5.0) and a quadratic Lundart lar (slope =2.5). The quadratic lay clearly fails to fit the data, but the agreenent between the best ifting linear law and the regression is not as good statistically as the figure might lead one to believe, although it is obvious that the linear 15ir gives a much better fit to the data than does the quadratic one. The slope of the regression is $A=4.16 \pm 0.44$, a resurt which is comparable to some of the slopes obtained for galades by Huason, Mavall and sendage (118). [They obtained, for exampie, a slope $A=4.33 \pm 0.38$ using a sample of $90 \mathrm{SC}$ and SBC galades with $\left.2.2<\log \left(\mathrm{V}_{\mathbf{r}}\right)<4.0.\right]$ The correlation coefficient for the regression is 0.884 , and the t-statistic for testing it is 9.476 , giving significance at a leicl greater than 99.95\%. The t-statistic for testing the slope against slope $=5.0$ is $t=-1.904$, a value which rejects the linear Huible law at about the $96.4 \%$ level. More precisely, if the Hubble law were truly valid, ther the probability of obtaining a slope as low as $A=4.164$ by chance is only 3.6\%. The quadratic law is rejected at an even greater level of significance (greater than $99.95 \%$ ).

At this point one should not attach too much sfgnificance to the apparent statistical refestion of the linear Hubble law. The sample does not extend to very large red shifts. For the amaller values of $\log \left(v_{r}\right)$, the random motions of the galaxies are comparable to the systematic distance effects. Because of the weightine introduced by taking logarithms of the $v_{r}$, variations introduced by these random motions will be unsymetrical and predominant].y dommard in the diagram. Another possible source error is the absorption corrections. These should not 
cause systenatic effects in a large sample, but in a small sample ther: is a slight probability that 2 or 3 very inaccurate corrections in the sane direction at one end of the diagram could introduce a bias.

Another intrinsic source of error in the present sample is the large scatter in absolute magnitudes wich vas introduced by combining the tur distinct luinosity groups. It is apparent from Figure 13-1 that the two groups do have distinct luminosit; characteristics, for even though they are not widely separated in the diagran, the points for the nore luminous group lie systematically to the left of those for the less luminous group. In Chapter 11 the means and standard deviations for the absoiute magnitudes of the two groups vere estimated as $\bar{M}_{0}=-20.17 \pm 0.69$ and $\overline{\mathbf{M}}_{0}=-18.74 \pm 0.56$. Taken separately, eact. group gives a much better approximation to the ideal single-luminosity class. The $\log \left(v_{r}\right)-m_{0}$ analysis was therefore periormed on the two groups separately even though the number of sample points in each case was small. The results of all of the regressions are compared in Table 13-1. The correlation coefficient, was improved in both cases by taking the groups separately, but both of them rejected the linear Hubble model at a high level of statistical significanse. The analysis was also performed on the reconciled sample discussed in the preceding chapter. The results, which are 11lustrated in Flgure 13-2, are very similar to those given in Table 13-1, with both the linear and quadratic laws being rejected at high levels of significance.

Although the present data seem to indicate that the true velocitydistance relation lies somewhere between a linear and a quadratic law, 1t is important to keep in mind that the present sample is dominated 
Tosle 13-1

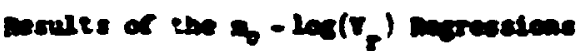

\begin{tabular}{|c|c|c|c|}
\hline & The In Croperes & nom & Leas \\
\hline $\mathbf{a}$ & 27 & 14 & 12 \\
\hline 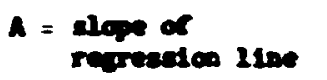 & $2.164 \neq 0.459$ & $3.548=0.499$ & $-.265=0.365$ \\
\hline$B=$ interegpt & $-1.606=1.423$ & $-0.428+1.560$ & $-1.293=1.213$ \\
\hline $\begin{aligned} &- \text { corrulation } \\
& \text { coenriclese }\end{aligned}$ & $0.6 e 4$ & 0.900 & 0.965 \\
\hline $\begin{array}{l}\text { t-rentiatie for } \\
\text { textios }\end{array}$ & $9.4-5$ & $? .147$ & $1 \mathrm{u.68?}$ \\
\hline donifienoce level & prenter thes 99.954 & crester the 99.95s & 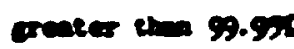 \\
\hline 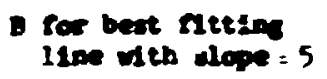 & $1.2: 0$ & 4.802 & -3.680 \\
\hline 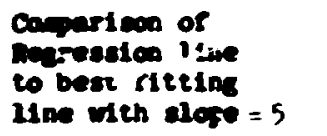 & $\begin{array}{l}\text { p. - i.9ol } \\
\text { resected ot the } \\
\text { ge.bl level }\end{array}$ & $\begin{array}{l}t=2.868 \\
\text { rejected at the } \\
99.21 \mathrm{cml}\end{array}$ & $\begin{array}{l}\text { e } 2.015 \\
\text { redeeted at the } \\
\text { 96.31 level }\end{array}$ \\
\hline
\end{tabular}




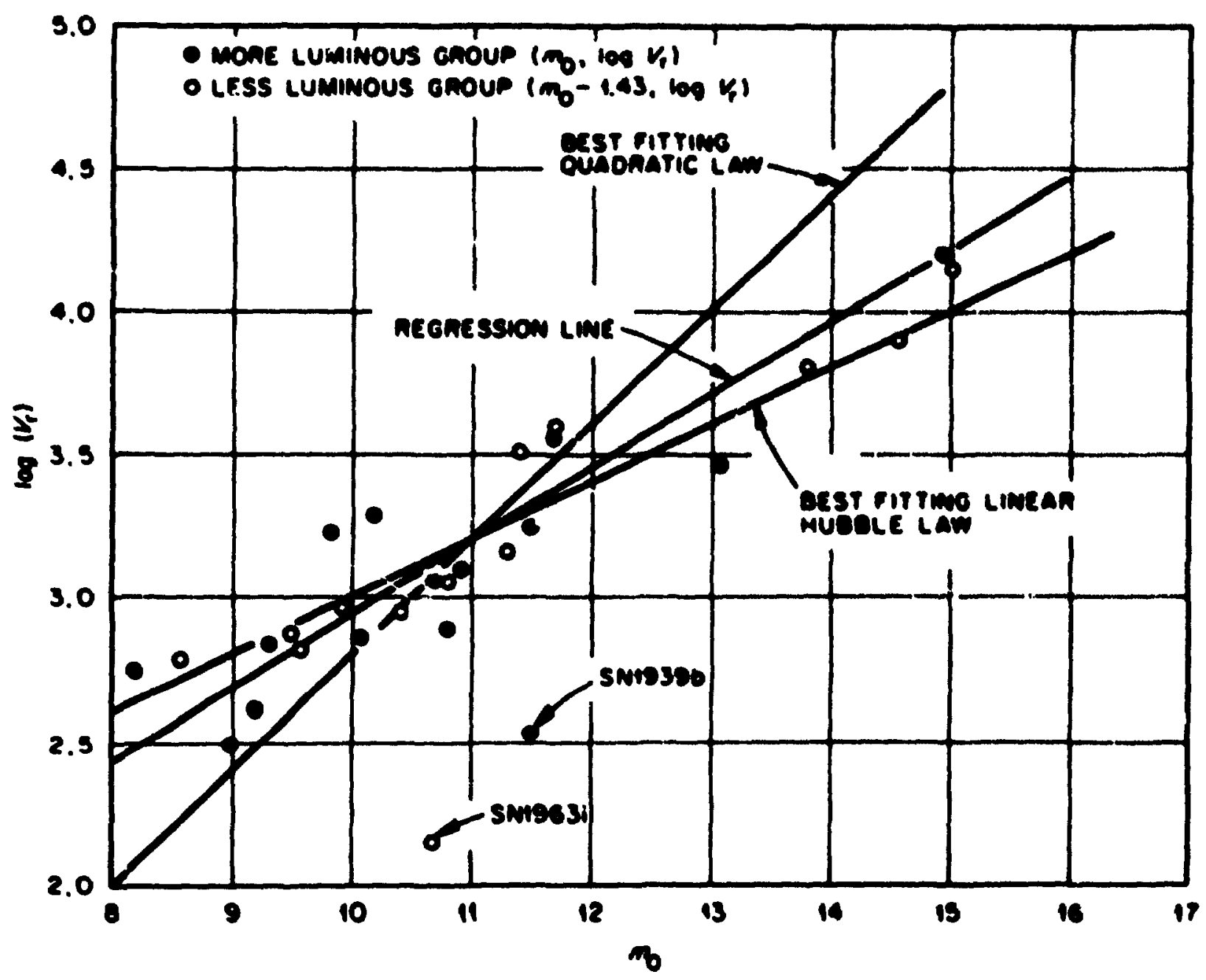

Maure 13-2. The $n_{0}-\log \left(v_{r}\right)$ Relation ror the Reconelled sample. 
by relatively low red shifts. Wot only are the relative errors due to randon wotions greater for lour red-shist galadies, but thes are also given an inordinately high statistical welght by the use in the regression of the logarithede scale for the $\mathrm{V}_{\mathbf{r}}$. The relative weights of the points are quile differest when plotted in Iinear scales as $v_{r}[\mathrm{lo} /$ sec] against $r[$ p c ]. Furthernore, there 1s a grouding body of evidence [cf. de Vaucouleurs (146), Rubin et al. (171)] that tine velocity-iistance reiation for local gelaxies deviates significantly from that of the general field. Therefore, unt1l more data are available on supernove with sybalic velocities Greater than, say, $2500 \mathrm{kd} / \mathrm{sec}$, it would be prenature to rule out the linear Hubble law. By the same reasoning, it is also too soor. to reject the quadratic Lundwark lar.

If the Ifrear Hubble law is accepted, then the best fitting line of alope $=5$ for each of the luminosity groups, combined with the $M_{0}-\Delta t c$ regreasion line for that group, provides a new wethod for estinating the Hubble constant. Figure 13-3 shows the two best-fitting lines with slope -5 . Together they appear to give an adequate fit of the two luninosity groups. The idea for estimating the Hubble constant is based on Equation (23-5), $[B=\bar{M}-5-5 \log H]$, although that equation cannot Itself be used because the average absolute magnitude $\bar{M}=\bar{M}_{0}$ is not knom. In Chapter 9 eatinates were given for the values of $\mu_{0}$ for the supernovae, but these eatjiates were calculated on the assumption that $H=100 \mathrm{rod} / \mathrm{sec} /$ mpe. The basic eqintion for estinating $M_{0}$ had the frorm

$$
\begin{aligned}
M_{0} & =m_{0}+5 \log \left(\frac{V_{I}}{H}\right)+\text { constant } \\
& =m_{0}+5 \log \left(V_{r}\right)-5 \log (H)+\text { constant. }
\end{aligned}
$$




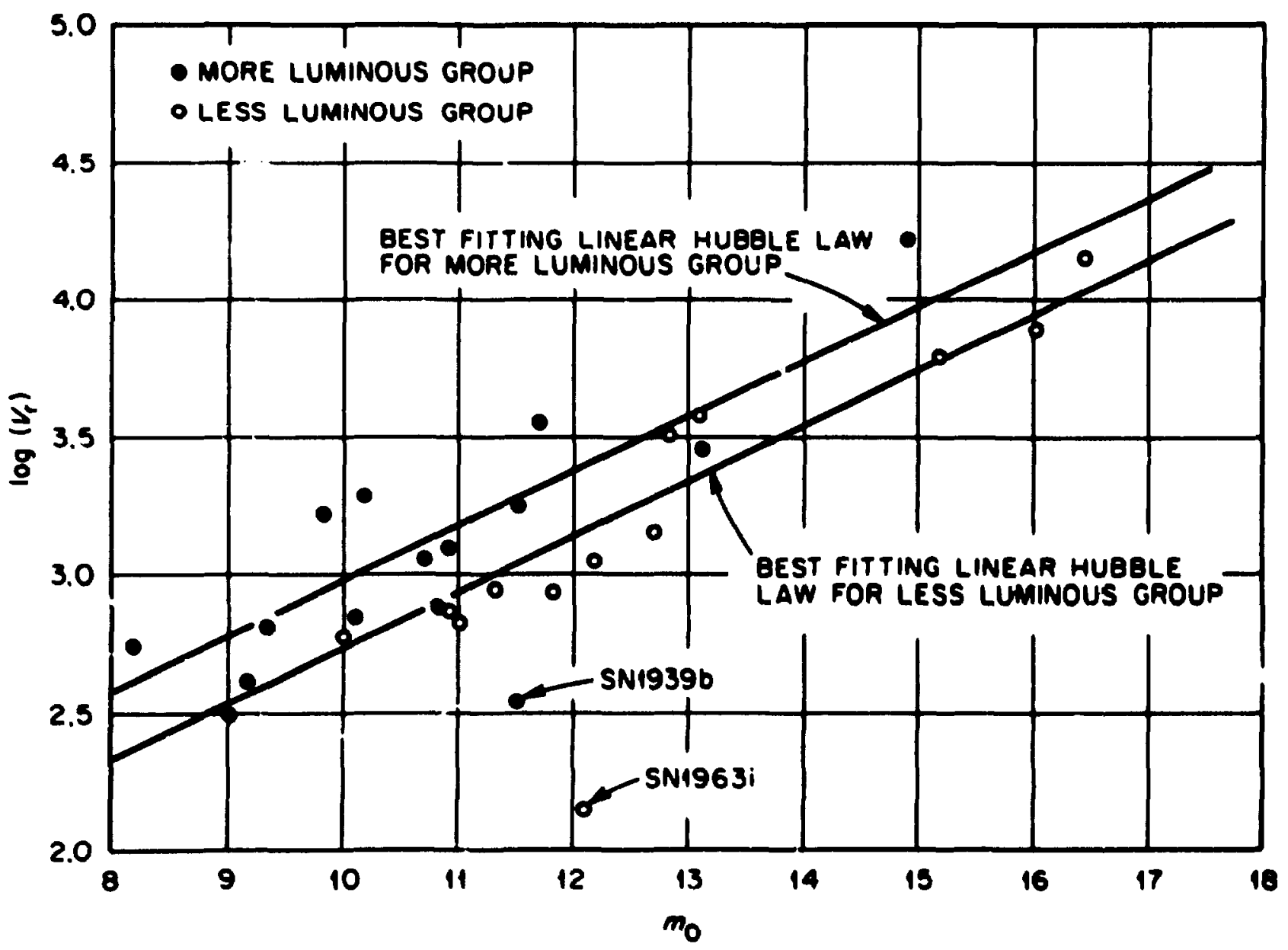

Figure 13-3. The Best-Fltting Linear Hubble Iaw for Bach of the Two Luminosity Groups. 
of course, some of the extinated vere obtained from gelax luninosity functions, but cost of these vere calibrated using an asound value oi i. and the formule for changing the calibration value is derfied from the above equation. The ifportant thing to notice about the equation is that any error in $h$ produces the sane constant error in 11 or the $M_{0}$ This means that the $M_{0}-\Delta t c$ relations defined by the two luninosity Broupa ny have zero-point errors, but the alspes are not affected by veriations in H. Thus, the slope, a, of the regression line

$$
M_{0}=a \Delta t_{c}+b
$$

for each group is correctly deterined by the data, but the intercept b is in error by an awount which depends on the error in $\mathrm{H}$. The regresition line (13-9) passes through the average point $\left(\overline{\Delta t}, \overline{M_{0}}\right)$ so Eq. (13-9) can be substituted Into Bq. (13-5); solving for $\log (H)$ and at the same time converting $H$ to units of $\mathrm{k} / \mathrm{sec} / \mathrm{hpc}$ gives

$$
\log H=1 / 5\left(\overline{\Delta t_{c}}+b-5-B\right)+6
$$

The only unknown on the right hend side of the equation is $\underline{\mathrm{b}}$.

In order to use Eq. (13-10) It is necessary to find a sethod for estiwating b independently of $\mathrm{H}$. In particular, wat is needed are supernovae occurrences in galadies wose distance noduli can be determined by sone Independent weans. If $(m-M)_{k}$ is such a know distance nodulus, then substitution of Bq. (13-9) into the identity $m_{0}-M_{0}=(m-M)_{k}$ leads to

$$
b=m_{0}-a \Delta t_{c}-(m-M)_{k}
$$

The values of $m_{0}$ and $\Delta t_{c}$ are measured and the value of $a$ is correctly deterwined by the regression of the estimated $\mu_{0}$ on $\Delta t_{c}$ colputing a 
corrected $\underline{b}$ by this method mounts to chifting the regresulon line (13-9) ve-tically along the $H_{0}$ ads untll the abcolute nonitude that it predicts for the supernove in question is consistent with the manitude calculated by $M_{0}=m_{0}-(n-M)_{k}$. The flan eatimate of $\underline{b}$ should be the mean of severne Independent deterdnations of this ind in order to average out the intrinale ludnosty veriation of the apperwome. The nethod jurt outlined for deterinirg $\mathrm{h}$ renoves one of the principal difficulties ascocisted with the classical nethods which use the relation $V_{Y}=\mathrm{Hr}$. That afficulty is to select galades that are near enough so that their distances can be determned by prifary distance Indicators like cepheid variables, povae, brightent stars, angular dimenstions of HII regions, etc., and at the sane time are far enough ary so that their peculiar velocities $(\sim 300 \mathrm{kd} / \mathrm{sec})$ do not sienificantly contendnate thedr red shifts. This is a problem that woy not eren be anenable to a solution by averaging if the red shift-magitude relation for local galadies actually does deviate signifleantly from that of nore distant ones. The present method avolds the problen because it does not require the anbolic velocities. It anst be used with care, however, because $0:$ the apparent coorelation between $\Delta t_{c}$ and $v_{r^{*}}$ the velue of the slops, $t$, in Egs. $(13-10,11)$ and the value of $\overline{\Delta t}$ in $(13-10)$ should be deternined by seples of relatively locel supernoves. The latter paranster 1s wore sensitive to this effect then the forwer. If there is no luainosity salection in the seple, then a subsaple contalning the wore distant supernovae will hase the sane proportions of lon at and high 4 ; values as a cubsample of nearer ones. The $\Delta t_{c}$ velue for all of the supernove in the former subseple wll, howrer, be syateatically 
higher than the ones in the latter because of the $\Delta t_{c}-v_{Y}$ correlation. The net effect on the $H_{0}-\Delta t c$ diagran will be to increase the scatter Ir: the direction of the $\Delta t_{c}-a x i s$. As long as the saple does not extend to such large distance that the $H_{0}-\Delta t c$ correlation is destroyed, the inclision of aderately wore distant supernove should not produce a bias in the estimate of the slope a. The estimate of $\overline{\Delta t}$, by contrast, should be deteringed by a saple of locel supernovae, since otherulse the value of it predicted by Eq. $(13-10)$ would depend on how far out the sample extended.

An Ideal sample for determining the parameter b, using Eq. (13-11), would be a collection of supernovae in Local Group galaxies since these galaxies are the ones with the best determined distances. Unforturately, there was only one such supernova in the present study (Sm885a), and the absorption correction for its peak magnitude was rather crude. The sample that was ured consisted of the six supernovae which occurred in the virgo cluster. The value adopted for the distance modulus of the cluster was "the best current estinate" given recently by de Vaucouleurs (146) wo obtained it by averaging several independent determinations [cf. (146) and the references given there]. That value is $(\mathrm{m}-\mathrm{M})_{k}=30.65$. Four of the six supernove used belong to the more lund nous group and two belong to the less luminous group. The values of $\mathbf{a}$ for these two groups were taken Airectly from the regressions of $M_{0}$ on $\Delta t c i c r$. Chapter 11]. The two average values or b obtained by Eq. (13-11) rere $b_{M L}=-18.24$ and $b_{L L}--16.85$ for the more luminous and the less luminous group, respectively. These values compare favnrably with the values originally obtained frow the regressions, -18.08 and -16.74 . 


\section{$21 \geq$}

The average values $\overline{\Delta t}$ for the two groups were caiculated using oaly the 21 supernove with $v_{r}<2000 \mathrm{~km} / \mathrm{sec}$. Of these, $1 \geqslant$ belong to the wore luminous group and had $\left(\overline{\Delta t}_{\mathrm{c}}\right)_{\mathrm{ML}}=15.89$ days. The elght belonging to the less luninous group had $(\overline{\Delta t})_{L L}=17.85$ days. Conbinine these values with the $b_{M L}$ and $b_{L L}$ and with the two values of $B$ obtained from the separate regressions of $m_{0}$ on $\log \left(v_{r}\right)$ [cf. Table 13-1] gi:es by Eq. $(13-10)$ the estimates $H_{M L}=87.1$ and $H_{L L}=101.4 \mathrm{~km} / \mathrm{sec} / \mathrm{hpc}$. Taking a welghted average of these two values gives for the final estimate $\mathrm{H}=92 \mathrm{rm} / \mathrm{sec} / \mathrm{mpc}$.

This value of $\mathrm{H}$ should be regarded as a provisional determination by the present method. The obvious shortcomings of the determination are the amallness of the samples involved in the regressions of $m_{0}$ on $\log \left(v_{r}\right)$, the regressions of $\mu_{0}$ on $\Delta t{ }_{c}$, and in colibrating the zero point of the $\mu_{0}-\Delta t_{c}$ relation. In spite of this, the value obtained is extremely close to the value obtained by de vaucouleurs in his survey of nearby groups of jelaxies (146). Using $(m-M)=30.65$ for the virgo cluster, he obtained $H=94 \mathrm{ka} / \mathrm{sec} / \mathrm{Mpc}$. If the average value of $(\mathrm{m}-\mathrm{M})$ 18 replaced ing the extreae estimates used in obtaining that average, then the fresent method gives $H=69$ and $H=107 \mathrm{~km} / \mathrm{sec} / \mathrm{Mpc}$ corrasponding to $(m-M)_{\max }=31.25$ and $(m-M)_{\text {min }}=30.3$. Both of these values are in reasonable agreement with the current best estimates by other methods. If the debate about the slope of the $\log \mathrm{V}_{\mathrm{r}}$ - - relation is finally settled in favor of the linear Hubble law, then as more supernova light curves becosie availabie, the present method will provide a powerful mens for estimsting $H$. Furthermore, the aceurate calibration of the zeru poir. of the $M_{0} \cdot \Delta t_{c}$ relation will provide significant refineant in the use of that relation as an extragalactic distance indicator-a possibility that will be discussed in the noxt chepter. 
CHAPTER 14

\section{A REU METHOD FOR ESTDUTITG ExTRAGaractic distances}

In chapter 11 it was shown that there are two distinct luainosity groups of type I supernove and that each of these groups has a welldefined $\mu_{0}-\Delta t t_{c}$ relation. In Chapter 13 it was shown that the eatimates of the slopes of these two relations are not affected by an error in the value of $H$ used for computing the $M_{0}$ or by the variation in $\Delta t_{c}$ Introduced by the $\Delta t_{c}-v_{r}$ relation, so long as the sample is confined to relatively locel supernove; but shese errors do introduce inaccuraries into the deterainations of the intercepts. Fortunate?y, these zero-point errors can be resoved by recalsbrating the intercepts using supernove which occurred in galaxies whrse distances can be deterwined by other methods. This was done in the preceding chapter using the six cccurrences in the Virgo cluster. The resulting recalibrated relations are

$$
\left(M_{0}\right)_{M U}=-0.122 \Delta t_{c}-18.24,
$$

and

$$
\left(H_{c}\right)_{L L}=-0.101 \Delta t_{c}-16.65
$$

for the wre luanous and the lass luntnous groups, respectively.

The above relations can be considered to be the sipernova ana: chues of the period-luanosity reiations for cepheid variable stars. They can be used to estinate the distance to a given supernuva. The nethod consists essentially of measuring its light curve and using the value of $\Delta c_{c}$ thus determined to predict its zbso!ute magnitute and hence its distanse nodulus froa the appropriete $H_{0}-\Delta t c$ regression line. of course, 


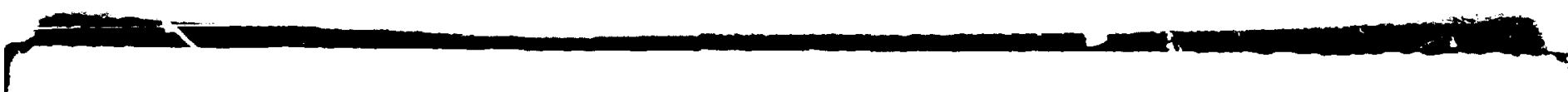

BLANK PAGE 
It is necessary to assign the supernova to its proper ininosity group so that the correct regression line is used. This choice can probably be ade from a rough estimate of the distance modulus of the parent galexy like the ones used earlier to determine the two $H_{b}-\Delta t_{c}$ relations. Since the gap between the two bands is so pronounced, the estimate would probably give an unabiguous determination in most cases, though a more ideal situation would be to have sone independent means of distinguishing between the two groups. Such a tecunique may be developid from systematic studies of supernova spectra or the time variation of their color curves. There is one other complication in the method. That is the dependence of $\Delta t_{c}$ on $v_{r}$ and hence on distance. This variation appears almost certainly to be significant, even though the exact slope is still uncertain. It will not have much effect on estimates of the distances to local supernorie, but it will have to be taken into account for wore distant ones.

In order to test the method, the distances to the aupernove in the present saple were calculated using the recalibrated relations $(14-1,2)$. The observed values of $\Delta t_{c}$ vere corrected before substituting them into these relations. The correction equation,

$$
\left(\Delta t_{c}\right)_{\text {correc. }}=\left(j t_{c}\right)_{\text {obs. }}-\left(2.80 \times 10^{-4}\right) v_{r} \text {, }
$$

was obtalned f:ca the rsgression relation for the resonclled sample [Figure $i 2-2]$. These corrections were not very large for the nearby supernovae (out to $30 \mathrm{kpc}$, sor example), but they were significant for the more distant ones. In viev of the present uncertalnty in the correction relation, the latter estimates should probably not be given too much credence. 


\section{7}

For $r<30 \mathrm{Mpc}$, the velocity-distance relation defined by the new distant estinate: is quite interesting. A plot of the relation is given in Figure 14-1. The plot of the supernove relation is superimposed on a plot of the velocity-distance relation for nearby groups in the north galscisic hemisphere given in the study by de vaucouleurs (146). With the exception of the two outliers Sm939j and Sm963i, which have beer discarded in all the $m_{3}-\log \left(v_{I}\right)$ regressions, the agreement between the two difierent samples is excepicionally good. The two independent methods yield the same quadratic relation even down to the magnitude of the scatter: This, the new method of calculating distances is consistent with tise averaging methods for clusters used by de vaucouleurs, and the new distance estimates support his claim that locally the velocity-distance law is quadratic rather than linear. 


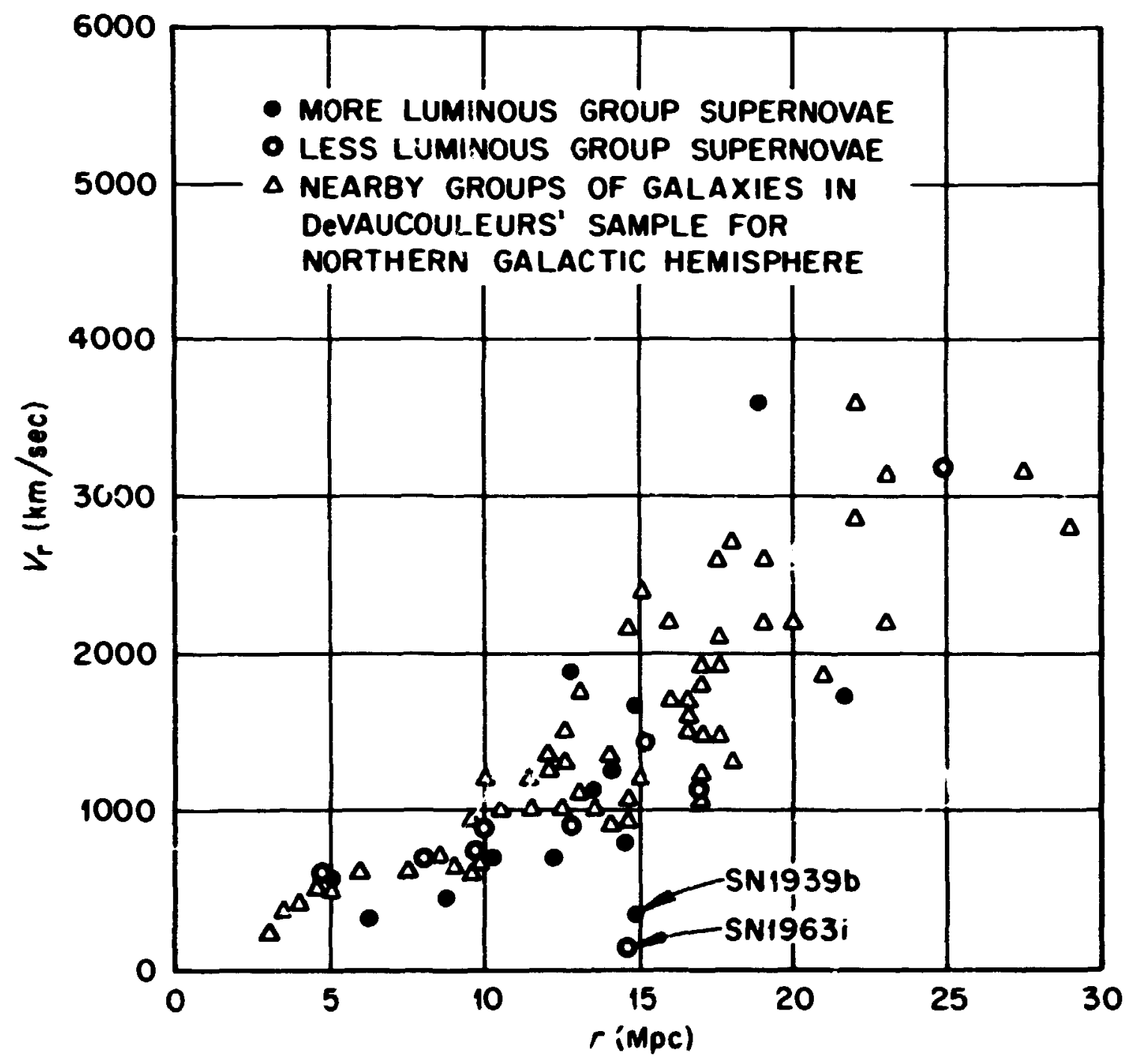

Figure 14-1. The Velocity-Distance Relation for the Local Nelghborhood. 


\section{CHAPTER 15}

\section{SUMARY AND DISCUSSIOA OF RESULTS}

The analysis ir this thesis has been based on 37 l-ght curves observed during an 86 year period beginning with the fi:st extragalactic supernova discorery (Sin865a). This sample contains every light curve that could be found which had a well observed initial rapidiy declining segment, including one (smgili) observed by the author and his colleagues at Prairie Ubservatory. The iight curves were originaliy measured in several different photometric systens, but they were all reduced to the international $\mathrm{m}_{\mathrm{pg}}$ system. The resulting light curves, given in Appendices 1 and 2, constitute a consistent sample for statistical studies. The reduction procedure made extensive use of Pskovikil's fundamental work on the time evolutson of simernova co: ors combined rith photometric conversion formulas originally derived for normal stars. Many of the light curves were measured in both the $m_{\mathrm{pg}}$ and in other systems. The ngreewent obtained in these cases between the measured and the converted $m_{\mathrm{pg}}$ magnitudes validate the reduction procedures. Pskovskif's work on the form of the type I light curve was used extensively in estimating the parameters of the brightness peak for fraguentary light curves measured in the $\mathrm{m}_{\mathrm{pg}}$ system. An iterative method was teveloped wich combines these techriques with the color curve to simultaneously convert to $\mathrm{m}_{\mathrm{PB}}$ and estimate the parameters of the peak for fragmentary light curves peasured in other photometric systems.

More than half of the supernovae in the sample had measured colors. For these supernovas, Pskovskil's color curve was combined wth the absorption-reddening ? lation to give estimates of the absorptions 
within the parent galades and peak agnitudes corrected for absorption. These absorption corrections represent the first attent lnow to the present author to obtain corrected agnitudes for wich the correction in each case is consistent with the observed reddening. An analysis of the average corrections within various types of golaxies gave rough estinates of the absorption corrections for the supernovee wich did not have measured colors. The corrected peak magnitudes thus obtained were used to calculate estimates of the corrected peak absolute magnitudes $M_{0}$. Bxtensive tests of the magnitudes obtained indicated the c. . sistency of the two methods of correcting for absorption.

Each of the light, curves in the sample was fitted with the optical reverberation model of Morrison axd Furtor1. Previously this model has been used only for fitting the later, slowly declining segent of the Iight curve, but in the present study it ras applied, whth good results, to the early, rapidly declining segment. Tests of the model shored that it gives excellent fits to either segment taken alone, but it cannot fit the two together or the transition region between the two segments. If the model is valid, then these results can be interpreted as evidence that there are two distinct regions in the responding medium (e.g., a circumstellar envelope and the interstellar mediva).

Regardless of whether or not the Morrison-Sartori model is valid, it provided a fitting function which does an excellent job of "filling in" or extrapolating fragmentary light curves. The fitted curves were also used to define a comparison parameter $\Delta t_{c}$ (the number of days required for the apparent brightness to decline from $m_{0}+0.5$ tu $m_{0}+2.5$ ), which gives a consistent measure of the rates of decline of the light 
curves that is relatively insensitive to errors in the estinates of the paraneters of peak brightness $b_{0}$ - peak apparent menitude and $t_{0}=$ date of peak).

The estinates of $\mathrm{H}_{b}$ and $\Delta t_{c}$ for the supernove in this saple provide a date base containing wch usenul information both for supernova theory and cosmoracical tests. A tino ifh the $\Delta t_{c}$ apparentiy do increaze with increasing sybolic velocity $V_{\mathbf{r}}$, it was possible to get a good estimate of the intrinsic distribution by considering the supernovae in the sample with $v_{r}<2000 \mathrm{k} / \mathrm{szc}$. The estimates of $y_{0}$ provided confirmatory evidence for two correlations previously reported by Pakovskil [cP. Appendix 4]: (1) a correlation between $k_{0}$ and the Hubble type of the parent galaxy and (2) a correlation between $x_{0}$ and the luminosity of the parent galaxy.

The estimates of $\mathrm{M}_{0}$ and $\Delta t_{c}$ taken together provide very strong evidence that there are two distinct populations of type I supernovae having different average values ${\overline{M_{0}}}_{0}$ and $\overline{\Delta t}{ }_{c}$. The two groups, which were salled the more luminous group $\left(\overline{F_{0}}=-i 0.17, \overline{\Delta t_{c}}=17.1\right.$ days $)$ and the less luminous group $\left(\overline{\bar{t}}_{0}=-18.74, \overline{\Delta t_{c}}=19.9\right.$ days), were extensively tested [cf. Appendix 5] to determine whether or not they might have been the result of systematic errors in estimating the $\mathrm{K}_{0}$ rather than being real distinct populations. Wo systematic effects were found. The two groups were compared with subgrouping schemes proposed by previous authors, and it was shom that the present scheme gives a more significant zubdivision than the preceding ones.

It is the relationship between $M_{0}$ and $\Delta t$ that defines the division into two luminosity groups and indicates the significance of the division. The groups appear in the plot of $\mu_{0}$ agalnst $\Delta t c$ as two well separated 
bands with a highy significant linear correlation vithin each bans. These two linear relations shouid bav far-reiching consequences for future resenrch on supernove. They will provide validnting relations for theoretical nodels. Thes ean also be used for distance estimation In a mnner analsous to the use of the period-ludinosity relations for Cepheld rariables.

In order to use the $\mathrm{H}_{\mathrm{b}}-\Delta \mathrm{t}_{\mathrm{c}}$ relations for distance estimation, it was necessary to recalibrate then. The orifinal estimates of $n_{0}$ were cotained using an assuned value of the Hobble constant $H . M 1 s 0$, since the $\Delta t_{c}$ are correlated with $V_{r}$, variation in the latter parceter introduces scatter in the $\mathrm{H}_{\mathrm{o}}-\Delta \mathrm{t}_{\mathrm{c}}$ relation. In Chapter 13 it $\mathrm{w}$ show that these uncertainties do not affect the slope of the $\mu_{0}-\Delta t$ relation. Therefore it was recessury to correct only the intercept. This was done by using the aix supernorae which occurred in the virgo cluster together with de Vaucouleurs' "best" average estinate of the distance nodulus of that. cluster. This recalibrated relation can thes be used to estinte the absolute aggitude of a Given supernova from the measured value of the comparison parameter $\Delta t_{c}$ -

There are two comlications in using the above described method. One is deterining the group memership for the given supernov. Until sone independent nethod is found, an initial estinate of $M_{0}$ using the sane techniques that mere used to deternine the $H_{b}-\Delta t$ relations will probably suffice to deternine wich group to use. The other complication arises from the correlation between $\Delta t_{c}$ and $V_{\mathbf{r}}$. The measured $\Delta t_{c}$ must be corrected for this effect. The correction is negligible for relatively local supernovae, but it wy be significant for distant ones. 
The chier task of this thesis was to exanine the $\Delta t_{C}-V_{T}$ relation in order to test the expension hypothesis. In chapter 8 the correlation between these two qunntities for the present semple was show to be sipnificant at the 9\% level, but the slope of the regression line was auch larger than the values predicted by both the static Buclidean and the classical expansion hypotheses. Chapter 10 gave a revies of some of the theories that bave been proposed as alternatives, and it was shown that only one of then gave a prediction that differed from those two hypotbeses. That one was derived by the present author using the corariant chronogeconetry proposed recerilly by the mathentician I. E. angi. The resulting prediction gave much better agreenent with the regression line than the other two predictions.

In Chepter 8 extensive tests were described wich show that the unexpectedly large slope of the $\Delta t_{c}-V_{r}$ relation did not arise froc systentic errors in the data reduction, and in Chapter 9 it was show that the result was not caused by a lunosity selestion effect. In Chapter 12 a reconciled suple was constructed by combining the two luninosity groups so that they simulated a single luafnosity population. The $\Delta t_{c}-V_{r}$ regression for the reconclled sample gave essentially the save results as the original saple, so the unexpected slope was not caused by a population effect.

Although the regression line of $\Delta t_{c}$ on $v_{r}$ gives the best agreement with segal's theory and rejects the classical expansion hypothesis at the 91\% level, one cannot anke the clain that the former theory is correct and the latter is wong. There is a very wde scatter in the $\Delta t_{c}$ data and the sample points are clustered toward the lower end of the $v_{r}$ 
224

renge, which extends out to only $V_{Y}=16,000 \mathrm{iol} / \mathrm{sec}$. The t-statistics for coputing the sfonif: ace ievels of the various tests teke all of these factors into account. Thus, the gil level obtained for refecting the expansion hopothesis is a valid relue, but it is considerbly less than the treditionally ecceptable 956 level. Dea $\infty$, the level is large enough to encourage sone doubt as to the validity of the expantion uppothesis and to ephasize the need for further wock in order to verif or disverify it.

Another nethod for distingulaing between conological theories is the redinift-monitude relation. The slope of this relation deterines the fore of the velocity-distance relation. The classical expansion hypothesis predicts toe linear Hubble law. Segal's theory priaflets a quadratic 10 ( $\left(V_{Y} \sim r^{2}\right)$. Observations of galadies caniot be used to five an independent eatinte of the slope because thes require aperture corrections which in turn require assunptions about the geonetry of apace-tive and hence about the form of the velocity-distance relation. Because they are highly luninous point sources, supernove are the idsal candidates for this analysis.

When (in Chapter 13) the superwovae in the present anple were subjected to the $H_{0}, \log \left(v_{r}\right)$ analysis, the resulting regreasion line had a slope intermediate between the values corresponding to the inear Kubble Iaw and the quadratic law. The correlation wa highly sionifleant and both lans were rejected at signiflcance levels exceeding 955! The anple was doufnated by $10 \mathrm{w}-2$ and hence relatively local supernove. In view of the recent work that has been dosi on locel anisotroples in and deviations from the Hubble law, one aust consider the possibility 
that the reault renects a purely looel enfect. If so, it is prometure to rule out the firbble lan-but it is also presture to rule ont a quadratic In.

In Chepter 14 the ner nethod of distance extintion uding the

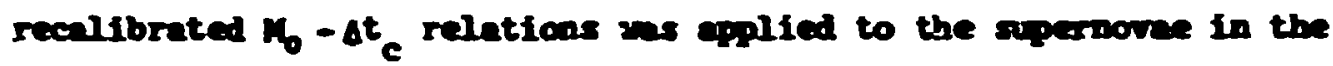
saple vith distances less than about 30 mpe in ceder to coastruct the loed reloefty-distance relntion. Since the $V_{Y}$ for the superwove

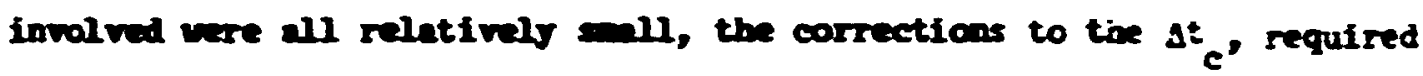
by the $\Delta t_{c}-v_{1}$ correlation, were all; it did not entter that the enct slope of the $\Delta t_{c}-V_{r}$ relation is not jet well deternined. The resulting

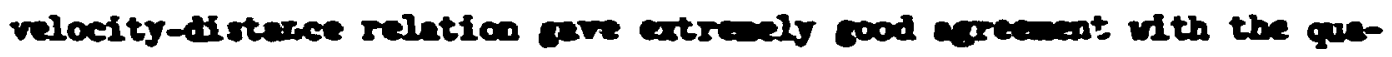
dratic relation recently found by de vaucoulcurs using averages for nearby roups and clusters of alndes. This result fives confinding evidence for his result, indicetes that the nev wethod of distance estimetion is consistent with the older methods, and surgests that the result: obtained in Cnopter 13 were indeed nore indicative of a local effect then of the true velocity-distance relation for the generel field.

If the validity of the linear hubble las is sccepted, then the recalibrated ${n_{b}-\Delta t}_{c}$ relation can be combined with the $\mathrm{n}_{0}-\log \left(v_{\mathbf{r}}\right)$ andysis to dre a new wethod for extinating the Huble constant. Older methods, based on the formule $v_{r}=\mathrm{Hr}$, require primary distance Indicators (11ke Cepheids) close enough to be vialble and yet far enoun wany so that the $v_{I}$ are not dorinated by randon noticas. Inis would be a difficult proble even in the absence of local anomiles in the tubble relation. The new nethod svolds the proble because it does not use the velue of $v_{I}$ in the deternination. When it was applited to the present scople, the resulting estinate wes $H=92 \mathrm{kV} / \mathrm{sec} / \mathrm{Hpc}$. 
Wost of the analyses and tests perforned in this theals have been provisional or not copletely concluatre because the present spele of light curves is not exteasive enoph. In particulnr, the $\Delta t_{c}-v_{T}$ tests ware only arginally sighificant becanse there ware not enough light curves for Inger velues of $v_{y}$. In Cupte: 12 the recouclied sople uns uod to estinte the saple requirenats for diserindinting at the $95 ;$ level between verious pairs of alternative bypotheses. The results were quite encouraging. They indicate that if seon's theory is correct, oaly a molin-large telescope will be needed to gather the lifht curves requirel to reject the static Boclidean and the classical eqparion hypotheses, and furthernore, aly a fer wore light curves will be seeded. If one of the latter tro bypotheses is correct, a really large telescope will be required, but again only a fer mare light curves will be peeded to distinguish between thea. In view of the prelfminary indications of the results obtained fron the present andjais, it wolld seen that the collection of these additional light curves should be fiven wish priority. Wot on:s noijd they make the $\Delta t_{c}-v_{r}$ test definitive, but they also figt resolve the question of the form of the relocity-distance relation, five a better eatinate of $\mathrm{H}$, and refine the new nethod of distance estimation. The author will consider this thesis a creat success if it hastens the gathering of these new date. 
LIST of naperes

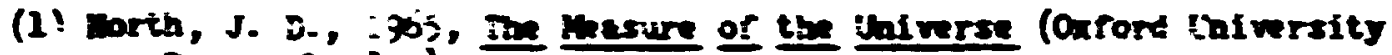
Press, Loadoa).

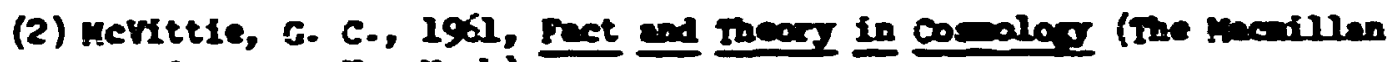
Compan, Dart Yort.

(5) mintoustd, R. and allson, 0. C., 1956, The Astrophrsicel Journal, 123, 573.

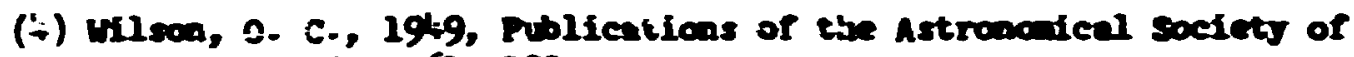
the Pacific, Si, 132.

(5) Kert, F. J., Kinstan, J. V., end Bobinecen, B. J., 1954, Aurtrelien Journal of Fustes, I, 29?.

(6) ven de thlst, H. C., Reinond, E., ven Hoerden, H., 195?, Bulletin of the Astrosciciel Institutes of the Ietherlands, $\underline{14}, 1$.

(7) Pord, U. K., Rubin, V. C., and Noberts, H. S., 19!1, The Astrononical Journal, 76,22 .

(8) ATp, К. C., 191, seleace, 174, 1189.

(9) ArP, H. C., 1970, in External Galexies and ganel-stellar bojects,

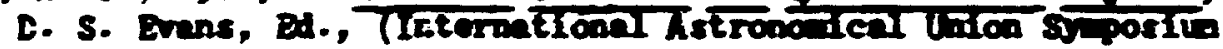
Do. ith, Uppsale), 38:-3,8

(10) schudt, H., 196\%, sature, 197, $10 t 0$.

(11) Jefrregs, W. H., 196,, the Astronodeal Jourmel, 69, 255.

(12) Lutien, 4. J., and sath, J. h., 1966, The Astrophysical Journel, $14 \equiv, 366$.

(13) Hoyle, g., and surbide, G. R., 1966, Mature, 210, 1346.

(24) Abell, G. 0., 1958, The Astrophysicsl Journel supplement series, 3. 211 .

(15) Bahcall, J. .., 1969, The Astrophysical Jourmal, 158, 187.

(16) ounn, J. E., 1971, The Astrophysical Journal, 25i, 113.

(1T) Robinson, I. B. and Warpler, R. J., 1972, The Astrophysical Journal, 171, LA3-186.

(18) Arp, H. C., 1970, The Ast rophysicel Journel, 162, 811-813. 
(19) Arp, X. $2 ., 196 \%$, the Astrophysteal Jourtal supplente Series, $16,1-20$.

(20) AP, H. C., 1970. The Astronchieal Journel, T5, 1.

(21) IP, H. C., 1907, the Astrophysicel Journal, 148, 321.

(z2) ArP, H. C., 1971, Astrophysied Letters, 9, 1d.

(23) Burbide, E. M., Burbidxe, G. R., Salonon, P. M., and strittmeter, P. A., 197, The Astroptoricel Jerinal, $170,233-240$.

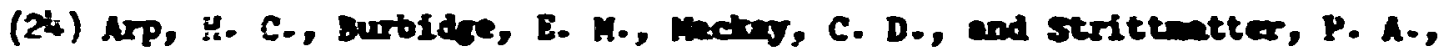
19:2, the Astrophysical Jourwal, 171, L41-145.

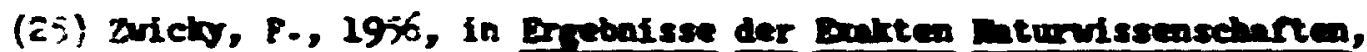

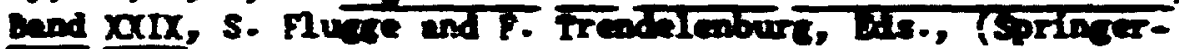
VerI G, Eerlin).

(25) sarcent, H. L. H., 2968, the Astrophysical Journal, 153, L135L13:.

(2-) Burbidge, E. M. and Burbide, G. R., 1961, the Astroptrotsical Journal, 13:4, 244-247.

(25) AP, H. C., 19:0, Astrophysied ietters, 5, 257-260.

(29) Arp, 4. C., 1971, Astrophysical Leters, I, 221-x24.

(30i Arp, 4. C., 1970, Nature, 225, 1033-1035.

(31) Leris, B. M., 1971, Weture Physical sciesce, 230, 13-15.

(52) Arp, K. C., 19:1, Eature Phosicel science, 2j,1, 105-104.

(33) Jeaktole, T., 1971, Rature, 234, 534-535.

(3) Hecrea, u. H., 1955, Zeitschrift fur Astrophysik, 9, 290-514.

(35) wilson, 0. C., L;5t, The Ast.raphysical Journel, 过, 634-636.

(56) Milford, s. N., 1955, the Astrophysical sournal, 122, 13-23.

(5-) Milford, S. N., 1953, the Astronodical Journal, 58, 43-44.

(35) Pinzi, A., 1961, Annales D'Astrophysique, 24, 68-7C.

(99) Burbidge, E. M., Burbitge, G. R., Fouler, H. A., and Hogle, P., 1957, Reviews of Modern Physics, 29, $547-649$.

(iso) Minalas, D., 1959, Publications of the Astronond cal snciety of the Pacifie, 75, 255-26A. 
(41) Pecker, J. C., Roberts, A. P., ard Vigier, J. F., 19:2, hature, 25?, 22?-229.

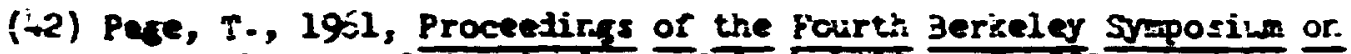
Metbeatical Statistics and Probabilit ty, 3,2,

(-3) Page, T., 190, The Astropinysical Joirtal, 1:9, T91.

(-4) antky, F., 195-, Handbuct, der Physik, 江, S. 5lugs?, Et., Fó-? is (Springer-Verlag, Berlin!.

(45) Zuricky, F., 19:j, stars and stellar systems, jol. UIII, stellar Structure, Aller and YcLeugilin, Eds., $3=2$; The Triversity of (xicero).

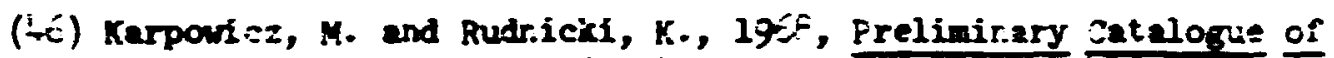
Superrove Discovered Till tine Dnd of Ig-, Pisticaticns of the Astronofical cbservatory of the Warsaw University, Volve 15 (inersaw Iniversity Press).

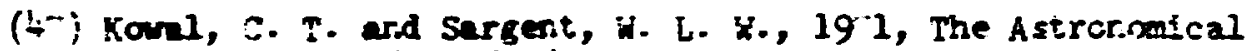
Jourral, $1 \dot{E}, 75$ - jót.

(iff) Minkowsiki, R., 19:i, Anrual Reviers of Astronony and Asiropisysies, Vol. 2 (Annual Reviers, Inc., PaIo AIto), p. 2-

(49) Kown, C. T., 195\%, The Astroromical Journal, -3, 1021-102:.

(50) Pskorskii, Yu. P., 19:-, Soviet Astronom - AJ, 11, 6j-69.

(51) Pskovskil, Yu. P., 19:1, Soriet Astronomy - لd, 1!., 79:-805.

(52) Deaira: D., Rust, B., and Olson, E., 19:, Publicatior.s of trie Astronomical Society or the Pacific, $521-527$.

(33) Dunlap, J. R., 1971, International Astronomical Union Circular k. $2 ; 30$, June $2,19: 1$.

(;4) van de Hulst, :. C., 19'1, International Astronomical Union Circular No. 2334, June 1\%, $19 \% 1$.

(55) van Herk, G. and Schoenmaker, A. A., 1922, Astroromy and Astrophysics, $17,146-147$.

(56) Huruhata, M., 1971, International Astronomical inion Circular Ho. 2332 , June 2, 1971.

(57) Parenago, P. P., 1949, Peremennye 7vezdy, i, 109-123.

(58) Gaposchkin, S., 19501, sky and Telescope, 21, 326-127.

(59) Shapley, 14., 1939, Proceedings of the National Academy of science USA, 25, 569-571. 
(6s) Bsade, W. end Zricky, F., 1938, The Astrophysi zal Jcurnal, 33, 411-421.

(6́1) Deutsch, A. II., 1939, Poulkovo Observatory Circular No. 28, 73-75.

(62) jiclas, i.. L., 1939, Publications of the fstronomical Society of the Pacific, 21, 166-168.

(6j) Berteud, C., 194i, Astronomie, 25, 161-162.

(j4) Shapley, fi., 1939, Harvard College Observatory Announcement Card No. 437 , June $1,+339$.

(65) Wild, P., 1960, Publications of the Astrononical Society of the Pacific, I2, 97-135.

(66) Pletra, S.. 1955, Memorie della sncieta Astronomica Italiana, 26, $181-188$.

(67) Zwicky, F., 1956, Publications of the Astronomical Soc1ety of the Pacific, 68, 271-272.

(68) 2sicky, F. and Karpowicz, M., 1964, Th: Astronomical Journal, 69, $759-751$.

(69) Zaricky, F. and Karpowicz, M., 1965, The Astronomical Journal, $70,564-565$.

(70) Bertola, F., 1964, The Astroncmical Journal, 69, 236-242.

(7) Henzel, W., 1957, Nachricintenblatt der Astronomischen 7.entralstelle Astrouani schen Rechen-Institut Heidelberg, 11, 14 .

(72) Gotz, W., 1958, Astronomische Nachrichten, 284, 141-142.

(73) T,j Tuin, 19;i, Acta Astronomica Sinica, 5, 321-323.

(74) Mihalas, D., 1962, Publications of the Astronomical Society of the Pacific, 74, 116-124.

(75) Rowano, G., 1957, La Ricerca Scientifica, 27, N. 10, 3-5.

(j) Huth, H., 1960, Circuladre, Bureau Centrale Interrationale des Telegranme. Astronomiques, No. 1723.

(77) Kulikov, V. I., 1950, Astronamicheski1 Tsirkular Nc. 215, 2-4.

(78) Tempest1, P., 1961, Memorie della Societa Astronanica Italiana, 32, $21.4-253$ 
(73) Mannino, G., 1362, Memorie della Soci, ta Astronomica Jtaliana, 23, 147-147.

(30) Zaitseva, G. V., 1661, Astronomicheskii Tsirkular No. 223, 1-2.

(91) Gates, H. S., 1XXl, Harvard College Observatory Announcement Card No. $: 521$.

(32) Zvicks, F., 1961, Publications of the Astronswical Society of the Pacific, 73, 135-190.

(33) Romano, G., 1962, Memorie della Societa Astroriomica Italiana, $33,17-37$.

(34) Zricky, F. and Barbon, R., 1967, The Astronomical Journal, 72, 1306.

(85) Rudnicki, K. and Zwicky, F., 1967, The Astroncmical Jounal, I2, $407-409$.

(36) Bertola, F., 1965, Menorie della Societa Astronomica Italiana, $36,299-307$.

(37) Bertola, F., 176i, Annales 'Astrophysique, 27, 319-326.

(88) Rnsino, L., 1963, Coelum, 21, 52-53.

(99) Rosino, L., 1963, Information Bulletin on Variable Stars of Comission 27, International Astronomical Union, No. 37.

(90) Kosino, L., 1964, Annales D'Astrophysique, 27, 314.

(91) Zaitseva, C. V., 1964, Peremennye Zvozdy, 15, 107-100.

(92) Lo.hel, K., 1963, Information Bullet,in on Variable Stars of Coumission 27, International Astronomical Union, No. 30.

(93) Lochel, K., 1965, Sterne, 41, 218-122.

(94) Zwicky, F., 1964, Publications of the Astronomicsl Society of the Pacific, $76,326$.

(95) W1ld, P., 1963, Harvard College Observatory insouncement Card No. 1601 .

(96) Chincarin1, G. and Margonl, R., 1964, Memorie della Societa Astronomica Italiana, 35, 129-1.32.

(97) Bertola, F., Mamano, A. and Perinotto, M., 1965, Contributi Dell'Osservatorio Astrofisico Dell'Universita di Padova in Astago, No. 174 . 
(98) rmo, S., 1967, Tolvo Artronadicel bulletin, Second Series, E. 176.

(99) Loves, M., 1964, Inforation Bulletin on Verieble stars of Comission 27, Internationel Artroscaical Union, Ho. 50.

(10) Ahnert, P., 1964, Infonation Bulletin on Varieble stars of Co ission 27. Intarnetional Astronenisal Union, .0. 56.

(101) Chande, A. D., 1964, Astraschichesldi Tsirtuin Do. 291, 1-2.

(102) Zaitseve, C. V., 1964, Artronaicheskil Isirtoular Do. 301, 1.

(103) Lochel, K., 1966, Mittellungen uber Veranderliche sterne, ג $195-197$.

(104) Van Lrong, L. and Panarin, J. P., 1966, Perenenmye zrezdy, 16, $90-91$.

(105) Clatt1, F. and Barbon, R., 197, Menorie della Societa Artroncica Itaitana, $42,145-161$.

(106) Wild, P., 1966, Internationel Artrononical Union Cireular 10.1986.

(107) Chincarini, G. and Perinotto, M., 1968, Menorie delle Societa Astronciea Italiana, 39, 189-99.

(108) Knho, S., 1368, Tokyo Artronanical Bulletin, Second Series, fio. 189 .

(109) Rudnickf, K., 1967, Astronoulische Nachrickten, 290, 135-139.

(110) de Vaucouleurs, G., Solhein, J. E. and Brown, ji., 1967, Antrofizika, 1, 565 .

(111) Karx, S. and PFar, H., 1967, Infornation Bulletin on Variable Stars of Conassion 27, Internetional Astrancaical Union, No. 206.

(112) Borzov, G. G., Dibal, E. A., Esipor. V. P. and Pronik, V. I., 1959, soviet Atronou - $\omega, 13,423-426$.

(113) Chuadze, A. D. and Barblishvil1, T. I., 1969, Byull. Abartumansk Astroriz. Obs. 10. 37, 9-12.

(114) Chavira, E., 1968, International Astroncofeal Union Circular 10.2061.

(115) Bertola, P. and Ciatt1, P., 1971, Menorie della societa Atroncica Italiana, $42,67-72$. 


$$
2 ; 3
$$

(116) Scovil, C. B., 197, Internationel Artronanical Union Cirenlar 10. 2338, July 2, 197 .

(117) Vescouleurs, G. de and Vaucouleurs, A. de, 196t, Reference Catelo ue of Brint Gelexies, (University of Texas Press, Austin).

(118) theson, M. L., Mavell, R. U. and Sandege, A. R., 1956, The Artroncilce. Journel, 61, 97-162.

(119) Hol-berG, E., 1964, Arkiv for Astrononi, 3, 387-438.

(120) Holmbers, E., 1958, Iund Keddelanden, II, Ho. 136.

(121) Pettit, E., 1954, The Astrophysicel Journel, 120, 413-438.

(122) Bigw, J. H., 1951, Nancles d'Astrophysique, 14, 319-366.

(123) Zuricky, F., Herzog, E. and Wild, P., 1961, Catalowe of Gelexdes and clusters of Geledies, Vol. 1, (Callfornia Institute of Technology, Pasadena).

(124) Zurcky, F. and Herzos, E., 1963, Cateloque of Galades and clusters of Geladies, Vol. 2, (California Instituice of Technology, Pasadena).

(125) Pskovskif, Yu. P., 1968, Soviet A-troncuy - MJ, 1ㅡ, 570-575.

(126) Beyer, M., 1939, Ntronouische Nachrichten, 268, 350-354.

(127) Beyer, M., 1954, Nachrichtenblatt der Astrononischen Zentralstelle, 8. 34 .

(128) Wellman, P., 1955, Zeitschrift rur Astrophysik, 35, 205-209.

(129) Morrison, P. and Sartori, I., 1966, Fuysical Review Letters, 16,414 .

(130) Morrison, P. and 8artori, L., 1969, The Astrophysical Journal, $158,541-570$.

(131) Arnett, W. D., 197, The Astrophysical Journal, 163, 11-16.

(132) Houscholder, A. 8., 1964, The Theory of Matrices in Herical Anclysis (Randa House (Blatsdell), New York).

(133) Golub, G., 1965, Mnerische Matheant1k, I, 206-216.

(13i) IIM, Technical Publications Departaent, 1967, Bysted/360 Bcientiflc subroutine Peckere, Vercion II, Protr.er's Vamul, 3601-Ch-03x, (IEA, Technical Publicatioss, White Flatns, New York), pp. 191-195. 


$$
234
$$

(135) Dotd, p. 161-163.

(136) Grubb, F. B., 1950, Anavis of Mathenaticel Statistics, 21, $27-58$

(137) van den Bergh, S., 1960, Zeitschrift our Nirophrsik, 49, 201-205.

(138) Sharpless, S., 1963, Sters and Steller Srotens, Val. III, Basic Astroncical Date, K. A. A. Strand, Bd., 225-240, (The University of (Chicaco Preas).

(139) Wihalas, D., 1968, Gelectic Artronary, 68-77, (H. H. Preenan and Co., San Pransaisco).

(140) van den Bergh, S., 1900, The Astrophysical Journal, 131, 215-223.

(141) van den Bergh, S., 130, The Astrophysical Journel, 131, 558-573.

(142) de Vucouleurs, G., 1962, Probless of Dtre-Galectic Research, INU Syeasiu Ho. 15, G. C. McVittie, Ed., 3-21, (Hacililian).

(143) de Vaucouleurs, G., 1963, The Astrophysical Journal supplenent Series, Suppleaent muber 74, Vol. VIII, 31-98.

(144) Allen, C. W., 1963, Astrophrsical Cuntities, and Eation, (The Althone Press, Univ. of Iondon).

(145) Pakovskil, Yu. P., 1962, Soviet Astronow - NJ, 2, 498-502.

(146) de Vaucouleurs, G., 1972, External Gelaxies and cuasi-steller Objects, INU Syposiv 10. 44, D. S. Bvans, Ed., 353-366, (D. Reldel Publ. Co.).

(147) Bertola, F. and suss1, M. G., 1965, Contribut1 Dell'Osservatorio Astrofisico Dell'Universite df Padova in Asfago, No. 176.

(148) Zarlcky, F., 1960-65, Circular letter on 8upernovae. No. 1-8.

(149) Zuricly, P., 1964, List of Supernovae Discovered stnce 1885, California Institute of Technolod.

(150) Barbon, R., Ciatti, F. and Rosino, I., 1973, Artronony and Astrophysics, 25, 241-248.

(151) scha1dt, T., 1957, Zeltschr1ft fur Aetrophysik, 41, 182.

(152) Mackillen, H. D., 1918, The Astroplosical Journa, 48, 35-49. 
(153) Mactille, W. D., 1923, Seientie, 33, 3-12, 103-112.

(154) recilllan, W. D., 1925, Setence, 62, 63-72, 96-99, 121-127.

(155) Pinlw-Preundlich, B., 19:4, Futlocophical Magaside, 45, 303-319.

(156) Ceiesin, A., 1969, Astropivsicel Letters, $4,51-54$.

(157) Freund, F. G. 0., Mebesturari, A. and Schoobert, E., 1969, The Astrophysical Journal, 157, 857-867.

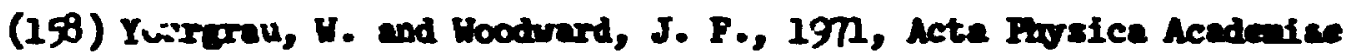
scientiaru hongaricee, $30,323-329$.

(159) Milne, B. A., 1935, Reintivity, Grevitation and Norld-Structure, (Oxford University Press, Iondon).

(160) Mine, B. A., 1948, Kinenatic Relativity, (Jurund University Press, Iondon).

(161) Johnson, M., 1947, I1 Kne, Knorledre and the Lebules, (Dover Publications, New York).

(162) Bellert, S., 1969, setrophysics and space science, 3, 268-282.

(163) Bellert, S., 1970, Astrophysics and space science 7, 211-230.

(164) Segel, I., 1972, Atronow and Atrophysics, 18, 143-148.

(165) Segal, I. E., 1973, Coveriont Chroogsecetry and Butragelectic Atroncis, (in namuscript, Massachusetts Institute of Technology).

(166) Robb, A. A., 1936, Geonetry of Mine and space, (Combridge University Press, Cembidge).

(167) Pokker, A. D., 1965, Tine and space, Veipht and Inertia, (Pergenon Press, Oxtord).

(168) Agekyan, T. A., 1969, Fhraice of 8tars and 8tellar Bratens, A. A. Mithallov, ed., (Israel Progren for scientific Translations, Jeruselea, MASA TT P-506) 631-703.

(169) Lundark, K., 1925, Monthly Notices of the Royal Astrononical soctety, 85, 865-895.

(170) Hawk10s, 0. 8., 1962, Iature, 194, 563-564.

(171) Rub1n, V. C., Pord, W. K. and Rub1n, J. 8., 1973, The Astrophysicul Journal, 183, ILII-LIIS. 


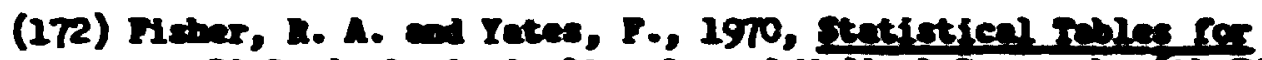

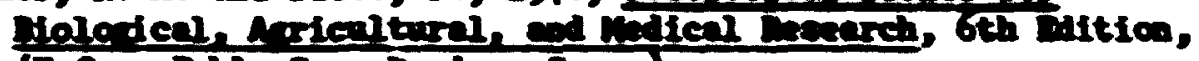
(Boner Pobl. Co., Darlen, Cone.).

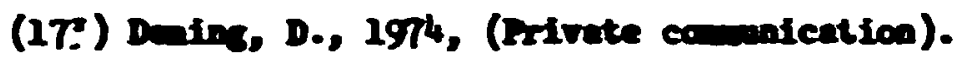

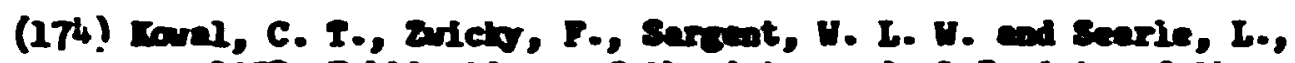
1973, Fublicetion of the Arircusical societs of the reific, $427-435$. 
AFPDDX 1

THE OSSEIVD ND REOUCED DATA

Fables M-1.1 throunh 12-1.37 give the observed and reduced data used for constructing the light curves in this etudy. The original observations are fiven on the left side of the tables with the source and angitude systea identified at the top of each colunn. The abreviations for the angitude systeas are the sane as those used in Tables 5-2, 6-3, and 6-4. The date given for each observation is in the for given by the original observer, sonetines in Julian days and sonetines in the no/da/yr notation. The tines which are given with sone of the dates are in the U.T. system. The estinates $\mathrm{m}_{0}$ and $t_{0}$ or peak photograpbic brightbess and date of peak are given at the head of each table. The redured data used for construating the ifgt curves are given in the final two colums of each table. The coluan labeled $t$ gives the tise in days relative to $t_{0}$ of the observation, and the coluan labeled a gives the magnitude reduced to the $m_{\mathrm{pg}}$ system. The steps of the conversion techniques used in each case are sumarized in Tables 6-5, and 6-4. Por some supernovae, sose of the observed nagnitudes vere not used in constructing the final light curves so there are aissing entries in the final two coluns. In wost of these cases the unused observations were used, however, in calculating the color excesses given in Table 6-4 a they are included in the following tables. 


\section{8}

Table Al - 1.1

\begin{tabular}{|c|c|c|c|c|}
\hline Date & $\begin{array}{l}\text { Obs. } \\
\text { nos }\end{array}$ & Source & $\mathbf{t}$ & np \\
\hline JD2409771 & 7.0 & Ceposhlin (58) & -5 & 6.4 \\
\hline IDetogT74 & 6.0 & Parenago (57) & -2 & 5.5 \\
\hline 779 & 6.0 & & 3 & 5.6 \\
\hline 781 & 7.0 & & 5 & 6.7 \\
\hline 783 & 7.3 & & 7 & 7.0 \\
\hline 785 & T.T7 & & 9 & 7.6 \\
\hline 786 & 7.85 & & 10 & 7.7 \\
\hline 787 & 7.95 & & 11 & 7.8 \\
\hline 788 & 8.06 & & 12 & 8.0 \\
\hline 789 & 8.27 & & 13 & 8.2 \\
\hline 790 & 8.27 & & 14 & 3.3 \\
\hline 791 & 8.40 & & 15 & 8.5 \\
\hline 752 & 8.37 & & 16 & 8.5 \\
\hline 793 & 8.54 & & 17 & 8.7 \\
\hline 734 & 8.60 & & 18 & 8.8 \\
\hline 795 & 8.82 & & 19 & $9 . i$ \\
\hline 796 & 8.88 & & 20 & 9.2 \\
\hline 797 & 9.00 & & 21 & 9.4 \\
\hline 798 & 9.02 & & 22 & 9.4 \\
\hline 799 & 9.05 & & 23 & 9.5 \\
\hline 800 & 3.11 & & 24 & 9.6 \\
\hline 801 & 9.07 & & 25 & 9.7 \\
\hline 802 & 9.22 & & 26 & 9.9 \\
\hline 803 & 9.29 & & 27 & 10.0 \\
\hline 804 & 9.34 & & 28 & 10.1 \\
\hline 805 & 9.54 & & 29 & 10.4 \\
\hline 806 & 9.60 & & 30 & 20.4 \\
\hline 807 & 9.59 & & 31 & 10.5 \\
\hline
\end{tabular}




$$
2: 9
$$

Table $\mu 1-1.1$ (Coctinued)

\begin{tabular}{|c|c|c|c|c|}
\hline sw1885a & & $t_{0}=\sqrt{102409776}$ & & $=5.2$ \\
\hline Date & $\begin{array}{l}\text { Obs. } \\
\text { aris }\end{array}$ & Source & t & er \\
\hline 800 & 9.54 & & 32 & 10.4 \\
\hline 809 & 3.68 & & 33 & 10.6 \\
\hline JD2409810 & 9.67 & Parenago (57) & 34 & 10.6 \\
\hline 811 & 9.79 & & 35 & 10.7 \\
\hline 612 & 9.76 & & 36 & 10.6 \\
\hline 813 & 9.97 & & 37 & 10.8 \\
\hline 814 & 10.08 & & 38 & 10.9 \\
\hline 815 & 10.05 & & 39 & 31.9 \\
\hline 816 & 10.20 & & 40 & iz.o \\
\hline 817 & 10.18 & & 41 & 11.0 \\
\hline 818 & 10.26 & & 42 & 11.1 \\
\hline 819 & 10.46 & & 43 & 11.3 \\
\hline 920 & 10.36 & & 44 & 11.2 \\
\hline 821 & 10.41 & & 45 & 11.2 \\
\hline 822 & 10.53 & & 46 & 11.3 \\
\hline 824 & 10.54 & & 48 & 11.3 \\
\hline 825 & 10.52 & & 49 & 11.3 \\
\hline 826 & 10.57 & & 50 & .11 .3 \\
\hline 827 & 10.56 & & 51 & 11.3 \\
\hline 828 & 10.68 & & 52 & 11.4 \\
\hline 829 & 10.66 & & 53 & 11.4 \\
\hline 830 & 10.69 & & 54 & 11.4 \\
\hline 831 & 10.59 & & 55 & 11.3 \\
\hline 832 & 10.37 & & 56 & 11.0 \\
\hline 833 & 10.72 & & 57 & 21.4 \\
\hline 834 & 10.96 & & 58 & 11.6 \\
\hline 836 & 10.74 & & 60 & 11.4 \\
\hline 837 & 10.68 & & 61 & 11.3 \\
\hline
\end{tabular}


moble 41 - 1.1 icontinuad)

\begin{tabular}{|c|c|c|c|c|}
\hline $\sin 1885 A$ & & $t_{0}=$ JDehogT76 & & $=5.2$ \\
\hline Date & $\begin{array}{l}\text { Ob. } \\
\text { neis }\end{array}$ & Souree & $t$ & ax \\
\hline 836 & 10.8 & & 62 & 11.4 \\
\hline 839 & 11.00 & & 63 & 11.6 \\
\hline 840 & 11.20 & & 64 & 11.8 \\
\hline 841 & 11.17 & & 65 & 11.7 \\
\hline 842 & 11.03 & & 66 & $\mathbf{2 1 . 6}$ \\
\hline 844 & 11.25 & & 68 & 11.8 \\
\hline 845 & $\mathcal{1 1} 0$ & & 69 & 11.5 \\
\hline JD24098i46 & 11.33 & Parengo (57) & 70 & 11.8 \\
\hline 848 & 11.25 & & 72 & $\mathbf{1 1 . 7}$ \\
\hline 949 & 11.05 & & 73 & 11.5 \\
\hline 850 & 11.18 & & 74 & 11.6 \\
\hline 851 & 11.18 & & 75 & 11.6 \\
\hline 852 & 11.4 & & 76 & 11.8 \\
\hline 853 & 11.05 & & $T 7$ & 11.5 \\
\hline 856 & 11.4 & & 80 & 11.8 \\
\hline 858 & 11.6 & & 82 & 12.0 \\
\hline 860 & 11.5 & & 84 & 11.8 \\
\hline 862 & 11.4 & & 86 & 11.7 \\
\hline 864 & 11.8 & & 88 & 12.1 \\
\hline 869 & 11.5 & & 93 & 11.7 \\
\hline 879 & 11.8 & & 94 & 12.0 \\
\hline $87:$ & 12.0 & & 95 & 12.2 \\
\hline 874 & 1.95 & & 98 & 12.1 \\
\hline 876 & 12.05 & & 100 & 12.2 \\
\hline 877 & 12.0 & & 101 & 12.2 \\
\hline 878 & 12.3 & & 102 & 12.4 \\
\hline 880 & 12.2 & & 204 & 12.3 \\
\hline 882 & 11.9 & & 206 & 12.0 \\
\hline
\end{tabular}


241

Telle $\mathrm{M}$ - 1.1 (Coetinued)

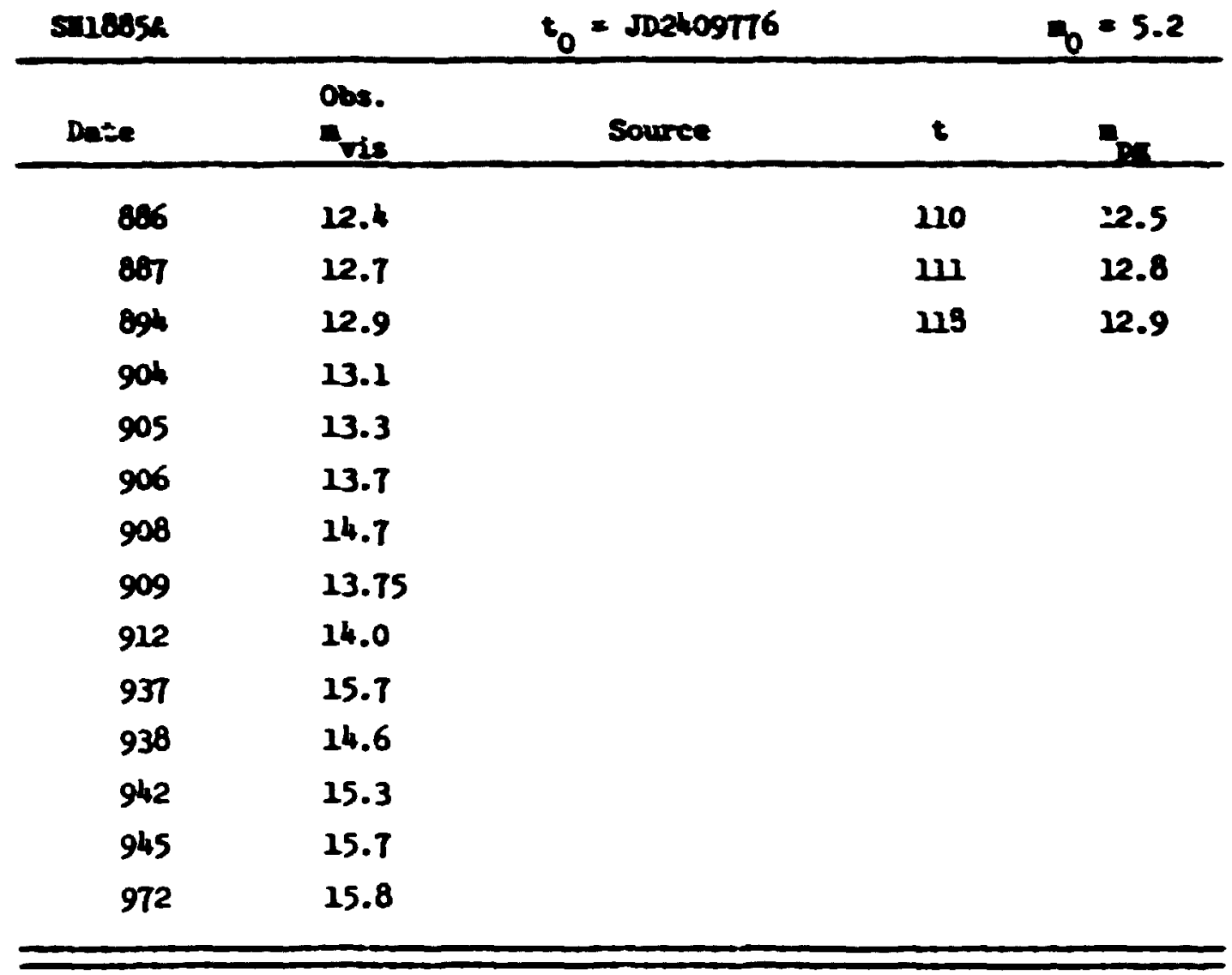




\section{$2 \div 2$}

rable $\mu-1.2$

\begin{tabular}{|c|c|c|c|c|}
\hline Date & Obe. & Souree & t & \\
\hline $12 / 5 / 22$ & 11.1 & Shaples (59) & -4 & 11.1 \\
\hline $12 / 7 / 21$ & 11.1 & & 2 & 11.1 \\
\hline $12 / 8 / 21$ & 11.1 & & -1 & 11.1 \\
\hline $12 / 8 / 21$ & 11.0 & & -1 & $\mathbf{1 1 . 0}$ \\
\hline $12 / 11 / 21$ & 21.0 & & 2 & 12.0 \\
\hline $12 / 19 / 21$ & 11.2 & & 10 & $\mathbf{H . 2}$ \\
\hline $12 / 21 / 21$ & 11.5 & & 12 & 21.5 \\
\hline $12 / 27 / 21$ & 11.8 & & 18 & 11.8 \\
\hline $1 / 1 / 22$ & 12.8 & & 23 & $1 \% .8$ \\
\hline $1 / 26 / 22$ & 15.1 & & 48 & 14.1 \\
\hline
\end{tabular}


243

Table al -1.3

\begin{tabular}{|c|c|c|c|c|c|c|}
\hline \multirow{2}{*}{$\frac{5 \times 1937=}{\text { Date }}$} & \multicolumn{4}{|c|}{$t_{0}=J D 2428768.0$} & \multicolumn{2}{|c|}{$z_{0}=8.4$} \\
\hline & $\begin{array}{c}\text { Bande } \\
\text { zurich (60) } \\
\text { n }\end{array}$ & $\begin{array}{c}\text { Parenaco } \\
\text { (57) } \\
n_{p c} \\
\end{array}$ & $\begin{array}{c}\text { Deuts:h } \\
\text { (61) } \\
\text { : }\end{array}$ & $\begin{array}{l}\text { Darer } \\
\text { (126) } \\
\text { nis } \\
\end{array}$ & $t$ & pes \\
\hline$J 02428762.4$ & & 8.85 & & & -5.6 & 8.85 \\
\hline 772.7 & & 8.4 & & & 4.7 & $8 . \$ 0$ \\
\hline 774.7 & 8.48 & 8.58 & & & 6.7 & 8.58 \\
\hline 775.7 & 8.63 & 8.63 & & & 7.7 & 8.63 \\
\hline 776.7 & 8.62 & $8.6 c$ & & & 8.7 & 8.62 \\
\hline$\pi 77.5$ & & 8.68 & & & 9.5 & 8.68 \\
\hline$\pi 77 \cdot 7$ & 8.64 & & & & 9.7 & 8.64 \\
\hline 778.5 & & 8.74 & & & 20.5 & 8.74 \\
\hline 778.7 & 8.74 & & & & 10.7 & 8.74 \\
\hline$\pi 79.3$ & & & & 8.76 & & \\
\hline 779.5 & & 8.93 & & & 11.5 & 8.93 \\
\hline 779.6 & 8.83 & & & & 11.6 & 8.83 \\
\hline 779.7 & 8.98 & & & & 11.7 & 8.98 \\
\hline 180.3 & & & 9.2 & 8.90 & 12.3 & 9.20 \\
\hline 780.6 & 9.25 & & & & 12.6 & 9.25 \\
\hline 780.6 & & 9.15 & & & 12.6 & 9.15 \\
\hline 780.7 & 9.14 & & & & 12.7 & 9.14 \\
\hline 781.3 & & & & 8.79 & & \\
\hline 781.6 & & 9.13 & & & 13.6 & 9.13 \\
\hline 781.7 & 9.13 & & & & 13.7 & 9.13 \\
\hline 781.7 & 9.09 & & & & 13.7 & 9.09 \\
\hline 781.7 & 9.24 & & & & 13.7 & 9.24 \\
\hline $7 \varepsilon 2.3$ & & & 9.3 & & 14.3 & 9.30 \\
\hline 782.4 & & & & 8.95 & & \\
\hline 782.5 & & 9.31 & & & 14.5 & 9.31 \\
\hline 782.7 & 9.50 & & & & 14.7 & 9.50 \\
\hline 783.3 & & & & 8.99 & & \\
\hline
\end{tabular}


244

Table Al - 1.3 (Continued)

\begin{tabular}{|c|c|c|c|c|c|c|}
\hline su1937e & & JD242876 & & & & $=8.4$ \\
\hline Date & $\begin{array}{l}\text { Bande \& } \\
\text { Zuich }(60) \\
\end{array}$ & $\begin{array}{c}\text { Parenago } \\
(57) \\
0\end{array}$ & $\begin{array}{c}\text { Deutseh } \\
(61) \\
=\end{array}$ & $\begin{array}{l}\text { Begrer } \\
(126) \\
\text { n vis } \\
\end{array}$ & $t$ & p6 \\
\hline JD2428783.4 & & & & 9.09 & & \\
\hline 783.5 & & 9.55 & & & 15.5 & 9.55 \\
\hline 763.7 & 9.54 & & & & 15.7 & 3.54 \\
\hline 783.7 & 9.55 & & & & 15.7 & 9.55 \\
\hline $\mathrm{JD} 2428784.3$ & & & & 9.03 & & \\
\hline 784.4 & & 9.55 & & & 16.4 & 9.55 \\
\hline 784.6 & 9.58 & & & & 16.6 & 9.58 \\
\hline 784.6 & 9.55 & & & & 16.6 & 9.55 \\
\hline 785.4 & & & & 9.19 & & \\
\hline 785.5 & & 9.72 & & & 17.5 & 9.72 \\
\hline 785.6 & 9.78 & & & & 27.6 & 9.78 \\
\hline 785.6 & 9.77 & & & & 17.6 & 9.77 \\
\hline 786.3 & & & 9.9 & & 18.3 & 9.90 \\
\hline 706.3 & & & & 9.21 & & \\
\hline 786.6 & 9.81. & & & & 18.6 & 9.31 \\
\hline 786.6 & 9.89 & & & & 18.6 & 9.89 \\
\hline 786.6 & & 9.87 & & & 18.6 & 9.87 \\
\hline 787.3 & & & 9.9 & & 19.3 & 9.90 \\
\hline 787.3 & & & & 9.26 & & \\
\hline 787.6 & 9.93 & & & & 19.6 & 9.93 \\
\hline 787.6 & 9.93 & & & & 19.6 & 9.93 \\
\hline 787.6 & & 9.92 & & & 19.6 & 9.92 \\
\hline 788.3 & & & 10.0 & & 20.3 & 10.00 \\
\hline 788.6 & 10.08 & & & & 20.6 & 10.08 \\
\hline 788.6 & 10.30 & & & & 20.6 & 10.30 \\
\hline 788.6 & & 10.08 & & & 20.6 & 10.08 \\
\hline 788.7 & 9.92 & & & & 20.7 & 9.92 \\
\hline
\end{tabular}


Table Al - 1.3 (Continued)

\begin{tabular}{|c|c|c|c|c|c|c|}
\hline S:1937: & & $=\mathrm{JD} 24287$ & 8.0 & & $t_{0}=$ & 8.4 \\
\hline Date & $\begin{array}{l}\text { Bende } \\
\text { suricic }(60)\end{array}$ & $\begin{array}{c}\text { Parenseo } \\
\text { (57) } \\
\\
\end{array}$ & $\begin{array}{l}\text { Deutseh } \\
\text { (ól) } \\
\\
\end{array}$ & $\begin{array}{l}\text { Beyer } \\
(126) \\
\text { vis }\end{array}$ & $t$ & f6 \\
\hline JD242878@.6 & 10.11 & & & & 21.6 & 10.11 \\
\hline 799.6 & 10.45 & & & & 21.6 & 10.45 \\
\hline 789.6 & & 10.27 & & & 21.6 & 10.27 \\
\hline 789.7 & 10.24 & & & & 21.7 & 10.24 \\
\hline 790.3 & & & & 9.49 & & \\
\hline 790.6 & 10.22 & & & & 22.6 & 10.22 \\
\hline 790.6 & 10.37 & & & & 22.6 & 10.37 \\
\hline 790.6 & & 10.30 & & & 22.6 & 10.30 \\
\hline 790.7 & 10.32 & & & & 22.7 & 10.32 \\
\hline 791.6 & 10.37 & & & & 23.6 & 10.37 \\
\hline 791.6 & 10.54 & & & & 23.6 & 10.54 \\
\hline JD2428791.6 & & 10.46 & & & 23.6 & 10.46 \\
\hline 792.6 & 10.56 & & & & 24.6 & 10.56 \\
\hline 792.; & 10.42 & & & & 24.6 & 10.41 \\
\hline 792.6 & & 10.48 & & & 24.6 & 10.48 \\
\hline 793.4 & & & & 9.67 & & \\
\hline 793.6 & 1C. 52 & & & & 25.6 & 10.52 \\
\hline 793.6 & 10.56 & & & & 25.6 & 10.56 \\
\hline 793.6 & & 20.54 & & & 25.6 & 10.54 \\
\hline 794.3 & & & & 9.72 & & \\
\hline 734.6 & 10.79 & & & & 26.6 & 10.79 \\
\hline 794.6 & 10.68 & & & & 26.6 & 10.68 \\
\hline 794.6 & & 10.74 & & & 26.6 & 10.74 \\
\hline 797.3 & & 10.7 & & 9.80 & 29.3 & 10.70 \\
\hline 798.0 & & 11.0 & & & 30.0 & 11.00 \\
\hline 798.3 & & & 11.0 & 9.91 & 30.3 & 11.00 \\
\hline 799.6 & 11.12 & & & & 31.6 & 11.12 \\
\hline
\end{tabular}


246

Table AI - 1.3 (Continued)

\begin{tabular}{|c|c|c|c|c|c|c|}
\hline sug37e & \multicolumn{3}{|c|}{$t_{0}=J D 2426768.0$} & \multicolumn{3}{|c|}{$\theta_{0}=8.4$} \\
\hline Date & $\begin{array}{l}\text { Bande } \\
\text { zuricks (60) } \\
\text { mer }\end{array}$ & $\begin{array}{c}\text { Parenago } \\
(57) \\
n_{\mathrm{pc}}\end{array}$ & $\begin{array}{c}\text { Deutsch } \\
\text { (61) } \\
\text { p. }\end{array}$ & $\begin{array}{l}\text { Beyer } \\
\text { (126) } \\
\text { nis } \\
\end{array}$ & $\mathbf{t}$ & pe \\
\hline JD2420799.6 & 11.31 & & & & 31.6 & 11.31 \\
\hline 799.6 & & 11.22 & & & 31.6 & 11.22 \\
\hline 800.3 & & & & 10.3 & & \\
\hline 800.6 & 11.25 & & & & 32.6 & $\mathbf{1 1 . 2 5}$ \\
\hline 800.6 & 21.19 & & & & 32.6 & 11.19 \\
\hline 800.6 & & 11.18 & & & 32.6 & 11.18 \\
\hline 801.3 & & & & 10.20 & & \\
\hline 801.6 & 11.30 & & & & 23.6 & 11.30 \\
\hline 801.6 & 11.16 & & & & 33.6 & 21.16 \\
\hline 801.6 & & 11.23 & & & 33.6 & 21.23 \\
\hline 802.5 & & 11.31 & & & 34.5 & 12.31 \\
\hline 802.6 & 11.27 & & & & 34.6 & 11.27 \\
\hline 802.6 & 11.25 & & & & 34.6 & 11.25 \\
\hline 803.3 & & & 21.3 & & 35.3 & 11.30 \\
\hline 803.5 & & 11.32 & & & 35.5 & 11.32 \\
\hline 803.6 & 11.31 & & & & 35.6 & 11.31 \\
\hline 803.6 & 11.26 & & & & 35.6 & 11.26 \\
\hline 804.3 & & & 11.4 & 10.33 & 36.3 & 11.40 \\
\hline JD2428804.5 & & 11.35 & & & 36.5 & 21.35 \\
\hline 804.6 & 11.33 & & & & 36.6 & 11.33 \\
\hline 805.3 & & 11.40 & & & 37.3 & 21.40 \\
\hline 805.3 & & & 11.4 & & 37.3 & 11.40 \\
\hline 806.3 & & & & 10.36 & & \\
\hline 806.6 & 11.29 & & & & 38.6 & 12.29 \\
\hline 806.6 & 11.31 & & & & 38.6 & 11.31 \\
\hline 806.6 & & 21.30 & & & 38.6 & 11.30 \\
\hline 807.2 & & & 11.4 & & 39.2 & 11.40 \\
\hline
\end{tabular}


Table Al - 1.3 (Continued)

\begin{tabular}{|c|c|c|c|c|c|c|}
\hline \multirow{2}{*}{$\frac{\text { Sul937c }}{\text { Date }}$} & \multicolumn{3}{|c|}{$t_{0}=J v 2428768.0$} & \multicolumn{3}{|c|}{$7_{0}=8.4$} \\
\hline & $\begin{array}{l}\text { Bande } \\
\text { Zuich }(60) \\
\text { n }\end{array}$ & $\begin{array}{c}\text { Purenaso } \\
\text { (57) } \\
\text { n }\end{array}$ & $\begin{array}{l}\text { Deutsch } \\
(61) \\
\end{array}$ & $\begin{array}{l}\text { Pater } \\
(126) \\
n\end{array}$ & $t$ & pes \\
\hline JD2428807.3 & & & & 10.48 & & \\
\hline 807.5 & & 11.40 & & & 39.5 & 11.40 \\
\hline 807.6 & 11.42 & & & & 39.6 & 11.42 \\
\hline 907.6 & 11.39 & & & & 39.6 & 11.39 \\
\hline 808.5 & & 21.43 & & & 40.5 & 11.43 \\
\hline 808.6 & 11.36 & & & & 40.6 & 11.36 \\
\hline 808.6 & 11.35 & & & & 40.6 & 11.35 \\
\hline 809.2 & & & 11.5 & & 41.2 & 11.50 \\
\hline 809.3 & & 21.50 & & & 41.3 & 11.50 \\
\hline 810.2 & & & 11.5 & & 42.2 & 11.50 \\
\hline 810.4 & & 11.51 & & & 42.4 & 11.51 \\
\hline 810.6 & 11.52 & & & & 42.6 & 11.52 \\
\hline 811.2 & & 11.5 & & & 43.2 & 11.50 \\
\hline 811.2 & & & 11.5 & & 43.2 & 11.50 \\
\hline 812.2 & & 11.5 & & & 44.2 & 11.50 \\
\hline 812.2 & & & 11.5 & & 44.2 & 11.511 \\
\hline 812.3 & & & & 10.59 & & \\
\hline 813.3 & & & & 20.56 & & \\
\hline 813.6 & 11.46 & 11.46 & & & 45.6 & 11.46 \\
\hline 814.2 & & 11.50 & 11.5 & & 46.2 & 11.50 \\
\hline 814.3 & & & & 10.72 & & \\
\hline 815.6 & 11.62 & 11.62 & & & 47.6 & 11.62 \\
\hline 817.3 & & & & 10.74 & & \\
\hline 818.3 & & & & 10.74 & & \\
\hline 818.6 & 11.72 & 21.72 & & & 50.6 & 11.72 \\
\hline 819.3 & & 11.70 & & 10.76 & 51.3 & 11.70 \\
\hline 820.6 & 11.86 & 11.86 & & & $j 2.6$ & 11.86 \\
\hline 822.3 & & & & 10.89 & & \\
\hline
\end{tabular}


248

Table $\mu \mathrm{l}-1.3$ (Continued)

\begin{tabular}{|c|c|c|c|c|c|c|}
\hline sung37c & & $t_{0}=$ JD2h & 768.0 & & $0=$ & \\
\hline Date & $\begin{array}{c}\text { Bande } \\
\text { zuricty }(60) \\
\text { a. }\end{array}$ & $\begin{array}{c}\text { Parenanos } \\
\text { (57) } \\
n\end{array}$ & $\begin{array}{c}\text { Deutsch } \\
\text { (61) } \\
\text { p. }\end{array}$ & $\begin{array}{l}\text { Beyer } \\
\text { (126) } \\
\text { vis }\end{array}$ & $t$ & $n_{\text {pe }}$ \\
\hline JD2426826.2 & & 11.9 & 11.9 & & 58.2 & 11.90 \\
\hline 827.2 & & & & 11.12 & & \\
\hline 829.3 & & & & 11.19 & & \\
\hline 830.2 & & 11.8 & 11.8 & & 62.2 & 21.80 \\
\hline 831.0 & 11.94 & & & & 63.0 & 21.94 \\
\hline 831.1 & & 11.92 & & & 63.1 & 11.92 \\
\hline 831.2 & & & 11.9 & 11.03 & 63.2 & 11.90 \\
\hline 833.0 & 12.03 & 12.03 & & & 65.0 & 12.03 \\
\hline 833.2 & & & & 11.13 & & \\
\hline 836.6 & & 12.00 & & & 68.6 & 12.00 \\
\hline 837.0 & 12.02 & & & & 69.0 & 12.02 \\
\hline 840.2 & & & & 11.26 & & \\
\hline 940.6 & & & & 11.22 & & \\
\hline 8 hi2.0 & 12.05 & & & & 74.0 & 12.05 \\
\hline 842.0 & & 12.07 & & & 74.0 & 12.07 \\
\hline 842.1 & & & 12.1 & & 74.1 & 12.10 \\
\hline 853.6 & & & & 11.62 & & \\
\hline 854.6 & & & & 1.71 & & \\
\hline 862.9 & 12.38 & 12.38 & & & 94.9 & 12.38 \\
\hline 865.0 & 12.40 & & & & 97.0 & 12.10 \\
\hline 865.0 & 12.46 & & & & 97.0 & 12.46 \\
\hline 865.0 & 12.42 & & & & 97.0 & 12.42 \\
\hline 865.0 & 12.43 & 12.43 & & & 97.0 & 12.43 \\
\hline 865.6 & & & & 11.93 & & \\
\hline 866.1 & 22.49 & & & & 98.0 & 12.49 \\
\hline 866.0 & 12.43 & & & & 98.0 & 12.43 \\
\hline 866.0 & & 12.46 & & & 98.0 & 12.46 \\
\hline
\end{tabular}


249

Table $\Lambda 1-1.3$ (Continued)

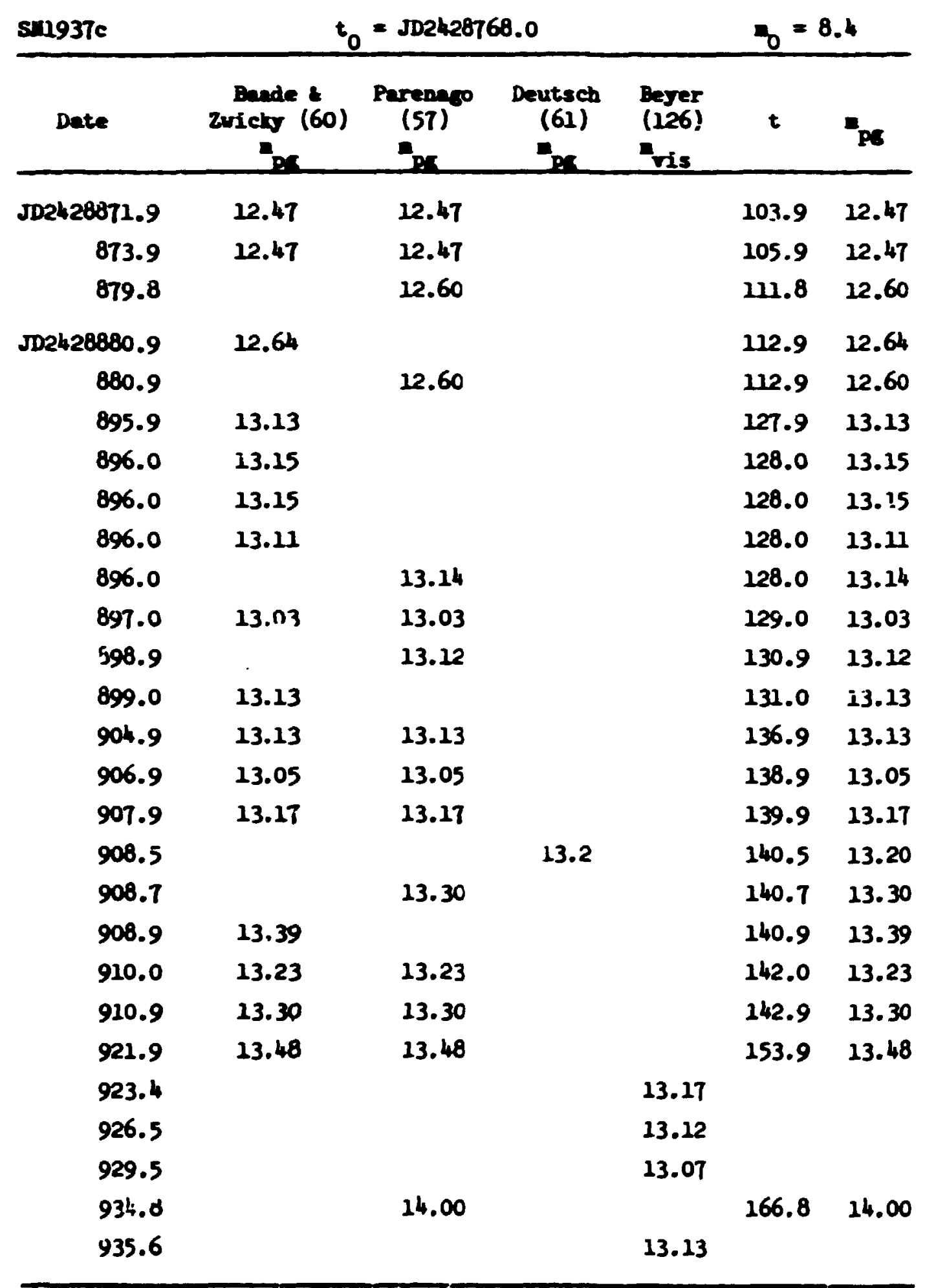


Table $\mu$ - -1.3 (Coctinuad)

\begin{tabular}{|c|c|c|c|c|c|c|}
\hline sug37e & & $=J D 2420$ & 8.0 & & $\mathbf{n}_{\mathbf{3}}=$ & \\
\hline Date & $\begin{array}{c}\text { nade } \\
\text { zuriely }(60) \\
\text { nor }\end{array}$ & $\begin{array}{c}\text { Pureanapo } \\
\text { (57) } \\
n\end{array}$ & $\begin{array}{c}\text { Deutseh } \\
\text { (6:) } \\
0_{:}\end{array}$ & $\begin{array}{l}\text { Eyer } \\
\text { (126) } \\
\text { vis }\end{array}$ & $t$ & $a_{10}$ \\
\hline$J 02428937.8$ & & 13.60 & & & 169.8 & 13.60 \\
\hline 946.3 & & $14 . c 5$ & 14.0 & & 178.3 & 14.00 \\
\hline 947.8 & 13.65 & 13.65 & & & 179.0 & 13.65 \\
\hline 948.16 & & & & 13.24 & & \\
\hline 949.4 & & & & 13.29 & & \\
\hline 949.8 & 13.71 & 13.71 & & & 181.8 & 23.71 \\
\hline 950.3 & & & 14.0 & & 182.3 & 14.00 \\
\hline 950.5 & & & & 13.39 & & \\
\hline 950.6 & & 13.86 & & & 182.6 & 23.86 \\
\hline 950.8 & 13.72 & & & & 182.8 & 13.72 \\
\hline JD2428951.4 & & & 13.9 & & 283.4 & 13.90 \\
\hline 951.6 & & 13.80 & & & 183.6 & 13.60 \\
\hline 951.8 & 13.71 & & & & 183.8 & 13.71 \\
\hline 952.5 & & & & 13.39 & & \\
\hline 952.8 & 16.13 & 14.13 & & & 184.6 & 14.13 \\
\hline 953.8 & 14.13 & & & & 185.6 & 14.13 \\
\hline $95+.0$ & & 14.22 & & & 186.0 & 14.12 \\
\hline 954.5 & & & & 13.44 & & \\
\hline 954.8 & 13.92 & & & & 186.8 & 13.92 \\
\hline 955.0 & & 14.01 & & & 187.0 & 14.01 \\
\hline 955.6 & & & 13.8 & 13.44 & 187.6 & 13.80 \\
\hline 955.8 & 13.94 & & & & 187.8 & 13.94 \\
\hline 956.0 & & 13.96 & & & 188.0 & 13.96 \\
\hline 960.4 & & 14.0 & 14.0 & & 192.4 & 14.00 \\
\hline 963.6 & & 14.05 & & & i95.6 & 24.05 \\
\hline 963.9 & 24.10 & & & & 195.9 & 24.10 \\
\hline 967.5 & & 14.1 & 14.1 & & 199.5 & 14.10 \\
\hline
\end{tabular}


251

Teble Al - 1.3 (Continued)

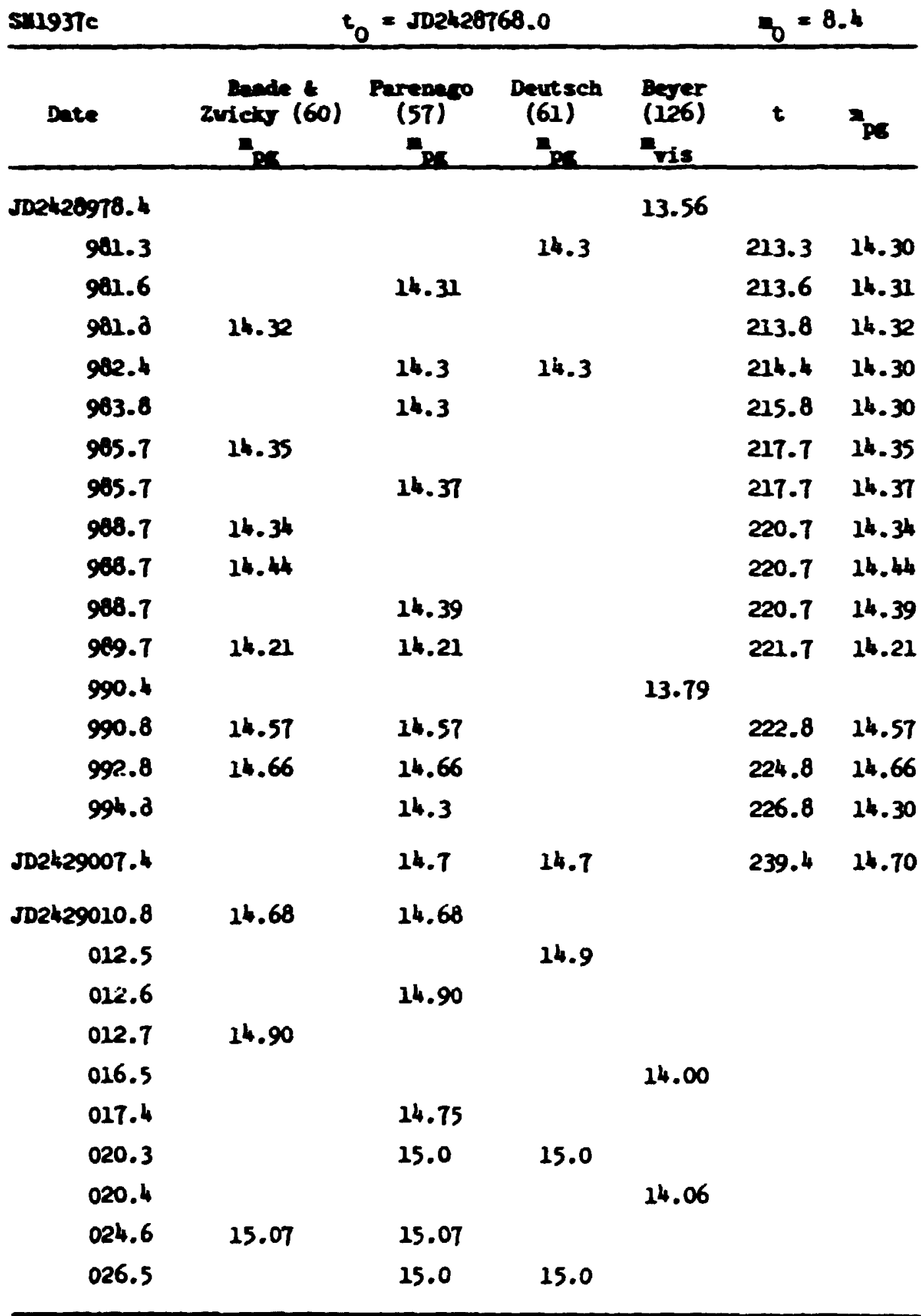


Table $\Lambda$ - 1.3 (Contimed)

\begin{tabular}{|c|c|c|c|c|c|}
\hline sng37e & & $0^{=}$JD2kze & 68.0 & & 8 \\
\hline Date & $\begin{array}{c}\text { Bande } \\
\text { zuricty }(60) \\
\text { ne. }\end{array}$ & $\begin{array}{c}\text { Paremeo } \\
\text { (57) } \\
0: 1\end{array}$ & $\begin{array}{c}\text { Deutseh } \\
\text { (61) } \\
\end{array}$ & $\begin{array}{l}\text { Eeyer } \\
\text { (126) } \\
\text { eds }\end{array}$ & $t$ \\
\hline JDet29039.5 & & & & 14.1 & \\
\hline 040.8 & 15.28 & 15.28 & & & \\
\hline 048.8 & 15.57 & 15.57 & & & \\
\hline 049.8 & 15.57 & 15.57 & & & \\
\hline 058.0 & & 15.6 & & & \\
\hline
\end{tabular}


Table Al - 1.4

\begin{tabular}{|c|c|c|c|c|c|c|}
\hline \multirow{2}{*}{$\frac{\text { stigsid }}{\text { Date }}$} & \multicolumn{3}{|c|}{$t_{0}=J D 2428792.0$} & \multicolumn{3}{|c|}{$b_{0}=12.8$} \\
\hline & $\begin{array}{l}\text { Dande } \\
\text { zurich }(60)\end{array}$ & $\begin{array}{l}\text { Hetanan } \\
\text { (60) } \\
\text {. }\end{array}$ & $\begin{array}{l}\text { Parenaco } \\
\text { (5T) } \\
=\end{array}$ & $\begin{array}{l}\text { Burer } \\
\text { (126) }\end{array}$ & t & $\mathbf{P s}_{\mathrm{ps}}$ \\
\hline JD2428776.8 & & & 12.70 & & $-15 . ?$ & 12.70 \\
\hline$\pi 7.8$ & & & 12.40 & & -14.2 & 12.40 \\
\hline 782.6 & & 13.73 & & & -9.4 & 23.73 \\
\hline$T 82.8$ & & & 13.00 & & -9.2 & 13.00 \\
\hline 784.5 & & 13.28 & & & -7.5 & 13.28 \\
\hline 787.8 & 12.98 & & 12.98 & & -4.2 & 12.98 \\
\hline 788.8 & 13.01 & & & & -3.2 & 13.01 \\
\hline 788.8 & & & 13.06 & & -3.2 & 13.06 \\
\hline 788.9 & 13.12 & & & & -3.1 & 13.12 \\
\hline 789.8 & 13.16 & & 13.16 & & $-2 . \bar{c}$ & 13.16 \\
\hline 790.8 & 12.85 & & & & $-1 . \bar{c}$ & 12.85 \\
\hline 790.8 & & & 12.84 & & -1.2 & 12.84 \\
\hline 790.9 & 12.84 & & & & -1.1 & 12.84 \\
\hline 791.8 & & & 12.84 & & -0.2 & 12.84 \\
\hline 791.9 & 12.67 & & & & -0.1 & 12.67 \\
\hline 791.9 & 12.89 & & & & -0.1 & 12.69 \\
\hline 792.7 & & & 12.97 & & 0.7 & 12.97 \\
\hline 792.9 & 12.90 & & & & 0.9 & 12.90 \\
\hline 793.9 & 13.11 & & 13.11 & & 1.3 & 13.11 \\
\hline 794.5 & & & & 12.16 & & \\
\hline 794.9 & 13.00 & & 13.00 & & 2.9 & 13.00 \\
\hline 795.3 & & & & 12.18 & & \\
\hline$: 95.8$ & & & $13 . c 0$ & & 3.8 & 13.00 \\
\hline 735.9 & 13.00 & & & & 3.9 & 13.00 \\
\hline 796.7 & & & 13.00 & & 4.7 & 13.00 \\
\hline 797.3 & & & & $(11.9)$ & & \\
\hline 797.6 & & & 13.03 & & 5.6 & 23.03 \\
\hline
\end{tabular}


Table $11-1.4$ (Contious)

\begin{tabular}{|c|c|c|c|c|c|c|}
\hline \multirow{2}{*}{$\begin{array}{l}\text { Smes7d } \\
\text { Date }\end{array}$} & \multicolumn{4}{|c|}{$t_{0}=J D 2+20792.0$} & \multicolumn{2}{|c|}{$z_{0}=12.8$} \\
\hline & $\begin{array}{c}\text { Dande } \\
\text { zuricts }(60) \\
0.1\end{array}$ & $\begin{array}{l}\text { Uhebman } \\
\text { (60) } \\
n \\
\end{array}$ & $\begin{array}{l}\text { Parenepo } \\
(5 T) \\
n_{x}\end{array}$ & $\begin{array}{l}\text { Drer } \\
\text { (126) } \\
\text { nds } \\
\end{array}$ & $t$ & nos \\
\hline JD2428798. 3 & & & & 12.59 & & \\
\hline 798.5 & & & & 12.52 & & \\
\hline 798.8 & & & 13.20 & & 6.8 & 13.20 \\
\hline 799.7 & 13.19 & & & & 7.7 & 13.19 \\
\hline JD2428T99.7 & 12.93 & & & & 7.7 & 12.93 \\
\hline 799.7 & & & 13.07 & & 7.7 & 13.07 \\
\hline 800.3 & & & & 12.56 & & \\
\hline 800.7 & 13.10 & & & & 8.7 & 13.10 \\
\hline 800.7 & & & 13.20 & & 8.1 & 13.20 \\
\hline 801.3 & & & & 12.60 & & \\
\hline 801.7 & 13.39 & & & & 9.7 & 13.39 \\
\hline 801.7 & & & 13.30 & & 9.7 & 13.30 \\
\hline 801.8 & 13.20 & & & & 9.8 & 13.20 \\
\hline 802.5 & & & 13.68 & & 10.5 & 13.68 \\
\hline 802.7 & 13.69 & & & & 10.7 & 13.69 \\
\hline 803.5 & & & 13.67 & 12.93 & 11.5 & 13.67 \\
\hline 803.7 & 13.66 & & & & 11.7 & 13.66 \\
\hline 804.4 & & & & 13.05 & & \\
\hline 804.5 & & & 13.81 & & 12.5 & 13.81 \\
\hline 804.8 & 13.79 & & & & 12.8 & 13.79 \\
\hline 805.8 & 13.90 & & 13.90 & & 13.8 & 13.90 \\
\hline 806.4 & & & & 13.11 & & \\
\hline 806.5 & & & & 13.11 & & \\
\hline 806.6 & & & 14.01 & & 14.6 & 24.01 \\
\hline 807.4 & & & & 13.17 & & \\
\hline 807.7 & & & 14.20 & & 15.7 & 14.20 \\
\hline 807.3 & 14.26 & & & & 15.9 & 14.26 \\
\hline
\end{tabular}


Table $\mu$ - 1.4 (Coatinined)

\begin{tabular}{|c|c|c|c|c|c|c|}
\hline sul937d & & $=\sqrt[J D 242879]{ }$ & 2.0 & & $z_{0}=2$ & 2.8 \\
\hline Date & $\begin{array}{l}\text { Bade } \\
\text { zuriety }(60) \\
n\end{array}$ & $\begin{array}{l}\text { Wechnon } \\
(60) \\
\text { pe }\end{array}$ & $\begin{array}{c}\text { Paremero } \\
(57) \\
n \\
\end{array}$ & $\begin{array}{l}\text { Beser } \\
(126) \\
\text { = ris } \\
\end{array}$ & $t$ & Es $_{\text {pS }}$ \\
\hline JD2428808.6 & & & 14.21 & & $1 E .6$ & 14.21 \\
\hline 808.8 & 14.27 & & & & 16.8 & 14.27 \\
\hline 808.9 & 14.27 & & & & 16.9 & 14.27 \\
\hline 809.6 & & & 14.35 & & 17.6 & 14.35 \\
\hline 810.5 & & & 14.30 & & 18.5 & 14.30 \\
\hline 811.6 & & & 14.35 & & 19.6 & 14.35 \\
\hline 812.3 & & & & 13.46 & & \\
\hline 812.7 & 14.68 & & & & 20.7 & 14.68 \\
\hline 812.8 & & & 14.64 & & 20.8 & .24 .54 \\
\hline 812.9 & 14.61 & & & & 20.9 & 24.61 \\
\hline 813.3 & & & & 13.47 & & \\
\hline 813.9 & 14.61 & & & & 21.9 & 14.61 \\
\hline JD2428813.9 & & & 14.62 & & 21.9 & 14.62 \\
\hline 814.0 & 14.64 & & & & 22.0 & 14.64 \\
\hline 814.3 & & & & 13.52 & & \\
\hline 814.6 & & & 14.64 & & 22.6 & 14.64 \\
\hline 814.7 & 14.71 & & & & 22.7 & 14.71 \\
\hline 815.5 & & & 14.90 & & 23.5 & 14.90 \\
\hline 816.5 & & & & $13.7^{4}$ & & \\
\hline 816.5 & & & & 13.76 & & \\
\hline 817.4 & & & & 13.84 & & \\
\hline 818.5 & & & & 13.82 & & \\
\hline 819.2 & & & 15.13 & & 27.2 & 15.13 \\
\hline 820.8 & 15.03 & & 15.03 & & 28.8 & 15.03 \\
\hline 821.7 & & & 15.20 & & 29.7 & 15.20 \\
\hline 822.4 & & & & 13.87 & & \\
\hline 822.5 & & & 15.33 & & 30.05 & 15.33 \\
\hline
\end{tabular}




\section{6}

Teble $\mathrm{A}-1.4$ (Costinued)

\begin{tabular}{|c|c|c|c|c|c|c|}
\hline sw1937d & & $=\mathrm{JD2} 2 \mathrm{2}$ & 2.0 & & $b^{2}$ & 12.8 \\
\hline Date & $\begin{array}{c}\text { Bande } \\
\text { 2wicky }(60) \\
\text { ne }\end{array}$ & $\begin{array}{c}\text { Mechanon } \\
(60) \\
n \\
\mathrm{pa}\end{array}$ & $\begin{array}{c}\text { Parenapo } \\
(57) \\
= \\
\end{array}$ & $\begin{array}{l}\text { Deyer } \\
(126) \\
n_{\text {ris }}\end{array}$ & $t$ & Est \\
\hline J02428824.T & & & 15.30 & & 32.7 & 15.30 \\
\hline 829.3 & & & & (13.5) & & \\
\hline 830.4 & & & & 13.98 & & \\
\hline 830.5 & & & 15.80 & & 38.5 & 15.80 \\
\hline 831.5 & & & & 214.0 & & \\
\hline 832.5 & & & 15.63 & & 40.5 & 15.63 \\
\hline .334 .2 & & & 25.75 & & 42.2 & 15.75 \\
\hline 834.3 & & & & $(13.8)$ & & \\
\hline 837.2 & & & 15.73 & & 45.2 & 25.73 \\
\hline 838.8 & & & 25.69 & & 46.8 & 15.69 \\
\hline 838.9 & 15.80 & & & & 46.9 & 15.80 \\
\hline 839.9 & 15.68 & & & & 46.9 & 15.68 \\
\hline 840.5 & & & & 24.16 & & \\
\hline 840.8 & 25.69 & & & & 48.8 & 15.69 \\
\hline 840.8 & & & 15.71 & & 48.8 & 15.71 \\
\hline 840.9 & 15.73 & & & & 48.9 & 15.73 \\
\hline 844.7 & & & 16.20 & & 52.7 & 16.20 \\
\hline 847.3 & & & & $(14.1)$ & & \\
\hline 848.7 & & & 16.20 & & 56.7 & 16.20 \\
\hline 861.7 & & & 16.50 & & 69.7 & 16.50 \\
\hline JD2428863.7 & 16.42 & & 16.42 & & 71.7 & 16.42 \\
\hline $865 . i$ & 16.47 & & 26.47 & & 73.7 & 16.47 \\
\hline 872.6 & 16.55 & & & & 80.6 & 16.55 \\
\hline 872.7 & & & 16.52 & & 80.7 & 16.52 \\
\hline 895.6 & 16.93 & & & & 103.6 & 16.93 \\
\hline 895.7 & & & 26.94 & & 103.7 & 16.94 \\
\hline 895.8 & 16.95 & & & & 103.8 & 16.95 \\
\hline
\end{tabular}


Table $\mu 1-1.4$ (Continued)

\begin{tabular}{|c|c|c|c|c|c|c|}
\hline sw1937d & & $=\mathrm{JD} 24287$ & 2.0 & & $0=$ & \\
\hline Dete & $\begin{array}{c}\text { Bande } \\
\text { 2wicky }(60) \\
\text { par }\end{array}$ & $\begin{array}{l}\text { Wachnono } \\
(60) \\
\text { pr }\end{array}$ & $\begin{array}{c}\text { Parenaso } \\
\text { (57) } \\
=\end{array}$ & $\begin{array}{l}\text { Beyer } \\
(126) \\
\text { vis }\end{array}$ & $t$ & Pt \\
\hline J02428697.8 & 16.91 & & 16.91 & & 205.8 & 16.91 \\
\hline 898.7 & 16.99 & & 16.99 & & 106.7 & 16.99 \\
\hline 929.8 & 17.05 & & 17.05 & & 137.8 & 17.05 \\
\hline 954.6 & 27.41 & & 17.41 & & 162.6 & 17.41 \\
\hline 955.6 & 17.42 & & 17.42 & & 163.6 & 17.42 \\
\hline 990.6 & 17.43 & & 17.43 & & 198.6 & 17.43 \\
\hline
\end{tabular}




\section{8}

Table Al - 1.5

\begin{tabular}{|c|c|c|c|c|c|c|}
\hline \multirow{2}{*}{$\frac{\text { sils } 39 a}{\text { Date }}$} & \multicolumn{4}{|c|}{$t_{0}=J 12429290.0$} & \multicolumn{2}{|c|}{$n_{0}=12.60$} \\
\hline & $\begin{array}{c}\text { Hoffleit } \\
(63) \\
n_{p .} \\
\end{array}$ & $\begin{array}{c}\text { Gicles } \\
(62) \\
\text { ge? }\end{array}$ & $\begin{array}{l}\text { Bance } \\
(48) \\
\text { ngs }\end{array}$ & $\begin{array}{l}\text { Bejer } \\
(126) \\
\text { nis } \\
\end{array}$ & $t$ & p8 \\
\hline JD242928: & & & 14.8 & & -9.0 & 14.8 \\
\hline 282 & & & 13.4 & & -8.0 & $13 .:$ \\
\hline 284 & 12.5 & & & & -6.0 & 13.0 \\
\hline 284 & & & 12.8 & & -6.0 & 12.8 \\
\hline $286^{\circ}$ & 12.2 & & 12.7 & & -4.0 & $12 . ?$ \\
\hline 287 & & & 12.7 & & -3.0 & 12.7 \\
\hline 287.9 & & $\therefore 2.8$ & & & -2.1 & iz. 9 \\
\hline 288.7 & & & & 12.35 & & \\
\hline 288.9 & & 13.0 & & & -1.1 & 13.0 \\
\hline 289 & 12.5 & & & & -1.0 & 13.0 \\
\hline $289.0^{\circ}$ & & & & 12.24 & & \\
\hline 289.9 & & 12.8 & & & -0.1 & 12.8 \\
\hline 290 & & & 12.6 & & 0.0 & 12.6 \\
\hline 290.9 & & 12.8 & & & 0.9 & 12.8 \\
\hline 291 & 12.3 & & & & 1.0 & 12.8 \\
\hline 291 & 11.8 & & & & 1.0 & 12.3 \\
\hline $29<.9$ & & 12.9 & & & 2.9 & 12.9 \\
\hline 293.5 & & & & 12.25 & & \\
\hline 294 & & & 12.6 & & 4.0 & 12.6 \\
\hline 294 & & & $12 .:$ & & 4.0 & 12.7 \\
\hline 297.0 & & 13.1 & & & 7.0 & 13.1 \\
\hline 297 & & & 12.8 & & 7.0 & 22.8 \\
\hline 304.8 & & 14.0 & & & 14.8 & 14.0 \\
\hline 306 & & & 24.7 & & 16.6 & 14.7 \\
\hline 306.9 & & 14.3 & & & 16.3 & 14.3 \\
\hline 307 & & 14.6 & & & $\therefore 7.0$ & 14.6 \\
\hline 308.6 & & & & 13.79 & & \\
\hline
\end{tabular}


Table Al - 1.5 (Continued)

\begin{tabular}{|c|c|c|c|c|c|c|}
\hline Date & $\begin{array}{l}\text { Ho:rleit } \\
\text { (63) }\end{array}$ & $\begin{array}{l}\text { Gielns } \\
\text { ((12) }\end{array}$ & $\begin{array}{l}\text { Bande } \\
\text { (48) }\end{array}$ & $\begin{array}{l}\text { Beyer } \\
\text { (126) }\end{array}$ & $t$ & pos \\
\hline JD2429308.8 & & 24.6 & & & 18.8 & 14.6 \\
\hline 309 & & & 24.8 & & 19.0 & 14.8 \\
\hline 310.9 & & 14.6 & & & 20.9 & 14.6 \\
\hline 315.8 & & -5.0 & & & 25.8 & 15.0 \\
\hline 316.8 & & 14.7 & & & 26.8 & 14.7 \\
\hline JD2429318 & & & 15.2 & & 28.0 & 15.2 \\
\hline 343 & & & 15.6 & & 53.c & 1.5 .6 \\
\hline 344 & & & 15.5 & & 54.0 & 15.5 \\
\hline 347 & & & 15.7 & & 57.0 & 15.7 \\
\hline 375 & & & 16.2 & & 85.0 & 16.2 \\
\hline 399 & & & 26.7 & & 109.0 & 16.7 \\
\hline 400 & & & 16.7 & & 111.0 & 16.7 \\
\hline 431 & & & 27.0 & & 241.0 & 17.0 \\
\hline 432 & & & 17.1 & & 142.0 & 17.1 \\
\hline 458 & & & 17.7 & & $168 . n$ & 17.7 \\
\hline
\end{tabular}


Table $\mu 1-1.6$

sng390

\begin{tabular}{|c|c|c|c|c|}
\hline Date & $\begin{array}{c}\text { Shaples } \\
(6 h) \\
\end{array}$ & $\begin{array}{l}\text { Bande } \\
(48) \\
\end{array}$ & $t$ & $m_{\text {s }}$ \\
\hline JD2429376 & & $i 3.9$ & -9 & $13 . \bar{y}$ \\
\hline $4 / 23 / 39$ & 13.6 & & -8 & 13.6 \\
\hline JD2429379 & 12.7 & $12 . ?$ & -6 & 12.7 \\
\hline $5 / 6 / 39$ & 12.2 & & 5 & 12.2 \\
\hline $5 / 6 / 39$ & 12.1 & & 5 & 12.1 \\
\hline $5 / 7 / 39$ & 12.6 & & 6 & 12.6 \\
\hline JD2429391 & & 12.2 & 6 & 12.2 \\
\hline $5 / 8 / 39$ & 12.9 & & 7 & 12.9 \\
\hline JD2429392 & & 12.6 & T & 12.6 \\
\hline 393 & & 13.0 & 8 & 13.0 \\
\hline $5 / 2.0 / 39$ & 13.5 & & 9 & 13.5 \\
\hline $5 / 11 / 39$ & 13.2 & & 10 & 13.2 \\
\hline JD2429395 & & 13.5 & 10 & 13.5 \\
\hline 395 & & 13.8 & 10 & 13.8 \\
\hline $5 / 12 / 39$ & 13.6 & & $\mathbf{u}$ & 13.6 \\
\hline $5 / 12 / 39$ & 13.3 & & 2.1 & 13.3 \\
\hline JD2429396 & 13.7 & & $\mathbf{u}$ & 13.7 \\
\hline 396 & 24.0 & & 11 & $14 . C$ \\
\hline $5 / 13 / 39$ & $13 . i$ & & 12 & $\therefore 2.7$ \\
\hline JD2429397 & & it.e & 12 & 14.2 \\
\hline $5 / 14 / 39$ & 13.9 & & $: 3$ & 13.9 \\
\hline D2429398 & & 14.1 & 13 & 14.1 \\
\hline $5 / 15 / 39$ & $i 3.8$ & & 14 & 13.8 \\
\hline $5 / 16 / 39$ & 13.7 & & 15 & 13.7 \\
\hline $5 / 16 / 39$ & 13.8 & & 25 & 13.8 \\
\hline
\end{tabular}

$t_{0}=$ JD2429385.0 $\quad g_{0}=11.8$ 
261

Table $\Lambda 1-1.6$ (Continued)

\begin{tabular}{|c|c|c|c|c|}
\hline sul9396 & $t_{0}=J$ & 5.0 & & 11.8 \\
\hline Date & $\begin{array}{c}\text { Saspley } \\
(64)\end{array}$ & $\begin{array}{l}\text { Bande } \\
\text { (48) }\end{array}$ & $t$ & ${ }_{p 6}$ \\
\hline JD2429h02 & & 15.3 & 17 & 15.3 \\
\hline 403 & & 15.2 & 18 & 15.2 \\
\hline 406 & & 15.3 & 21 & 15.3 \\
\hline 424 & & 15.9 & 39 & 15.9 \\
\hline 427 & & 16.2 & 42 & 16.2 \\
\hline 428 & & 16.1 & 43 & 16.1 \\
\hline JD2429430 & & 16.2 & 45 & 16.2 \\
\hline 432 & & 16.2 & 47 & 16.2 \\
\hline 435 & & 16.1 & 50 & 16.1 \\
\hline 437 & & 16.3 & 52 & 16.3 \\
\hline 458 & & 16.3 & 73 & 16.3 \\
\hline 458 & & 16.4 & 73 & 16.4 \\
\hline 612 & & 18.8 & 227 & 18.8 \\
\hline
\end{tabular}


262

Table $\mu 1-1.7$

\begin{tabular}{|c|c|c|c|c|c|c|}
\hline \multirow{2}{*}{ Sngshe } & \multicolumn{3}{|c|}{$t_{0}=J 02434851.0$} & \multicolumn{3}{|c|}{$z_{0}=9.50$} \\
\hline & wha & $\begin{array}{l}\text { Borpmeister } \\
\text { (66) }\end{array}$ & $\begin{array}{l}\text { Pietre } \\
(65,66)\end{array}$ & $\begin{array}{l}\text { Beser } \\
\text { (128) }\end{array}$ & $t$ & $\mathbf{m p}$ \\
\hline$J 02434843.0$ & & 10.8 & & & -8.0 & 10.8 \\
\hline 955.9 & & 20.1 & & & 4.9 & 10.1 \\
\hline 857.9 & & 10.4 & & & 6.9 & 10.4 \\
\hline 867.4 & & & 11.7 & & 16.4 & 21.7 \\
\hline 888.9 & & 12.4 & & & 37.9 & 12.4 \\
\hline 5/30/5h, $T^{h}$ og & 12.43 & & & & 42.3 & 12.43 \\
\hline $5 / 32 / 54,935$ & 12.32 & & & & 43.4 & 12.32 \\
\hline $6 / 1 / 54,515$ & 12.66 & & & & 44.2 & 12.66 \\
\hline $6 / 2 / 54,721$ & 12.59 & & & & 44.3 & 12.59 \\
\hline $6 / 2 / 54, \quad 5 \quad 63$ & 12.57 & & & & 45.2 & 12.57 \\
\hline $6 / 2 / 54,608$ & 12.65 & & & & 45.3 & 12.65 \\
\hline $6 / 2 / 54,651$ & 12.56 & & & & 45.3 & 22.56 \\
\hline $6 / 2 / 54,725$ & $12.60^{\circ}$ & & & & 45.3 & 12.66 \\
\hline $6 / 4 / 54$ & & & & 11.8 & & \\
\hline $6 / 4 / 54,5^{h} 20^{\circ}$ & 12.67 & & & & 47.2 & 12.67 \\
\hline $6 / 4 / 54,600$ & 12.68 & & & & 47.3 & 12.68 \\
\hline $6 / 4 / 54,611$ & 12.67 & & & & 47.3 & 12.07 \\
\hline $6 / 4 / 54,627$ & 12.69 & & & & 47.3 & 12.69 \\
\hline $6 / 5 / 54$ & & & & 11.8 & & \\
\hline $\mathrm{JD2} 434899.4$ & & & 12.2 & & 48.4 & 12.2 \\
\hline $6 / 6 / 54$ & & & & 11.9 & & \\
\hline J02434900.4 & & & 12.4 & & 49.4 & 12.4 \\
\hline 901.4 & & & 12.5 & & 50.4 & 12.5 \\
\hline $6 / 8 / 54$ & & & & 11.9 & & \\
\hline
\end{tabular}


Table 11 - 1.7 (Continued)

\begin{tabular}{|c|c|c|c|c|c|c|c|}
\hline & Su1954e & & $0=J D 2434851$ & & & $b=9$ & \\
\hline • & Date & $\begin{array}{l}\text { Wild } \\
(65) \\
0 \\
\end{array}$ & $\begin{array}{c}\text { Horn eister } \\
(66) \\
\text { p? }\end{array}$ & $\begin{array}{c}\text { Pietre } \\
(65,66) \\
0\end{array}$ & $\begin{array}{c}\text { Beyer } \\
(128) \\
n_{p y} \\
\end{array}$ & $\mathbf{t}$ & ns \\
\hline & JD2434902.4 & & & 12.4 & & 51.4 & 12.4 \\
\hline & $6 / 9 / 54,6^{b} 00^{n}$ & 12.76 & & & & 52.3 & 12.76 \\
\hline & $6 / 10 / 54$ & & & & 22.0 & & \\
\hline & $6 / 10 / 54, T^{h} 55^{m}$ & 12.75 & & & & 23.3 & 12.75 \\
\hline & $6 / 11 / 54$ & & & & 12.0 & & \\
\hline & $6 / 11 / 54,4^{n} 42^{m}$ & 12.72 & & & & 54.2 & 12.72 \\
\hline & $6 / 12 / 54,7 \quad 55$ & 12.69 & & & & 55.3 & 12.69 \\
\hline & $6 / 13 / 54$ & & & & 12.1 & & \\
\hline & $6 / 14 / 54$ & & & & 12.0 & & \\
\hline & $6 / 16 / 54$ & & & & 12.1 & & \\
\hline • & $6 / 17 / 54,7^{\mathrm{h}} 12^{\mathrm{m}}$ & 22.82 & & & & 60.3 & 12.82 \\
\hline & JD2434915.4 & & & 12.6 & & 64.4 & 12.6 \\
\hline 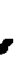 & $6 / 22 / 54$ & & & & 12.2 & & \\
\hline & JD2434916.4 & & & 12.4 & & 65.4 & 12.4 \\
\hline & 919.4 & & & 12.9 & & 68.4 & 12.9 \\
\hline & $6 / 27 / 54$ & & & & 12.3 & & \\
\hline & $6 / 28 / 54$ & & & & 12.2 & & \\
\hline & $J D 2434922.4$ & & & 12.9 & & 71.4 & 12.9 \\
\hline & $6 / 30 / 54$ & & & & 12.3 & & \\
\hline & $6 / 30 / 54,5^{\mathrm{h}} 56^{\mathrm{m}}$ & 13.01 & & & & 73.2 & 13.01 \\
\hline & $J 02434924.4$ & & & 12.8 & & 73.4 & 12.8 \\
\hline & $7 / 1 / 54$ & & & & 12.3 & & \\
\hline • & $7 / 2 / 54$ & & & & 12.4 & & \\
\hline
\end{tabular}




$$
20
$$

Foble $11-1.7$ (Continued)

\begin{tabular}{|c|c|c|c|c|c|c|}
\hline \multirow{2}{*}{ Sengste } & \multicolumn{3}{|c|}{$t_{0}=\operatorname{spet} 364051.0$} & \multicolumn{3}{|c|}{$B_{0}=9.50$} \\
\hline & $\begin{array}{l}\text { nud } \\
(65) \\
3 \\
\end{array}$ & $\begin{array}{c}\text { Eornesioter } \\
(66) \\
3 .\end{array}$ & 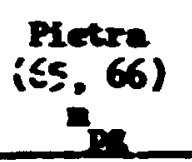 & $\begin{array}{l}\text { Dyer } \\
(126) \\
0 \\
00\end{array}$ & t & p $_{\text {pec }}$ \\
\hline Johelusee6.4 & & & 13.0 & & $T 5.4$ & 13.0 \\
\hline $7 / 5 / 54$ & & & & 12.4 & & \\
\hline $7 / 6 / 54$ & & & & 12.6 & & \\
\hline $7 / 9 / 5 h, h^{h} 36^{2}$ & 13.19 & & & & 82.2 & 13.19 \\
\hline $7 / 10 / 54$ & & & & 12.t & & \\
\hline JDet3hgh5.4 & & & 13.3 & & 9k.4 & 13.3 \\
\hline 947.4 & & & 13.1 & & 96.4 & 13.1 \\
\hline 948.4 & & & 23.5 & & 97.4 & 13.5 \\
\hline 953.4 & & & 13.2 & & 102.4 & 13.2 \\
\hline $7 / 31 / 54,4^{h} 45^{n}$ & 13.42 & & & & 104.2 & 13.42 \\
\hline JD2434957.4 & & & 13.9 & & 106.4 & 13.9 \\
\hline 959.4 & & & 13.8 & & 108.4 & 13.8 \\
\hline 8/5/5h, $h^{h}+0^{0}$ & 13.48 & & & & 109.2 & 13.48 \\
\hline JD243h961.4 & & & 13.9 & & 110.4 & 13.9 \\
\hline $8 / 29 / 54,3^{h} 35^{n}$ & 14.03 & & & & 133.1 & 14.03 \\
\hline $8 / 29 / 54,20$ & 14.39 & & & & 133.2 & 14.39 \\
\hline JDeh 34987.3 & & & 14.2 & & 136.3 & 14.2 \\
\hline $10 / 25 / 5 h, 12^{h}$ & 15.11 & & & & 190.5 & 15.11 \\
\hline JD2435043.6 & & & 15.6 & & 192.6 & 15.6 \\
\hline 050.6 & & & 15.7 & & 199.6 & 15.7 \\
\hline 067.6 & & & 15.8 & & 226.6 & 15.8 \\
\hline JD2435096.6 & & & 16.4 & & & \\
\hline 200.6 & & & 26.3 & & & \\
\hline 201.6 & & & 16.4 & & & \\
\hline
\end{tabular}


265

Table M - 1.7 (Continued)

\begin{tabular}{|c|c|c|c|c|c|c|}
\hline sugste & & $t_{0}=\sqrt{D 2} 24348$ & 2.0 & & & 9.50 \\
\hline Date & $\begin{array}{l}\text { Hidd } \\
(65) \\
0\end{array}$ & $\begin{array}{c}\text { Horreister } \\
\text { (66) } \\
\text { s. }\end{array}$ & $\begin{array}{c}\text { Pietre } \\
(65,66) \\
\text { p }\end{array}$ & $\begin{array}{c}\text { Beyer } \\
(128) \\
n_{p r}\end{array}$ & $\mathbf{t}$ & \\
\hline $1 / 28 / 55,9^{b} 39^{n}$ & 16.88 & & & & & \\
\hline $2 / 14 / 55,9 \quad 2:$ & 17.08 & & & & & \\
\hline $3 / 2 / 55,10 \quad 34$ & 17.58 & & & & & \\
\hline $\begin{array}{l}\text { JD2435185.5 } \\
3 / 27 / 55,8^{\text {h }} 12^{\text {m }}\end{array}$ & 17.66 & 17.7 & & & & 。 \\
\hline
\end{tabular}


Table al - 1.8

\begin{tabular}{|c|c|c|c|c|c|c|c|}
\hline \multirow{2}{*}{ sulgstb } & & & \multicolumn{3}{|c|}{$t_{0}=5 / 3 / 54$} & \multicolumn{2}{|c|}{$n_{0}=12.50$} \\
\hline & & & Nild & $\begin{array}{c}\text { Pietre } \\
(65,66)\end{array}$ & ${ }_{(65)}^{\text {Mild }}$ & $\mathbf{t}$ & pe \\
\hline $5 / 2 / 54$ & $8^{h}$ & $u^{*}$ & 12.44 & & & -0.7 & 12.44 \\
\hline \multirow[t]{2}{*}{$5 / 3 / 54$} & 8 & 37 & 12.75 & & & 0.4 & 12.75 \\
\hline & 8 & 46 & 12.88 & & & 0.4 & 12.88 \\
\hline \multirow[t]{2}{*}{$5 / 4 / 54$} & 8 & 59 & 12.65 & & & 1.4 & 12.65 \\
\hline & 9 & 37 & 12.57 & & & 1.4 & 12.57 \\
\hline \multirow[t]{5}{*}{$5 / 5 / 54$} & 5 & 41 & 22.45 & & & 2.2 & 12.45 \\
\hline & 6 & 11 & 12.67 & & & 2.3 & 12.67 \\
\hline & 6 & 33 & 12.62 & & & 2.3 & 12.62 \\
\hline & 6 & 36 & 12.78 & & & 2.3 & 12.78 \\
\hline & 7 & 15 & 12.98 & & & 2.3 & 12.98 \\
\hline $5 / 6 / 54$ & 9 & 44 & 13.02 & - & & 3.4 & 13.02 \\
\hline $5 / 7 / 54$ & 10 & 30 & 13.33 & & & 4.4 & 13.33 \\
\hline $5 / 8 / 54$ & 6 & 53 & 13.07 & & & 5.3 & 13.07 \\
\hline \multicolumn{3}{|c|}{ JD2434871.4 } & & 13.6 & & 5.4 & 13.6 \\
\hline \multirow[t]{5}{*}{$5 / 9 / 54$} & $T^{n}$ & $45^{\mathrm{m}}$ & 13.03 & & 0.27 & 6.3 & 13.03 \\
\hline & 8 & 25 & 13.30 & & & 6.4 & 13.30 \\
\hline & 8 & 30 & 13.19 & & & 6.4 & 13.19 \\
\hline & 8 & 53 & 13.05 & & & 6.4 & 13.05 \\
\hline & 9 & 20 & 13.46 & & & 6.4 & 13.46 \\
\hline \multirow[t]{3}{*}{$5 / 10 / 54$} & 5 & 50 & 13.06 & & 0.20 & 7.2 & 13.06 \\
\hline & 8 & $\infty$ & 12.95 & & & 7.3 & 12.95 \\
\hline & 9 & 53 & 13.52 & & & 7.4 & 13.52 \\
\hline $5 / 11 / 54$ & 5 & 50 & 13.20 & & 0.36 & 8.2 & 13.20 \\
\hline $5 / 12 / 54$ & 5 & 36 & 13.24 & & 0.26 & 9.2 & 13.24 \\
\hline \multirow[t]{2}{*}{$5 / 21 / 54$} & 5 & 16 & 14.22 & & & 18.2 & 14.22 \\
\hline & 5 & 32 & 14.36 & & & 18.2 & 14.36 \\
\hline
\end{tabular}


267

Toble Al - 1.8 (Continued)

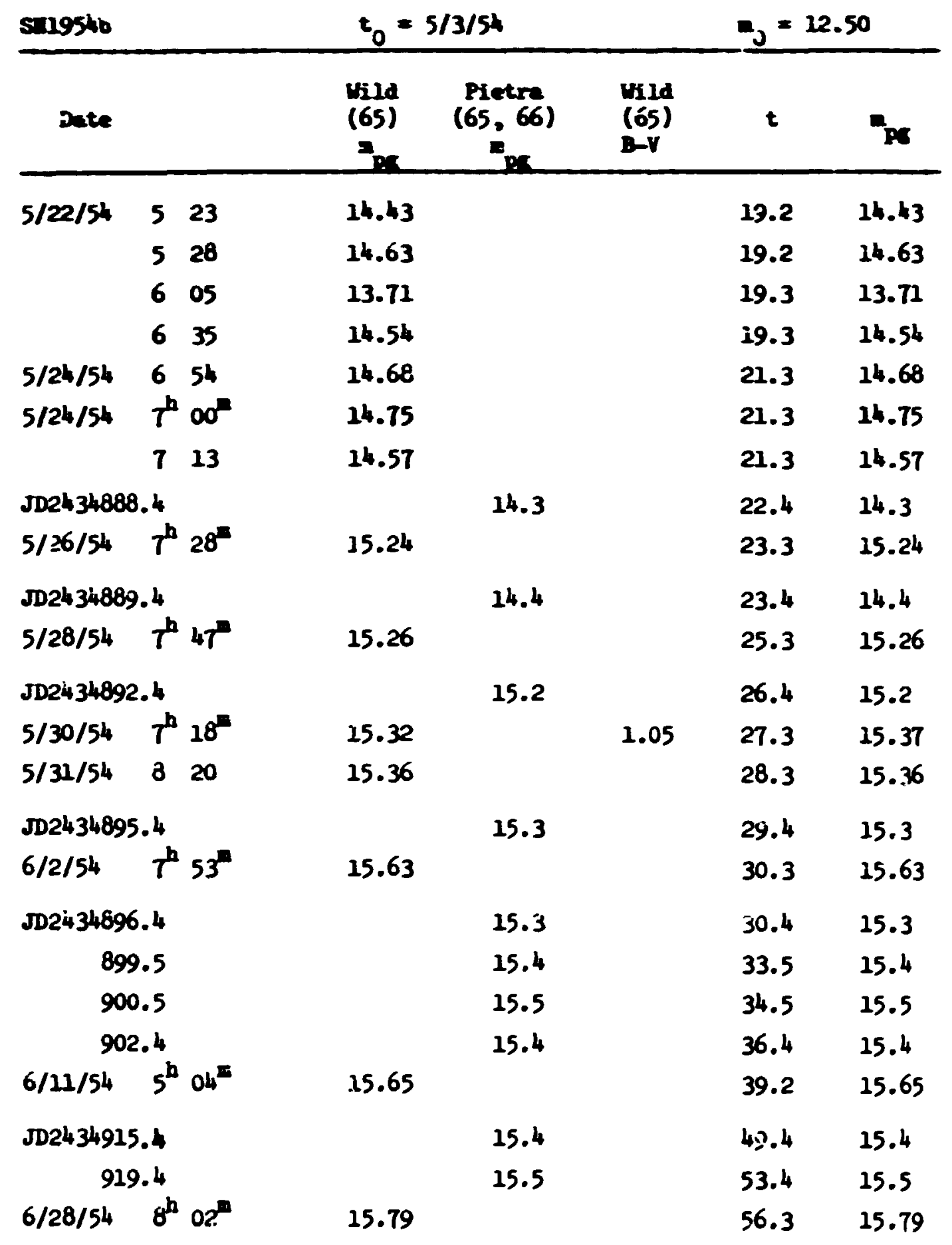


Table 11 - 1.8 (Continued)

\begin{tabular}{|c|c|c|c|c|c|}
\hline $\operatorname{sen} 954 b$ & $t_{0}=$ & $13 / 54$ & & b & 12.50 \\
\hline Date & nild & $\begin{array}{c}\text { Pietye } \\
(65,66) \\
\end{array}$ & $\begin{array}{l}\text { Wild } \\
(65) \\
B-V\end{array}$ & $t$ & $a_{p t}$ \\
\hline JD2434922.4 & & 15.6 & & 56.4 & 15.6 \\
\hline 923.4 & & 15.7 & & 57.4 & 15.7 \\
\hline $7 / 2 / 54 \quad T^{\mathrm{h}} 58^{\mathrm{a}}$ & 25.97 & & & 60.3 & 15.97 \\
\hline JD2434926.5 & & 15.8 & & 60.5 & 15.8 \\
\hline $7 / 9 / 54 \quad 4^{\text {h }} 45^{\text {m }}$ & 16.11 & & & 67.2 & 16.11 \\
\hline JD2434945.4 & & 16.2 & & 79.4 & 16.2 \\
\hline 948.4 & & 16.0 & & 82.4 & 16.0 \\
\hline 949.4 & & 15.9 & & 83.4 & 15.9 \\
\hline $7 / 31 / 54 \quad 5^{h} 10^{m}$ & 16.53 & & & 89.2 & 16.53 \\
\hline JD2434955.4 & & 16.2 & & 89.4 & 16.2 \\
\hline $8 / 1 / 54 \quad 5^{h} 30^{m}$ & 16.17 & & & 90.2 & 16.17 \\
\hline JD2434958.4 & & 16.2 & & 92.4 & 16.2 \\
\hline $8 / 26 / 54 \quad 3^{\text {h }}: 8^{m}$ & 16.96 & & & 115.2 & 16.96 \\
\hline
\end{tabular}




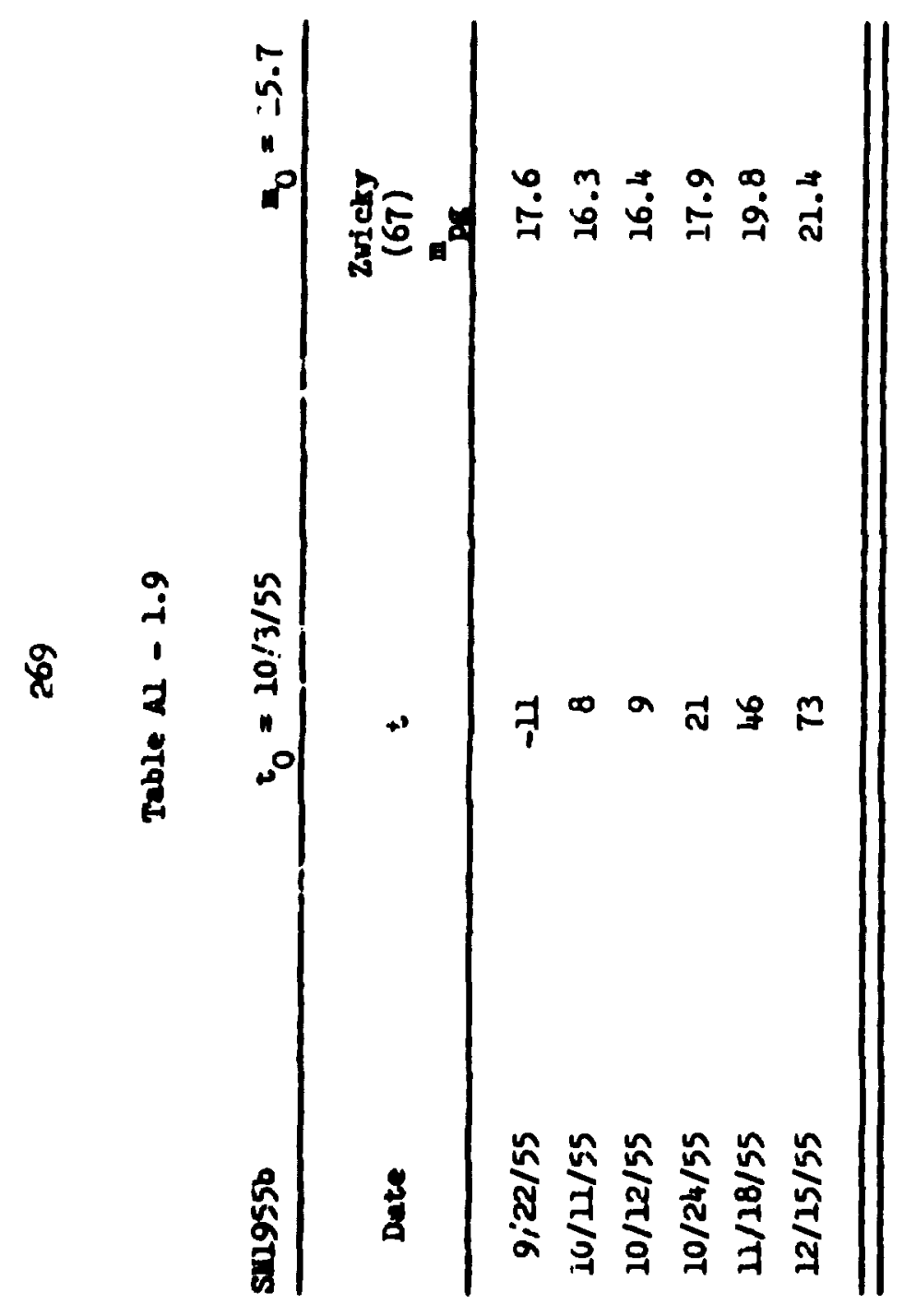




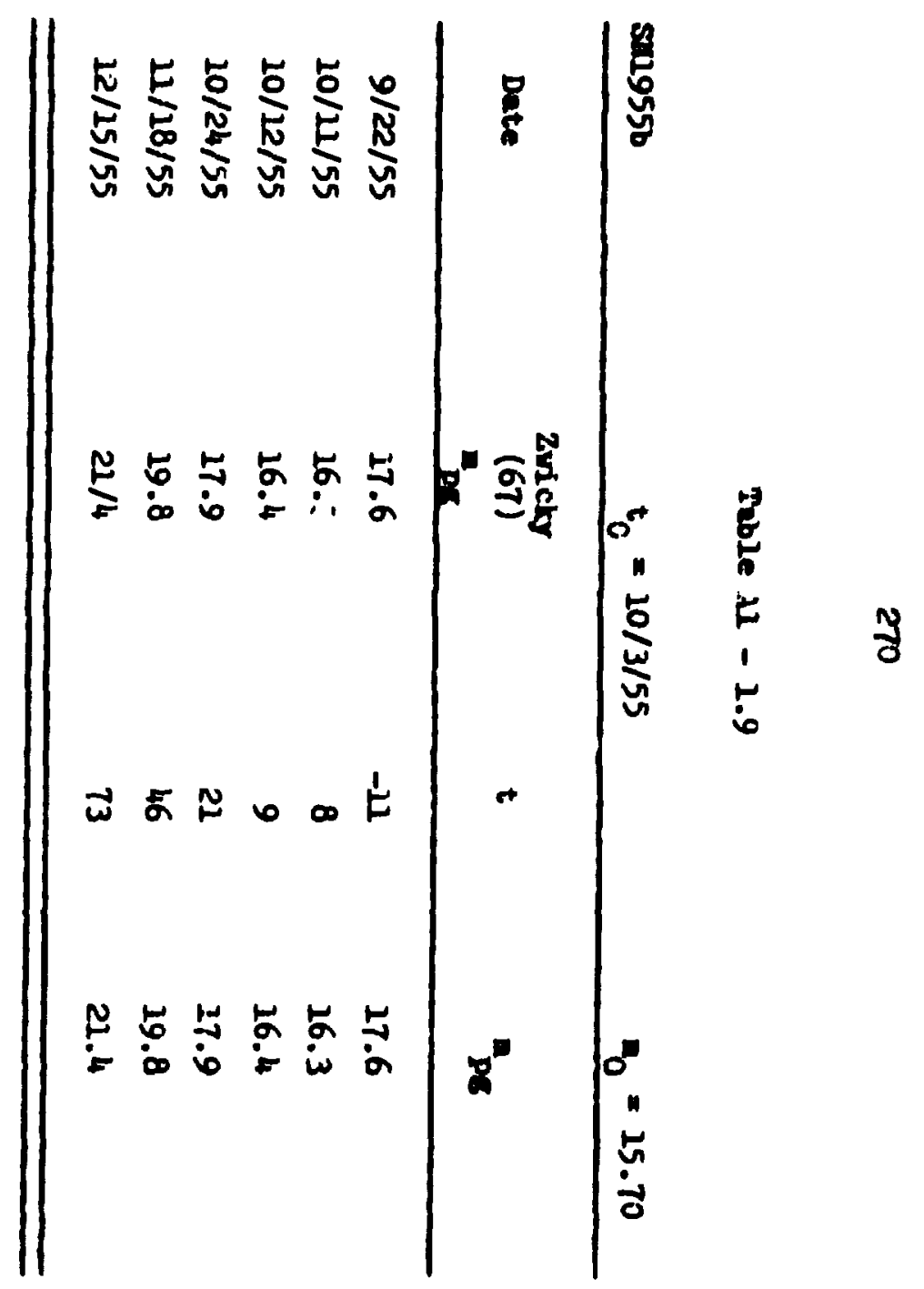

1 8 
$27 !$

Table $11-1.10$

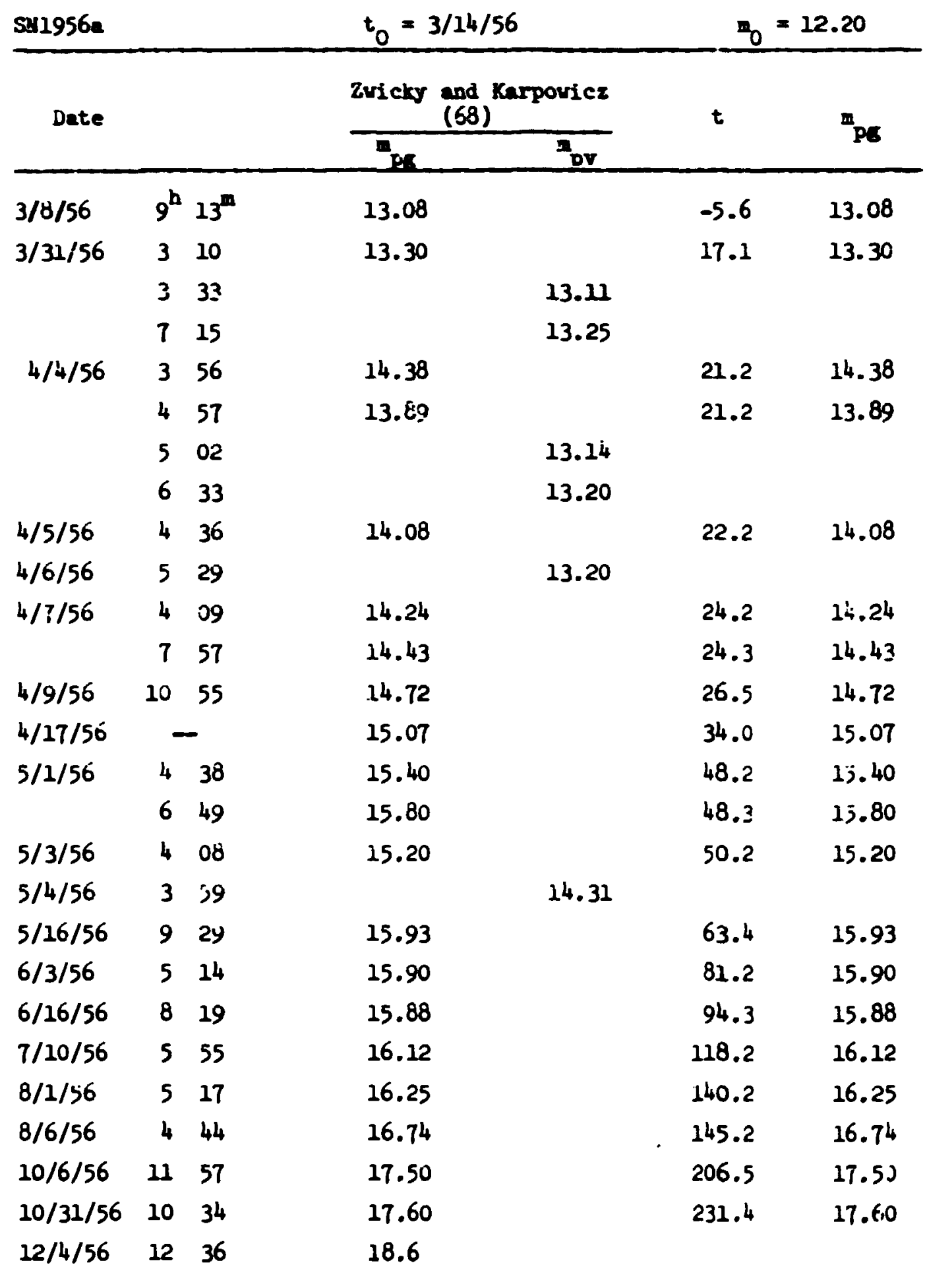


Table $\mu$ - 2.10 (Continued)

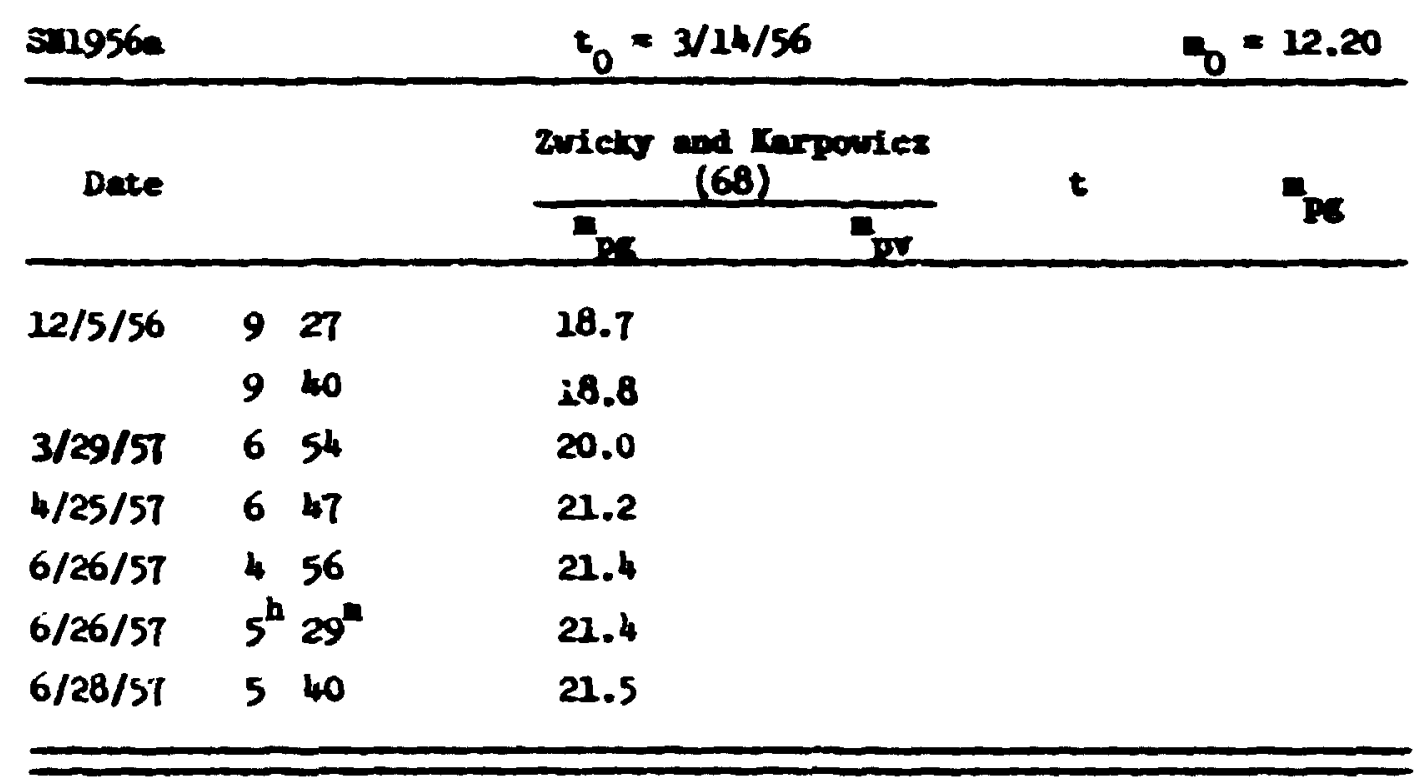


273

Table Al - 1.12

\begin{tabular}{|c|c|c|c|c|c|c|c|c|}
\hline \multirow{2}{*}{$\frac{\text { Sul957a }}{\text { Date }}$} & \multicolumn{5}{|c|}{$t_{0}=2 / 27 / 57$} & \multicolumn{3}{|c|}{$n_{0}=13.85$} \\
\hline & & & \multicolumn{2}{|c|}{$\begin{array}{l}\text { Zvicky and Karpowicz } \\
(69)\end{array}$} & $\begin{array}{c}\text { Bertola } \\
(70) \\
\\
\end{array}$ & $\begin{array}{l}\text { Uenzel } \\
(71) \\
n_{\mathrm{PL}}\end{array}$ & $t$ & pe \\
\hline $2 / 26 / 57$ & & $2 T^{*}$ & 15.2 & & & & -0.8 & 15.2 \\
\hline $3 / 1 / 57$ & - & - & 14.0 & & & & 2.0 & 14.0 \\
\hline $3 / 5 / 57$ & 21 & 50 & & & & 14.4 & 6.9 & 14.6 \\
\hline $3 / 6 / 57$ & 0 & $2 \mathbf{i}$ & & & & 14.4 & 7.0 & 14.6 \\
\hline \multirow[t]{2}{*}{$3 / 7 / 57$} & 3 & 44 & 14.7 & & & & 8.2 & 14.7 \\
\hline & 4 & 37 & & 13.8 & & & & \\
\hline \multirow[t]{2}{*}{$3 / 8 / 57$} & 4 & 25 & 15.2 & & & & 9.2 & 5.2 \\
\hline & 4 & 52 & & 13.9 & & & & \\
\hline $3 / 9 / 57$ & 1 & 05 & & & & 14.8 & 10.0 & 15.0 \\
\hline $3 / 12 / 57$ & 3 & 01 & & & & 15.3 & 12.1 & 15.5 \\
\hline $3 / 25, / 57$ & 19 & 49 & & & & 16.2 & 21.8 & 16.4 \\
\hline $3 / 21 / 57$ & 21 & 14 & & & & 16.3 & 22.9 & 16.5 \\
\hline $3 / 22 / 57$ & 19 & 55 & & & & 16.3 & 23.8 & 16.5 \\
\hline $3 / 23 / 57$ & 19 & 40 & & & & 16.4 & 24.8 & 16.6 \\
\hline $3 / 26 / 57$ & 21 & 1: & & & & 16.4 & 27.9 & 16.6 \\
\hline \multirow[t]{2}{*}{$3 / 28 / 57$} & 6 & 52 & & 15.4 & & & & \\
\hline & $i$ & 05 & 16.8 & & & & 29.3 & 16.8 \\
\hline \multirow[t]{2}{*}{$3 / 29 / 57$} & 5 & 38 & & 15.6 & & & & \\
\hline & 6 & 02 & 16.6 & & & & 30.3 & 16.6 \\
\hline \multirow[t]{2}{*}{$3 / 30 / 47$} & 5 & 29 & 16.8 & & & & 31.2 & 16.8 \\
\hline & 6 & 50 & & 15.4 & & & & \\
\hline \multirow[t]{2}{*}{$3 / 31 / 57$} & 6 & 23 & 15.9 & & & & 32.3 & 16.9 \\
\hline & 6 & 30 & & 25.4 & & & & \\
\hline $3 / 31 / 57$ & 21 & 29 & & & & 16.7 & 32.9 & 16.9 \\
\hline $4 / 1 / 57$ & 4 & 10 & 16.7 & & & & 33.2 & 16.7 \\
\hline $4 / 1 / 57$ & 19 & 46 & & & & 16.6 & 33.8 & 16.8 \\
\hline $4 / 2 / 57$ & 20 & 47 & & & & 16.5 & 34.9 & 16.7 \\
\hline
\end{tabular}


274

Table Ai - 1.11 (Continued)

\begin{tabular}{|c|c|c|c|c|c|c|c|c|}
\hline \multirow{2}{*}{$\frac{\text { Sul95ia }}{\text { Date }}$} & & & \multicolumn{3}{|c|}{$t_{0}=2 / 27 / 57$} & \multicolumn{3}{|c|}{$m_{0}=13.85$} \\
\hline & & & \multicolumn{2}{|c|}{$\begin{array}{l}\text { Zwicky and Karporicz } \\
(69)\end{array}$} & $\begin{array}{c}\text { Bertole } \\
\text { (70) } \\
\text { pe }\end{array}$ & $\begin{array}{c}\text { Wenzel } \\
\text { (71) } \\
\text { ga }\end{array}$ & $\mathbf{t}$ & P6 \\
\hline $4 / 3 / 5 T$ & 21 & 31 & & & & 16.4 & 35.9 & 16.6 \\
\hline $4 / 4 / 5 ?$ & 22 & 33 & & & & 16.6 & 36.9 & 16.8 \\
\hline $4 / 4 / 57$ & 20 & 47 & & & & 16.6 & 41.9 & 16.8 \\
\hline $4 / 16 / 57$ & 20 & 42 & & & & 17.1 & 48.9 & 17.3 \\
\hline $4 / 18 / 57$ & 23 & 09 & & & 27.40 & & 51.0 & 17.40 \\
\hline $4,22 / 57$ & $23^{h}$ & $23^{m}$ & & & & 27.3 & 55.0 & 17.5 \\
\hline $4 / 23 / 57$ & 0 & 15 & & & 17.45 & & $5 ; .0$ & 17.45 \\
\hline $4 / 23 / 57$ & 22 & 42 & & & & 17.3 & 55.9 & 17.5 \\
\hline $4 / 23 / 57$ & 22 & 43 & & & 17.40 & & 55.9 & 17.40 \\
\hline \multirow[t]{2}{*}{$4 / 25 / 57$} & 3 & 39 & 17.3 & & & & 57.2 & 17.3 \\
\hline & 6 & 1.5 & & 16.2 & & & & \\
\hline $4 / 26 / 57$ & 23 & 23 & & & 17.65 & & 59.0 & 17.65 \\
\hline $4 / 29 / 57$ & 0 & 15 & & & & 17.3 & 61.0 & 17.5 \\
\hline $4 / 29 / 57$ & 5 & 28 & 17.2 & & & & 61.2 & 17.2 \\
\hline $5 / 2 / 57$ & 1 & 00 & & & & 17.4 & 64.0 & 27.6 \\
\hline \multirow[t]{2}{*}{$5 / 3 / 57$} & 5 & $5 \hat{0}$ & & 16.6 & & & & \\
\hline & 6 & 24 & 17.5 & & & & 65.3 & 17.5 \\
\hline $3 / 5 / 57$ & 1 & 53 & & & 17.75 & & 67.1 & 17.75 \\
\hline \multirow[t]{2}{*}{$5 / 5 / 57$} & 7 & 25 & & 16.4 & & & & \\
\hline & 7 & 43 & 17.8 & & & & 67.3 & 17.8 \\
\hline $5 / 22 / 57$ & 23 & 30 & & & 18.00 & & 85.0 & 18.00 \\
\hline $5 / 29 / 57$ & 22 & 36 & & & & 17.9 & 91.9 & 18.1 \\
\hline \multirow[t]{2}{*}{$5 / 30 / 57$} & 4 & 29 & & 17.2 & & & & \\
\hline & 4 & 46 & 18.1 & & & & 92.2 & 18.1 \\
\hline $6 / 1 / 57$ & 22 & 40 & & & 18.20 & & 94.9 & 18.26 \\
\hline $6 / 1 / 57$ & 23 & 42 & & & & .17 .9 & 95.0 & 18.1 \\
\hline $6 / 27 / 57$ & 4 & 39 & 18.3 & & & & 120.2 & 18.3 \\
\hline $6 / 27 / 57$ & 4 & 46 & & 17.4 & & & & \\
\hline
\end{tabular}


Table $1 \mathrm{~L}-1.12$

\begin{tabular}{|c|c|c|c|c|c|c|c|}
\hline \multicolumn{2}{|l|}{ Sw195To } & \multicolumn{3}{|c|}{$t_{0}=5 / 9 / 57$} & \multicolumn{3}{|c|}{$0_{0}=12.10$} \\
\hline \multicolumn{2}{|l|}{ Dete } & $\begin{array}{l}\text { Bertole } \\
(70)\end{array}$ & $\begin{array}{l}\text { Romeno } \\
\text { (TS) }\end{array}$ & $\begin{array}{l}\cot 2 \\
(72)\end{array}$ & $\begin{array}{c}\text { Li Tzin } \\
\text { (73) }\end{array}$ & $\mathbf{t}$ & pe \\
\hline \multicolumn{2}{|c|}{ JD2435952.3 } & & 14.0 & & & -15.0 & 14.8 \\
\hline \multicolumn{2}{|c|}{955.4} & & 13.6 & & & -12.0 & 14.4 \\
\hline \multicolumn{2}{|c|}{957.4} & & 13.0 & & & -10.0 & 13.8 \\
\hline \multirow[t]{2}{*}{$5 / 3 / 57$} & $22^{h} 35^{n}$ & & & 12.5 & & -5.2 & 12.5 \\
\hline & $23^{\mathrm{h}} 06^{\mathrm{n}}$ & & & 12.5 & & -5.0 & 12.5 \\
\hline \multicolumn{2}{|c|}{ JD2435977.4 } & & 12.2 & & & 10.0 & 13.0 \\
\hline \multicolumn{2}{|c|}{978.4} & & 12.2 & & & 11.0 & 23.0 \\
\hline $5 / 21 / 5 T$ & $23^{h} 17$ & 13.20 & & & & 13.0 & 13.20 \\
\hline $5 / 22 / 57$ & 2259 & 13.30 & & & & 14.0 & 13.30 \\
\hline $5 / 23 / 57$ & 2153 & & & 13.4 & & 14.9 & 13.4 \\
\hline \multicolumn{2}{|c|}{ JD2435982.4 } & & 12.6 & & & 15.0 & 13.4 \\
\hline $5 / 23 / 57$ & $23^{h} 31^{m}$ & & & 13.4 & & 15.0 & $: 3.4$ \\
\hline $5 ! 25 / 57$ & $20 \quad 38$ & & & & 13.16 & 16.9 & 13.24 \\
\hline $5 / 25 / 57$ & 2157 & & & 13.6 & & 16.9 & 13.6 \\
\hline $5 / 25 / 57$ & $<248$ & & & 13.7 & & 17.0 & 13.7 \\
\hline $5 / 26 / 57$ & 2157 & & & 13.8 & & 17.9 & 13.8 \\
\hline $5 / 28 / 57$ & 2149 & & & 13.9 & & 19.9 & 13.9 \\
\hline $5 / 29 / 57$ & 2130 & & & 14.1 & & 20.9 & 14.2 \\
\hline $5 / 29 / 57$ & 2159 & & & & 13.87 & 20.9 & 13.95 \\
\hline $5 / 30 / 57$ & 2203 & & & 14.2 & & 21.9 & 14.2 \\
\hline $5 / 31 / 57$ & $22 \quad 26$ & & & & 14.18 & 22.9 & 14.26 \\
\hline $5 / 31 / 57$ & 2259 & & & 14.2 & & 23.0 & 14.2 \\
\hline \multicolumn{2}{|c|}{ JD2435990.4 } & & 13.5 & & & 23.0 & 14.3 \\
\hline $5 / 31 / 57$ & 2301 & 14.45 & & & & 23.0 & 14.45 \\
\hline \multicolumn{2}{|c|}{ JD2435991.4 } & & 13.6 & & & 24.0 & 24.4 \\
\hline $6 / 1 / 57$ & $23^{\mathrm{h}} 06^{\mathrm{m}}$ & 14.60 & & & & 24.0 & 34.60 \\
\hline
\end{tabular}


270

Table $\mu-1.12$ (Costlaned)

\begin{tabular}{|c|c|c|c|c|c|c|c|c|}
\hline Date & & & $\begin{array}{l}\text { Bertale } \\
\text { (70) }\end{array}$ & $\frac{R 000}{(75)}$ & $\begin{array}{l}\text { Cotz } \\
(T 2)\end{array}$ & $\begin{array}{c}\text { 4 Tel }= \\
(73)\end{array}$ & $t$ & $e_{x}$ \\
\hline $0 / 2 / 57$ & 21 & 13 & & & & 6. 17 & 26.9 & $i=.3$ \\
\hline $6 / 2 / 57$ & 22 & 16 & & & 14.6 & & 24.9 & 16.6 \\
\hline JD243599 & & & & 13.6 & & & 25.0 & $16 . k$ \\
\hline $6 / 6 / 57$ & $23^{h}$ & $\mathbf{u}^{\mathbf{n}}$ & & & 16.3 & & 29.0 & 14.3 \\
\hline $6 / 8 / 57$ & 21 & 35 & & & & 14.98 & 30.9 & 15.06 \\
\hline $6 / 12 / 57$ & 21 & 49 & & & & 15.06 & 34.9 & 15.14 \\
\hline $6 / 16 / 57$ & $21^{b}$ & $48^{8}$ & & & 16.7 & & 38.9 & 16.7 \\
\hline $6 / 17 / 57$ & il & 30 & & & & 15.22 & 39.9 & 15.30 \\
\hline $6 / 17 / 57$ & 22 & 46 & 15.20 & & & & 39.9 & 15.20 \\
\hline $6 / 17 / 57$ & 23 & $i^{2}$ & 15.15 & & & & $\$ 0.0$ & 15.15 \\
\hline $6 ! 10 / 57$ & 21 & 18 & & & & 15.56 & 10.9 & 15.64 \\
\hline $6 / 20 / 57$ & 22 & 11 & & & 15.4 & & 12.9 & 15.4 \\
\hline $6 /<8 / 56$ & 20 & 40 & & & & 25.61 & 50.9 & 15.69 \\
\hline $6 / 2 c^{2}: 57$ & 21 & 51 & & & 25.5 & & 30.9 & 25.5 \\
\hline $6 / 28 / 5 i$ & 22 & 30 & 15.60 & & & & 50.9 & 15.60 \\
\hline $6 / 29 / 57$ & 21 & 30 & & & & 25.59 & 51.9 & 15.67 \\
\hline $7 / 4 / 57$ & 20 & 51 & & & & 15.49 & 56.9 & 15.57 \\
\hline $7 / 4 / 57$ & 22 & 36 & & & 15.6 & & 56.9 & 15.6 \\
\hline $7 / 9 / 57$ & 20 & 30 & & & & 15.53 & 61.9 & 15.61 \\
\hline $7 / 9 / 57$ & 20 & 39 & & & & 15.56 & 61.9 & 15.62 \\
\hline $7 / 16 / 57$ & 20 & 47 & & & & 25.61 & 68.9 & 25.69 \\
\hline $7 / 19 / 57$ & 20 & 46 & & & & 15.90 & 71.9 & 15.90 \\
\hline $7 / 20 / 57$ & 22 & 01 & 15.90 & & & & 72.9 & 15.90 \\
\hline$T / 21 / 57$ & 20 & 48 & & & & 15.91 & 73.9 & 16.05 \\
\hline $7 / 30 / 57$ & 21 & 46 & 16.00 & & & & 82.9 & 26.00 \\
\hline
\end{tabular}




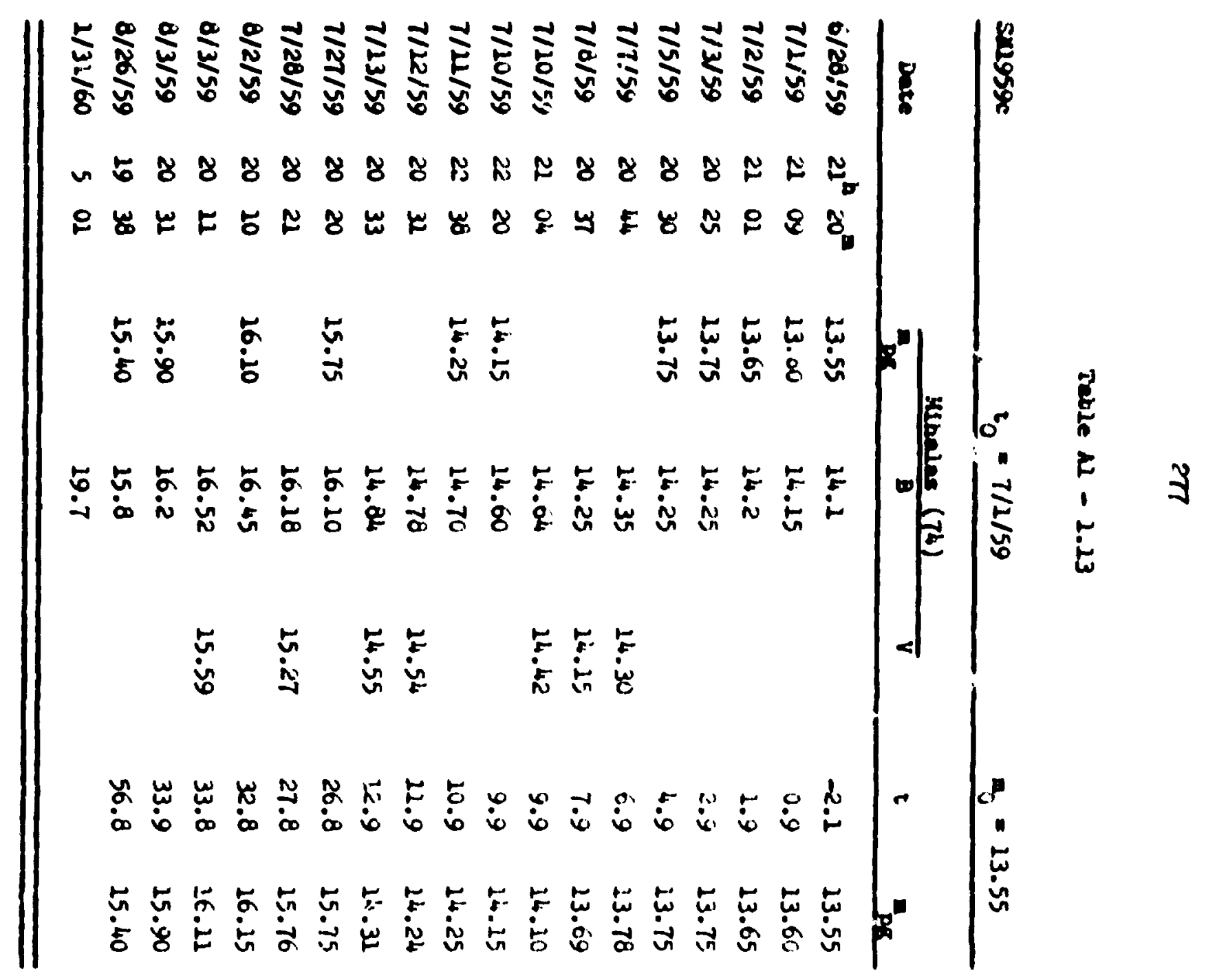


Table $41-1.14$

\begin{tabular}{|c|c|c|c|c|c|c|c|c|}
\hline sung6or & & & $t_{0}=$ & $4 / 16 / 60$ & & & $c=11$ & .60 \\
\hline Date & & $\begin{array}{l}\text { Bertole } \\
\text { (70) }\end{array}$ & $\begin{array}{l}\text { Huth } \\
\text { (76) }\end{array}$ & $\begin{array}{l}\text { Rultikor } \\
\text { (TI) }\end{array}$ & $\begin{array}{c}\text { Te-pesti } \\
(78)\end{array}$ & $\begin{array}{c}\text { Mannino } \\
(79)\end{array}$ & $t$ & P6 \\
\hline $4 / 14 / 60$ & $9^{h} 06^{n}$ & & 10.6 & & & & -1.6 & 11.45 \\
\hline $4 / 15 / 60$ & 936 & & 10.8 & & & & -0.6 & 11.65 \\
\hline $4 / 16 / 60$ & 951 & & $\mathrm{n.1}$ & & & & 0.4 & 11.95 \\
\hline $4 / 19 / 60$ & 936 & & 10.8 & & & & 3.4 & 13.65 \\
\hline $4 / 20 / 60$ & 936 & & 10.8 & & & & 4.4 & 11.65 \\
\hline JD243704.6 & & & & & & 11.53 & 5.4 & 11.53 \\
\hline $4 / 21 / 60$ & $20^{3} 1 T^{n}$ & 11.5 & & • & & & 5.8 & 11.6 \\
\hline JD2437047 & & & & & & 12.74 & 6.3 & 212.74 \\
\hline $4 / 22 / 60$ & $19^{a} 55^{m}$ & & & 11.42 & & & 6.8 & 11.84 \\
\hline JD2437046 & & & & & & 12.05 & 7.4 & 12.05 \\
\hline 049 & & & & & & 12.16 & 8.4 & 22.16 \\
\hline 050 & & & & & & 12.10 & 9.5 & 12.10 \\
\hline $4 / 25 / 60$ & $20^{b} 24^{=}$ & & & 11.55 & & & 9.8 & 11.97 \\
\hline $4 / 26 / 60$ & $19 \quad 55$ & & & 12.91 & & & 10.8 & 12.33 \\
\hline $4 / 27 / 60$ & 1941 & & & 11.62 & & & 22.8 & 12.04 \\
\hline JD2437056 & & & & & & 12.52 & 15.5 & 12.52 \\
\hline $5 / 1 / 60$ & $21^{b} 00^{n}$ & 12.55 & & & & & 15.9 & 12.55 \\
\hline JD2437057 & & & & & & 12.68 & 16.4 & 12.68 \\
\hline $5 / 3 / 60$ & $0^{\mathrm{h}} \infty 0^{\mathrm{D}}$ & & & & 12.10 & & 17.0 & 12.71 \\
\hline JD2437058 & & & & & & 12.78 & 17.4 & 12.78 \\
\hline 069 & & & & & & 13.68 & 28.3 & 12.68 \\
\hline 070 & & & & & & 14.05 & 29.4 & 14.05 \\
\hline $5 / 16 / 60$ & $22^{\mathrm{h}} 21^{\mathrm{m}}$ & 14.10 & & & & & 30.9 & 14.10 \\
\hline JD2437072 & & & & & & 14.11 & 31.4 & 14.21 \\
\hline $5 / 17 / 60$ & $19^{b} 26^{m}$ & & & 13.56 & & & 31.8 & 13.98 \\
\hline
\end{tabular}


Fab]e Al - 1.14 , Zontinued)

\begin{tabular}{|c|c|c|c|c|c|c|c|}
\hline Sinl9oor & & $t_{0}=$ & $4 / 16 / 60$ & & & $=11$. & \\
\hline Date & $\begin{array}{c}\text { Bertola } \\
(70) \\
0 \\
\end{array}$ & $\begin{array}{l}\text { Huch } \\
(76) \\
\text { mog } \\
\end{array}$ & $\begin{array}{c}\text { Kulikor } \\
(77) \\
\text { mpg }\end{array}$ & $\begin{array}{c}\text { Tempesti } \\
(78) \\
m_{p k} \\
\end{array}$ & $\begin{array}{c}\text { Mannino } \\
(79) \\
\text { mgg }\end{array}$ & $t$ & ${ }^{\mathbf{E}} \mathbf{F E}$ \\
\hline JD2437073.4 & & & & & 14.21 & 32.4 & 14.21 \\
\hline $5 / 19 / 60 \quad 19^{h} 41^{m}$ & & & 13.53 & & & 33.8 & 13.95 \\
\hline JD2437075.4 & & & & & 14.27 & 34.4 & 14.27 \\
\hline 076.4 & & & & & 14.37 & 35.4 & 14.37 \\
\hline $5 / 21 / 60 \quad 21^{h} 50^{m}$ & & & & 13.75 & & 35.9 & 14.36 \\
\hline JD2437077.4 & & & & & 24.42 & 36.4 & 14.42 \\
\hline $5 / 22 / 60 \quad 19^{\mathrm{b}} 55^{\mathrm{m}}$ & & & 13.92 & & & 36.8 & 14.34 \\
\hline JD2437078.5 & & & & & 14.42 & 37.5 & 14.42 \\
\hline $5 / 23 / 60 \quad 19^{\mathrm{n}} 41^{\mathrm{m}}$ & & & 14.02 & & & 37.8 & 14.44 \\
\hline JD2437079.4 & & & & & 14.53 & 38.4 & 14.53 \\
\hline $5 / 24 / 60 \quad 18^{h} 53^{m}$ & & & 14.10 & & & 38.8 & 14.52 \\
\hline JD24.3708C.4 & & & & & 14.48 & 39.4 & 14.48 \\
\hline $5 / 25 / 60 \quad 18^{h} 58^{m}$ & & & 14.26 & & & 39.8 & -4.68 \\
\hline $5 / 26 / 60 \quad 21 \quad 36$ & & & & 24.05 & & 40.9 & 14.66 \\
\hline $5 / 26 / 60 \quad 22 \quad 58$ & 24.48 & & & & & 41.0 & 14.48 \\
\hline $\mathrm{JD} 2437082.4$ & & & & & 14.60 & 41.4 & 14.60 \\
\hline $5 / 28 / 60 \quad 20^{h} 53^{m}$ & & & & 13.85 & & 42.9 & 14.46 \\
\hline $\mathrm{JD} 2437085.4$ & & & & & 14.75 & 44.4 & 14.75 \\
\hline $5 / 30 / 60 \quad 23^{h} 46^{m}$ & & & & 14.05 & & 45.0 & 14.66 \\
\hline JD2 437086.4 & & & & & 14.75 & 45.4 & 14.75 \\
\hline $6 / 1 / 60 \quad 19^{h} 12^{m}$ & & & $14: 30$ & & & 46.8 & 14.72 \\
\hline JD24 37098.4 & & & & & 15.05 & 57.4 & 15.05 \\
\hline JD2437099.4 & & & & & 14.97 & 58.4 & 14.97 \\
\hline $6 / 13 / 60 \quad 19^{h} 41^{m}$ & & & 24.64 & & & 58.8 & 15.06 \\
\hline
\end{tabular}


260

Table 11 - 1.14 (Continued)

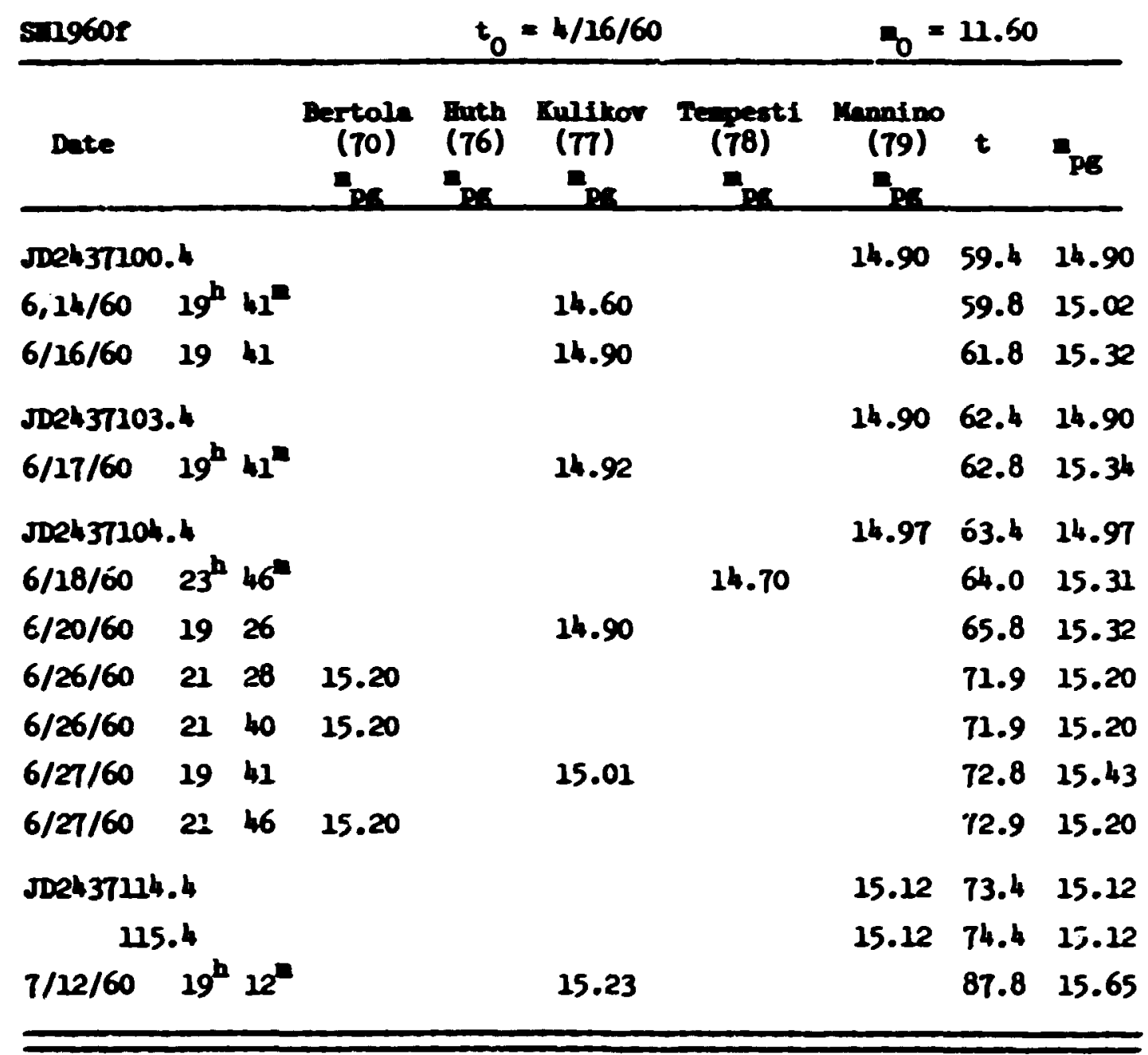


281

Tat le AI - 1.15

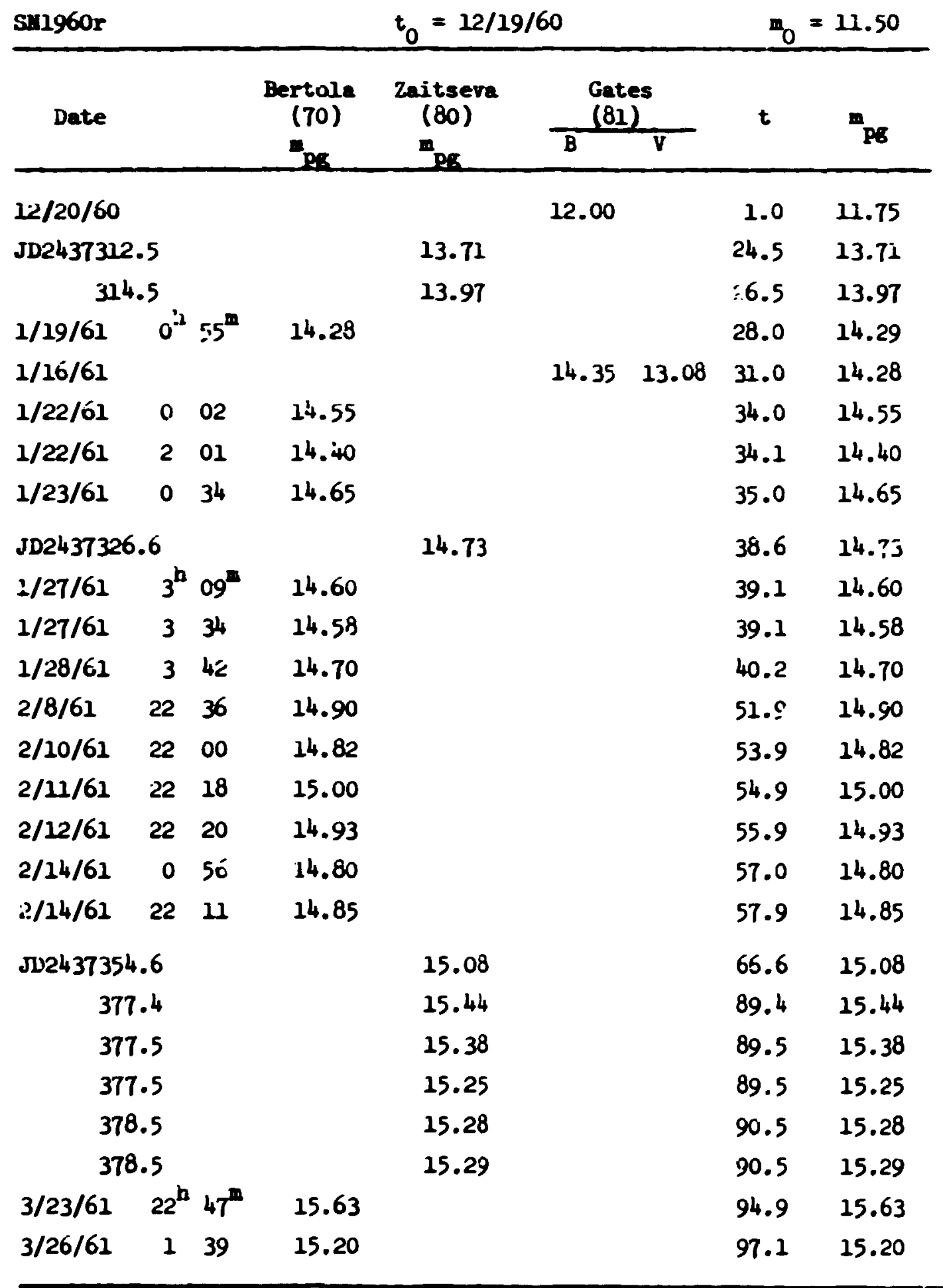




\begin{tabular}{|c|c|c|c|c|c|c|c|}
\hline \multicolumn{3}{|l|}{$\operatorname{sul} 960 \mathrm{r}$} & \multicolumn{3}{|c|}{$\begin{array}{c}\text { Table Al - } 2.15 \text { (Continued) } \\
t_{C}=12 / 19 i 60\end{array}$} & \multicolumn{2}{|c|}{$g_{0}=11.50$} \\
\hline Date & & & $\begin{array}{c}\text { Bertola } \\
(70)\end{array}$ & $\begin{array}{c}\text { Zaitsera } \\
(80)\end{array}$ & $\begin{array}{l}\text { Gates } \\
(81) \\
\end{array}$ & $t$ & $m_{p 8}$ \\
\hline $4 / 6 / 61$ & 2.3 & 04 & 15.57 & & & 109.0 & 15.57 \\
\hline $4 / 7 / 61$ & 23 & 39 & 15.60 & & & 110.0 & 15.60 \\
\hline $4 / 8 / 61$ & 23 & 28 & 15.65 & & & 121.0 & 15.65 \\
\hline$J_{2} 2437405$ & & & & 15.90 & & 117.3 & 15.90 \\
\hline $4 / 19 / 61$ & $20^{h}$ & $41^{m}$ & 15.80 & & & 221.9 & +5.80 \\
\hline $4 / 19 / 61$ & 23 & 55 & 25.78 & & & 122.0 & 15.78 \\
\hline $5 / 2 / 61$ & $19^{h}$ & $47^{m}$ & 15.90 & & & 134.8 & 15.90 \\
\hline $5 / 5 / 61$ & 21 & 56 & 16.03 & & & 137.9 & 16.03 \\
\hline $5 / 7 / 61$ & $2 \hat{c}$ & 37 & 15.93 & & & 139.9 & 15.93 \\
\hline $5 / 7 / 61$ & 23 & 25 & 15.90 & & & 140.0 & 15.90 \\
\hline $5 / 9 / 61$ & 23 & 06 & 15.95 & & & 242.0 & 15.95 \\
\hline $5 / 10 / 61$ & 23 & 21 & 15.98 & & & 143.0 & 15.98 \\
\hline $5 / 13 / 61$ & 0 & 25 & 16.05 & & & 145.0 & 26.05 \\
\hline
\end{tabular}




\section{$25:$}

Table Al - 1.16

\begin{tabular}{|c|c|c|c|c|}
\hline $\sin 1961 \alpha$ & & 1/17/61 & & $\mathrm{m}_{0}=16.20$ \\
\hline \multirow[t]{2}{*}{ Date } & \multicolumn{2}{|c|}{$\begin{array}{c}\text { Zwriaky } \\
(22)\end{array}$} & \multirow[t]{2}{*}{$t$} & \multirow{2}{*}{${ }_{\text {FG }}$} \\
\hline & $9 g$ & $u_{p p}$ & & \\
\hline $12 / 22 / 60$ & & 21 & & \\
\hline $12 / 23 / 60$ & & 21.6 & & \\
\hline $12 / 24 / 60$ & & 20.4 & & \\
\hline $1 / 15 / 61$ & & $16.7 \mathrm{~L}$ & $-\hat{c} .0$ & 16.23 \\
\hline $1 / 21 / 61$ & & 16.95 & 4.0 & 16.64 \\
\hline $1 / 24 / 61$ & & 17.05 & $7 . C$ & 26.83 \\
\hline $2 / 11 / 61$ & 10.75 & & 25.0 & 18.75 \\
\hline $2 / 13 / 61$ & & 18.20 & 27.0 & 18.96 \\
\hline $2 ; 21 / 61$ & & 18.50 & 35.0 & 19.41 \\
\hline $2 / 22 / 61$ & & 18.45 & 35.0 & 19.36 \\
\hline $2 / 23 / 61$ & & 18.45 & 37.0 & 19.35 \\
\hline $3 / 11 / 61$ & & 18.80 & 53.0 & 29.55 \\
\hline $3 / 11 / 61$ & 19.55 & & 53.0 & 19.54 \\
\hline
\end{tabular}


284

Table AI - $1.1 T$

\begin{tabular}{llll} 
Sull961h & \multicolumn{2}{c}{$t_{0}=5 / 8 / 61$} & $m_{0}=11.20$ \\
\hline Date & $\begin{array}{c}\text { Romano } \\
(83) \\
m_{\text {pg }}\end{array}$ & $t$ & $m_{\text {PG }}$ \\
\hline $5 / 2 / 61$ & 11.4 & -6.0 & 11.4 \\
$5 / 5 / 61$ & 11.3 & -3.0 & 11.3 \\
$5 / 7 / 61$ & 11.2 & -1.0 & 11.2 \\
$5 / 9 / 61$ & 11.2 & 1.0 & 11.2 \\
$5 / 10 / 61$ & 10.9 & 2.0 & 10.9 \\
$5 / 13 / 61$ & 11.3 & 3.0 & 11.3 \\
$5 / 12 / 61$ & 11.4 & 4.0 & 11.4 \\
$5 / 18 / 61$ & 11.8 & 10.0 & 11.8 \\
$6 / 1 / 61$ & 12.7 & 24.0 & 12.7 \\
$6 / 2 / 61$ & 13.0 & 25.0 & 13.0 \\
\hline
\end{tabular}


Table Al - 1.18

\begin{tabular}{|c|c|c|c|c|c|}
\hline \multicolumn{3}{|l|}{ SH1y61p } & \multicolumn{2}{|c|}{$t_{0}=9 / 11 / 61$} & $0=14.30$ \\
\hline Date & & & $\begin{array}{c}\text { Bertola } \\
(70) \\
m_{\mathrm{pg}}\end{array}$ & $t$ & $m_{p g}$ \\
\hline $9 / 1 / 61$ & $22^{h}$ & $36^{m}$ & 14.95 & -9.1 & 14.95 \\
\hline $9 / 3 / 61$ & 21 & 14 & 14.63 & -7.1 & 14.63 \\
\hline $9 / 4 ; 61$ & 23 & 58 & 14.40 & -6.0 & 14.40 \\
\hline $9 / 6 / 6 i$ & 23 & 24 & 14.50 & -4.0 & 14.50 \\
\hline 9/8/01 & 0 & 46 & 14.42 & -3.0 & 14.42 \\
\hline У/Giúi & 23 & 02 & 14.05 & -1.0 & 14.05 \\
\hline 9/10/61 & 22 & 59 & 14.35 & 0.0 & 14.35 \\
\hline $8 / 13 / 61$ & 22 & 25 & 14.28 & 2.9 & 14.28 \\
\hline $9 / 13 / 61$ & 23 & 07 & 14.35 & 3.0 & 14.35 \\
\hline 9/15/61 & 23 & 00 & 14.32 & 5.0 & 14.32 \\
\hline $9 / 16 / 61$ & 22 & 58 & 14.32 & 6.0 & 14.32 \\
\hline $9 / 17 / 61$ & 23 & 59 & 14.38 & 7.0 & 14.38 \\
\hline $9 / 18 / 6 i$ & 1 & 50 & 14.45 & 7.1 & 14.45 \\
\hline $9 / 19 / 61$ & 0 & 25 & 14.40 & 8.0 & 14.48 \\
\hline 9/20/61 & 1 & 09 & 14.68 & 9.0 & 14.68 \\
\hline $9 / 21 / 61$ & 1 & 57 & 14.70 & 10.1 & 14.70 \\
\hline $9 / 22 / 61$ & 2 & 10 & 14.70 & 11.1 & 14.70 \\
\hline $10 / 2 / 61$ & 22 & 27 & 15.03 & 21.9 & 15.063 \\
\hline $10 / 9 / 61$ & 22 & 48 & 16.28 & 28.9 & 16.28 \\
\hline $10 / 10 / 61$ & 23 & 20 & 16.18 & 30.0 & 16.18 \\
\hline $10 / 11 / 61$ & 23 & 49 & 16.23 & 31.0 & 16.23 \\
\hline $10 / 31 / 61$ & 21 & 03 & 17.12 & 50.9 & 17.12 \\
\hline $11 / 1 / 61$ & 19 & 19 & 17.30 & 51.8 & 17.30 \\
\hline $11 / 1 / 61$ & 19 & 58 & 17.30 & 51.8 & 17.30 \\
\hline $11 / 2 / 61$ & 23 & 40 & 17.25 & 53.0 & 17.25 \\
\hline $11 / 5 / 61$ & 18 & 07 & 17.20 & 55.8 & 17.20 \\
\hline $11 / 10 / 61$ & 23 & 12 & 17.32 & 61.0 & 17.32 \\
\hline
\end{tabular}


sule $\mu 1$ - 1.18 (Continand)

\begin{tabular}{|c|c|c|c|c|c|}
\hline Date & & & (70) & $t$ & \\
\hline $22 / 2+/ 62$ & 22 & 25 & 27.30 & C.9 & 27.30 \\
\hline $21 / 25 / 61$ & 22 & 28 & 27.30 & 65.9 & 27.30 \\
\hline $11 / 25 / 61$ & 22 & 55 & 17.25 & 6.0 & 17.25 \\
\hline $12 / 27 / 61$ & 1 & 18 & 17.35 & 67.1 & 17.35 \\
\hline $21 / 17 / 61$ & 19 & 03 & 17.35 & 67.8 & 27.35 \\
\hline $2 / 10 / 61$ & $\mathbf{1}^{\mathbf{h}}$ & $2 T$ & 17.52 & 6.1 & 27.39 \\
\hline $2 / 29 / 62$ & 2 & 13 & 27.55 & 6.1 & 27.55 \\
\hline $12 / 20 / 61$ & 27 & 36 & 27.50 & 76.7 & 27.50 \\
\hline $12 / 8 / 61$ & 20 & 22 & 17.48 & 8.8 & 17.6 \\
\hline $12 / 11 / 61$ & 17 & 13 & 27.75 & 91.7 & 27.75 \\
\hline $12 / 12 / 61$ & 17 & 46 & 17.65 & 92.7 & 17.65 \\
\hline $12 / 15 / 61$ & 0 & 42 & 17.90 & 95.0 & 17.50 \\
\hline $1 / 6 / 62$ & 27 & 22 & 18.00 & 227.7 & 28.00 \\
\hline $2 / 8 / 62$ & 27 & 4 & 27.90 & 219.7 & 27.90 \\
\hline $1 / 8 / 62$ & 21 & 55 & 27.95 & 119.9 & 17.95 \\
\hline $1 / 24 / 62$ & 18 & $\mathbf{M 1}$ & 28.10 & 235.8 & 26.10 \\
\hline $1 / 25 / 62$ & 19 & $\infty$ & 18.10 & 236.8 & 28.10 \\
\hline $1 / 31 / 62$ & 18 & 47 & 18.10 & 142.8 & 16.10 \\
\hline $2 / 6 / 62$ & 21 & 37 & 10.42 & 216.9 & 18.42 \\
\hline
\end{tabular}


Toble $\mu 2$ - 2.29

\begin{tabular}{|c|c|c|c|c|c|c|}
\hline Date & & & Indets & rive & $\bullet$ & \\
\hline $2 / 6 / 62$ & $30^{2}$ & st & & 28.65 & -8.5 & 18.05 \\
\hline Mo/62 & 10 & 20 & & 28.10 & -6.6 & 27.56 \\
\hline $2 / 9 / 6$ & 10 & 43 & 17.6 & & -5.5 & 27.6 \\
\hline $2 / 9 / 62$ & 10 & 58 & & 17.84 & -5.5 & 27.32 \\
\hline $2 / 2 / 62$ & 9 & 50 & & 16.05 & 18.4 & 16.34 \\
\hline $2 / 3 / 62$ & 10 & 48 & 16.25 & & 19.5 & 16.25 \\
\hline $2 / 3 / 62$ & $\boldsymbol{u}$ & $a$ & & 15.86 & 19.5 & 16.21 \\
\hline $3 / 2 / 62$ & 2) & $\infty$ & & 17.24 & 6.4 & 18.11 \\
\hline $3 / 6 / 62$ & 7 & 51 & & 27.87 & 50.3 & 18.70 \\
\hline $3 / 20 / 62$ & 6 & 37 & 18.70 & & T2.3 & 28.70 \\
\hline $3 / 29 / 62$ & 7 & 25 & & 18.47 & 73.3 & 19.04 \\
\hline $3 / 31 / 62$ & $B$ & 20 & 18.85 & & 75.3 & 18.63 \\
\hline$b / 8 / 6 a$ & 8 & $\infty$ & & 28.67 & 83.3 & 19.12 \\
\hline $5 / 1 / 62$ & 5 & 46 & 19.20 & & 106.2 & 19.20 \\
\hline $5 / 3 / 62$ & 8 & 25 & & 19.22 & 100.1 & 19.40 \\
\hline $5 / 5 / 62$ & 4 & 50 & & 19.22 & 210.2 & 19.33 \\
\hline $5 / 6 / 62$ & $T$ & 24 & 19.49 & & 211.3 & 29.69 \\
\hline $5 / 23: 62$ & 7 & 20 & & 20.00 & 234.3 & 19.92 \\
\hline $5 / 30 / 68$ & 5 & $\pi$ & 19.56 & & 135.2 & 19.56 \\
\hline $6 / 30 / 62$ & 6 & 12 & 19.4 & & 166.3 & 29.4 \\
\hline
\end{tabular}


mole $11-1.20$

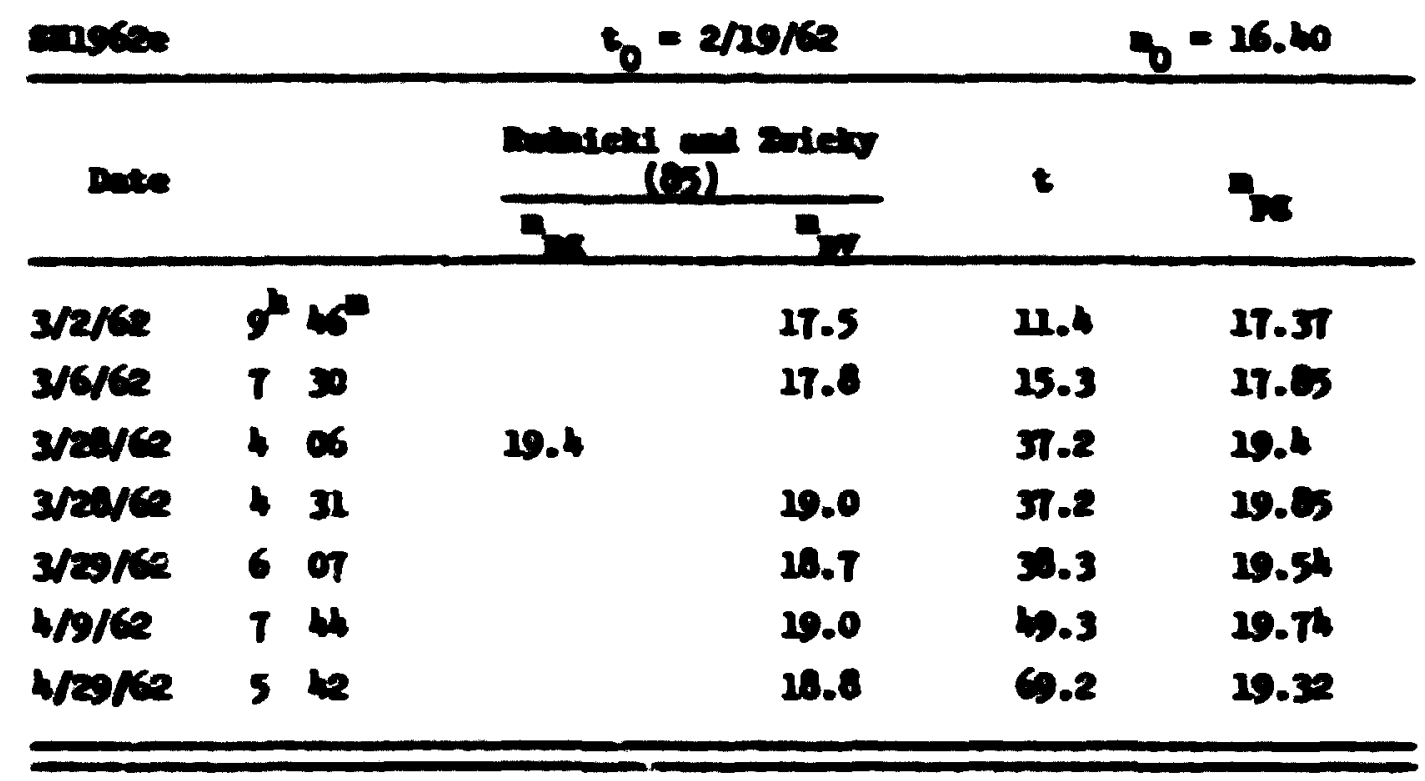


whe $11-2.2$

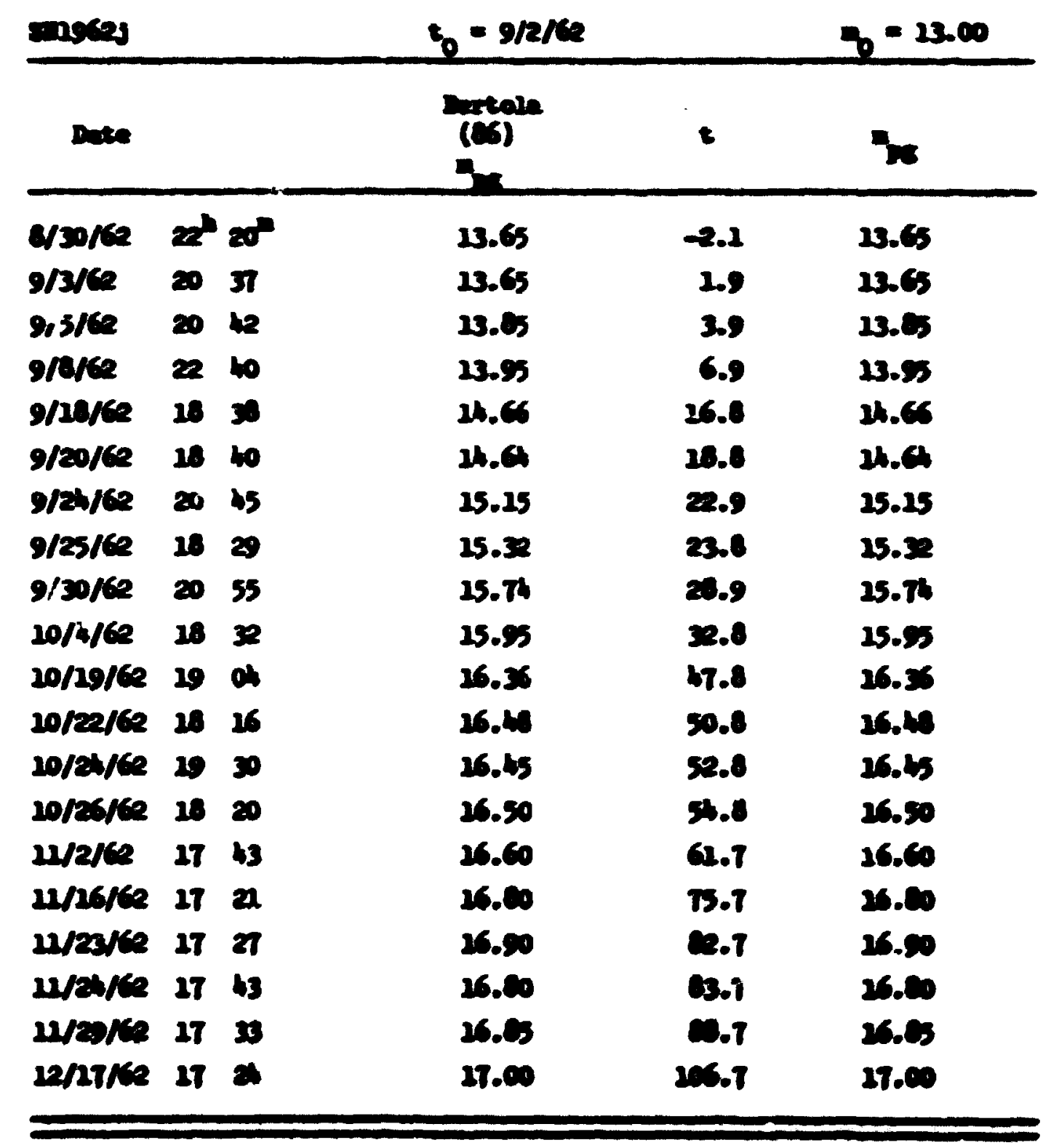




\section{0}

\section{whe $\mu 1-12$}

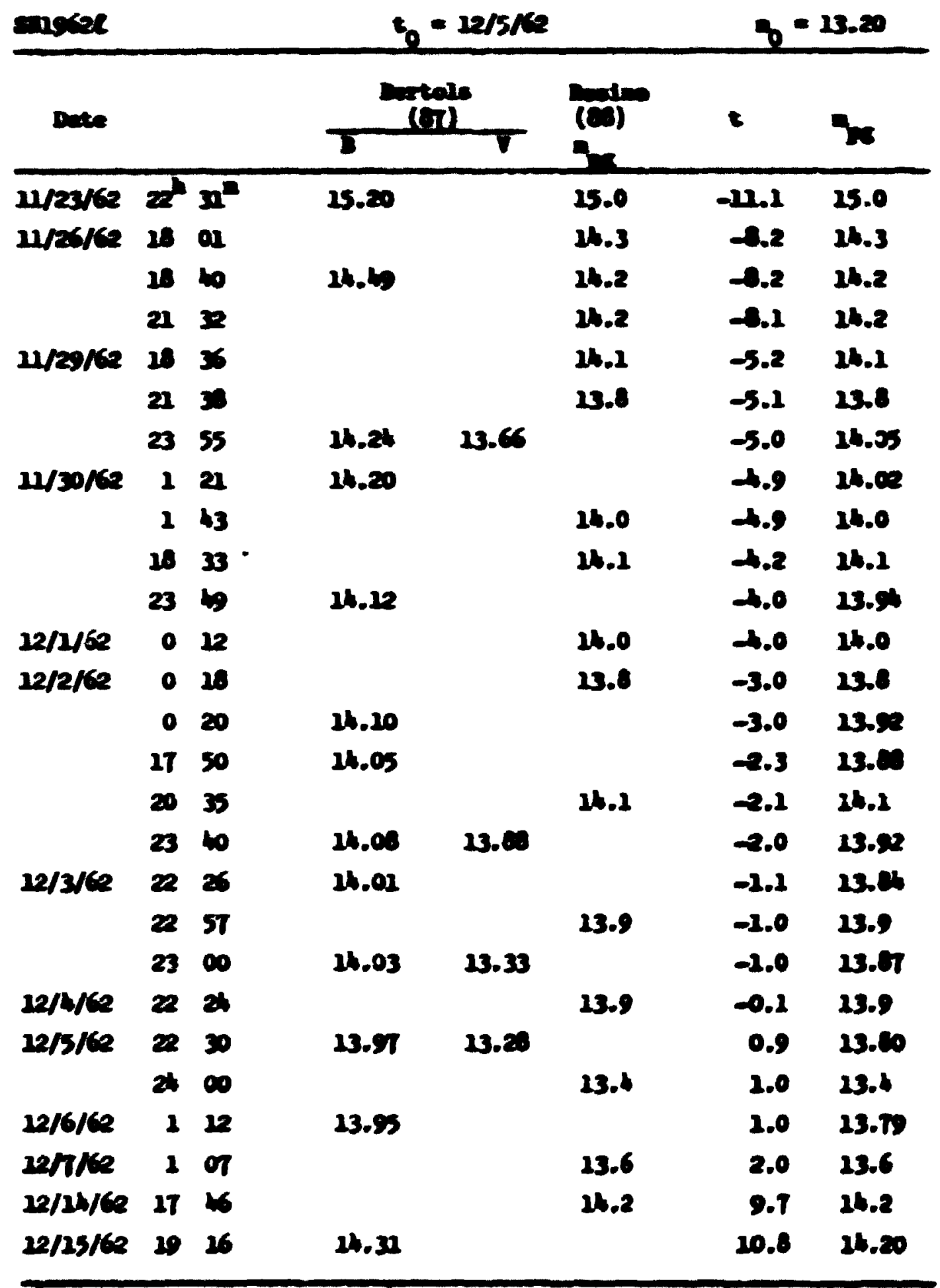


291

Int e $N 1-1.22$ (Continued)

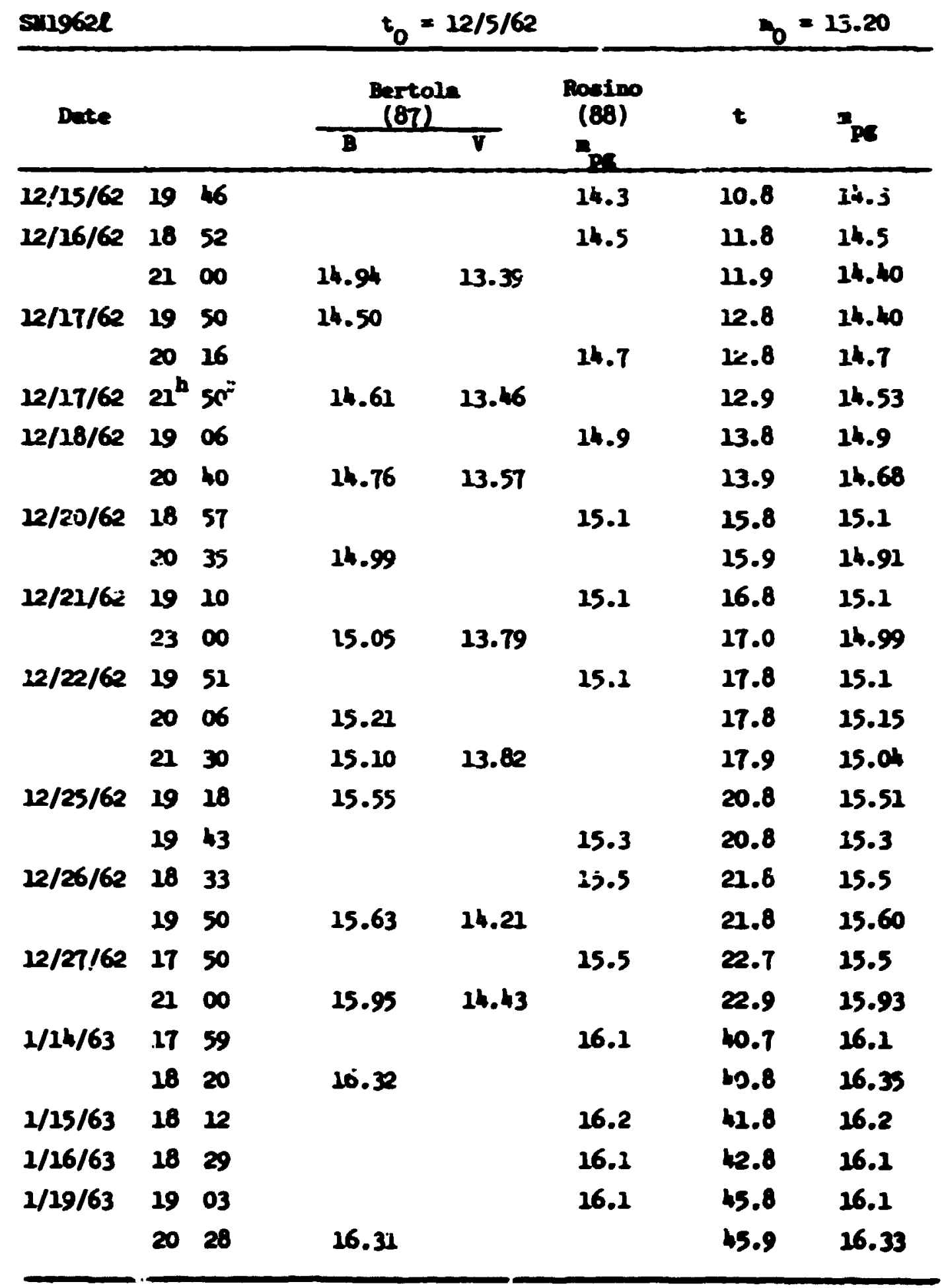




\section{2}

Table 11 - 1.22 (Continued)

\begin{tabular}{|c|c|c|c|c|c|c|}
\hline Date & & & $\begin{array}{l}\text { bertole } \\
\text { (87) }\end{array}$ & $\begin{array}{c}\text { Dasino } \\
(83) \\
\end{array}$ & $t$ & mos \\
\hline \multirow[t]{2}{*}{$1 / 20 / 63$} & 17 & 49 & & 16.2 & 46.1 & 16.2 \\
\hline & 20 & $\infty$ & 16.35 & & 46.8 & 16.37 \\
\hline $1 / 2</ 63$ & 18 & 29 & & 16.2 & 48.8 & 16.2 \\
\hline \multirow[t]{2}{*}{$1 / 24 / 63$} & 18 & 13 & & 16.4 & 50.3 & 16.4 \\
\hline & 18 & 21 & 16.35 & & 50.8 & 16.37 \\
\hline $1 / 25 / 63$ & 18 & 10 & & 16.4 & 51.8 & 16.4 \\
\hline $1 / 26 / 63$ & 18 & 48 & & 16.4 & 52.8 & 16.4 \\
\hline $1 / 27 / 63$ & $\mathbf{I P}$ & 32 & 16.41 & & 53.8 & 16.12 \\
\hline $2 / 23 / 63$ & 19 & 23 & 16.95 & & 80.8 & 16.92 \\
\hline $2 / 25 / 63$ & 19 & 20 & 16.89 & & 82.8 & 16.85 \\
\hline
\end{tabular}


Table Al - 1.23

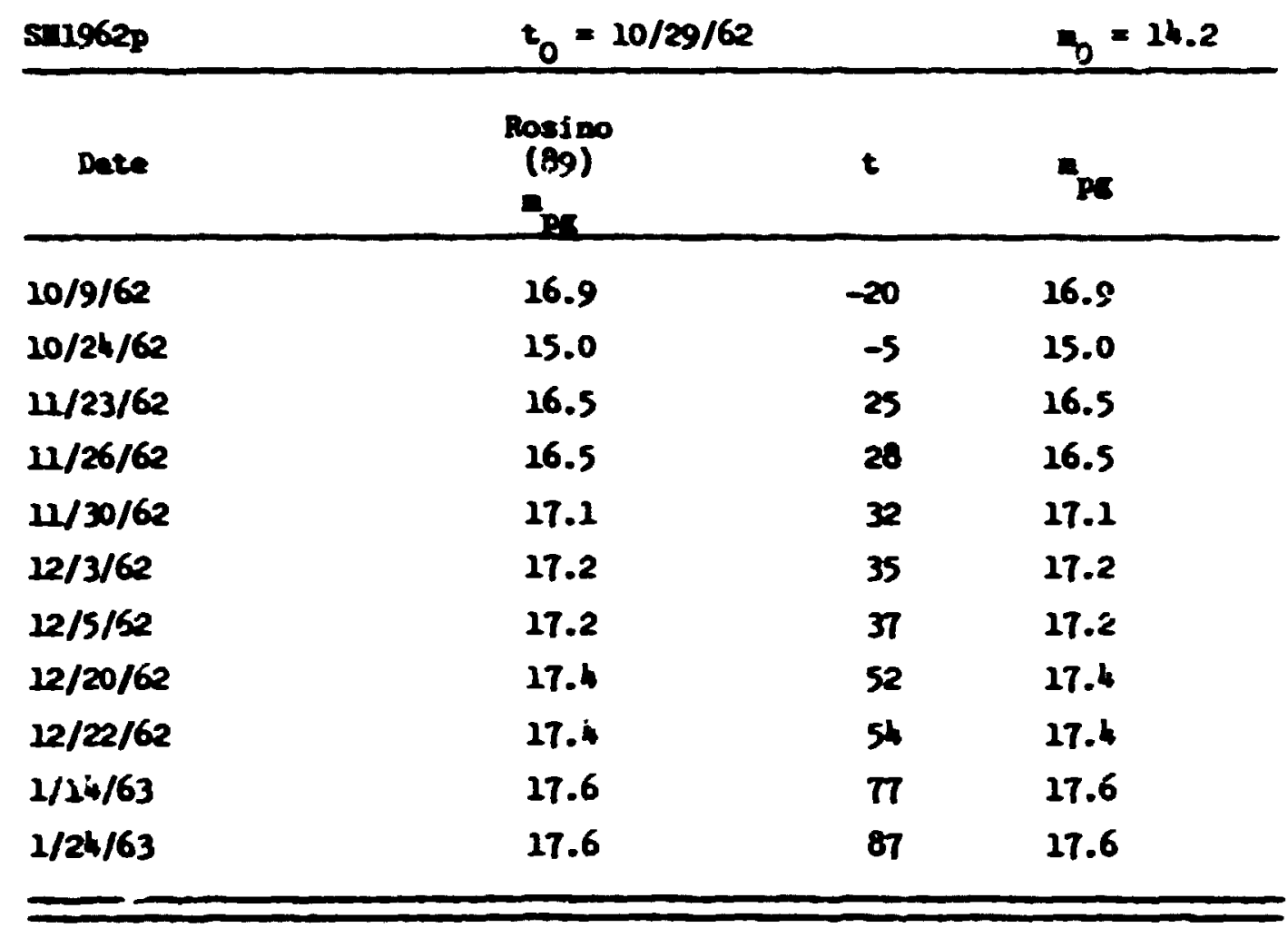




\section{4}

Table Al - 1.24

\begin{tabular}{|c|c|c|c|c|c|c|}
\hline Date & & & $\begin{array}{l}\text { Dertale } \\
\text { (es) }\end{array}$ & (90) & $t$ & prs \\
\hline $1 / 22 / 63$ & & & & 15.5 & 2 & 15.5 \\
\hline $2 / 25 / 63$ & $\sigma^{2}$ & 0. & & 15.90 & 5.0 & 15.90 \\
\hline $1 / 27 / 63$ & 0 & $\infty$ & & 16.00 & 1.0 & 16.00 \\
\hline $1 / 20 / 63$ & 0 & 14 & & 16.10 & 8.0 & 16.10 \\
\hline $1 / 32 / 63$ & 0 & 30 & & 16.40 & 12.0 & 26.10 \\
\hline $2 / 24 / 63$ & 0 & 03 & & 18.85 & 35.0 & 18.85 \\
\hline $2 / 25 / 63$ & 23 & 59 & & 10.90 & 37.0 & 18.90 \\
\hline $3 / 1 / 63$ & 0 & 25 & & 18.95 & 10.0 & 18.95 \\
\hline $3 / 14 / 63$ & 2 & 37 & & 19.05 & 53.9 & 15.05 \\
\hline $3 / 17 / 63$ & 22 & 45 & & 19.05 & 56.9 & 19.05 \\
\hline $4 / 30 / 63$ & 8 & $\pi$ & & 19.35 & 100.4 & 19.35 \\
\hline
\end{tabular}


Table $21-1.25$

\begin{tabular}{|c|c|c|c|c|c|c|c|}
\hline \multirow{2}{*}{$\frac{\text { Sulgs3i }}{\text { Date }}$} & & & \multicolumn{2}{|c|}{$t_{0}=5 / 5 / 63$} & \multicolumn{3}{|c|}{$b_{0}=12.90$} \\
\hline & & & $\begin{array}{l}\text { zateserve } \\
\text { (91) }\end{array}$ & $\begin{array}{c}\text { loebel } \\
(92)\end{array}$ & $\begin{array}{l}\text { Betcan } \\
(93)\end{array}$ & $t$ & 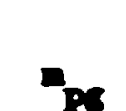 \\
\hline $4 / 22 / 6 ?$ & & & & 15.8 & & -13 & 15.8 \\
\hline $4 / 27 / 63$ & & & & & 14.3 & -8 & 14.3 \\
\hline \multirow[t]{2}{*}{$5 / 14 / 63$} & $19^{h}$ & $\infty$ & 13.90 & & & 9.8 & 13.9 \\
\hline & $2 i$ & $\infty$ & 13.90 & & & 9.9 & 13.90 \\
\hline \multirow[t]{2}{*}{$5 / 16 / 63$} & 20 & $\infty$ & 16.01 & & & 11.8 & 16.01 \\
\hline & 21 & $\infty$ & 13.98 & & & 11.9 & 13.98 \\
\hline $5 / 20 / 63$ & & & & $1 \% .3$ & & 15 & 14.3 \\
\hline $5 / 21 / 63$ & 19 & $\infty$ & 36.57 & & & 16.8 & 14.57 \\
\hline $5 / 22 / 63$ & 20 & $\infty$ & 14.68 & & & 17.8 & 14.68 \\
\hline $5 / 23 / 63$ & 21 & $\infty$ & 14.81 & & & 18.9 & 14.81 \\
\hline $5 / 25 / 63$ & 20 & $\infty$ & 15.07 & & & 20.8 & 15.07 \\
\hline $5 / 26 / 63$ & 19 & $\infty$ & 15.16 & & & 22.6 & 15.16 \\
\hline $6 / 10 / 63$ & 20 & $\infty$ & 15.71 & & & 36.8 & 15.71 \\
\hline $6 / 16 / 63$ & 20 & $\infty$ & 15.80 & & & 12.8 & 15.80 \\
\hline
\end{tabular}




\section{6}

Table 41 - 1.26

\begin{tabular}{|c|c|c|c|c|c|c|c|}
\hline Date & & & $\frac{\operatorname{tat}}{(\sin )}$ & $\frac{\text { und }}{(95)}$ & $\begin{array}{l}\text { Chincerini ond } \\
\text { naroui (96) }\end{array}$ & t & $m$ \\
\hline $5 / 28 / 63$ & & & 12.5 & & & 8 & 12.5 \\
\hline $5 / 20 / 63$ & & & & 13.0 & & 10 & 13.0 \\
\hline $5 / 22 / 63$ & $2 k^{h}$ & 13 & & & 13.05 & & \\
\hline $5 / 25 / 63$ & 20 & 56 & & & 13.7 & 15.9 & 13.7 \\
\hline $5 / 26 / 63$ & 23 & o & & & 13.75 & 17.0 & 13.75 \\
\hline $5 / 20 / 63$ & 24 & $\boldsymbol{\alpha}$ & & & 13.8 & 29.0 & 13.8 \\
\hline $5 / 30 / 63$ & 24 & 59 & & & 13.8 & 21.0 & 13.8 \\
\hline $5 / 31 / 63$ & 25 & $\omega$ & & & 13.9 & 22.0 & 13.9 \\
\hline $6 / 9 / 63$ & 2 & 14 & & & 14.3 & 30.9 & 24.3 \\
\hline $6 / 12 / 63$ & 23 & $\infty$ & & & 14.8 & 34.0 & 24.8 \\
\hline $6 / 17 / 63$ & 22 & $\boldsymbol{H}$ & & & 14.9 & 30.9 & 24.9 \\
\hline $6 / 23 / 63$ & 22 & 52 & & & 15.4 & 4.9 & 15.4 \\
\hline $6 / 25 / 63$ & 23 & 35 & & & 15.5 & 47.0 & 15.5 \\
\hline $6 / 26 / 63$ & 23 & 13 & & & 15.4 & 48.0 & 25.4 \\
\hline $7 / 11 / 63$ & 21 & 33 & & & 16.1 & 65.9 & 16.1 \\
\hline $7 / 16 / 63$ & 21 & 56 & & & 16.3 & 67.9 & 16.3 \\
\hline $7 / 28 / 63$ & 22 & or & & & 16.4 & 69.9 & 16.4 \\
\hline $7 / 10 / 63$ & 22 & 50 & & & 16.4 & 70.9 & 16.4 \\
\hline
\end{tabular}


Table $A$ - 1.27

\begin{tabular}{|c|c|c|c|c|c|c|}
\hline \multicolumn{3}{|l|}{ Date } & \multirow{2}{*}{$\frac{e_{\mathrm{B}}^{\text {Dertaln }}}{2(97)}$} & \multirow[t]{2}{*}{$\begin{array}{c}\text { Tho } \\
(98) \\
K_{\mathbf{K}}\end{array}$} & \multirow[t]{2}{*}{$t$} & \multirow[t]{2}{*}{ ns } \\
\hline $9 / 22 / 63$ & $\infty^{h}$ & $25^{m}$ & & & & \\
\hline $9 / 23 / 63$ & 23 & 53 & 14.15 & & -3.0 & 13.81 \\
\hline $9 / 27 / 63$ & 0 & 24 & 14.05 & & 0.0 & 13.72 \\
\hline $10 / 9 / 63$ & 23 & 34 & 14.70 & & 13.0 & 24.43 \\
\hline $10 / 13 / 63$ & 0 & O4 & 15.15 & & 16.0 & 14.90 \\
\hline \multicolumn{3}{|c|}{ JD2438321.1 } & & 15.33 & 21.1 & 35.45 \\
\hline \multicolumn{2}{|c|}{322.1} & & & 15.88 & 22.1 & 16.04 \\
\hline $10 / 19 / 63$ & $3^{n}$ & $17^{n}$ & 25.95 & & 22.1 & 25.74 \\
\hline $10 / 22 / 63$ & 0 & 01 & 16.45 & & 25.0 & 16.27 \\
\hline $10 / 23 / 63$ & 3 & 19 & 16.50 & & 26.1 & 16.33 \\
\hline $10 / 25 / 63$ & 23 & 34 & 16.70 & & 29.0 & 16.55 \\
\hline \multirow[t]{2}{*}{$10 / 26 / 63$} & 23 & 37 & 16.70 & & 30.0 & 16.76 \\
\hline & 23 & 58 & 16.85 & & 30.0 & 16.71 \\
\hline \multicolumn{3}{|c|}{$J D 2438345.1$} & & 16.67 & 45.1 & 17.18 \\
\hline \multicolumn{3}{|c|}{345.1} & & 16.76 & 45.1 & 17.33 \\
\hline \multicolumn{3}{|c|}{346.1} & & 16.62 & 46.2 & 17.09 \\
\hline \multicolumn{3}{|c|}{346.2} & & 16.72 & 46.2 & 17.26 \\
\hline $21 / 17 / 63$ & $23^{h}$ & $12^{\circ}$ & 17.50 & & 52.0 & 17.31 \\
\hline $11 / 22 / 63$ & 22 & 50 & 27.55 & & 57.0 & 17.41 \\
\hline $12 / 12 / 63$ & 21 & 18 & 17.80 & & 16.9 & 17.63 \\
\hline \multicolumn{3}{|c|}{$J D 2 h 38382.1$} & & 17.04 & $\$ 2.1$ & 17.83 \\
\hline \multicolumn{3}{|c|}{383.0} & & $16 ́ .92$ & 83.0 & 27.54 \\
\hline \multicolumn{3}{|c|}{383.0} & & 17.00 & 82.0 & 27.73 \\
\hline \multirow[t]{2}{*}{$1 / 8 / 64$} & $19^{h}$ & $51^{2}$ & 18.50 & & 103.8 & 18.28 \\
\hline & 20 & 13 & 18.60 & & 103.8 & 18.38 \\
\hline $1 / 29 / 6 b$ & 19 & 30 & 18.80 & & 114.8 & 18.56 \\
\hline
\end{tabular}


c

e

298

Table Al - 1.27 (Continued)

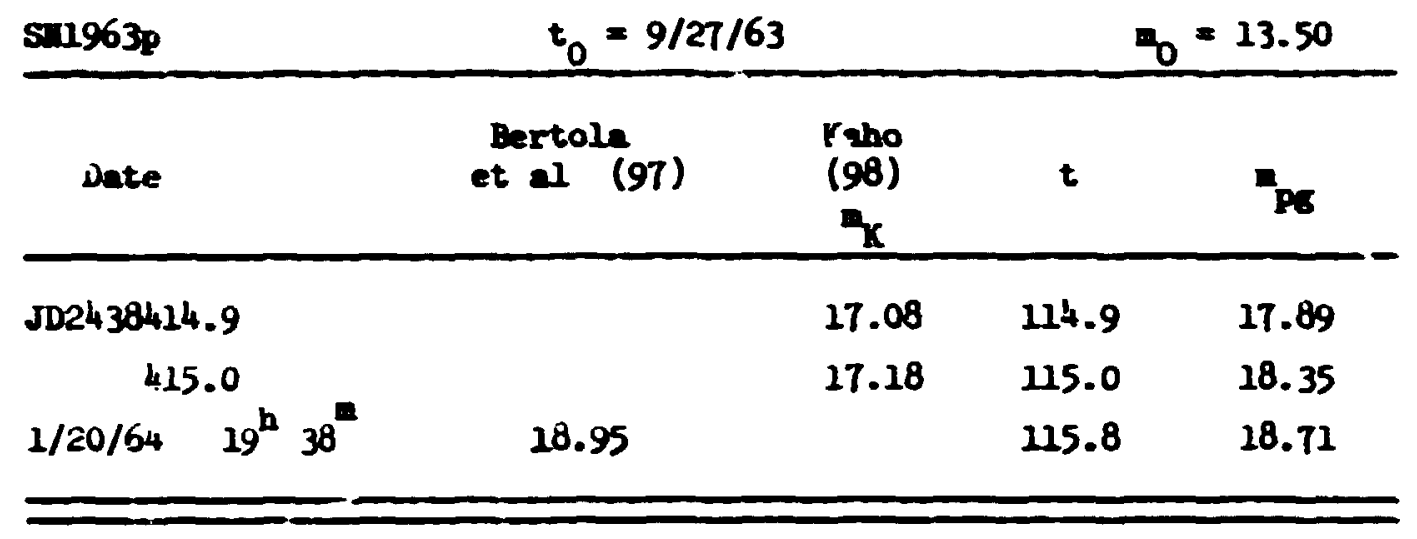




$$
\begin{aligned}
& 299
\end{aligned}
$$

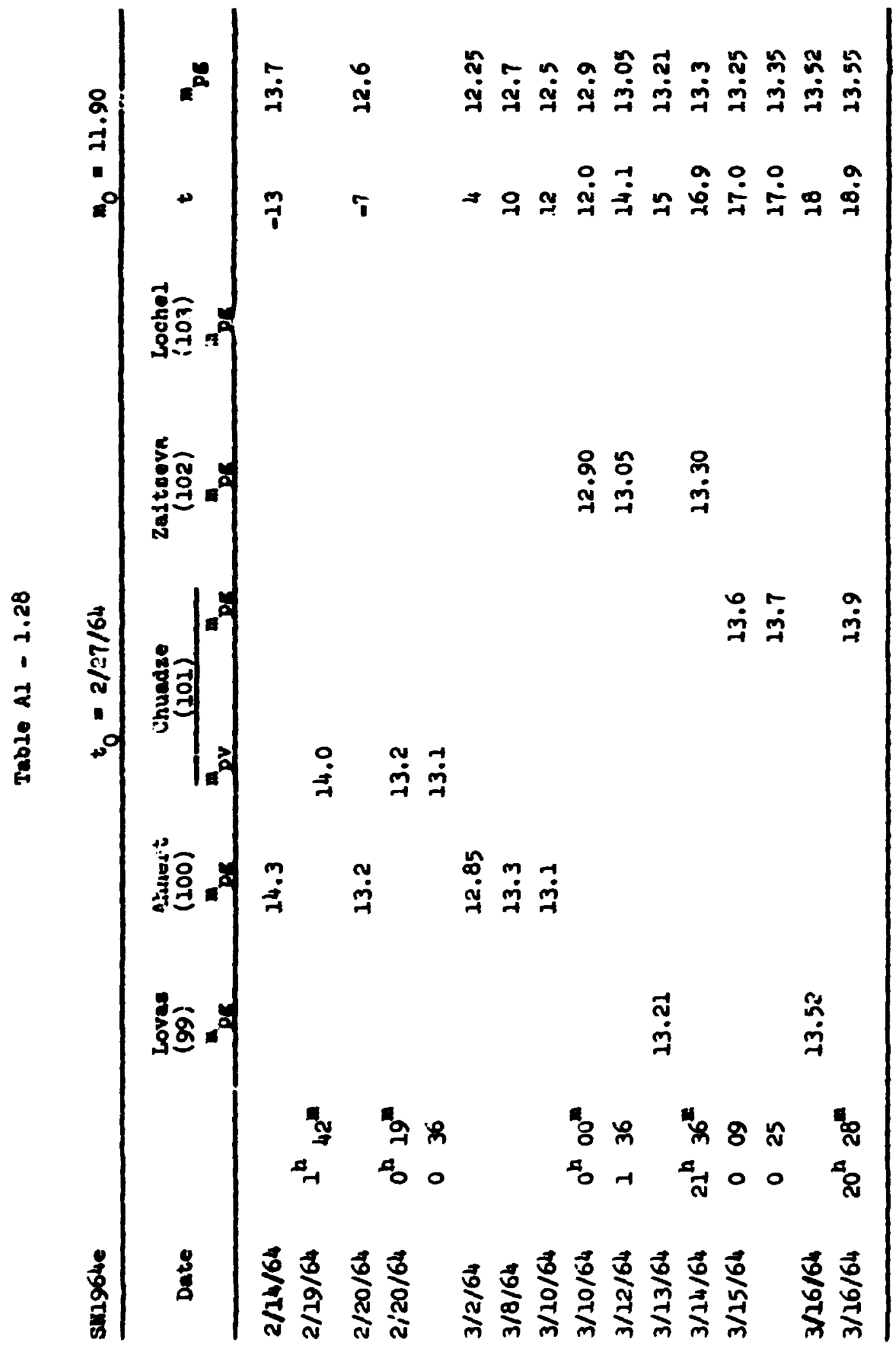




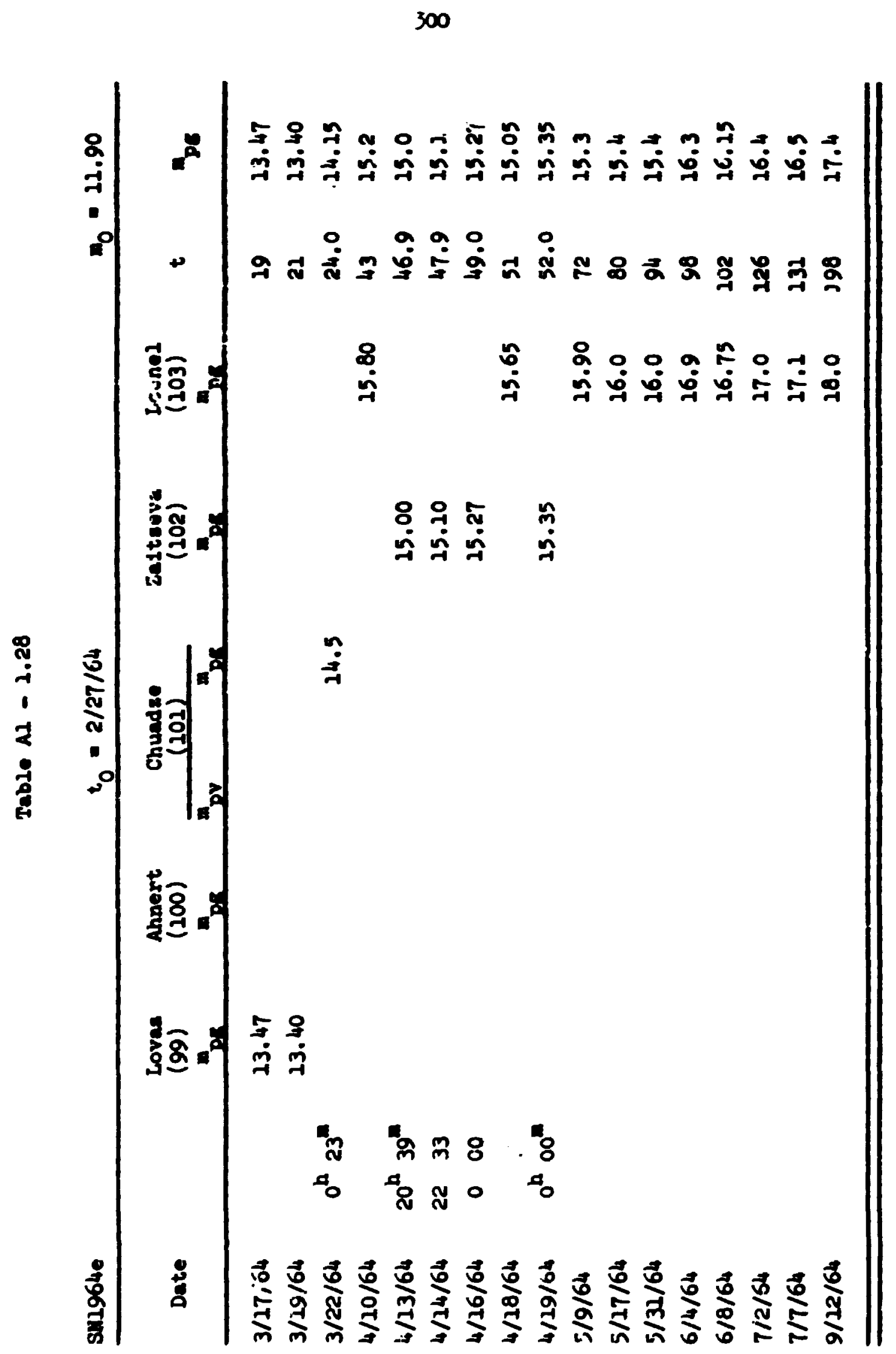


301

Table Al - 1.29

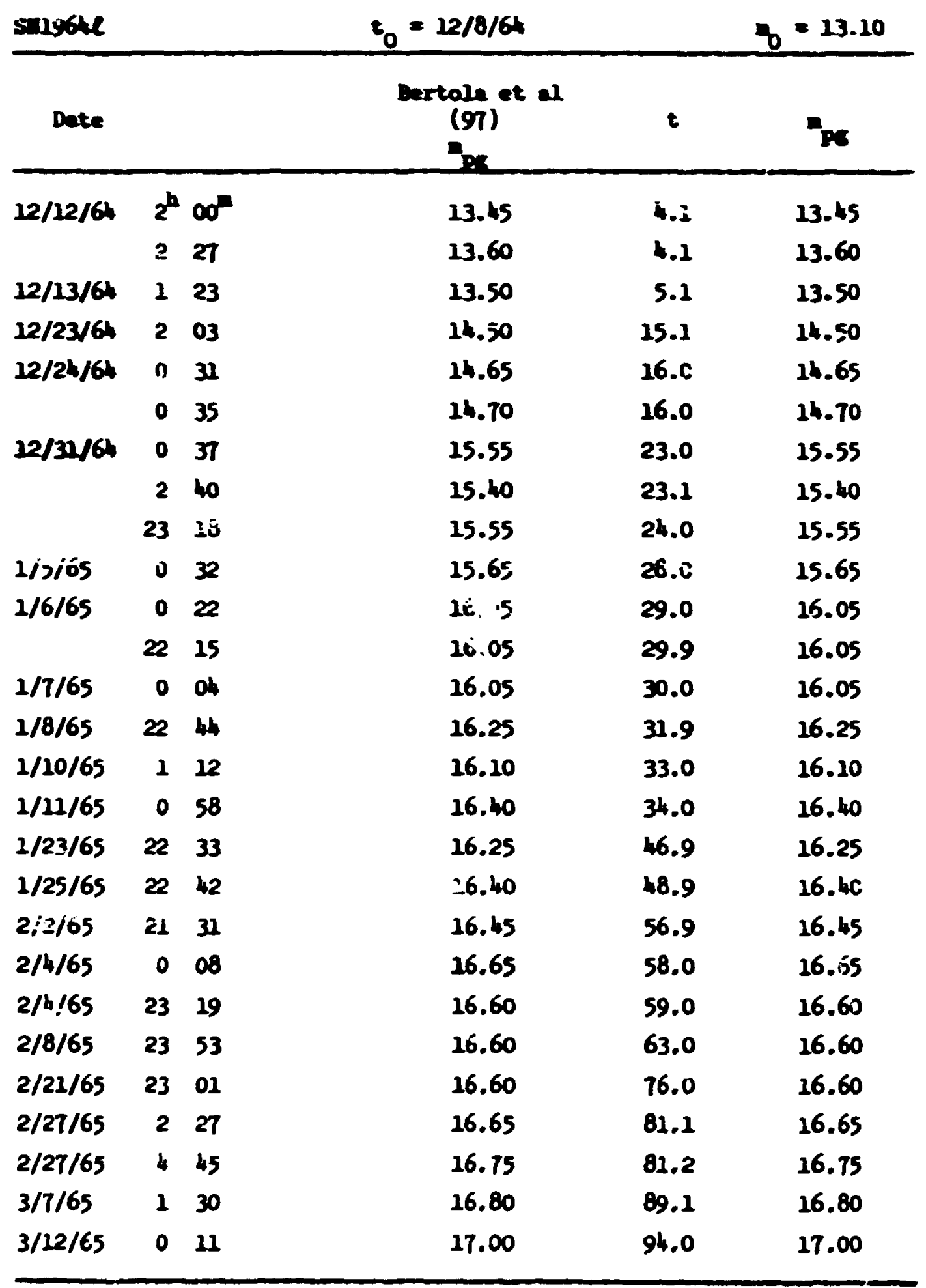


Toble Al - 1.29 (Coutinned)

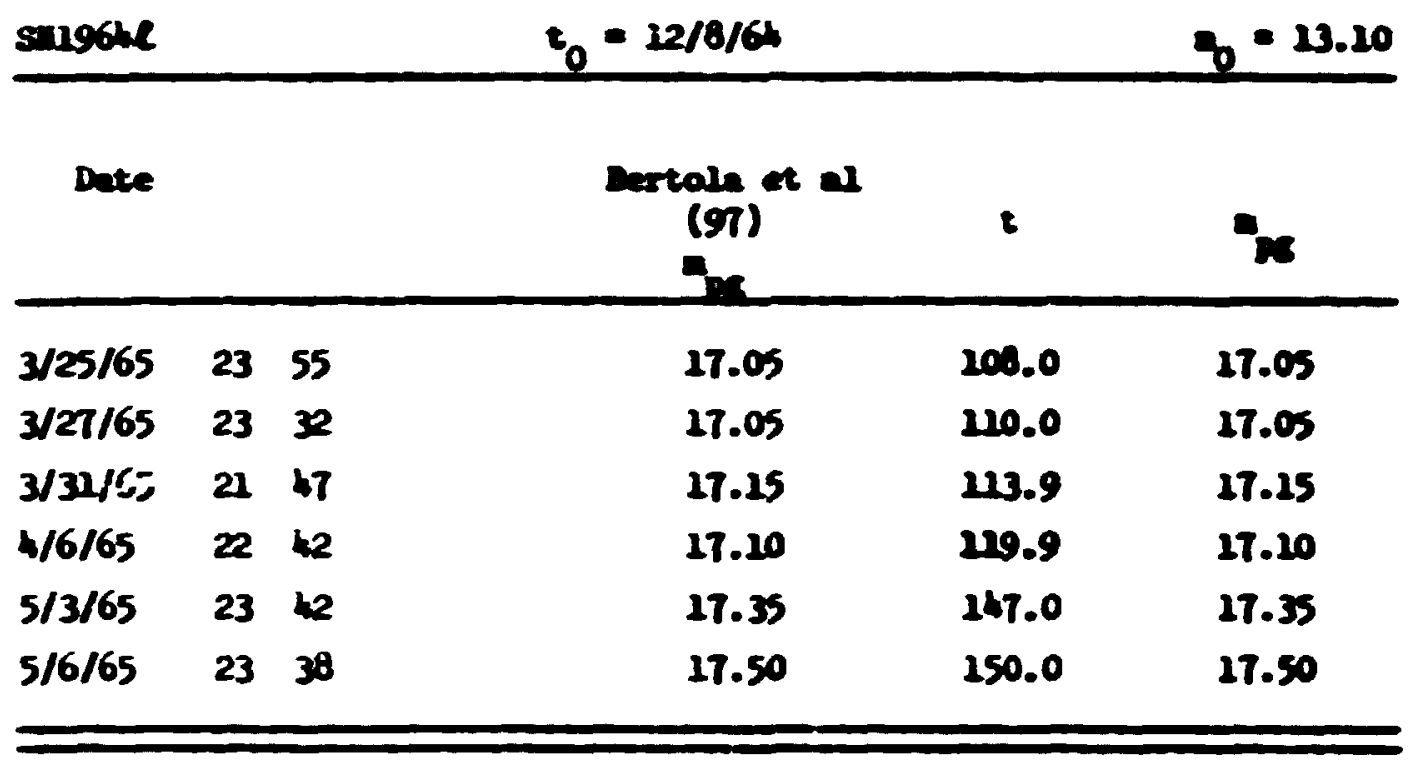


mole $41-2.30$

\begin{tabular}{|c|c|c|c|c|c|c|c|}
\hline $\begin{array}{c}\text { emerst } \\
\text { tase }\end{array}$ & & & & elest & 5) & 2 & 9 \\
\hline \multicolumn{3}{|c|}{ stobyens.3 } & 16.00 & & & -9.7 & 26.09 \\
\hline \multicolumn{3}{|c|}{926.3} & 25.67 & & & -8.7 & 25.67 \\
\hline $6 / 186 / 65$ & $\mathbf{u}^{*}$ & $\mathbf{u}^{\mathbf{n}}$ & & & $\mathbf{2 . 6 0}$ & 5.9 & 21.56 \\
\hline \multicolumn{2}{|c|}{502.3092 .3} & & 22.58 & & & 7.3 & 22.58 \\
\hline \multirow{2}{*}{$6 / 20.168$} & $\mathbf{u}^{\mathbf{3}}$ & $\infty$ & & & 22.45 & 7.9 & 22.27 \\
\hline & 21 & $\mathbf{2}$ & & & 12.58 & 7.9 & 25.37 \\
\hline \multicolumn{2}{|c|}{$J 0243532.04$} & & 12.68 & & & 8.4 & 22.60 \\
\hline \multirow[t]{5}{*}{$6 / 22 / 6 t$} & $a^{b}$ & $\infty^{\infty}$ & & & 12.70 & & \\
\hline & $\mathbf{2}$ & 22 & & 22.60 & & 9.9 & 22.50 \\
\hline & 21 & 28 & & 12.65 & & 9.9 & 22.55 \\
\hline & 22 & $\boldsymbol{\alpha}$ & & 12.70 & & 9.9 & 22.60 \\
\hline & 22 & 2 & & & 22.75 & & \\
\hline \multicolumn{2}{|c|}{ Jo2h3e935.h } & & 12.70 & & & 20.6 & 22.70 \\
\hline \multirow[t]{2}{*}{$6 / 23 / 65$} & $22^{b}$ & $\infty \infty^{n}$ & & & 22.80 & & \\
\hline & $\boldsymbol{2}$ & 26 & & 12.75 & & 10.9 & 12.65 \\
\hline \multicolumn{2}{|c|}{ J024 39936.3 } & & 22.73 & & & $\mathbf{1 1 . 1 3}$ & 12.73 \\
\hline \multirow[t]{5}{*}{$6 / 24 / 65$} & $20^{h}$ & 34 & & & 12.80 & & \\
\hline & 22 & ¿0 & & & 22.85 & & \\
\hline & 21 & 21 & & 12.80 & & 12.9 & 22.72 \\
\hline & 21 & 20 & & 12.95 & & 21.9 & 22.87 \\
\hline & $2 \mathbf{2}$ & 30 & & 12.90 & & $\mathbf{1 2 . 9}$ & 22.82 \\
\hline \multirow[t]{3}{*}{$6 / 25 / 65$} & 21 & 10 & & & 12.95 & & \\
\hline & 21 & 16 & & & 12.90 & & \\
\hline & 21 & 25 & & 13.10 & & 12.9 & 13.03 \\
\hline 4 & 21 & 30 & & 13.00 & & 12.9 & 12.93 \\
\hline \multicolumn{3}{|c|}{ JD2h38938.3 } & 13.00 & & & 13.3 & 13.00 \\
\hline \multicolumn{2}{|c|}{939.3} & & $12.8 i$ & & & 14.3 & 12.81 \\
\hline
\end{tabular}


304

Inve 41 - $1.30(\cos t i n a)$

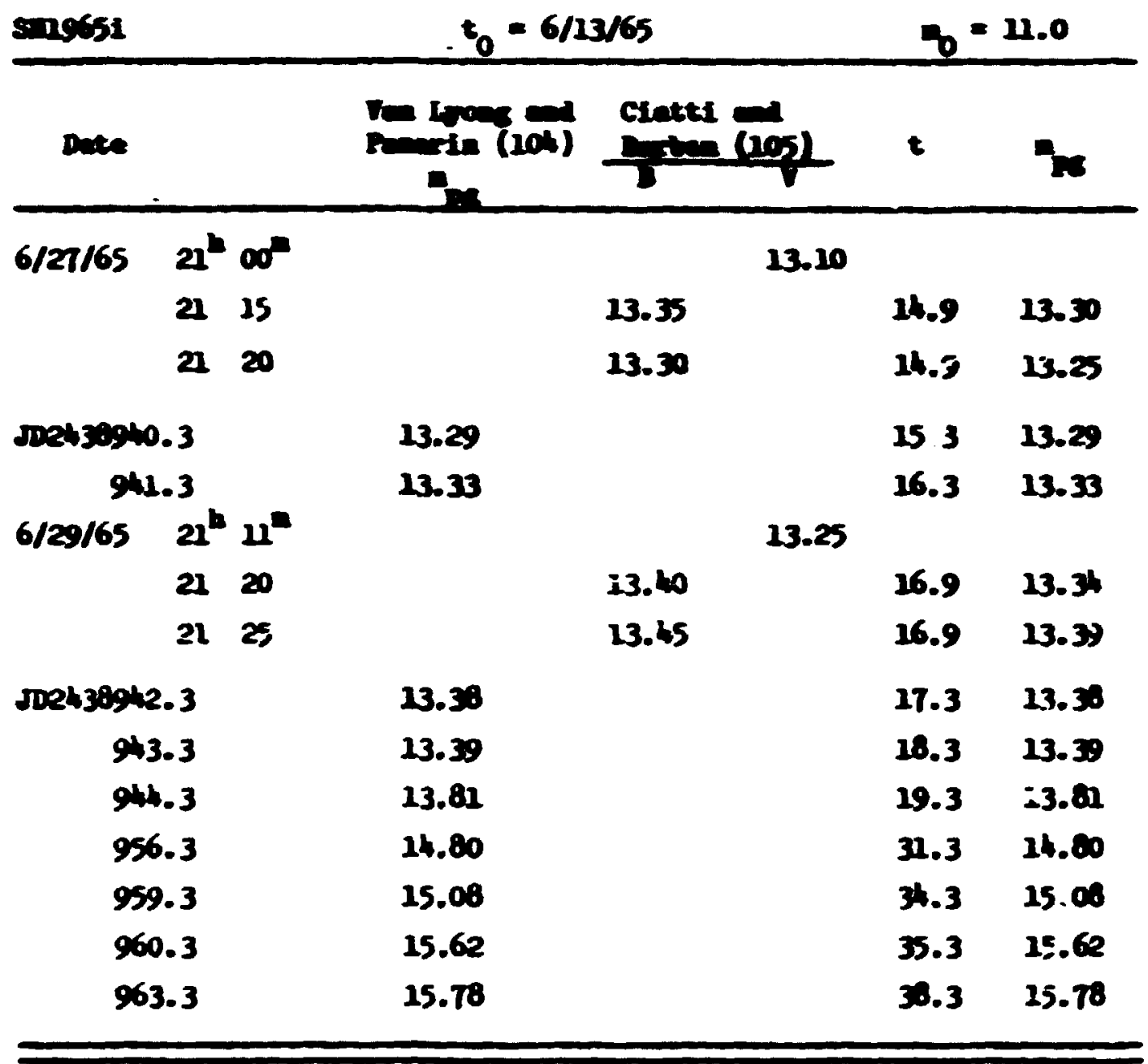


Ible $\Delta 1$ - 1.31

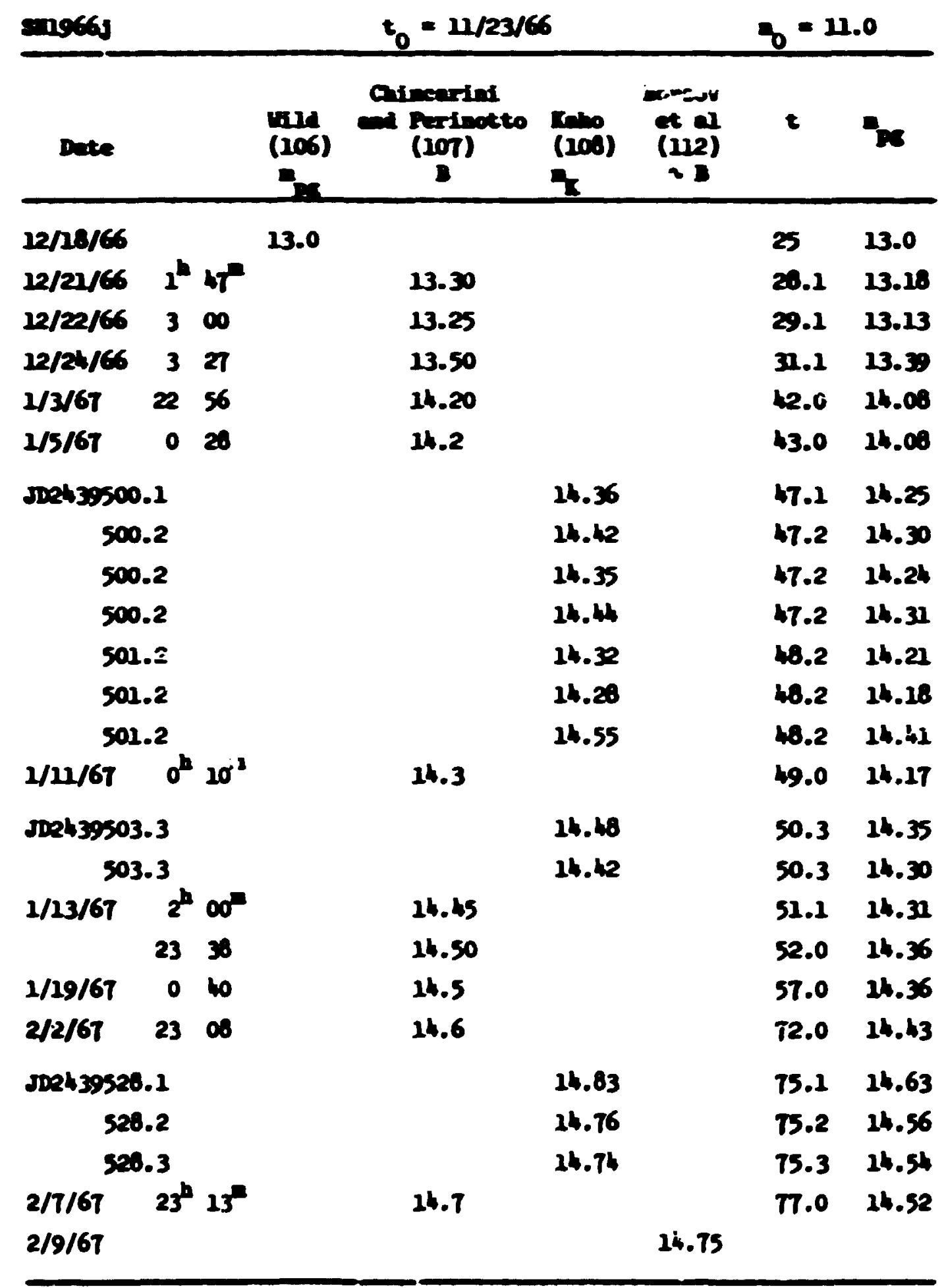



Dole $42-1.32$

\begin{tabular}{|c|c|c|c|c|}
\hline Dete & & & $t$ & \\
\hline spossotias & & 28.4 & -10.1 & 17.9 \\
\hline 478.9 & 17.8 & & -9.1 & 17.0 \\
\hline 478.9 & & 18.2 & -9.1 & 17.7 \\
\hline $\sec 00$ & & 27.6 & 16.0 & 17.9 \\
\hline secks & 18.1 & & 17.9 & 28.1 \\
\hline 536.0 & & 19.0 & 45.0 & 20.0 \\
\hline 551.0 & & 18.9 & 62.8 & 19.7 \\
\hline 552.7 & & 20.2 & 63.7 & 20.0 \\
\hline 5st.7 & & 19.5 & 75.7 & 20.1 \\
\hline 54.8 & 19.6 & & 15.8 & 29.6 \\
\hline
\end{tabular}


reble $11-1.33$

\begin{tabular}{|c|c|c|c|c|}
\hline Dace & & Cietti (105) & $t$ & as \\
\hline 10/11/65 & $\sigma_{34}$ & 24.70 & 7.0 & 14.70 \\
\hline 11/T/Ks & 223 & 16.90 & 31.9 & 16.90 \\
\hline $11 / 14 / 66$ & 005 & 16.95 & 33.0 & 16.95 \\
\hline $11 / 16 / 66$ & - 17 & 17.10 & $\$ 0.0$ & 17.10 \\
\hline $11 / 19 / 66$ & 034 & 17.30 & 43.0 & 17.30 \\
\hline $12 / 6 / 66$ & 2235 & 17.60 & 60.9 & 17.60 \\
\hline $12 / 8 / 66$ & 2135 & 17.65 & 62.9 & 17.65 \\
\hline $12 / 9 / 66$ & 22 ot & 17.70 & 63.9 & 17.75 \\
\hline $12 / 10 / 66$ & 2110 & 17.70 & 6.9 & 17.70 \\
\hline $12 / 21 / 66$ & 2106 & 17.60 & 65.9 & 17.80 \\
\hline $1 / 4 / 67$ & 1911 & 18.00 & 89.8 & 10.00 \\
\hline
\end{tabular}




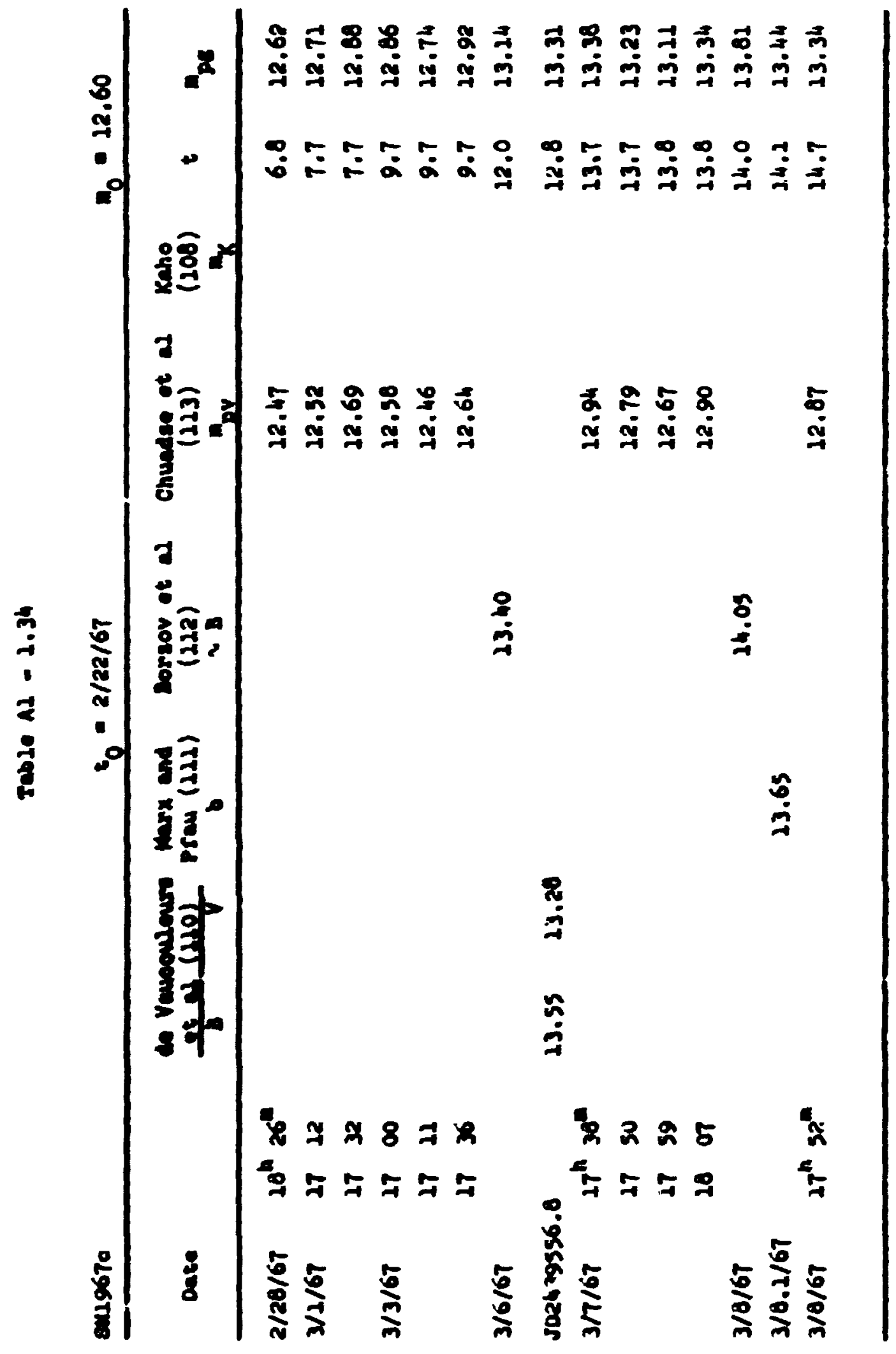




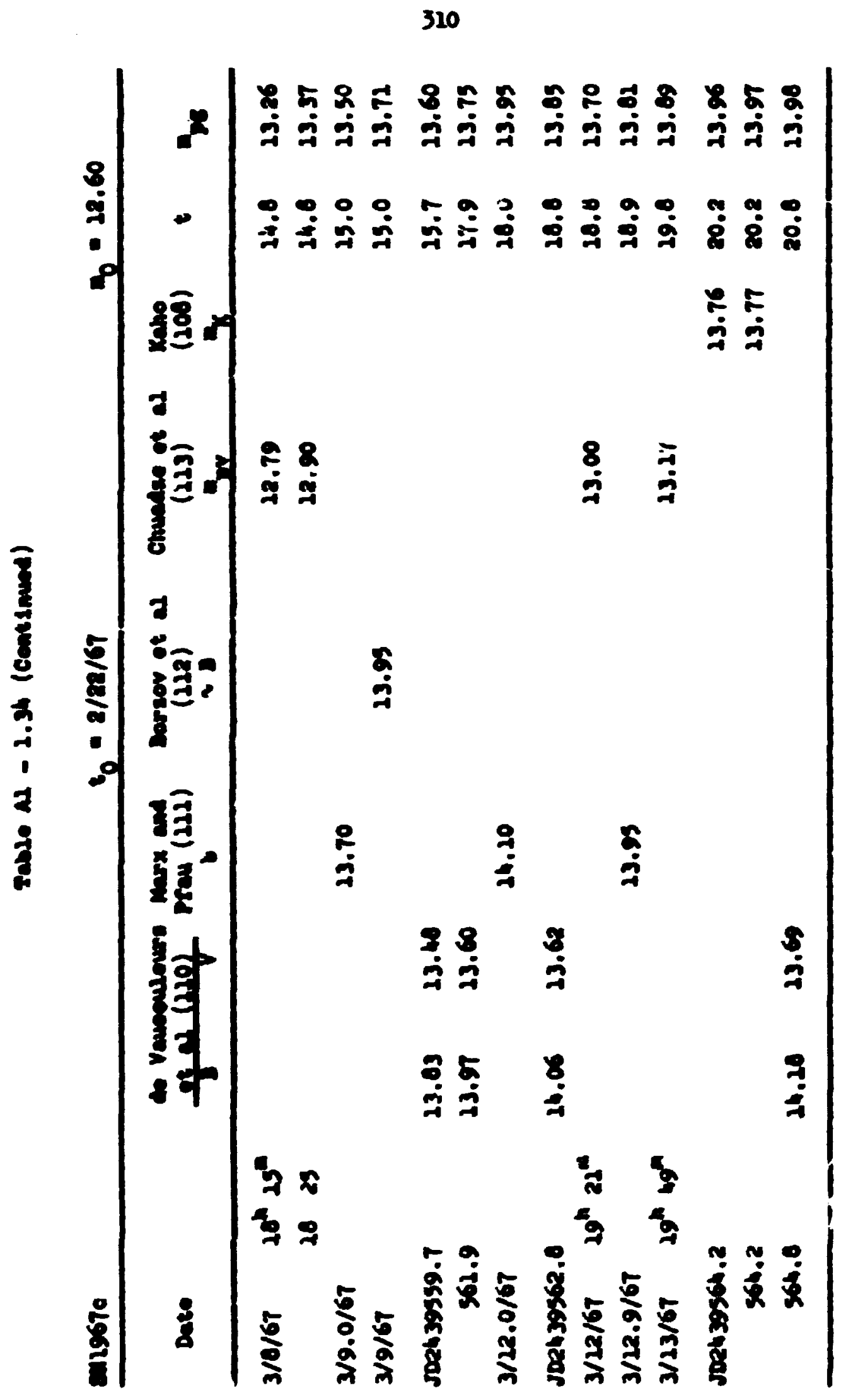




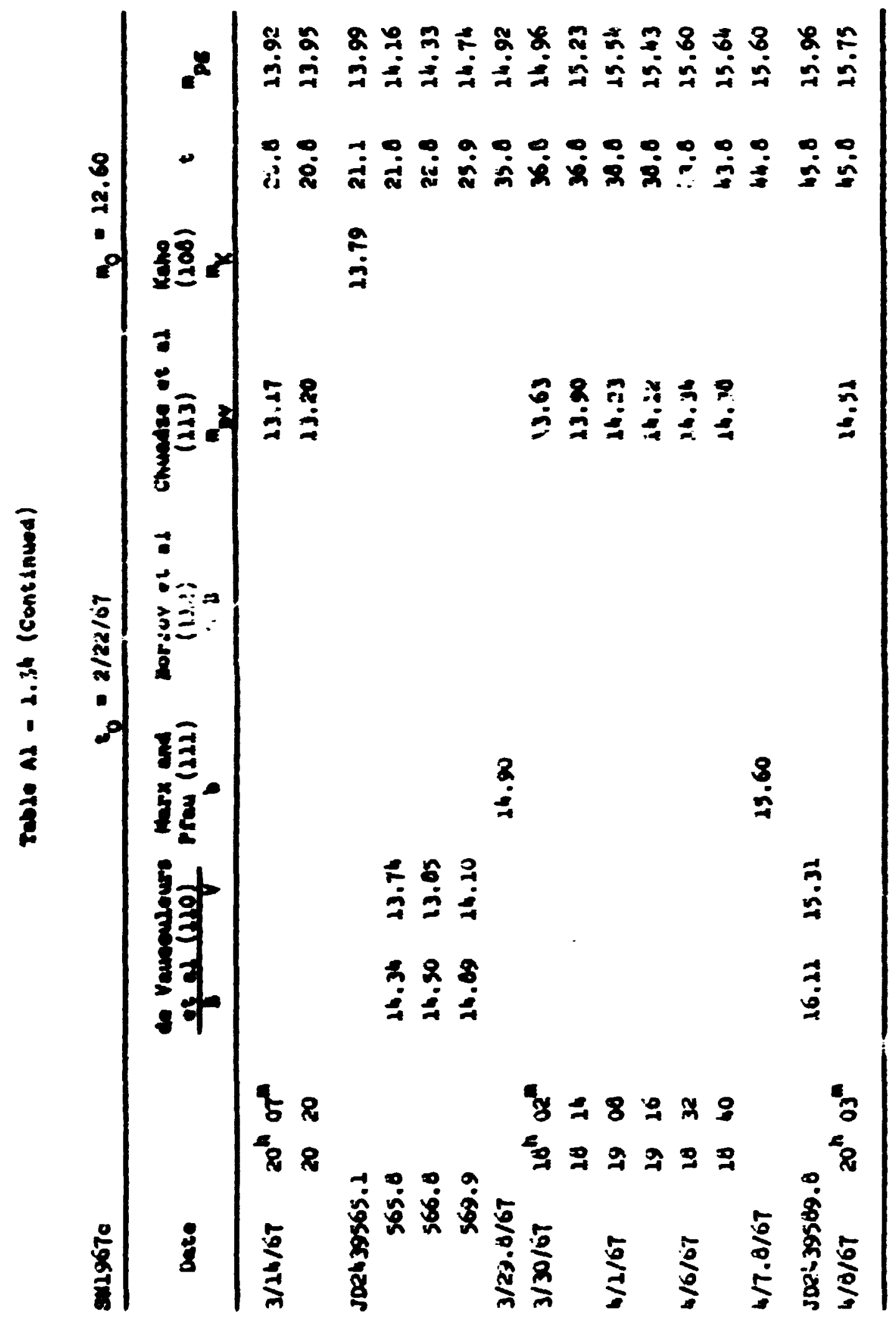




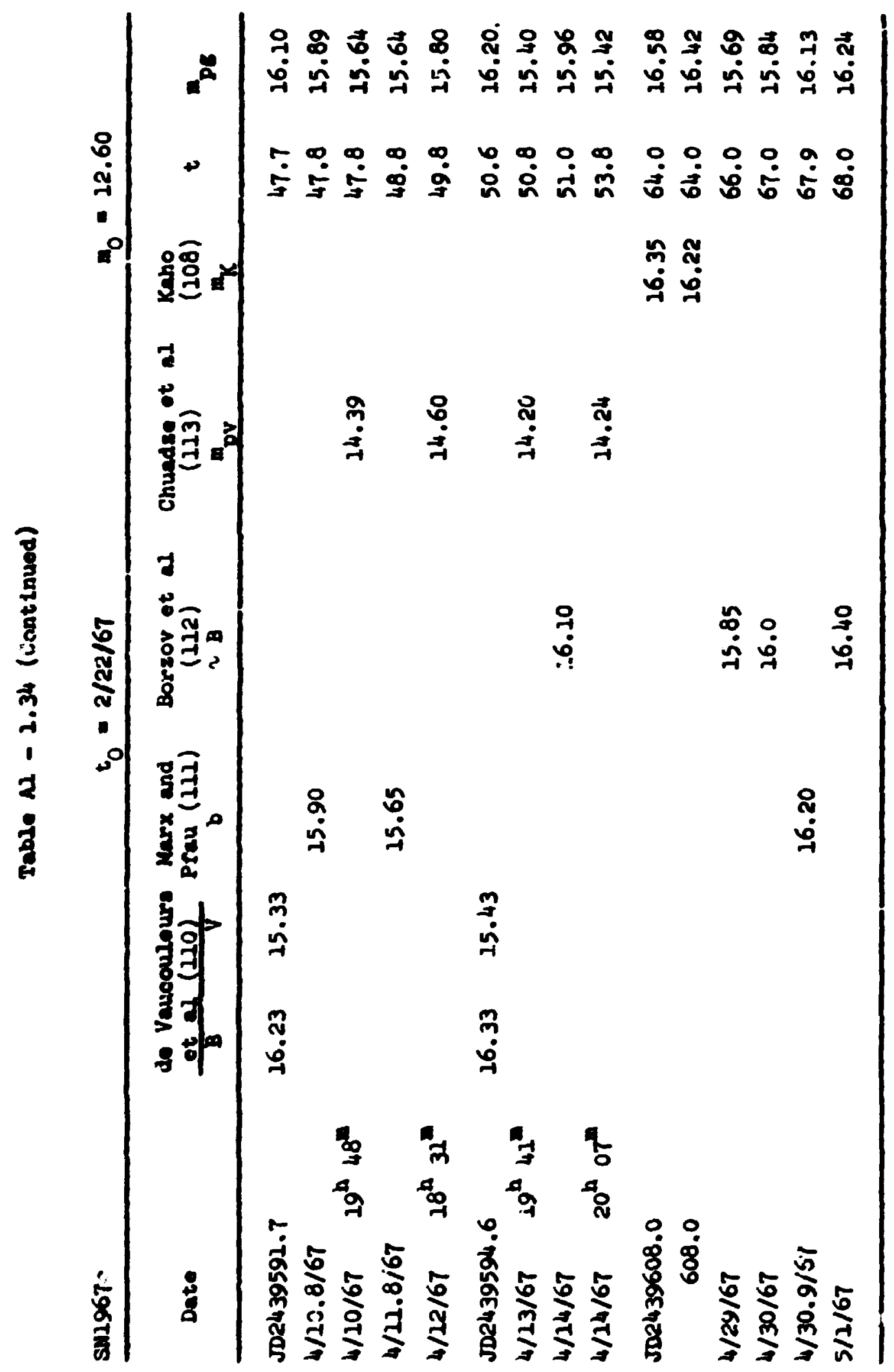


Table Al - 2.34 (Continued)

\begin{tabular}{|c|c|c|c|c|c|c|c|}
\hline \multirow{2}{*}{$\frac{\operatorname{sun} 967 c}{\text { Date }}$} & \multicolumn{4}{|c|}{$t_{0}=2 / 22 / 6 r$} & \multicolumn{2}{|c|}{$m_{0}-12.60$} & \multirow[b]{2}{*}{$m_{p s}$} \\
\hline & $\begin{array}{l}\text { de Vaucouleura } \\
\frac{\text { et a (210) }}{\mathrm{B}}\end{array}$ & $\underset{b}{\operatorname{Marx}}$ and & $\begin{array}{c}\text { Borzov ot al } \\
(112) \\
2 \mathrm{~B}\end{array}$ & $\begin{array}{c}\text { Chuadse tt al } \\
\text { (123) } \\
n_{p y}\end{array}$ & $\begin{array}{c}\text { Kaho } \\
(208) \\
n_{K}\end{array}$ & $t$ & \\
\hline JD2439613.7 & 16.35 & & & & & 69.7 & 26.19 \\
\hline 613.7 & 20.43 & & & & & 69.7 & 16.27 \\
\hline 616.7 & 16.65 & & & & & 72.7 & 26.48 \\
\hline 618.7 & 26.45 & & & & & 74.7 & 26.28 \\
\hline $5 / 7.9 / 67$ & & 26.20 & & & & 74.9 & 16.12 \\
\hline JD: 439619.7 & 16.85 & & & & & 75.7 & 16.68 \\
\hline 621.7 & 16.73 & & & & & 77.7 & 16.56 \\
\hline $5 / 10.9 / 67$ & & 16.20 & & & & 77.9 & 16.10 \\
\hline $3 / 11.9 / 67$ & & 26.30 & & & & 78.9 & 16.20 \\
\hline JD2439623.7 & 16.94 & & & & & 79.7 & 16.76 \\
\hline 043.7 & 17.50 & & & & & $99 . ?$ & 17.29 \\
\hline 645.7 & 17.40 & & & & & 101.7 & 27.29 \\
\hline 64.5 .0 & & & & & 16.60 & 102.0 & 26.90 \\
\hline 646.0 & & & & & 16.57 & 102.0 & 26.85 \\
\hline JD2439649.7 & 27.38 & & & & & 205.7 & 27.16 \\
\hline 650.7 & 17.78 & & & & & 106.7 & 17.56 \\
\hline
\end{tabular}


Table Al - 1.35

\begin{tabular}{|c|c|c|c|c|c|c|}
\hline \multirow{3}{*}{$\begin{array}{l}\text { sug68e } \\
\text { Date }\end{array}$} & \multicolumn{4}{|c|}{$t_{0}=3 / 15 / 68$} & \multicolumn{2}{|c|}{$z_{0}=12.70$} \\
\hline & \multirow{2}{*}{$\begin{array}{c}\text { Chavize } \\
\text { (114) } \\
=\end{array}$} & \multirow{2}{*}{$\begin{array}{l}\text { Ruser } \\
\text { (51) } \\
\text { pe }\end{array}$} & \multicolumn{2}{|c|}{$\begin{array}{l}\text { Siatti and Darbon } \\
\text { (105) }\end{array}$} & \multirow{2}{*}{$\mathbf{t}$} & \multirow{2}{*}{ Pe } \\
\hline & & & B & V & & \\
\hline $3 / 21 / 68$ & 13.5 & & & & 6 & 13.5 \\
\hline $3 / 25 / 68 \quad 21^{h} 30^{\circ}$ & & & 15.50 & 14.85 & 10.9 & 14.43 \\
\hline JD2439943 & & 14.7 & & & 12 & 14.7 \\
\hline $3 / 27 / 68 \quad 20^{h} 30^{\circ}$ & & & 15.60 & 15.00 & 1ิ.. & 14.65 \\
\hline JD243994h & & 14.8 & & & 13 & 14.8 \\
\hline $3 / 29 / 6822^{h}$ of & & & 15.60 & 15.25 & 13.9 & 14.95 \\
\hline JD2433945 & & 14.75 & & & 14 & 14.75 \\
\hline ghé & & 14.9 & & & 15 & 14.9 \\
\hline $3 / 30 / 68 \quad 20^{4} \quad 35^{n}$ & & & 15.70 & $15 . \because$ & 15.9 & 15.08 \\
\hline $4 / 3 / 68 \quad 24 \quad 00$ & & & 16.10 & 15.65 & 20.0 & 15.63 \\
\hline JD2439963 & & 15.8 & & & 32 & 15.8 \\
\hline 966 & & 15.95 & & & 35 & 15.95 \\
\hline $4 / 23 / 68 \quad 20^{b} 13^{n}$ & & & 17.20 & & & \\
\hline
\end{tabular}


rable Al -1.36

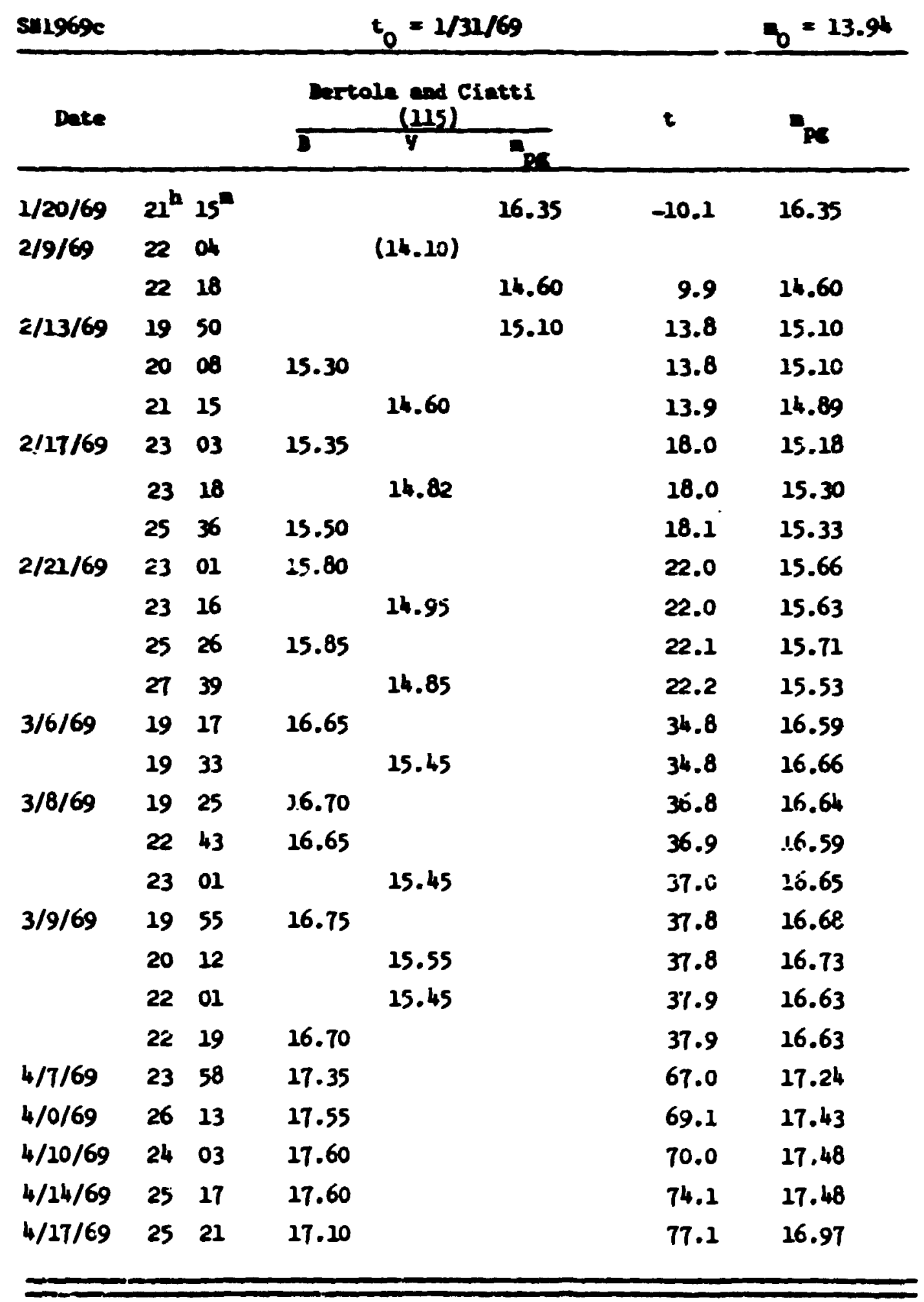


Table $\mu$ - 1.36 (Contined)

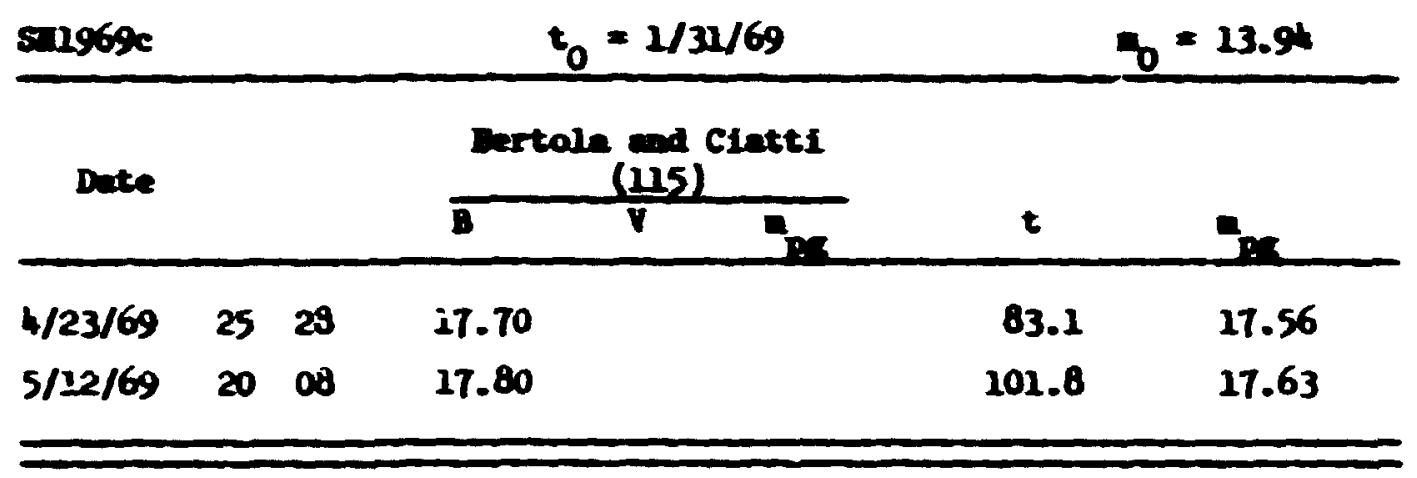




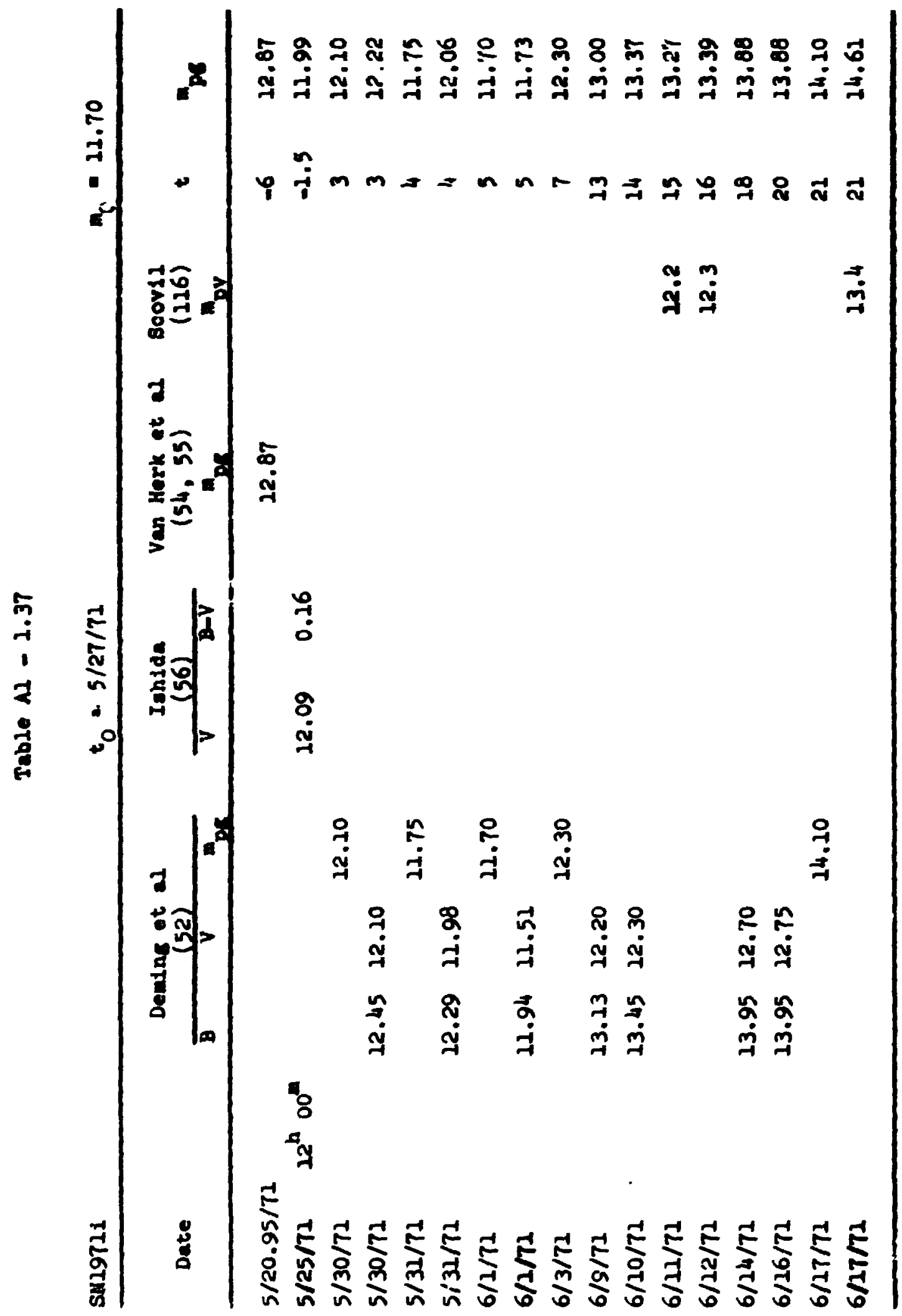


Table al - 1.37 (Continued)

\begin{tabular}{|c|c|c|c|c|c|c|c|c|}
\hline \multirow{3}{*}{$\frac{\text { SN19711 }}{\text { Date }}$} & \multicolumn{6}{|c|}{$t_{0}=5 / 27 / 71$} & \multicolumn{2}{|c|}{$n_{0}=11.70$} \\
\hline & \multicolumn{3}{|c|}{ Dening ot al } & $\begin{array}{l}\text { Ionsida } \\
(56)\end{array}$ & \multirow{2}{*}{$\begin{array}{c}\text { Van Hork ot al } \\
(54,55) \\
i .0\end{array}$} & \multirow{2}{*}{$\begin{array}{c}800011 \\
(116) \\
n_{n y}\end{array}$} & \multirow{2}{*}{$\bullet$} & \multirow{2}{*}{$x_{86}$} \\
\hline & $\overline{\mathbf{B}}$ & V & $n_{p}$ & $\begin{array}{ll}V & B-V\end{array}$ & & & & \\
\hline $6,22 / 72$ & 14.70 & 23.35 & & & & & 26 & 24.65 \\
\hline $6 / 22 / 71$ & & & 14.60 & & & & 26 & 24.60 \\
\hline $6 / 23 / 71$ & 14.58 & 23.39 & & & & & 27 & 24.50 \\
\hline $6 / 27 / 71$ & & & & & & 23.7 & 31 & 24.92 \\
\hline $6 / 29 / 71$ & 25.06 & 13.83 & & & $\cdot$ & & 33 & 14.99 \\
\hline $7 / 3 / 71$ & 24.83 & 13.97 & & & & & 37 & 24,69 \\
\hline $7 / 14 / 71$ & 25.25 & 24.05 & & & & & 48 & 23.18 \\
\hline T/16/71 & 15.35 & 14.50 & & & & & 50 & 15.21 \\
\hline $7 / 16 / 71$ & & & 15.25 & & & & 50 & 25.25 \\
\hline$T / 29 / 71$ & 15.45 & 14.90 & & & & & 63 & 25.26 \\
\hline$T / 31 / 71$ & 15.50 & 15.00 & & & & & 65 & 25.30 \\
\hline $8 / 2 / 71$ & 15.50 & 24.90 & & & & & 67 & 25.32 \\
\hline $8 / 3 / 71$ & 15.30 & 25.05 & & & & & 60 & 25.06 \\
\hline $8 / 14 / 71$ & 25.8 & & & & & & 79 & 25.47 \\
\hline
\end{tabular}


ApFrotx 2

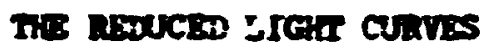

Foures $N 2-1.1$ throwh $12-1.37$ give the finel reduced light errves used fxe the anelysis. All megitudes heve been comerted ts the ap system and an mecesserg zero-point corrections bave been applifed. Difrerent symals have been used for the effferent soservers In eact rurve. The rertical straicht lines at $t=0$ represent the estinates of $a_{0}$. The ritted curves ore the fits of the Mrrisonsartorl andel which were used to estinste tine ;olues of the comparison parwater $\Delta t_{c}$. The values of the perweters $C$ and $A$ which define these ritted curves are civen in colums 9 and 10 or Table 8-1. 


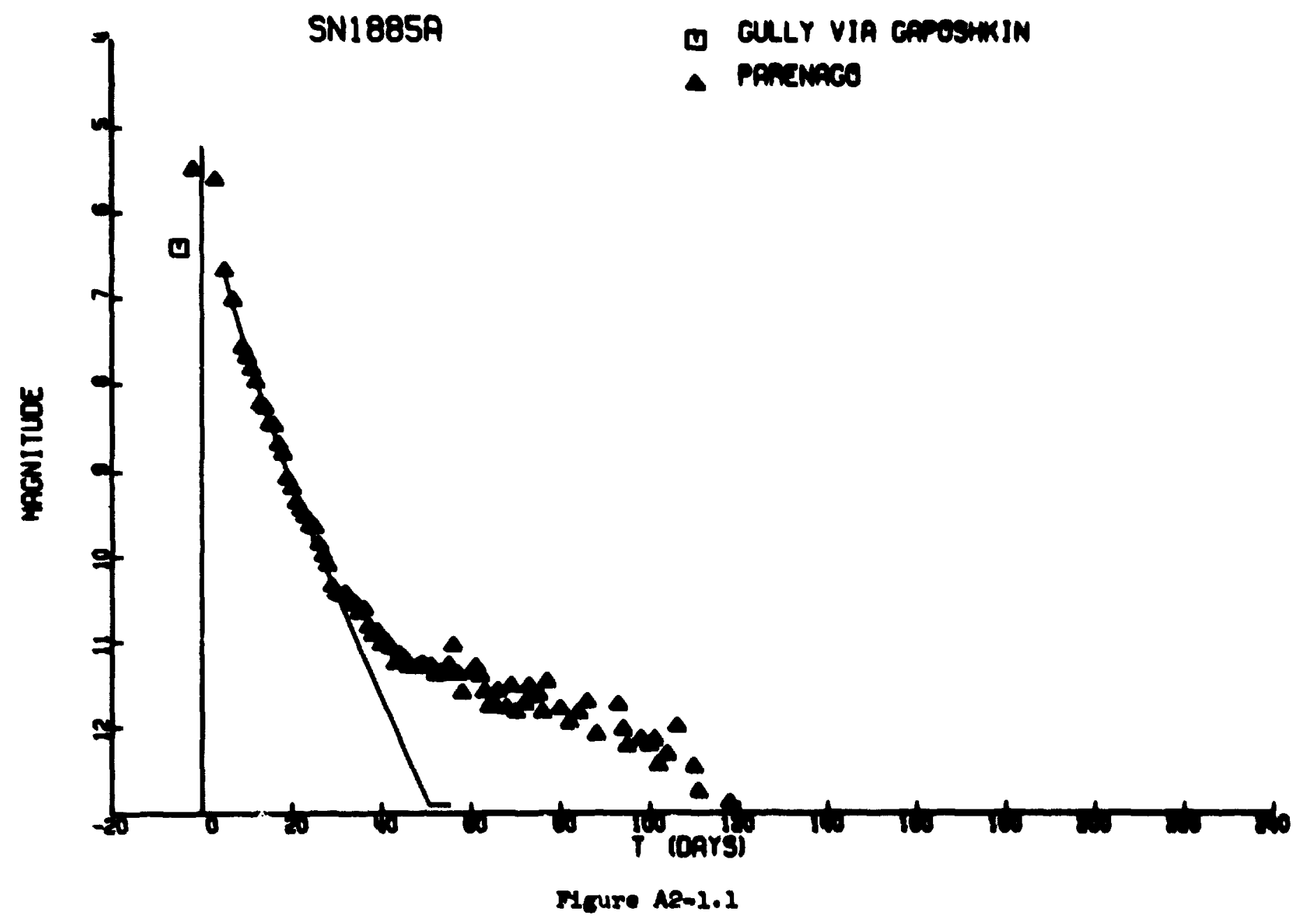

8 
321

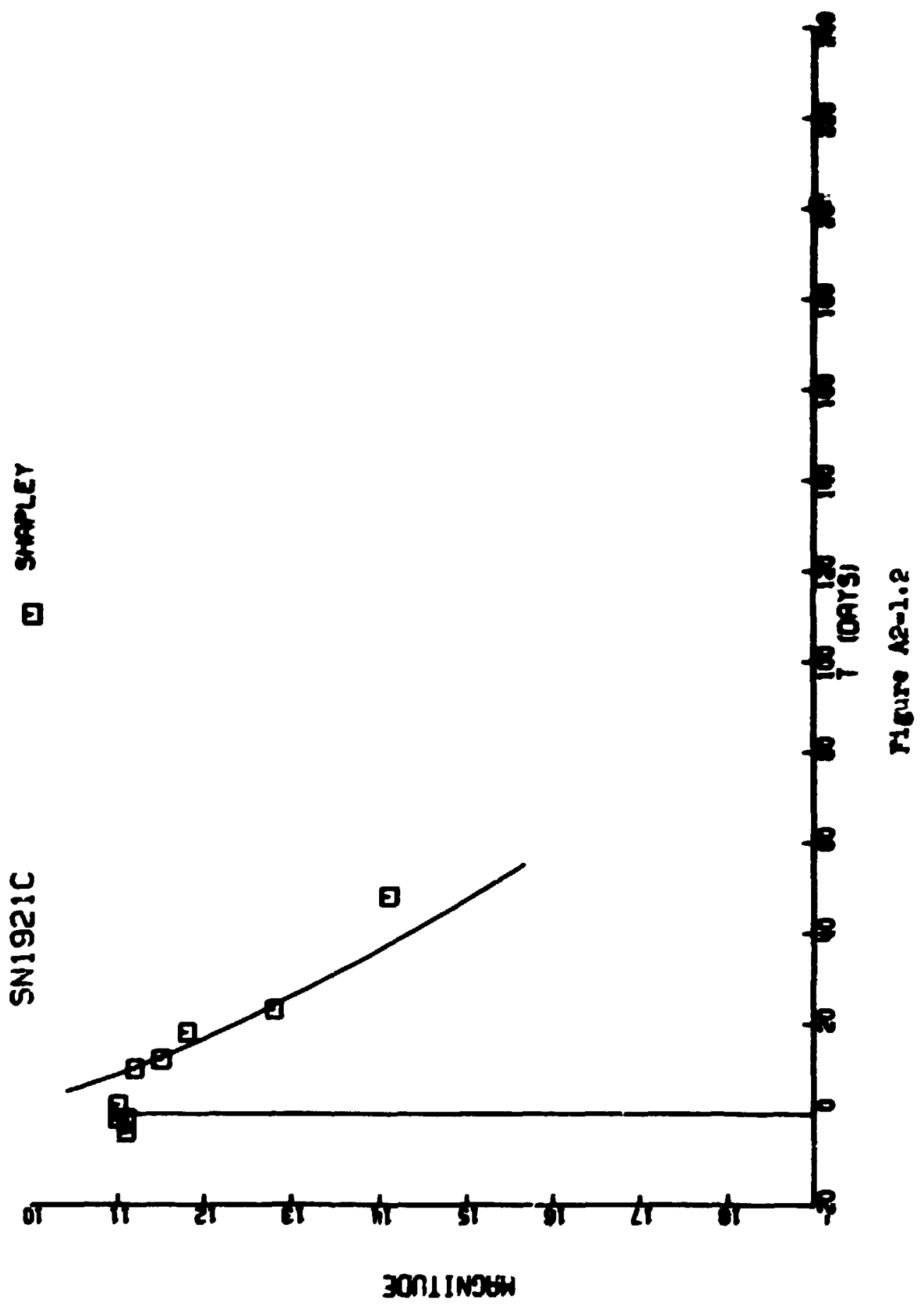




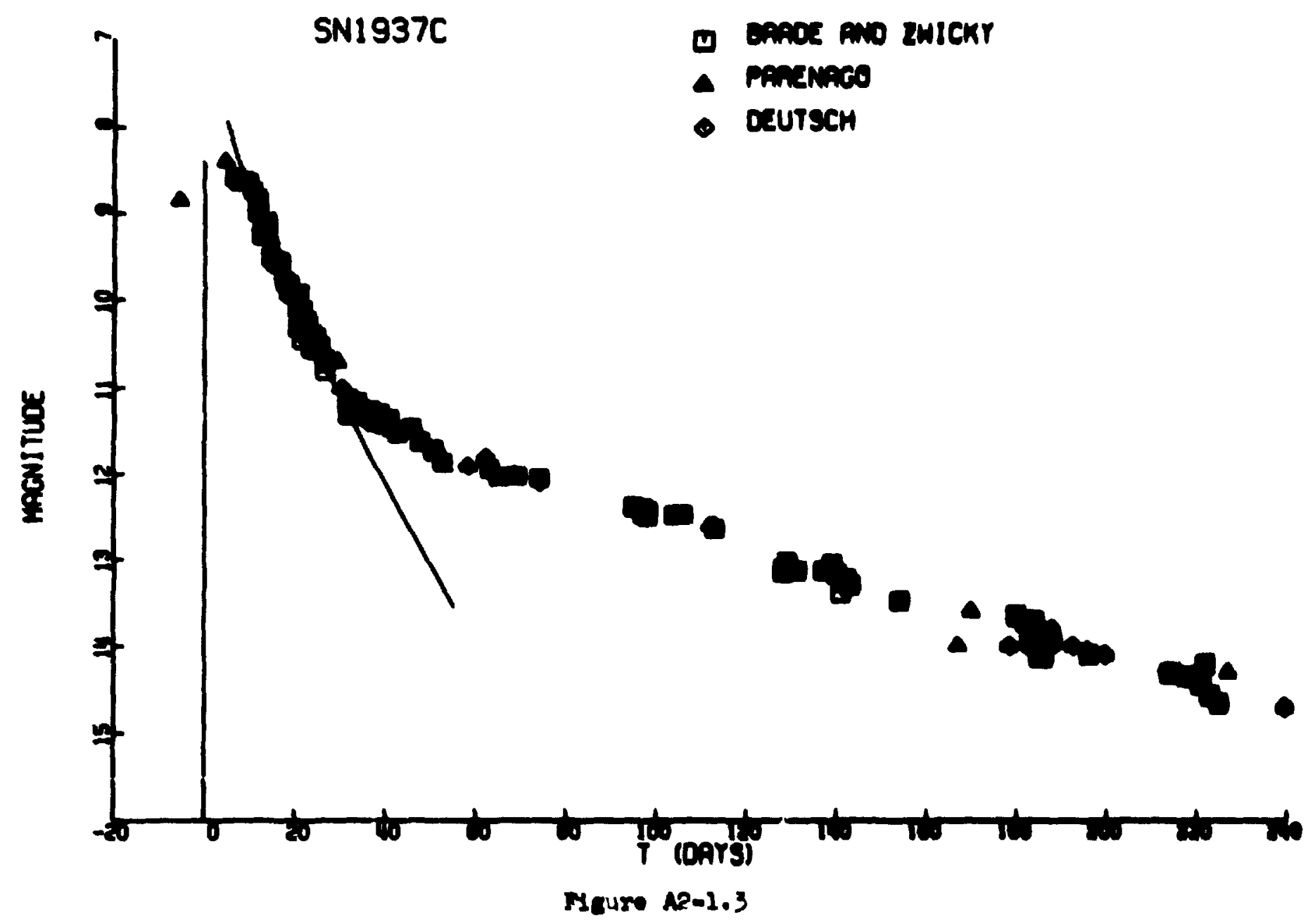




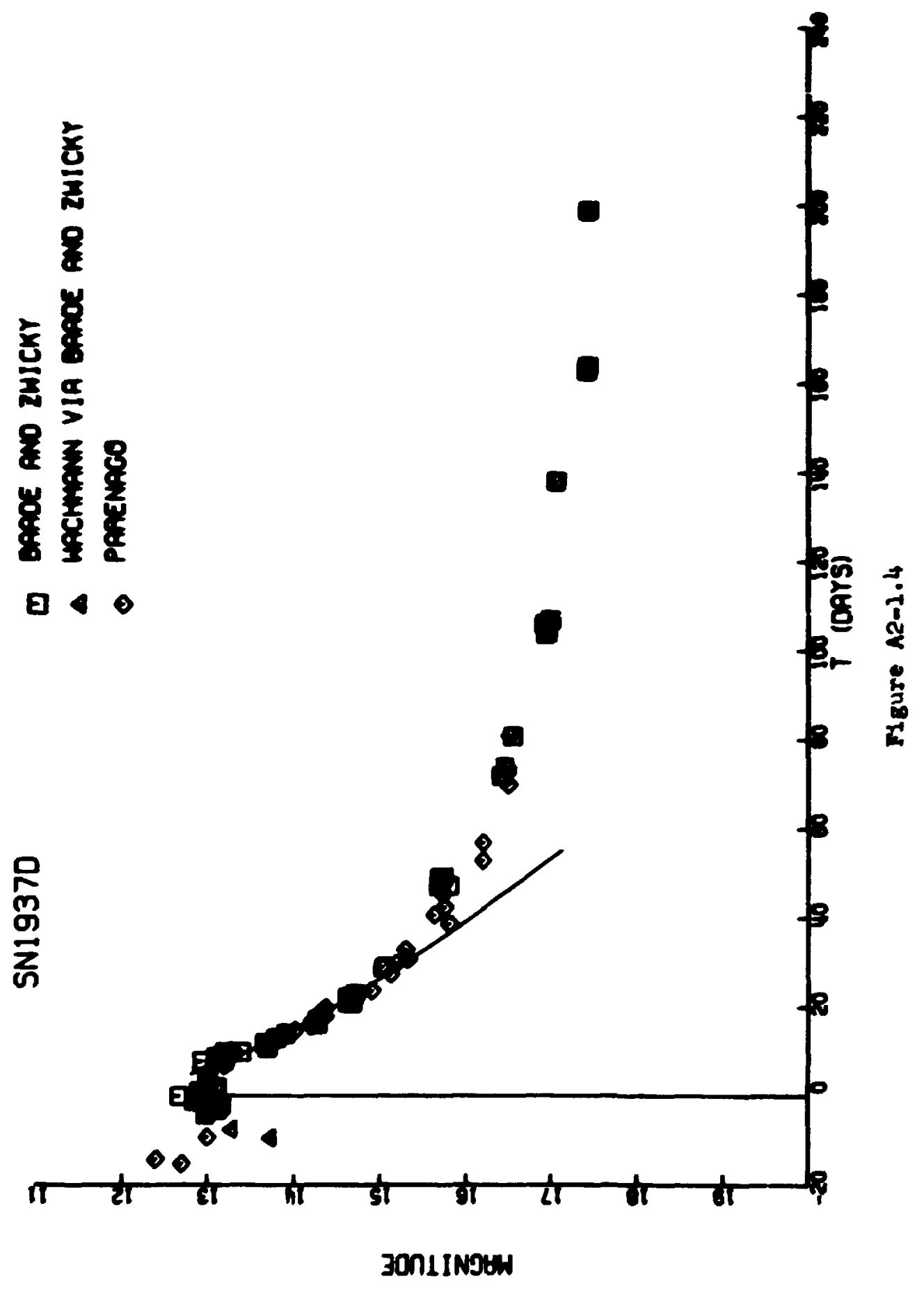



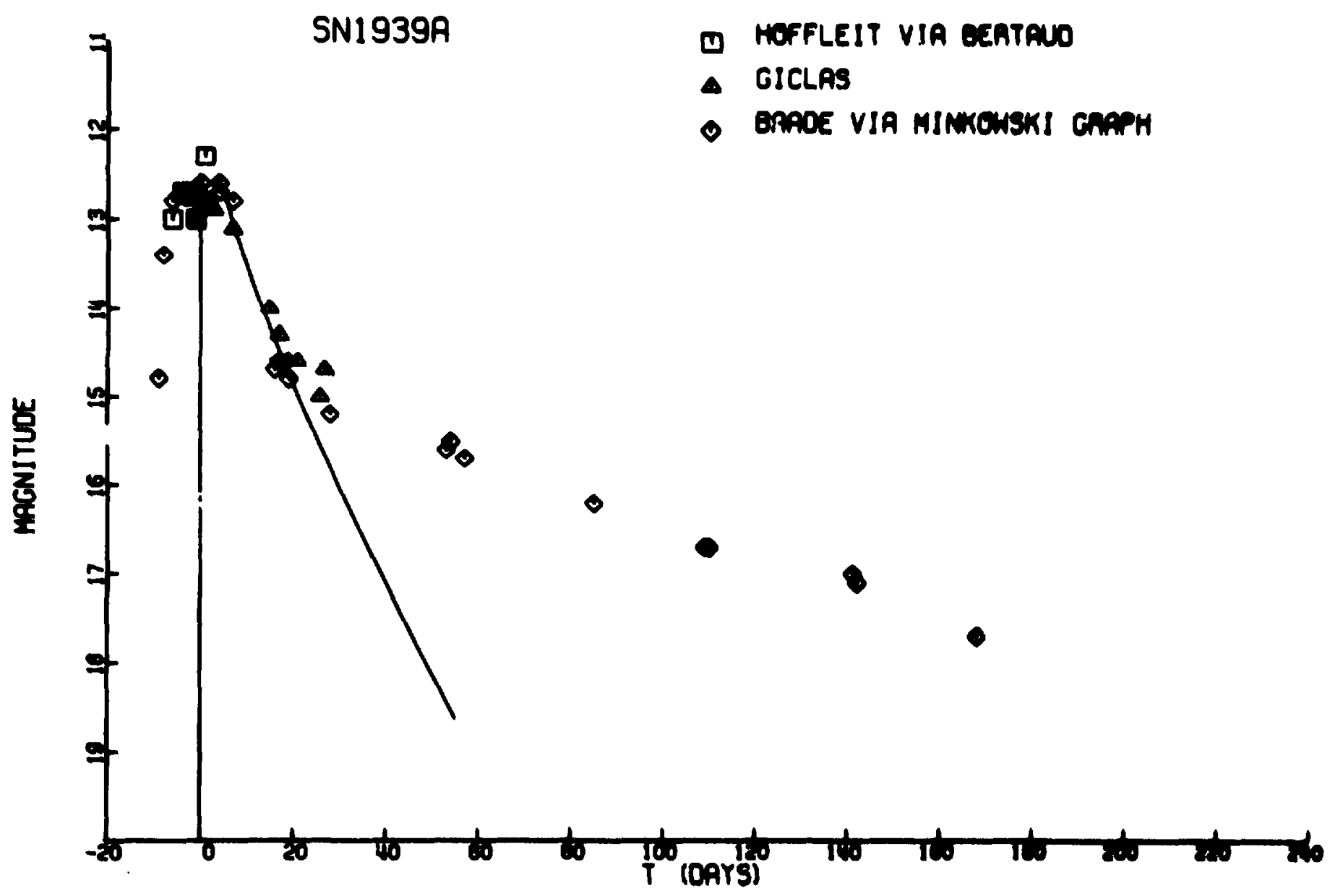

P1gure A2-1.5 


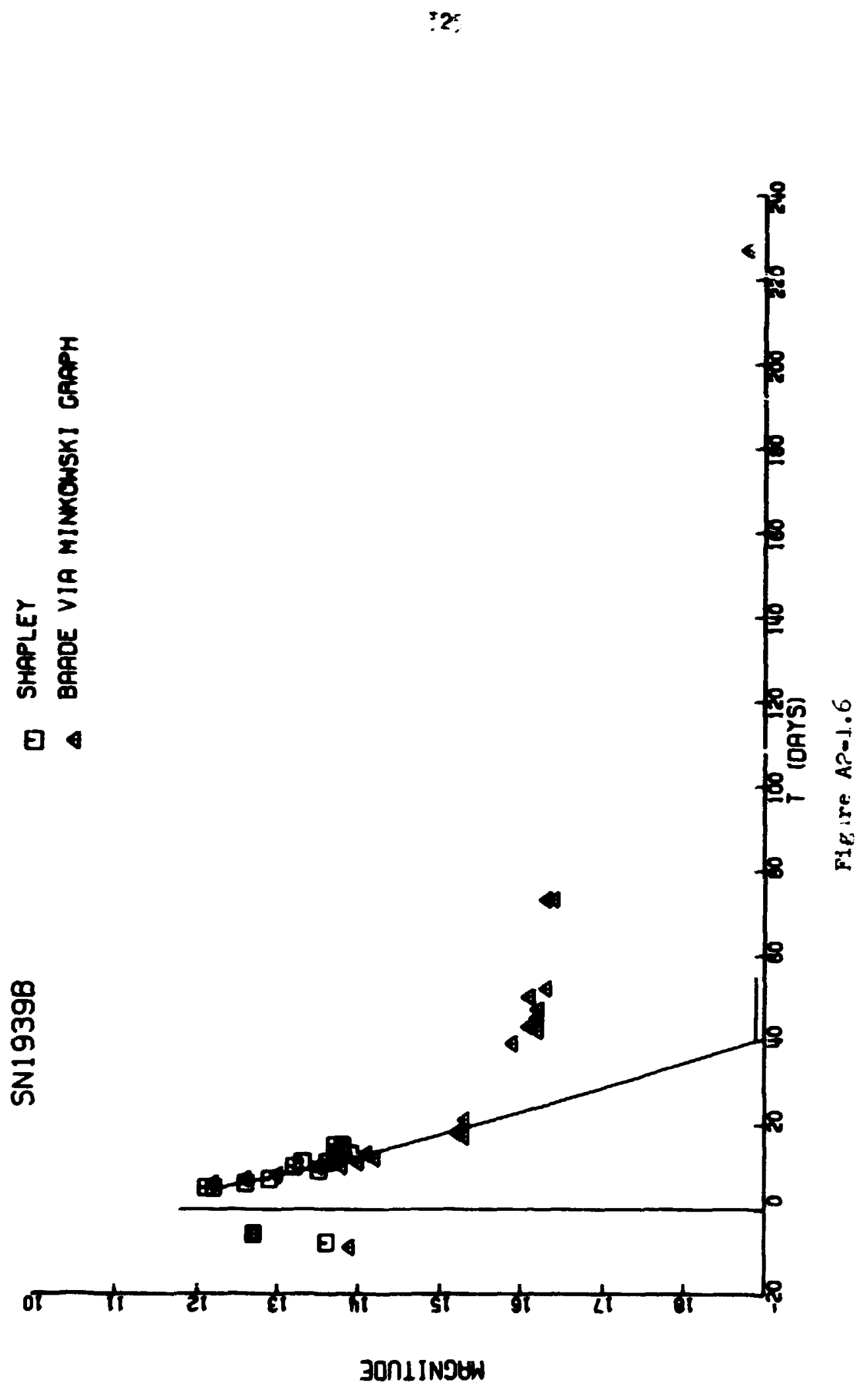




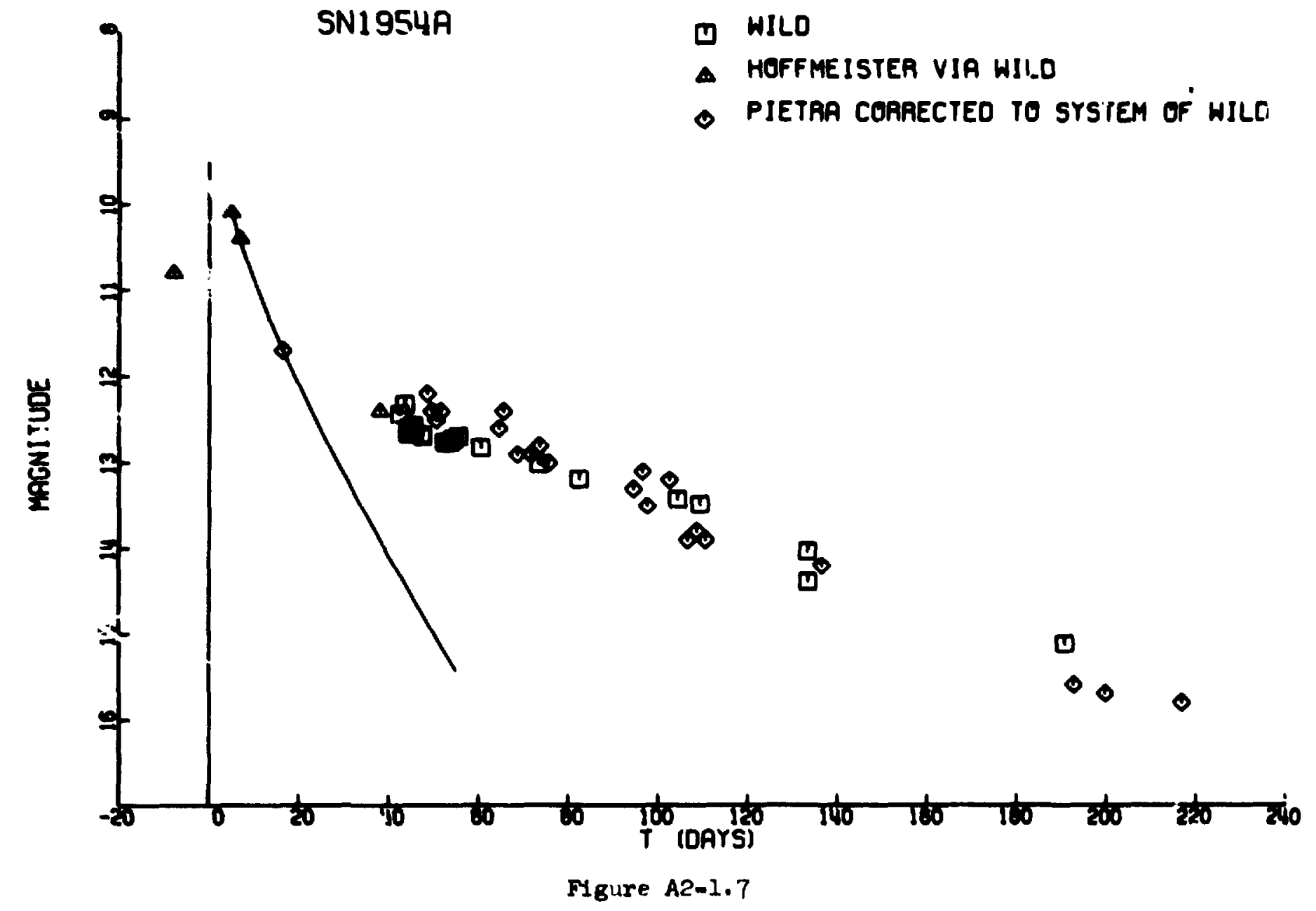




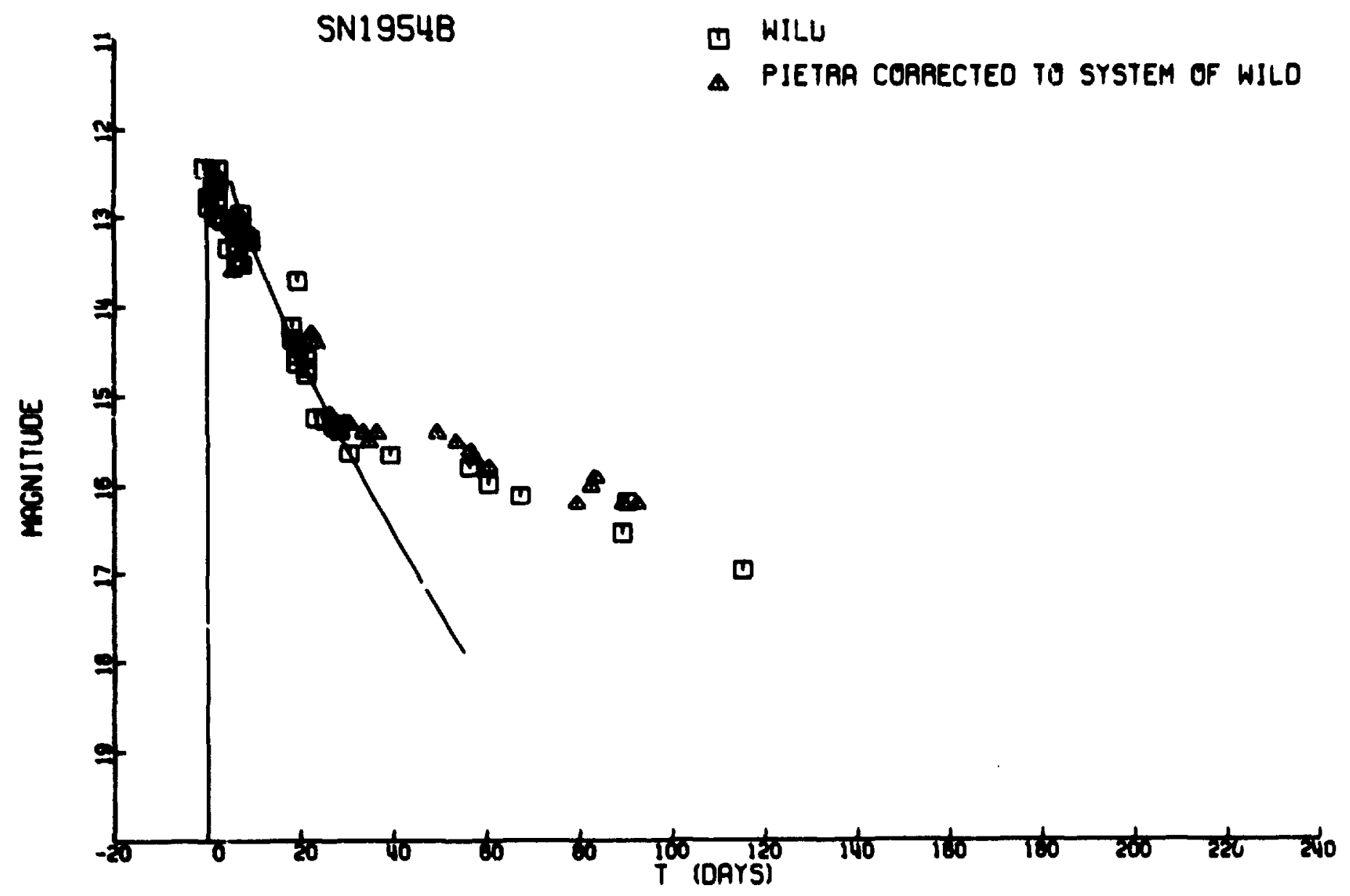

Fig ire A?-1.8 


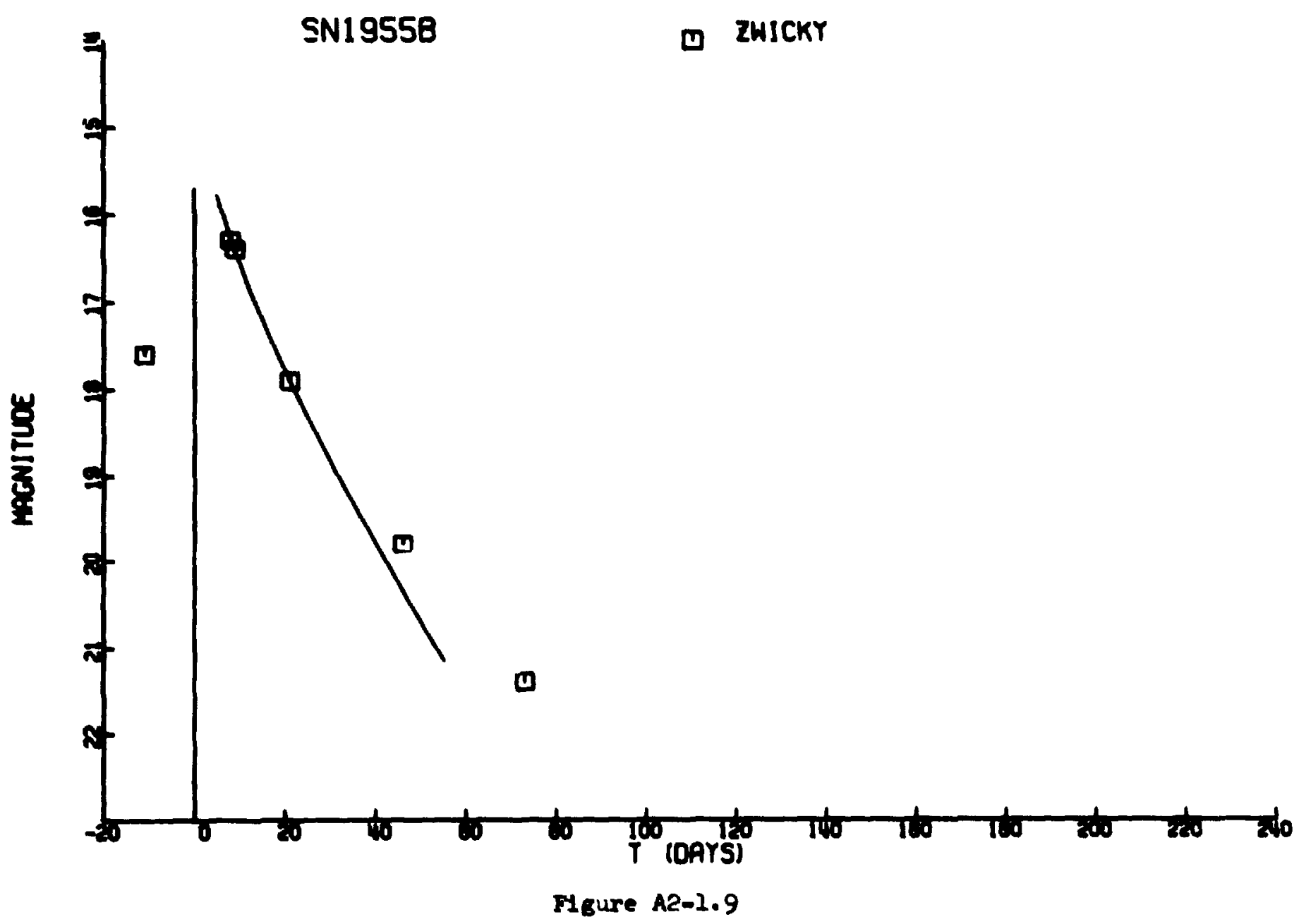




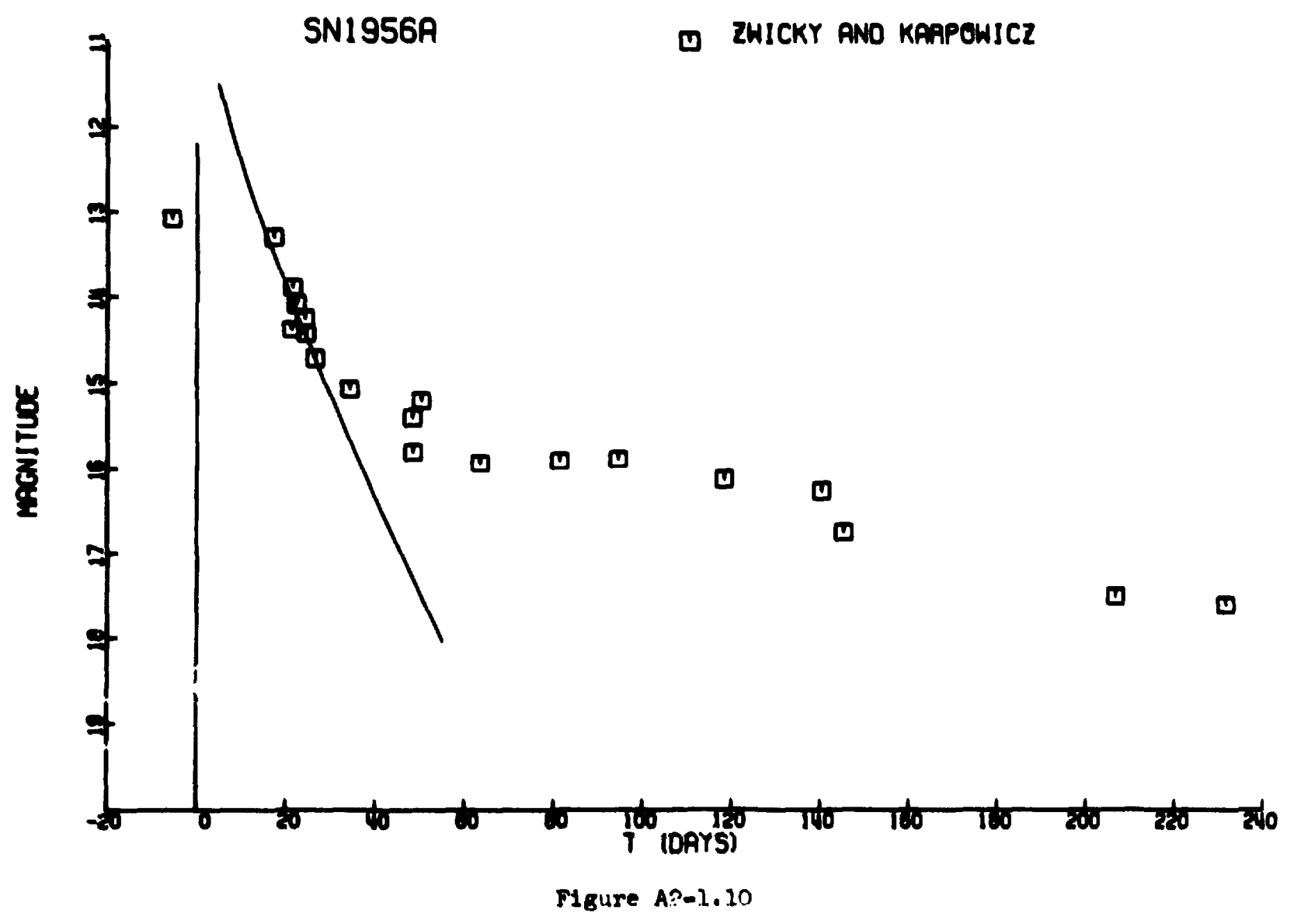




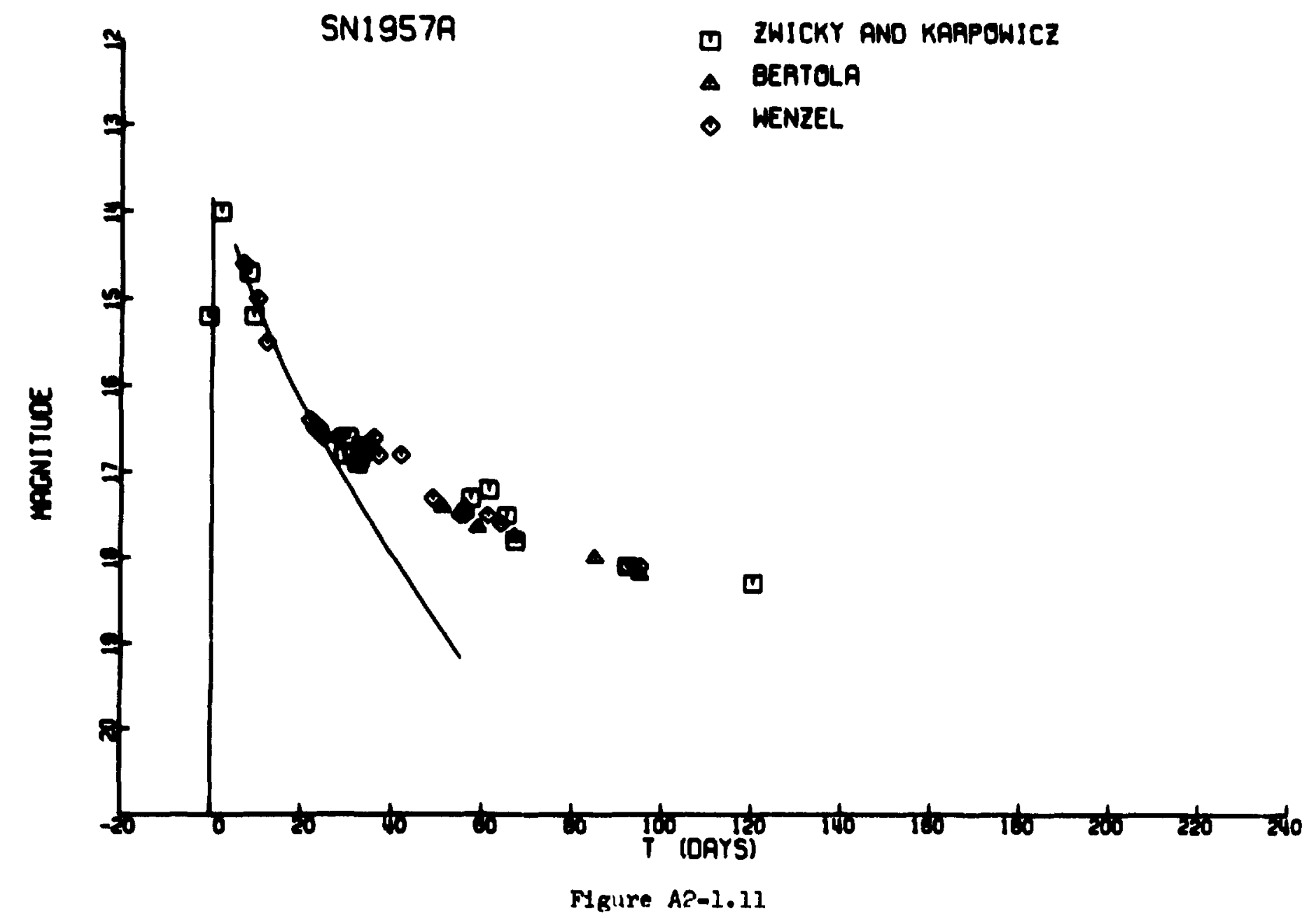




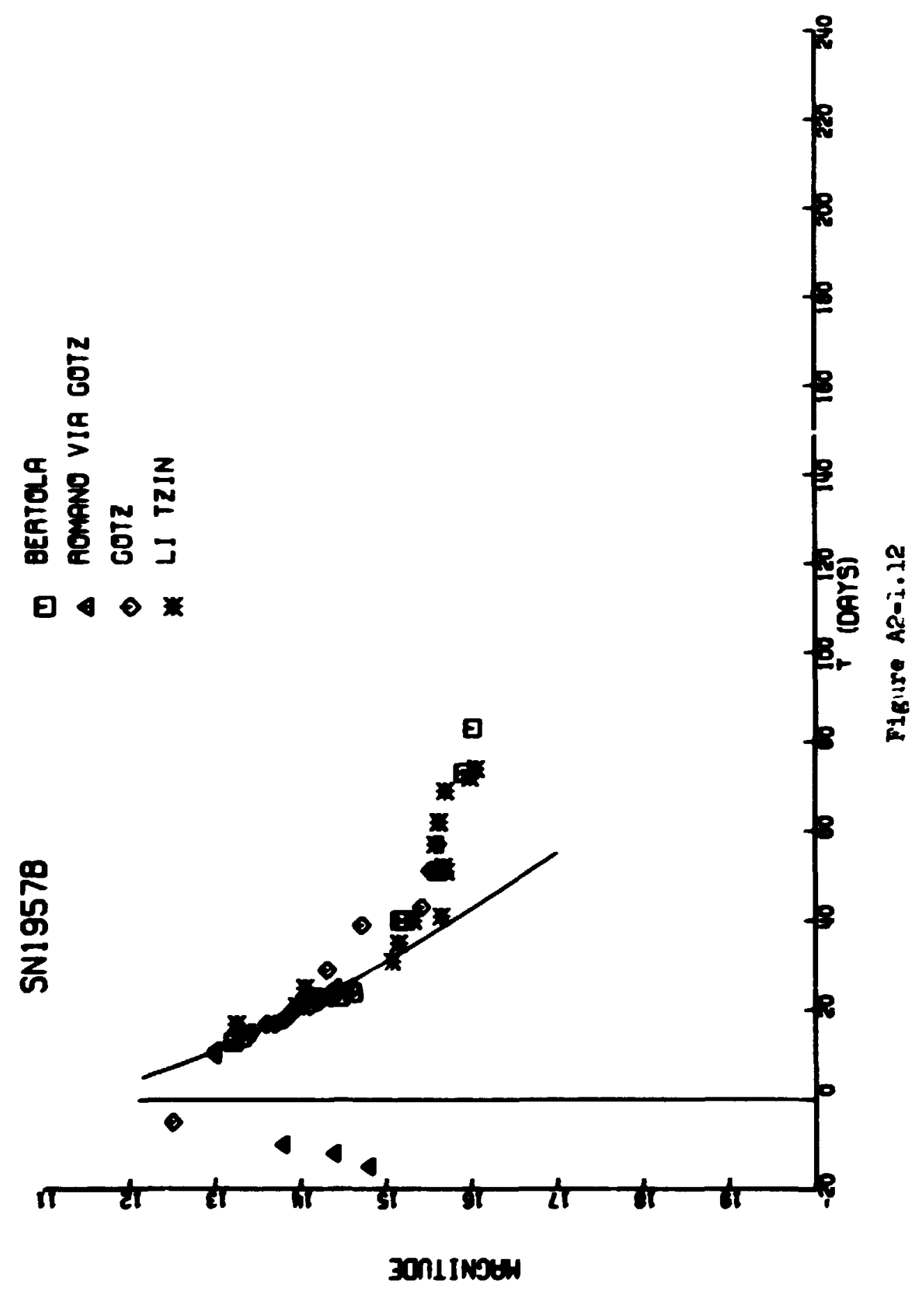




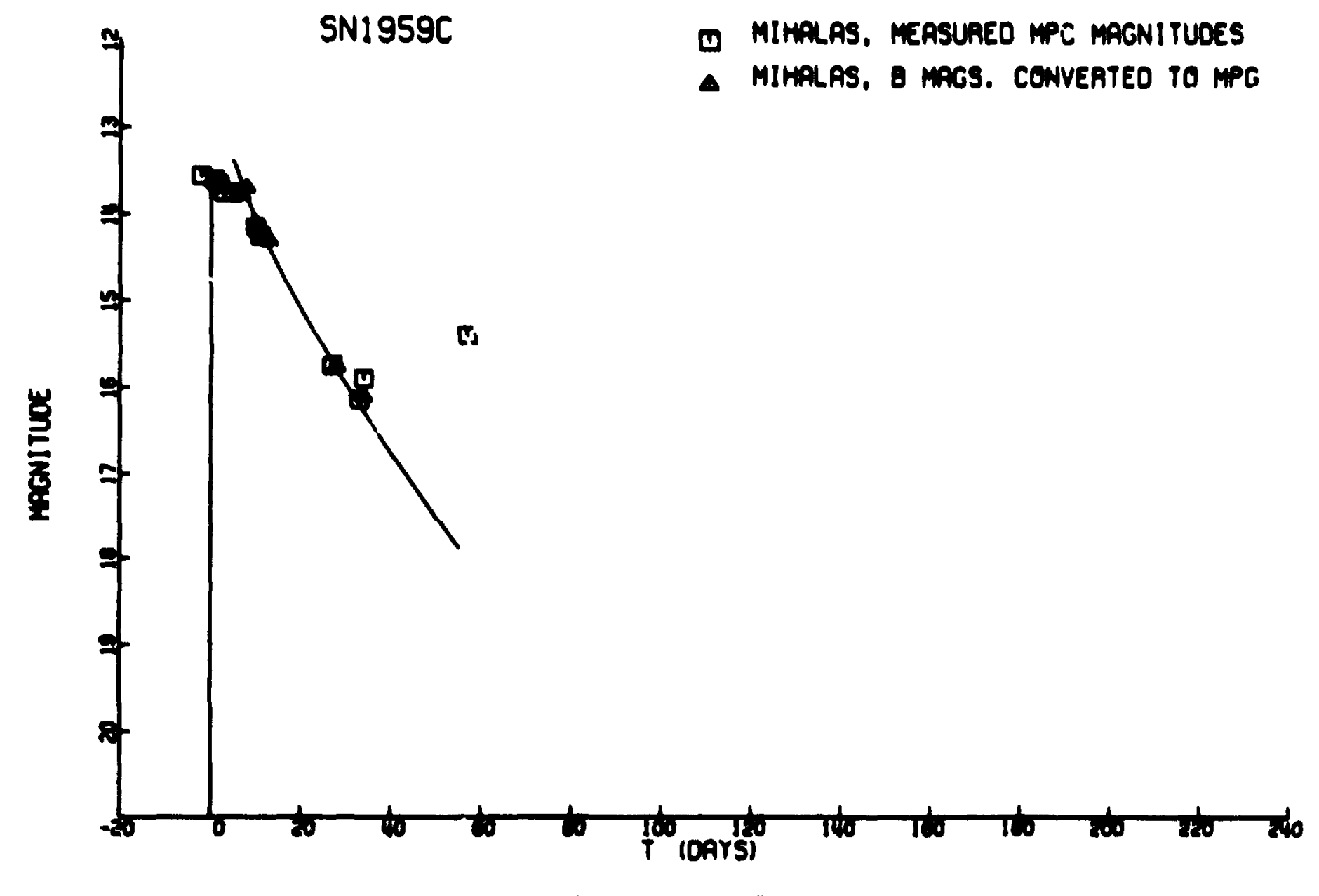

Plgure AP-1.1.X 


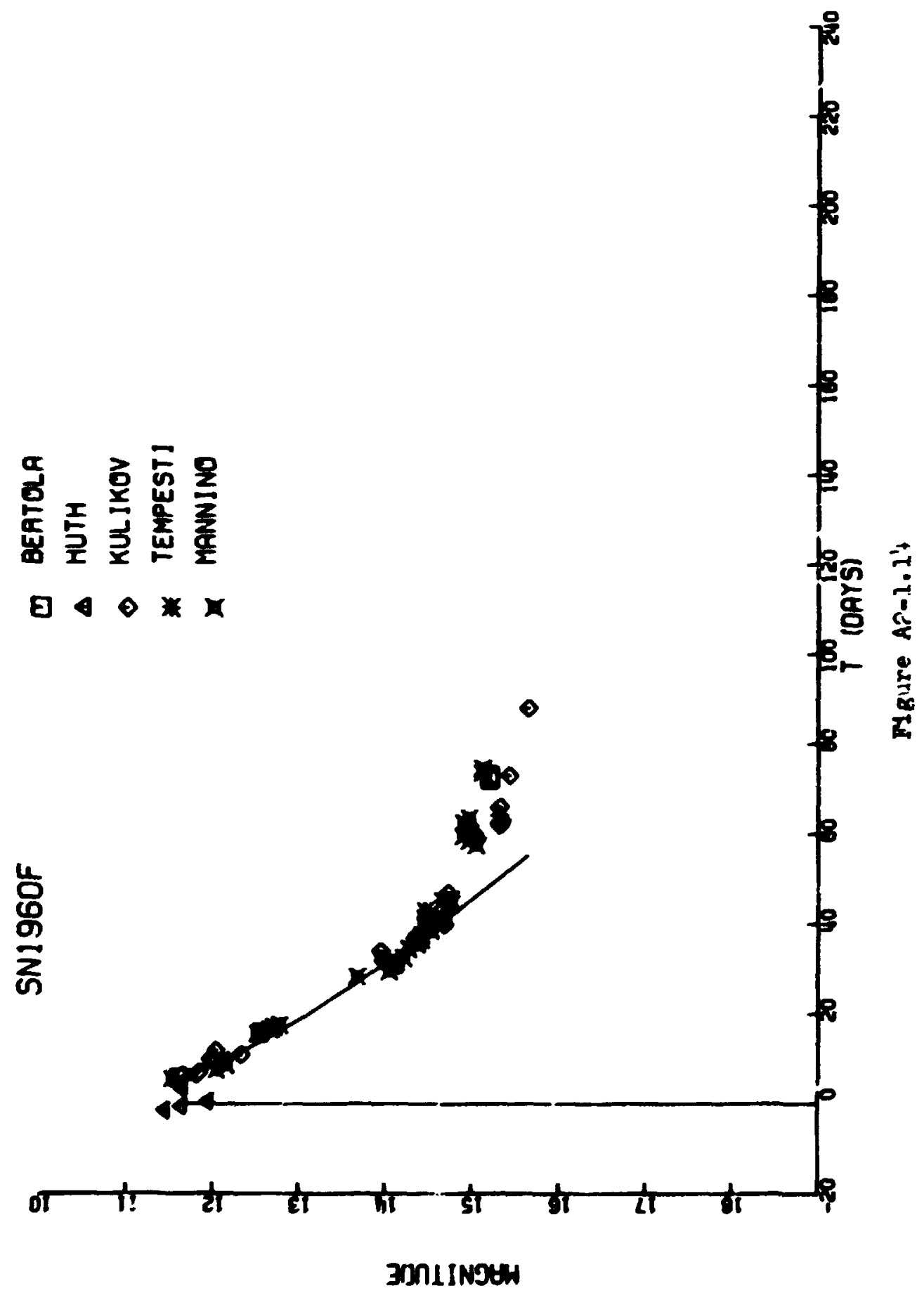




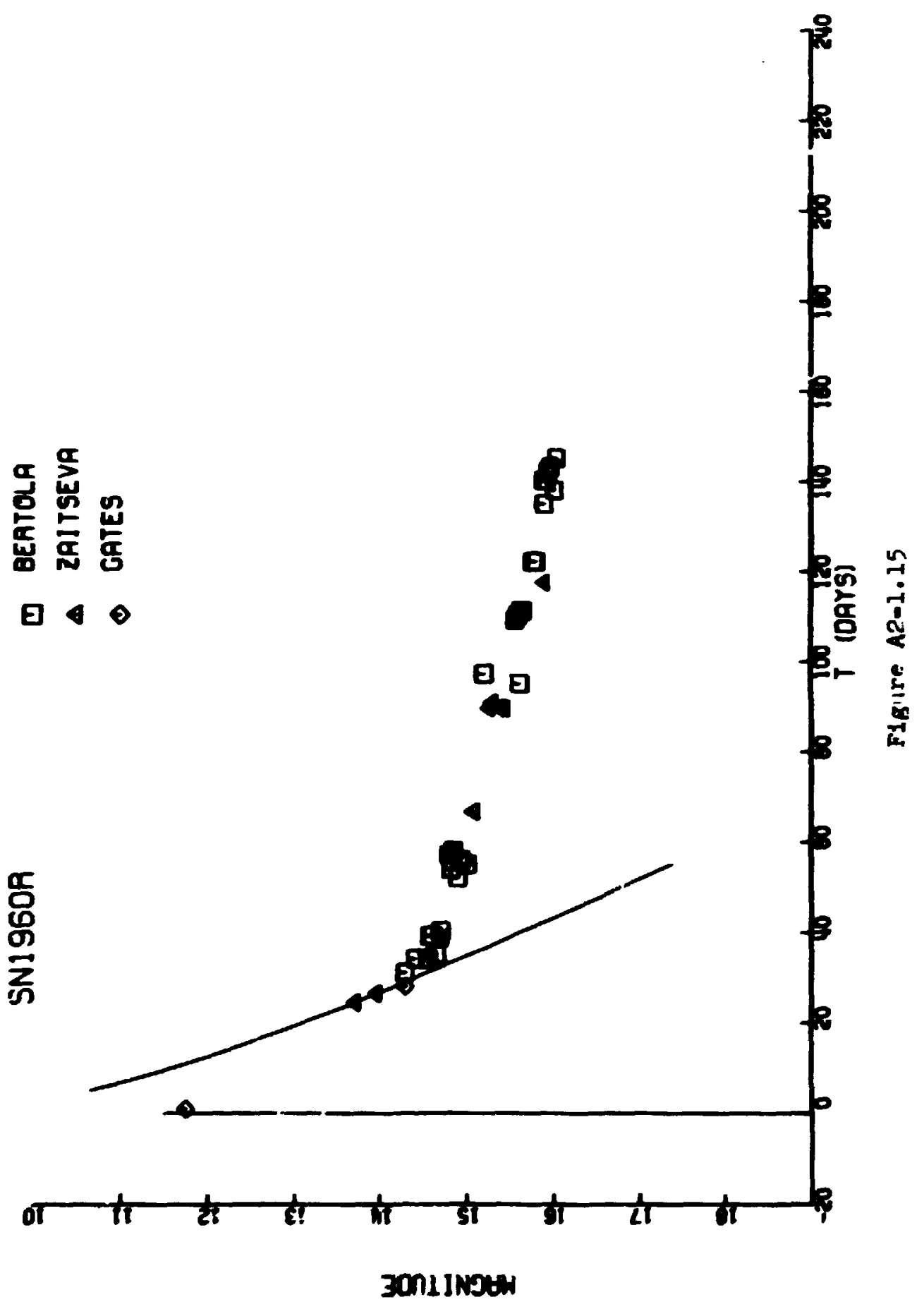




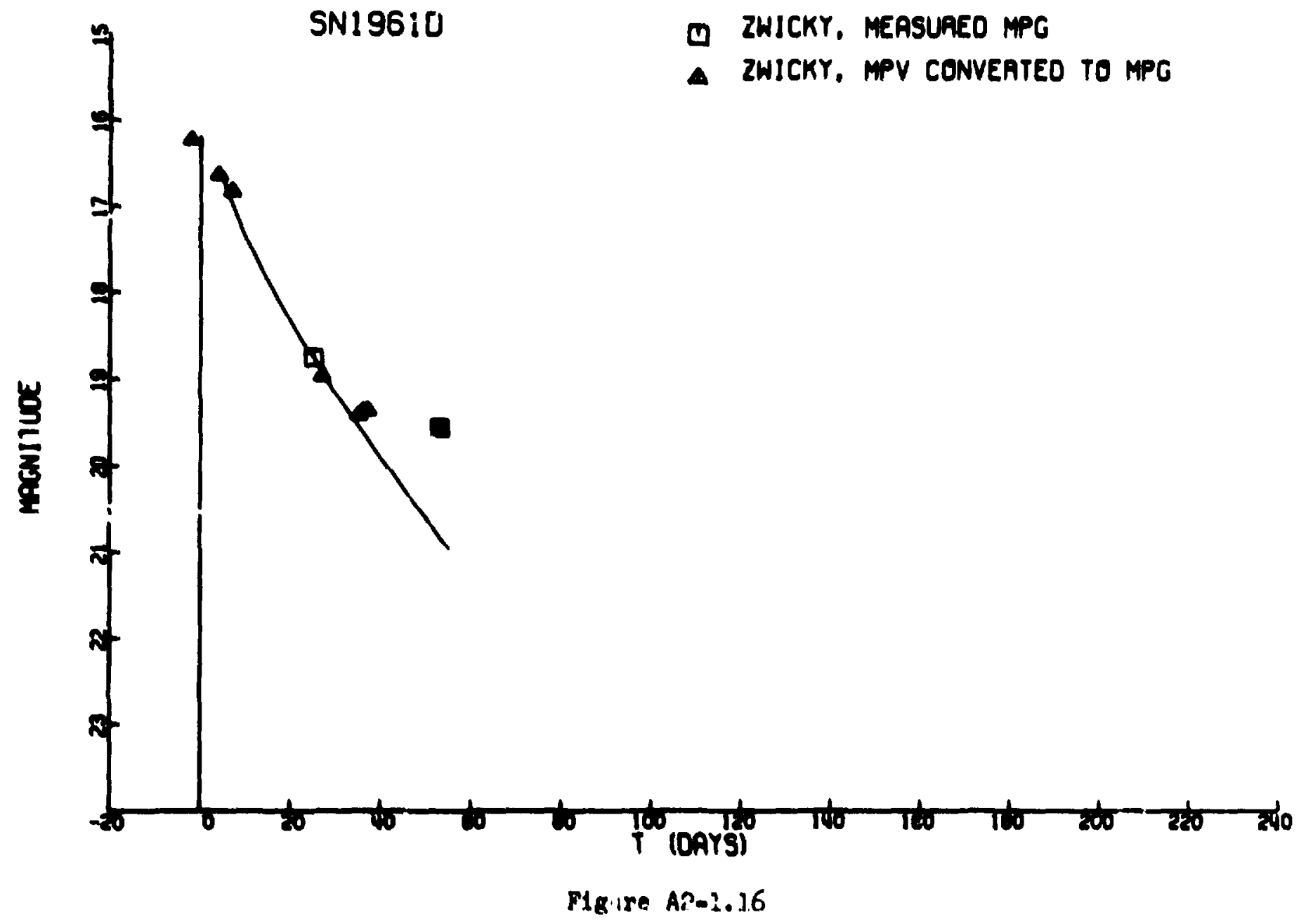




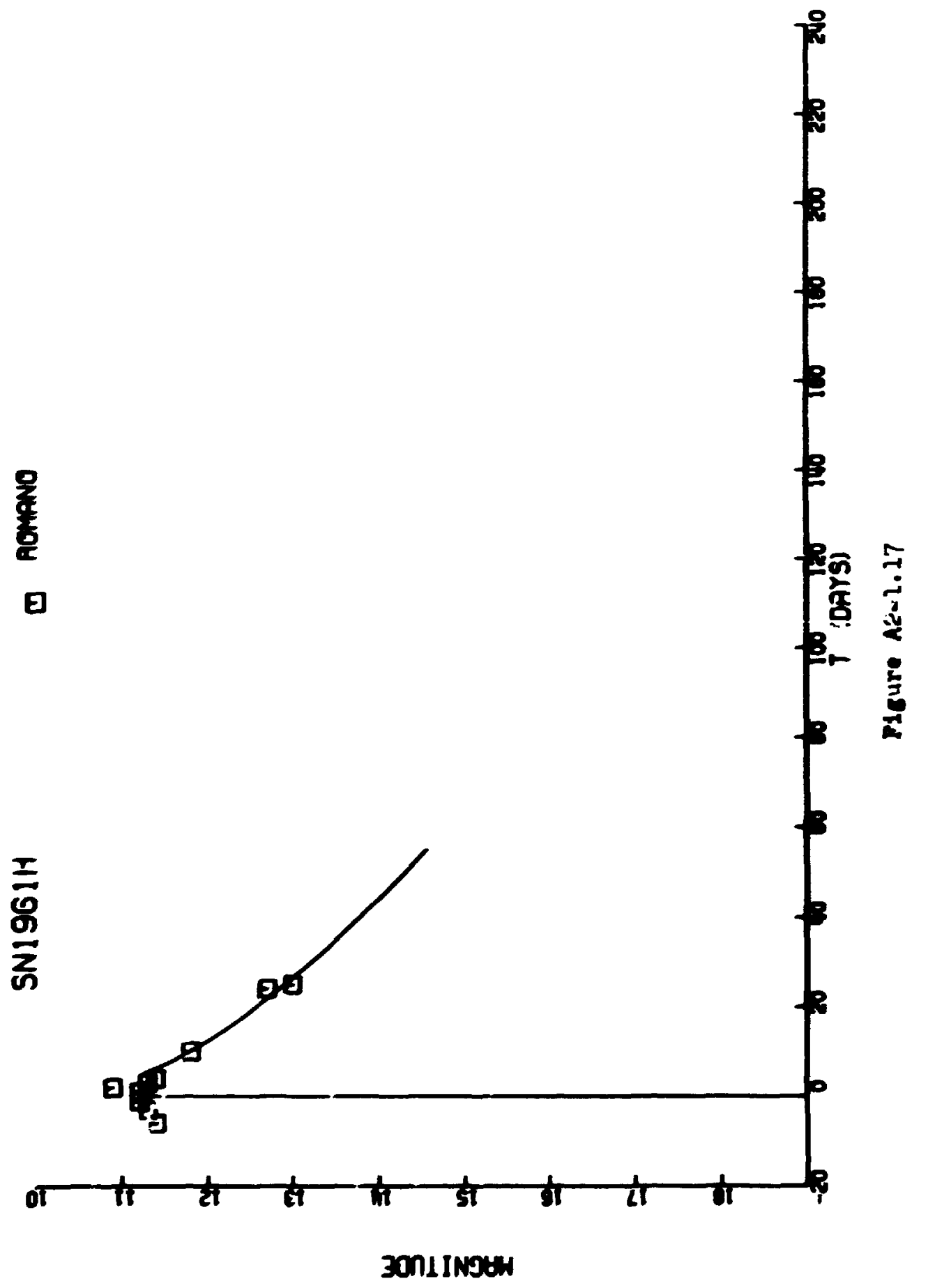




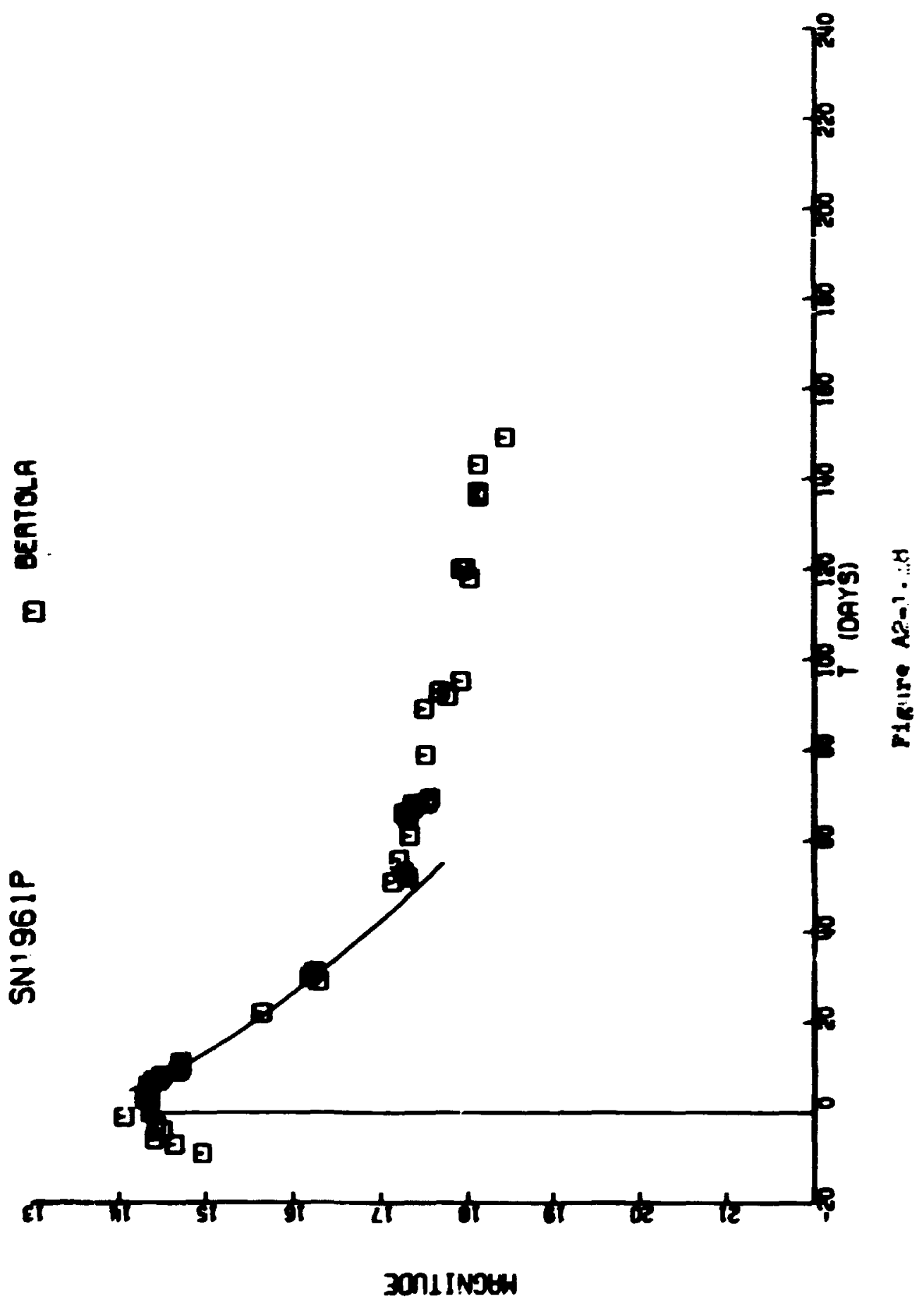



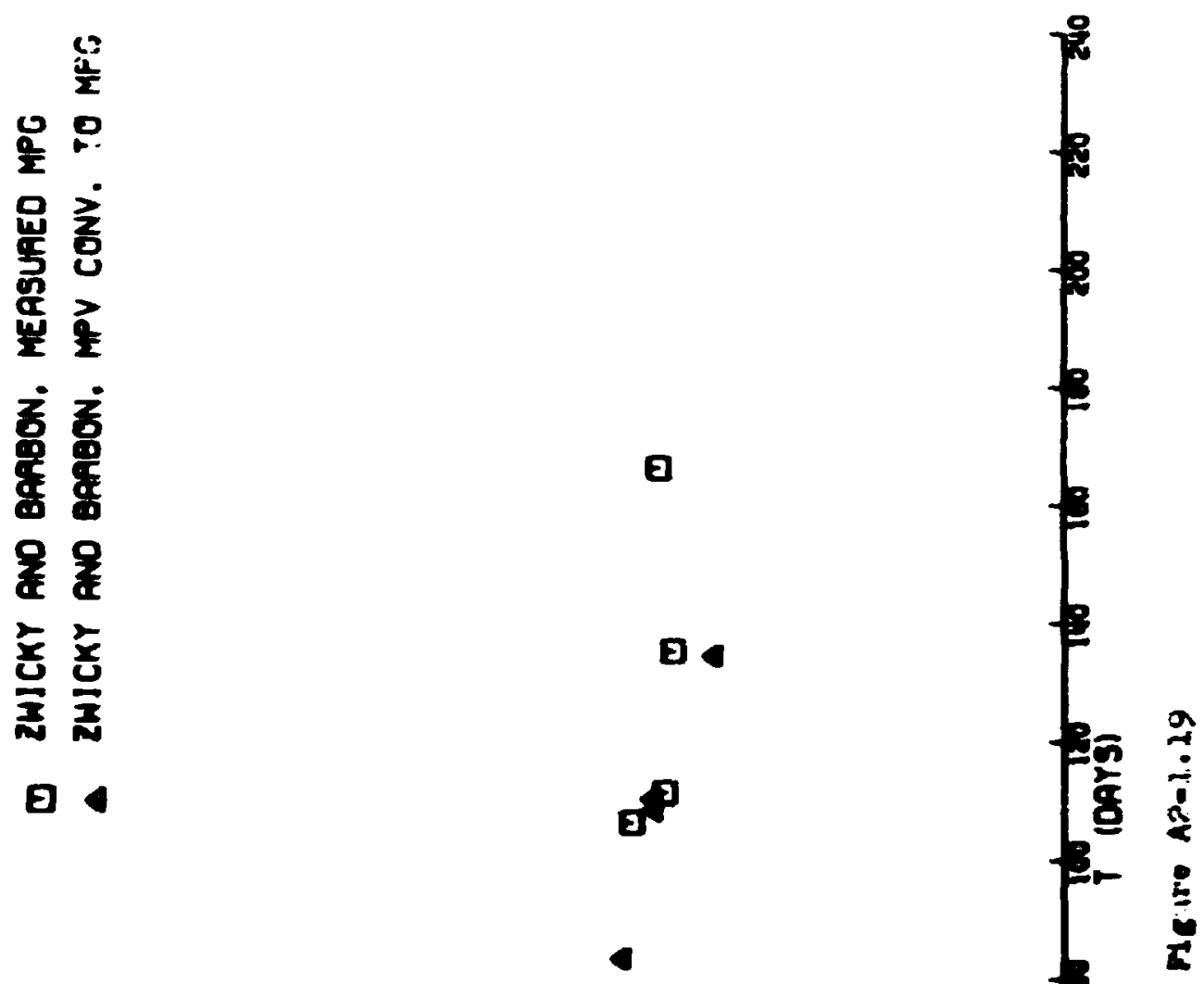

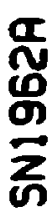

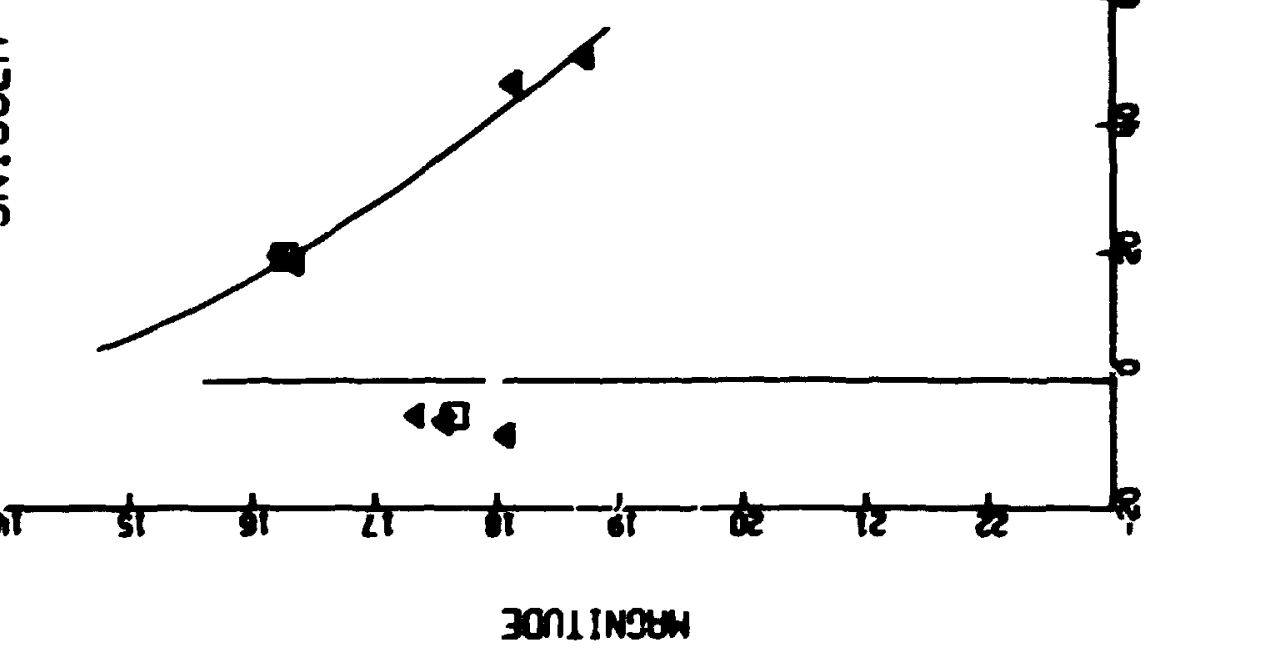




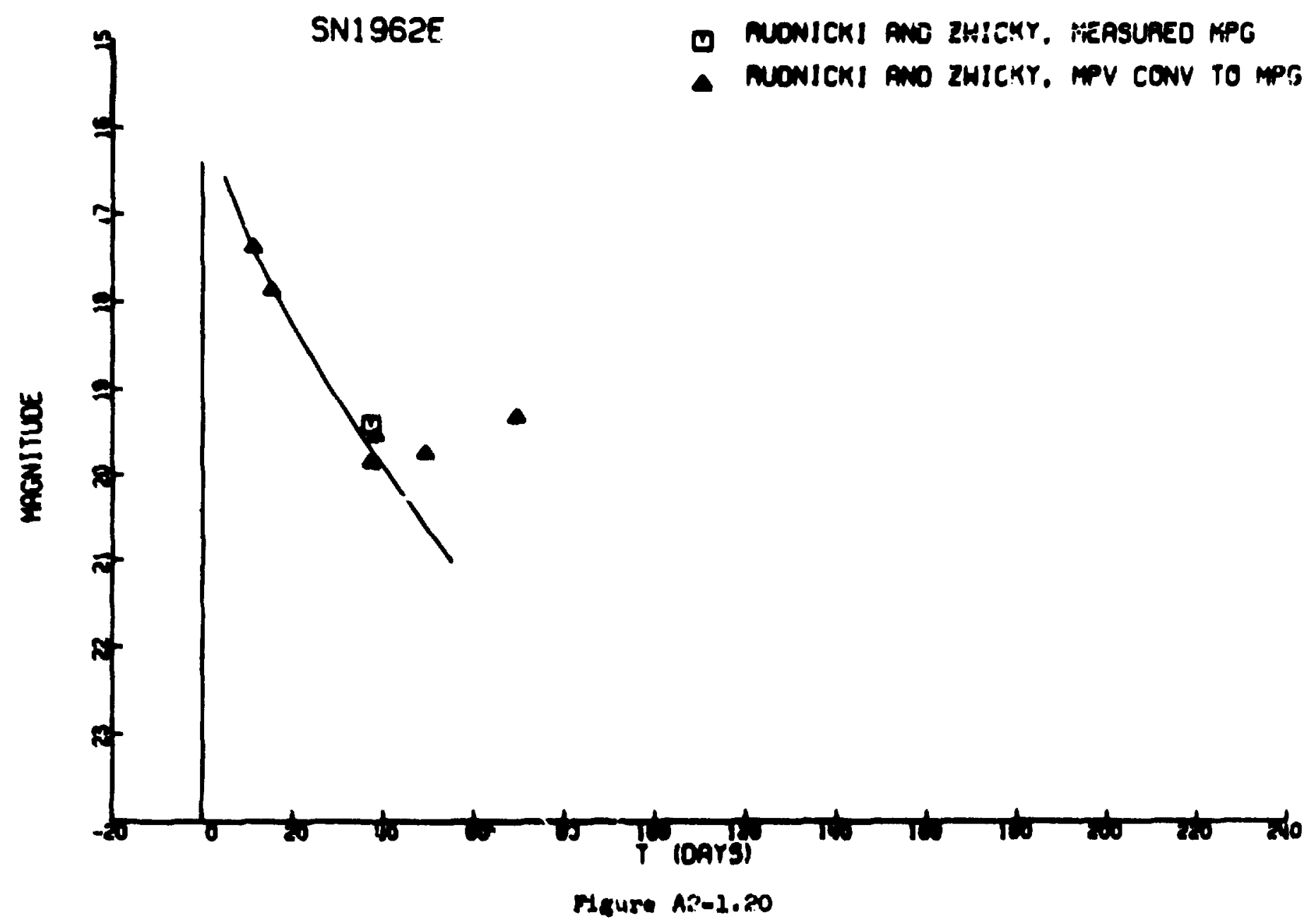




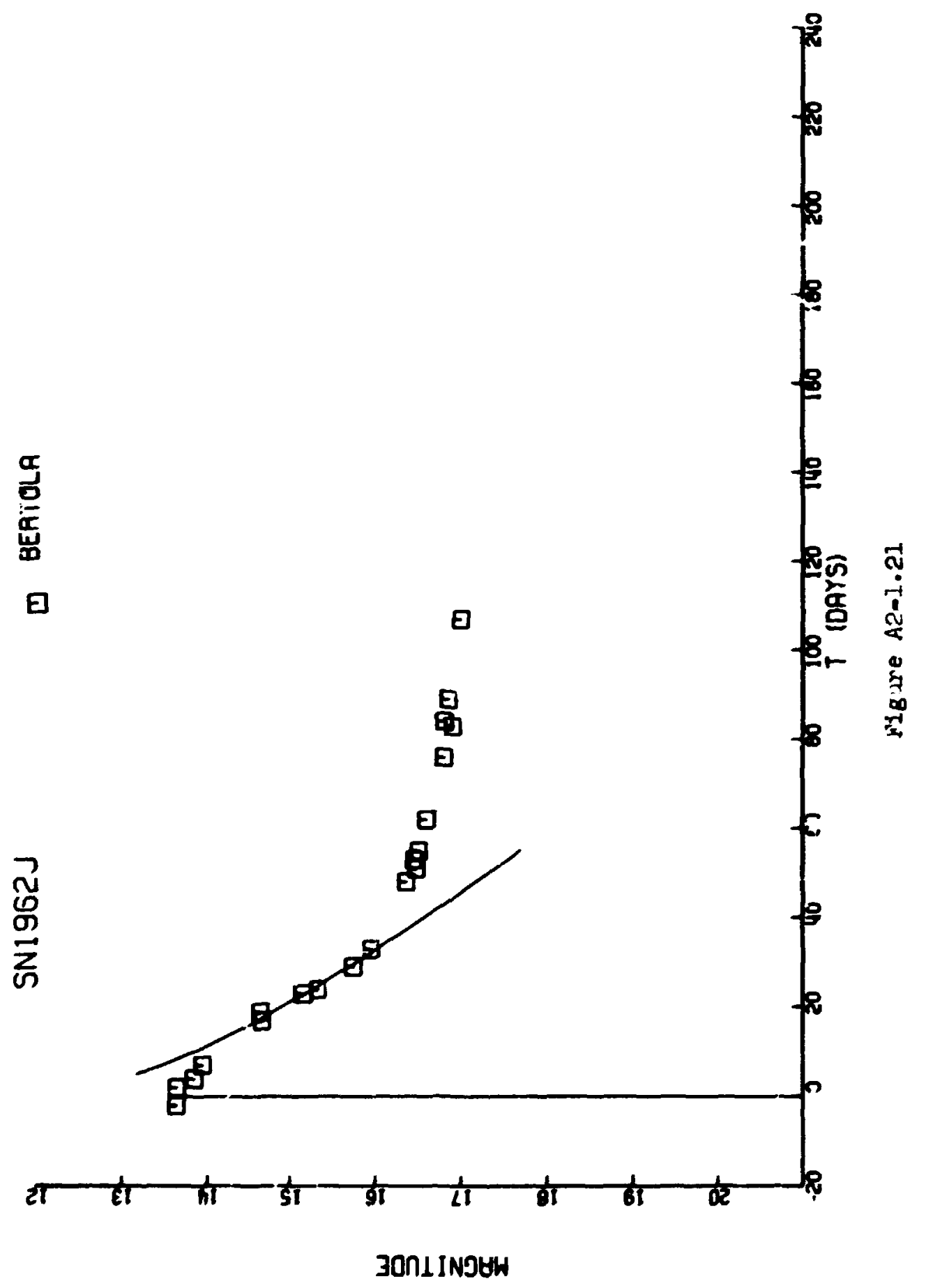




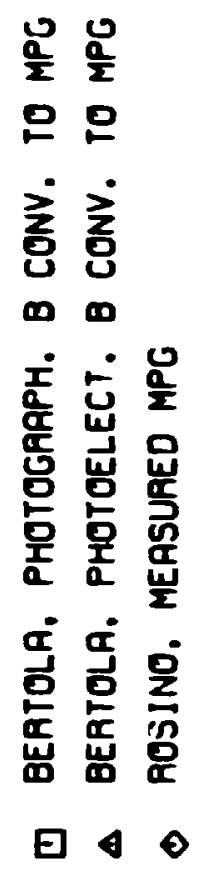

甲

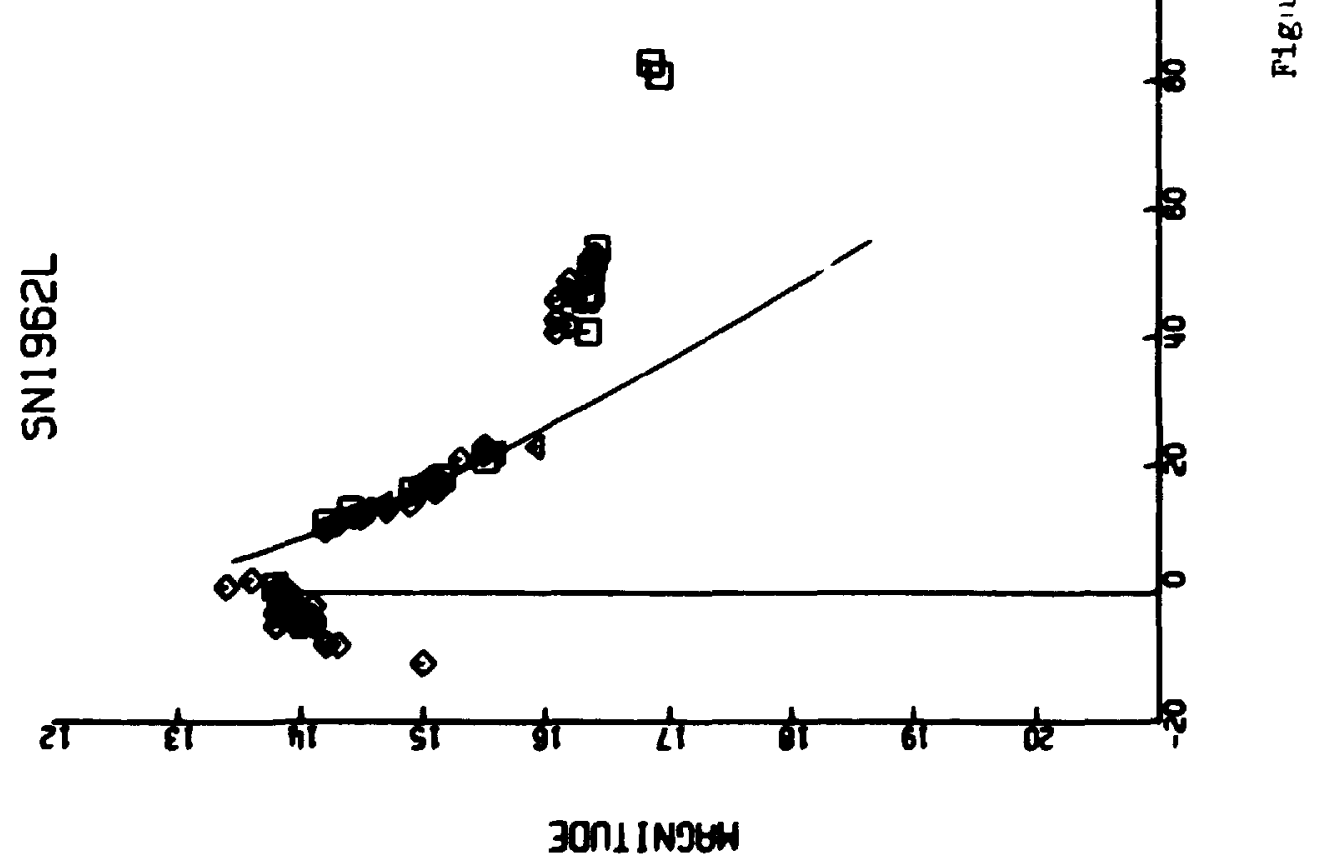




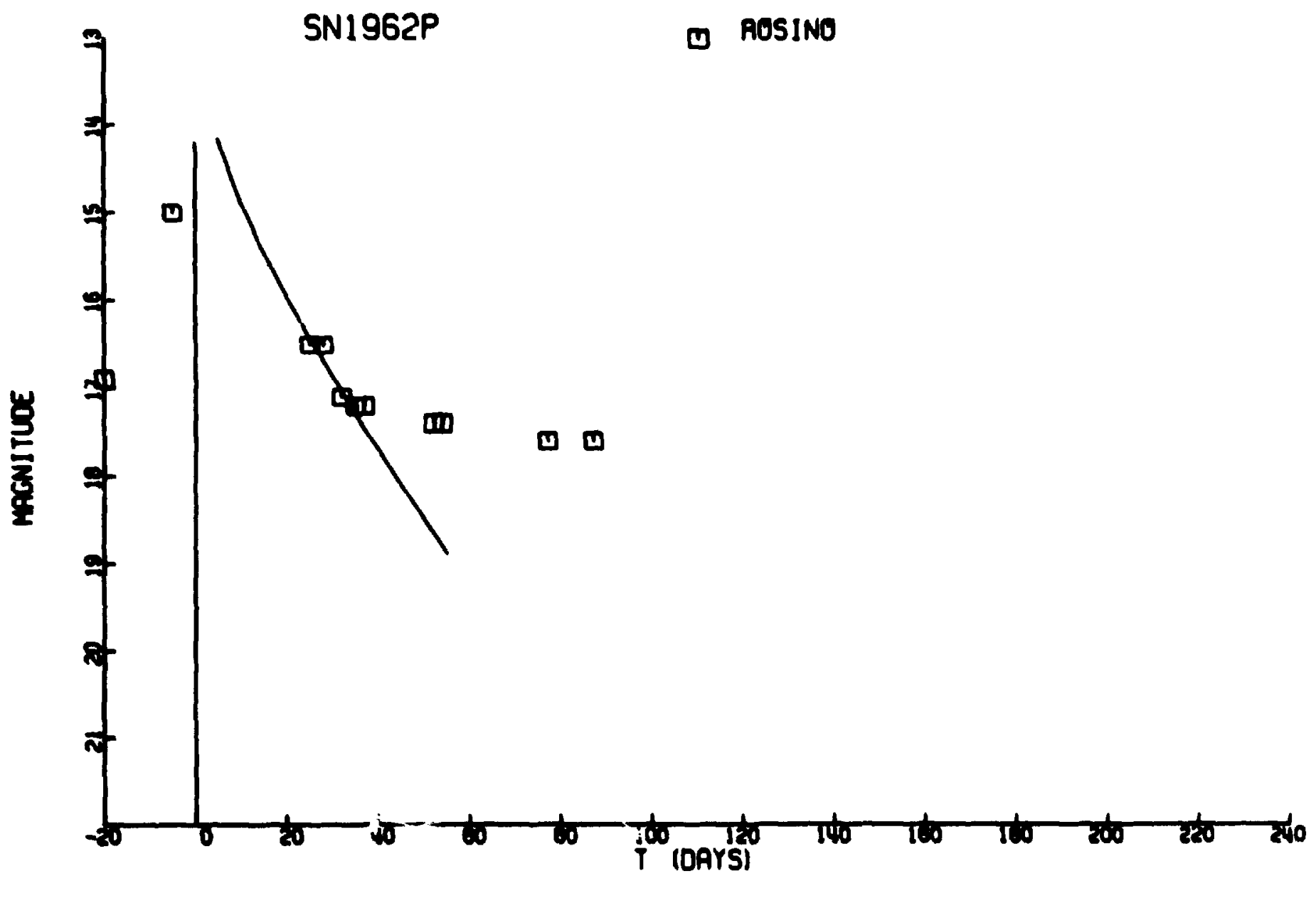

Mgure A2-1.23 


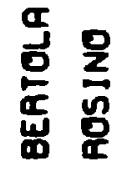

อ 9

星

อ
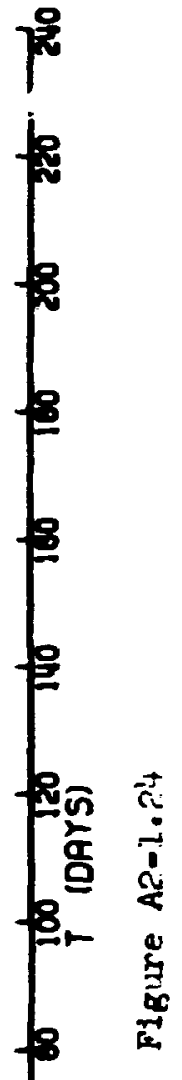

目

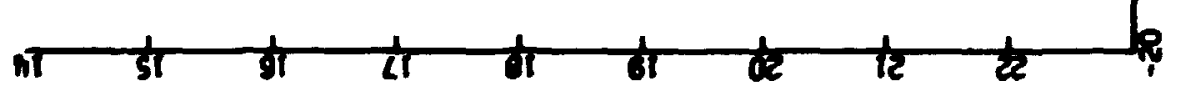

30n1 INgex 


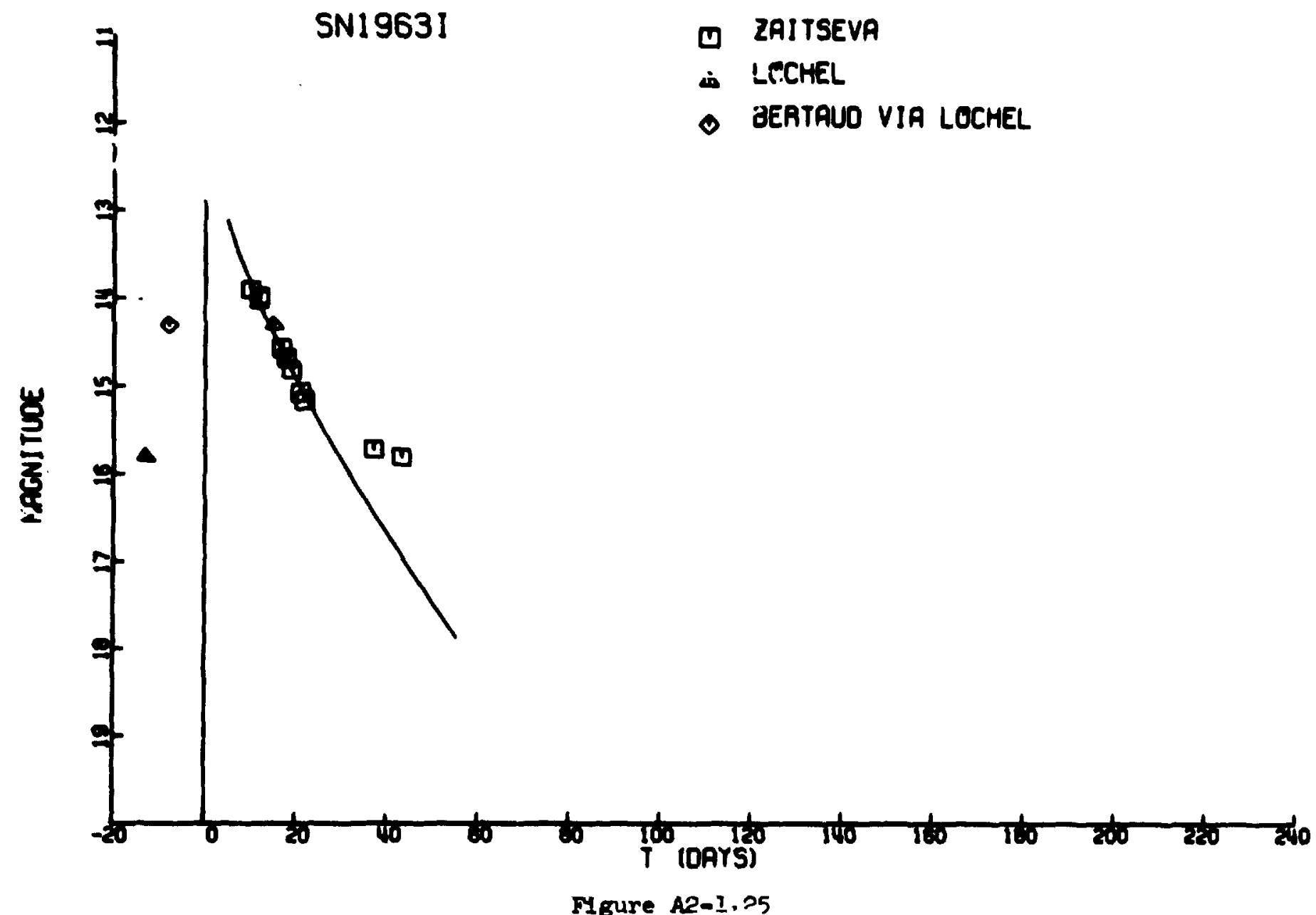

Fyure A2-1.05 


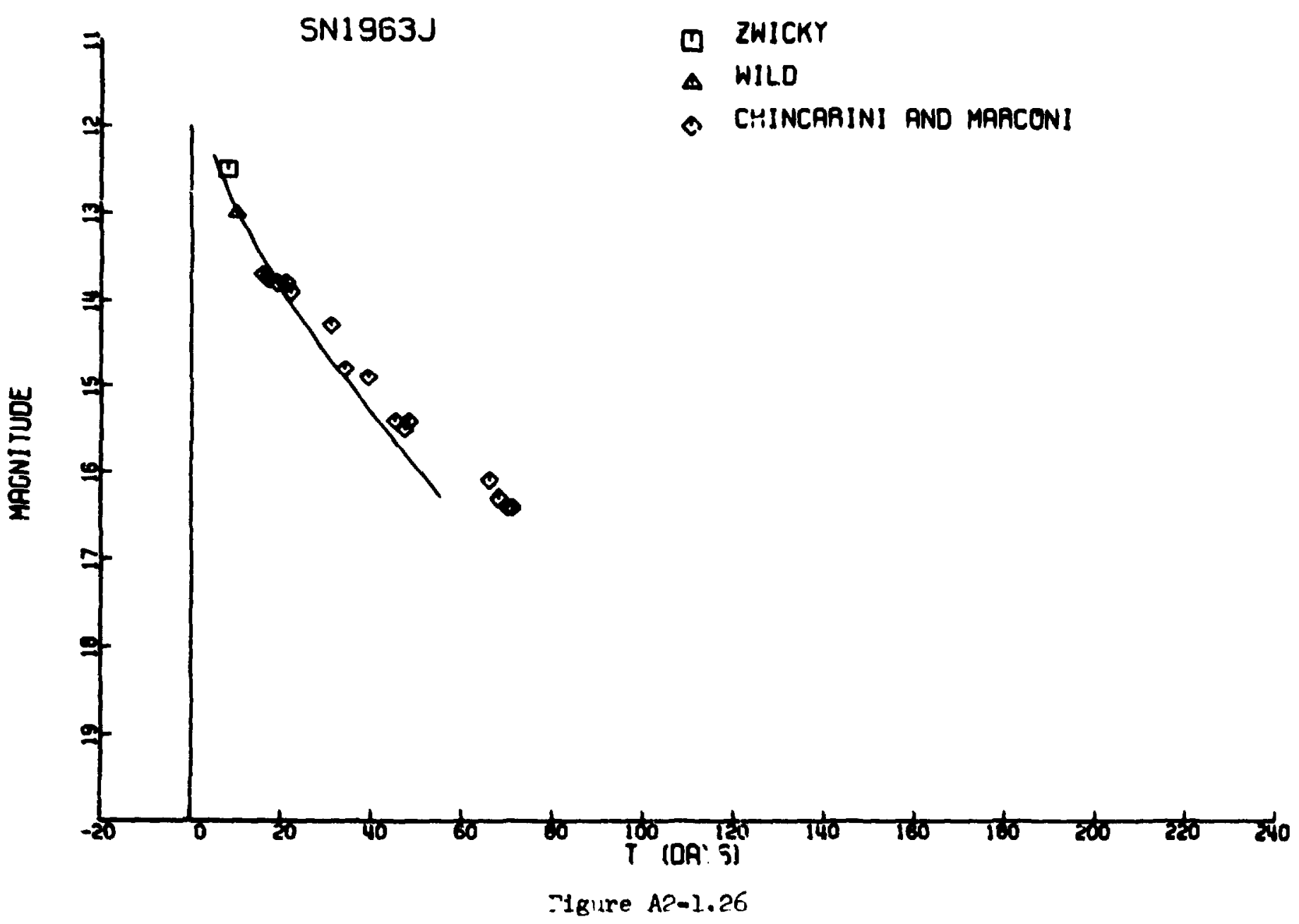




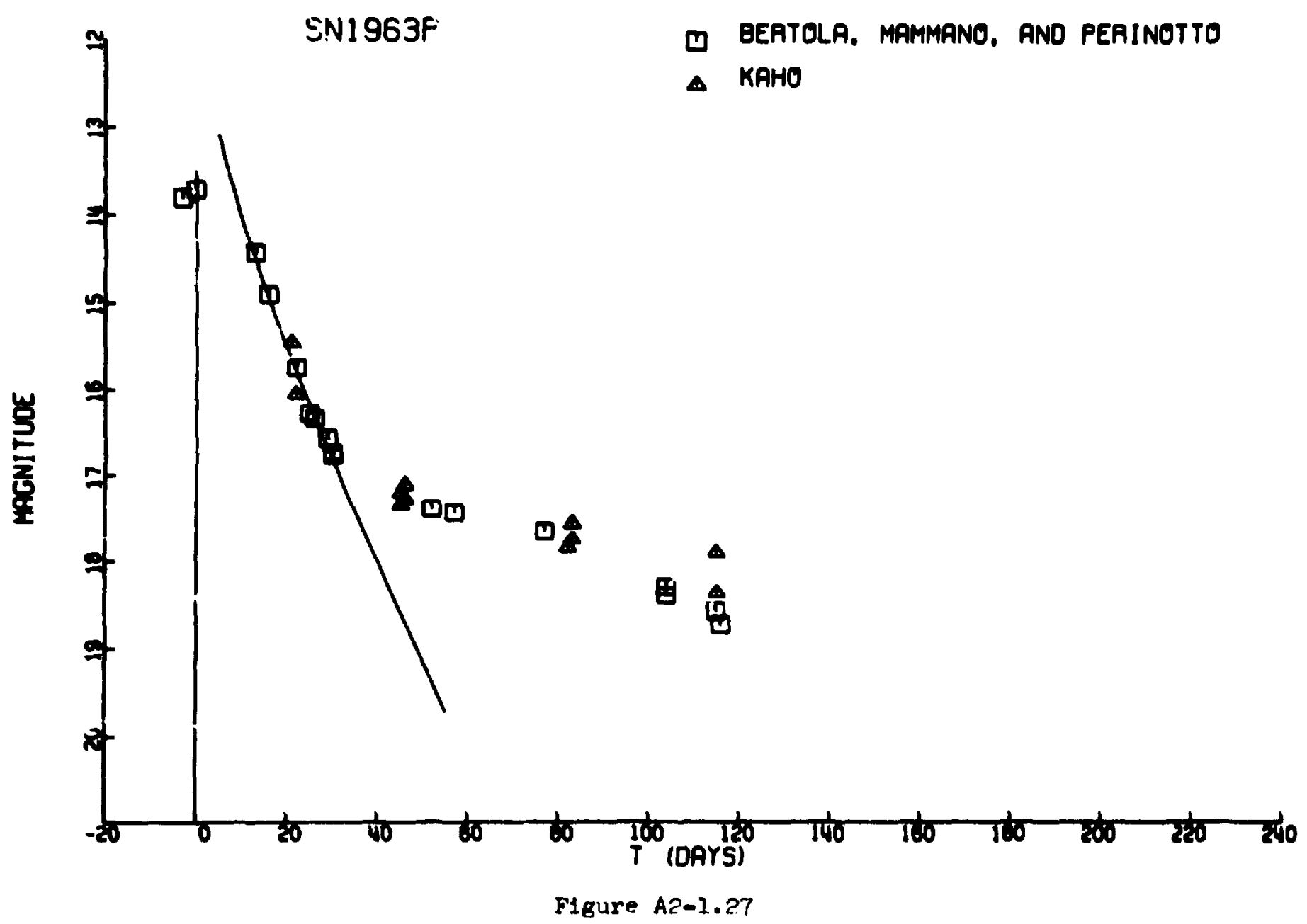

क्ष 


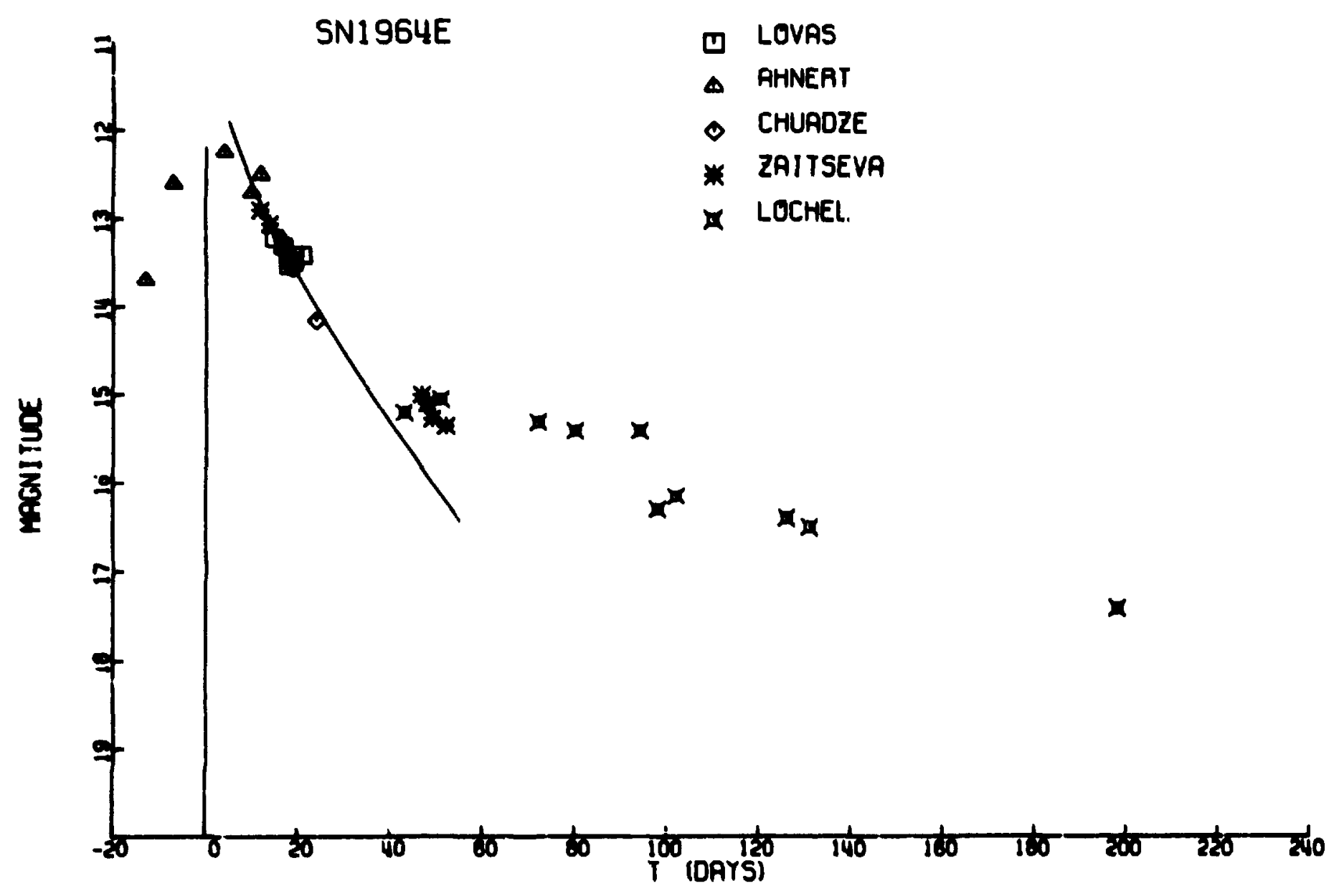

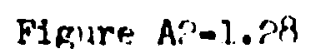




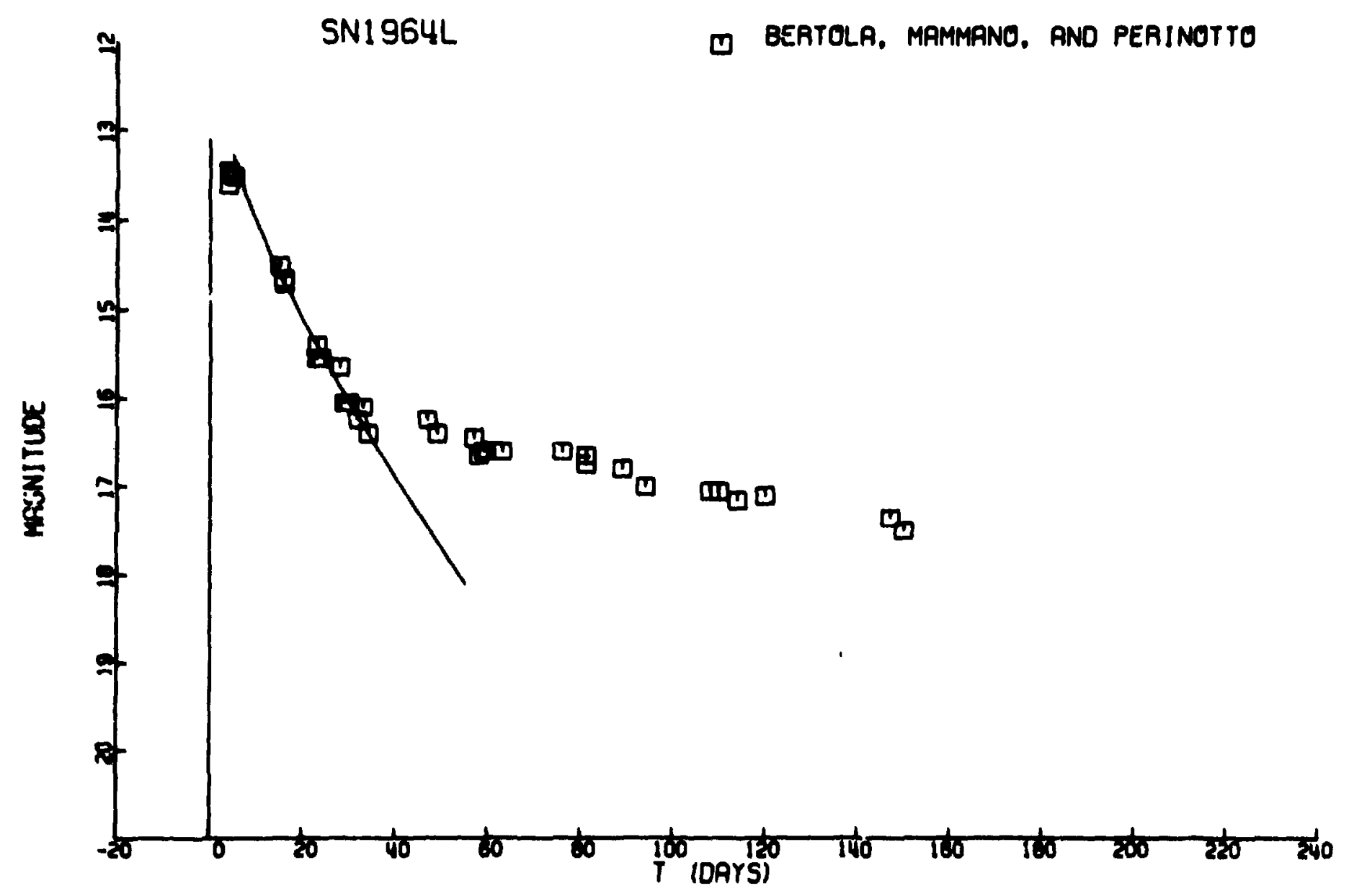

Figure Ap-1.29) 


\section{$\vdots . .5$}

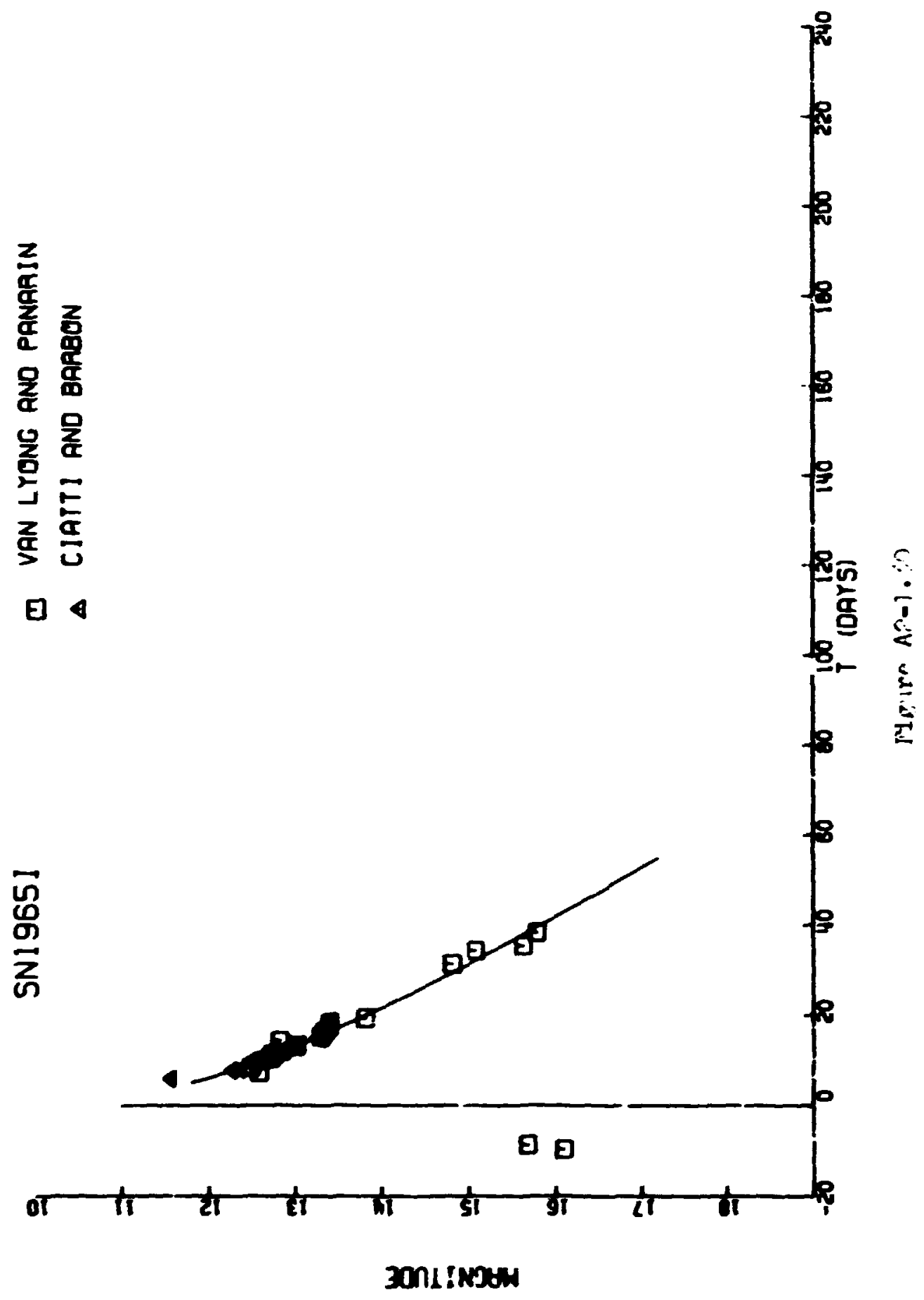




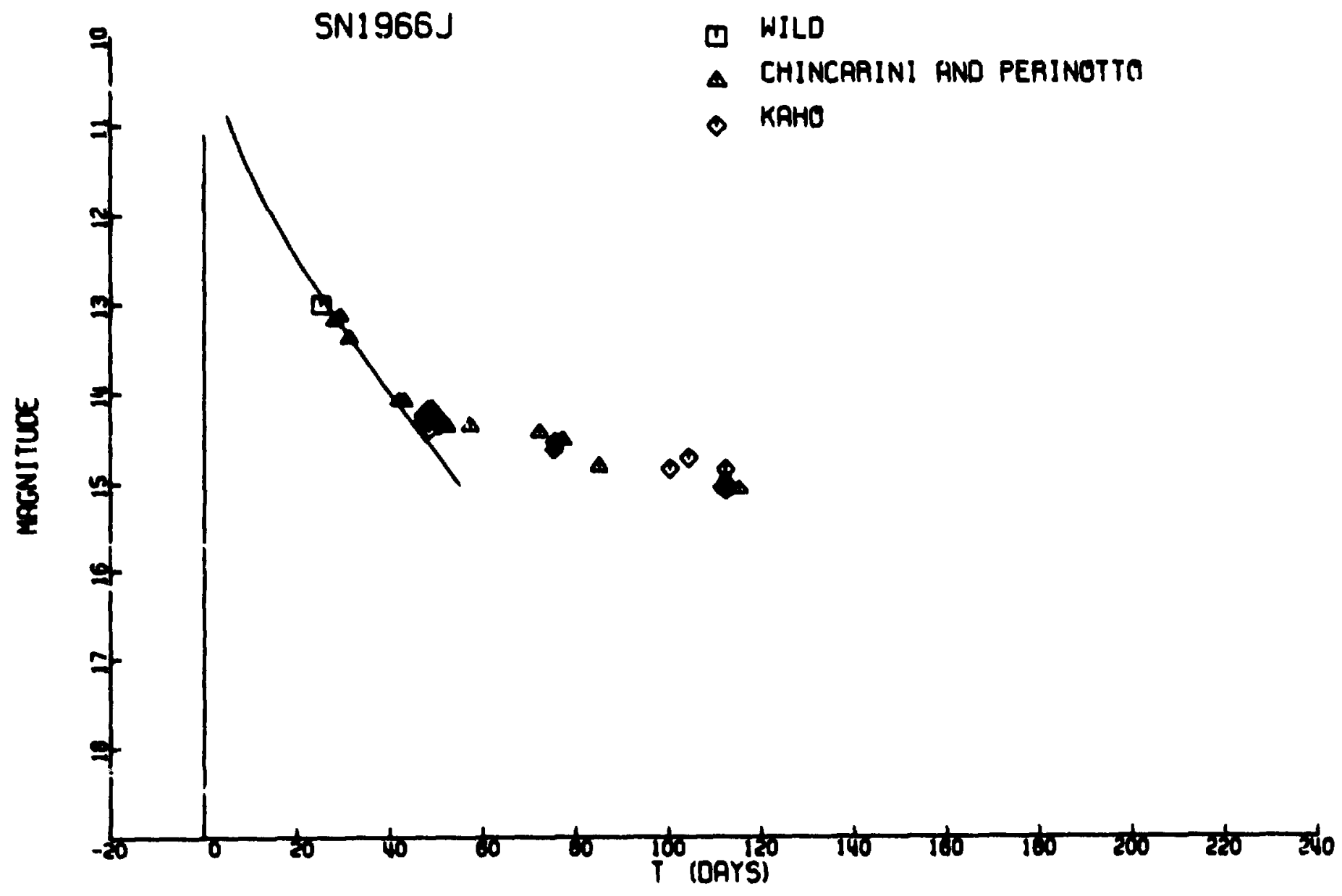

Fifo:dre AP-1. 31

过

$-$

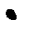




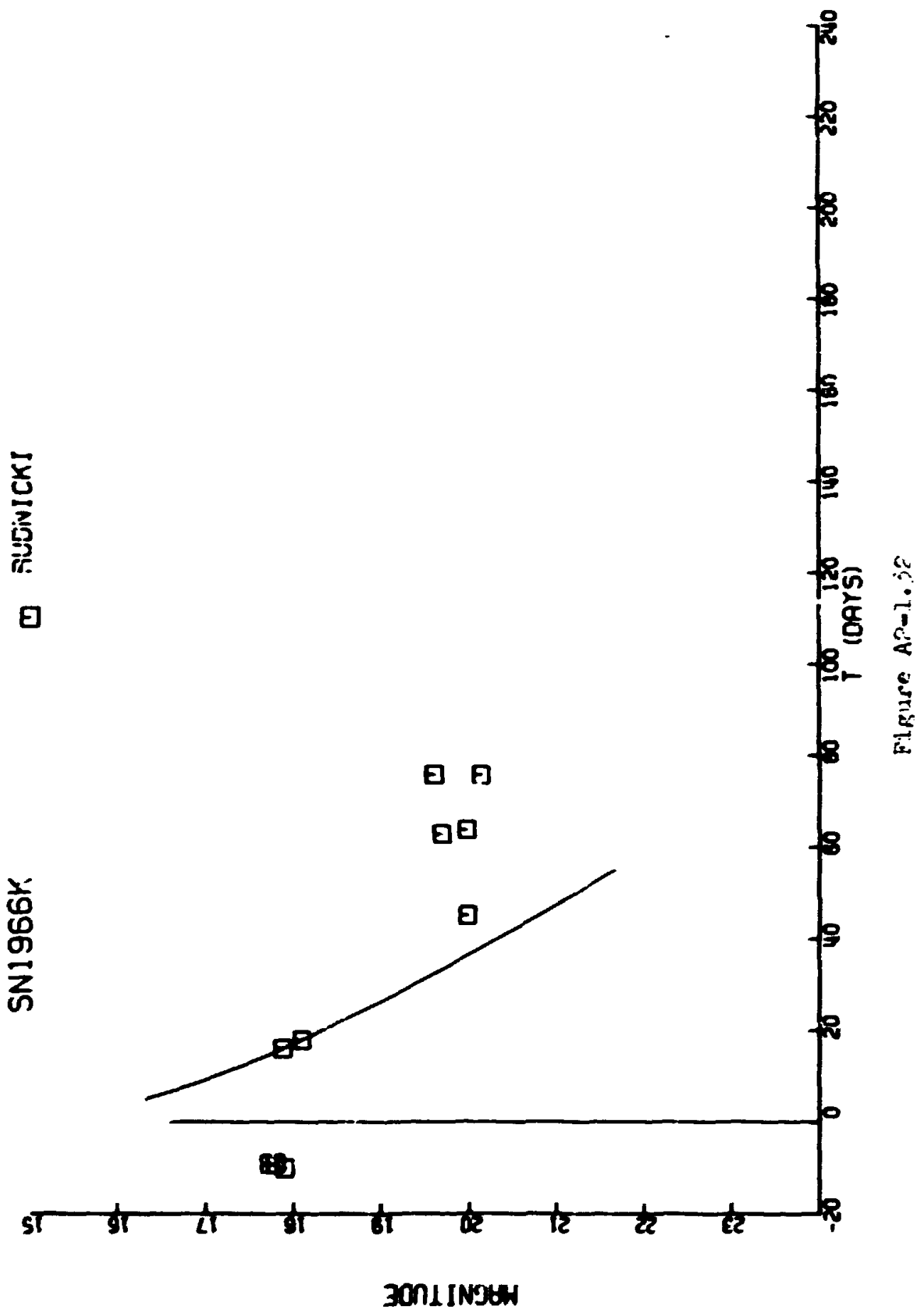




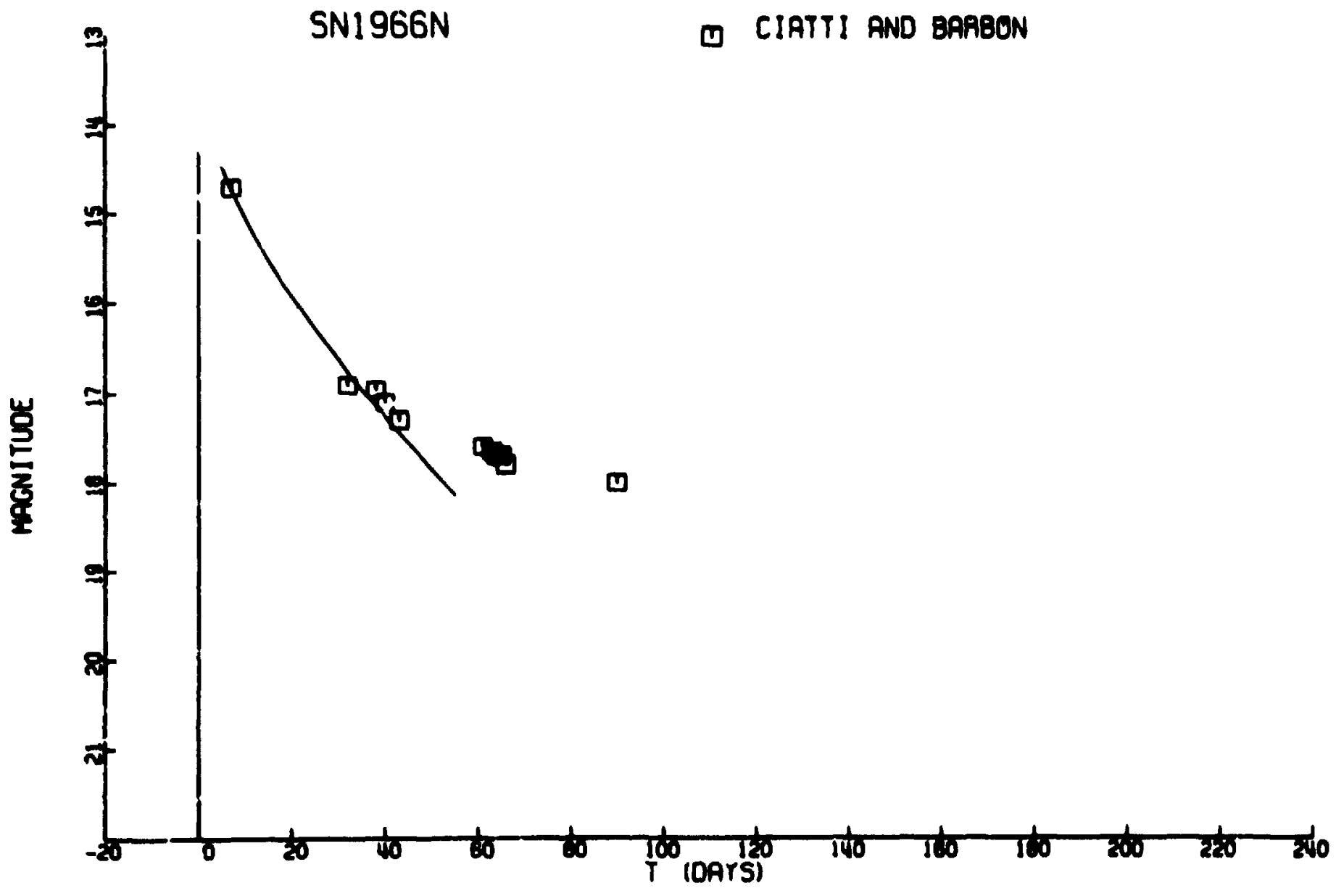

Flgure A2-1.33 


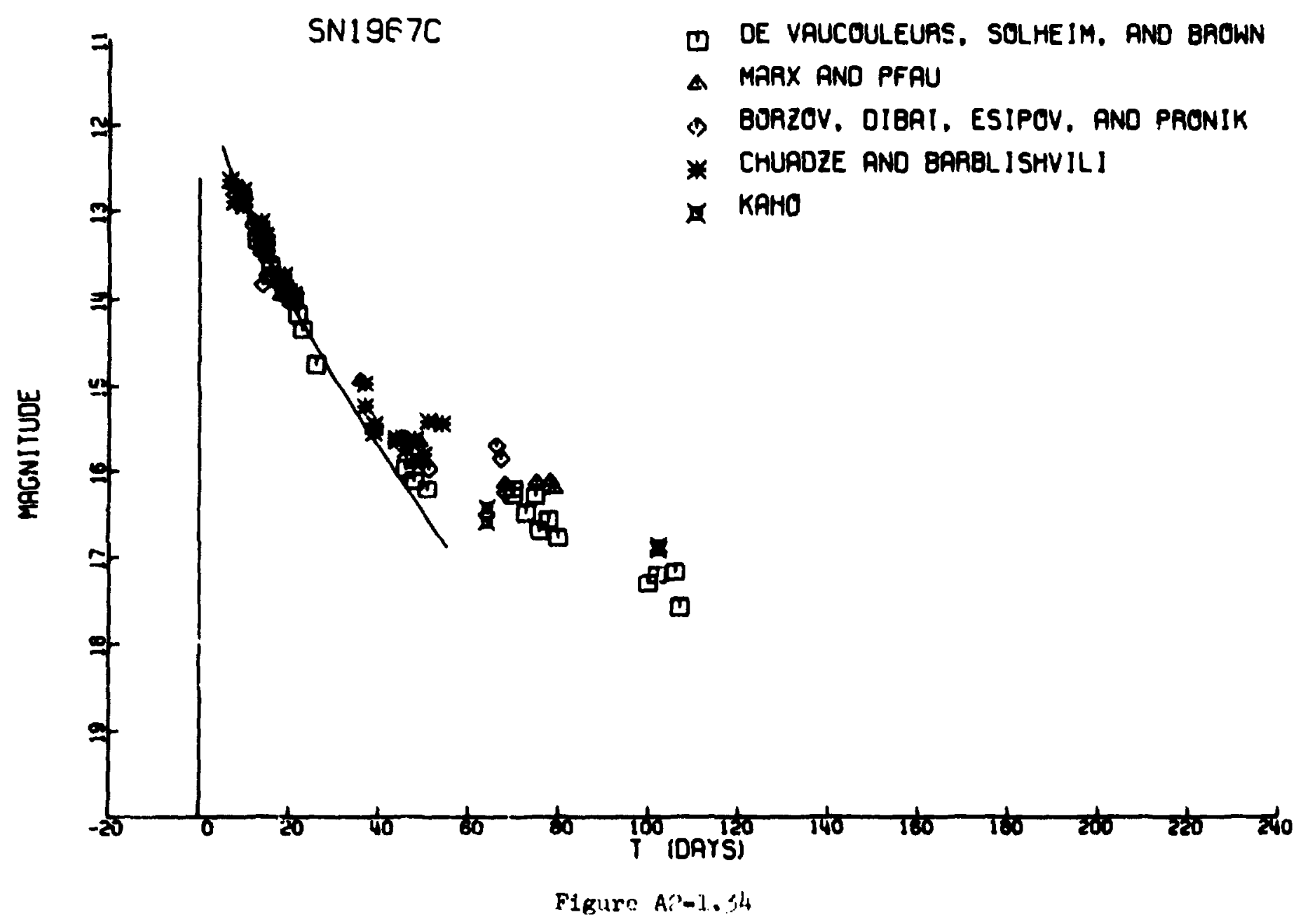




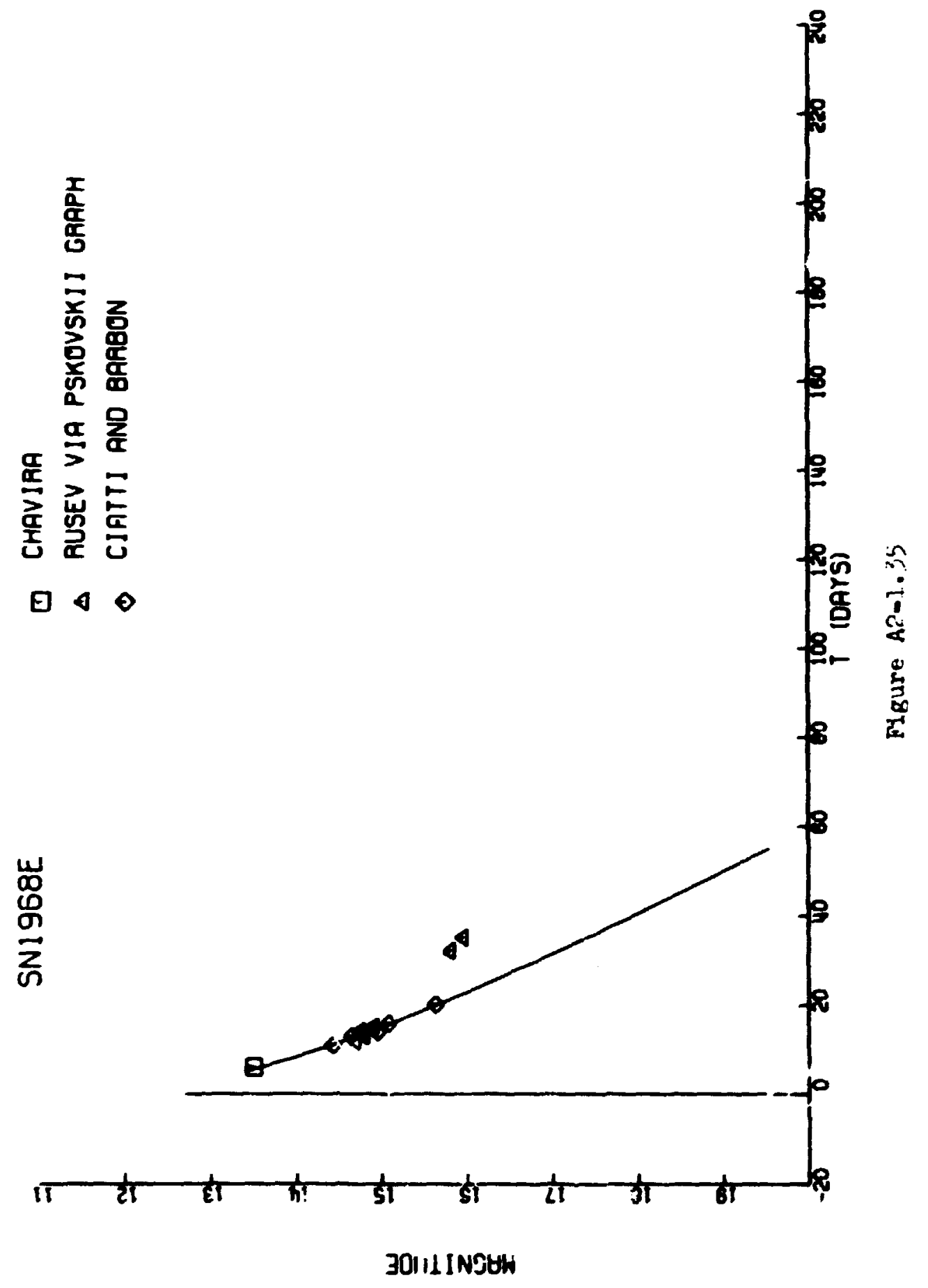




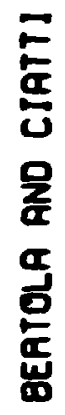

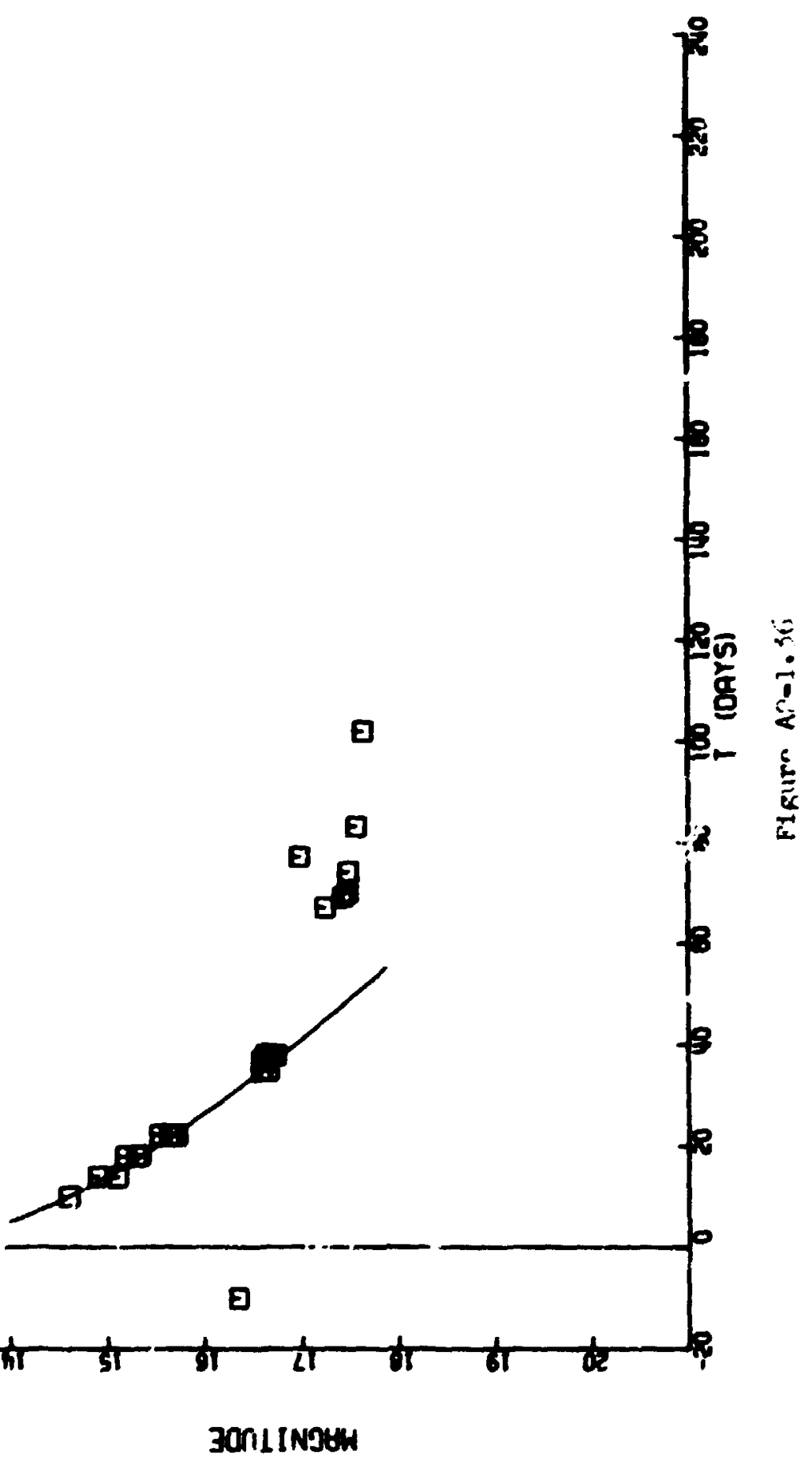




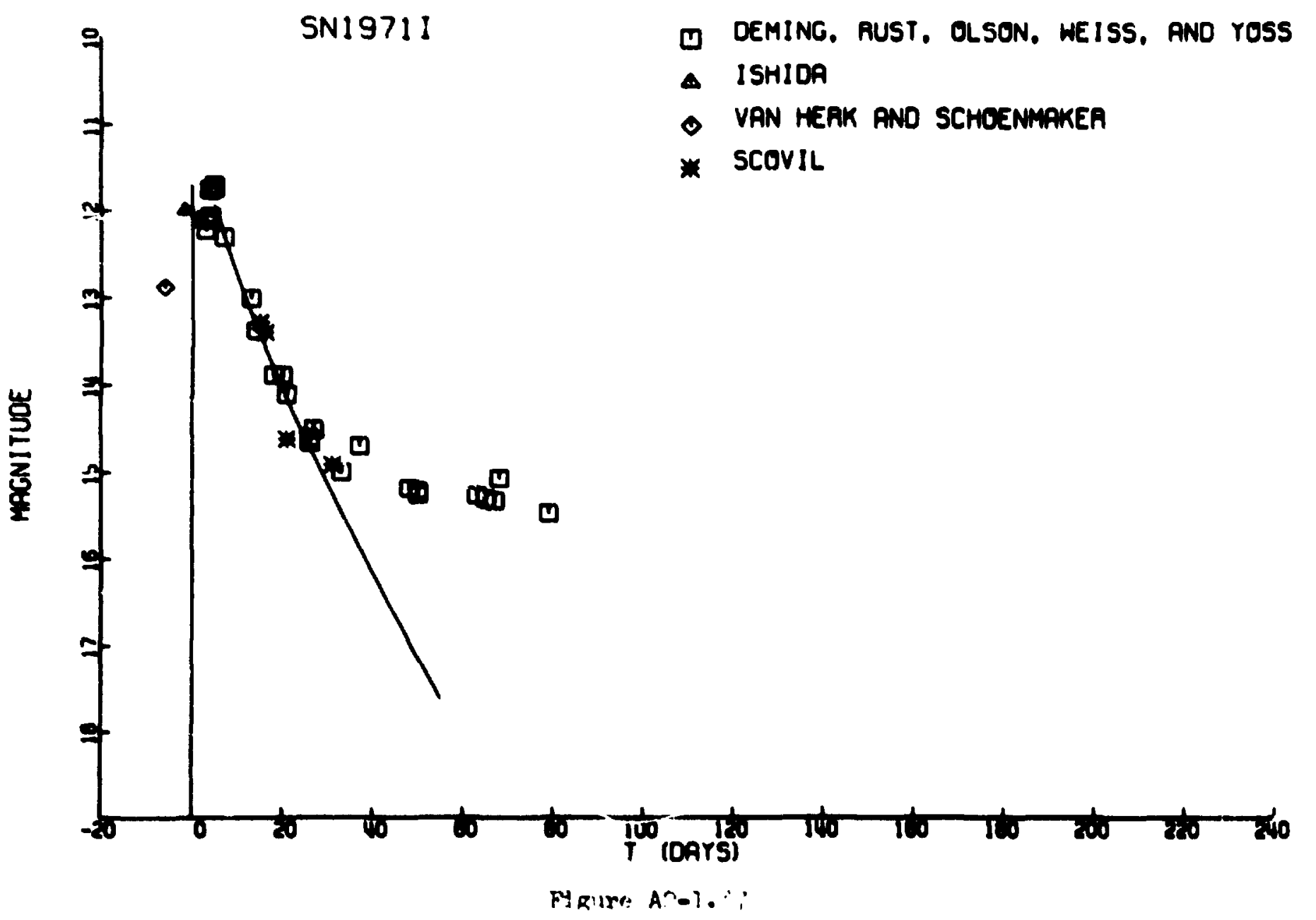


AFFEIDIX:

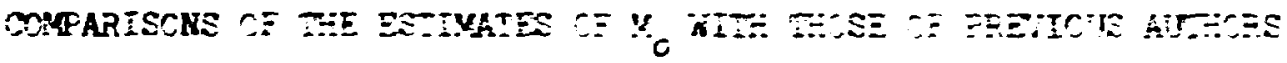

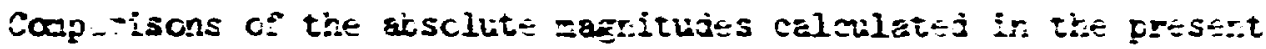

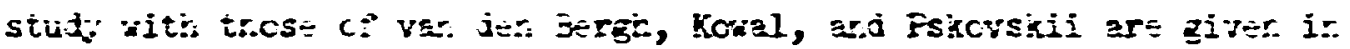

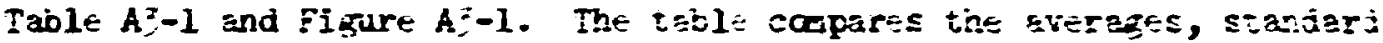

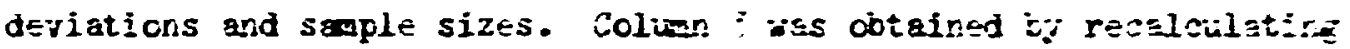
the ibsclute nagnitude. in the present stud with the peEk apparer.t magnitudes, $z_{0}$, ccrrected only fcr asscrption withi our own Elaxy.

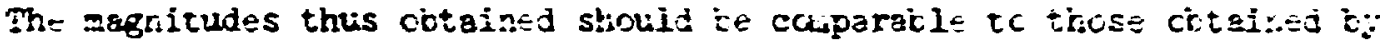
var den jergh: and kowel. The table 1ndicates an extrezel $;$ gcai agresmer.t on the averege dith those of van der. Eerght and "afrl: gocj acrout with those of kowal. The jiscrepanc; between the average valu. of just and that of Kowal is

TAELE $A:-1$

Compariscn of the Absolute dagnitudes ditr: Thos c: Previcus Studirs

\begin{tabular}{|c|c|c|c|c|c|}
\hline Statistic & $\begin{array}{l}\text { Pran den } \\
\text { Bergh:'s } \\
4_{0}\end{array}$ & $\begin{array}{c}\text { Kowal's } \\
y_{0}\end{array}$ & $\begin{array}{l}\text { Rust's }: 4 \\
\text { correct }=9 \\
\text { only' :cr } \\
\text { gos in } \\
\text { our } \\
\text { galary }\end{array}$ & $\begin{array}{c}\text { Pskovskif o } \\
\because_{0}\end{array}$ & $\begin{array}{l}\text { Rusi's } \\
\text { rInsi } \\
\text { yo } \\
\text { corrected } \\
\text { for } \\
\text { everything }\end{array}$ \\
\hline Averaze & $-1: 7$ & $-13 . e$ & $-1, .=$ & ت1. & $-1 \% 1$ \\
\hline $\begin{array}{l}\text { Standari } \\
\text { Deviation }\end{array}$ & $1: 1$ & $m$ & 17 & : & $m$ \\
\hline $\begin{array}{l}\text { Sanvie } \\
\text { siz. }\end{array}$ & $?:$ & 1 . & 7 & $\therefore$ & $\therefore$ \\
\hline
\end{tabular}


0.27 with the Bust angitudes being the brighter. There are 19 supernove comon to the two studies. Pigure A3-1(a) is a plot of howal's estinates egeinat the partielly corrected estinates in this study for those 19 camai supernove. The straight line, which has a $45^{\circ}$ slope, is the relation

$$
\mu_{0}(\text { rowal })=M_{0}(\text { Rurt })+0.2 T
$$

Athough the scatter around the line is large, there are no obvious systenatic deviations from it.

Colun 5 of Table A3-1 Gives the average and standard deviation of the absolute angnitudes given in colven 8 of Table $\supsetneq 3$. The magnitudes have been corrected for absorption both in our own and in the parent galaxy. They should be comparable to the magnitudes calculated by Pukovak11. The average affere from that of Pskovskil by 3.33 with the Rust eatinates being the brighter. The discrepancy is less than half of either of the standard deviations, which dffer by only f.09. Figure A3-1(b) gives a plot of Pskovskil's estimates against those of this stuay for the 21 anpernovae camon to the two samples. The atraight line is the relation

$$
u_{0}(\text { Pakovakif })=\mu_{0} \text { (Rust) }+0^{m} .33
$$

Clearly the scatter around the Iine is random and there are no systematic deviations from it.

The agreesent between the $:$ nal estimates of this study and those of Pukovskif is good when one considers that the methods for estimating the absorption in the parent giang were very different. Pakovakil took 

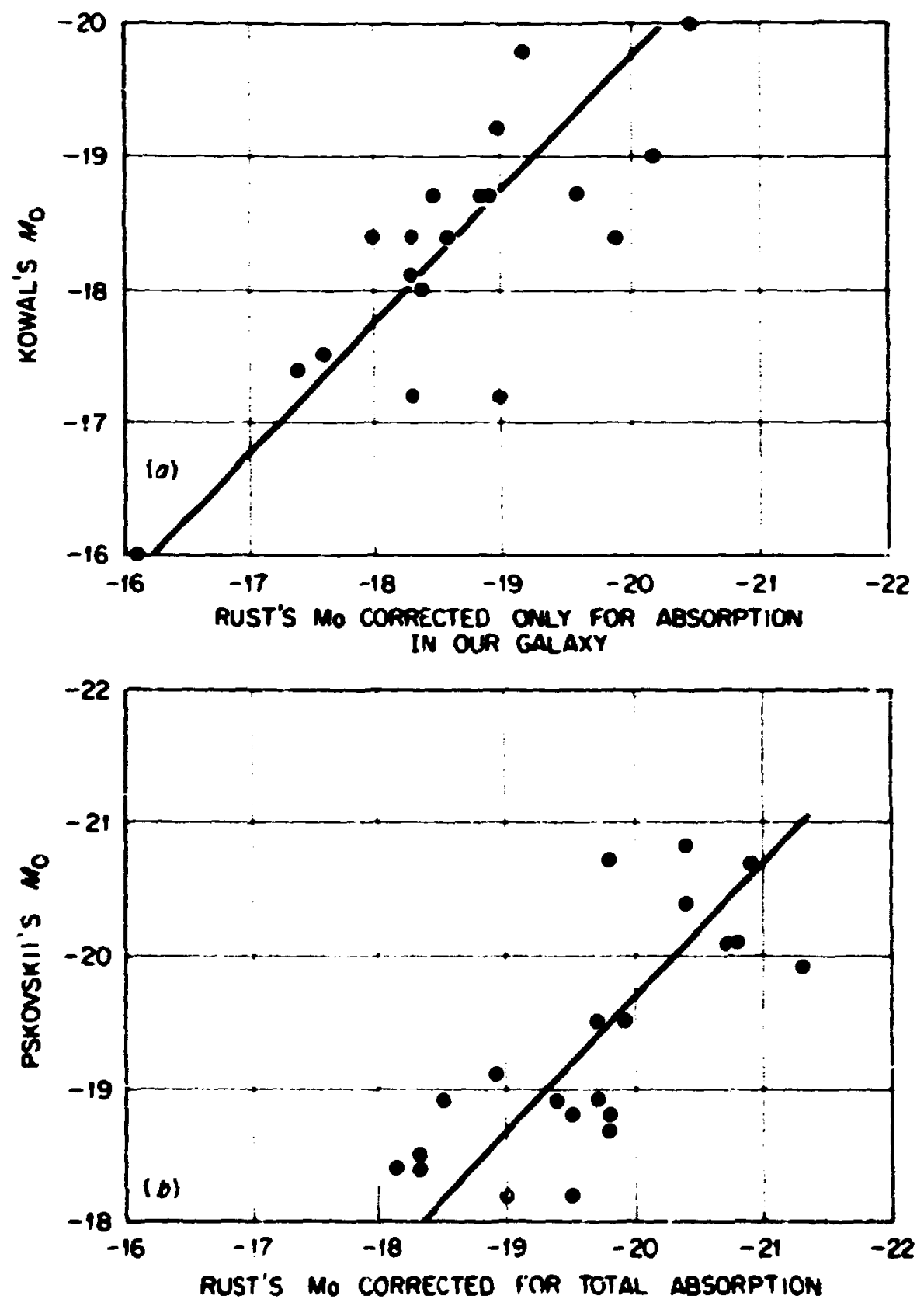

Figur. A:-1. Comparison of the Absolute Magnitines with those Obturned by Previous Aidthors. 


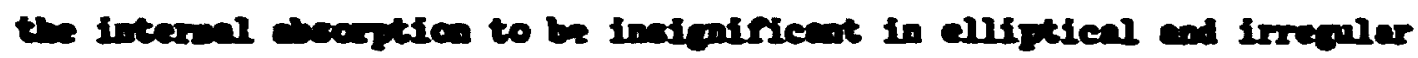

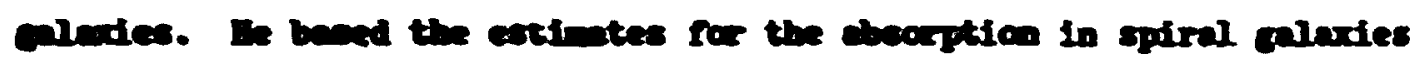

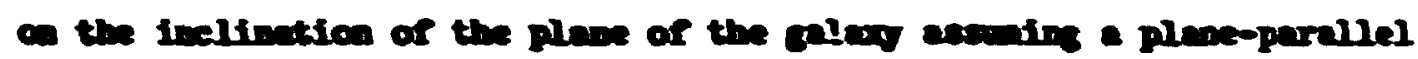

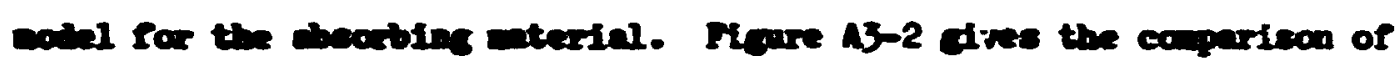

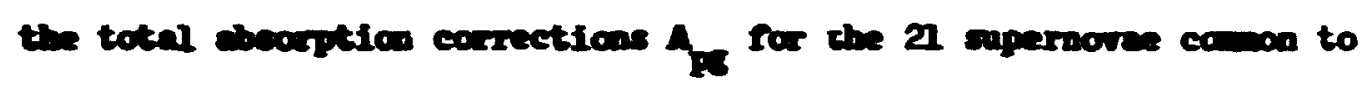
the two somples. The calid line is the $45^{\circ}$ life

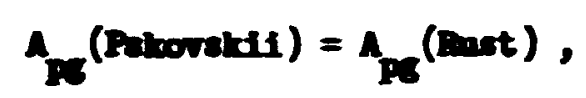

ad the two dached lines represent \pm 0.5 deviations. A closer excenination of the 9 points 1 fing arteide the beod described by the two deshed lines reveale that for 7 of thean, the calculated A (fout) are based on obcerved color excesces, and only two of the (shown encircled) represent estinates. This inplies that nost of the corrections in the present otady which deviats widely froe the corresponding corrections of Pukovikif are wons the nore reliably deternined corrections in this study. This concluation is atrensthened nuther by Figure $13-3$, which is a plot of the total cbsorption correction apinst color excess for the 12 mupernoves with seavured color excesces which were camon to the two studies. Pobovakif's corrections are ahown as filled clrcles while the corrections for the present study are chown as open circles. It is bot ourprieing that the latter lie aloag a otraicht line since they were conputed by Iq. (9-5). Pakovikil's corrections, in contrent, do not exhibit aw alonificunt correletion with the color excess. Tro eatrwe cases are ang5ge and 19621 which have observed color excescen of d.10 and $\mathrm{d} 85$ reopectively. Pakovokil's estinated for the abeorption corrections are 1"7 and 0.7 reppectively. Thece estimates are inconsistem, with the 


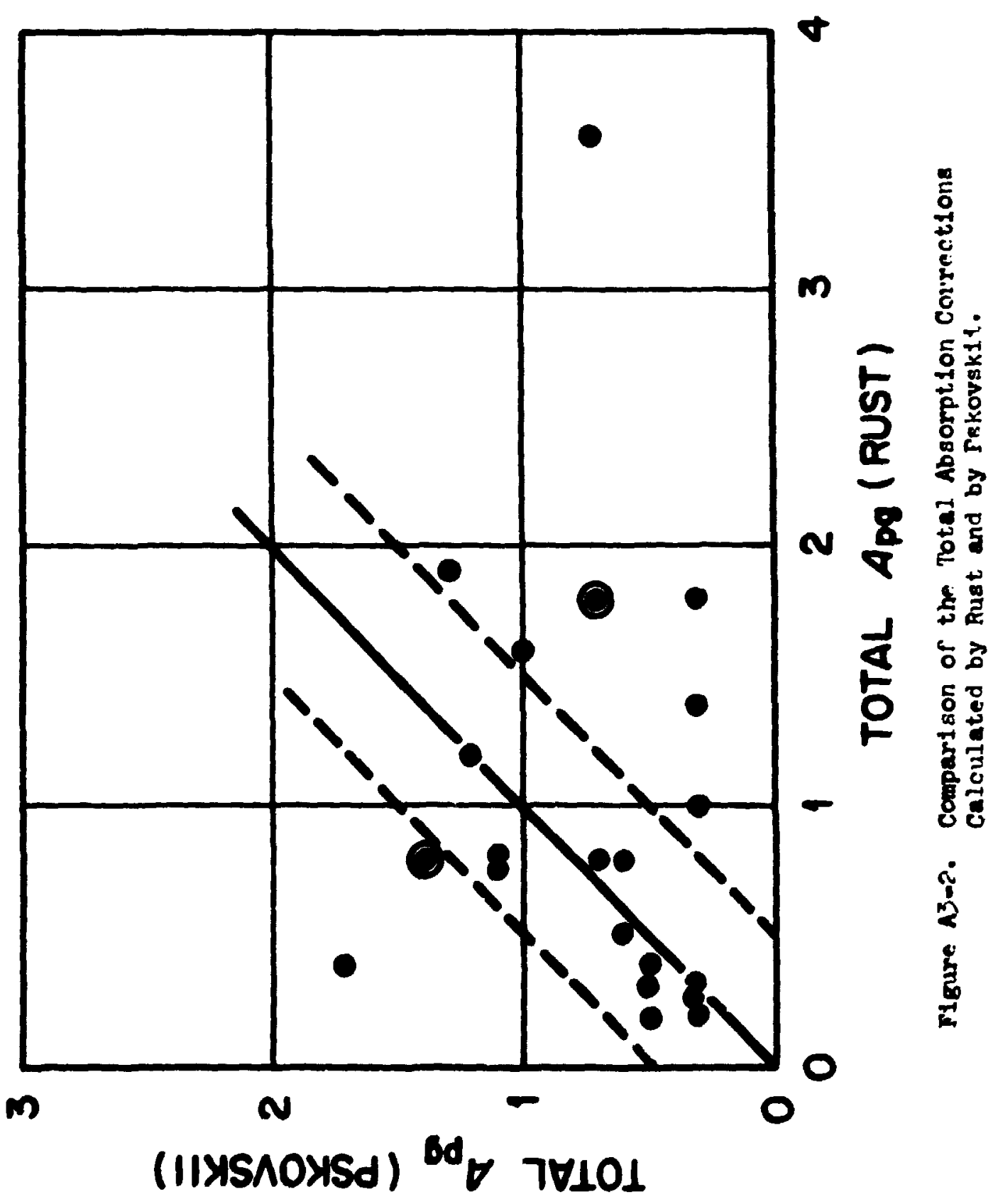




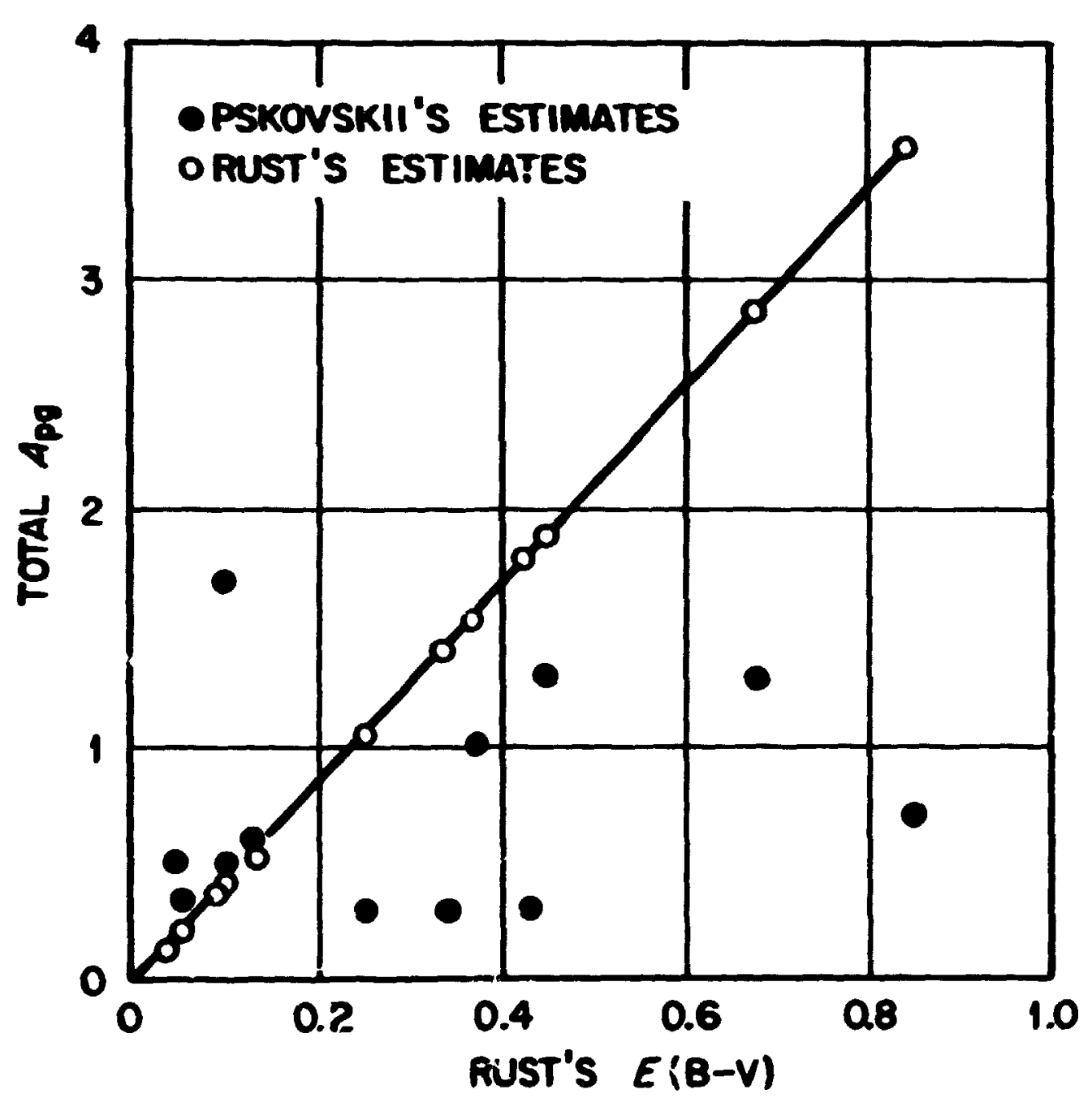

Pigure 13-3. Total Absorption Cosrection as a Fution of Color Fxcess. 


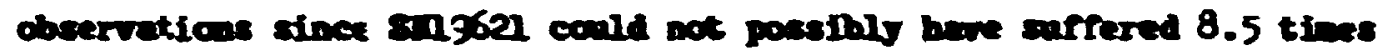

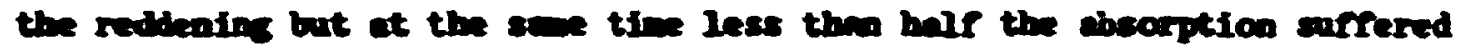
bs angse. It wond apper then that the color encess nethod is a nore consistent whod for calenleting shorption correction then the inclination wethod, and, since nout of the deviations in Fis. 13-2 are In the direction $A_{p s}$ (bust) $>A_{p s}$ (Pikorsidi), that the inclination wethod no be on the average too conservative. Ins would certainfy sccount

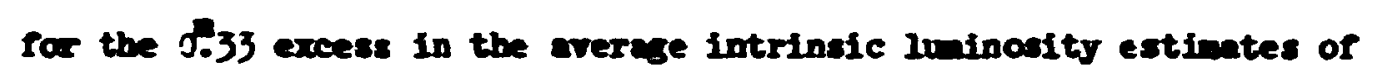
the present study over those of Pakovsld. 


\section{5}

\section{Aran 4

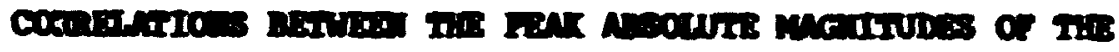

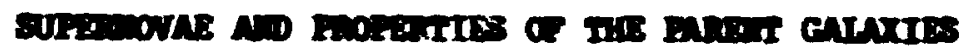

In his 1967 pepper (50), Fibovald found a weak correlation between the peat sbalute seonitudes of the suppesnovere and the hubble types of the parent saledes. Ploure $14-1$ dive a plot of the eagitudes verous the fubble types both for Pulovidil's extinates, stom as walld circles, ad for the estinates of the present study, shom es open cfrcles. There does appear to be a sifigt correlation, with the brightness Ircreasizg as the type of the galax progresses through the Hubble sequence rrom elliptical to irregular. The correlation is perhaps more clearly indicated in the lorer graph, which is a plot of the ave rage angaltude for each type. These avex'ages, together with the standard deviations are given in Table $A+1$. In the plot, the average values are connected by straight line segents (Pwkovikil's by solid lines and Rust's by broken lines) in order to emphasize the difference between the two sets of averages: (1) The averages of funt increase nore woothly alcons the sequence of galaxies than do those of Pakovakil, and (2) The range of the increase is less for the estimates of Rust than for those of Pakovsk11, the ranges being $(-18.8,-19.8)$, respectively. Thus, the correlation eppears to be wore regular but less prosounced for the estimates of Rust than for those of Pskovskif. It is difficult to assess the significance of the correlation, considering the range of standard deviation of the estimates about the averages. 


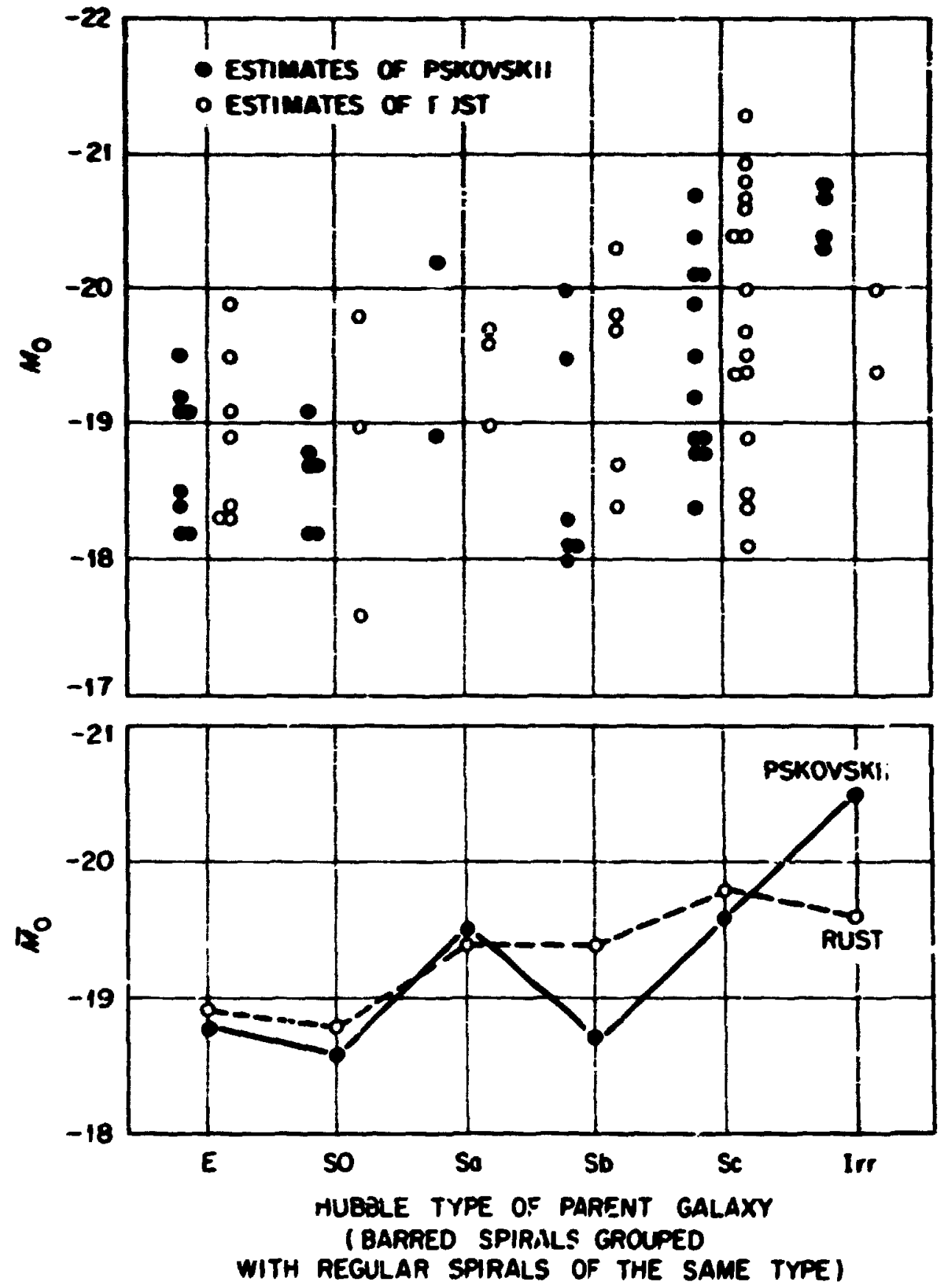

Pigure A4-1. Peak Absolute Magnitude as a Punction of the Hubble Type of the Parent Galaxy. 
TARTE A4-1

Average Peak Nbsolute Mapitudes as a Punction of Gelexy Iype for the Batinates of Prkovikil and Ront

\begin{tabular}{|c|c|c|c|c|}
\hline \multirow{2}{*}{$\begin{array}{l}\text { Type of } \\
\text { Galay }\end{array}$} & \multicolumn{2}{|c|}{ Pokovsly's Batinates } & \multicolumn{2}{|c|}{ Dunt's Estinates } \\
\hline & & $\bar{H}_{0} \pm \sigma\left(\mu_{0}\right)$ & No. & $\bar{H}_{0} \neq \sigma\left(H_{0}\right)$ \\
\hline $\mathbf{E}$ & 8 & $-13.8 \pm 0.5$ & 7 & $-18.91 \pm 0.63$ \\
\hline so & 6 & $-18.6 \neq 0.4$ & 3 & $-18.80 \pm 1.11$ \\
\hline $\mathbf{s e}^{*}$ & 2 & $-29.5 \pm 0.9$ & 3 & $-19.43 \neq 0.38$ \\
\hline $\mathbf{s b}^{*}$ & 6 & $-18.7 \pm 0.9$ & 5 & $-19.38 \neq 0.80$ \\
\hline $\mathrm{Sc}^{*}$ & 12 & $-19.5 \pm 0.7$ & 26 & $-19.81 \neq 0.98$ \\
\hline Irr & 4 & $-20.5 \pm 0.2$ & 2 & $-19.60 \pm 0.28$ \\
\hline
\end{tabular}

"Barred spirals are grouped with regular spirals of the sure type.

In an earlier paper (145), Pskovskif reparted a correlation between the peak absolute magnitudes of the supernovae and the integrated absolute magnitudes of the parent galaxies. In his 1967 paper $(50)$ be said that the correlation is not rellably determined becunse of the large dispersion in $\mathrm{M}_{0}$ and the lacis of data on supernovae in low Iuminosity galaxier. Pigure A4-2 illustrates the regression of Pakovskif's estimates of $\mathrm{M}_{0}$ on $\mathrm{his}$ extimates of the integrated absolute magnitudes $M_{\text {galary }}$ using all the supernorac in his 1767 sample tor which he gave estimates of $M_{\text {galerg }}$ The iquation of the best fitting regression line, shown in the flgure as a solid line, is

$$
1: 0-(26.57 \pm 2.34)-(0.379 \pm 0.121) M_{\text {galax }}
$$


and the correlation coefficient is $==-2.3 \mathrm{z}$. . The t-stati.itic for testing the significance of the slope has the value $t=-3.1+$ which gives, for the 27 points in the sample, signiricance at about the 99.$)^{\prime}$ level. The regression was performed both with and without the point at the uppor leit corner 'SN1 3372' in order to show that it did not have an inordinate influence ir. deterwining the slope. Without that point, the regressicn line is

$$
\begin{aligned}
& \left.M_{0}=. \cdot(x 6.16 \pm z .16)-\because 25: 3 \pm 0.162\right) M_{\text {galarg }},
\end{aligned}
$$

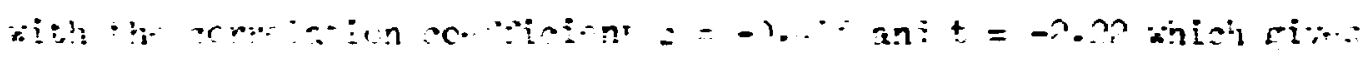

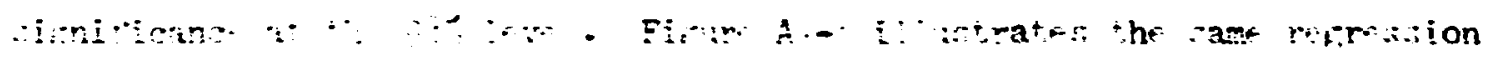

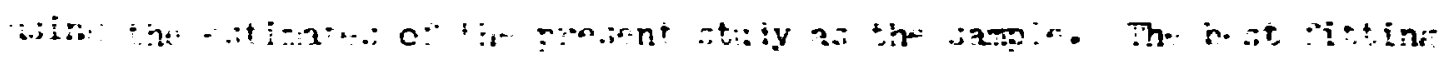

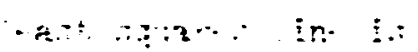

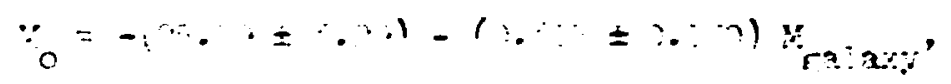

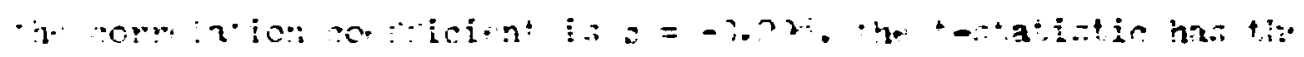$$
\text { value } t=-1.3 \% \text {, and there are } 37 \text { points in the samp?.e so the corelation }
$$$$
\text { is significart at the } x: \text { level. When the left hand extreme point, }
$$$$
\text { SNI ) } 37 \mathrm{C} \text {, is onitted the results are }
$$$$
\left.M_{0}=-(27 .): \pm 3.3\right)-(0.366 \pm 3.262) M_{\text {galax }},
$$

$=-7.275$, and $t=-1.67$ which gives significance at the $\gamma^{4} .7:$ level. It would appear then that there is a significant correlation between the estimates of $M_{0}$ and the estimates of $M_{\text {galaxy }}$ in both studies, but there is a side scatter in the $M_{0}$ estimates. The two sets of estimates give similar values of the slope of the regression line but the correlation is not as pronounced in the present sample which contains i? supernovae more than the sample of Pskovskif. 


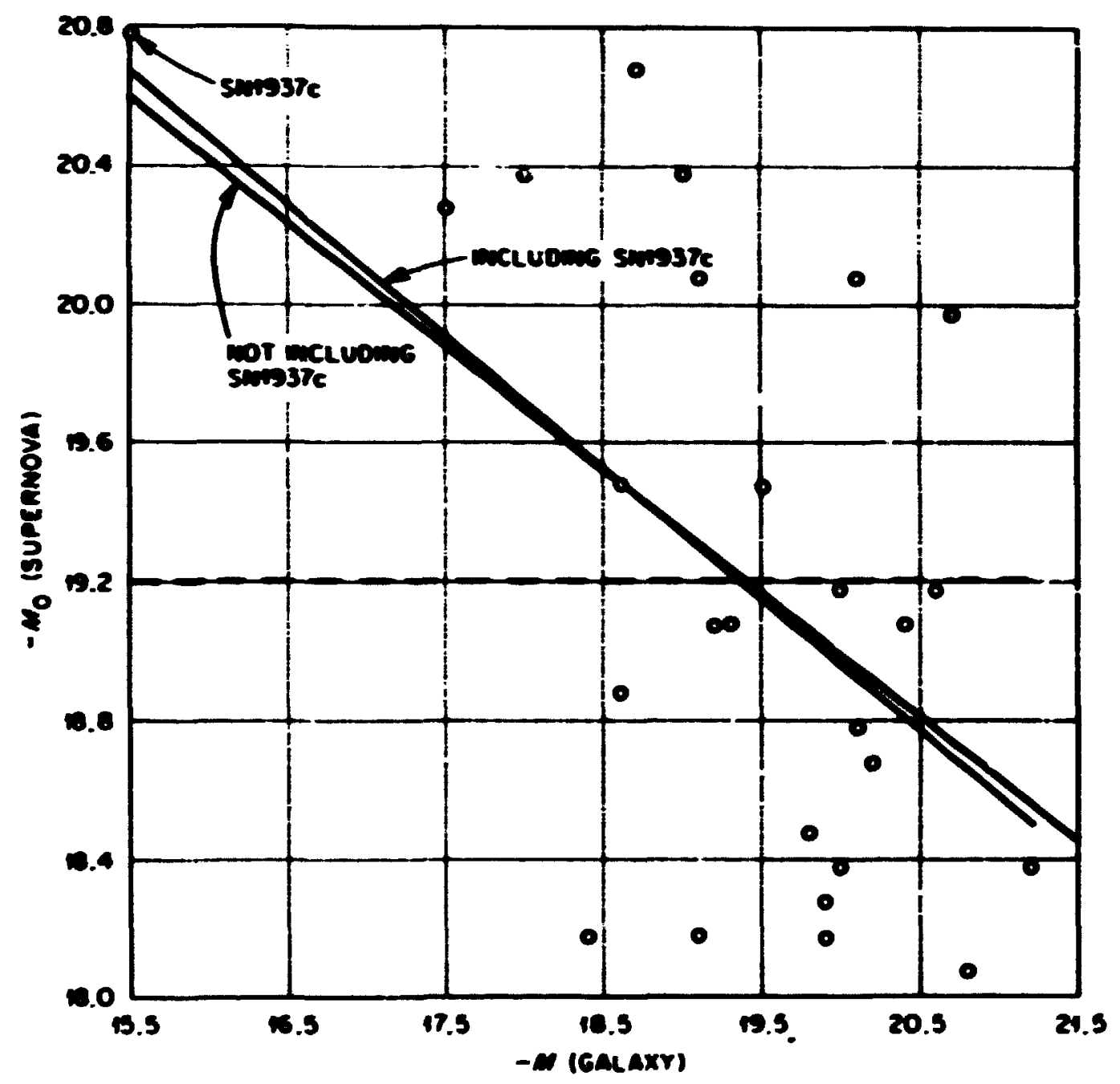

Pigure Ah-2. Rigression of Peaic Absolute Manitude on the integrated Absolute magnitude of the Parent Calexy for Pakorskil's Sample. 


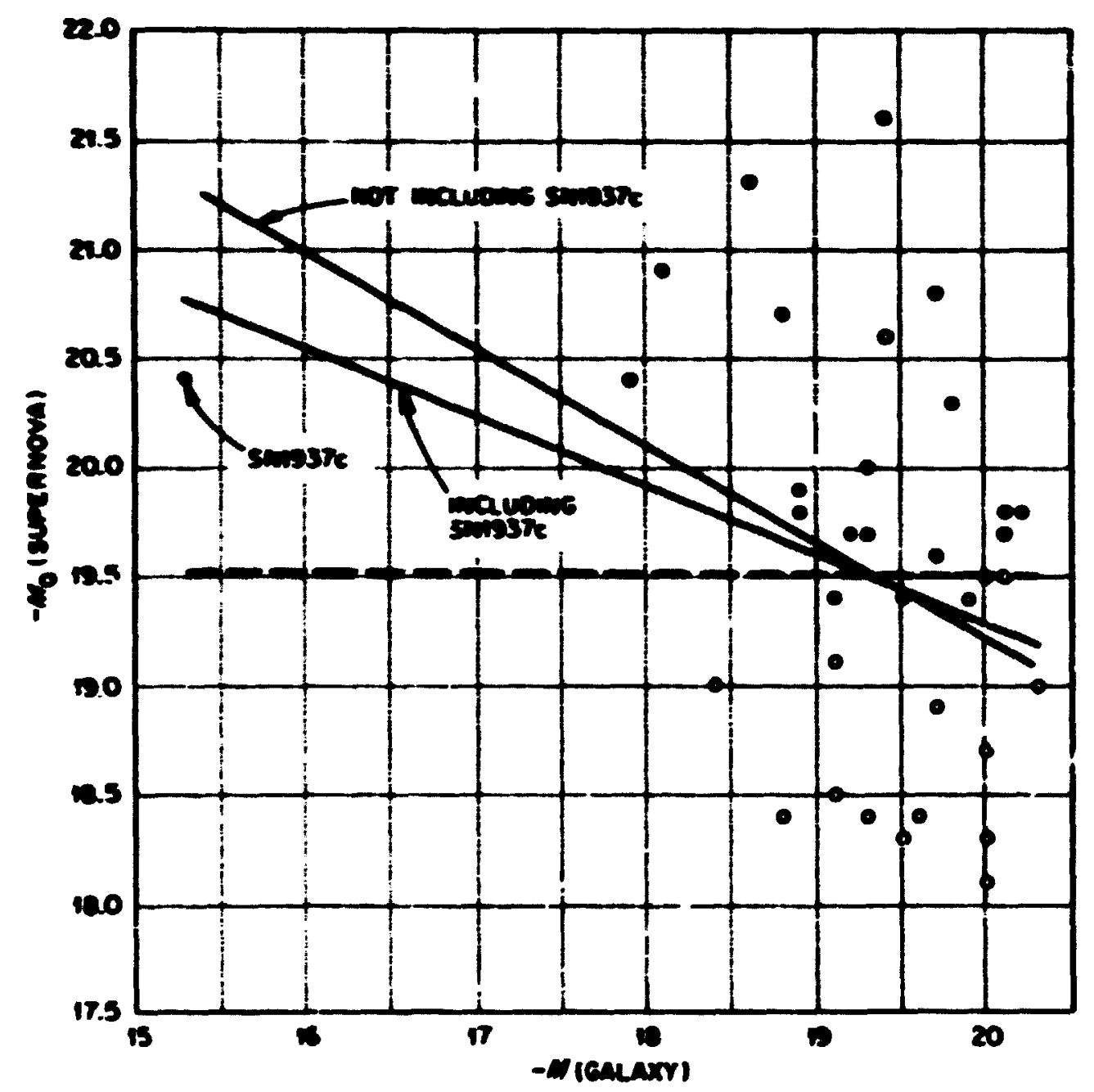

Mgure Ab-5. Regression or Peak Absolute Hanitude on the Integrated Abeolute Monitude of the Parent. Galexy for Rust's Sapls. 


\section{APFIDIX 5 \\ TESTS POA STSTRUTIC ERTETS IS BSTMUTIG THE $n_{0}$}

Pour tifrerent wethods yere used far estinating the original

uncorrected $m_{0}:$ (i) inspection of the observed lieht curve, (2)

Pskovskif's estinates by his point $k$ method, (3) Pakovildi's estinates

by his average light curre wethod, and (4) Aust's estinates ising

Pskovstil's point is nethod. Table A5-1 gives a sumary of the muber

of times each of these methods was used in the two luninosity groups.

\section{TABLE A5-1}

Sumary of the Number of Times Jach Meti:od of Estimating a was Used fer the Iwo Irminosity Groups

\begin{tabular}{|c|c|c|c|}
\hline Method & $\begin{array}{l}\text { Kumber is More } \\
\text { Luminous Group }\end{array}$ & $\begin{array}{l}\text { Number in Less } \\
\text { Lurinous Group }\end{array}$ & $M_{0} \neq s\left(M_{0}\right)$ \\
\hline Observed light curve & $\varepsilon$ & 4 & $-19.65 \pm 0.65$ \\
\hline Pskoyskil's point $k$ & 3 & 2 & $-19.42 \neq 0.76$ \\
\hline $\begin{array}{c}\text { Pskovskii's av. light } \\
\text { curve }\end{array}$ & 2 & 5 & $-18.94 \pm 0.69$ \\
\hline Rust's point $k$ & 6 & 6 & $-19.72 \pm 1.31$ \\
\hline
\end{tabular}

Clearly there is no strongly exclusive association of either group with any of the methods. Furthemore the average values of $M_{0}$ for the various methods are very similar except perhaps for Pskovsk11's average light curve method which is lower because of the 5 to 2 ratio of the less luminous group to the more luminous group. This imbelanse is 


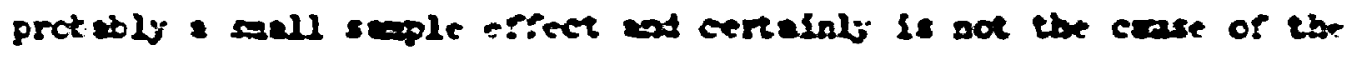
sep. Thus, it a bles we bullt 20 to the estimates of $a_{c}$, It gust havt accury is is ecrrection process.

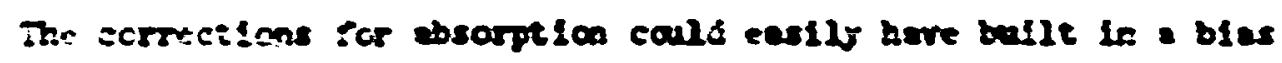
i: the correcticos applied : 2 part of the $z_{p}$. wre grtenatically and

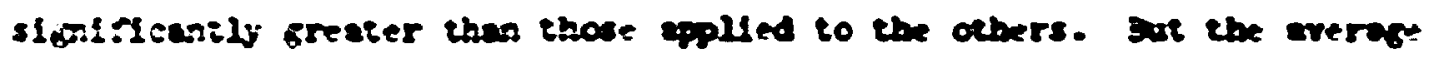

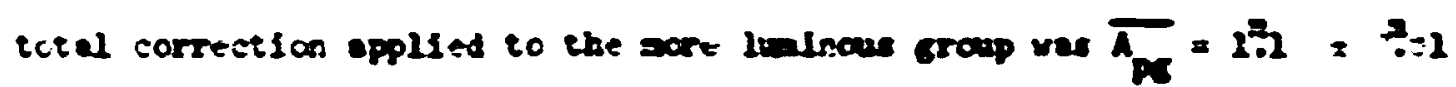

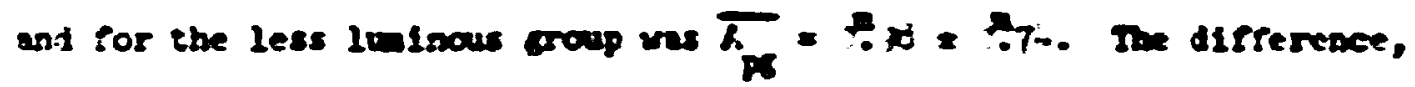

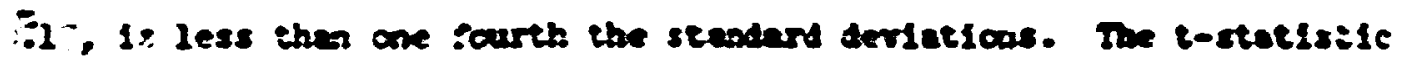

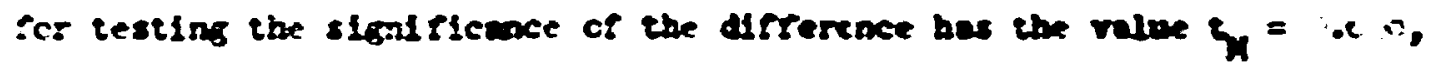
whtch even with 3- degrees of rreedon is not sioniflcant the ? leyol. El:erl; the an yes aot cansed by systeaticelly correcting

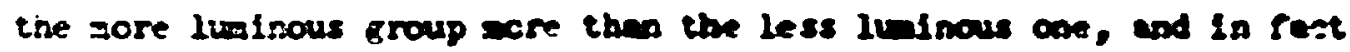
If ofther group irere systemetically corrected Mrther to alke it: aggitudes consistent with the veher group, then e biss would be bullt 1. and the corrections for thin group rould be sjstematicelly different irac those of the otker. It is 1 colncidence the: the 1 , to 17 retio of the iwc lualiosfij aroups is itentical so the retlo of the nuber of a correcit. by the ctserved color excess aethod to the maber for which the absorption wits:- the parent galex ves obtained by estination. That it is no more then a colnctidence is clearly shom by Table A-2 which gives the number of thes each nethod of correcting for absorption was used in each luminosity sorup. 
TAENE $A-\varepsilon$

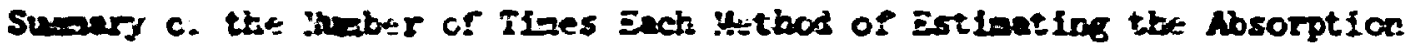

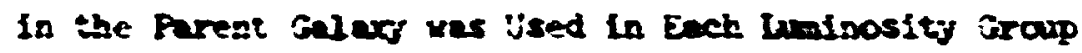

\begin{tabular}{|c|c|c|c|}
\hline Yethod & $\begin{array}{l}\text { insber in ifore } \\
\text { Lnatnous Group }\end{array}$ & $\begin{array}{l}\text { Thaber in Les. } \\
\text { Lraf nous Grasp }\end{array}$ & $u_{c}=s\left(y_{c}\right)$ \\
\hline Observed Color Dxesss & 1 & ; & $-1 ; \cdot y^{3}-\cdots=\cdot \dot{x}$ \\
\hline Est. $\approx$ 'sllpticn) & 1 & $\Xi$ & \\
\hline Dst. $\rightleftharpoons$ (Splral) & & & $-1 ; 0.0=1.2$ \\
\hline Est. 1. (SpIral) & $\Xi$ & 11 & \\
\hline
\end{tabular}

Clearli there 18 so strong assceletion of efther grcup with ax: c: tise sethods. Purtherwore the werage $H_{0}$ for the observed cclor excess group

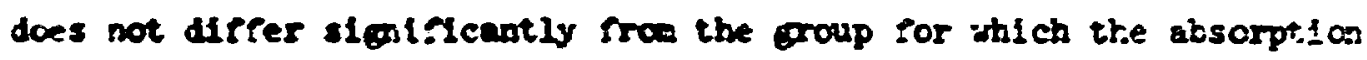
correction ves obtainec by estination. 
AFPaD 6

DISTREUIO OP THE SUPATCNA IH THS

STUDI a THE CETSSTLL SFHSRE

Figure ak-1 is a plot in equatorial coorsinates o: the jositio:?s In the sto of the 36 supernover in the present saple. The pattern of cccurrences reflects the areas patralled in the regular surveys rather than real preferences for certain directions. The two different ludnasity groupe are distinguished bs open and closed circles. Clearly the two groups coexist in the sane parts of the shy. This fuct indicates that they were not sased by an anisotropg in the lhoble law. 


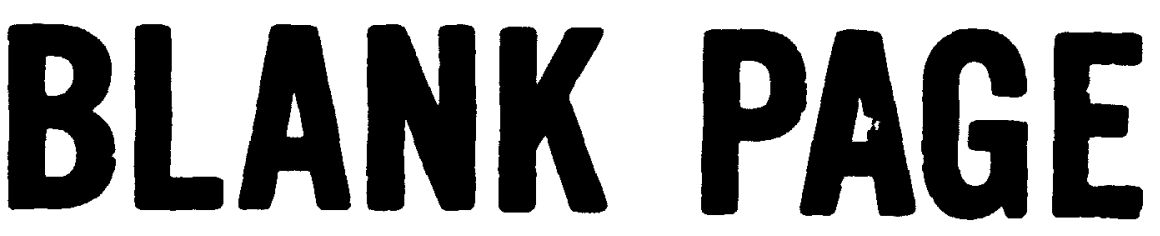




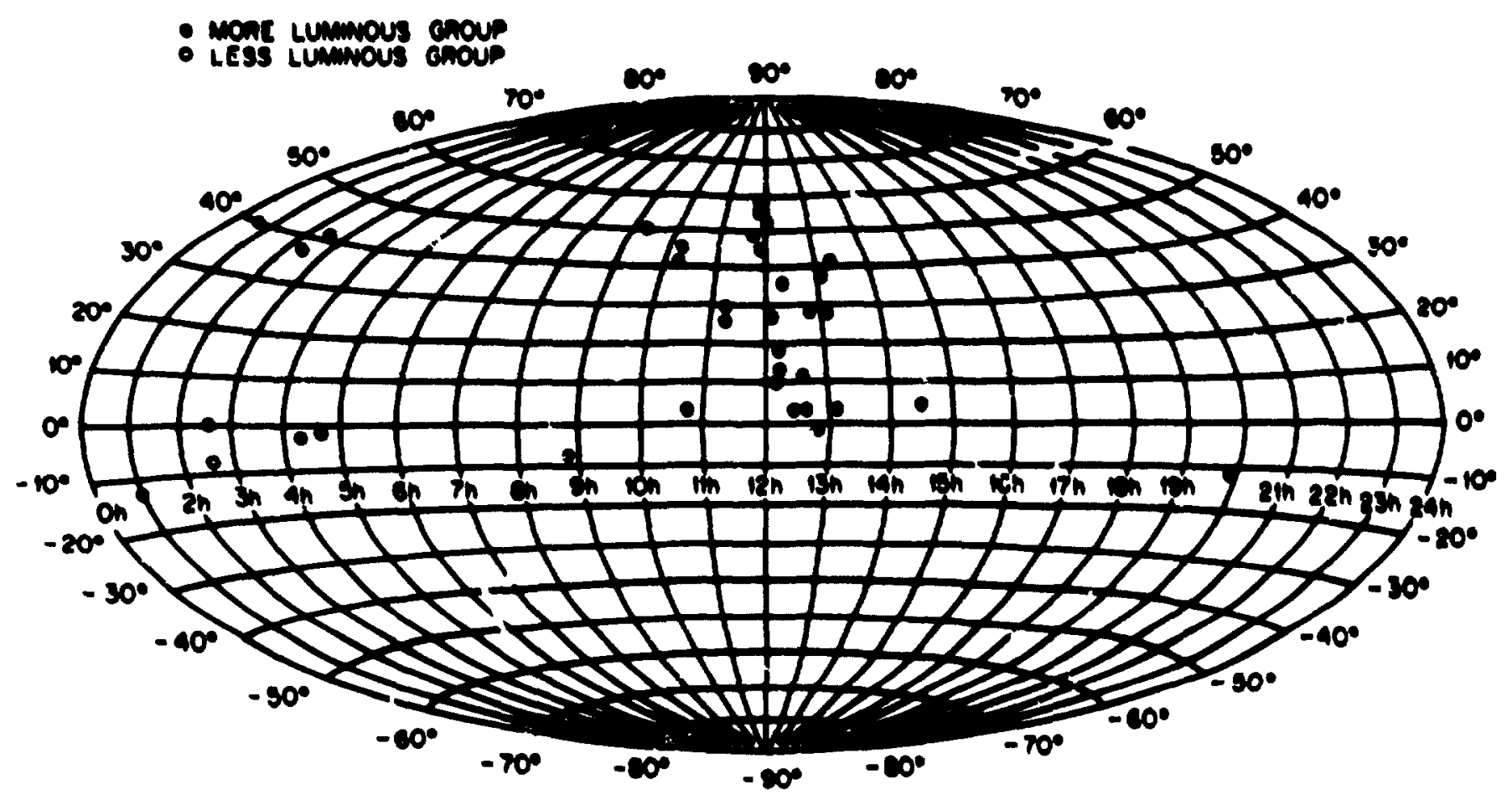

F1gure i6-1. Dintritution In Fquatorial Coordinatog of the Bupernovar. in Thls Study. 


\section{AFPDDX 7}

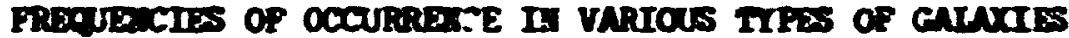

Bartaln and Sussf (1;); sugrested that there are twe kixds of Doe I supernome associated with Populatios I ad Popalation II sters. Their only efidence was an analysis of tice freguengr of cocurrance in different linds of galades. Using as their saple iq type I supernorse taken frow verious lists published by $\mathrm{Zrick}(14,3,1-9)$ and from various other sources, they obtafned a distributioc having two frequency andina

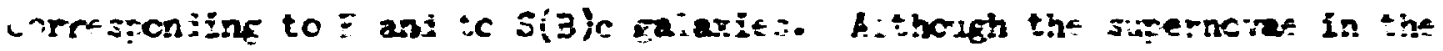

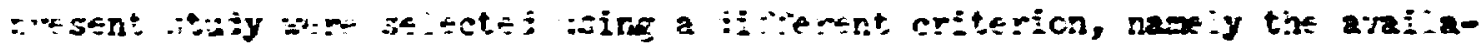

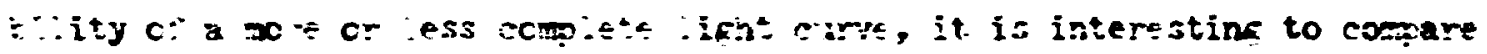

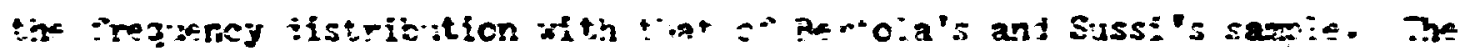
Irequency distribution with that of Bertola's and Sussi's saple. The two distributions are show in Figure :-9-1, plotted as nuber of necurrences versus habble type of the parent galex without any corrections for the frequency distribution of galaxies sccording to type. Ints latter correction vould have the effect of enhancling the E-galay peak ad lowering the sc-onlexy peak. Bven so, the correction would leave intact the double-peaked structure which is clearly evident in both ilstributions.

It is also interesting to consider the alstribution of the two luninosity types in the present sapple. Inis is indicated in the figure by the shaded and unshoded areas, and is dren in detadl in Table A7-1. supernore 1366n we ondted because the exact type of its parent galexy is not knom with certainty though it is known to be a spiral. Note 
373
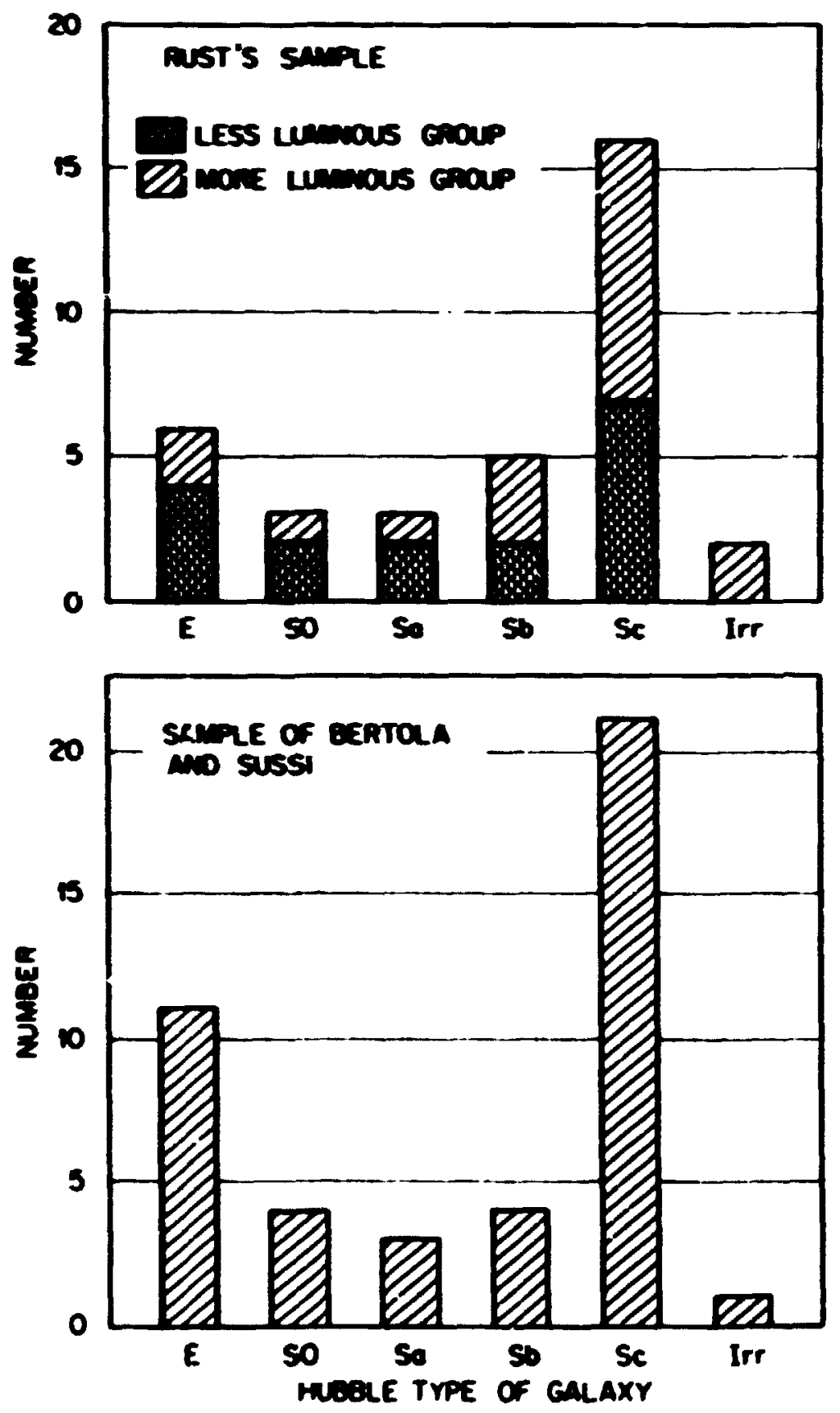

Pigure A7-1. Distribution of Supernove in the Varichs Types of ralaries. 
TABIS $A 7-1$

Whiber of Superncve in Different Types of Galaries

\begin{tabular}{|c|c|c|c|c|c|c|}
\hline \multirow{2}{*}{$\begin{array}{l}\text { Galexy } \\
\text { Iype }\end{array}$} & More Indinous & Group & Less Inutaous & Group & Both Groups & Togetiner \\
\hline & Enber & $\because$ & Thuber & - & Rumber & $\because$ \\
\hline $\mathbf{E}$ & 2 & 11.1 & $\therefore$ & $23 \cdot j$ & $c$ & $17 \cdot 1$ \\
\hline so & 1 & $5 . ;$ & 2 & il. & 3 & $3 . \dot{c}$ \\
\hline Sa & 1 & 55 & 2 & $11 . \overline{5}$ & $z$ & J.E \\
\hline Sb & 3 & lé.7 & 2 & H.ה & $\doteqdot$ & $1 \div .3$ \\
\hline Se & 3 & 50.2 & 7 & -1.2 & $1 E$ & $\therefore 5.7$ \\
\hline Irr & 2 & 21.1 & ? & 3 & 2 & 5.7 \\
\hline
\end{tabular}

that both luninosity groups have occurred in all the galaxy types except Irr in willch there were only two occurrences in the entire sauple. In particular, brth luainosity groups occur in elliptical galaxies, a fact which rules out an identification of the with Populations $I$ and $I i$ stars. There appears to be a slight trend for the more luminous group to occur more orten in galaxies of later type (Sb, Sc, IrT) and for the less luninous group to predoninate in earlier types (E, S.), Sa). The nubers In the various tymes are too mall to judge whether this trend is statistically sionificant, but such a tendency would explain the correlation of $M_{0}$ with galax type shom in Figure $A_{4-1}$ and perhaps the correlation of $M_{0}$ wth the absolute magnitude of the parent galaxy shown in Pigure $14-3$. 


\author{
ORIL- -4953 \\ UC-34b \\ Physics - Cosinic and Terrestrial
}

IATEREAL DISTRIBUTIOA

1-3. Central Research Library

4. ORNL - Y-12 Technical Library Document Heference Section

5. K-25 Library

6-55. Laboratory Records Department

56. Laboratory Records, ORML R.C.

57. ORML Patent Orfice

58. K. T. Berry

59. A. A. Brooks

60-69. J. A. Carpenter

70. H. P. Carter

71. J. S. Crowell

72. F. L. Culler

73. D. L. DeAnzelis
74. R. E. Funderlic

75. C. M. Hariand

76. R. F. Hibbs

77. J. B. Mankin

78. J. K. Hunro

79. S. K. Penny

80. Hersaan Postma

81-110. Bert H. Rust

111. H. C. Schweinler

112. J. o. Sullivan

113. P. R. Vanstru

114. G. H. Vestley

115. C. E. Whitesides

\title{
EXMTERHAL DISTRIBUTIOR
}

116. G. O. Abe11, Department of Astronody, University of California, Los Angeles, California 90024

117. B. Abramenko, AEG Rechenzentrum, Frankfurt (Yain), Federal Republic of Germany

118. V. A. Ambartsumiau, Academy oi Sciences, Erevan, Armenia, U.S.S.R.

119. R. J. Angione, Astronomy Department, California State University, San Diego, California

120. H. C. Arf, Hale Observatories, 813 Santa Barbara Street, Pasadena, California 91106

121. J. N. Bahcall, Institute for Advanced Study, Princeton, New Jersey 08540

i22. Neia A. Bahcall, Princeton University iuservatory, Prínceton, New Jersey

123. R. Barbor, Asiago Astrophysical Observatory, University of Padova, I-36012 Asiago, Itely

124. Ronnie C. Barnes, Physics Department, University of Missouri, Columbia, Missouri 65201

125. Jeno M. Barnothy, 833 Lincoln Street, Evarston, Illinois 60201

126. S. Bellert, Department of Electronics, Warsaw Technical University, Warsaw, Poland

127. S. van den Bergh, David Duniap Observatory, University of Toronto, Fichmond Hill, Ontario, Canada

128. Ch. Bertaud, Observatoire de Paris-Meudon, F-92190 Meudon, France

129. F. Bertola, Asiago Astrophysical Observatory, University of Padova, Asiago, Italy

130. S. Bonometto, Instituto di Fisica "Galileo Galilei", Padova, Italy 


\section{BLANK PAGE}


131. E. H. Burbidre, Depertent of Phrsics, Univissity of Celifornie, Sen Dieco, Le Jolle, Californie 92037

132. G. A. Burbidge, University of Californie, San Diego, Box 109, Le Joile, Celifornie 92037

133. H. R. Eurrus, Tennecoup Systems, Inc., 795 Oak Ridze Turapike, Oak Ridge, Tennessee 37830

134. J. H. Cahn, University of Illinois Observatory, Urbank, Illinois 61801

135. E. Chavire, Obsarvatorio Astrofisico, Ancional, Aptdo Postal 216, Puebla Pue, Mexico

136. F. Ciett, Asiego Astrophysical Ciservatory, University of Padore, I-3601? Asiago, Ital:

137. S. A. Colgate, Mew Mexico Technical Institute, Socorro, Weu Vexico 87801

138. S. Colliz-Souffrin, Obserrat.oire de Meudoa, P-92190 Meudon, Prance

139. . Dallapurte, Instituto di Astrononia deli' Universite, Vicolo dell' Observatorio, 5, I-35100 Pedove, Itely

140. D. Deming, Department of Astronow, Unizersity of Illinois Observator, Urbene, Illinois 61801

141. John R. Dickel, University of Illino:s Observatory, Urbane, Illinois 61801

i42. P. A. M. Direc, Florida State lifiversity, Tellahassee, Florida

143. J. R. Dunlap, 1629 st,jll Drive, Les Cruces, sew Mexico 88001

144. George B. Field, iepartment of Astronomy, Universat-y of California, Berkeley, Califarnia 94720

145. A. Finzi, Israeli Institute of Technolog, Departwent of Mathematics, Haira, Issael

146. H. K. Ford, 'Tr., 7400 surmi: Avenue, Chery Chase, Maryland 20015

147. Wayne L. Fullerton, Los Alamos Scientific Laboratory, Jos Alamos, New Hexiso 87544

148. B. J. Geldzahler, Department of Astronomy, University of Pennsylvania, Philadelphia, Pennsylvania 19104

149. T. Gold, Department of Astronomy, Cornell University, 410 Space Science Building, Ithaca, Mev York 14850

150. G. Golub, Eidgenossische, Technische Hochschule Zurich, Seminar fur Angevandte Mathematik, Clausiusstrasse 55, 8006 Zurich, Switzerland

151. J. E. Gunn, California Institute of Technology, Robinson Laboratory, Pasadena, Califcrnia 91109

152. P. A. Y. Gunter, Department of Philosophy, North Texas State University, Denton, Texas

153. Michael J. Haggerty, Departmant of Physics, University of Texas, Austin, Texas 72712

154. E. R. Harrison, Departnent of Physics art Astronomy, University of Massacinusetts, Amharst, Massachusetts

155. G. S. Hawkins, Dickinsun College, Department or Physics and Astronony, Carlisle,' Pennsyluania 17013

356. M. T. Heath, Computer Science Department, Serra House, Stanford Untversity, Stanford, California

157. P. W. Hodge, Astronomy Department, University of Washington, Seattle, Washington 98105 
158. Sebestien ron floerner, M.R.A.O., Greenbenk, West Virginie

159. Alan Hor man, Joseph lienry Leboratories, Physics Department, Princeton University, Princeton, Hew Jersey

160. E. Holmbers, Astroncinical ibservatory, Uppsale, Sveden

161. F. Hoyle, 1 Clarkson Close, Cabridge, Dacland

162. M. L. Humson, P. O. Box 165, Mendocino, Californie

163. I. Iben, University of Illinois Observetory, Urbene, Illinois 61801

164. T. Jakklole, Observatorio Ja Astrofysiiken Leboratorio, Tahtitorninaki, SF-00130 Helsinki 13, Finland

165. James Kaler, University of Illinois Observatory, Urbens, Illinols 61801

166. M. Kerpowicz, Astronomical Observatory, Werssu University, Harsay, Poland

167. K. I. Kellermann, Rational Radio Astronomy Observatory, Green Bank, Wast Virginia

168. Janes Kercher, Lawrence Livermore Laboratory, Lirermore, Californis

169. C. T. Kowel, Depertment of Astrophysics, Californie Institute of Technology, Pasadene, Califiomie 91106

170. J. Meslowski, Astrononical Observatory of the Jagielloufan University, Cracow, Poland

171. H. H. McCrea, University of Sussex, Astronomy Centre, Fhysics Building, Falmer, Friahton, BN 19 QH England

172. W. H. McCutcheon, Physics Department, University of British Columbie, Vancouver 8 , Canade

173. G. C. McVittie, 7t Old Dover Road, Canterbury, Kent, England

174. T. L. May, 5034 Westminster Terrace, San Diego, California 92116

175. S. N. Milford, Department of Physics, University of Queenslend, St. Lucia, Brisbane, Queensland 4067, Australia

176. R. Minkouski, Radio Astronouy Laboratory, University of Californie, Berkeley, Californie 94720

277. P. Morrivon, Room 6-308, Massachusetts Institute of Technology, Cambridg:, Massactusetts 02139

178. J. V. Nerlikar, Tata Institute of Fundamental Research, Bombiay 400005 , India

179. G. D. Mickes, 2040 York Street, 115, Vancouver, B.C., Canada V6J 157

180. J. Nicoll, Rn 13-3126, M.I.T., Carbridge, Mussachusetts 02139

181. I homas H. Noonar, Brockport State College, Brockport, New York

182. E. C. Olson, Department of Astronony, University of Illinois Cuservatory, Urbana, Illinois 61801

183. T. L. Page, Mational Aeronautics and Space Aimintstration, Manned Spacecraft Center, Houston, Texas $77 C 58$

184. J. C. Pecker, College de France, I. A. P., 98 bis Bld Arago, F-75014 Paris, France

185. P. J. E. Peebles, Princeton University, Department of Physics, Joseph Henry l,aboratories, Princeton, New Jersey 08540

186. Yu. P. Pskovskif, Sterriberg Astronomical Institute, Moscow K-234, 117234 U.S.S.R.

197. M. S. Roberts, National Radio Astronomy Observatory, Edgemont Road, Charlottesville, Virginit 22901 
188. G. Romano, Viale S. Antonio 7, 31100 Treviso, Italy

189. Herbert J. Rood, Astronow Department, Michien State University, Enst Lansing, Mchigan 48823

190. L. Rosino, Asiagn Astrophysicel Observetory, University of Padore, I-36012 Asiago, Italy

191. V. C. Rubin, Department of Terrestrial Hagnetisen, 5241 Brond Branch Roed, Weshingten, D.C. 20015

192. K. Rudnicki, Observatoriun Astrononiczne U.H., Aleje Ujazdouskie 4. Marsaw, Poland

193. A. R. Sandage, Hale Observatories, 813 Santa Barbara, Pasadene, Californie 91106

194. K. L. W. Sargent, Astronouy Department, Caifornie Institute of Technolozy, Pasadena, California 9110s

195. K. Schidt, California Institute of Technolugy, Hale Observatorfes, 1201 East California Blvd., Pasadena, California 31109

196. I. E. Segal, K1000 2-244, Massachusetts Institute of Technology, Cambride, Massachusetts 02139

197. Harlon J. Suith, istronory Department, University of Texas, Austin, Texas 78712

198. P. A. St-ittmatter, Unijersity of Californis at San Diego, Physics Lipartment, Box 109, La Jolla, Califormia

199. G. H. Swenso:: Jr., Electrical Engineering Department, University of Illinois, Urbane, Illinols 61801

200. G. A. Tamann, liale Obseryatcries, 813 Santa Barbara Street, Pasadena, California 91106

201. William G. Tiift, Steward Observatory, University of Arizona, Tueson, Arizona 85721

202. H. M. Tovmassian, Byurakan Observarory, Armenian Arademy of Science, Byurakan, U.S.S.R.

203. Thomas C. Van Flandem, U.S. Havel Jbservatory, Hashington, D.C. 20390

204. T. de Vaucouleurs, Depertment of Astronowy, Uriversity of Texas. Austin, Texas 7871 ?

205. G. L. Verschuur, iational hadio Astronomy Observatory, ireen Bark, West Virginia

206. E. - Wampler, il i=k jbservatory, Ut.iversity of Califarmia, zanta cruz, Cailformia 95060

207. $\therefore$. Webber, Univerity of 111 ino:s itservatory, Urbene, Ilis.ols 6180]

208. S. Weinbere, Physics Department 6-320, Massechusetts Institute of Technoloby, Cambridge, Messschusetts 02139

209. D. Hi. Weinstein, The Jugerior Gil Company, Houston, Texes T7004

210. Raymond E. White, Math and Physical Eclences Division, Mational Sclences Foundetion, $1800 \mathrm{C}$ Street, H.H., Washinoton, D.C. 20550

211. E. F. Wigner, 8 ober Foad, Frinceton, Mew Jersey

212. A. G. Hillis, Sterrewacht, Lelden, The Jetherlands

213. I. C. Wilson, jaile Observitorles, 813 janta Barbara sireet, Pasadena, Cali fornia 91106

214. Y.. 7. Hitz, Sathematise Depertment, univers:ty or IIIInols, Altzelt Hall, Urbana, II:Snols ć!bo!

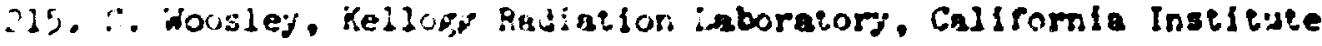
of Zechroions, Yasadena, Cuifrornia 91109 
216. S. P. Hyatt, Univerity of Illinols Observatory, Urbane, Illinois 61801

217. K. M. Yoss, University of Illinois Observatory, Urbane, Illinois 61801

218. Aarae Karjelainen Observatorio, 90101 Oulu, Findand

219. Air Force Cambridge Research Laboretcries, L. G. Hanscor Field, Bedford, Yasachusetts 01730

220. Air Fcree Office of Scientific Research, 1400 Wilson Blvd., Arlington, Virginie 22209

221. Allegheay Observatory Librery, University of Pittsburgh, Rivervier Park, Pittsburgh, Pennsylvania 15214

222. All-Union Society of Astronon and Geodesy, Leninsly Prospekt 14, Hoscow V-71, U.S.S.R.

223. The American Museun of Matural History, Central Park Vest at 79 th Street, New York, New York 10024

224. Arragh Observatory, Armagh, Horthern Ireland

225. Astrononical Council, Ulftse Vavilove 34, Hoscor, U.S.S.R.

226. Astronomical Institute, Konkoly Thege M. Litca 13-17, Budapest XII, Hungery

2.27. Astronowy Institute Lłbrary, 38 Astroncenicheskaya, Tashkent, U.S.S.R.

228. Astronowy Library, F-inceton University Observetory, Peyton Hall, Princeton, Dew Jersey 08540

229. Astronows Library, Yale Lniversity, Box 2023, Yale Station, llew Haven, Connecticut 06520

230. Astronomy-thathematics-Stat isties Library, University of Californis, 113 Cambell tiall, Berkeley, Californte 94720

231. Astronomy-Physi cs-thathematics Library, Surain Hall, Indiane University, Blocmington, Indiane 47401

232. Astrchysical Observatory, Smithsonian institution, 60 Garden S'reet, Combridge, Vessechusetts 02138

233. Astrophysical Observatory Lfbrary, Zelezchuk, Stavropol Fegion, U. S.S.R.

23L. As.rophysical Cbservatory of Abestumani, inyubill Vount, Abeseumani, Georgian SSR, U.S.S.R.

235. Astrophysical Cbservatory of Byurakau, Byurakals, Ashtarak Region, Armenian SSR, U.S.S.R.

236. Astrophysical Observatory or the Crtice, :/B Lauchay, Crimea, Ukranian SSR, U..S.S.R.

237. istrophysicai Joservatory of Fadue University, Asiago, :ta];

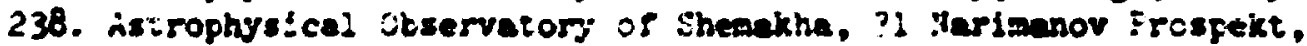
Baks, U.E.S.R.

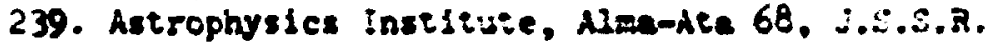

240. Astroghysics isstlete, Viftse Sulfidente 22, Jushanbe i2, IadzhiK SSR, U.S.S.R.

241. Bossche Observacory, iesbaras, irdonesis

242. Ceskosiovenske Akedeale Ved, istronombal institute, Eudecsin 6 , Vinohredy, Prache 2, Esechoslovakla

263. Thenlstry-Fhysics Library, Uol versity of Kentisky, Lexing.cr. Kentucky 10506

2hb. Dearborn vbeerratory ilbrary, indhefrer istronchlcal Research Center, Horebuesters. University, Evanseon, :IIInols 60201 
245. Departanent of Astroncs and Observatory, Boston Univer sity, T25 Coundealth A reave, Bosion, Masuchusetts

246. Cole Meorial Library of Pussics, Ohio State University, 174 Wes' 18th Aveave, Colunbus, Ohio 43210

247. Division of the Farsical Selences, University of Chicago, 1118 Bast Soth Street, Chicaso, Iilinois 6063?

248. Dudles Observetorg, 100 Puller Rond, Albeng, Lev York

249. Bagineering anc Pursics Library, 410 Weil fill, University of Ploride, Gainestille, Florida 32601

250. Buropean Soutbern Observatory, Bergedorfer Strasse 131 , 205 Heburb, West Cermany

251. The Pranklin Institute Library, Bewjanin Pranklin Parkway at 20th Street, Philadelphie, Pennsylvania 19103

252. Prank P. Brackett Observatory, Pomona Coilege, Claremont, Californie 91711

253. George C. Marshall Space FIight Center Technical Library, Marsball Space Flight Certer, Alabana 35812

254. Gersteazang Scieace Library, Brandeis University, 415 South Street, Walthen, Massachusetts 02154

255. Henburg Observatory, Cojenbergsweg 112, 2050 Hanburg 80, Gernany FR

256. High Nititude Observatory Library, National Center for Atmospheric Research, F. O. Box 1558, Boulder, Colorado

257. Institut Intional D'Astrononie et de Ceophysique, 5 place Jules Janssen, 92 Meudon, Prance

258. Kaptejn Atronouical Laboratory, Broerstraat T, Groningen, The Netherlands

259. Kaptesn Observatory, Mensirgeveg 20, Roden, The Hetherlands

260. Kiev Astrononical Observatory Library, Coloseevo, Kiev 127, Uurainien SSR, U.S.S.R.

261. Kitt Peak Dational Observatory Library, P. O. Box 4130, Tucson, Arizona 85717

262. Konkoly Observatory, Budapest, Hungery

269. Leander McCornick Observatory, Box 3818, University Station, Charlottesville, Virginia 22903

270. Leningrad Central Astrononical Observatory ilbrary, Pulkovo, Leningrad, U.S.S.R.

271. Mathenatics-Physics Library, University of Pennsylvania, 209 South 33d Street, Philadelphia, Pennsylvanin 19104

272. Wax Planck Institute for Astronon, 69 Heidelberg-Konigstuhl, Germany PR

273. War Plenck Institut Pur Physik und Astrophysik, Fohringer Ring 6, 8 Munich 23, Cermany FR

274. Melton Memorial Observatory, Department of Physics and Astronowy, University of South Carolina, Columbie, South Caroltna 29208

275. Hount Cube Astrononical Observatory Library, P. O. Box 3915, Greenville, Delemare 19807

276. Mount, Stroalo Observatory, Canberrs, Australis

277. Mational Observatory of Athens, Lophos Nymphon, Athens 306, Greece

278. Dationel Radio Astronony Observatory Lfbrery, Bdgemont Roed, Charlottesville, Virginie 22901 
279. Navel Ob servatory Library, Massachusetts Arenue and 3hth Street, A.W., Washington, D.C. 20390

280. Observatoire de Paris, 61 Arenue de 1 'Obs' rvatoire, 75 Paris14e, Prance

281. Observatoire Royal de Belgique, Arenue Cireulaire 3, 1180 Brussels, Belfium

282. Observatoriet, Oster Voldgade 3, DK-1350 Copenhagen K, Dennark

283. Observetory Library Georgetown University, 37th and 0 Streets, M.H., Heshington, D.C. 20007

284. Observatory Librery, University of Illinois, Urbane, Illinois 61601

285. Perxins Observatory Library, P. O. Box 449, Delavare, Ohio 43015

286. Phillips Librery, Harvard College Observatory, 60 Carden Street, Cambridge, Massaciusetts 02138

287. Physical Sciences Isibrary, Brown University, Proridence, Rhode Islend 02912

288. Physical Sciences I.ibrary, Clark Hall, Cornell University, Ithace, New York 14850

289. Physics and Astronon Institute Library, Tiakhetorn, Tartu, U.S.S.R.

290. 290 Physics Astronady Library, University of Michigen, Ann Arbor, Michigan 48104

291. Physics Library, 801 Pupin Building, Columbie University, Nev York, Rew York 10027

292. Physice Library, The University of Texas, Austin, Texas 78712

293. Redstone Scientific Information Center, U.S. Army Missile Command, Redstone Arsenal, Alahane 35809

294. Royel Observatory, Blackford Hill, Edinburgh EH9 3H, United Kingdom

295. Royal University Observatory, Lund, Sweden

296. Science and Engineering Library, University of Californ:a, San Diego, P. 0. Box 109, Le Jolla, California 92037

297. Sciences and Engineering Library, $\operatorname{Lan}$ Diego State College, 5402 College Avenue, San Diegu, Callfornia 92115

298. Science and Technolog; ifibrary, University of Colorade Libraries, Boulder, Colorado 80302

299. Science Division, University of Oregon Library, Eugene, Oregon 97403

300. Science/Technology Information Center, University of Virginie Library, Charlottesville, Virginis 22901

301. Steward Observatory, University of Arizona, Tucson, Arizone 85717

302. Strnubridge Observatory Library, Haverford College, Haverford, Pennsylvanis 19041

303. University Astronomical Observatory, Uppsale, Sweden

304. University Library, University of Havali, Honolulu, Hawali 96822

305. University Observatory, Bologna, Italy

306. University of Washington Libraries, Seatt.1e, Mashington 98105

307. Van Vleck Observatory Library, Hesleyan University, Middletom, Conneeticut 06457 


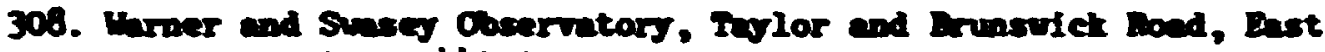
Cleveland, Ohio Hh12

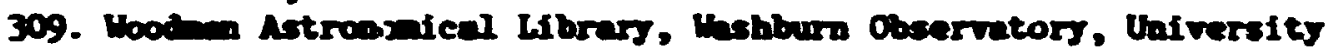
of Hisconstin, Hadison, Hisconsin 53706

310. Yertes Observetory Liberar, Tertes Observetory, Hilles bu, Misconsin 53191

31. V. A. Tenth, Sefentific Mdvisor, Attention: P. R. Patwardhen,

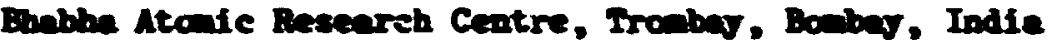

312. J. I. Rogers, Division 8321, Sandie Laboretories, P. O. Dox 969, Livernore, Callformie 94550

313. Hilton E. Bose, Whthentien and Conputer Selences Progren, Malecular Sefences ad Dorry Resenreh, Division of Pussical Research, U.S. Atodic Dheros Condission, Weshington, D.C. 20545

314. R. D. HeCulloch, IAR, Keerntner Ring 11, P. O. Box 6h5, A-1010, Vieana, Austria

315. Research and Technical Support Division, $A x$, ono

316-399. Given distribution as shown in THo-frno under Physics - Cosnic and Terrestrial category (25 cupies - irIS) 